\title{
DELICLAE NATURAE SEIECTAE
}

\section{CORALS AND SHEUS}

\author{
THOLTR
}

1766 


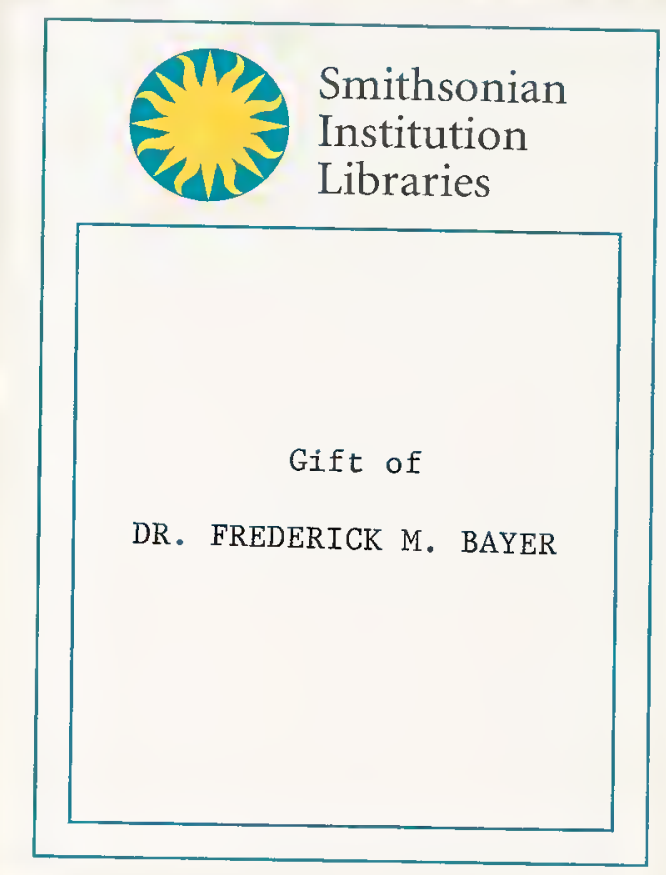


Jonsun 




\section{DEL IC I A E \\ NATURAE SELECTAE}

DDer

a Hácleieneb

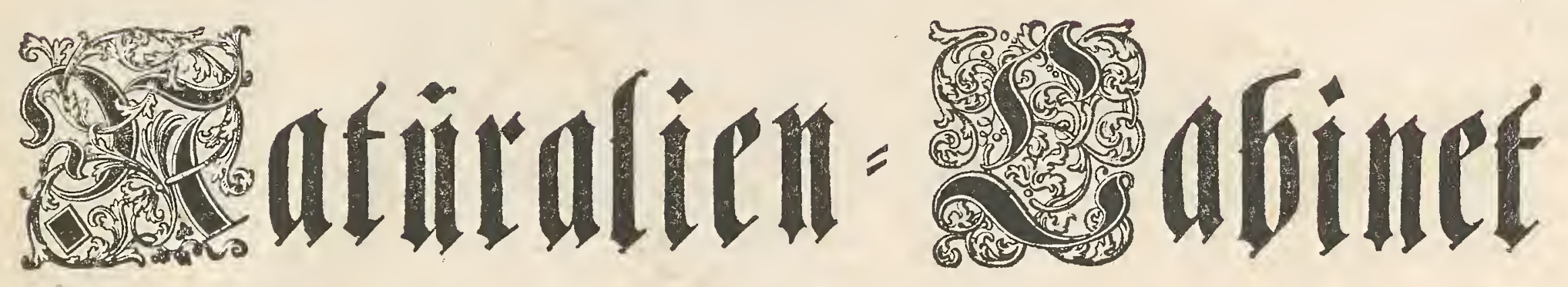

\section{sueldies aแs ben \\ Drty \\ zeiget,}

waz son curiberen Riebfabern anfbeljalten unto gefanmlet gul werden berdientet.

C5femahls berauzggegeben

bon

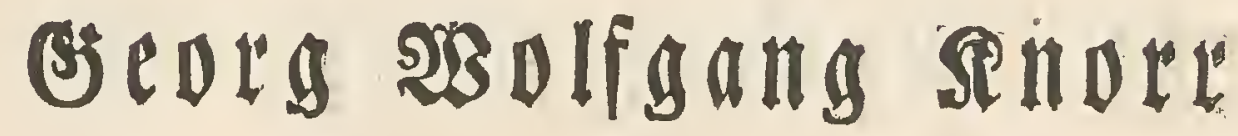

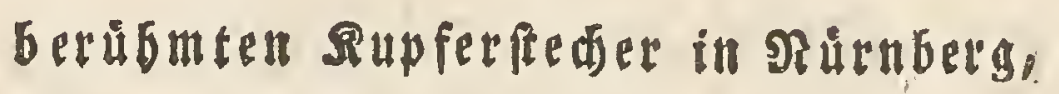

fortgefeget

oon

Deffente Ėten,

Befdriebent

von

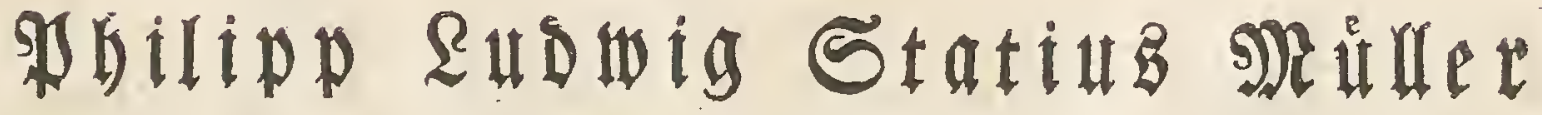

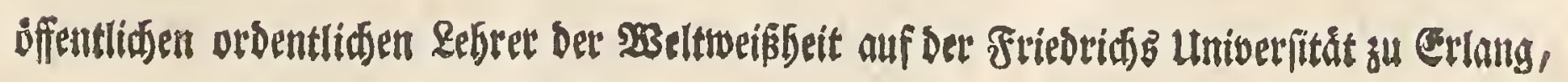

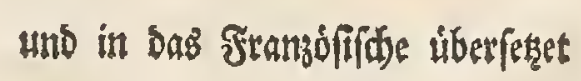

oon

Mattbån Berdier de la Slaquiere

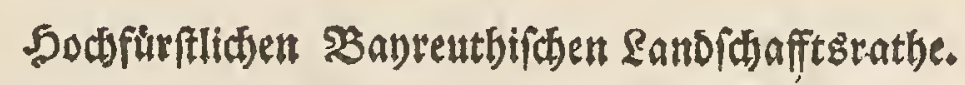




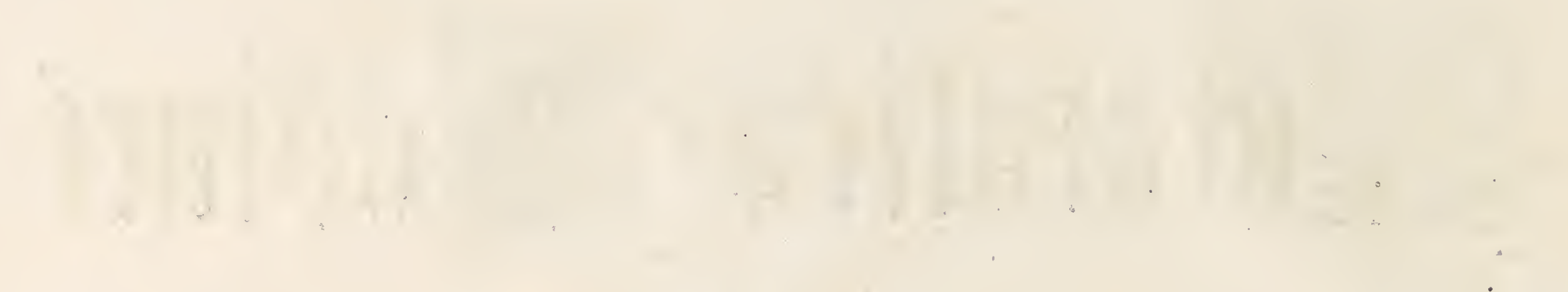

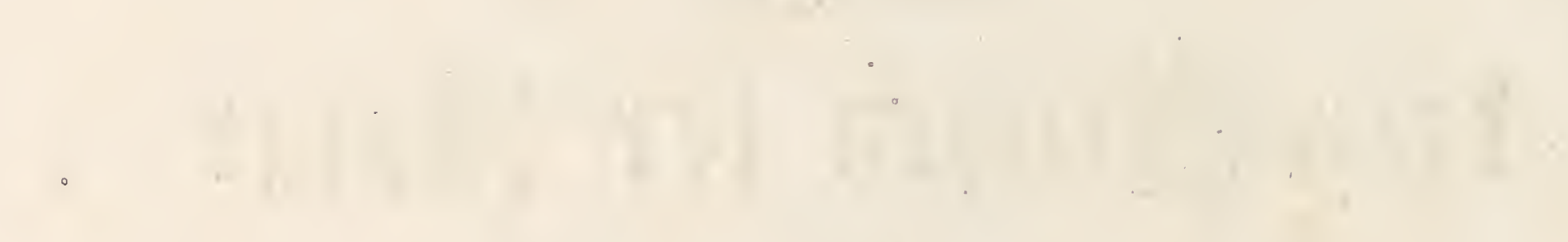




\section{E L I C E S \\ PHYSIQUES CHOISIES, \\ OU}

\section{H O I X \\ DE T.OUT CE QUE \\ LES TROIS REGNES DE LA NATURE. \\ RENFERMENT}

DE PLUS DIGNE DES RECHERCHES D'UN AMATEUR CURIEUX,

POUR EN FORMER

uN
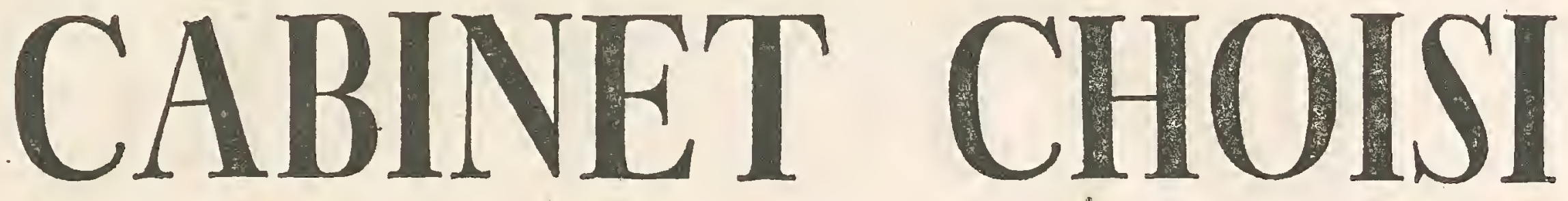

DE

\section{CURIOSITEZ NATURELLES,}

OUVRAGE COMMUNIQUE CY-DEVANT AU PUBLIC

PAR

GEORGE WOLFGANG KNORR

CELEBRE AR'TISTE DE NUREMBERG

CONTINUE PAR

SES HERITIERS

AVEC LES DESCRIPTIONS ET REMARQUES

$D E$

PHILIPPE LOUIS STACE MÜLLER

PROFESSEUR PUBLIC ORDINAIRE EN PHILOSÖPHIE A LUNIVERSITE D'ERLANG

ET TRADUIT EN FRANCOIS

PAR

MATHIEU VERDIER DE LA BLAQLIERE,

CONSEILLER A LA CHAMBRE PROVINCIALE DE BAYREUTH.

$N U R E M B E R G$, MDCCLXVI。 


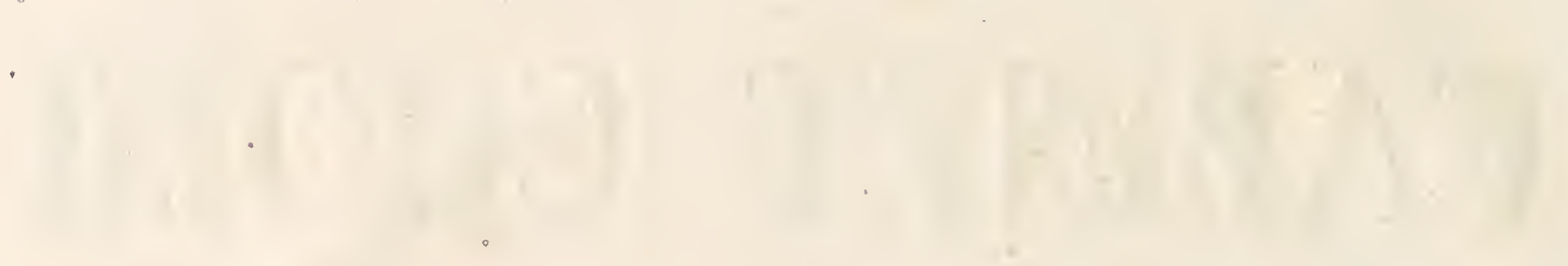

the 


\section{ROTHER.}

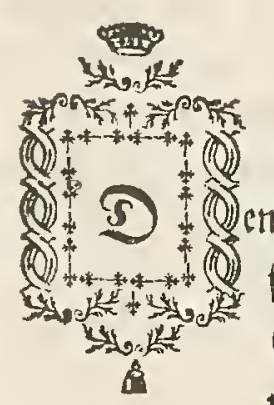

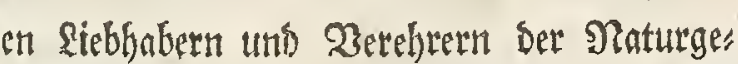
fibidte wiro in gegentrairtigem 2 Berte eine Sammlung won Den beten, obolffarnbigften undo mit iheen natülichen Farben prangen

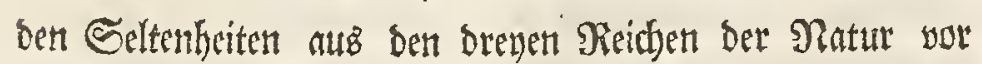
Itugen geleget, Seren Sriginale hin uno wieser in Den Sas bineten berienigen bohen Sionner anjutteffen find, weldike

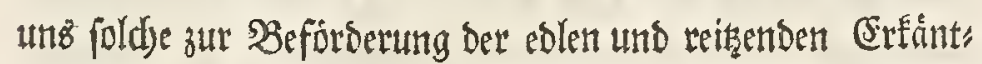

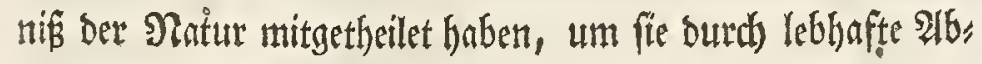

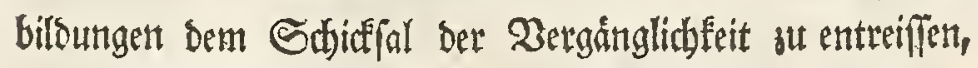
und bie Borftellungen Dawon um fo mehte allgemein zu mas dyen, ba bergleidyen Sriginale und Meeifterftutefe ber Matur ifrer Seltentyeit halber nidyt in allen Sabineten pflegen beds fammen gefunden ä wetben.

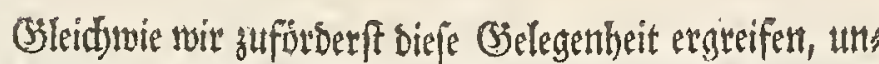
jeren bohen (Stonnern fir biefe bodjgeneigte Mittheilung um,

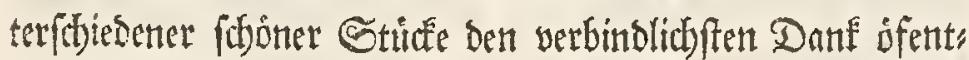
lid) abzuftatten; - alfo ermangeln wir nicht, ben fämetlidjent

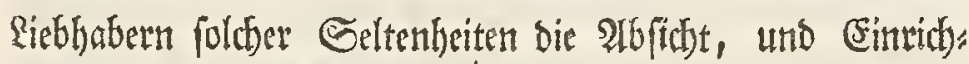

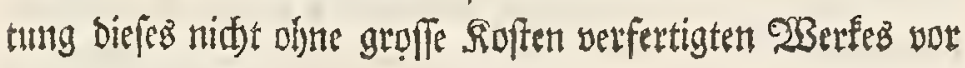
武ugen zu legen.

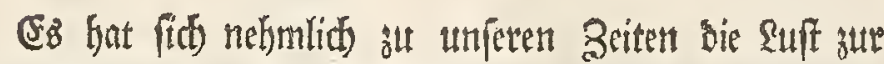
Faturgejtbichte Durd) Den Korgang unterifbiedener beribm

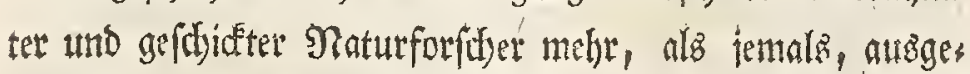
breitet, und allgemein gemadt. Diefer ede Trieb bat fo gar

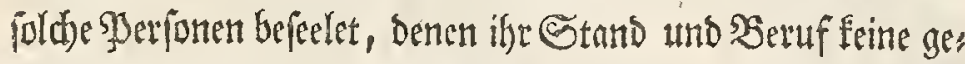

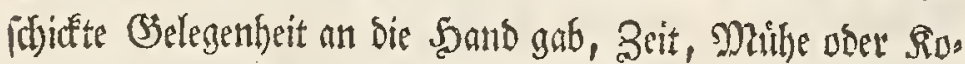

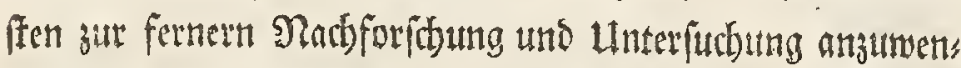
Den; uns wir finden, Daf fowohl Ungelebrte, als (Stelebrte

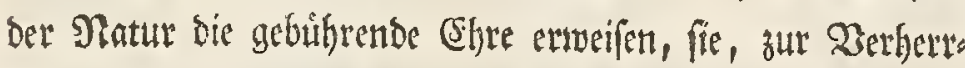

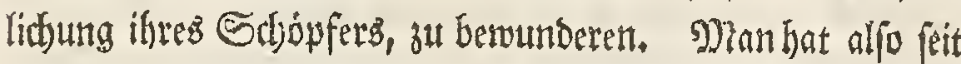

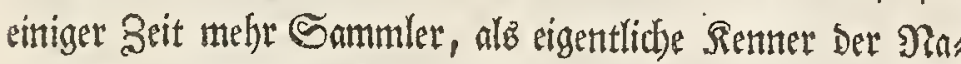

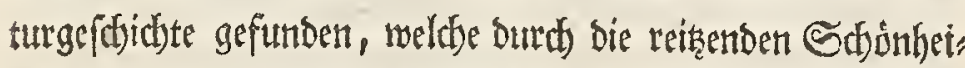

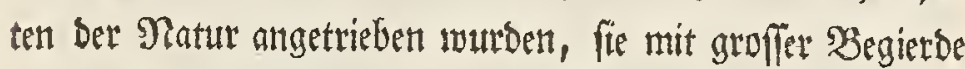

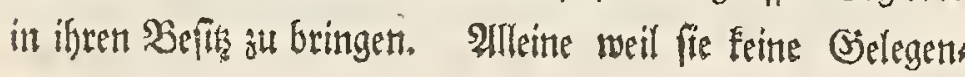

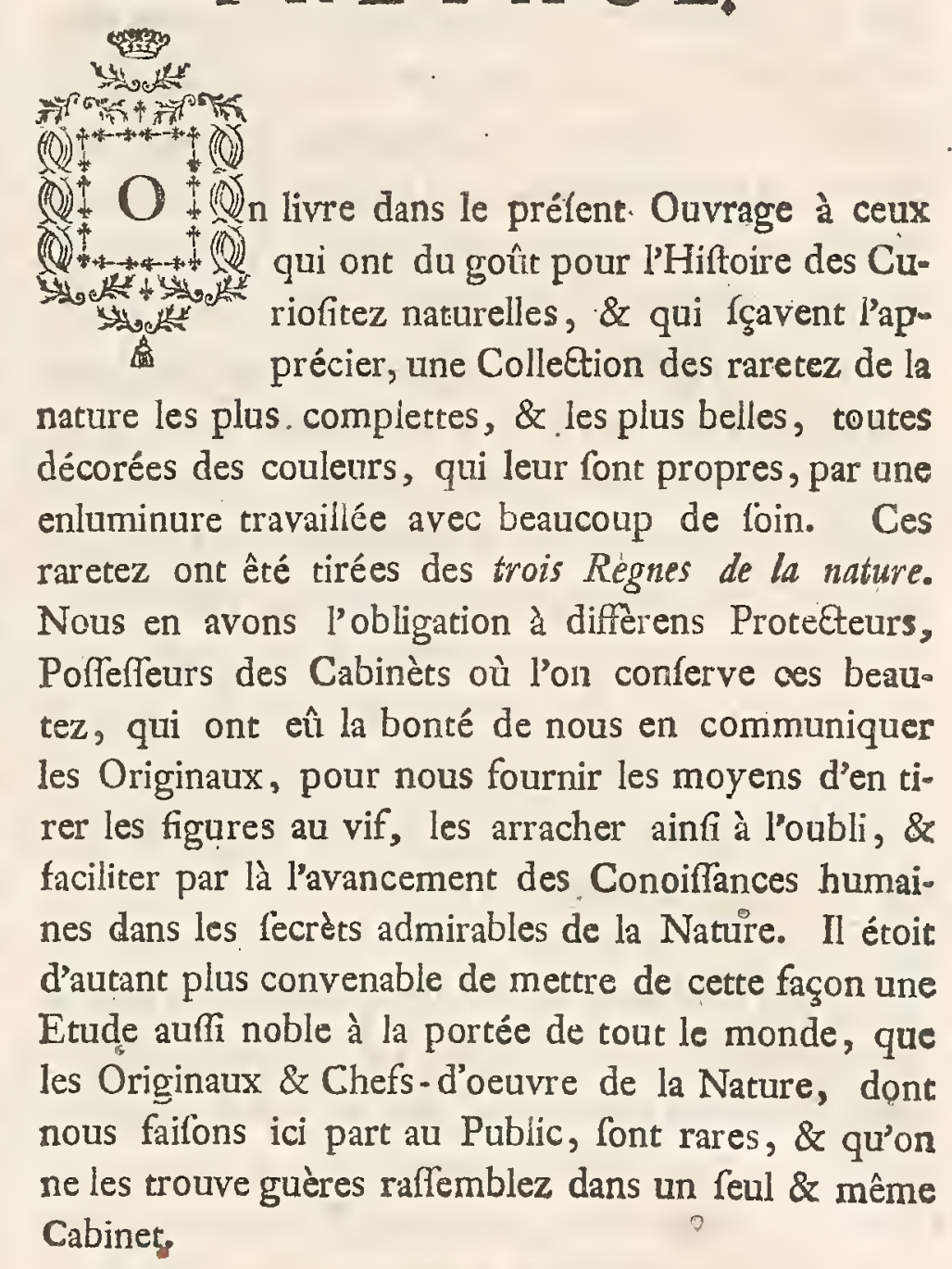

PRE' F A C E。

Nous prions d'abord ces Perfonnes, qui one bien voulu étayer nôtre Collection choijie, en nous communiquant les Originaux de diverfes trés-magnifiques piecès, d'agréer ici les juftes remercimens que nous reconnoiffons leur devoir, \& dont nous nous faifons un honneur de nous aquitter publiquement. Après celà nous allons rendre compte aux Amateurs des Curiofitez naturelles de nôtre but, auffi bien que de l'Ordre \& de l'Arrangement que nous nous fommes propofé d'oblerver dans cet Ouvrage, dont il eft aifé de' juger que nous ne fommes venus à bout qu'avec de trés - grands frais.

Plufieurs Phyficiens, auffi célèbres, qu’habiles, ont contribué par leur exemple à exciter l'inclination génèrale pour ce genre d'étude, \& une noble émulation à cet égard a affecté jusques à des perfonnes, à qui leur état \& vocation ne laiffoient guères ni l'occafion ni le tems de s'apliquer à de pareilles recherches, ni en partie le pouvoir d'y employer la peine \& les frais, qu'elles exigent, quand on veut les aprofondir, \& nous trouvons que des Amateurs Lettrez \& non Lettrez y puifent des motifs d'admiration, qui ten. dent tous à la gloire du $\mathrm{C}$ éateur. Ainfi depuis un certain tems il eft arrivé que plufieurs perfonnes touchées des beautez, que l'on obferve fur ces thréfors de la Nature, fe font effurcées avidement d'en aquerir le plus qu'elles ont pû. Mais ces Perfonnes n'étant proprement que Collecteurs, \& non Conoiffeurs des ri-

cheffes 


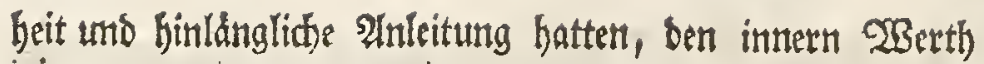

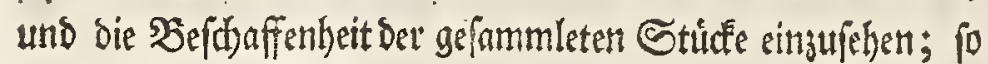
Enten fie noch weniger etwa bon iherer Soronumg, (Einthei: lung und Benentutng, am allerwenigften aber von Der Maan nidffaltigfeit und Abreidung, voer von Dem Urjprung, 23 : terlande und Nutrenen derfelben, angeben. \a felbft folde Sielebrte, Deren 2siffenifhaft nicht unmittelbar auf bie Unt

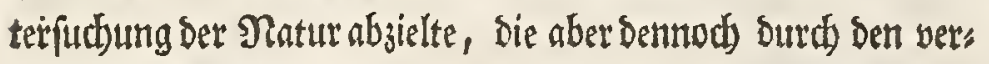

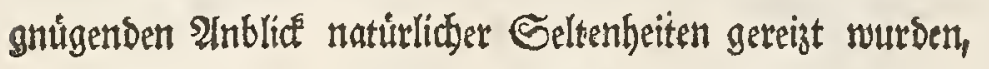
aud) Werefrer und Sammler zutverden, babett f́fterz gerwun:

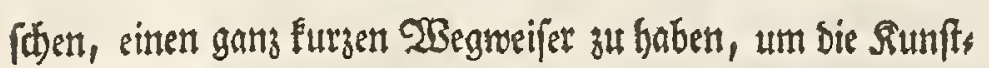
fturfe der Natur genauer fennen ou Kernen. Dann ba ifnen bie Schriften Der betrifmten Naturforfider nid)t fo bäufig unter bie Salnbe fommen, aud) bie Beit zut Unterfutbung folder Sdbriften mangelte; fo trugen fie billig nad) einem Werfe Berfangen, wo fie in Den Stand gejest surtuen, ifre gejammleten Stirfe, in denlebbaften und genau erleutcos

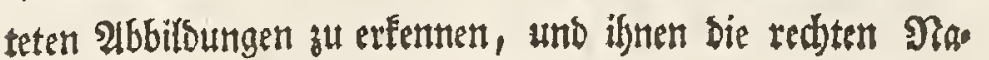
men beulegen ä fọmen.

Diefeb Derlangen murte Defto allgemeiner, je mebte eis nem jegliden Siebhaber einleuthtete, Daß ein Dergleidjen WBer

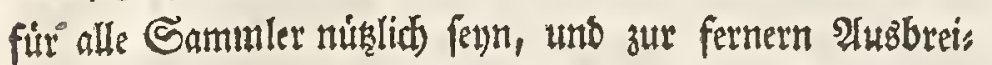

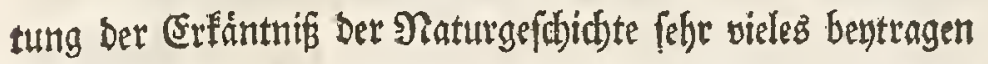

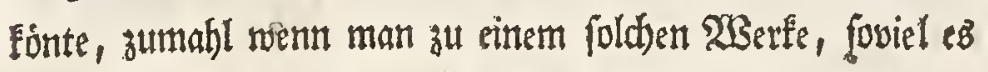
móglich ift, bie ruserlefenften Stúcte mit iffen eigentlitben Farben nehmen, und daben eine allsugroffe, beroríglide, uno

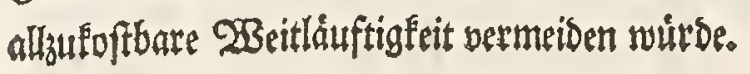

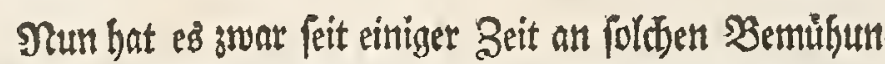
gen nibjt gefehlt, weldfe diefem Werlangen ber Siebfaber in

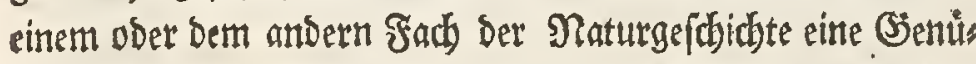
ge haben leiften fonnen; und es find hin und roieder iflummis nirte 2 bbildungen von befonderen Claffen in einem ober bem

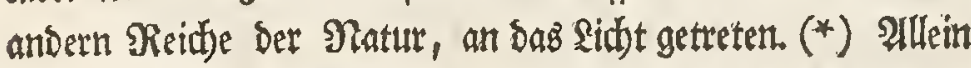

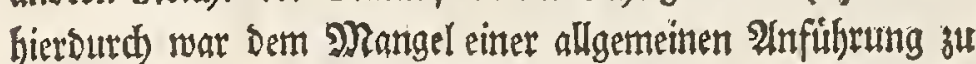
allen breyen Reitien nod) nidft abgeholfen, - unto man fahe fich immer utad einem folden 2 Berfe um, worinnen man bie allerwiditigften, fobomfen und rareften Stúcfe, als aus: erlefene Dufter ber Arbeitfamfeit Der Natur, mit famt ben Benennungen zufatmmen finden mógte, woraus man fich bers nad) yon ben úbrigen, und in anderen $23 e r f e n$ seitláuftis ger aubzgefuthrten uno vorgeftellten Sađjen einen fernern Begrif madben fỏnte.

Den erfen Broanfen su eintem polden SBetfe befam

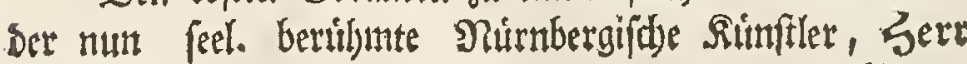
Georg

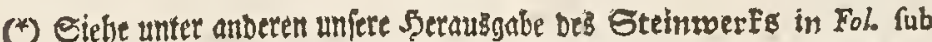
Titulo: Lapides diluvii univerfalis teftes. Defgleiden Dab MTufarelo Titulo: Lapides diluvii univerfalis teftes. Dep
wert in quarto fub titulo: Dergnugen ber 2lugen uno bes Gemuths etc, in imen Theilen, jeber 30 . Supfertafeln enthaltend Cobann Das 3Itumentwere fub titulo: Tbejaurus rep beybaria Hor senfisque univerlalis \&. oDer: Zllgenteines 2 lumen Kráater

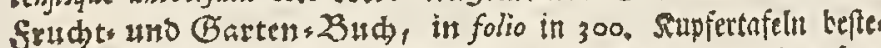

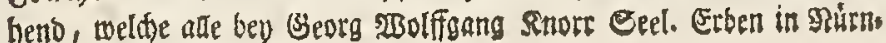
berg st faben finb. cheffes qu' elles raffembloient, \& manquant d'occafion \& d'inftruetion pour conoître le prix intérieur, \& les proprietez des piecès, qui leur tomboient entre les mains, elles n'avoient aucunes lumières fur leur ordre, divifions, \& dénominations, \& encore moins fur leur diverfité, \& les anomalies, qui s'y rencontrent. D'où il s'eft efffuivi que même des Sçavans, qui dans leurs Etudes n'avoient pas juftement la recherche des Secrèts de la nature pour objèt principal \& immèdiat, mais qui, attirez par la vûë de tant de beautez qui s’y trouvent, ne laiffoient pas d'en être amateurs, \& de travailler eux mêmes à des Collections, ont fouvent fouhaité d'avoir un guide, qui les conduifit par le chemin le plus court à parvenir aux Conoiffances, qui leur manquoient. Car les ouvrages des plus célèbres Phyficiens étant rares, \& d'ailleurs manquant de tems pour examiner à fonds les Ecrits qui pouvoient leur tomber entre les mains, il étoit fort naturel à ces Sça. vans d'en défirer un, qui les mît en état par des Figures vives \& exactement enluminées au naturel de conoître le prix \& la dénomination jufte des pièces dont ils fe trouvoient en polfeffion.

Ce défrir eft devenu d’autant plus génèral, que chaque Amateur a compris l'utilité dont un pareil Ouvrage feroit pour tous les Collecteurs, \& combien il pourroit contribuer à étendre nos Conoiffances dans le vafte champ de l'Hiftoire naturelle, fur tout en faifant un Choix des plus belles pièces, quil feroit poffible de rafiembler, \& en les décorant exątement des Couleurs qui leur font propres, fans oublier d'éviter une trop grande prolixité, Couvent ennuyeufe, \& toûnjours coûteufe.

On a commencé à travailler dans ce goût pour la fatisfaction des amateurs, \& on a taché de les con. tenter en partie, en publiant des figures enluminées de quelques Claffes particulières de l'un ou de l'autre Règne de la nature, ce qui éclairciffoit quelques articles de l'Hiftoire des Curiofitez naturelles. $\left(^{*}\right)$ Mais tout cela ne fupléoit pas fuffifamment au défaut d'une Inftruction génèrale relative à tous les trois Règnes de la nature, \& l'on manquoit toûjours d'un Ouvrage, qui, en indiquant les pièces les plus rares, les plus importantes, \& les plus belles, avec leurs denominations, livrât une Colledion choifie de ces riches travaux de la Nature, \& les preuves de fon activité, \& mît le Leeteur en état de fe former une idée de tous les autres qu'on trouve décrits \& fpécifiez dans des Ouvrages plus étendus.

Le prẻmier qui forma le deffein d'exécuter un Plan pareil 'fut défunt Monfieur George Wolffgang

(*) Not. Voyez entre autres l'O Ouvrage in folio g̨ue nous avons don. né au Public fur les pierres, fous le tître: Lapides diluvii univerSalis teftes, de méme que nôtre autre Traité in quarto des Co.

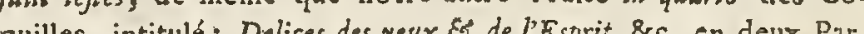
quilles, intitulé: Delices des yeux $\mathbb{E}$ de $l$ Esprit, \&c. en deux Par-
ties dont chacune contient 30 . Planches en Taille-douce. On peut voir encore nôtre Traité des fleurs, qui a parû in folio fous le tître de Thefaurus rei bỉbaria Hortenfisque univerfalis $8 \mathrm{cc}$. enrichi de 300. Planches en Taille douce, ouvrages que l'on trouve tous à Nuremberg chez les Héritiers de George Wolfigang Knorr. 
Georg Wolftgang Znorr; ber wegen feiner andern

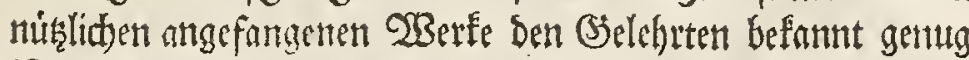

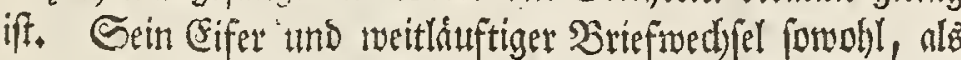
aud) Die grope. (Senvagentheit reiner Bjonner gaben ifm Das Zetmógen, eitten folden Altrfang zu madien, ober einten

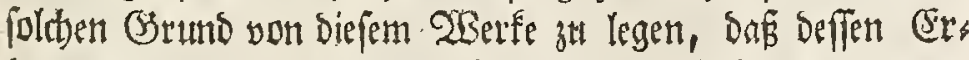
ben yolffonmen im Stanbe find, bas nod) úbrige hinjuzts fersen. Dant ba er in feitem Seben bercits io vieles vor" gearbeitet, und biśs zur Aubgabe berfertigt hat', fo if $\mathrm{eB}$

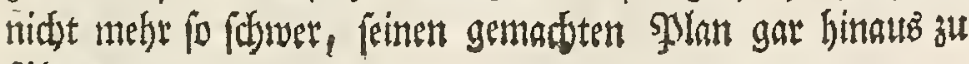
fiubren.

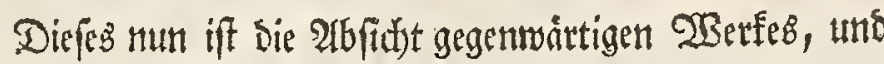

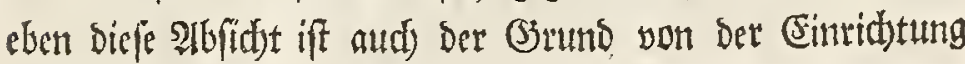

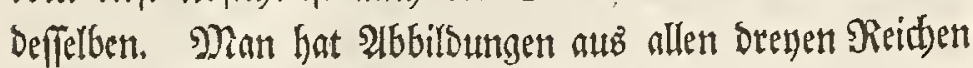
gegeben, auts der unzảáligen Mlenge Der Dinge nur Da fohonfre, bas vollfommenfte uno bab foltenfte gewoihlet, bie minter befanten Sacken den befanteren und gemeinen vors

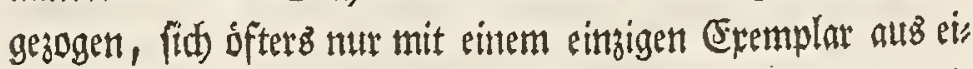
nem gatzen (Stefbledt begniget, uno wo in anbern illumis

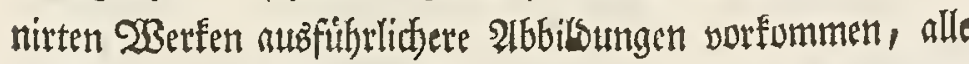

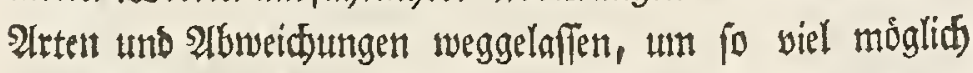

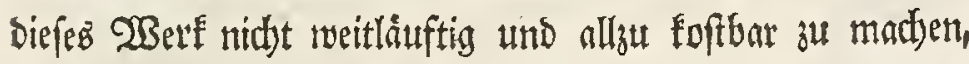
Dber Die Siebbaber mit einer Menge Sachen aufzuhalten, die

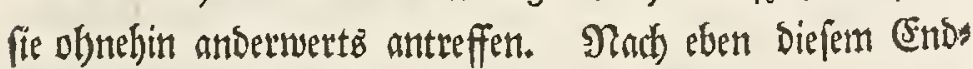

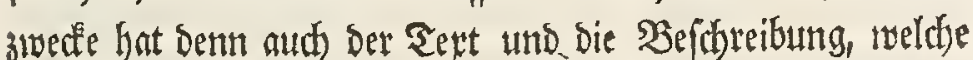
Den Scerrn \$rofeffior Muiller in Erlang zum Werfaffer hat, eingeridtet rwerden muifen. Denn bie ganze alsficht gehet nur Dafin, Dett Figuren bie Senennungen und einige furze

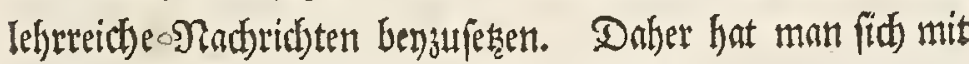

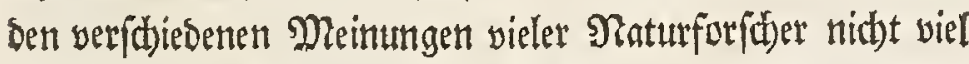
einthefen, und biefelbent prúfen fónnetr. Da auch bie Figus

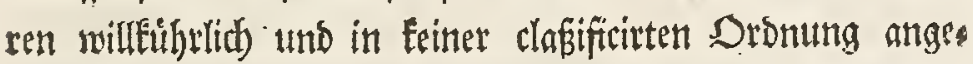

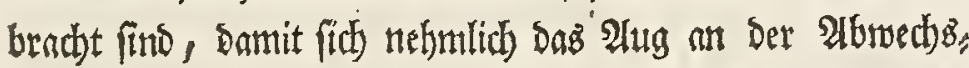

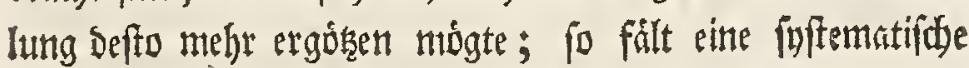
Eintheilung weg, weldje fid um fo viel weniget bey foldsen

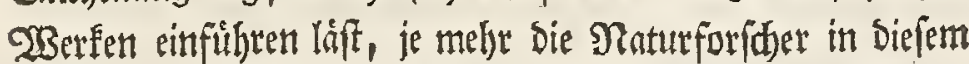

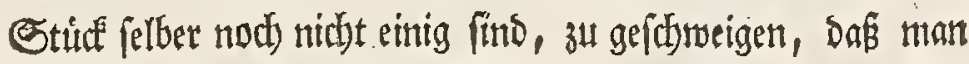
in unferm $23 e r f e$ nidjt alle Arten, fondern nute sinige ber vortehmiften Stúce hat vorftellig madten wollen. Nur bies

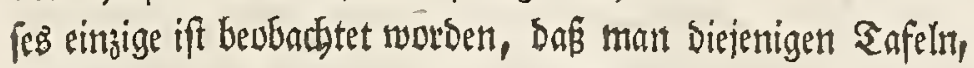
weld)e lauter Sadyen won eirerley J̧auptgattung yor bie গ্A biefe Dronung hat Dem Serrn Zerfaffer SEelegentheit geges ben, in Der Befdreibung, bey einter foldyen Tafel, wo ein gants anderez frad) Der Naturgefibidtete angehet, eine Furze, jebod) unterribtente (Eintleitung tiber bie ganje Sanuptgat tung, weldys in Den folgenten Situfertafeln vorfómt, cinzu

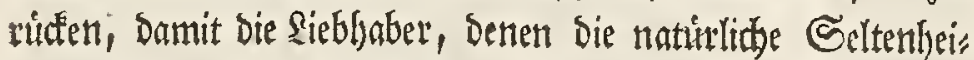
ten not) etwab wirbefant find, einen furien und leidten

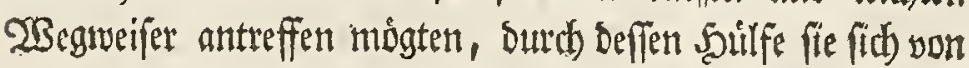
den vifrigen und in biefem $23 e r f e$ nidyt abgebildeten Curiofis, und von beren Sromung unt Miannigfaltigfeit cinen mehr ausgebreiteten Begrif madhen fdonnen.

Wiet.
KNORR, celebre Artifte de Nuremberg, affez connu dans la Republique des Lettres par les ouvrages utiles qu'il a entrepris. Son Zèle, fa Correfpondance étenduë, \& l'appui de plufieurs perfonnes de confidération, qui l'eftimoient, l'avoient mis en éeat de commencer cet Ouvrage, \& d'y poler un fondement tel, qu'il eft facile à les Heritiers d'achever l'édifice, \& de le conduire à la perfection. Car ce que feu Monfr. KNORR avoit déjà travaillé pendant fa vie, \& qui étoit avan. cé au point de le pouvoir mettre fous preffe, fournit tous les moyens de complèter parfaitement ce qui manquoit encore à l'execution entierè de fon projet.

Voilà le Leeteur informé du but du préfent Ou. vrage, \& ce même but fervira de règle à l'arrangé. ment qu'on y obfervera. Ainfi en donnant des figures tirées des trois Règnes de la nature, on s'eft attaché à choifir parmi un nombre innombrable de piéces les plus belles, les plus parfaites \& les plus rares; on a préferé celles qui font moins connues à celles qui le font davantage, \& qui par cette raifon font plus com. munes; on s'eft contenté fouvent de ne produire qu'une feule pièce de toute une Claffe, \& à l'égard de celles, dont on trouve les figures enluminées dans d'autres Ouvrages, on s'eft difpenfé d'en allègner toutes les efpèces \& anomalies, pour que cet Ouvrage ne devint ni trop prolixe, ni trop coûtenx, \& pour ne paș mettre auffi le Lecteur dans le cas défagréable de retrouver ici ce qu'il a vî ou pû voir autrepart. Le 'Texte \& les Defcriptions, qui ont Monfr. MüLLER, Profeffeur à l'Univerfité $d^{\prime}$ 'Erlang pour Auteur, ont eté di. rigées felon ces Vîës. Car on ne s'eft propoté de join. dre aux Figures que les dénominations \& quelques informations utiles. Par cette raifon on n'a pû s'enga. ger à raporter \& à examiner les différentes opinions de plufieurs Phyficiens. Et comme on a placé les Figures arbitrairement, fans s'arrêter à les ranger en Claffes, \& cela pour recréer davantage les yeux du LeEteur par une variation agréable, il ne faut point s'attendre à trouver ici une Divifion Syftímatique, qu'il eft d'autant plus difficile d'employer dans un Ouvrage de cette nature, que les Sçavans ne font pas encore d'accord fur cet article. D'ailleurs nôtre intention ne fut jamais de repréfenter toutes les efpèces, mais feu. lement les principales pièces. Cependant on a obfervé de mettre de fuite les Planches, dont toutes les pièces apartiennent à une feule \& mềme Claffe principale. Et de là Monfr. le Profeffeur à pris occafion de joindre toûjours à fes defcriptions au devant de chacune de ces Planches, où commence un article tout - à - fait nouveau de l'Hiftoire des Curiofitez na. turelles, une Introduction inftructive, quoiqu' abregée, à la Conoiffance de la Claffe principale entière des Pièces, qui fe trouvent fur la Planche, afin que les Amateurs, à qui telle ou telle rareté naturelle pourroit encore être inconnue rencontrent ici un guide $\&$ un fecours, au moyen duquel ils puiffent fe former aufí une idée plus jufte \& plus complette des autres Curiofitez, qui ne font point dépeintes dans le préfent ouvrage, auffi bien que de leur ordre, \& de leur diverfité.

$A 2$ 
Dielleidat aber mógte uns der Zormurf semadt) wer" Den, warum nir eben nut siejenigen Sticfe in siefem 20 erfe zeigen, tweldbe darinneri angetroffen weroen, und feine ande, re? Da dod) fehre viele, und genug botante Eatten in Den Sabineten roáren, bie ifgrer Structur uno ben farben nad) nidft minoer ungemein pratutis fins, und eben fo wofl eine genaue 26bildutng berbietcren? Sf nitbt, werbent moere

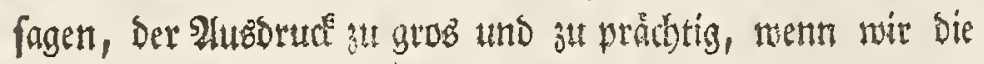
allbier abgebilbeten Eadjen Seltenbetren nennen, und bem ganzen $23 e r f e$ den Titel eines auserlefenen Saturatien= Sabiute geben, aud mituflid) bebaupten, Dap sieje Sa

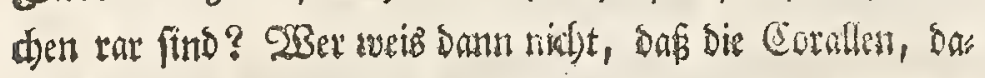

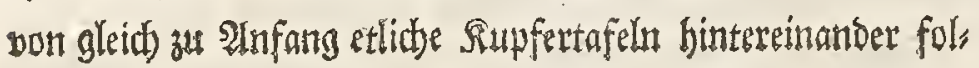
gen, Liberall in Den Officinen und bey Sen Mgaterialiffen ans zutreffen find? Wert hat nidht gehort, woer gelefen, Daß man in Den Siegendert von Inbien, no fie am Strande bálfig gefunden werben, Sialib Dawon brenne, um bie Mauren ba:

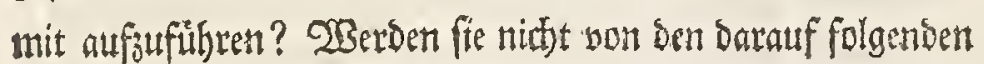

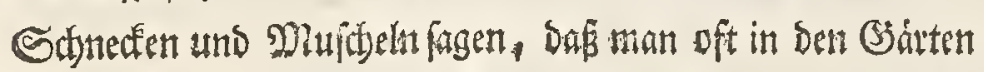

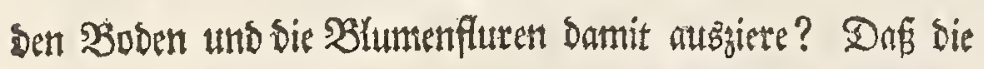
Sdymetterlinge in ifren Siegenten thetall in Dienge herum fliegen? Dap bie Ceeapfel mefyrentheilb in groffer Menge

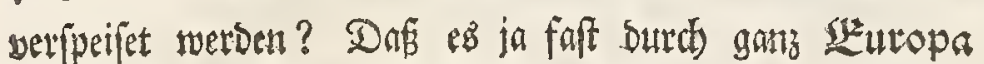
Bergmerte gebe, wo man fubóne Stufen antreffe? Und swet:

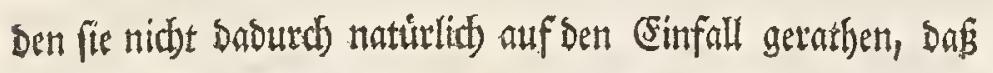

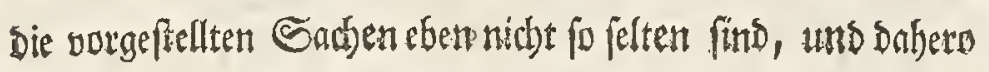

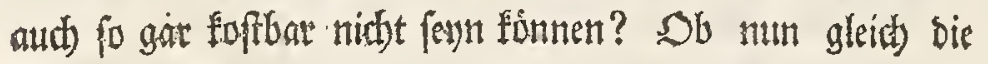
táglidye Erfährung injontorbeit Dem ležteren \$Juncte, went

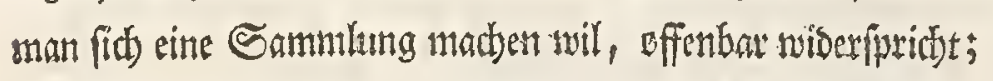
fo wallen wir dod biefen und andern Dergleiden Einwendun

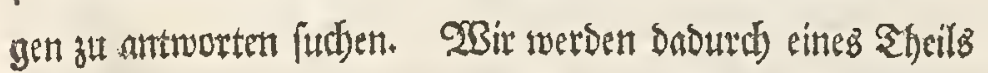
bie 2Babi Der Stukfe, bie wir in biefem 283 erfe getroffen baben, rectifertigess, und anderen Stbeils ein ziemlith allge"

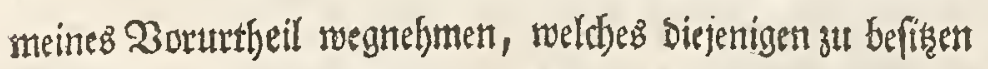

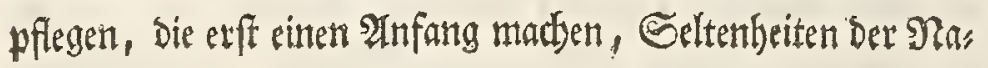
tur zu fammlet, und weldye in Der Einbilloung feften, Dos man folde Curiofa jegr leidbt, und mit wenigern Roffen exhalten

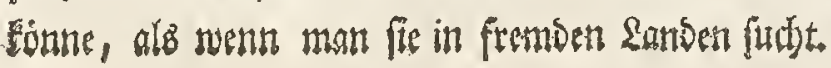

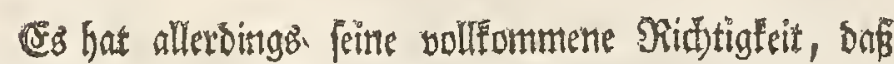
Die Natur, too fie ohne Saindernifie und gleidjam in der Stils

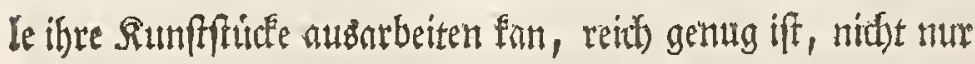

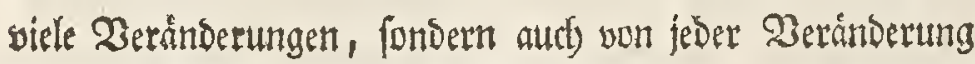
eine unglaublidbe Menge hervor zu bringen, who fie thut auch joldes wirflich, wo nidyt mit allen, sod) mit bert mei,

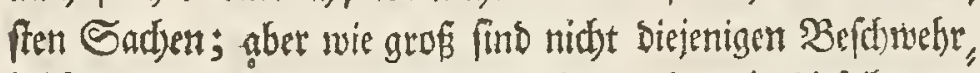
lidfeiten, twomit wir zu freiten baban, ebe wir diefelten er,
Il y a quelques Objections qu'on pourroit nous faire, \& que nous fommes bien aifes de prévenir. On pourroit par exemple nous demander pourquoi nous avons juftement donné les Figures qu'on trouve dans le préfent ouvrage, \& pourquoi dans nôtre choix nous n'en avcns point admis d’autres? vû qu'il y a dans les Cabiners des Curienx quantité de pièces, \& même des pièces affez conuës, qui quant à leur ftruCure \& à leurs couleurs, ne font pas moins magnifiques que les nôtres, \& meriteroient tout autant d’être definées \& énluminées avec la même exactitude. D'autres s'avifier ont peut - être de nous reprocher que nous nous fommes fervís d'une exprefíon trop faAtueufe en donnant le nom de Raretez aux pièces, dont nous préfentons les Figures à nos Lecteurs, ou qu'il y a de la vaine gloire dans nôtre fait, quand nous voulons que nôtre Ouvrage foit confidèré comme un Recueil choiff, pour former un Cabinet de Curiofitez naturelles, \& que nous foutenons que les Pièces qui le compofent font réellement rares. Car qui ne fait que les Coraux, dont nous livions dés-le Commencement quelques Planches de fuite, fe trouvent dans les Apoticaireries, \& dans les boutiques des Droguiftes? Qui n'a pas ouĩ ou lû que dans ces Contrées des $I_{n-}$ des, où lon trouve les Coraux en quantité fur le rivage, on en cuir de la Chaux, dont les habitans fe fervent pour bâtir des murailies? Ne peuvent-ils pas dire encore qu'on fe fert des Coquilles \& des Moules, qui viennent après ces Planches, pour embellir dans les Jardins les Allées \& les Parterres? N'y peuvent* ils pas ajouter qu'on voir voitiger les Papillons en quantité chez eux? \& des Heriffons de Mer en abondance fur toutes les tables bien fervies? Peut- on nier de plus que tous les Païs de l'Europe ne foient fournis de mines, d'où l'on tire les plus belles glèbes? Et toutes ces Confidétations ne cunduiront - elles pas ces Faifeurs d'objections à penfer que nos pièces ne méritent pas tant l'épithète de rares, \& ne fauroient par conséquent être fi précieufes? Il n'y a point de Collezteur, qui ne fçache par fa propre expérience que ces raifons, \& particulièrement la dernière, ne font nullement fondées. Cela ne nous empêchera pas d'y répondre, non feulement parceque nous aurons par là le moyen de jultifier le choix que nous avons fair des pièces qui compofent le préfent rẹcueíl, mais auffi parceque cela nous fournira l'occafion de détruire un Préjugé affez génèral, qqu’ont ordinairement tous ceux, qui commencent à faire une Collection de Curiofitez naturelles, \& qui croient qu'on peut raf. fembler ces raretez avec facilité, \& à peu de frais, fans les aller chercher dans les Païs étrangers.

Nous n’avons garde de difconvenir que la Nature, quand rien ne l'empêche de pelfectionner l'es opérations, \& qu'elle peut ainfi parachever fes chefsd'oeuvre fans obftacle, \& tranquillement pour ainfi dire, eft affez riche, pour produire non feulement des Ouvrages variez à l'infini, mais aufí pour fournir une quantité incroyable d'individus de chaque variation, \& c'eft ce qu'elle fait le plus fouvent, fi ce n'eft à tous égards. Mais par combien de difficultez n'ert- 


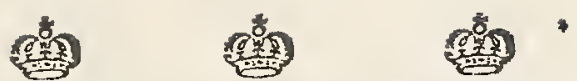

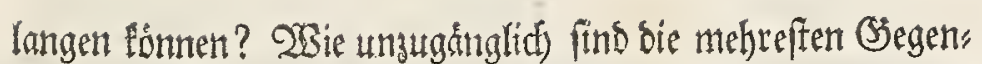
Den, Da biefe Sunfrftute Der arbeitfamen शaatur gefunden werben? OSie wentig gibt es seute, Denen man die Eurge

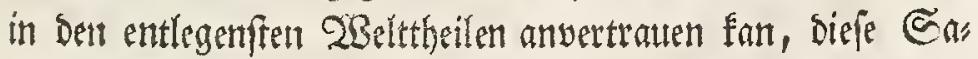
djen zu futhen? Ind wie viele mithe und Soften verurfad)et

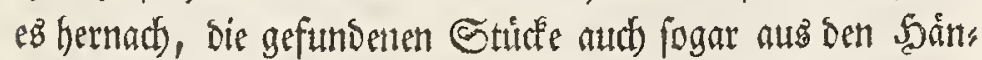
Den Der Uumiffenden zu lofen, unt fie vor Dem, auf allerfand Art mơgliden Untergang in unfere Siabineter in Eichertheit

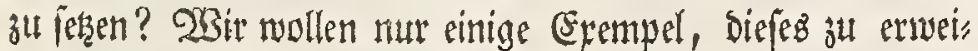

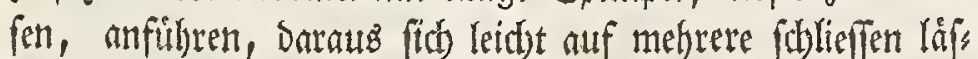

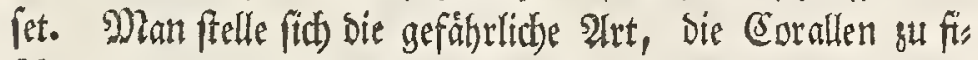
forten, einmal vor. Sie fitsen an Den Slippen Des Meeres in einer unteriftiesenen Siefe von vielen Slaftern. Die Giegenders ifses silufenthalts milfen meth errathen, als mit einer Buverlåfigfeit beftimmet merben. EB uriro einige Mlaminfhaft nit Den geborigen Banquen, Ebaluppen, uno

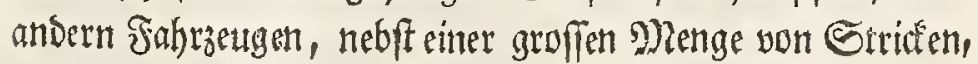

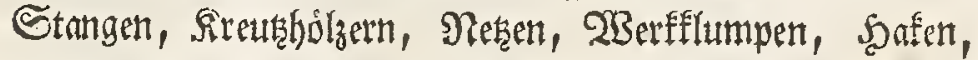
und bergleicten, erfordert, eine Siftherey anzuftellen. Mit

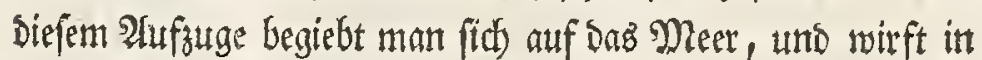

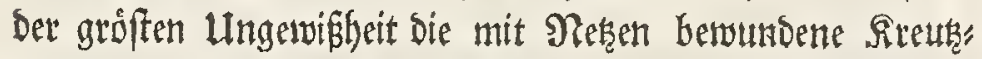

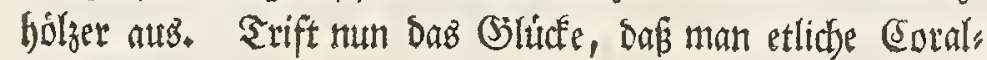
lengemáchje zu pacten befómmt; fo ridjtet bie (Stenalt, two" mit man bie Striffe nieber in bie bidge winden mus, um die Corallen won den Rlippen absureiffen, oft in Sen fitgonfen Sturefen bie grófte Berftshthung an. Ltno wann fie auth nur an Den zarteften Spisen abbrechen, fo beftehet bod ber gan" ze Fang in einer Menge unanfehnlider Erummer. Bumei"

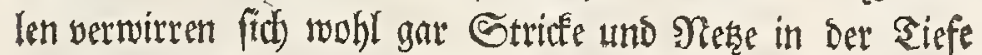
fo untafloflict), Das man alles im Stidbe laffen, und abfaps pen mus. 2rsie ungemein felten trift es Demnad, Dás eins mabl sin ganjers und aud) nur einigermaffen volffrándiges

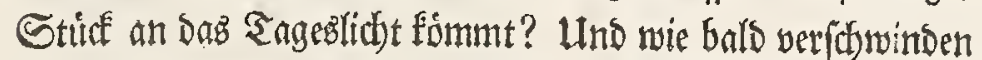

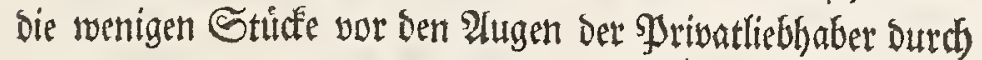

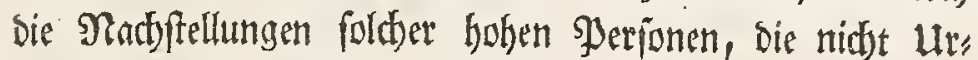
fache haben, ben Beuttel zu Siathe zu ziehen, uno fitjon vont langer Beit her wadben, foldse felten vorgefundene Cabinets

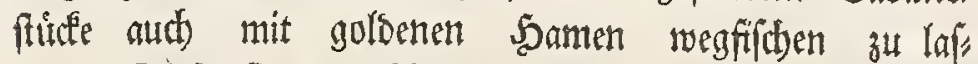
fen? Diefes find mun fogon bie Shidefaale der in Fabrifen unt in Den Officinen braudbGaren rothen uno weiffen Corals

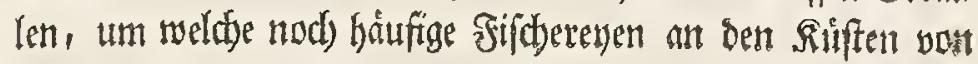

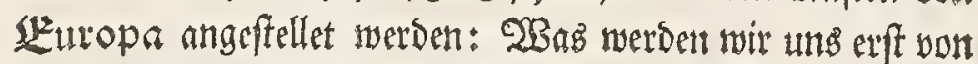

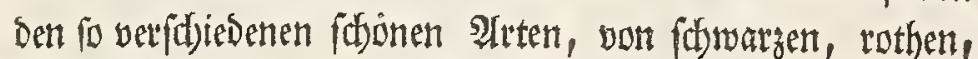
weiffen, ád)ten uno unád)ten Corallen vorftellen múffen, wels 4) bie entlegenen Indien zum 23aterlande haben? Lm wets

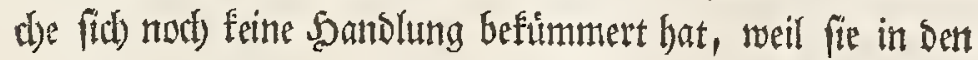
Officinen und rabrifen nidbt gefuchet werben, fondern blok zut Bierath Der Cabineter bienent? Man findet tibetbies in Den Dafigen (Begenten nidgt Seute genug, Die fich Damit abger bon, und sarum berwerben. Eineztbeils feflet es ifnen an

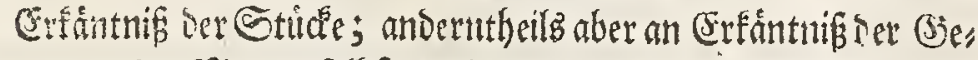

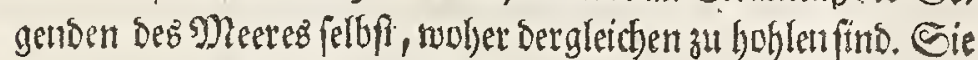

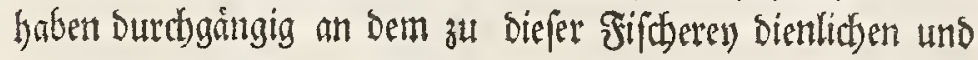

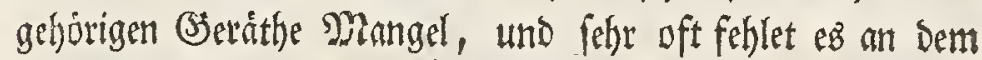
zutreidyettoen $3 e r l a g$, um bie Lunfoften zu einer fo ungentifent Gache in einem gelbreidyen Sande, wo alles fecthsfact bezabs:

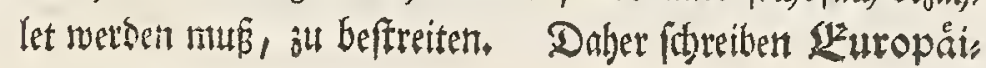

on pas arrêtè quand on veut fe piocurer ces tréfors? Et quelle ftérilité ne rencontre- $t$-on pas dans la plûpart des Contrées-même où l'on croit trouver, de ces raretez? Veut - on les faire venir des Paîs les plus éloignez dans toutes les parties du monde connu, où trouvera-t - on des perfonnes à qui l'on puiffe confier le foin d'une pareille recherche? Et quels travaux \& quels frais n'en coute- $t-i l$ pas enfuite pour arracher les pièces trouvées des mains des ignorans, \& les mettre en fûreté dans nos Cabinets, comme dans l'unique afyle, où elles puifent être en fûreté contre toute forte de dépériffement. Illuftrons ce que nous avançons par quelque exemple, d'où l'on puiffe tirer des Conséquences ultérieures. Qu'on fe reprélente d'abord tous les dangers qui accompagnent la pêche du Corail. Les Coraux font attachez dans la Mer à des rochers, à profondeur inégale, mais qui eft toûjours au moins de plufieurs braffes. Il faut deviner les Contrées ou on en trouve, car il n'y a point de règle sûre à cet égard. Plufieurs Travailleurs y font employez, avec les Barques, Chaloupe, \& autres bâtîmens néceffaires. Cette Pêche exige outre cela une grande quantitê de Cordages, de perches, de barreaux en croix, de rêts, de pelotons d'etoupes de crocs \& outils pareils. C'eft avec cet attirail qu'on fe met en Mer, \& que, trés - incertain da fuccès, on y jette, les barreaux en croix garnis de leurs rêts. Supofé qu'on ait le bonheur de rencontrer quelques plantes de Corail, \& qu'on veuille guinder les cordes, pour arracher les Coraux du Rocher, où ils fe trouvent attachez, il arrive fouvent qu'on en ruine \& détruife les plus belles pièces, \& quand on n'en briferoit que les bouts ou chevilles, toute la capture ne confifte alors que dans quelques morceaux rompus, qui ne lont d'aucune confidération. Il arrive auffi quelquefois que les Cordages \& les rêts s'entortillent \& s'embrouillent tellement au fond de la mer, qu'il n'eft plus poffible de les démêler, \& alors il ne refte d'autre parti à prendre que celui de tout abandonner, \& de couper les Cables. Il eft donc trés - rare qu'on parvienne à tirer de la Mer un arbufte entier, ou tant foit peu complet, \& le petit nombre de pièces pareilles eft d'abord enlevé aux Perfonnes de Condition privée par celles de haut rang, qui font à l'afut, \& que leurs richeffes mettent à même de prodiguer l'or pour fe fatisfaire \& pofsèder de ces Pièces de Cabinet à l'aquifition desquelles on parvient fi rarement. Il en arrive ainfi du Corail rouge ou blane, pour lequel on en. voye tant de gẹns en péche fur les côtes d'Europe, pour l'ufage des Fabriques \& des Apoticaireries. A plus forte raifon $a-t-o n$ de bien plus grands ob. ftacles à vaincre pour le procurer la poffeffion de tant de beaux Coraux divers, noirs, rouges, blancs, véritables \& bâtards, qu'on ne peut trouver qu’aux Indes, \& pour lesquels les Negocians ne fe donnent aucune peine, parceque ces belles pièces ne font d’aucun ufage pour les Apoticaireries \& pour les Fabriques, \& qu'elles fervent fimplement à orner un Cabinet. Dailleurs on ne trouve pas facilement aux Indes des gens qui veuillent s'employer à cette

pêche, 


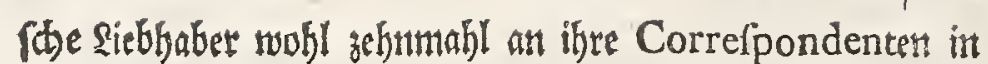

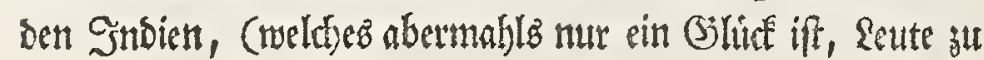
einem folden (Jefdhafte zu befommen, ) ebe fie nur cinmaht mit einem feltenen $233 e r f e$ Der Siature erfiteuct werben. Lino wenn man fith gegen Dergleithen Dienfffertigfeit nicht unge: mein frengebig bezeiget; fo mus man lange anf ein 3ncys tes Stuid warter. Bespect nun aber, man biste biefen Sunct in Ridt)tigfeit gebratbt; fo finben bie Correfpon-

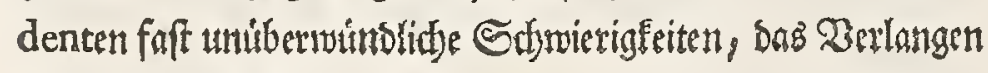
oet siebbaber a futllen.

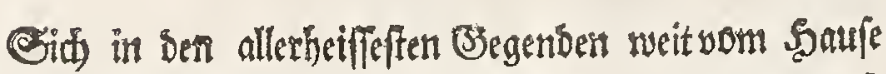
mad Dem Strande bin zut entfernen, wo man of ters mit feiner Barquen, Der Rlippen balber, bintoms

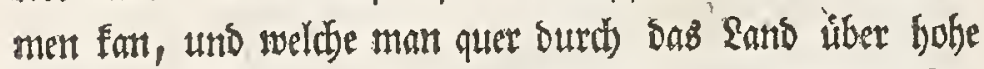
Berge erft sull erfteigen hat; Dafelbft etlicbe ungejojifte Int

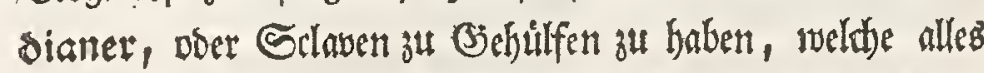
verfehtet angreifen, bie gefundenen Struffe robe und grob bes handeltu, bie zarte Structur, Daran Sen Siebhabern am meis ffen gelegen ift, Durd Unworfidtigfeit zerfredyen und ver Derben, uno hertach ambehutam rtlidye Meilen weit mady Saufe tragen; ferther bey folden nidbt obne viele Soffen ans

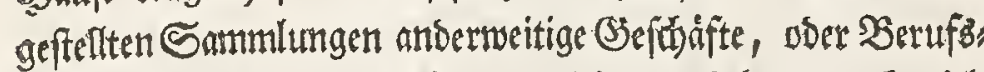

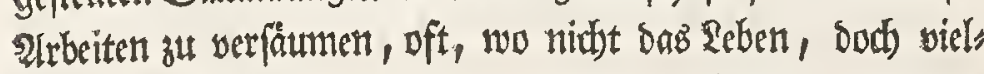

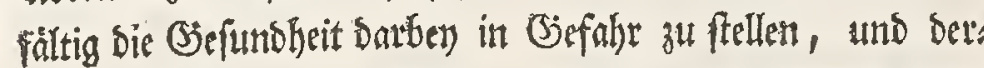

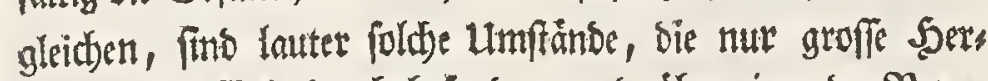

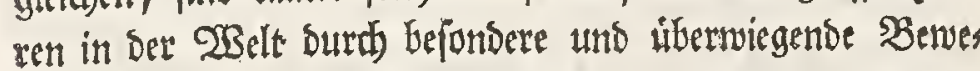

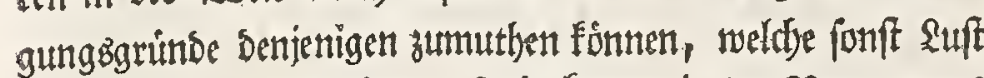
genug haben, zur Siebe ber Entserfungen in ber Natur etwa

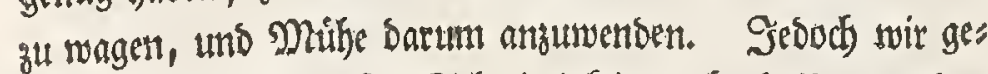
ben zu, Daf atth biefer Ectwierigketen abgebolfen werden

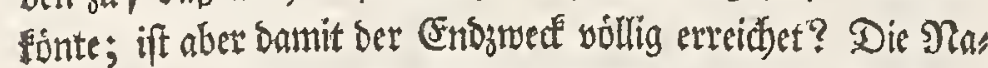

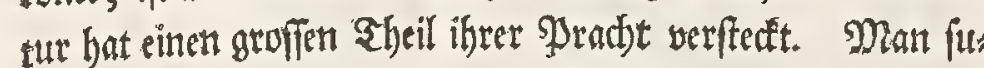
d)et oft eine gante $\mathfrak{W o d b e}$, unt findet bod nichts. Mian fifhet, und fîngt nidfts, weldyes alle sie gemtatiten grofien

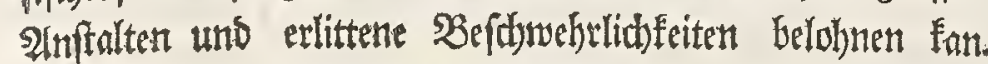
Denn man irret fith, wenn man glauten wolte, es lígent bies fe Geltentheiten in Den Sonbien úberall ba, und man sórfte fie wur auffeben. Sat man berm endlich cin unto andere Stricfe

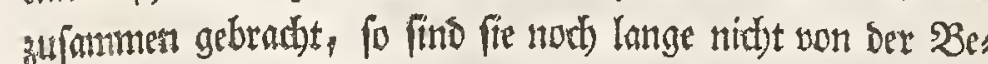
(1) affenheit, wie biejerige, welche wir allbier abgebille lies

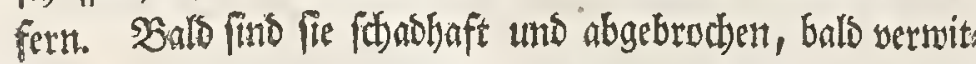
tere, woer mit einem faldjidten Seefolam úberzogen, ballo mangeln ifnen bie Farben, Deer Der Btant, Doer bie feine

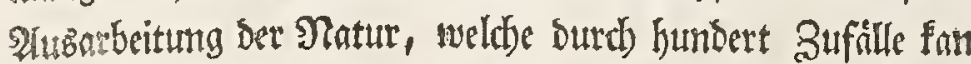

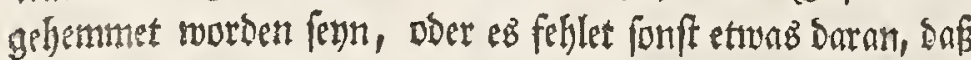

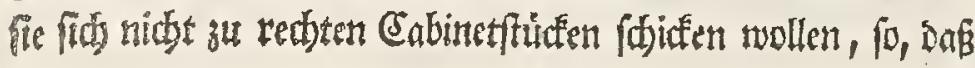

pêche, \& fe charger dun pareil travail, fuit qu'ilsmanquent des Conoiffances nécelfaires, foit qu'ils ne foient pas au fait des Plages de la Mer où il faut chercher le Corail. En génèral ils manquent tous des attirails \& des outils néceffaires à cette Pêche, \& trés-fouvent des facultez qu'exigent les frais dont le fuccés eft fi incertain. Car dans ces paîs où l'or \& l'argent abondent, le travail des hommes eft fix fois plus cher que dans nos Climats. Delà vient que les Amateurs Européers, en cas-même qu'ils ayent le bonheur fingulier d'avoir aux Indes quelque Ami, qui veuille bien pour l'amour d'eux fe charger de s'employer à une pêche pareille, ce qui eft déjà trés-difficile à trouver, écrivent bien dix Lettres à leur Correfpondant Indien, avant d'en pouvoir tirer une feule pièce rare. Et s'ils ne font pas prodigues dans leurs recompenfent, \& qu'ils ne payent pas libéralement le Correfpondant qui les a lervis, c'eft en vain qu'ils s'attendront à un fecond Envoi。

Mais fupofons que cet Article foit regléa la latisfaction reciproque de celui qui donne \& de celui qui reçoit, il y a bien d'autres difficultez presque infurmontables, qui s'opofent à-la fatisfation des Amateurs, \& mettent leurs Correfpondans dans une efpéce d'impoffibilité de remplir leurs défirs. Car de fe transporter dans ces Païs brulans de chez foi jusques à des rivages, dont fort fouvent les barques ne peuvent s'aprocher à caule des rochers \& des écueils, \& auxquels mêmes on ne peut parvenir, qu'apì̀s avoir franchi de hautes Montagnes en traverfant le Païs; n'avoir d'autre aide pour le travail que quelques Indiens ou Efclaves mal-adroits, qui font-tout à rebours, \& qui en maniant avec rudeffe \& groffièrement les pièces trouvées, en rompent, brifent, \& ruinent imprudemment la ftructure délicate \& fine, dont la Confervation importe le plus à l'Amateur; qui d'ailleurs en portant ces pièces au Logis à la diftance de quelques lieuës n'ufent d'aucune précaution ni ménagement; négliger avec cela fes propres affaires \& d'autres occupations pour s'employer à une Collection incertaine, \& toûjours fujette à des frais confidérables, hazarder fouvent fa fanté \& quelques fois la vie, \&c. forme un total de différens facrifices qu'un grand Prince feul peut exiger. Encore faut-il qu'il employe pour 'cela les motifs les plus preffans, \& que celui qu'il employe foit porté par fápropre inclination \& par l'envie d'aquerir des Conoiffances dans l'Hiftoire de la Nature, à hazarder quelque chofe, \& à braver tous les travaux. Accordons encore que cela puiffe arriver ainfi. On n'a pas atteint entiérement le but pour cela. La Nature a caché une grande partie de fes richesfes. On cherche des lemaines entières fans rien trouver. On pêche, \& on ne prend rien qui puilfe dédommager des peines qu'on s'eft donné, ni des incommodités qu'on a efluyé. Car on fe tromperoit fort fil'on croioit, que ces raretez fe trouvent par tout aux Indes, \& que dans ce païs il n'y a qu'à fe bailier \& prendre. Je veux qu'aprés bien des frais \& des travaux, on ait enfin ramalfé quelques pièces, il s'en faudra encore de beaucoup que ces piéces puif- 
总 踲

ez in Den Jindien feltbit, und an den Dertern, wo man bie

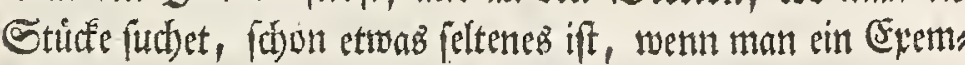

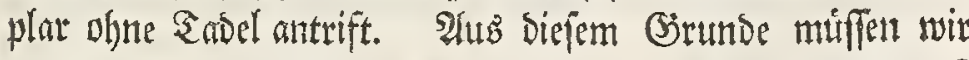

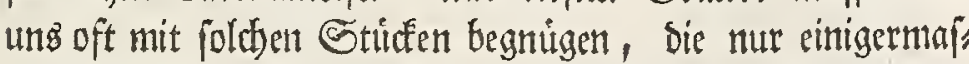

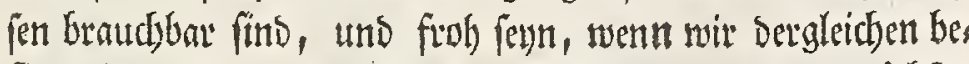

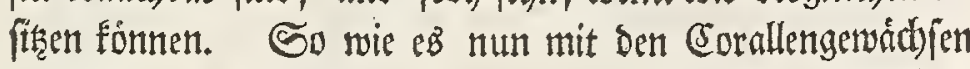

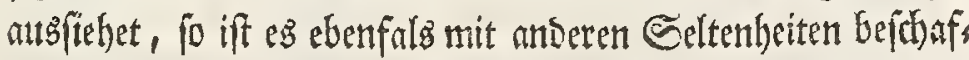

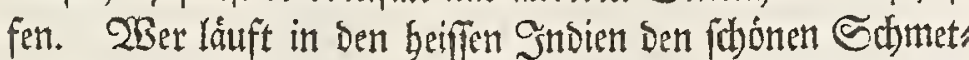

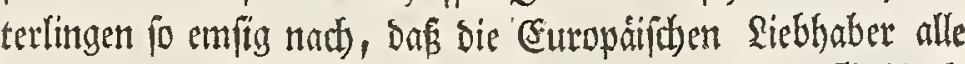

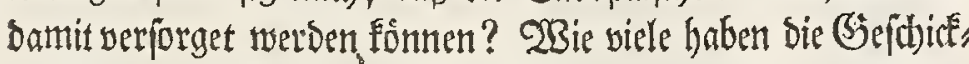

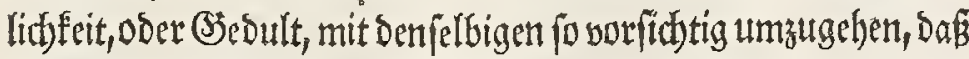

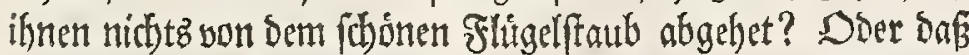

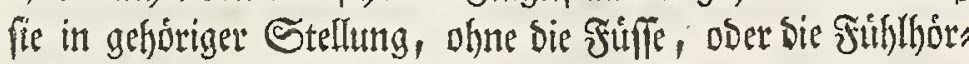

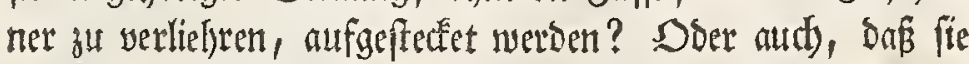

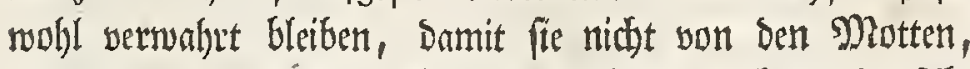

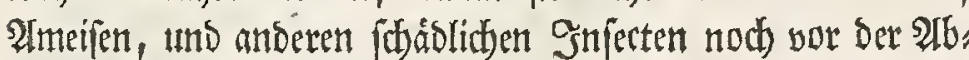
fendung bavon getragen wersen? WBe felten werben bie

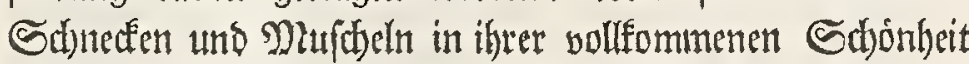
gefunten, Da befant iff, Daß Feinem an bem Strand getwor,

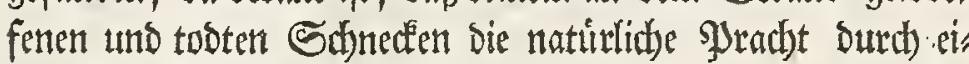

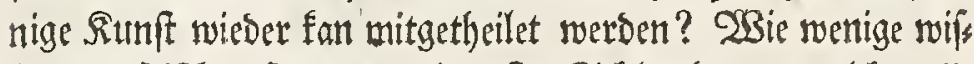

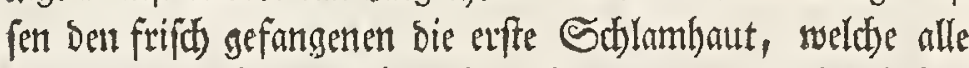
Ectjóngeit verbirget, absunehmen? Lund wie wenige habent

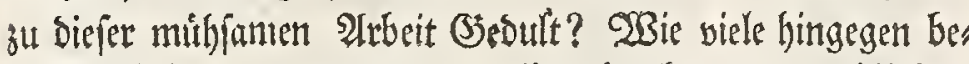

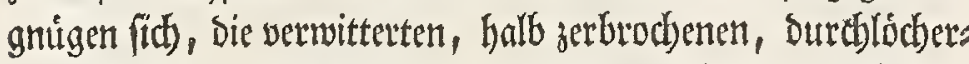

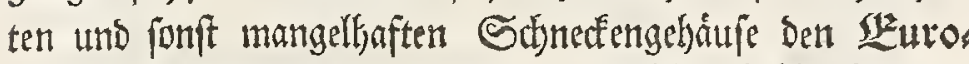

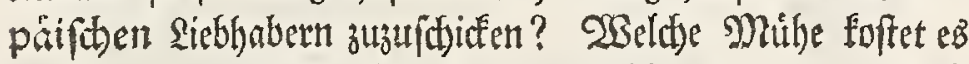
nicht, bie groffen Seefferne in einer gehórigen \&age zu trof?

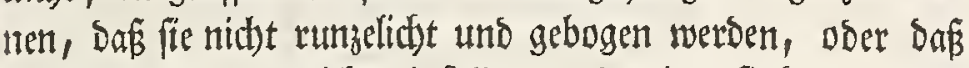

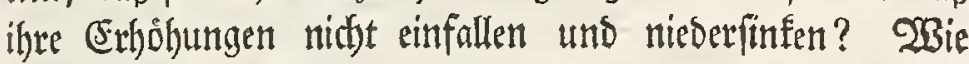

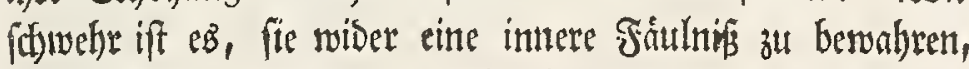

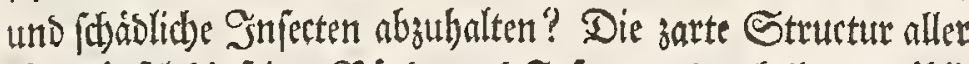

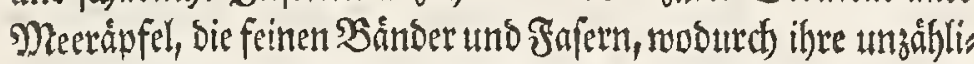

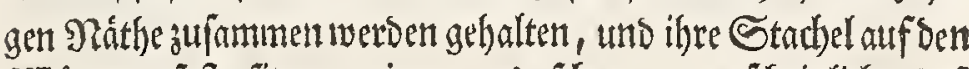

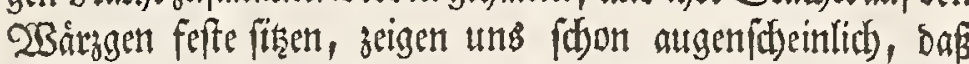

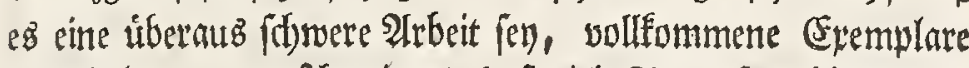

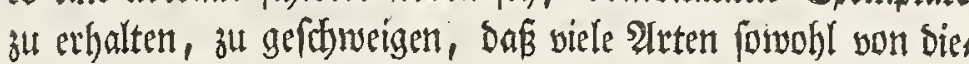

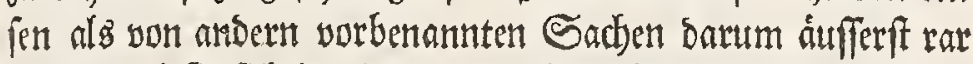
find, weil fie fith in einer unergrinthblidyen Fiefe bez Mieres

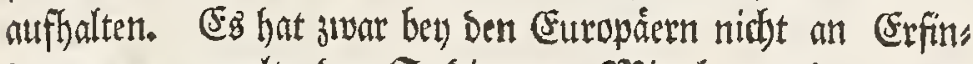
bungen gemangelt, Den Indisnetn Mittel za zeigen, wie

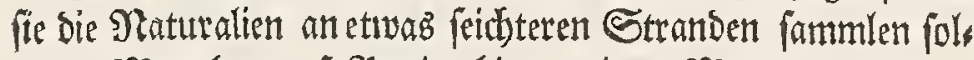
Ien. Dian hat auf Jyapier finter einer Menge gemablten

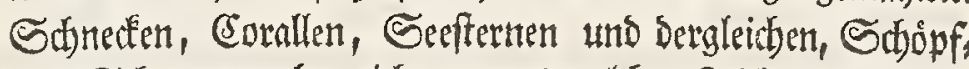

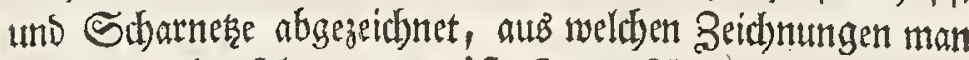

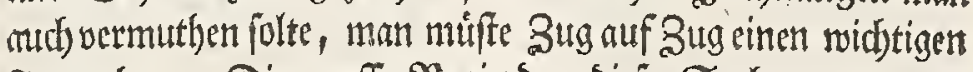
Fanng thun. Die groffe פBegierse, Diefe Sachen aus bem Dieere heraus at bringen, Gat ferner bie Riebbaber in Den

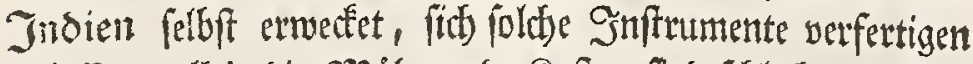

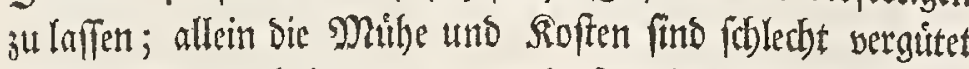
worben. Denn bald zog man mit freetbiger SBegierbe eine grofle saft aus bem 23 affer, und fiebe,

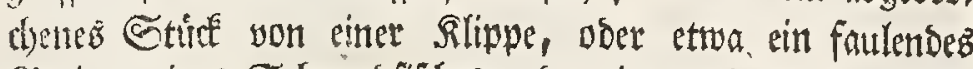

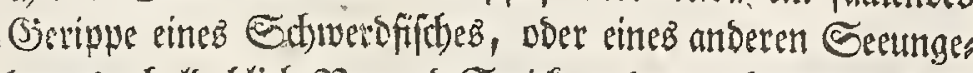

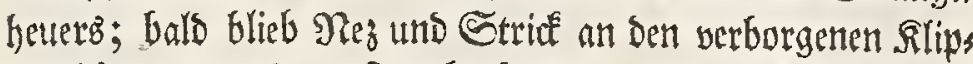
pen bången, und murfe abgefappet werben; ballo langete

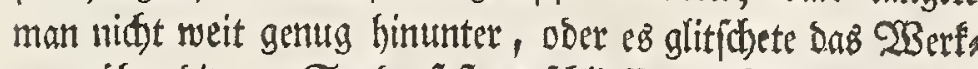
zeng úber bie am Sanbe fefte anithlieffente Meertfiere weg. Es bleibet alp beftaindig eine múbjame Eache, weldhe nur

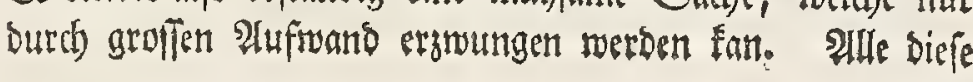

\section{8}

fent être comparées à celles, dont nous préfentons ici la figure à nos Lecteurs. 'Tantôt elles font endommagées \& rompuës, tantôt elles lont gâtées par les injures des faifons, ou couvertes d'un enduit visqueux qui eft une efpèce de chaux, tantôt elles font défectueufes par les couleurs, par le brillant, ou parce que la nature n'y a pas mis la dernière main, ce que toutes fortes d'accidens peuvent interrompre, ou elles pèchent par quelque autre défaut, qui les exclut de tout Cabinet de pièces choifies. Car aux Indes, \& aux plages même, où l'on à coûtume de chercher ces pieces, il eft rare d'en trouver une feule, qui n'ait point d'imperfeEtion. Cela nous met fouvent dans le cas de nous contenter de pièces, quil foient tant foit peu préfentables, heureux encore quand nous pouvons en aquerir de pareilles. Il en eft des autres raretez, comme des Plantes coralines. Qui eft - ce, qui dansle Climat brulant des Indes fe refoudra à s'expofer aux ardeurs du foleil, pour courir a la Chaffe des plus beaux Papillons, pour en fournir à tous les Cabinets des Européens qui font des Collections? Peut - on fe prometre de trouver des Commiffionnaires, qui ayent l'adrelfe, la patience, \& la circonfpection néceffaires, pour faire parve. nir ces Papillons, en Europe, fans que cette pouf fière, qui fait toutella beauté des ailes, fouffre aucun déchêt? ou qu'en les empaquetant on ufe des précautions convenables pour qu'ils ne perdent en chemin ni jambe, ni corne? ou qu'on pourvoye à ce que les tignes, les fourmis, \& d'autres Infectes malfaifans n'y puiffent aporter aucun dommage, mếme avant l'envoi? Et pour parler d'un autre article ne fait-on pas qu'il n'eft pas poffible de rendre par aucun art aux moules, ou aux Efcargots morts, jettez fur le rivage, leur beauté naturelle, \& par conféquent trés-rare d'en avoir qui foient parfaits? Et quand on les a pris vifs, peu de gens s'entendent à leur ôter cette prémière peau visqueufe, qui cache toutes leurs beautez. Où prendre des gens qui veuil. lent fe charger d'une occupation fi pénible? Le plus fouvent le Commiffionnaire fe flatte d'avoir fatisfait à tout ce qu'on peut exiger de lui, quand il a envoyé à fes Amis d'Europe quelques Coquilles gấtées par l'intemperrie des élemens, à demi brifées, trouées, ou autrement défectueufes. Quelle peine n'en coute - $t$ - il pas pour fécher les grands poiffons formez en étoile, (") dans la pofition convenable, pour qu'elles ne fe rident ni ne fe courbent, \& pour que leurs élèvations ne s'affaiffent pas? Quelles diffcultez ne trouve-t-on pas à les garantir d'une pourriture intérieure, ou des Infeetes nuifibles au de. hors. La Conftruation délicate de tous les Heriffons de mer, les ligamens \& filèts fubtils, qui tiennent leurs futures innombrables jointes, \& leurs aiguil lons affermis fur leurs bouts, font autant de parties qui rendent trés - difficile \& trés - rare le bonheur d'en aquerir, qui foient accomplis de tout point, fans compter qu'il n'eft nullement ordinaire d'en trouver, par ce que ces animaux fe tiennent au fond des abîmes de la Mer, où il n'eft guères poffible de pénètrer. Il eft vrai que les Européens n’ont pas manqué d'Inventions pour enfeigner aux Indiens les moiens de pêcher \& de ramaffer des Curiofitez natuo relles à des rivages, où la Mer eft moins profonde. On leur a fourni des deffeins d'épervier, de tramail, \& d'autres filèts derrière quantité de figures-d'Escargots, de Moules, de Coraux, d'Etoiles de mer \&c. dépeintes fur du papier, \& en voyant ces deffeins on eft tenté de croire, qu'avec de tels lecours on ne fçauroit manquer de faire coup fur coup des prifes confidérables. Le défir extréme de tirer ces ra. retez de la mer a auffi porté les Amateurs domiciliez $\mathrm{B} 2$

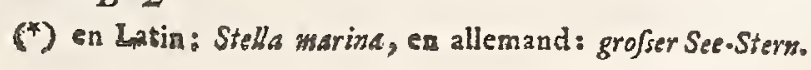




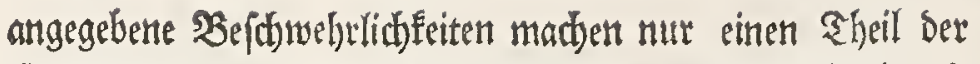
Sinberniffe aub, warum bie (Eabineter nict)t burd)gángig mit

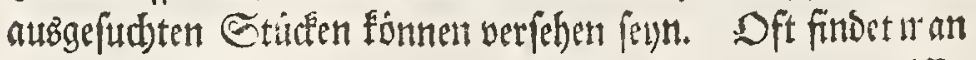
wobl gutte Stelegentheit ou einer Sadte; aber man bermifiet

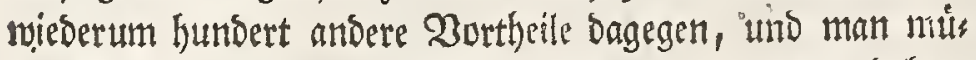
fte faft burch Die ganze $2 B$ elt Diener und Sreutbe baben, wernt man mit allen Irten ber Sadjen veriorget fenth wrolls

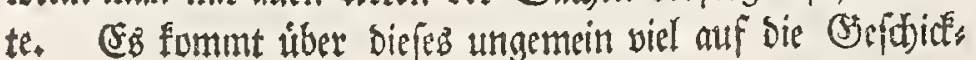

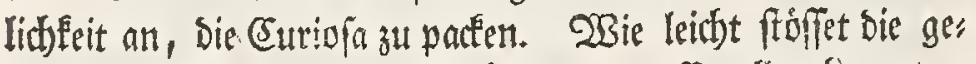
ringfte Erifhitterung eine Binfe won ben Corallen berunter, ober fprenget bie Seeaepfel autseinander, ober reibet bie Jjo, Inpentinde won dem bornecoral herab? Woie gerne giehen sie

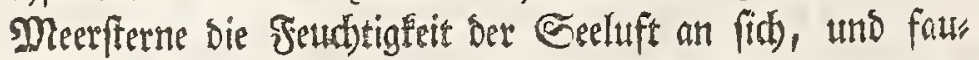
len, aller Borfictst unetadtet? SBie oft beformmt man bie Snlecten won Den Motten Durdffreffen? WBie oft wirt Daz,

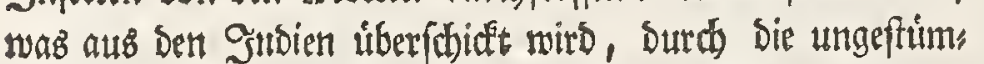
men Wellen Dez Meeres in den Abgrunto verfenfet? Soder wie oft mangelt es an einet getretuen SBeftellung? Dod swir

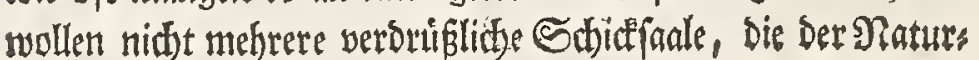
gefdjitite begegnen funnen, anfilfren.

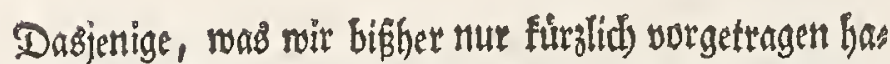
ben, wirb indeffen, wie wir glauben, genug fern, ben Ens gued reditfertigen, und wir hoffen foldhe Stuide bor Itugen geles get ju haben, bie nidts jeber Sanmler, boer Siebfaber befitet ja bie nicht einjeber, wenigftenz nidht in wollfommener bractst geêhen hat. SBir behauptent aud, Das unfere Exemplare zum Theil nidot allegeit und úberall jo bátufig uno gemein zu baben fints, bas fite ein jeber Siebbaber, deren 2 (ntabl ia alle Tage groffer wirb, fo bald sula ammen befommen werbe. Wir theilen enslids Stute mit, beren Uriprung, Name, Baterlanto und Dergleidfen nidyt einem jeden fo fehr befant feyn werben. Wenn wir bemnach bie vorfommenten Sadjen

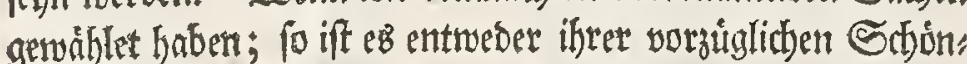

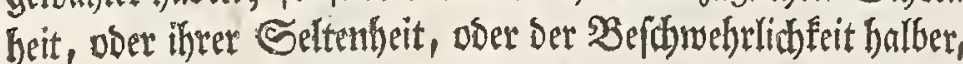

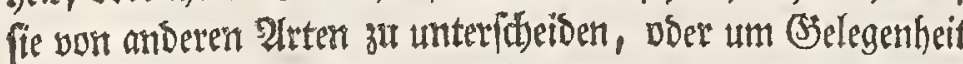

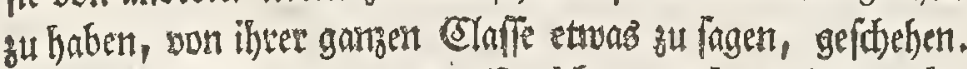

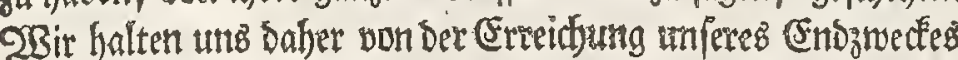

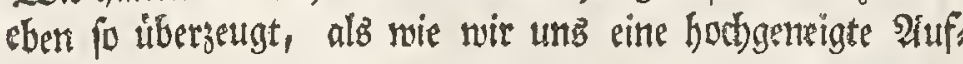

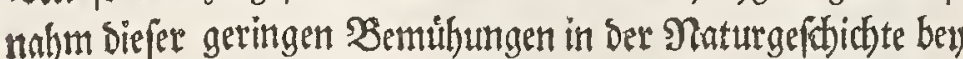
Denenjenigen Siebrabern verfuredten, welche miffen, Das bie

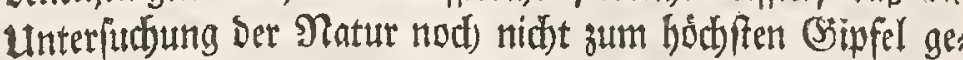

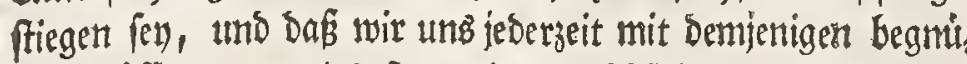

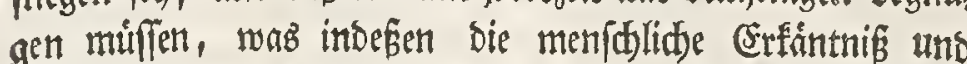
Muibe entoectert fonte, bís sine weitere Unterfutumg ge lehrter Mlánner an bas Sages sidft bringet, was bié hieher rod in Der গatur vor unferen 2Atgen werborgen geblieben iff. aux Indes à fe pourvoir de pareils inftrumens. Mais leurs frais \& leurs peines ont êté peu recompensées. Tantôt la joye des Pêcheurs étoit excitée par quelque gros fardeau, dont la pélanteur encourageost leurs efpérances, \& quand ils l'avoient tiré de l'eau à force de travail, ce n'etoit qu'une pièce détachée de quelque rocher, ou la charogne à demi - purrie de quelque efpadon, ou d’un autre Monftre marin; tantôt les filèts \& les cordages s'accrochoient à des rochers cachez fous l'eau, de façon qu'on étoit forcé de les couper; d'autres fois on n'avançoit pas affez vers le fond, ou les outils gliffoient fur les Animaux marins fermement attachez au fable. 'Tout cela procive combien ces recherches font pénibles, \& qu'on ne peut $s^{\prime} e n$ 'promettre quelque fuccès qu'en $y$ lacrifiant de trés - grands frais. Avec cela toutes ces difficultez ne font encore qu' une partie des obftacles, qui empêchent que tous les Cabinèts ne puiffent être pourvứs de pièces choifies. Il fe préfente par fois une occafion favorable, pour avoir quelque bonne pièce, \& en échange on manque autrepart cent autres avantages. Il faudroit avoir presque dans tous les paìs du Monde des amis \& des ferviteurs à em. ploier, fi l'on vouloit avoir des pièces de toutes les efpèces. Un point trés - important, c'eft le talent d'empaqueter les Curiofitez. Le moindre Cahotement peut mettre à bas un bout, ou Cherille, d'un Corail, ou brifer un Heriffon de mer, ou détacher l'Ecorce de Polype de deffus le Corail de nature de corne. Les Etoiles marines attirent beaucoup à elles l'humidité del'air de la mer, ce qui les fait pourrir, malgré toutes les précautions qu'on peut prendre. Combien de fois n'arrive-t-il pas que les Infeetes nous parviennent rongez par les tignes? ou que les Caiffes entières périffent fur Mer, telies qu'on les a expèdiées des Indes, ou qu'un Expèditeur infidèle nous dupe? Mais c'eft affez parlé des accidens facheux auxquels les Amateurs des Curiofitez naturelles font expofez, avant de parvenir à leur poffeffion.

Ce que nons avons dit fuffit pour juftfer parfaitement nôtre 'Titre, de même que le but \& l'arrangement de tout nôtre Ouvrage, dans lequel nos Leeteurs trouveront des pièces, que tout Collecteur ou Amateur ne poffede pas, \& que le plus grand nombre d'entre eux n'a peut-être jamais vûës, du moins dans ce dégré de perfection. Nons croions pouvoir ajouter que les pièces que nous livrons, ne fe trouvent gas toûjours \& par tout en affez grande quantité, pour que tous les Amateurs, dont le nombre croit journellement, puiffent les raffembler aifément. Enfin nous communiquons des pièces dont l'Origine, les Noms, les Climats quiles produifent, \& d'autres Circunftances acceffoires le trouveront être encore inconnuës à plufieurs de nos Lecteurs. C'eft ou la beauté extraordinaire des pièces, ou leur rareté, ou la difficulté de les diftinguer de celles d'une autre efpèce, qui nous a déteıminé dans notre Choix, \& nous avons toûjours pris occafion de dire quelque chofe de la Claffe entière de chacune. Ainti nous nous perfuadons d'avoir rempli nô. tre Plan, \& nous nous flatons que les Leeteurs, initruits que l'Etude de la Nature n'a pas êté pouffée encore à fon pius haut dégré, voudront bien accneillir favorablement nôtre travail, Ccachant que nous rommes obligez de nous contenter des Conoiffances auxquelles il a êté poffible d'atteindre jusques ici, en attendant que quelque Scavant laborieux sille plus loin dans fes recherches, \& nous découvre des Secrèts que la Nature tient encore voilez à nos yeux. 


\section{(sinleitutg}

in

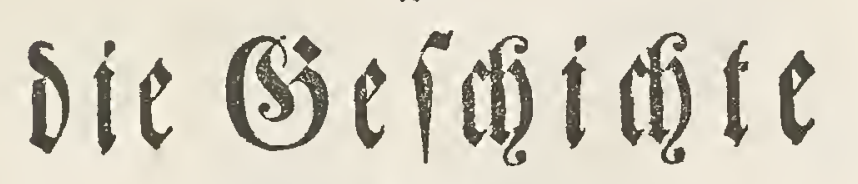

der Corallen.

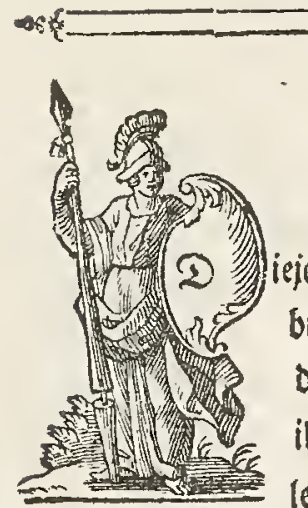

iejenigen pflangenartige, und fowobl barte, als biegfame Eorper, weltse in bem Deer gefuns Den weroen, find fifon son Den erfen Zeiten ihrer Entbectung an mit Dem গamen Coralo len beleget rourden. Man theilte fie anfângs lid in Steincorallen (Lithodendra) uno Spurncurallen (Keratophyta) uder hornartige गुfangen ein. Nan fahe fie audh

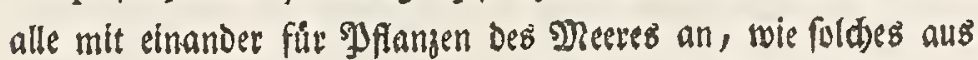
Den alten und neuern Sdrifftellern, Dem Dvibius, SPli= nius, Sảfalpinus, Seşner, Bautbin, Smperatus und anderen 34 erfeten if. Sur glaubtesman, Daf fie unter bem Tranfer weid wåren; aber auf bie nuiroefte Berúhrung, ober menigftens, wenn fie an bie Ruft Edmen, feeinhart wứs. Den. Diefe Neinung hat man immer beybehalten, whneractet man Eeine ordentlicte OSBurseln, Eeine Blăttet, Eeine Blüthen

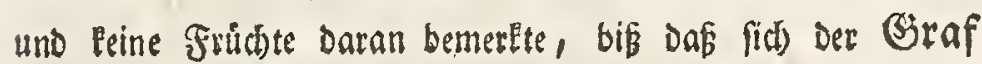

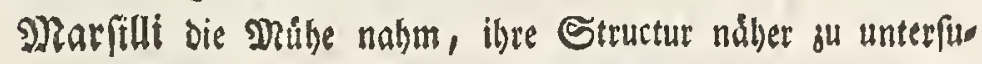
Wen, und ithen, als vegetabiliffen Esprpern, aut) eine in einem Sefáfe mit $23 a f f e r$ wahrgenommene Blüthe zuftoriebe. Singegen fah Reaumur die Corallen fúr ein Gebdude oun Wrsurmern an: ba viele andere in einer Unifuläfigleit blieben, vb. man biefe Eeccorper für Steinuflanjen, ober fár Behaufungen Der Shiere zu halten habe. Der f(tharfíthtige Engellánder Erlite brath endidi mit ber Sadje berbor, uno belautptete aus langmierigen genauen $25 a b$ bnehmungen, es máren alle Corallen, formobl bie Stein als Surncoralle, mit Jnbegrif ber zartefen Seegemadbfe, nidtsts anders, als ein

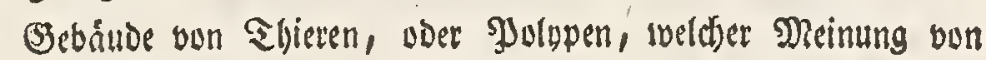
Dem groffen Rinutrús bengepflictet wurbe, daß er bie Coralo

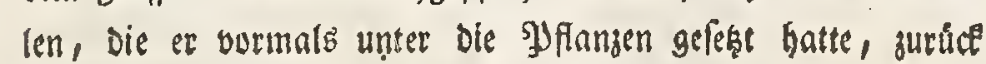

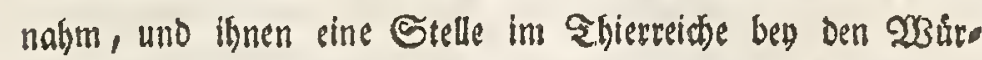
mern annieg. Buleşt Pam auth Der berúbmte STtaliåner Bitaliano Donati zum Burftein, um biefe হReinung auf eitumabl aufer allen sivelfel zu reşen, und sab aus feinen mit guvfer Sorgfalt angeffelleten Beobactungen bie Erlåuterung,

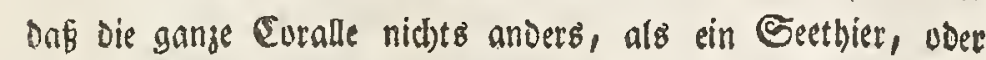
Yolupe fey, melcte fid Durch eine befrandige Dermelyrung bes

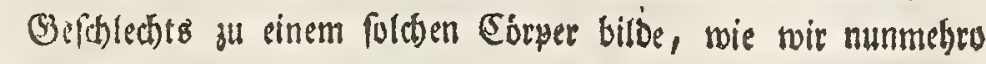
bic Eorallen vor uns fthen. Diefe DReinuug baben nun bin uno wieber bie fotharfinnigften Selefreten angenommen.

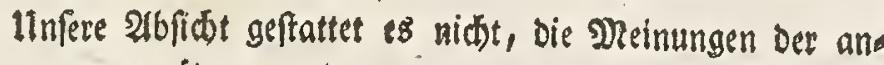
gefiulletten unermidoeten und verbienffoullen Naturforftier weito låuftig amsuführen, wder ibnen mit unferen saguen biß unter
INTR ODUCTION

à LHISTOIRE

DES CORAUX.

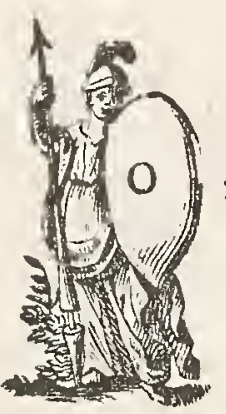

In a donné le nom de Coraux aux Corps de nature végetable, qu' on trouve dans les mers, foit $\mathrm{qu}^{2}$ ils foient durs \& folides, foit qu'ils foient tendres \& thexibles, dés-le tems qu'on en a fait les prémières découvertes. On les diftingua au commencement par les noms de Litho. dendra, ou Coraux pierreux, \& de Keratophyta, c'eft à dire Plantes qui tiennent de la nature de la corne. En général on les a confidèré tous fans exception comme des Planies maritimes, fur quoi on peut s'en raporter au témoignage des Auteurs anciens \& modernes, tels qu' Ovide, Pline, Cefalpin, Guefsner, Baubin, Imperatus, \& autres. On étoit feulement dans l'idée que ces Plantes n'étoient tendres, qu' autant qu'elles étoient fous l'Eau, \& qu'au moindre attou. chement, ou au moins dés-qu'on les portoit à l'air, elles devenoient dures comme de la pierre. Et cette opinion. a prévalu, quoiqu' on ne remarquât aux Coraux ni racine: regulièrement formées, ni feuilles, ni fleurs, ni fruits, jusques à ce que le Comte de Marfilli fe fut donné la peine d'en examiner la ftructure plus exactement, \& leur eût attribué comme aux autres Végètaux, des fleurs qu'il avoit obfervées en les confidérant dans un Vaiffeau plein d'eau. Reaumur cependant les a pris pour des Amas de Vers, pendant que bien d'autres font demeurez incertains s'il fa. loit décider que ces Corps Maritimes devoient être regardez comme des Vegetaux pierreux, ou comme des Habitations d'animaux. Tel étoit l'état de la Controverfe lorsqu' Ellis, cet Anglois clairvoyant, trancha net la queftion, en foutenant d'après de longues, fréquentes, \& d'exątes oblervations que tous les Coraux, tant pierreux que de nature de Corne, y compris les Végetaux maritimes les plus fubtils, ne font autre chofe qu'un Compofé d'Animaux ou de Polypes, fentiment que le grand Linnaeus adopta, en revo, quant ce qu'il avoit avancé précèdement en difart que les Coraux étoient des Plantes, \& en leur accordant à préfent une place dans le Règne animal parmi les Vers. Enfin Vitaliano Donati, célèbre Italien, parût fur les rangs, \& pour mettre tout d'un coup cette nouvelle Opinion hors de tout doute, après des Obfervations faites avec beaucoup de foin, il dit que les Coraux entiers $n^{*}$ étoient autre chofe qu' un Animal de Mer, ou Polype, lequel par une propagation continuelle de fon efpece fe formoit en corps, tel que nous voyons les Coraux. Les plus éclairez des Sçavans ont adhéré au méme fentiment.

Le but du préfent Ouvrage ne nous permet pas de nous étendre ici en raportant au long les Opinions des Sçavans dont nous venons de parler, dont les travaux infatigables 


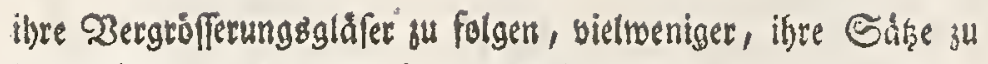

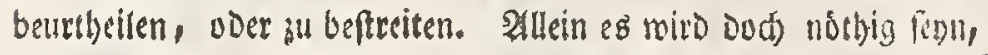

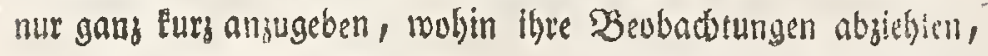

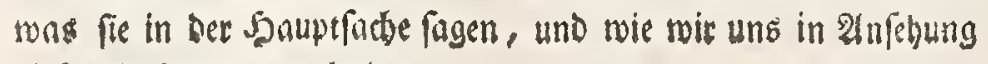
diefer Meinungen verbalten.

Ein eingiger Fुorupe feger fid auf einen Stein, ober Sdtnen cé voer einem anveren (Eorper in Seere an, nábret fich, und bildet son feinem Eafte eine Zelle, bie thn und feinem Eusper

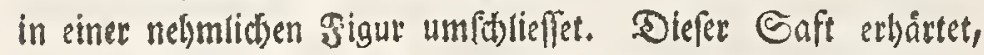

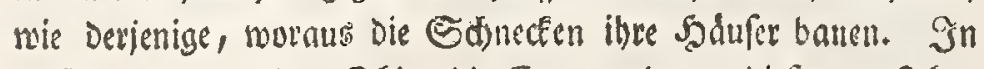
Diefer Belle leget Das Shier bie Elyer, und aus diefem entfethen wieber andere Đyolypen, bie auf eben die 2att aud) aus itheem Saft ibre Sammern ober auf der erfen bouen. Uno fo wids fet Dann Die auffere Esthale immer fort, theilet fit in 2efte, oder breite Blåtter, je nachoern die Fortpflangung Des Sbicres bor fich, und gut von fratten gebet. Da nut die झुolupen, viele voer twe nigere Strablen haben, groffe, ober undenellid Fleine, mitbin inibrer 2 ert getwaltig bon einander unterfofieden fint; fo entfere bet Daraus der gruffe Hinterftheid Der Eurallen, und if Die Utracte eben bierinnen ju fuchen, warum bie Farben, Die Didtigliteit der

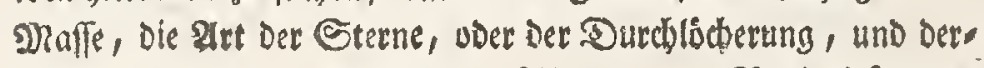

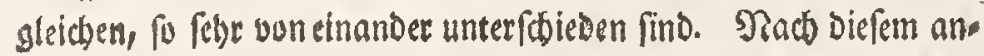
genommenen Grand Faţe find aud die borncoralle ₹biere. Dab

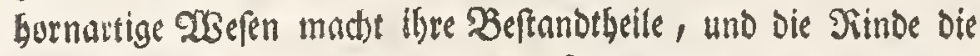
Sarut aus, bie biefen ₹gieren eben fo unentbefrtict ift, als uns

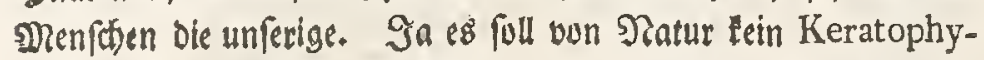
ton ohine Crufta vorthanden fewn, und diejenigen, weldbe obne diefe Seaut gefunden worden, follen fie nuะ zuffáliger 23 eife vertobeen Gaben.

Diefes Elinget freylid gan: anders, als man vor ciniger Seit von Den (Surallen nad) glaubte. Und wer weí, weldhe 23 uns

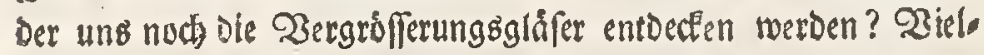

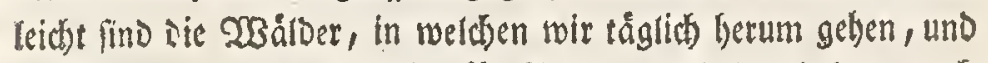

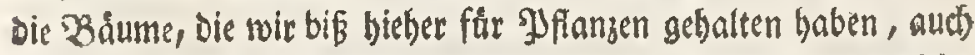
Sibitre? Denn es wiro igr शabrungsfaft zwifben Den fibrófen

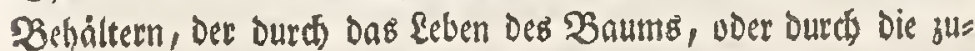
rúcteftuffende und anjiebende Siraft Der Eleinften Fheidt)en, (wann wir etwa den taufendften sbeit Davon an einem wadjenden Baum unter bas Dergrofferungsglas bringet/) eine 2 berwegung, cinen Eúrper, ein seben vosfellen, Die man ja wohl mit leidter

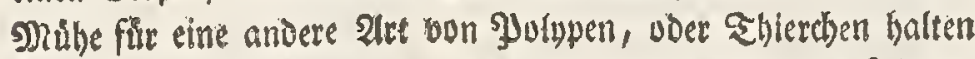

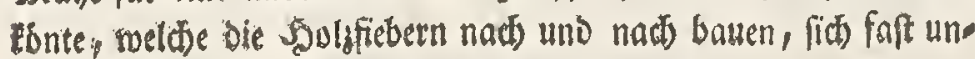
enofict) vermethen, und in 2efte ausbeeiten, aud befondere

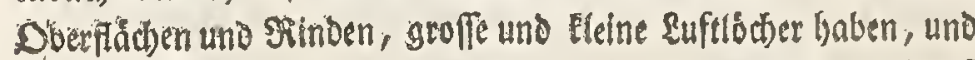

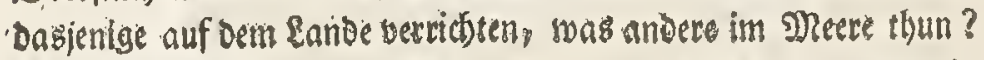

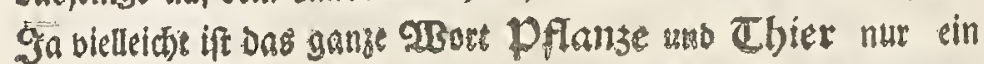

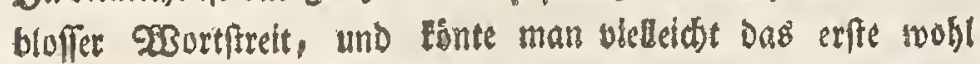

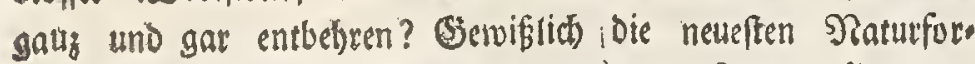
finer find ouf biefer $\mathfrak{B a f h n}$, und reden von Shierpflanzen, uno Pflanzenthieren. Sie wollen nel)mlid eine Gete der Gerfispfe behaupten, Da bie Ereaturen allmáblig won Dem Pflanzenreiche it Das Ibierreich úbergehen. Dieps aber ift eine Sache, die uns nod zu Dunet ift, bon ber wir uns feibfen nod Eeine redsten Begriffe maiten, uno die wite Daber aud unmoglids beutlid befimmen finnen. Denn fo lange wir Eeine andern Definitiones von Den $23 s u r t e r n$ Pflanse ano Thier baben, alö bibger betent genefen fino: ont affurément leur grand mérite, ni de fuivre de nos yeux leurs Obfervations au travers de leurs Microfcopes, \& encore moins nous convient -il de critiquer ou de combattre leurs Ouvrages. Cependant il fera néceffaire de dire quelque chofe en abrègé du but de leurs obfervations, de ce quils avancent fur la matiere principale, $\&$ de ce que nous penfons nous - mènes à l'égard de ces opinions.

Un Polype unique fe pofe dans la Mer fur une Pierre, fur un Efcargot, ou fur quelque autre corps. Il fe nourrit \& fe bâtit de fon propre fuc une Cellule, ou Loge, qui l'embraffe lui \& fon corps dans la méme figure qu'il a lui-méme. Ce fuc fe durcit tout comme celui dont les Efcargots conftruifent leurs Coquilles. C'eft dans cette Cellule que l' Animal pond fes oeufs, qui produifent d'autres Polypes lesquels fe bâtifient auffi de leur propre fuc des Chambrettes aus deffirs de la prèmière. C'eft ainfi que la Coquille extérieure reçoit fon accroiffement, \& fe partage en rameaux, ou feuilles étenduës felon que la Propagation de l'Animal fe fait, \& fuccède. Ces Polypes diffèrent beaucoup entre eux, \& ont plus ou moins de raïon, lesquels raïons font ou grands, ou infiniment petits, ce qui indique la raifon de la grande diffèrence, qui fe trouve entre les Coraux mèmes, qui font fi divers à l' égard de leurs Couleurs, de la' folidité de leur Mafé, de l'efpèce de leurs étoiles, des trous qu'on y remarque, \& d'acceffoires pareils. En acceptart ce principe, il faudra admettre que les Coraux qui, quant à leur confiftence, tiennent de la nature de la corne, font auffi des animaux. Cette fubftance femblable à la corne forme les Parties dont le Tout eft compofé, \& l'Ecorce en eft la pear, partie auffi effentielleńnent néceffaire à ces animaux, qu'elle l'eft à l'homme, On prétend même qu'il n'exifte abfolument aucun Keratopbyton fans croûte, \& que ceux que l'on trouve denuez de cette envelope ne peuvent que l'avoir perduë accidentellement.

Il n'y a pas fort long tems que l'on étoit encore bien éloigné d'avoir de pareilles idées des Coraux. Et qui lait quelles merveilles nous pourrons encore découvrir par le moyen des Microfcopes? Peut -étre que les forèts, dans lesquelles nous nous promenons journellement, \& ces arbres que nous avons pris jusques à préfent pour des Plantes, font auffi des animaux. Car en prenant, dirai-je la millième partie de ce fuc nourriffier, qui pénetre a entre les loges \& les fibres à travers la moëlle de l'arbre, ou travers la vertu attractive \& repouffantes de fes plus petites particules, \& la pofant fous le Microfcope fur un arbre qui croit, nous y remarquerons un mouvement, un corps, une efpece de vie, qui nous pourroit aifément conduire à penfer qu'il y a là une autre forte de Polypes, ou d'Animalcules, qui conftruifent peu-à - peu ces fibres des arbres, qui s'y mul. tiplient à l'infini, \& fe divifent en rameaux, \& ont leurs fuperficies \& Envelopes particulières, de mème que de grands \& de petits foûpiraux, faifant fur le Continent les mèmes Opérations, que les autres Polypes dans les Mers? Qui fçait mème fi les termes de Plante \& d'Animal ne reviennent pas à une pure Logomachie, \& fil l'on ne pourroit pas fe paffer abfolument du prémier? Il eft au moins de fait que les fcrutateurs les plus modernes des fecréts de la $\mathrm{Na}$ ture font déjà fur les voyes, \& commencent. à parier d'Animaux - plantes, \& de Plantes-Animaux. Leur idée eft de ftatuer une Chaine fucceffive, ou une gradation des Créatures, felon laquelle elles puffent par dégrez du Règne végìtal au Règne animal. Mais c'eft-là précirément l'hypothèfe que nous tronvons encore envelopée de nuages épais, 
fo bleibt allemableine Mflange Gimmeltweit von einem Ibitere unterf(bieden, und eine Ihbierpflange, voer ein Jjflangentfier

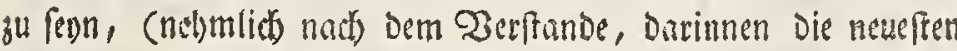

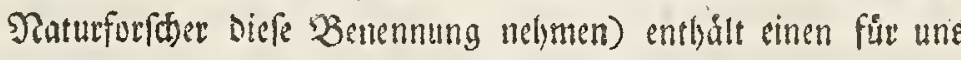

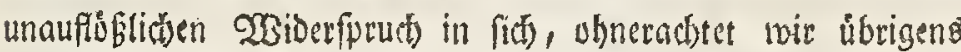
roblerkennen, Dafí Die Stuffen Der Erraturen Fehr nahe an ein.

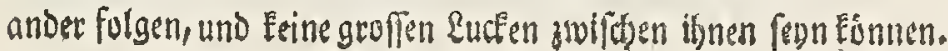

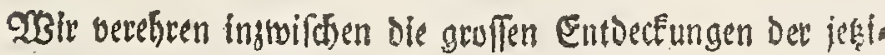

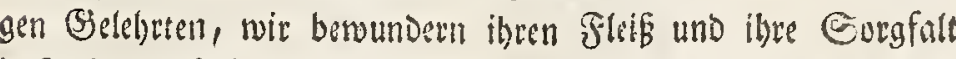

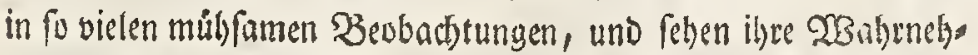
mungen als einen $23 e g$ an, auf weldfem wir zu einer tiefern Ero

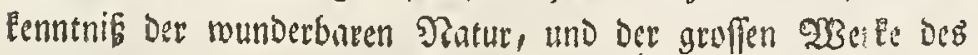

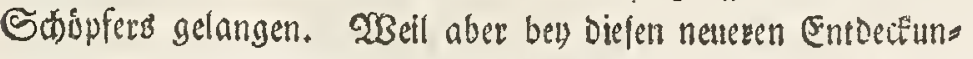
gen bie Sact)en bergeftalt in bas Ileine linein laufen, wo nuct) nidft genug erfurftet morden if, mas Der $\mathfrak{H}$ metreis ber Såfte

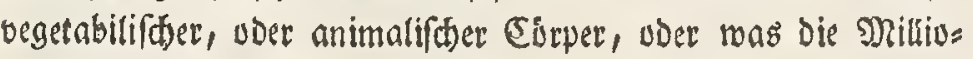
nenmabl verlesinerte anzlegende uder zuréceffuffende Siraft Der

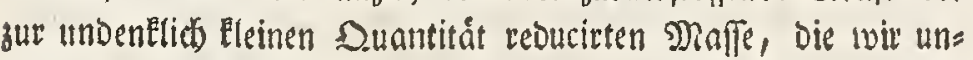
ter Das Dergruffertunggglas bey biefen Beubact)tungen bringen, ober was bie fafgigten Sheilcten bes Meetwaffers, Die in einem jesen Sreiflauf mit allen ihren Spitheren im Berregung fethen,

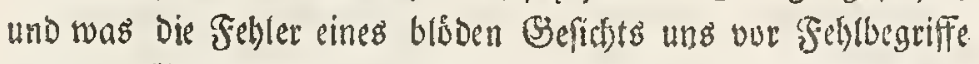
von Den Befrandetbeilen Der Corper; die wir unter unfere 2 er,

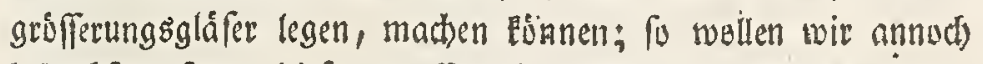
behuthfam Feyn, Diefen groffen Entveckungen vollevinmen beys

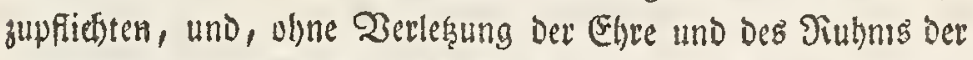
fämllichen Erfinder, Die ganze Sadte etwas mebr aus bem ro. Gen betracteten. Denn die Micrufcopia zrigen uns wuble cine

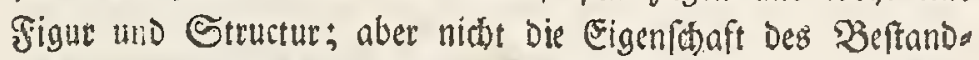
wefens, mitbin if es móglid), sâk (Ellis uno Donati etnas vegetabilifthes yor etmas animalifter anfehen, gletch wie

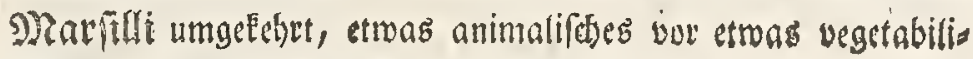
ficez inter feinem 3 ergrufferungsglas anfahge

Ein vegetabiliftes und ein animalifthes Seben find smen unterfásievene Sachen. Sie linnen unferes Erathtens nouht in

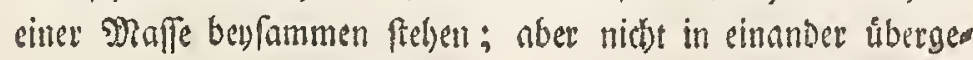
ben, woer mit einander verwecthelt wersen. OTSir extennen vor

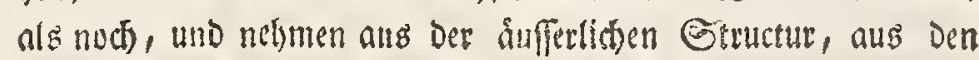
breiten 23 urzelftưcén, aus dem aud) fogar an Den Steincurals len wahrgenummenen faferigten Crsefen, Damit Die ganje Daffe

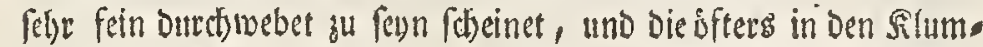

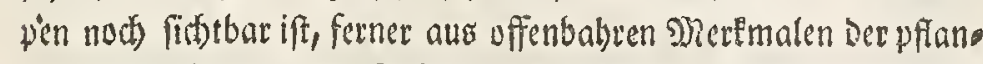
jenartigen 2tugen und \&eften, und melyeren anderen Girúnden, ein vegetabitifotes झुrincipium in allen Evrallen, wenigftens in

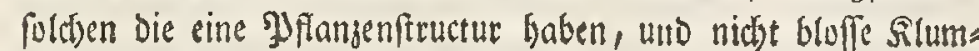
pen find, an, und wir haben bierinnen siele gruffe Sielefrten, die biefer Meinung annud bespficteten; wir glauben aber Dobery

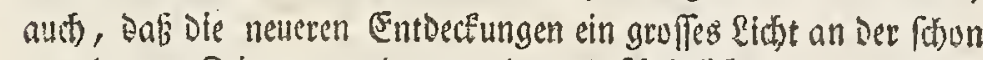
vor langer Beit vermutbeten und bathrideentidid getwefenen $\mathfrak{B}_{\text {Bes }}$

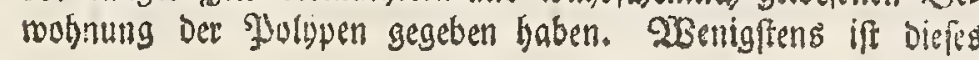

épais, dont nous ne pouvons pas nous former des idées diftinctes \& fîres, ni hazarder par confequent une décifion abfolue, vû que tant que les anciennes défrititions de ce qu'il faut entendre par Plante \& par Animal fubfifteront, la diffëence fera toûjours immenfe entre la plante \& l' Animal. ' Car l'Animal-plante, ou la Plante-Animal, à prendre ces termes dans le fens qu'y attachent les plus nouveaux Auteurs, portent felon nous avec foi une Contradietion, qu'il ne paroit pas poffible de lever, quoique nous reconoiffions dailleurs de bonne foi que les diffèrens dégrez des Créatures fe fuivent de fort près, \& que les diftances de l'une a l'autre ne font pas extremement grandes.

Tout cela ne nous empéche pas d'avoir en fingulière vénèration les grandes Découvertes dont nous fommes redevables aux Sçavans de nôtre tems. Nous admirons leur Aplication, \& les peines quilis fe font données par tant d'opérations pénibles, pour mettre la verité dans un plus grand jour. Leurs Obfervations nous conduifent à une Conoiffance plus profonde des Merveilles de la Nature, \& des grands Ouvrages du Créateur. Mais comme toutes ces nouvelles Découvertes ne font fondées que fur des Expériences en mignature, \& que par conféquent, il n'a pas encore êté mis encore affez au clair à quelles erreurs nous peu. vent induire foit la Circulation des fucs dans les Végetaux \& dans les Animaux, ou la vertu attractive \& repouffante de la Maffe reduite à une Quantité presque imperceptible, que nous mettons fous les Microfcopes en faifant nos Obfer。 vations, ou l' effèt féduifant qui peut être caufé par les parties falées de l'Eau de la Mer, dont toutes les pointes aiguës font agitées à chaque Circulation, \& les fauffes impreffions que nous pouvons prendre de là dans nos Obferva. tions Microfcopiques - même, par raport aux parties dont chaque Corps eft comporé, par la foibleffe de nos yeux; nous croyons devoir procéder avec précantion, \& fans vouloir diminuer le moins du Monde la gloire ou le mérite de tous ceux auxquels on doit les grandes Découvertes, dont il a êté parlé cy-deffus, nous nous difpenferons encore d'ad. hèrer abfolument \& de tout point à leurs opinions, pour nous donner le tems d'examiner les chofes de plus prés. Les Microfcopes nous découvrent fans doute la figure \& la Itrueture de chaque Corps, mais non pas la proprieté des Parties dont il eft compofé. Ainfi il eft poffible qu'Ellis ou Donati ayent pris comme apartenant au Règne animal ce qui eft du Végètal, tout comme Ararilli peut avoir regardé, fous fon Microfcope comme apartenant au Règne Végètal ce qui apartient au Règne Apimal.

Une Vie Végètatıve \& une Vie Animale différent entre elles. Elles peuvent bien fübfifter enfemble dans un même corps, mais elles ne peuvent ni paffer de l'une à l'au. tre, ni être confonduës. Nous reconnoiffons dans tous les Coraux, du moins dans ceux dont la ftructure reffemble a celle des Plantes, \& qui ne font pas figurez en maffe informe, ou en tapon, un Principe végétatif, \& en ce point plu. fieurs Sçavans diftinguez font de même fentiment que nous. Leur ftrueture extérieure, les Parties étenduës de la racine, les fibres qu'on remarque aux Coraux pierreux dont toute 1ånaffe femble être finement tiffuë, \& qui paroiffent vifio blement lorsmême qu'ils font fimplement formez en Maffe, les yeux \& rameaux femblables à ceux des Plantes, \& bien d'autres bonnes raifons apuyent cette opinion, ce qui ne nous empéche pas de penfer que les nouvelles découvertes ont répandu beaucoup de lumière fur toute cette matière particulierement à l'égard de l'opinion qui établit l'Habita. $\mathrm{C} 2$ 
wohl gerois, Daf ole bon orm Grol Marfilli wabrgenummene

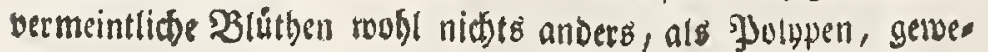
fen fint.

Solte és Denn wobl fo felir ungereint feun, bon den Gtein. curallen zu behaupten, Das eine urbentlictse feine im crsoffer aus cinander geftrecte Seepflanze die erfte Grundage ju ihree Crru stur gebe? Daf ferncr diefe mit einem jîhen Secfolam úber

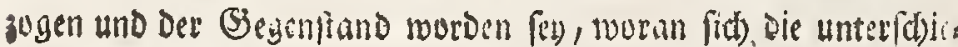
Denen Eeepolypen, Deren ein undentlith grofer uno verfebiete neg Seer feyn mag, angebangen baben? Daf fodann biefe Do lopen fict foldte Bellen und 28 shnungen gubereiteten, welche nad ibrer Etructur figuriert find, uno aus Dem lleberfun ibres Saf

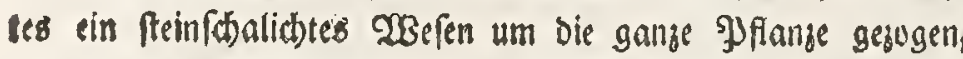

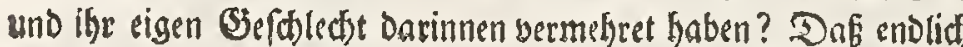
Durch Die falgigte Gobirfe bie mürtid) vegetabilifise Malle an gegriffen, und in ber Dicken berbirrteten Jolopenrinde verzebret twurben feu, fo, Dafe endidi nidts melgr, als bie Edale ber गुolupen Daran übrig geblieben? Orsenigftens glauben wir, nod alzuvicle Orano zu baben, als Das wir diefe Meinung fabeen laffen fotten. Denn wir baben, um nur eines Sirundes zu che wehnen, einen wothen Bactifetin mit ber netmliden Corallen. maffe in Der Bteite ủbersogen gefunoen, Da fonft an einem ors Dentliden Corallenbäumben bie Maffe in bie Siunoung uno

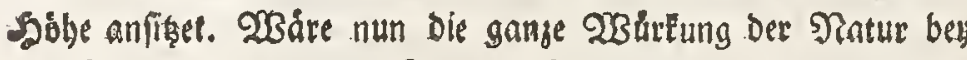
Den Curallen blof animalifo, und láge nidte oud) etwag anders

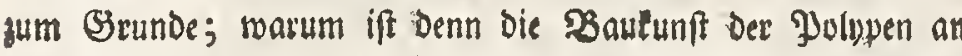
bem Bacfetein nidt eben fo wie an andern ábulietien. Corallen befdaffen? ODer, um now mebr ju fagen, wenn eine Coralle Durd Die erftaunlid ftarke Fortpflanjung Deg erften Đolupen ent ftebet, warum boret Denn Diefe ganje Gortpflanjung auf sin malji und an allen Binfen jugleidy auf, wenn die Corallen, twie

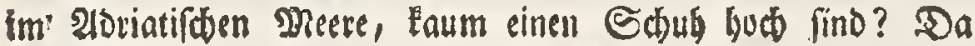
man Duth bey Dem angenommenen Saş bermuthen folte, die Eorallen Egnten wegen Der fortDaurenden Urfacte Der Furtpflan, gung ungeberer gruß biefer beftimmten Groffe nidjt diefe feun, daß cin Zegetabile,

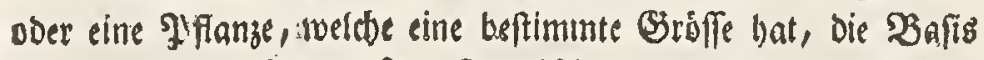
bun ber ganzen Curalle fet? Injwiføen wollen roir nidjt láug nen, Dafies Corallenmaffen in unformlicjen Rlumpen geben Eeonne, ba gar leill vegetabiliffes 2 Eefen frat findet. Denn es if ia móglich, Dak bie \$olgpen fich an einen rohen Gtein, oder irgend einen anderen Sieper, und eben nidjt an siner folcten feinen Iflanje, anfersen.

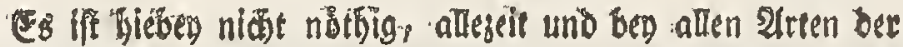
Steincoralie ethe bolleummene Seepflange burauszufesen, die

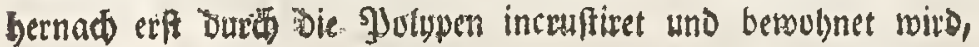
fondern wetn woir in etfiden Carsille ein segetabilifates uno ani.

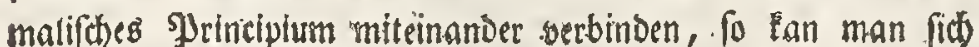
bie Erafe oud folgeribergeftalt als miglid' vorftellen.

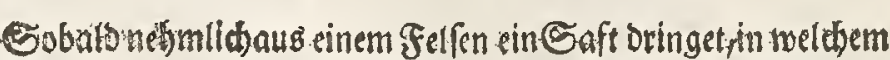

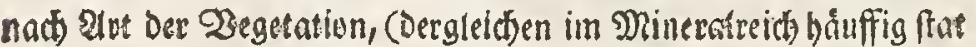
findet,) Die vegetabilifdye (Sinndage einer baumformigen Etruttur enthalten iff, und fobald fich biefer Creinfaft auf oer Dberfik. de eines S(ippen, es (cu Durch) einen Rrieb von unten, voer burd) bie anziehende Sraft beffelben shetlden einigermaffen in bie Shibe begiebet, fobalo neftelt fit) ein voer mebrere gु'olopen, Davon Das פheer mimmelt, auf Der annud rociden Sberfláche tion des Polypes dans les Coraux, ce qu'on regardoit comme vraifemblable, \& qu'on préfumoit depuis long-tems. Du moins paroit -il trés-certain que les prètendues Heurs, que le Comte de Marfilli croioit avoir remarquées dans fes Obfervations, n'étoient autre chofe que des Polypes.

Seroit-il donc fi fort abfurde de conjecturer à l'égard des Coraux pierreux qu'une Plante marine fine $\&$ étendue forme au fonds de l'eau la prémière bafe de leur conftruEtion? que cette bafe couverte au fond de l'eau par un limon marin visqueux devient un Objèt auquel s'attachent les differens Polypes, dont il y a aparence que la Mer fourmille? que ces Polypes fe conftruifent des Cellules \& fe for ment des habitations, dont la figure répond à la ftructure \& configuration de l'Animal, lequel enduit du fuperflu de fon fuc toute la Plante d'une Ecorce ou Envelope pierreufe, au dedans de inquelle il multiplie fon efpèce? qu'enfin une humeur acre \& falée s'y infinue, \& confume la Maffe véritab'emert végetative, qu'elle trouve au dedans de l'Envelope ou de la Croute exterieure, épaiffe $\&$ durcie, que les Polypes ont conftruite, laiffant enfin cette Envelope abfolument vuide? Nous croions avoir beaucoup de bonnes raifons pour ne pas rejetter cette opinion. Et pour n'en allèguer qu'une feule, nous avons trouvé une brique rouge enduite de la méme Mafie de Corail en large, au lieu qu'ordinairement aux arbriffeauz de Corail cette Maffe fe forme en rond $\&$ tend vers le haut. Or fi toute l'Opération de la Nature dans les Coraux n'étoit dirigée que par les régles du Règne animal, \& qu'il n'y eût pas là quelque autre principe agiffant, d'où vient que l'Architecture des Polypes s'eft à 1 brique altérée \& qu'elle a ceffé de produire les figures ordinaires? Ou, pour dire quelque chofe de plus, pourquoi arrive - $t$-il, que dans les cas oti da propagation du prémier Polype eft extraordinairement forte, cette propaga. tion ceffe tout - à - coup, à la fois, \& à tous les bouts de rameau enfemble, lorsque les Coraux ont à peine un pied de hauteur, ce dont le Golfe Adriatique fournit"les exemples? Car felon Thypothète, la Caule de la Propagation ne ceffant pas, les Coraux devroient parvenir à un dégré de grandeur étonnant. Ne doit-on donc pas conjecturer que la véritable caufe de ce dégré déterminé de grandeur n'a d'autre fondement, fi ce n'eft qu'un Corps vegetal, ou Plante, qui a auffi une dégré déterminé de Grandeur, fait la bafe de tout le Corail? Nous ne difconviendrons pas cependant qu' on peut trouver des Mafles Coralines figurées en tapon informe, ou l'on ne peut trouver aucune trace relative au Régne végètal. Car il eft poffible que les Polypes s'attachent aufii à une Pierre brute, ou à quelque autre corps, \& non à cette Plante fine donit nous avons parlé.

Il n'eft donc pas juftement néceffaire de fupofer toújours \& à toutes les efpèces de Coraux pierreux une Plante marine parfaite habitée par des Polypes qui P'incruftent; il fusfit d'établir dans quelques Coraux un principe vegetal allié au principe animal, \& la poffibilité de la chofe peut être conçûë de la manière fuivante.

Supofez qu'il forte d'un rocher un. fuc dans lequel il y ait le Principe végètatif d'une ftructure en forme d'arbre felon le fylteme de la Végetation (ce qui a fort rouvent lieu dans le Règne mineral.). Dés - que ce fuc pierreux dans fon origine commence à s'élever fur la fuperficie du rocher, foit que cela arrivé par une impulfion du dedaris, ou par une vertu attractive des parcelles dont il eft compofé, un ou plufieurs Polypes, dont la. Mer abonde, viennent fe nicher 


\section{譥}

Diefes Saftes ein, weil es ein bequentes Bette bieper Shiere in und die Figur biefers SGieres drúctet fobann biefem Eaffte cin

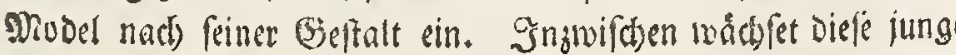
Eteinpflanze admáblig in bie Soube, uno betommt, nad 2 ir

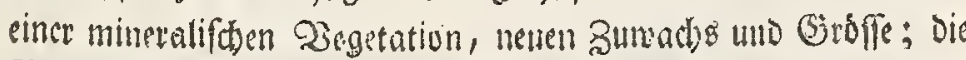
Dolypen bingegen vermeltren fich nitlerweile aud), uno matien

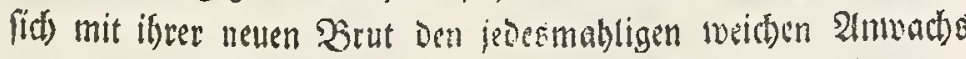

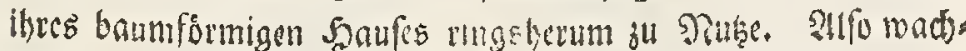

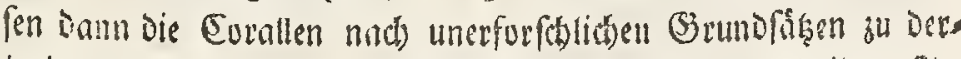
jenigen Etructur fort, Bie ithnen Der Eajowfer nad) ither airt in her Thetur beftimmet bat, und woju fie wadhen múrden, wenn

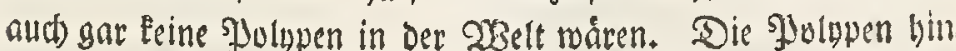
gegen wfanjen fieth in biefem, tor fie febr bequemlitben Neefte

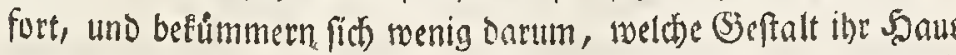
unter Der Saano befommt, mithin befinmet das Begetabi lifte bie Figur, swobin fith bie sgollypen anbauen fornnen, und

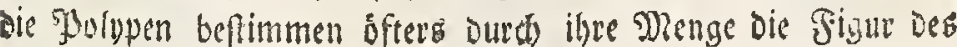

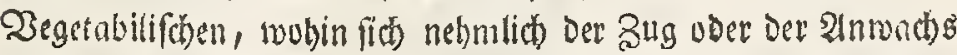
Des Eteinfaftes menten foll, mithin bilft eines Dem andern, und wenn die 'Segctation die niberall ibre Edrranten hat, ju Ende if fo gethet die an Den dufferften Episen folgende Brut Der Э̧bolepen aus Mangel eines bequemen Eafics sertubren, vier fudte fict andere Sórper auf, wo fie einen bequemen Eaft, Darinnen fie nifteln kan, findet.

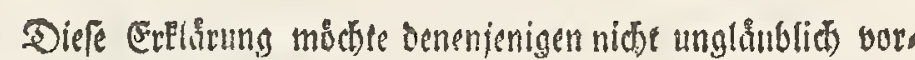

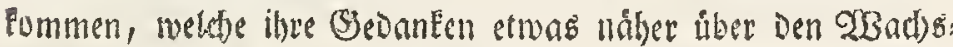

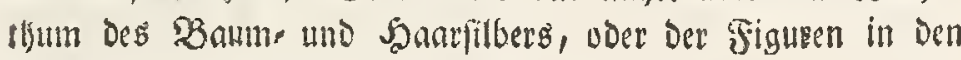
Dendriten voer Banumfeinen, voer auch åber il: $V$ cetation Des Sodtentopfs vom OBitriul ergeten lafen, zumabl wenn fie

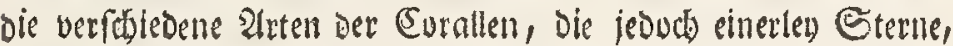
mithin einerlery Shiere zu Betwogner haben, gegell sinander ver

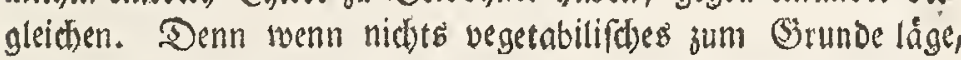

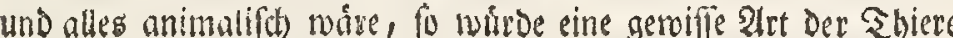
fich alleseit auf gleithe 2att aubauen, gleithwie bie 2meifen, bie

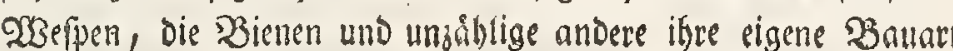

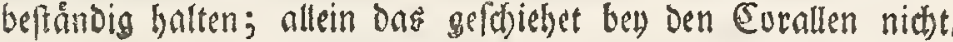

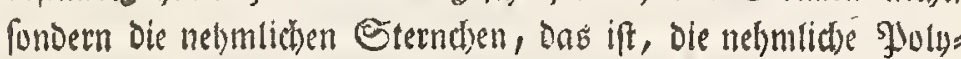

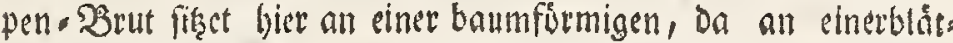
terförnigen, und Dort an einer Sd)wammformigen Corolle,

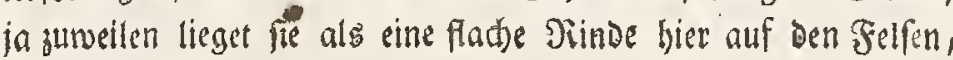

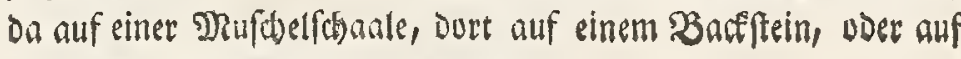
einem Stůce soly, voer Dergleiden.

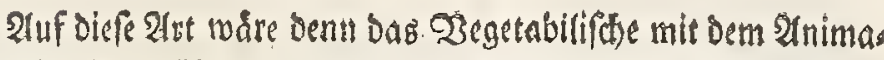

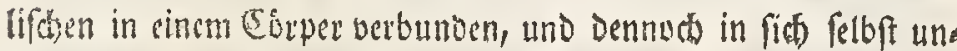
terfebiedsn, imbem man bevderler seben nid)t miteinander vero wreffelt. Ob aber das ucgetabilifitie und animalifthe seben

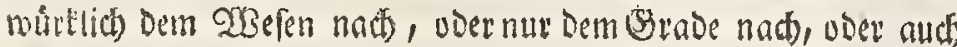
nur geniffer llmatśnde balber von einanoer unterf(c)ieden feu ? und ob

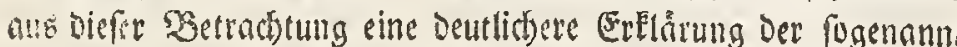

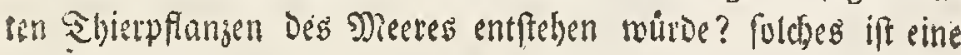

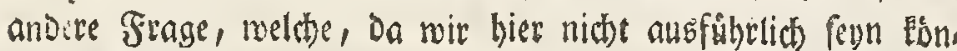

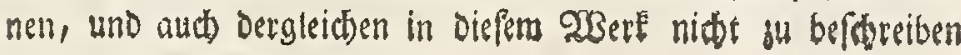
finden, nicht bieler gelgeret. fur la fuperficie encore tendre de ce fuc, parcequ'ils y trouvent un lit qui leur convient, \& PAnimal y imprime le inodèle de fa figure. Cette jeune Plante pierreufe venant à s'élèver peu - à - peu s'agrandit \& reçoit un nouvel accroif. fement, felon l'ordre de la Végètation minerale, pendant que de leur côté les Polypes fe multiplient, \& fe prévalent avec leur nourrain de l'accroiflement toûjours tendre de leur habitation formé en arbre, \& de là les Coraux par une fuite de principes incompréhenfibles parviennent à la Configuration que le Créateur a déterminé dans la nature pour leur efpèce, \& à laquelle ils parviendroient de même, quand il n'y auroit point de Polypes au monde. Cependant les Polypes contimuent à fe multiplier dans ce nid qui leur eft fi commode, \& fe mettent peu en peine de la figure que prend en attendant leur habitation. Ainfi la partie végètative détermine la figure de la Loge où les Polypes peuvent conftruire leur édifice, $\&$ les Polypes déterminent fouvent par leur nombre la figure de la partie végétative, c'eft à dire le côté ou l'alignement vers lequel le fuc pierreux doit s'accroître \& s'étendre; de cette façon ils fe prêtent reciproquement la main, \& quand la Végétation, qui dans tous les cas a fon terme, eft parvenue à fa fin, le nourrain des Polypes, qui fuccède aux ex. trèmitez perit, faute d'un fuc convenable, ou cherche fur d'autres corps un fuc qui lui convienne, \& où les Polypes puiffent fe nicher.

Cette explication ne paroîtra pas incroïable à ceux, qui méditent particulièrement fur l'accroiffement de l'argent qui croit dans les mines en arbrifleau (argentum nativum dendroides vel arbufculare) ou de l'argent que la nature y produit en filamens, (argentum nativum capillare), ou des figures d'arbre exprimées fur la marne, ou cette efpece d'Argille qui prend alors le nom de dendrites, ou fur la Végéta. , tion du Caput mortum du Vitriol, fur tout en comparant enfemble les diffèrentes efpèces de Coraux, qui cependan ont des étoiles uniformes, \& par conféquent pour habitans des animaux femblables. Car sil n'y avoit ici rien de vé. getal, \& que tout y fut Animal, ces animaux conftruiroient toûjours leurs habitations d'une mêrme manière, ainfi que font les fourmis, les guêpes, les abeilles, \& un nombre in. nombrable d'autres Animaux, qui obfervent conftamment les mêmes règles dans l'Architecture qui leur eft propre; mais il n'en eft pas de 'même des Coraux dont les mêmes Etoiles, c'eft - à - dire les mêmes nourrains de Polypes s'at. tachent tantôt à un Corail en forme d'arbriffeau, tantôt à un autre qui elt formé en feuille, ou encore à quelque autre qui a la figure d'un Champignon。 Qui plus eft, ils s'atta. chent encore à quelque écorce unie, ici fur un rocher, là fur une Coquille de Moule, fur quelque brique, fur une piè. ce de bois, ou fur d'autres matiěres femblables.

De cette façon la partie végètale feroit jointe à l'animale dans le même corps, quoiqu'en foi l'une diffère de l'au. tre, \& que l'on ne confonde point la vie de l'une avec celle de l'autre. Mais de décider fi la vie végétale diffère de l'animale réellement par fon effence, ou feulement par une gra. dation, ou relativement à quelques Circonftances acceffoires? ou, fi en méditant là deffus on pourroit parvenir à quelque explication plus diftincte de ce qu'on apelle Animaux-Plantes dans la mer? cela forme un autre objèt de queftion, fur lequel nous ne pouvons pas nous étendre ici, d'autant plus que nous ne trouverons point de defcription à faire, relativement à cet objèt dans le Cours du prédent Ouvrage.

Poutr 
23a nun ferner bie Saurncoralle bertift, fo find mir unges mein geneigt, biefe follecterdings für ein vegetabiliffes 283 efen

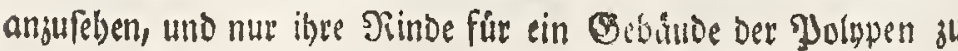

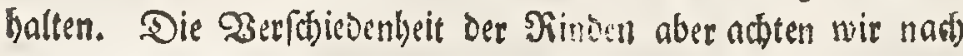

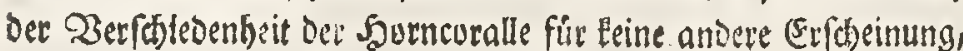

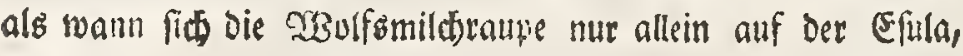

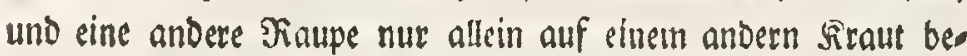
finoet. Ja wir fino fifun zuverlágig benaditidtiget worben, Daf es Esegenden in ben Indianifchen Mresen gebe, wu die nefmliden Sourncorallen, Die anderwerts allerbano Jolopen. SRinden Gaben, Eeine befisen follen, uno yan; glat und Eabl gefuno múrben.

Da a aud, wie Marfilli angiebt, bie Corallen unter fid madblen follen, balten wir nur für eine jufállige Sactbe, melde ourd) bie Eage Der Rlippen ju Beiten fan verurfact)et worben feyn;

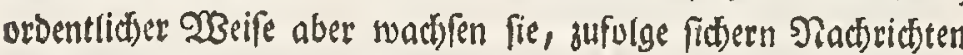
uno Erfabrungen, audi) gerabe uber fit in bie boshe, wie alle andere Degetabilia ju thun pfiegen.

So viel haben wir geglaubet, unumgånglid nittlig sul retn,

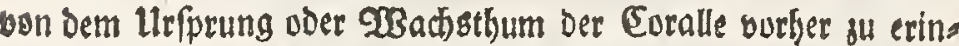

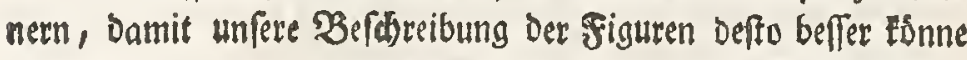
berffanben und von einem jeden seper fertuer nad 20 sublgefallen

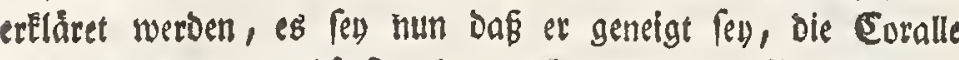

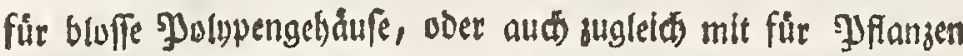
su balten. $293 i r$ roulten menigftens basjenige getreu in Der 2 eo refreibung anmerlen, was soir mit blofien 2 lugent an ben

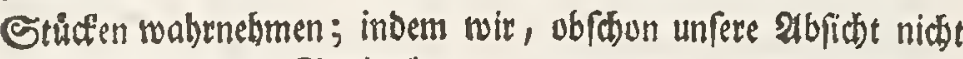

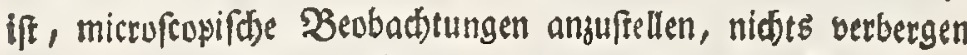
wollen, was der neuen Deinumg zu ftatten exumen lan.

Es werben if r rigens bie Corallen zu erfe cingetheilet in Steinco rallen, ober barte Eurallen (Lithodendra oder Lithophyta) und Sorncurallen, uder biegfame Curallen (Keratophyta). Das erfte

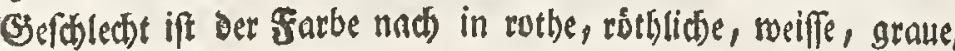

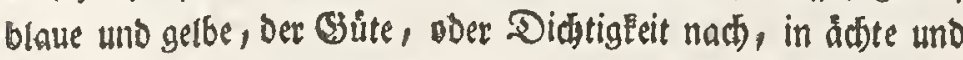

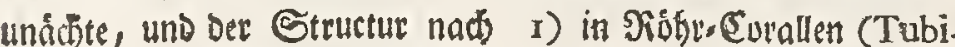
pora) 2) (tederictete, (Millepora) und 3) feernformige, (Madrepora) zu unterf(t)eiden. Wुon ber exften Art giebt es rothe, fotswarze und weiffe, mit genwutenen, geraben, parallet lauffen.

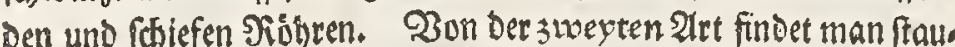
Denformige, (Millepora ramofa); blătteriđte (lobata); Şirfđ̆

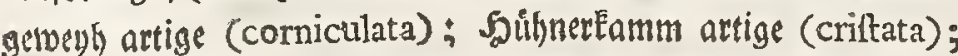
fingerfermige (digitata): $\mathfrak{B u n}$ Der britten 2 at finder man Madreporen snit gruffen und Bleinen, runden und länglidten, wel. cen uno bidst aneinander freftenden, vertieften uno erbabenen Eternen, Deren Strablen, adst, zethen, zmoiff, fectzelin, vier

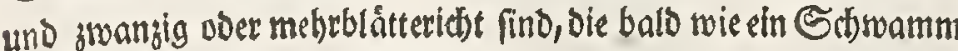
(fungites), balo wie ein Jrengang, (labyrinthiformis), bald wie ein (Sebirn, (Lithocerebrum), balo aber mie ein dffigeb, ober

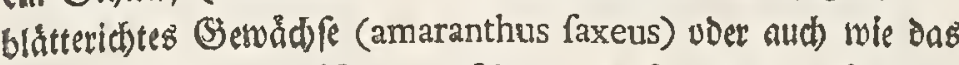
Corallium Abrotonoides, aubfeften, wber fonft aud auf vieler. (el) Ant abmeiden.
Pour en venir à préfent aux Coraux, qui tiennent de la nature de la Corne, nous tommes trés - difpofez à croire, quils font quelque chofe d'abfolument \& purement végétal, \& qu'il n'y a que leur écorce qui puife être confidérée comme l'ouvrage des Polypes. Quant à la Différence, qui exifte entre les Ecorces ou Envelopes, nous penfons que, vû la différence qui fubfifte entre ces Coralsx-même, on n'en peut donner d'autre raifon, fi ce n'eft la même, qui fait que la Chenille de l'Efule ne fe pofe jamais que fur l'Efule, \& qu'une autre efpece de Chenille ne fe place que fur une autre Plante uniquement. Nous avons d'ailleurs des Informations fûres que dans quelques plages de la Mer des Indes on trouve de ces mêmes Coraux de nature de corne, qui ayant par tout ailleurs des écorces de|Polype, n'ont point d'envelope du tout ici, où on les rencontre unis \& tout nuds.

I] fe peut, comme l'avance le Comte de Marfilli, qu'il y a des Coraux qui croiffent \& pouffent leurs branches par en bas, mass nous croyons en tout cas que cela n'arrive qu'accidentellement, \& ne peut être occafionné que quelque-fois par la pofition des rochers. Car nous fçavons par de bonnes informations, \& par des expèriences fûres, que régulierèment le Corail dans fon accroiffement tend en haut, comme tous les autres Végètaux.

Voilà ce que nous avons crû être indifpenfablement obligez de dire préliminairement fur l'Origine \& l'Accroiffement des Coraux, afin de rendre plus intelligibles les Defcriptions que nous allons donner de leur figure. Il dépendra enfuite de chaque Leeteur d'expliquer chaque defcription à fon propre goût, foit qu'il incline à croire que les Coraux ne font que des habitations de Polypes, foit qu'il veuille leur accorder en même tems la qualité de Plantes. $\mathrm{Du}$ moins promettons -nous d'indiquer fidèlement tout ce que nous remarquerons fimplement des yeux, \& fans le fecours du Microfcope, dans les defcriptions que nous donnerons, nôtre intention n'étant pas de publier des obfervations microfcopiques, mais auffi de ne rien diffimuler de tout ce qui peut étayer les nouvelles découvertes.

On diftingue dabord deux Claffes de Coraux, f̧̧avoir les Coraux pierreux, ou Coraux durs, qu' on apelle Litbodendra, ou Lithopbyta, \& les Coraux flexibles, ou de nature de Corne, qui portent le nom de Keratophyta. Quant à la Couleur de ceux de la prémière Claffe, on en trouve de rouges, de rougeâtres, de blancs, de gris. A l'egard de leur bonté ou de leur folidité, il y en a de véritables $\&$ de bâtards, \& felon leur ftructure on les fubdivife en I) Tubipora, ou Coraux en tuyau, 2) Millepora, Coraux trouez, \& 3) Madrepora, ou Coraux en étoile. De la prémière de ces efpèces il y en a de rouges, \& de noirs \& blancs. Les tuyaux en font ou tordus, ou droits, ou parallèles, ou obliques. De la seconde efpèce on en trouve en forme $\mathrm{d}^{2}$ Arbufte (Millepora ramofa), en feuilles, (lobata), de formez en bois de Cerf, (corniculata), en forme de Crête de Coq, (criftata), ou faits comme des doigts, (digitata). A l'égard de la troifième efpèce qui font les Madrepora, leurs étoiles font grandes ou petites, rondes ou oblongues, eloignées ou proches les unes des autres, enfoncées ou élevées, dont les feuilles font au nombre de huit, de dix, de douze, de feize, de vingt-quatre, \& davantage, \& reffemblent tantôt à un Champignon (Fungites), tantôt a un labyrinthe labyrintbiformis), tantôt à une Cervelle (Litbocerebrum), tantôt à une Plante pourvîë de noeuds \& de feuilles (amarantbus faxeus), ou 
Corail d' Auronne (Corallium Abrotonoides), ou ils font fouven de quelque autre figure anomale.

Die Keratophyta, ober Shorneorallen fint der farbe nad

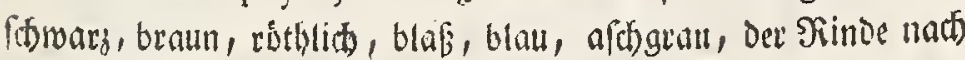
enttweder glatt, woer geftreift; Pahl, woer mit einer gelben, rothen, meiffen, Glauen, afchgrauen, purpurfárbigen, weer Ealdartigen IJolipentinde úbersugen, Daran die Zellen entweber runde, läng

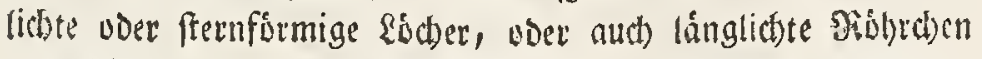

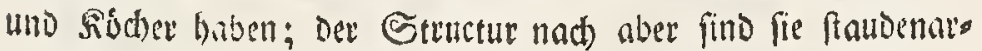
tig, bis) uno niebrig, breit, rund, ober plateffimmigt, mit und

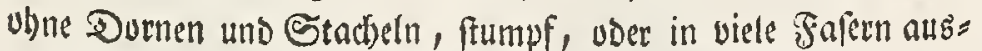
Laufend, mit gabelförmigen, Begeneinanber ûbertethenden, woer

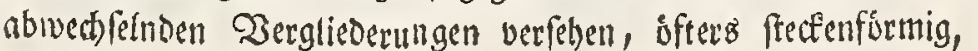

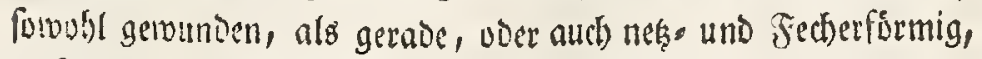

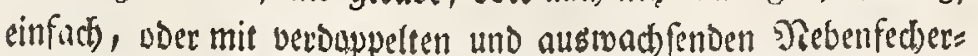
gen verfelen, wie wir foldtes bey Der Befdreribung Der Biguren überall anzeigen wollen, fo daf man uon Den Eorallen ibberhaupe toublưver bundert Arten zufammen bringen Ean, bavon eine inmer

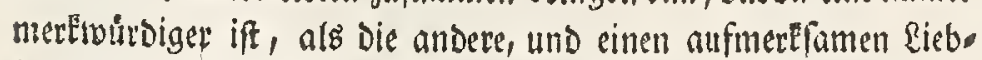

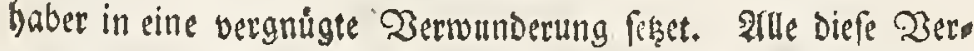

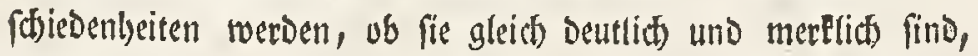

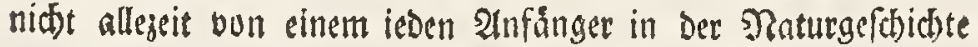
mahrgenummen. Denn bey niemano irift bas Spridjwort: Sie baben 2 (ugett, und fehen nictst, mefre und fiáufiger ein, alb bell Dem, Der erfteinen 2Infang madjet, auf bie Gelo

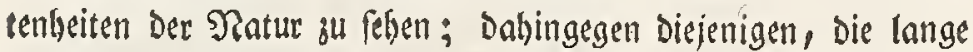

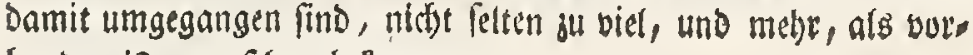
banden ift, ju fegen belumber.

Gedow wir fojreiten nun zur Eacte felbft, und liefern bie $\mathfrak{B e f d b r e i b u n g ~ D e r ~ i n ~ f o l g e n d e n ~ S u p f e r t a f e l n ~ v o u t o m m e n d e n ~}$ Stůcfe.

\section{TAB. A.}

Fig. I. Der 2 infang diefer twunderbaren (Sefchipfe wiro mit einer Gibten rothen Gteincoralle aus bem Mittel= låndifchen Dece gematst, melde an Zullemmenteit, Stáro

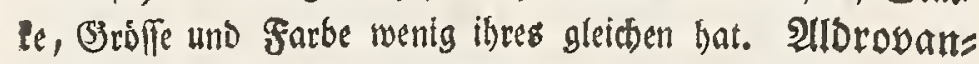
Dus, Jmperatus, Marfilli und andere nennen fie das Corallium verum rubrum arborefcens. Die $2 B_{3}$ ursel, woer bee Fuf, womit Diefe Coralle an Den Filipuen ganz bichte und fefte anfdlieffer, ift burdegangig rund und nad Den Erbsubungen Des Steins umgebogen, foreinet aud eine melfr bornattige und far

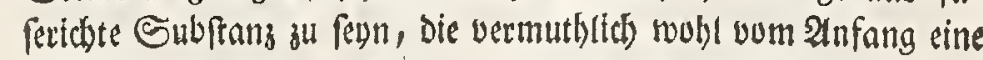
rothe Farbe gellabe, folche aber nach und nad berlobren hat.

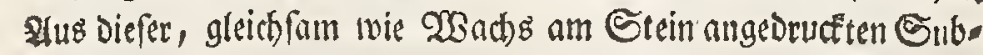
ftans feeiget eine runde Staude in bie Sjóne, die unten im Durd. fituitt faft einen Bull hålt, und/mebrentbeils in einem ordento

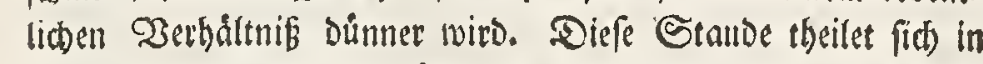

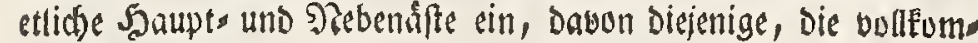
men ausgetwactsen, wber bon ben SJolypen ausgearbeitet find, (iid) melyentheils in grwey furge, fumpfe, auseinander fithende Episen endigen. Die åuffere Dberfiache ift zant geftreift, wie etwa die Riniamenten an beminneren und uberen Sheif eines Fin. Bers, uno Diefe Etreife begleiten Den 2Aft oft biş ủber die Shelfte, nov fie bued bie (Slätte und Den Stanj verftwinden, und nid)

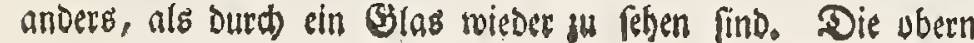

Les Keratopibyta, ou Coraux de nature de Corne, font quant à la couleur noirs, bruns, rougeâtres, pâles, bleus, ou cendrez. L'Envelope en eft unie ou rayée. On lestrouve ou nuds ou garnis d'une Ecorce de Polype reffemblante à un enduit de chaux, ou de couleur tantôt jaune, rouge, blanche, bleuë, cendrée, de pourpre, dont. les Cellules font ou rondes ou oblongues, ou formées en étoile. On y voit auff par fois des petits Tuyaux, ou Trous de figure oblongue. La ftrueture eft celle d'un arbufte, tantôt haute tan. tôt baffe, dont la tige eft large, ronde, ou platte, avec oss fans épincs ou aiguillons, qui fe termine en pointes obtures? oul s'étend en quantité de petits fils ou fibres, garnie de branches en fourchettes, dont les pointes font vis - خे - vig

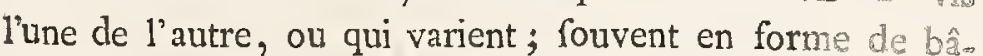
tons, tant lors que droits, ou en rêts, \& en Loges, lesquel. les font quelquefois fimples, quelquefois accompagnées d'autres petites Logettes de coté, comme nous l'indique. rons plus particulièrement à la defcription de chaque fioure. L'on pourroit dénombrer ainfi plus de cent fortes difiérentes de Coraux' dont' l'une feroit toûjours plus remarquable que l'autre, \& qui ne peuvent qu'exciter une admiration mêlée de plaifir en tout Amateur attentif. Quoique toutes ces différences foient remarquables \& diftinetément exprimées, elles ne laiffent pas d'échaper fouvent aux yeux de ceux, qui ne font que commencer à étudier l'Hiftoire des Curiofitez naturelles. Car le Proverbe qui dit qu'ils ont des yeux \& ne voyent point, ne peut jamais mieux être apliqué qu'aux Neophytes, qui ne font qu'entrer dans la Carrière des fecrèts \& des beautez de la Nature, pendant que ceux qui s'y font attachez long - tems y voyent affez fouvent trop, \& même plus đqu'il n'y a.

Il eft tems à préfent d' entamer 1' Ouvrage en procêdant à "la Defcription des Pièces qu'on va voir fur les Planches fuivantes.

\section{PLANCHE A.}

Figure 1. Dans nos Defcriptions de ces Oeuvres merveilleufes du Créateur nous debutons par préfenter à nos Lecteurs un corail pierreux rouge véritable tiré de la Mer mediterranté, dont on aura peine à trouver le femblable, tant il êt parfait, vû fa folidité, fa grandeur, \& fa couleur; Al. drovandus, Imperatus, Marfilli, \& d'autres le nomment $C_{0}$ rallium verum rubrum arborefcens. $\mathrm{La}$ racine, ou le pié, qua joint \& lie fermement cet arbufte de Corail au Rocher, abfolument rond \& ployé felon les élevations de la fuperi. cie du Rocher. Il paroit que ce pié eft une fubltance compolée de filamens de la nature de la Corne, \& qu'ot: ginairement il à êté rouge, mais que par fucceffion de tems il a perdu fa Couleur. De cette fubftance, attachée aus rocher pour ainfi dire comme un morceau de cire, s'élève un Arbufte rond, qui a au bas de fa tige presque un ponce de diamètre, \& quì à l'ordinaire va toûjours en dirninuant dans une gradation proportionelle. Cet arbufte fe partage en quelques gros rameaux, \& en quelques branches, qui en font des rejettons. Les plus parfaits de ceux-ci qui ont fait leur crû complet, c'elt-à-dire anxquels les Polypes ont achevé leur ouvrage, fe terminent.le plus fouvent en deux pointes courtes \& obtufes, feparées l'une de l'autre. La fuperficie extérieure eft marquée de raves fubtiles, à peu prés pareilles à celles qu' on obferve au dedans d'un $D_{2}$ 


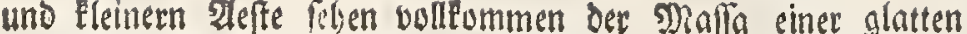
Stange von ben frinften rothen Siege(mnat)s gleith, und eben alfo fieft aud ter innere anbruct) einer Eoralle aus. Te âlter uno vollemmener bie Curalle ift, je róther uno fojoner ift aud

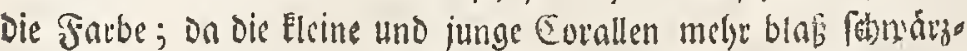

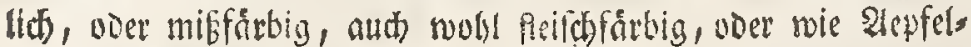

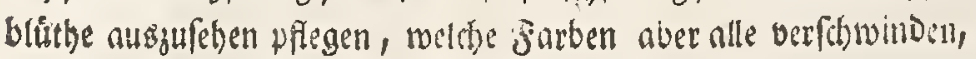
seen man die Eoralle an bas Seuer, doer in cin beennendes

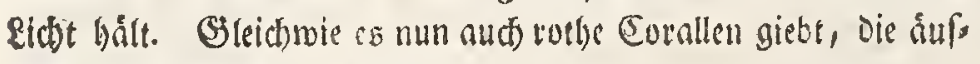

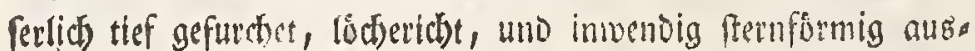
getsiglet find; alfo nimmt man an biefer alt mit bloffen 2lugen

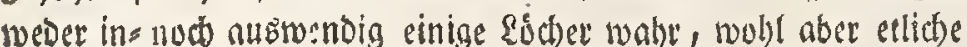

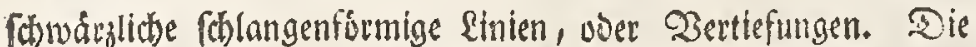

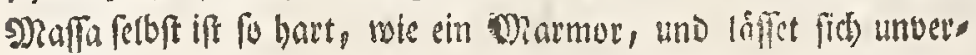

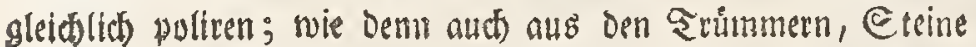

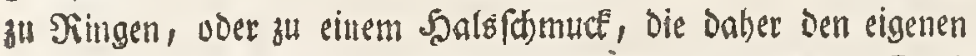
Samen Eurallen betummen baben, berfertiget merben. Dod find die vielfárbigen uder blabrothen Corallen Deșmegen; weil fie now jung fino, fo bart nieft. Intwendig legt fict) dic פraffa ringentoeife um einen Fentrectiten Bittelpunct, voer Sern an, wie

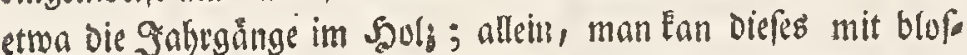

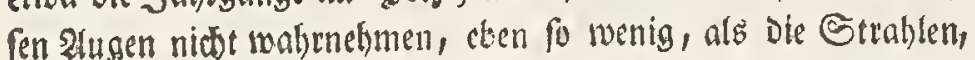

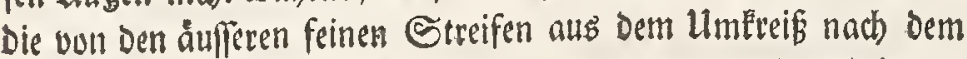

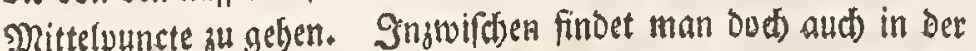

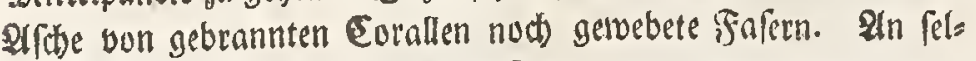
bigen nunfollen, wie Donatus will, noct) úbernus Eleine Siru

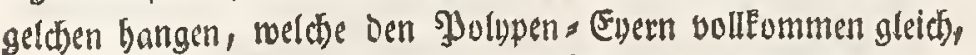
uno von ben গyolwsen abgeleget feun follen, woraus benn nebft Betradtung Der inmendig fich befinoenden undentlict) Eleinen

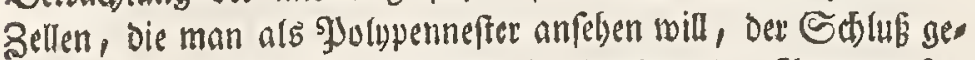
macht wird, Daß die Euralle nur ein Jyrobuct ber \$olupen fely. Ulebrigens baben bie Curallen eine verfüfende uno anbaltende Reaft, und rerber befiwegen aud in ber Medicin gebraudbto

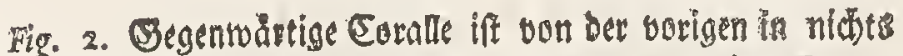

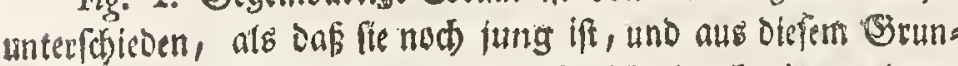
De Deutlidere Etreifen bat, Die nodil nicht Durd einen glatten

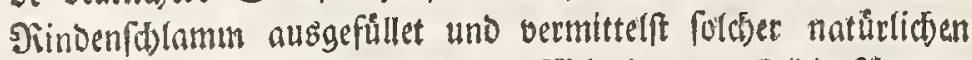
Jjulitur unfichtbar worben fimb. Wrsie Denn audi Die fotmarje

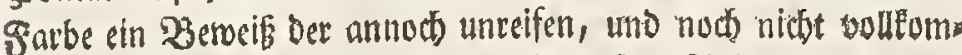
men ausgearbeiteten Corallenmaterie zu feyn fojeinet.

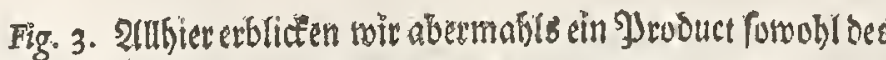
Mittellảnbif ben, als Sndianif melders eine Köhtcotalle, ober Tubipora iff, bie von dem Sritter Linnæo Den Namen Mufica befummen, bey Dem Sutnefort aber Tübularia purpurea, und bey ben \$̧aubin Alcyonium fiftulofum rubrum genennet wirb. Diefe Shaffa fdpeinet Eein 2 egetabile ju Feun, fondern ift melye einem Jefre,

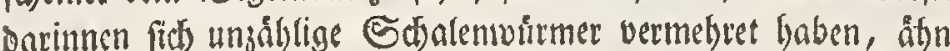

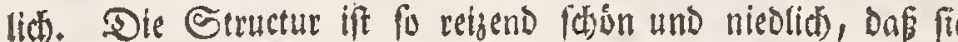
eine genauere 3 etractutung veroienet. Es ftehen nelyulict un. gáblige Sishbrthen parallel neben einander, unt find allenthalben vermittelft etficten quer Durdh bie ganze Daafe hinftreitbenden Querbåndern, als mit fo vielen awergfedlen, ooer Sadeidewån. doigt à fa partie fupèrieure, \& ces rayes accompagnent le rameau ,iusques au delà de fa moitié, ou elles font eclipCées foit par le brillant, foit par le poliment du Corail, \& ne peuvent plus être obfervées, fi ce n'elt au travers d'un verre. Les branches fupérieures \& plus petites reffemblent à la Mafie d'un bâton bien poli de la plus fine cire d'Efpagne, reffemblance qui a aufii lieu par raport aux bouts intérieurs quand on rompt l'un \& l'autre. Plus cet arbufte de Corai eft vicux \& parfait, plus fa couleur rouge eft belle \& éclatinte, au lieu que les petits Coraux, qui font encore jeunes, font plus pâies, noirâtres ou d'autre couleur désa? réable, ou quelque fois couleur de chair ou de celle des fieurs de ponme, lesquelles couleurs difparoiffent toutes, quand on aproche le Corail du feu, ou qu' on le tient fur une bougie allumée. Or on a des Coraux rouges, qui font garnis par dehors de fillons profonds, \& de trous, \& cavez intérieurement en forme d'étoile, mais à la préfente efpèce de Corail les yeux ne découvrent aucun trou ni cavité, ni au dehors, ni au dedans, mais feulement quelques lignes noirâtres ou cavitez qui vont en ferpentant. La Maffe ellemême eft dure comme du Marbre, \& l'on peut lui donner un poliment incomparable: auffi en emploie - $t$-on les petits morceaux à des bagues, où on les met en oeuvre, à des Carcans, \& à d'autres bijoux de femme. Cependant les Coraux àl plufieurs couleurs, ou dont le rouge eft pâle, n'ont pas la même dureté parcequiils font encore jeunes. Au dedans la Maffe fe forme en anneaux, autour d'un Centre, ou d'un cour perpèndiculaire, à peu près comme les années font marquees aux arbres, mais c'eft ce qu'on ne fçauroit voir avec les fimples yeux, non plus que les rayons, qui partant des fines rayes extérieures vont de la Peripherie au centre. Cependant on trouve même dans les Cendres des Coraux brulez encore des filamens tiffus, auxquels font attachez felon Donarus des globules extraordinairement petits, qui reffemblent à des oeufs de Polype, \& qu'on prétend avoir êté pondus par des Polypes, d'où l'on croit pouvoir conclure, en y joignant l'obfervation des Cellules infiniment petites qui fe trouvent dans le Corail, \& qu'on donne pour des nids de Polype, que le Corail eft un Produit de l'induftrie des Polypes. Au refte le Corail a une vertu adoucifante \& aftringente, qui fait qu'on s' en fert dans la Médécine.

Figure 2. Cet arbufte de Corail ne diffère du précèdent qu'en ce qu'il eft jeune, \& que par cette raifon les rayes cont il eft marqué font plus diftinetes, n'étant encore ni remplies par ce limon visqueux uni, qui forme l'écorce ou l'envelope, ni renduës invifibles par ce poliment naturel, tout comme la couleur noire, qu'on y obferve, fert de preuve qu'ils ne font pas encore parvenus à leur maturité, ni la matière qui les compofe à fa perfection.

Figure 3. Ceci eft encore un Produit de la Mer mediterranée, qu'on trouve auffi dans celle des Indes, \& dans la Mer rouge. C'eft un Corail a tuyau (tubipora) que le Chevalier Linnaus a nommé Mufica, mais à qui Tournefort a donné la dénomination de Tubularia purpurea, \& Baubin celle de Alcyonium fiftulofum rubrum. Cette Maffe ne paroit nullement être un Végétal; reffemblant beaucoup plûtôt à un nid, où un nom. bre infini de vers à coquille fe font multipliez. La ftructure en eft fi belle \& fi fine, qu'elle mérite bien une obferva. tion un peu détaillée. On y voit une infinité de petits tu. yaux rangez en lignes parallèles, qui font tous liez entre eux l'un a l' autre par des ligamens, qui traverfent toute la Malfe, comme par autant $\mathrm{d}^{2}$ attaches transverfales, ou de parois. 
Den aneinander zu einer Maffa verbunden. Tedez Jisbrefien if bic unten bu bobl, und fos weit, Daf man mit einer Etectnadel bi binunter Eummen fan, aber Dabey Febr Dỉnne, uno leidse zers brectlich. Das merewurtoigfe aber ift, das wheradtet bie Siobren parallet neben einander felten, (Dot) fo, daf fie einander

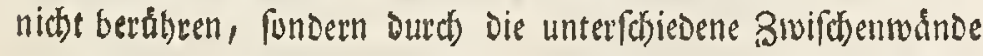
von einander sebalten werden) Dennuch aidht alle Siobleren bis ganz binunter jur Bafin Der פraffa lauffen, fondern bun unten

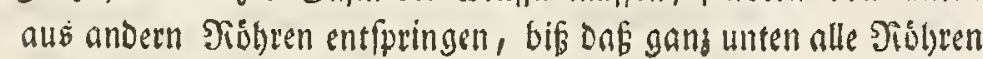
nact) und nach zufammen in trenige, weer wobl gar nur in eine eimbige, bie bie erfite und áltefte sioghe war, auslauffen. In. stwifhen if die eine Fistere fo weit, wie bie andere, und giebt

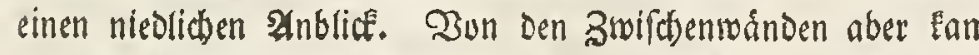

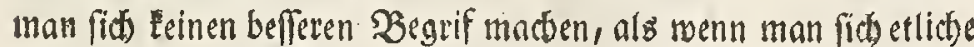

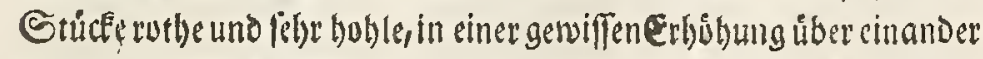

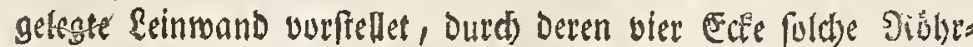

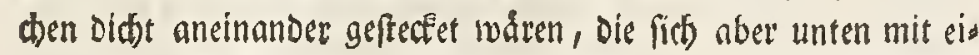
ner Eleinen Rrummung in einander fenfen, und alfo durch diefe

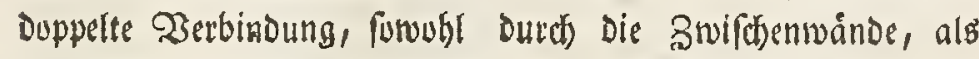
burd bie untere 2 ergfieberung, zu einer Maffa aneinander ge. madbjen find.

Diefe Etheibe. Wrande find ein wenig brafter, als bie rióbren felbft, aber übrigens von nelmmlicher Eubfran.

\section{T.AB. A. I.}

Fig. I. Fuf biefer Tafel pranget bey Der erfeth Sigur eine Der rareften Curallen, welde im Mlittellänbifchen Meer

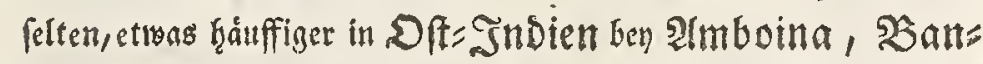

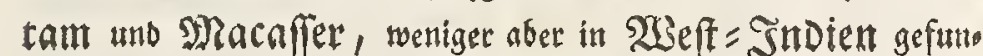

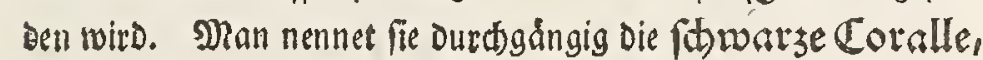
if aber Eeinesweges zu Den Stein s Eurallen ju rectinen, fondern verdienet unter ben Sornz Corallen (Keratophytis) Den aller.

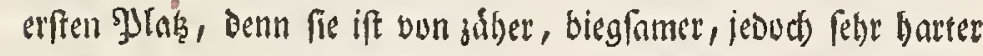
Sirbfranz, auswendig fitwars, glatt, und glánzend wie fitwar. ze\& Siegelwasths, innendig aber matt, wie föwarzes Eben.

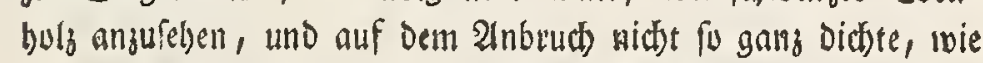
die ruthe Curalle, fondern urbentlict) mit unterfotiedenen úber eins

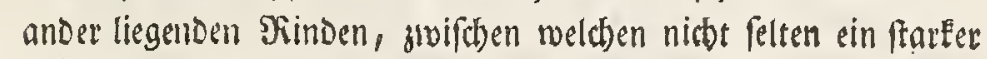
3nifflenraum ift, anzufeben. Die äuffere glatte Saaut bat aud

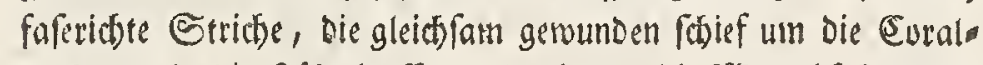

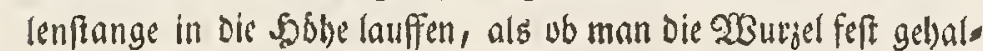
ten, und Den weern Sheil der Srange sinnably berum gedrefet bátte. SRan nennet fie nud bie fdiwarge unád)te Eoralle, Co. rallium nigrum adulterinum, uno if $D \in E$ Plinit Antipathes, melche Benennung fie dearwegen foll erh alten baben, weil fie der Sjárte buber im Gehen als ein Stue fan gebrauctit werden, uno bey Dem

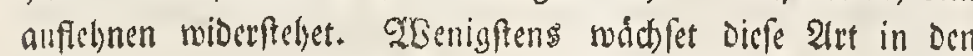
Jnoten oft ju cicken gernde in bie Shibe gehenden Stocten, Dabun efticte ganz gerade aurgefrect, andere bugigt, wie biefe, neth) andere fnutigt, und eine rare Ant wie eill Jy rupfenzicher ums

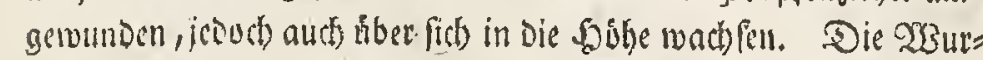

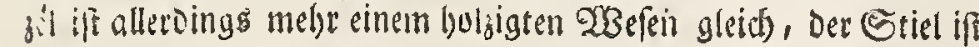

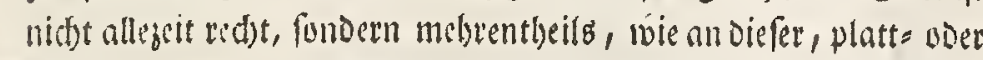
gecrucft muno. Die 2afigen find furs, biffe und wenig on ber

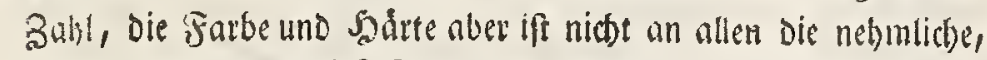
uno alsoann geter biefe 2int in Die gemeinere braunlidte Şorne curalle liber.
Chaque tuyau eft creux ou cave du haut en bas, de forte qu'on peut $y$ fourrer une épingle jusques au fond, mais ils font fort minces \& fort fragiles. Ce qu' il y a de plus remarquable, c'elt que quoique tous ees tuyaux foient difpofez en lignes parallèles, (de façon pourtant qu'ils ne fe touchent point, les diffèrentes parois mitoiennes les tenant féparez les uns des autres) ils ne s'étendent pourtant pas jusques z la bafe de toute la Maffe, mais qu'ils fortent d'autres tuyaux inférieurs, jusques à ce qu'ils fe terminent tout à faitau bout à un petit nombre de tulaux, ou quelques fois en un feul, qui eft alors le prèmier \& le plus vieux de tous., Cependant un tuyau a autant de diamètre que l'autre \& cela forme un total, qui réjouït la vûë. Quant aux parois mitoïennes, on ne peut s'en former mieux une idée, qu’en fe repréfentant quelques pièces de toile rouges \& creufes difpofées verticalement, au travers des quarrez desquelles on auroit paffé ces petits tuyaux l'un contre l'autre, lesquels fe rejoignent en bas par une petite courbure, \& font crûs enfemble en une feule \& mème Mafle par cette double liaifon, f̧avoir tant par les parois mitoiennes, que par les jointures infèrieu. res.

Ces Parois mitö̈ennes font un peu plus pâles en cou. leur que les tuiaux même, mais au refte de la même fubftance.

\section{PLANCHE A. I}

Figure I. L'on voit briller ici dans la première figure de cette Planche un des plus rares Coraux. On en trouve de pareils, mais peu, dans la Mer méditerranée, \& encore moins aux Indes occidentales. En revanche on en rencontre plus fouvent aux Indes Orientales près d'Amboina, de Bantam \& de Macafjer ou Macafar. Cette pièce eft nommè d'un commun accord le Corail noir. Ce n'eft point un Corail pierreux, mais il mérite la prémière place parmi les Coraux de nature de corne, (Keratopbyta), car quoiquili foit d'une fubltance très-dure, il eft néanmoins Hexible \& a quelque chofe de coriace. Sa Couleur extérieure eft noire, unie, \& luifante comme de la cire d'Efpagne, mais au dedans il eft noir \& mat comme de l'ebène. Là où il eft entamé on remarqué quelques écorces couchées l'une fur l'autre mais moins ferrées qu'aux Coraux rouges, entre lesquelles il y a affez fouvent un intervalle confidérable. L'Envelope extèrieure unie eft garnie de rayes en filamens qui font comme torfes \& vont du bas en haut en faifant obliquement le tour de l'arbufte, tout comme fi en tenant ferme le bas de l'arbufte on en avoit tordu le bout fupèrieur. On lui donne auffi le nom de Corail noir bâtard, (Corallium nigrum adulterinum). Pline l'apelle Antipatbes, nom qu'on prétend avoir êté donné á ce Corail, parceque, vû fa dureté, on peut s'en fervir comme d'une Canne, \& qu'il refifte quand on s'y apuye. On en voit aux Indes de cette efpèce, qui croiffent en bâtons épais \& hauts, dont quelques uns font droits, d'autres courbes, d'autres noueux, \& d'autres, mais qu'on rencontre rarement, font tournez en Tire-bouchon, tirant cependant toûjours vers le haut, La matière de la racine à quelque chofe de la rature du bois. La tige 'n' en eft pas toûjours égale, mais le plus fouvent platte, comme à la pièce figurée ici, ou d'une rondeur comprimée. Les petits rameaux font courts, épais, \& en petit nombre, maisleur Cou. leur \& dureté n'eft pus en tous la mêne. On met ceux, qui Fig. 
Fig. z. Die in biefer Figur abgevildete Maffe if die gemeine woiffe augigte Coralle des Baubin, ooce Corallium album oculatum offic. weldse in Den Novediften Deeren hdufig angetruffen und itt Den stputbecten gebraudt) twirt.

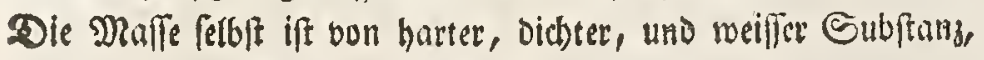
begm 2tnbruch nidt) volleummen glatt, fondern etwas geftreift und lodseridst, dufferlid) aber ift fie glatt und gleidsfont puliret, jebow trift man aud fulthe an, Die auf Der glatten Dberfláche geroundene, aber zarte Stridbe haben. Diefe Jaffen frişen in ifemlich unfórmficten Slumpen mit einer beeiten Fláthe auf Den

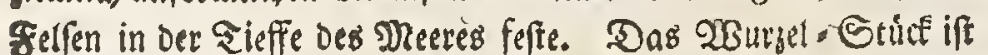
burdhgángig einem verwirtten Sifumpen åhnlidy, aus weld)en etlithe Fingers diafe uno mannidsfaltig gebegene Aefte balo ger rade, bald fitief, bald einzeln, bald mit andern verwadsen,

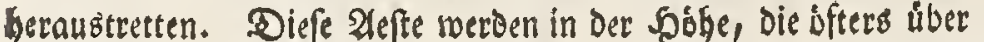
einen Stuuh reidet, groar je langer, je dơnner, haben aber fo biele diafe Rnoten, und unfórmlidse Bergliederungen, und fint Dergeftalt an einander gewadben, und wieder bun einanber mit allerbano אirummungen abgebogen, vber burchs uno in einander gefdoben, Daß man keine ordentlidje Jy flanzenartige Structur berausbringen Ean. An allen 2effen befinden fitt) von unten bis uben eine Menge sód)er, ober F(ugen, die erfitlich) nur els nen vieetels voer dorittels Zull weit vun elnander entfernet find; barnach finden fie fict) nur an sweyen gegen einander úberffelhen. Den Seiten uno stwar eins ums andere; orittens bretsen fie mit einer Errhóbung, oder einem Snuten in bie Dberfiadthe aus, uno

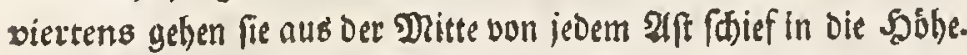
Die Etructur aller biefer 2lugen ift bey einem, wie bell Dem an. Dern rund fternformig; aber an Den Seiten Der Aefte ftetlen fie ein långlidtę ober gefțibenes Siund vor. Die innere Bauart oles

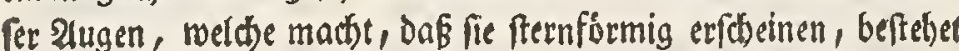
barinnen, das die bis in bie Mitte vun jeoem 2fit bineingehende Sbilung voller zarten fibieferidten Scheiberwånde frebet, welthe alle aus Dem Nittelpunct nath Dem Limfang Der Sajlung gehen' roie bie \$rabli eines Birletb. Dben aber, two fich Das 2lug auf Der Dberfiade bilbet, find diefe fternfürmige Sheidenánde et,

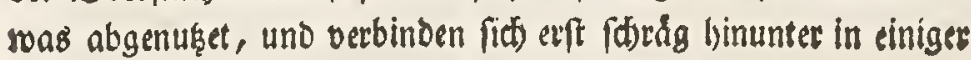
DSertiefung mit ibrem gemeinfibaftlidon Dittelpunst. dègenèrent à cet égard \& paffent la Claffe des Coraux de na. ture de corne, dont la couleur tire fur le brun.

Figure 2. La Maffe repréfentée dans cette figure eft le Corail commun plein $d^{3} y e u x$, de couleur blancbe, que Baubin nomme Corallium album occulatum officinale. On le trouve abondamment dans les Mers feptentrionales, \& les A poticaires en font ufage. La Maffe en eft en elle - même d'une fubftance dure, compacte, \& blanche en cour leur; elle n' eft pas parfaitement unie à l'entamure, quand on en rompt un morceau, car on y voit des rayes \& des trous, mais au dehors elle eft unie \& a une efpèce de poliment, mais on en voit auffi, qui fur cette furface unie ont de plus des fines liznes torfes. Ces Maffes fe trouvent au fond de la Mer attachées aux rochers dans une étenduë affez large, en tapons informes. Ce qui en forme la racine reffemble de tout point à un Peloton embrouillé, d'où l'on voit fortir quelques rameaux, epais de quelques doigts et courbez en diversfenc, tantôt en droite ligne, tantôt en ligne oblique, tantôt feuls, tantôt attachez à d' autres dans leur accroiffement. Ces rameaux à méfure qu'ils croiffent en hauteur, ce qui s'étend quelquefois à plus d'un pied, vont fans doute en diminuant, \& deviennent plus minces felon qu'ils s'élèvent, mais ils ont d'ailleurs tant de gros noeuds, \& d'articulations informes entrelacées les unes dans les autres, de même que des Courbures entremêlées qui fe dépaffent reciproquement, qu'il n'eft pas poffible d'y trouver la ftrueture telle qu' elle eft ordinaire aux végètaux. Il y a à tous ces rameaux du bas en haut une quantité de trous, ou d'yeux, qui d'abord font à un quar ou à un tiers de pouce de diftance l'un de l'autre, on les trouve enfuite en vis - à - vis aux deux côtez, en troijième lieu ils percent la fuperficie avec une élevation ou un nœud, \& quatrièmement ils fortent du milieu de cha. que rameaus en ligne oblique, tendant enhaut. La ftructure de tous ces yeux eft également à toutes les pièces formée en étoile ronde, excepté aux côtez ou ils fe préfentent en rond oblong, ou lenticulare. La Contrutution intérieure de ces yeux, \& celle qui fait qu'on les voit formez en étoiles, confifte en ce que leurs cavitez, qui vont depuis la furface extèrieure jusques au milieu de chaque rameau, font gas nies de plufieurs parois mitoïennes fort fines, écaillées, qui partant du Centre atteignent jusques à la périphèrie, tout comme les rayons d'un Cercle. Mais en haut, où l'Oeil fe forme à la furface, ces parois fe trouvent un peu ufees, \& ce n'eft qu'au dedans à un certain dégré de profondeur, qu'elles ront en ligne oblique fe réunir à leur centre commun.

Le nombre de ces parois attachées les unes aux autres
ques au centre va jusques à fix, qui font toutes difpo-

Die Anjahl biefer bis in Dem Mittelpunct aneinander befer filgten Ecteidetwánoe belauft fid rings herum auf fects, bie aille in einer gleidhen Entfernung von einander ftehen; zmifdien biefen aber hangen an Dem Umfang Der Şobllung eins ums andere nuch

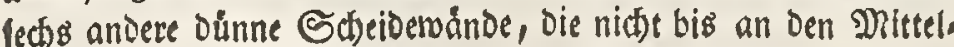
punct retiden, und jwifthen allen biefen, fo rwobl ganzen, als halben blätteridten Sdbeideménden trift man nud stwilf enba. bene Stridfe in Der innern Siundung an.

Die Dicfern Aefte des 23 urzel . Stưces find Durctigingis ganz buhl, und faceinen Siúbren zu fergn, in welden fid) Die alten Ed)eidemánde abgenuset baben, jeoud findet man in biefen giemlid) weitten Siottren Eleine Defnungen, Die fid bernach auf Dee Dberfaddbe in vielen fternfórmigen 2 ugen uffenbahren. T3ies twobl etlicte diefet grofen Sisbren gand diфte, glatt, uno mit einer fées à diftance égale l'une de l'autre; mais entre ces parois mitoïennes on en remarque encore fix autres plus minces à l'entrée de la cavité, qui n'atteignent pas jusques au centre, \& entre toutes tant parois entières que demi-parois feuilletées, on obferve dans la cirfonférence intérieure encore douze rayes élevées.

Les rameaux les plus épais de la racine font abfolument \& entièrement creux, \& il y a lieu de conjecturer que ce ne font plus que des tuïaux dont les vieilles parois mitoïennes fe font ufèes; cependant on trouve encore dans ces tuiäux qui font affez larges de petites ouvertures, qui vont fe cléclarer à la fuperficie en quantité d'yeux formez 


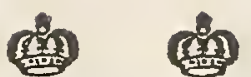

eigenen Maffe überzogen find bergleitsen bie fogenannten Sishr.

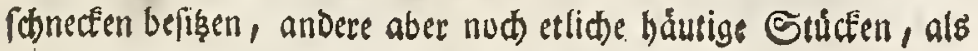
tleberbleibfel eines 223 urtmis bey fid fübren.

Fig. 3. Bon einer gang anderen Bauart if bie in biefer Fio gur abgebildete weifse geftirnte Coralle des Sauthin, die auds in Des Gloane Jam. ₹ab. 18. Fig. 4. angetruften und Corallium album ftellatum genennet wird, Da jenes ein

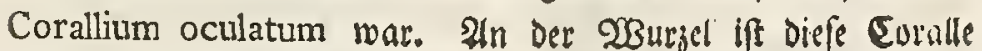
bey Den mebreften hubl, und man fiebet dafelbfit, Daf unterfoledene

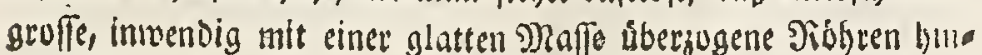
eingehen, fodaun aber die áuffere Maffe fiø in Edichten und fagen úbereinander geleget hat. Das obere (Sebáube tritt aus

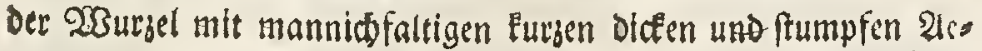
feen beraus, bie alle nifit zugefpizet find, fondern fith als runde

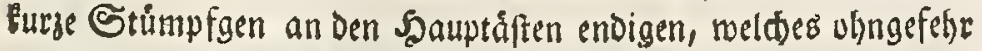

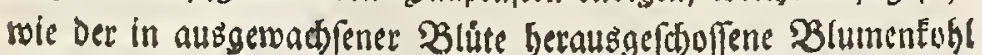
anzufeben ift. Dem anbrube nacb befethet biefe Euralle aus eben Den Beftandtheilen, weldhe bie surbejthriebene batte; aber fie if mit unzäbligen sodjern verfehen, Dergleidhen fith auf Der Oberfáde zeigen. Alle Diefe sóder frehen fo Dithte aneinander,

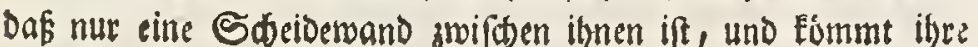
Bildung einer etwas graben Spise, bie ein pures (S)enebe v:n tleinen 2leuglein ift, rebr gleich. Ein jedes 2leuglein ift unges mein zant geftirnt, faft auf bie nebnaliche ant, twie wir burther befhrieben haben; an ftatt aber Dab bie Fefieferichte Blåtter, weldbe ben Pleuglein bie Sternformige (jeftalt geben, fich in eir nem Stüce tief in Die Sisfreten binunter fenten folten, fo find fire gleid mit einem Boden Die Duere unterlegt, weldyer die obere Belle, voer Den ubern Stern in Der Sidgere von Dem tiefer hinuno ter fetbenden und Durauf fulgenden Stern unterfiteidet; und Dergleitsen Suerlagen baven wir in sinem Jiübriben bey dem 2Anbruct mobl fünfe úbercinander lieggen feblen, eben alb ub man einen bublen Eilinder mit verfibiedenen fernfórmigen 2luffäkęen anfifllete, die alle burd einen eigenen :Boben bun einander unter. pebieden find.

Fig. 4. Diefe Maffa 化einet einem abgebrodienem Stúce uon Der im Muf. Besler. Tab. XXIII. abgebilbeten Planta faxea alba fehr álndid su feun, und if vor bes SBaubin Planta faxea Abrotonoides ju halten. E\& bat nemlid biefe Curalle eine Traubenfórmige Geftát, Daran nur bie Épiţgen nit einem Raldbartigen Eeefdlamm bicke überzogen und nid)t Deutlid find, obne Bmeifel aber unter die Siladreporen uder Curallen nit feernformigen 2leuglein muß gerednet merden. Dodb weil auf Der folgenden Siuptertafel ein Deutlideres Exermplar vorEummen.

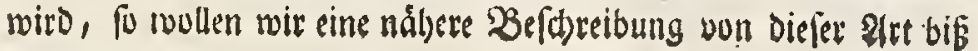
Dabin verfiabren.

Fig. 5. Ë gethoret biefe Staube unter die Şornartige Eregevdadfe, und ift bey Den Rráuterlebrern, als beym

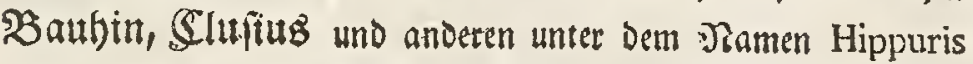
faxea betannt. Eie if zwar ungemein hart, swiftsen Den Oere

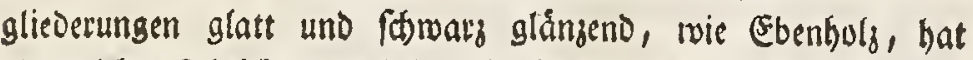

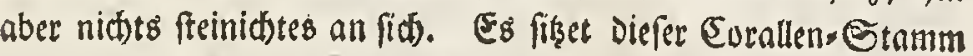
auf einem Stúcé bon einem Felfen, Den er nit einem burnartio

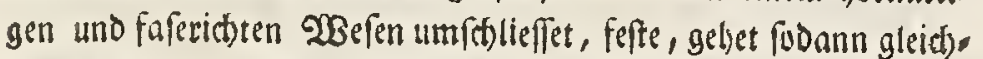
fam gerounden, und mit frovtigten Dergliederungen in bie Soube. en étoiles, quoiquîl foit de fait aufin, que quelques uns de ces grands tuyaux font fort compactes, uns, \& couverts d'une Maffe, qui leur eft propre, comme on en voit $2 u x$ Efcargots en tuyau, comme on les nomme, au lieu que l'on trouve dans quelques autres des reftes de pellicules, quj paroiffent dénoter qu'un Ver y a eû fon habitation.

Figure 3. Le Corail, dont nous venonś de parler, porte le nom d'oculatum, à caufe de la quantité de fes yeux. Celui que nous voyons dans la figure préfente eft d'une toute autre ftructure. Baubin l'apelle le Corail blanc étoilé, \& on le trouve dans Sloane, Famaica, Planche 18 , fig. 4. fous le nom de Corallium album 'Stellatum. La racine de ce Corail eft creufe le plus fouvent, \& l'on y voit entrer divers grands tuyaux, qui au dedans font enduits d'une Maffe unie, pen. dant que la Maffe extèrieure eft ftratifiée \& rangée en couches l'une fur l'autre. Divers rameaux courts, épais, $8 z$ obtus partent de cette racine \& forment le refte de l'édifice. Aucun de ces petits rameaux ne fe termine en pointe, mais en moignons ronds par le bout, \& courts, qui vont aboutir vers les gros rameaux, à peu près comme fe préfente la fleur des Choux - fleurs, qui germent, quand elle pouffe. Quand on en rompt un morceau, on remarque que ce Corail eft compofé de la même fubftance que le précedent, mais on y obferve un nombre infini de trous comme à la fuperficie. Tous ces trous font $\mathrm{fi}$ près les uns des autres, qu'une feule paroi mitoïenne peut avoir place entre - deux, par où ils reffemblent affez à une dentelle groffière, qui n'eft qu'un tiffu compofé de petits yeux. Chacun de ces petits yeux eft finement étoilé, presque com. me ceux dont nous avons donné la defcription cy - deffus. Nais au lieu que le feuilletage, \& l'écaillement, qui forme à ces yeux la figure d'étoile devroit defcendre tout de fuite jusques au fond des petits tuyaux, ils font dés le haut garnis d'un fond en travers, qui fépare la Cellule ou l'étoile fupèrieure de celle qui fuit. Nous avons trouvé ainfi dans un feul \& mème petit tuyau jusques à cinq de ces couches en travers, l'une au deffus de l'autre, comme fi l'on avoit rempli un Cylindre d'autant d'étages en forme d'étoile, tous feparez l'un de l'autre par un fond pareil.

Figure 4. Cette maffe paroît être un morceau rompu du Corail que l'on trouve figuré dans le Mufeum Beslerianum, Planche XXIII. fous le nom de Plante pierreufe blanche, en latin Planta Saxea alba, \& nous tenons que c'eft ce que Baubin apelle Planta Saxea Abrotonoides, ou Plante pierreufe d'Auronne. Ce Corail eft figuré en raijin, dont les pointes font couvertes d'un limon visqueux épais, qui tient de la chaux. Quoique ces pointes ne foient pas bien diftinetes, on doit cependant mettre cette pièce fans doute au rang des Madrepora, ou Coraux, qui ont de petits yeux en forme d'étoile. Mais comme on en verra fur la Planche fuivante un, qui eft exprimé plus nettement, nous renverrons à cet article - là la defcription que nous en voulons donner.

Figure 5. La préfénte Plante apartient à la Clafe des Coraux de nature de Corne, \& eft cellé que les Auteurs Botaniques, comme Baubin, Clufius, \& d'autres nomment Hippuris Saxea. Qnoiqu' elle foit trés - dure, \& dans l'intervalle des articulations unie, \& d'un brillant noir comme celui de l'ebène, elle n'a cependant rien de pierreux. Cette tige de Corail fe trouve fermement attachée fur quelque rocher qu' elle embraffe en filamens d' une matierè, qui tient de la cosne, \& de là elle s' gléve en figure torfe, où l'os obferve 


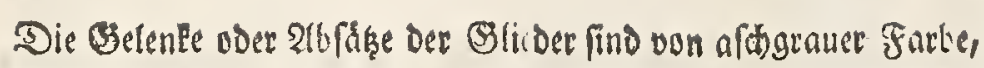
oft einen halben Soll und onriber breit, uno nusiwendig voller

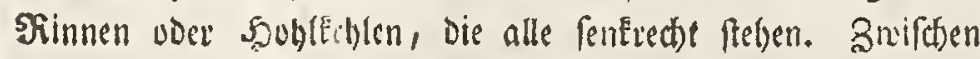
Diefen Geleuten, Die wie Singe um Den Stanm fteben, unt zrwiften dem eigentliden Stamm, tretten bin und nieder Neben. afte aus, Die eben fo, wie der Scaupt - Etanm vergliebert find.

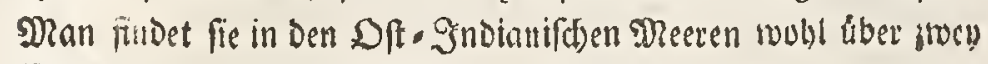

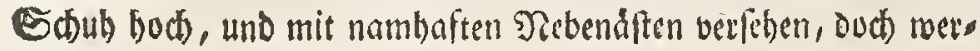
ben fie weit feltener, als andere Saurngewaid fe angetwuffen.

\section{TAB. A. II.}

Fig. I. Bey der vieten Figur Der vurfergellenten Supfero tafel berfipracten wir, bun Der Planta faxea Abrotonoides eine náhere $\mathfrak{B e f t h r e i b u n g ~ s u ~ g e b e n , ~ u n d ~ d i e ~ i n ~ j e s ̧ i g e r ~ F i g u r ~ a b g e b i l s ~}$

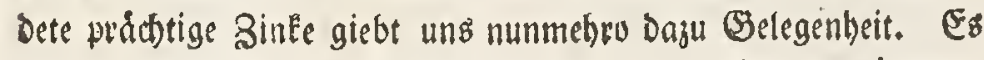
if aber biefeftige Das Corallium album porofum muricatum maximum, fo bey dem Sloane Jam. Tab. 18. fig. 3. gefunden wird, woer nudb Die Madrepora Abrotonoides major, Deren Clufius und Baubin Erwebnung thun. Bufferberfit if angumerlen,

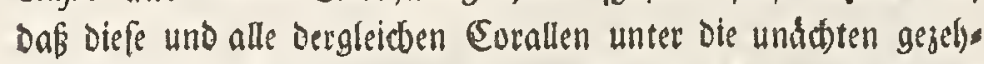
let werden, weil fie nidst von einer foldeten didten und harten Spaffe, wie die vorber beftitiebene rothe, uder mie bie ufficinelle weiffe Z(ugens und Sterncorallen, Jufammen geferget, fondern mebre Fiald)= artig aud múrber und brúdbiget find.

2ras aber nun bie Strutcur uno Banart biefer 25aum formitgen, rauben odev frabelidten Coralle betrifs, fo ift gegenmartiges Exemplar ein abgebrod)ener 2ift bon einer fulden Eurallenqflanze, Die oft allein, uft aber mit vielen anderen suglecid, Diuftweife, und wie cine lleine $283 a l$ ang auf einem

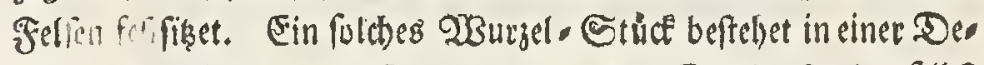
cee von gleicher hoblen Baauart, wie die Eurallenfraube felbft ift, uno welde einen Theil Des Felfens, als cin Sileid bebectet.

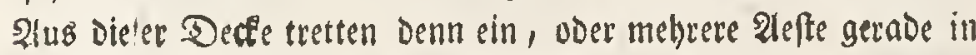
bie Shibe, die unten oft grwey Bull bice find, uno in einem veges

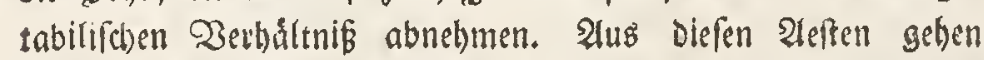
fersun sun unten an Rebendfte beraus, bie zumeiten mit Den 2leften des benadbarten Etammes berwach/en, fo das fith allo

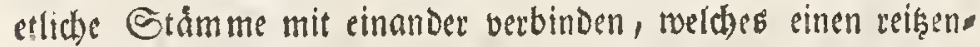
Den 2tnblicte giebt, zumabl wenn diefe Curalle, wie oft gefates bet, stoey Sctuly uno Daruber boch ifr.

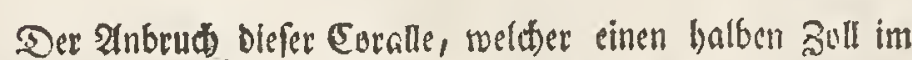

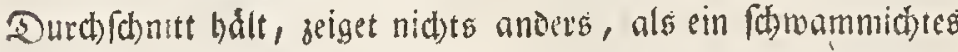

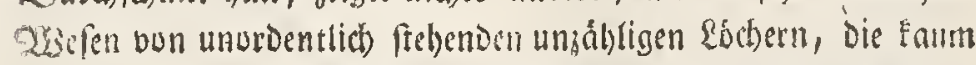

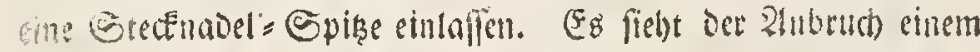

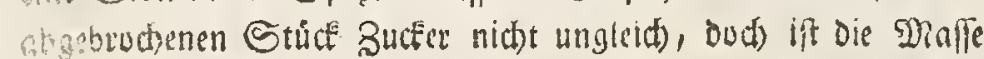

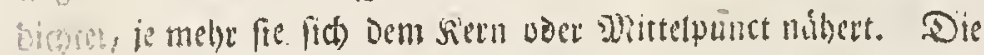

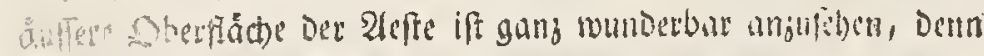

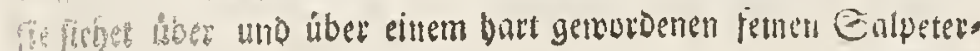

Sdins plufieurs articulations noibeufes. Les jointures, ou articulations qui féparent les intervalles, font de couleur cendrée, fouvent larges d'un demi - pouce ou de davantage, \& au dehors garnies de quantité de petits canaux, ou cannelures, toutes difpofées en ligne perpendiculaire. Entre ces jointures, qui embraffent la tige comme des anneaux, \& la tige mème, on obferve de petites branches de côté, qui ont les mèmes articulations que la tige principale. On en rencontre qui font hauts de, plus de deux pieds dans les Mers des Indes orientales, pourvùs de plufieurs de ces rameaux de côté, cependant il eft vrai qu'on trouve beaucoup plus rarement de ces Coraux - ci, que d'autres Plantes de nature de corne.

\section{PLANCHE A. II.}

Figure x. Nous avons promis en parlant de la figure quatrième de la Planche précèdente de donner ici une defcription détaillée de la Plante pierreufe d'Auronne, (Planta Saxea Abrotonoides), \& la branche fuperbe de Corail dépeinte dans la préfente figure nous fournit l'occafion d'effectuer nôtre promeffe. Ceci eft le grand Corail blanc poreux qui a des pointes en chaufe - trape, ou Corallium album porofum muricatum maximum qu' on voit dans Sloane, Fam. Tab. 18. fig. 3. \& c'eft le mème, dont Clufius \& Baubin font mention fous le nom de Madrepora Abrotonoides major, c'eft à dire, le grand Corail étoilé d' Auronne. Il faut d'abord obferver que ce $\mathrm{Co}$. rail, \& tous ceux de la mème efpèce, doivent être comptez parmi les bầtards, parceque leur Maffe n'eft pas auffi dure \& aufi compacte que celle du Corail rouge ou des Coraux blancs à yeux \& à étoiles, dont on fait ufage en Médécine, \& dont nous avons donné plus haut la defeription, cette $\mathrm{Maf}-$ fe - ci tenant-plus de la nature de la chaux, \& étant aufi plus fréle \& plus fragile.

Pour parler à préfent de la pièce que nôtre figure depeint, \& que nous apellons le Corail raboteux, ou à aiguillons formé en arbriffeau, $\left({ }^{*}\right)$ ceci eft une branche rompuë d'une de ces Plantes de Corail, que l'on trouve fouvent feules, \& fouvent aufi en quantité enfemble, fermement attachées fur quelque rocher, comme des buiffons, ou de petits bocages. Quant à fa ftructure, la pièce où la racine tient confifte en une Couverture, tout auffi creufe que l'arbufte-même, laquelle couvre, comme le pourroit faire un habillement, une partie du rocher. De cette Couverture fortent un ou plufieurs rameaux, qui s'élèvent vers le haut en ligne droite, \& ont en bas fouvent jusques à deux pouces d'épaiffeur, allant enfuite peu à peu en diminuant, felon la proportion, qui a ordinairement lieu dans le Règne végètal. Plufieurs rejettons proviennent de ces rameaux en commençant désle bas, lesquels fe joignent quelquefois aux branches de la tige voiline, \& croilfent avec elles en une mème maffe, ce qui forme un coup d'oeil charmant, fur tout quand ces Coraux ont deux pieds \& davantage de hauteur, ce qui arrive fouvent.

L'Entamure de ce corail, qui a un demi-pouce de diamètre, préfente une Maffe fpongieufe garnie d'une infinité de trous difpofer fans ordre, où l'on peut à peine four. rer la pointe d'une épingle. Cette entanure a affez de reffemblance avec un morceau de fucre rompu, avec cette diffèrence pourtant que la Malfe devient toújours plus com. pacte, à méfure qu'elle aproche du centre, ou de la moelle. La fuperficie extérieure des branches excite l'admiration,

(*) Die baumformige raube oder fackelicbie Coralis. 
Shimmel gleid, indem die gange Silnde aus Millionen Eleinen

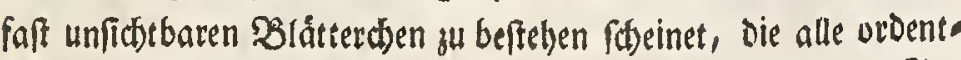
liđ), utto parallel neben einander fiegen, uno Derfelben oas 21n.

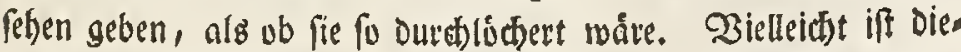
fer Die Urfache, roarum Der berühmte Sitter Linnæus biefe \&rt unter Die Milleporas gezehlet bat, ohneradtet die Dberflache gar Eeine Poros oder runde sober, wohl aber, undentich feitle und unjåno

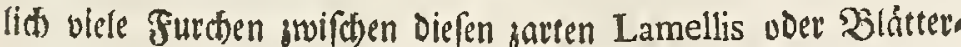
ben bat. Dak aber Diefe Coralle vielmehr zu Den Madreporis, uder fternformigen Corallen gehore, zeiget die fernere Structur die wir jezt befdreiben wollen. Es tretten nemlid) rings herum an allen 2leften aus Diefer vorbeffriebenen Oberflathe oder STin

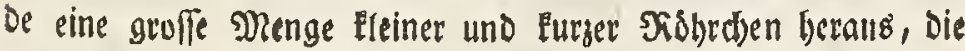
gang dichte, jedoct eing ums andere benfammen ffeben, uno die alle oben platt und bobl find. 2an biefen rofirben gehen bun auffen ringsherum bie vorber beftiriebenen zarten 3 látter fao rallet in Die Șube; inwendig aber bilbet jede Defnung an siefen Fiobrchen ein Sternden, reldes, wie bey Den vorigen Figu ren fobon if exllåret morben, lediglid) aus Den, von Dem UImfang nad) Dem Mittelpunct zu lauffenden Sdfieffern voer Stheice

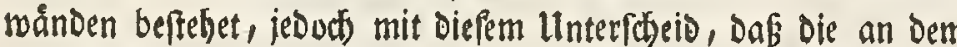

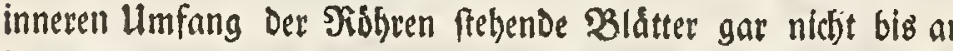
Den Dittelpunct reiden, folglid aud nidjt zufammen fummen. 2He Diefe Siobrchen fino an Der ganzen Eoralle ủberein, uno man nennet fie Defiregen Corallium Muricatum.

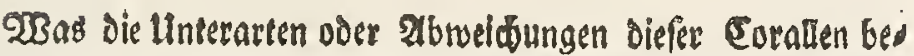
trift, fo fino fie foroobl Der auferliden Structur, als Der Farbe nad) unterfthieden. Denn man findes baumformige, wie diefe,

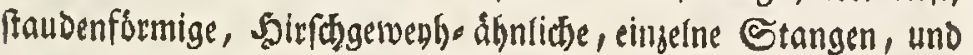

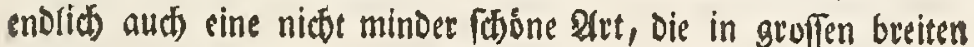
Eappen voer Sdilden beftebet, welde entweder ganz flach und rounderbarfids mit Sóbern uno Singen Durdsbrudsen, voer ganz frumm zufammen gerollet, oder autb mit Scbivibbogen eingetraufet und ausgezact find. Jn 2unfefung Der Farbe abec giebt es fanneerweiffe, afot)graue, åpfelblútbåhnfide, bellgelbe, buntelgelbe, uno blaue, die aber bud alle beym 2tnbruch gegen Die Mitte voer Den Rern weiflldtt find, welde Farben alle twots mebrentheils bun Dem Unterficied Des Deerwaffers in Den unter. fefiedenen Seerbufen, wo man fie findet, berculbren; weil bie Stuffe, Daraus Diefe Maffe, entfefet, nichts anders, als ein Paltbartiger skeerfdlamm ift, in weldsem die Jjolnpen, went (r) noch weids ift, fief einaifteln, und igm nad) iber eigenen Seructur eine folde Seftalt geben. Endicit) aber finden wir

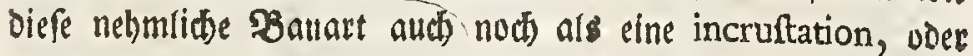
Sinde um eine genifle Surncuralle, reiltie man aud Defroegen Keratophyton crufta muricata nennet, uno Deren Crufta (d)ledterdings in alten Llmitanden mit Diefer Bauart úberein. ftimmet, wie soir bey Det Supfertafel A. VI, mil metheren ans seigen roetoen. quand on lla confidère, car elle reffemble de tout point à de la fine Ecume de Nitre, qui s'eft durcie, toute l'envelope, ou écorce, paroiffant être compofée d'un million de petites feuilles, presqu'invilibles toutes régulièrement difpofées à côté l'une de l'autre en ligne paralléle, \& qui la font paroître comme fi elle étoit ainfi percée. Peut - être eft.ce là la raifon qui a déterminé le célèbre Chevalier Linnaus a mettre cette efpèce au rang des Millepora $\left(^{*}\right)$, quoi qu'on ne remarque à la fuperficie ni pores, ni trous ronds, au lieu dequoi on obferve entre ces petites feuilles, ou petites lames fubtiles, une infinité de fillons d'une fineffe inexprimable. Mais une preuve que ce corail doit être plûtôt com. pté parmi les Madrepora, ou Coraux étoilez, eft tirée de la ftrukture qui fuit, \& que nous allons décrire. Car on voit à la fuperficie ouEcorce, dont nous venons de donner l'idée, tout autour, \& à tous les rameaux, une quantité de petits tuyaux courts, tous plats \& creux par le haut, \& ferrez de près l'un contre l'autre, quoique féparez. C'eft autour de ces petits tuiaux qu' on voit ces feuilles ou écailles fubtiles, que nous avons décrites cy-delfus, \& qui s'élèvent vers le haut en lignes parallèles. Au dedans de ces petits tuïaux chaque ouverture préfente une petite étoile, ce qui ne provient, comme nous l'avons expliqué à l'occafion des figures précèdentes, que de ces Ecailles ou Parois mitoïennes, qui vont de la Péripherie au Centre, cependant avec la différence, que les feuilles qu' on trouve à la periphérie intérieure, n'atteignent point au centre, \& ne parviennent par confequent pas à fe réunir. Tous ces petits Tuyaux du préfent Corail font égaux, \& c'eft de là que lui vient le nom de Corallium Muricatum. Corail à pointes.

Pour ce qui concerne les efpèces fubalternes, ou Anomalies de cette forte de Corail, elles diffèrent tant par raport à la ftructure extèrieure, qu'à l'égard de la couleur. Car on en a en forme d'arbriffeau comme celui - ci, il s'en trouve en buiffon, ou en arbufte, d'autres femblables à des Bois de Cerf, quelques uns en fimples bâtons, \& encore une autre forte tout - auffi belle, qui fe préfente en grands $\&$ larges lambeaux, ou écuffons, qui fe trouvent être ou plats, \& percez d'une façon fingulière en trous \& en cercles, ou courbez \& roulez, ou friféz en arc \& dentelez. Quant à la couleur il y en a qui font blancs comme neige, d'autres font cendrez, ou couleur de Heur de pomme, ou d'un jaune clair, ou d'un jaune foncé; il y en a auffi de bleus; cependant en cas d'entamûre tous font au bout blan. châtres vers le milieu, ou vers la moëlle. Toutes ces couleurs ne proviennent en grande partie que de la difference de l'eau de la Mer dans les diffèrens golfes, où les pièces fe trouvent. Car le fond de leur maffe n'eft autre chofe qu' un limon marin, qui eft une efpèce de chaux, dans lequel, lorqu'il n'eft pas encore durci, les Polypes fe nichent, \& lui font prendre cette figure, felon leur propre itrueture. Enfin nous retrouvons la même Conftruction dans la forme d'une incruftation ou écorce autour d'un certain Corail de nature de corne, auquel on donne par cette raifon le nom de Keratopbyton crufta muricata, c'eft à dire Corail de narure de Corne à pointes, dont la croûte eft à tous égards conforme à l'Architecture qu' on voit ici, comme nous aurons oc. cafion de le démontrer plus amplement, quand nous viendrons à la Planche A. VI.

(*) Il faut toujours entendre par Millepora les Coraux qui font marquez d' un norabre infini de points. 
14

Fig. 2. Die in biefer Gigur nergeffellete Madrepora fheinet nituts anderb, als nur eine Pleine tno Bufchwsis angebatie Stern. Euralle zu feyn, meldye bon ber, in voriger sigur tweit,

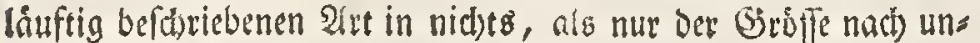
terfotieben iff, baber were ung bey felbiger nitgt aufbalten.

Fig. 3. Den Madreporis wiro ein ander Esefdefedt bon uno didsten Curallen bengefinget, tretthe Milleporæe genennet werben, uno wir treffen in Der angezeigten figur eine Dergleidien an. 23as bie Etructur Diefer Eorullen betrift, fo fino fie auf gleide

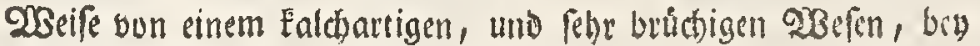

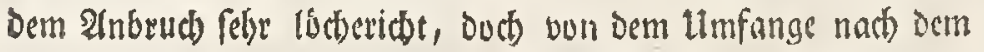
Dhittelpunct zu etwas frrablidt. Tiefe Etrahlen aber entfethen

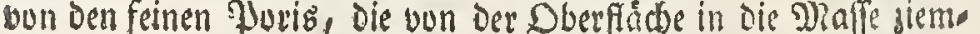
(iid) tief binein Dringen. Die Millionenmeife auf Der Dberfhät)e

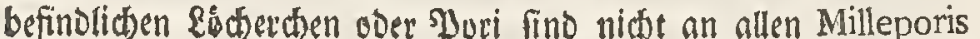

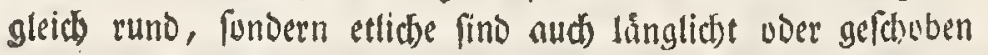

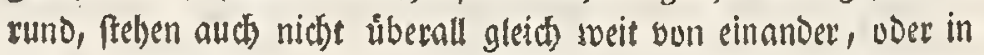
einer gerwifen Dronung, forbern bichte und morbentlich beufame men. Bey einigen ift eine feine Defnung unmittelbar an oer andern, bey anderen aber frehen fie in ciner fleinen Entfernung bon sinander, feben aber iberbaupt aus, wie ein \$apter, bas mit ber allerfeinften Stectnadel allenthalben Burdfluchert ift. 2tm

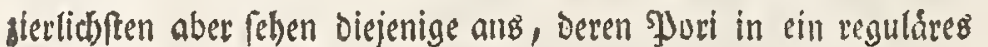
Funfecteftethen, fo ons allemabl eine gruffe Defnung in ber Ditite uno fünf lleine in ber Siundung gleich weit bon einander frehen, eben als ob eine alre gुolype nit fo vielen Gungen Darinnen woths neten, uder als ob ein funfertallidter undentlid Eleiner Seetern

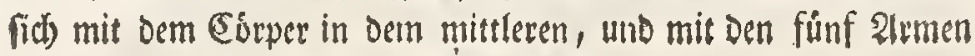
sn Den umberftebenden Jjuncten aufbielte.

In Ifnfefung Der' Figur aber weithen biefe Milleporæ gen waltig bon einanber ab, obneradjet bey ifnen bie innere Baus

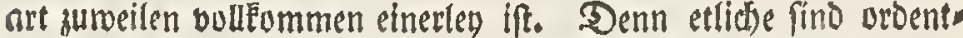

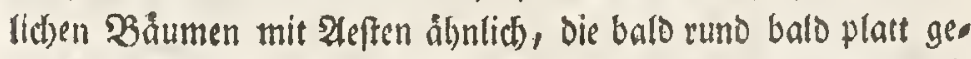
orucet erftheinen, uno zunveilen frey ftehen, zumeilen aber mit einanoer, und burcheinander verwadifen find. Indere befteben in groffen breiten \&appen, bie entweder in eins ourchgehen, voer swiederum in Eleinere Eavpen und Blatter unterfdieden find 2rieberum andere baben auf Dem oberen rande lange finger

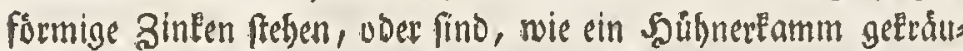

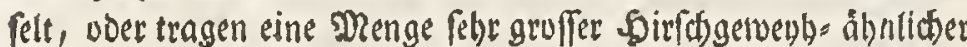
Şơner, wDer baben vermifdte Enoigungen wie bie gegentodrtige Coralle, beren 2lefre an einander verwadjen, platt ges Druct und von vermifoten Endigungen find. Der Farbe nach fino fie weis, grau, bellgelb, ober aud ouneelgelb wie biele, uno fethen burbigdngig alle auf einem breiten laldar tigen Fuf, Der weiter binunter felfidt und feeinigt wird.

Bon eben biefer nemlitien inneren Bauart, und bon forthem

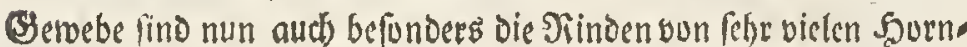
curallen, ja soir haben Eturce von biefen Garten Eteincural

\section{照}

Figure 2. Le Corail de l'efpèce des Madrepora, dont nous produifons ici la figure, ne nous paroit être autre chofe qu'un petit Corailét oilé conftruit en plante de buiffon, qui ne diffère en rien du précèdent, dont nous venons de donner une ample defcription, fi ce n'elt qu'il eft plus petit; ainfi nous ne nous y arréterons pas.

Figure 3. On a coutume de joindre aux Madrepores une autre forte de Coraux bâtards, qu' on apelle Millepores, \& tel eft celui, qui eft dépeint dans la préfente figure. Quant à la ftructure de cette efpèce de Coraux, leur Maffe tient comme aux aut es de la nature de la chaux, \& eft d'une matière trés-fragile. Quand on en rompt un morceau, l'extrèmité de l'entamure fe trouve être pleine de trous, cependant on y remarque auffi quelques rayons, qui vont de la périphérie au centre. Ces rayons proviennent des pores fins, qui de la furface pénètrent affez avant dans l'intérieur de la Maffe. Les Pores, ou petits trous, qu' on remarque à la fuperficie par millions, ne font pas à tous les Millepores d'une rondeur égale, car on en trouve d'oblongs, ou de figure lenticulaire; ils ne fe préfentent auffi pas fur tous les Millepores à une diftance égale $l$ 'un de l'autre, ni dans un certain ordre, car on yoit qu'ils font ferrez, \& fans aucun arrangement. A quelques uns ces ouvertures fines font immédiatement contiguës lune à l'autre, à d'autres on remarque une petite diftance entre deux, \& en génèral le tout reflemble à un Papier qu'on auroit piqué par tout avec l'épingle la plus fine, fans obferver aucun ordre. Les Coraux de cette efpèce, qui fe préfèntent dans le plus beau point de vûë font ceux dont les Pores forment un Pentagone regulier, de façon qu'il y a au milieu une Ouverture un peu plus grande, autour de laquelle on en voit cinq plus petites a diftance égale l'une de l'autre, tout comme fi c'étoit l' habitation d'un vieux Polype \& de cinq de fes Petits, ou comme fi une Etoile marine à cinq rayons d'une petiteffe imperceptible s'y étoit logée, le Corps dans le Pore du milieu, $\&{ }^{\prime}$ les bras dans les cinq points, qui forment le Pentagone tout autour.

Mais à šégard de la figure, ces Coraux diffèrent beaucoup les uns des autres en diverfes manières, quoique leur conftruction intérieure foit quelquefois parfaitement femblable. Car tantôt ils reffemblent dans les formes à des arbriffeaux ordinaires, pourvîs de rameaux, lesquels font quelquefois ronds, quelquefois applatis, quelquefois ifolez, \& d'autres fois joints \& entremêlez enfemble. Tantôt .ce ne font que des lambeaux grands \& larges, qui occupent. de fuite toute la figure, ou qui font feparez par d'autres petits lambeatx \& feuilles. Il y en a encore d'autres, fur les bords desquels on voit de longues chevilles, ou bouts, en forme de doigts, ou qui font frifez comme des crêtes, ou qui font furchargez de grandes cornes reffemblantes à des bois de Cerf, ou qui fe terminent en extrémitez entremèlées, comme à la préfente figure, qui dépeint le Corail dont les rameaux font joints enfemble छ̇ crî́s en une même Mafje, comprimez en figure platte, $\mathscr{G}^{2}$ à extrèmitez mêlées. Pour ce qui concerne la couleur, il y en a de blancs, de gris, d'un jaune ou clair, ou foncé, comme l'eft celui - ci, \& tous fans exception font poltez fur un pied large, qui reffemble a de la chaux, \& qui plus bas tient de la pierre \& du rocher fur lequel il fe trouve attaché.

Les Ecorces, ou Envelopes d'un grand nombre de Coraux de nature de corne, ont intérieurement la méme conftruction, \& font formez de même. Nous dirons outre 
len angetruffen, wo in Dem seen nud würlich eine gange horn: artige Euralle face, uder Da Der Sern Durd Singe und anbere Dergleichen Mertmahle die Eluren gab, daf́ vorzeiten eine baunformige Soralle Den Strund iu itrer baumartigen Stru ctur geleget babe, welde abcr ourch bie laldartige Sdbínfe

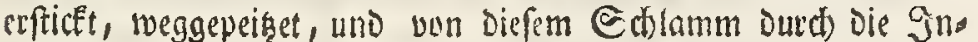
fecten mebr und mebr úberzogen worden. Fie man Denn aud fogar andere Curper, als Bactiteine und Siegel am Strande mit Madreporen uno Milleporen ủberzugen findet. 2Bab eno. (it) Die Srofe vicfer פrillepureir betrift, fo werden fie von gans

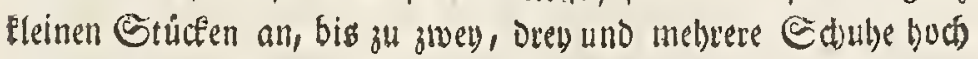
angetruffen, vermutblich nach Dem SBerhåltnuß, naci) Dem Die Sorncuralle, uder andere Mcerplangen gros waren, um tocls d) fich Diefer Sorallenartige Weetfhlamm, und mit Demfelben Die Sillionen Jolupen, anlegeten, Davon bie 2lntillifbent Snfuln fegr teich und ergiebig fint.

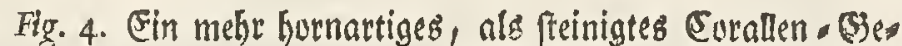
sådfe wirb uns in biefer Figur vorgeftellet, welđer ein Lithophyton aureum punctatum genennet wiro. Es if im 2lnbruch mit vielen runden Singen, Dergleicten Die Sabrgange am Solz

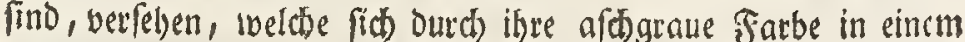
weislidten Grumbe Deutlich madten. Dic Maffe ift zwar bols zigt und faferict, jeDud) Dergeftalt mit Der Curallen Stein Maffe Durdbrungen, Daf fie Daber Didt und hart roorien. Die áffere Oberfliche ift jiegelrotl) uno zumeilen etwas mebr gilb= licht, Dabey aber boller Juncte, weld)e nidht tief binein zu geben ftheinen. Ulebrigens if bie áffere Etructur, die Bergliederung Der Aefte, uno Derfelben 2lusgang an Den Epiken jener rothen Euralle febr åhnliø), bie wir auf ber erften Safel betratbet ha. ben, wie fie Denn aut ebenfalls in Dem Mittellándifben Meer grtunoen wirt.

\section{TAB. A. III.}

Fig. I. Trir Fommen nunmefro aus an Die Earallen.

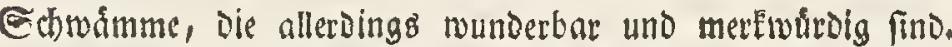
Heberbaupts werden fie zroar unter die SDabrepuren gerchies, (einige wenige auggenummen, bie aud) Milleporen genennet werven) allein bie wenigften uneer ibnen baben auf ber vberften Oberflåbe fternfórmige Defnungen, obgleich fonft Der mobrefte Sheil ibres (Sibaludes aus lanter fold)en Bláttern uno Sdbief. fern beffebet, Dle in anderen (Sorallen bie (Stendt)en ausmadsen; Denn beu Den mebreften Schrwammen liegen Die Shieffer in eir ner anderen, linglithten, uno Eeinesibeges volleommen frernfór. migen fage. WBir werven bievon mit mefreten ủbersenget wet. Den, wenn mir biefe Figur etwas genauer betracten.

Es zeiget fid nelmitid allier ein bey Den alten Sdriftfel lewn figenannter Amaranthus Saxeus, welityer aud wobl ber Ece = Stumen = Riobl genennet wit', Datan wir bie 23 uszel, Den Gtiel uno Die Sirune zu unterfuct)en baben.

Die 2 Burzel if ein falchartiger Rlipftein, auf weldsem als leroings bu erft ein Glátteridter Gtern den exfen Boden auss mathe cela que nous avons rencontré des pièces de ce Corail dur $\&$ pierreux, dans la moëlle desquelles il y avoit un Corail entier de nature de corne, \& où des anneaux \& d'autres veftiges faifoient conjeहturer, qu'originairement un Corail de forme d'arbriffeau avoit pofé les fondemens de cette ftrųture en arbre, lequel prémier Corail a peu - ł̀ - peu êté étouffé, maceré, \&z confumé par un humeur acre, quitient de la chaux, limon, dont les Infectes ont de plus en plus couvert \& enduit la plante, ce qui devient d'autant plus vraifemblable, quand on confidère qu'il fe trouve d'autres corps, te!s que des briques \& des tuiles fur le rivage, couverts ainfi de Madrepores \& de Millepores. A l'égard enfin de la grandeur de ces Millepores, il y en a de toutes fortes, depuis les pius petites piècés jusques à deux, ou trois pieds \& davantage de hauteur, vraifemblablement felon la proportion de la grandeur du Corail de nature de corne, ou d'autres Plantes marines, où ce limon de mer coralin \& des Millions de Polypes s'attachent. On en trouve abondamment aux lles Antilles.

Figure 4. Cette Figure reprèfente une Plante Coraline, qui eft beaucoup plus de nature de corne que pierreufe: on l'apelle cependant Lithopbyton aureum punctatum, ou le Corail pierreux d'or à points. Elle eft marquée à l'entamure de plufieurs anneatux ronds, pareils à ceux qui dénotent dans le bois l'age des arbres. Ces anneaux paroiffent diftineté. ment par leur conleur cendrée fur un fond blanchâtre. La Maffe a à la vérité quelque chofe de la nature du bois, \& on y obferve des filamens; cependant elle eft tellement imbibée de la Maffe pierreufe coraline, que cela la rend com. pacte \& dure. La fuperficie eft de couleur de tuile, tirant pourtant quelquefois fur le jaunâtre, de tonte pleine de points, qui ne paroiffent cependant pas pénètrer fort avant dans l'intérieur. Au refte quant à fa fructure extérieure $\&$ à l'arrangement de fon branchage, aufi bien que deg extrèmitez qui le terminent, elle refemble heaucoup à $c e$ beau Corail rouge que nous avons vû fur la prénijère Planche, \& on trouve aufi celui-ci de même dans la Mer mé. diterranée.

\section{PLANCHE A. III.}

Figure I. Nous voici arrivez aux Champignons coralins, qui font affürément d'une figure merveilleufe \& renz:quable. Il eft vrai que généralement on les met dans 12 Claffe des Madrepores, (en en exceptant un petit nombre auquel on donne auffi le nom de Millepores); cependant il y en a bien peu où l'on trouve des Ouvertures en forme d'b. toile à la fuperficie, quoique d'ailleurs leur ftrukture confifte pour la plus grande partie en des feuilles \& écailles, qui à d'autres Coraux forment les petites étoiles. 'Car à la plûpart des Champignons, ces écailles font difpofées en une aut tre figure oblongue, qui n'eft nullement propre à former une étoile parfaite. C' $C^{\prime}$ eft dequoi nous pourrons mieux nous convaincre en examinant de plus près la préfente figure.

Nous y trouvons ce que les anciens Auteurs avoient coûtume de nommer Amarantbus faxeus, l'Amarante pierreure. qu'on apelle auffi le Choufleur marin $(*)$. Ce que nous trouvons à y obferver, c'eft là racine, le pédicule, \& la couronne.

La Racine eft une Pierre de roche d'une nature femblable à celle de la chaux, fur laquelle une Etoile feuilletée, $\mathrm{F}_{2}$

(*) En Allemand: der See -Blumenkoblo 


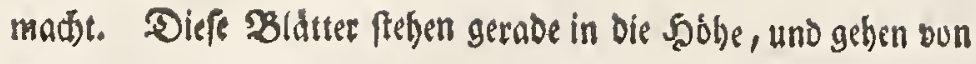
Dem runden Ulmfang bis an Den Mittelpunct, fo, Das fith) wentgs

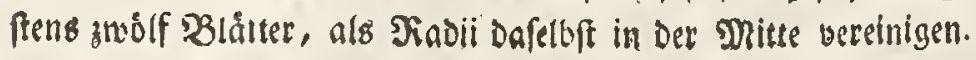

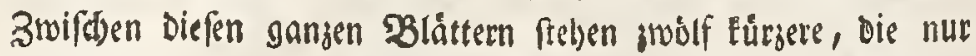
Den balben Siabiun nusmacten, und zwiften allen siefen, for nubl ganzen, alb halben Etheiderwánden, find an Dem Umfang nod vier und zmangig Eleinere Bidetter fidjtbar. Zun allen bies

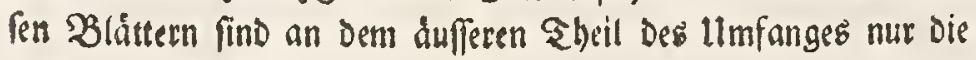

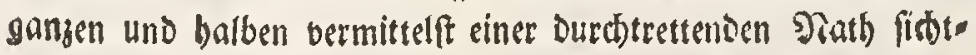
bax, fo daf fidf) Die auffere Siundung nunmebru, als ein or.

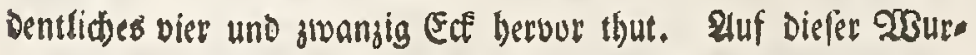
gel gebet nunmetho ein langer Ettel son gleicher Shunart in bie

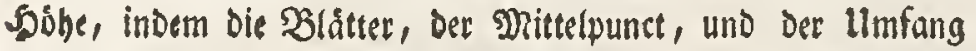

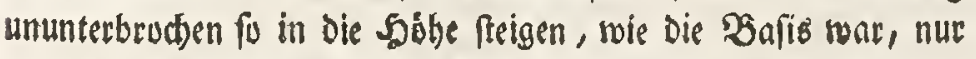
mit Dem Unterfateto, Daß ber Stiel je läner, je Dicker uno breiter wird; Dahero fich Denn audi naturlider oder Blåtter verlángern. SBis Dabin hat nun Diefer Etein. ftrwamm eine verwitterte Seftalt. Sobana aber folget Die Erone in einer folchen ausfübrliden uno prád)tigen Bauart, nls ver. mutbliti auch) am Stiele fratt batte, abe Desfesbige entweder leblug, woer gerwittert rourden iff.

Diefe Erone beftêtet ans vielen blätterifoten Bogen unb Srủmmungen, Die einer Siraufe nicht ungleich) Pehen, uno folgen Dergeffate entfrellen: Es F ideidet fich nemlid) Der Mittelpunct Des Stiels in vier, fünf bis żwolf und mehrere 2tefte, mie ein Subl. Mit allen Diefen abgefunderten Mittelpuncten, wDer Rern. gången fangen auch bie Blätter ober Scbieffer an, nad allen Seiten, um jeven abgefunderten Mittelpunct einen längliden

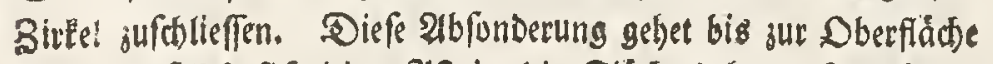

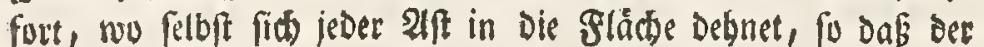
runde llmfang firt veråndert, und Der Rern nunmebro auf Der

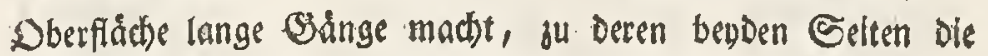

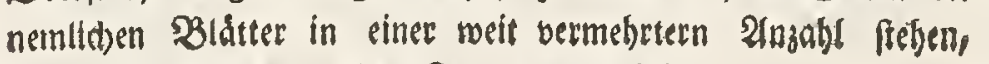
unt fiti beyderferts an Den serngang vereinigen.

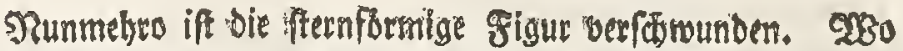
zubur Der runde llmfang stoilf gamze, zroblf halbe und vier und

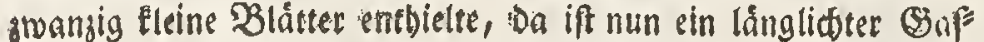
fenfurrmiger Umfang entfranoen, in weldtem zu benden Eeiten úber bundert ganze noch mehr halbe, uno mebr, als nuch ein.

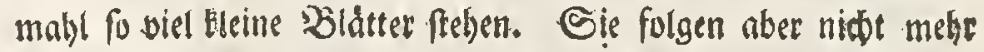
fo vroentlid) duf einander, fondern es feten balo zmey ganze, balo vier, sder fưnf lurze $\mathfrak{B l a ̊ t t e r ~ b e u f a m m e n . ~ B e y ~ D i e f e r ~}$

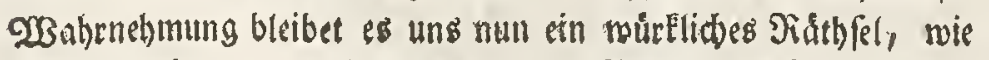

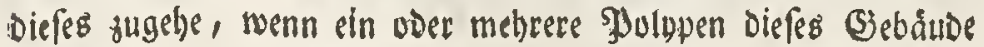
auffübren foulen, das fie enft Durdh eine adts und viessigectigte Geftalt Den Gramm bauen und bernact von ber alten Estuctur

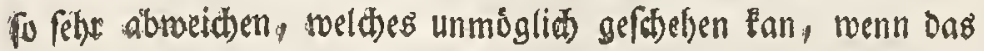

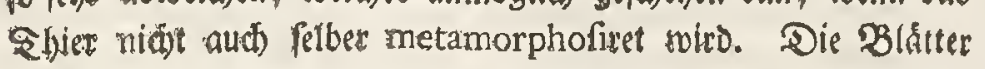

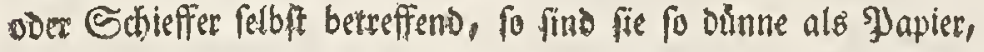
ar Den Enden voer an ihrem eigenen llmfang gejact unv eingeEerbe, fo, daf fie bun auffen und won uben und nact innen ju

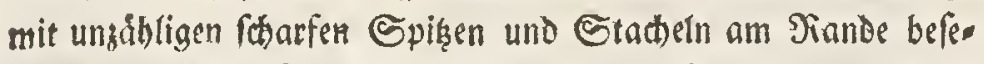

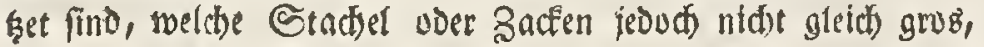
und aucs nidst gleith weit ven einanber entfernet find. Die ou écaillée, pofe le prémier fondement de cette pièce. Les feuilles s'élèvent en haut en droite ligne, $\& s^{\prime}$ arrangent depuis la circonfèrence, qui eft ronde, jusques au centre de telle façon, qu' on y peut compter tout au moins jusques à douze feuilles, qui fe réünifent au milieu, comme autant de rayons. Entre ces feuilles, dont la grandeur eft entière, il s'en trouve encore douze plus courtes, qui ne forment que des demi-rayons, \& entre toutes ces parois mitoiennes, tant entières que courtes, on remarque encore vingt - quatre feuilles plus petites à la périphérie. Il n'y a de vifibles à l'extrèmité de la circonfèrence que les feuilles entières, par une coûture, qui va tout au travers, de manière que toute la rondeur repréfente un Polygone à vingt - quatre angles dans toutes les formes. De cette racine part un long pédicule, de ftrueture conforme, puisque les feuilles, le centre, \& la Circonfè rence croiffent \& s'èlèvent fans interruption felon la figure de la bafe, avec cette unique diffèrence, que le pédicule grofit $\&$ s'élargit à méfure qu'il s'allonge; ce qui naturellement fait auffi allonger les rayons ou feuilles. Jusques - là ce Champignon pierreux fe préfente fous la forme d'une Production gâtée par les intempèries de l'air. Mais enfuite fe montre la Couronne dans une ftructure auffi complette \& aufi pompeufe, gu'avoit vraifemblament le Pédicule avant d'avöir perdu fon principe de vie, ou fouffert les injures des raifons

La Couronne eft compofée de plufieurs arcs \& parties courbes feuilletées, ne reffemblant pas mal à une fraife, telle qu'on portoit anciennement autour du Col, \& fe forme de la manière fuivante. Dabord le centre du pédicule fe partage en quatre ou cinq, rameaux \& davantage, comme un chou. C'eft de ces parties féparées du centre ou de ces rayons d'étoile que partent les feuilles, ou écailles, vers tous les cotez, pour former autour de chaque rayon féparé un rond oblong. Cette feparation continuë ainfi jusques au bout, ox̀ chaque branche s'étend en s'aplatiffant, de forte que ia Circonférence, ronde auparavant, change ici de figure, \& que la moëlle, ou le fuc vital, fe forme fur la fuperficie de longs canaux, aux deux cotez desquels les mêmes feuilles fe trouvent fort augmentées en nombre, \& fe réüniffent de part \& d'autre au, canal principal de la moëlle.

Voilà la figure đ’étoile difparue. Là-même, où une périphérie ronde contenoit douze feuilfes entières, autant de demi - feuilles, \& vingt -quatre petites, on ne voit plus qu' un Contour oblong en forme de ruë, où l'on remarque plus de cent feuilles entières, encore plus de demi-fevilles, \& plus du double des petites. Mais elles ne fe fuivent plus dans le même ordre. Tantôt on voit enfemble deux feuilles entières, tantôt quatre ou cinq courtes. A cet égard nous ne pouvons nous empêcher de dire que c'eft véritablement une énigme pour nous, que de penfer qu'un ou plufieurs Polypes puiffent avoir conftruit tout ce Compofé, \& avoir formé la tige en figure angulaire à quarante huit coins, \& qu'enfuite ils fe foient fi fort écartez de l'ancienne ftruEture, ce qui ne peut abfolument pas avoir lieu, à moins que l'Animal même ne fe métamorphofe auffi. Quant aux feuilles, ou aux écailles mêmes, elles font minces comme du papier, \& dentelées, ou entaillées, au bout, ou à leur propre circonférence. Depuis le déhors \& la partie fupérieure en tirant vers l'intèrieure on obferve une infinité de poirtes aiguës \& d'aiguillons au bord, lesquels aiguillons ou 
Sarbe if methentheils weis, voer aftagrau, uder gelb, uno gans oben allegeit am lebbafteften und am beften ousgentbeitet. Wan

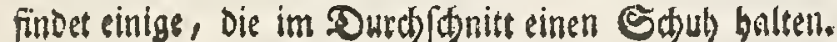

Fig. 2. Diefer Corallen = Cofframm ift bun gand anderer Ant als Der vorige. Denn da jener fid in oie Sjobe bauet, uno Da an Demfelbigen die Blátter 30 gentweife in Die Söbe Reben, fo modet hingegen diefer ans feiner enfen, auf vorbefdriebene

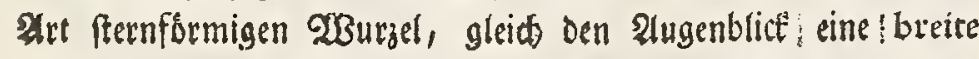

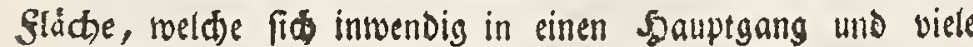

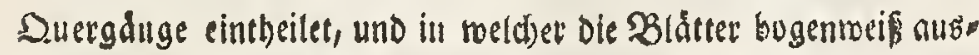
geboblet fino, fulglid bineinmaits uno vertieft freben, wie Das innere Sebáude eines Sdiffes. Alle diefe $\mathfrak{B l a ̊ t t e r ~ u n o ~}$ Schieffer fint gleid) breit, indem man Darunter Eeine lángere uno Eurzere, roic in Dem borigen Evrallen. Edtroamm antrift, jebuch fino fie rundum ungemein zart gezact, Dabun eine Bacfe eben fo gros, toie bie andere, uno jeoes $\mathfrak{B l a t}$ bulleummen wie eine Sage befdaffen ift. Man findet fie braun, weis, uno gelb.

Fig. 3. Die allbier vorgejeigfe Efchara marina retiformis,

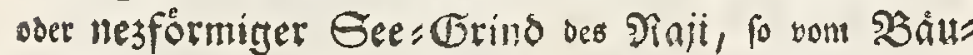
biit, Imperntus uno andern Efchara reticulata, retepora, aud) Porus reticulatus, bun Dem $\Re$ iitter Linnaus aber Millepora cellulofa genennet twiro, if ein beretblåttecicter, gebugener uno gefraufter, bem Ealat dhnlider Eurallen - échamm. Alü

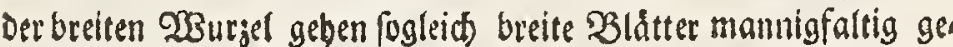
bugen in Die \$obhe. Diefe Blåtter fino fo dinne, wie ein Syapier,

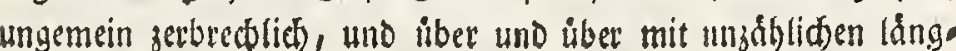
lidsten sodbern, wie eine Spişe, ganz Durcjbrudben. Die Sarbe if braunlidt, afdogra voer fonceweis, und von eben Diefer Shattung wirb nuch eine Nebenort gefundin, welthe in or. Dentlide Sweige ausgebet, an Denen ebenfalls fotche, aber etwas Elcinere $\mathfrak{B l}$ ldter fișen, uno frondipora Efchara, aud) Porus corallo affinis genennet niro; Dud aber nudb oun einem an beren Eurallen artigen Drobuct bes Dertes zu unterfteiden iff reld)es man Dab $\$$ ies, oder rete marinum nennet.

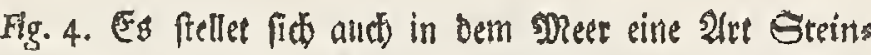
(d)wdrmme bar, Die in ber Baunt folechterdings mit Den ErD

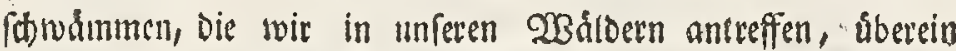
funme, nur mit bem llnterfbeid, Daß Die blåtteribte Structur Die bey Den Erdftwammen unten ift, bey Den Steinfobrämmen ween ftebet. 2Bir finden allfier ein Exemplar bor uns, weldes Der Fungus marinus lapideus uder Madrepora fungites genennet wird. Diefer blatterformige, platte Geebilis lieger flach auf Den Felfen ofne Etiel und beftebet auts tauter dúnnen, in bie Jiunde

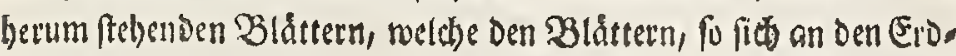
forminmen bon unten befinden, vollemmen gleid) find, aus. genommen, Dafi fie eine ungemein fteinigte Şarte haben. Diefe Blátter fino oben glatt, uno nicht selact. She vberer Siano gebet nide in einer geraben sinie, fondern úberbanpt etwas nat Dem dufferfien Fiande su berunter gebogen, uno if wellenformig. Swifthen jedem gam ourd)laufienden Blat fteben allegeit ein, voer auth wohl jtoey Elemere, nteorigere uno nict bis an Den Mittel

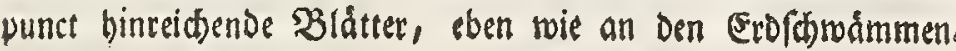
2lle Diefe Riláter aber liegen Eeinesroeges Didte aneinander Denn man fan Durd) fie alle biuleben, fondern es tretten feine

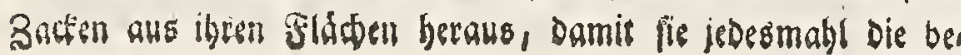

dens ne font cependant pas de grandeur égale, n⿳亠丷厂 en distance pareille l'un de l'autre. La Couleur de ces Plantes eft ordinairement blanche, ou cendrée, ou jaune, \& toû. jours trés-vive $\&$ parfaite vers le haut. On en trouve qui ont un pié de diamètre.

Figure. 2. Ce Champignon Coralin diffère de toust point du préceddent. Car au lieu que le dernier va toûjours en s'élèvant, \& que fes feuillcs tirent vers le haut en arc, celui - ci forme dés fa prémière racine, qui felon nôtre defcription a la figure d'une étoile, une face large, qui eft divifée intérieurement en un Canal principal, \& plufieurs Canaux en travers, où les feuilles formées en arc font caves \& par conféquent tournées vers l'intérieur \& enfoncées, femblables par là à la conftrution intérieure d'un Navire. Toutes ces feuilles \& écailles font de largeur égale. On n'en voit aucune qui foit plus longue \& plus courte, comme au Champignon Coralin précèdent. Cependant elles font dentelées finement tout autour, \& les dens font auffi grandes l'une que l'autre, ce qui fait que chaque feuille reffemble parfai. tement à une fcie. Les Champignons de cette efpèce font ou bruns, ou blancs, ou jaunes.

Figure 3. La figure repréfentée ici eft ce que Rajus apelle Efibara marina reticulata, ou la Cronte galeufe marine formée en rêts. Baubin, Imperatus, \& d'autres lui donnent le nom d'Efchara reticulata, ou retepora, ou celui de Porus reticulatus, \& le Chevalier Linnaus celui de Millepora cellulo fa. C'eft un Champignon coralin à feuilles larges, courbes, \& frifées, comme de la falade. Des feuilles larges, \& recourbées en diffèrens fens, s'élèvent de la racine, qui eft large auffi. Ces feuilles font minces comme du papier, trés fragiles, \& toutes percées comme une dentelle par une infinité de trous, dont la figure eft oblongue. La conleur en eft brunâtre, ou cendrée, ou blanche comme neige. Il y a encore un Champignon coralin à peu près de la même efpèce, pourvû́ dans tes formes de rameaux, qui ont auffi de pareilles feuil. les, mais un peu plus petites, auquel on donne le nom de frondipara Efchara, ou celui de Porus corallo affinis, ou le Pore aprocbant $d u$ Corail. Il faut difinguer celui - ci d'une autre Production de la Mer, de nature coraline, qu'on apelle le Rêts, ou Rete marinum.

Figure 4. On trouve encore dans la ther une efpece de de champignons pierreux, qui par raport à la ftructure reffem. blent de tout point aux Champignons, qui croiffent dans nos forêts, avec cette unique diffèrence, que le feuilletage, qui à nos Champignons terreftres eft au deffous, fe trouve placé au deffus aux Champignons pierreux de la mer. Celui qui eft dépeint ici s'apelle Fungus marinus lapideus ou Madrepora fungites (*). On rencóntre ce Champignon marin, que nô. tre Auteur nomme en allemand der blatterfoermige platte See. biltz $(* *)$, tout à plat fur les rochers, fans pédicule. I] n'eft compofé que de feuilles minces, dont on voit les pareilles tout autour, \& qui reffemblent parfaitement aux feuil. les que nos Champignons terreftres ont au deffous, excepté que celles des prémiers font trés - dures, à l'égal de la pierre. Ces feuilles font unies en haut \& n'ont point de dens. Leur bord fupèrieur ne va point en ligne droite, mais en géneral en ligne un peu courbée en defcendant vers le bord extèrieur, en onde. Entre chacune des feuilles qui s'étendent autant que le diamètre, il y en a toûjours une, ou G

(*) Le Champignon de mer pierreux, ou le Corail étoilté piepieux, (**) Le Champignon de mer plat \& fait en féuills. 
18

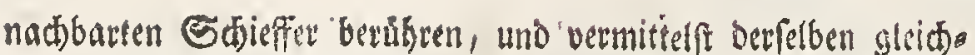
fam an einander gefútett find. Selpret man diefen Etcin fow wamm um, to finder man bafelbft an Dev untern Esite alle

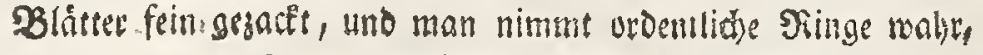

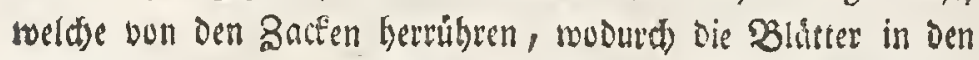
Flétion an eimonier feft balten. WBill man fite von Der Bawart an ser untern Ecite einen Begrif manen, fo Jarf man nur cine Edbeibe bun cinem gemeinen Siettig berunter fofneiter, uno biefelbe ins 253 affer legen, fo bat man vor unberwafnete 21 . gen die nelfmlidse Ettuctur. Hebrigeng aber giebt cs in Dies Fer Itrt Der Ereinforwanme getwaltig viele 2fbrveidungen, etlide find gand flats, andere mebre erbóbet, nod andere aber busiger

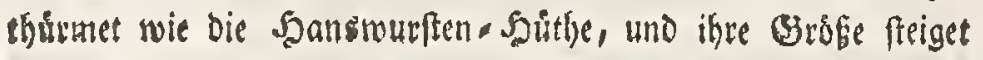

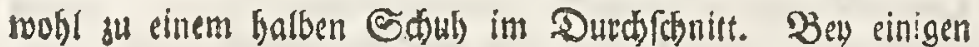
gehen bie beftriebene Ectieffer als ein geraber Rindius aus ben Mitteldunct, bey anderen aber find fie alle mitsinauber ges foflångelt und gefen gleidfam mie ein nidft sar zu Frummes

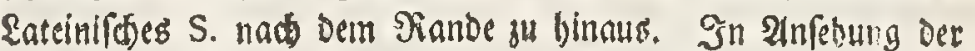
Farben find fie aut, wie bie burige, von der $\mathfrak{B} e$ fadafenteit Des Shlammes im Mreermaffer weis, gelb, ober braun.

\section{TAB. A. IV.}

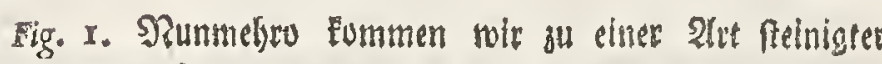
Corallen- Sobwåmme, welcbe, wie fie mannigfaltig uns ber

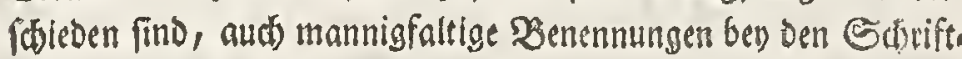
ftellern fứtren. Die gemeineften $\mathfrak{B} e n e n n u n g e n$ fino Madrepora Labyrinthiformis, Mæandrites, Mefenterites, Cerebrites user Lithocerebrum, uno biefe senennungen werben niot allen obne IInterfiteib beugeleget, fondern jede Rebenart betommt ifren cigenen গamen von biefen vieren. SRunmebru aber bleibet es ein

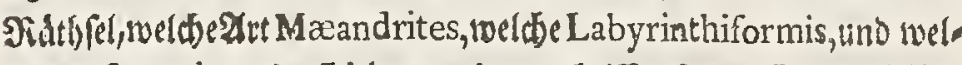
We Mefenterites ober Lithocerebrum beiffen follen. Denn dielln. rerifteibungs. Beidhen find bev Den mefreften Strifftellern nidst volletummen deutlich angegeben, (welthes aust in ber Shat bey fore

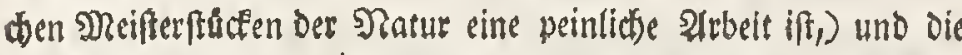
hin und weleder anzutreffende supfer fino nidft zart und fleifig genug ausgearbeitet, Das man fied einen ficheren \$egrif bon ic bem Exermplar maden linte. Heberbaupt Eummen alle 2atern Darinn ủberein, bas fie Itretgantge uno Rrummungen haben,

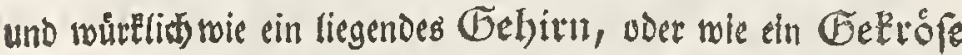

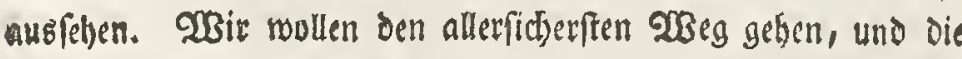
in unferer Figur abgebillete Madrepora Labyrinthiformis erf

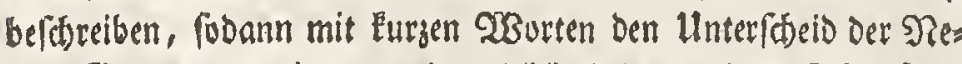
ben-Sattungen zeigen, und endict) brittens bem Sefer felbep

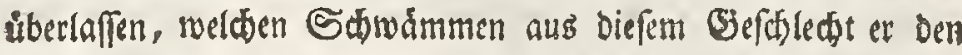

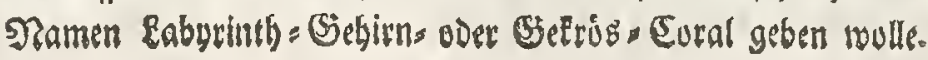

陽

quelquefois deux autres plus petites, plus baffes, \& qu n'atteignent pas jusques au centre, tout comme aux Champignons de terre. Il faut obferver que ces feuilles ne font point lerrées les unes contre les autres, car on peut voir tout l'entredeux, où l'on remarque des dens fines, qui fortent de leurs bords, qui touchent les écailles voifines, \& font par là pour ainfi dire comme cimentées \& maftiquées enfemble. En tournant ce Champignon pierreux, on trouve que toutes fes feuilles font finement dentelées, \& l'on y re. marque des anneaux réguliers, qui proviennent de ces dens là, \& qui tiennent les feuilles affermies l'une à l'autre daris leur emplacement. Si l'on veut fe former une idée de la ftructure de la partie inférieure, on n'a qu'à couper une rouëlle d'un raifort ordinaire, \& la mettre dans l'eau: on y vera la même ftrußture fimplement avec les yeux nuds, c'eft - à dire fans le fecours d'aucun Microfcope. Au refte il y a quantité de variations \& d'anomalies à remarquer à l'égard de cette efpèce de Champignons pierreux. Quel. ques uns font abfolument plats, d'autres plus élevez, d'autres tout - à - fait hauts en forme de tour, ou de Chapeav de Jean Fotage $(*), \&$ ils s'accroiffent d'ailleurs jusques à un demi-pied de diamètre. A quelqués uns les écailles, que nous avons décrites, vont du centre au bord en rayon droit, à d'autres elles font le même chemin en ferpentant un Feu dans la figure d'une grande $S$ qui ne feroit pas trop recourbé. Pour la couleur elle dépend, comme au précedent, de la qualité du limon de la mer, \& felon cela elle eft ou blanche, ou jaune, ou brune.

\section{PLANCHE A.IV.}

Figire I. Nous parvenons ici à une forte de Champignons coralins pierreux, auxquels les Auteurs ont donnè diverfes dénominations, eû egard à leur diverfité \& aux variations qu' on y obferve. Les noms les plus ordinaires font: Madrepora labyrintbiformis, Meandrites, Mefenterites, \& Cerebrites ou Lithocerebrum. Mais tous ces noms ne fe donnent pas à tous les Champignons coralins de cetteforte, carchaque efpèce particulière de cette Plante pierreufe a un nom particulier, mais toijours pris des quatre que nous venons d'exprimer. Il s'agit feulement de décider la queftion à quelle efpece on doit affecter le nom de Meandrites, à quelle celui de Labyrintbiformis, à quelle celui de Mefenterites, \& à quelle enfin celui de Lithocerebrum. Car la plîpart des Autcurs, qui ont écrit fur cette matière, n'ont pas indique les caractères diftinatifs de chaque elpèce avec affez de précifion, \& c'eft en effèt un travail pénible à l'égard ce ces Chefs d'oeuvre de la nature, que d'affigner à chacun le véritable nom qui lui convient. D'ailleurs les figures, qu'on en a'eûes jusques ici en taille-douce, ne font pas travaillóes avec affez de foin, d'exactitude, \& de fineffe, pour qu' on puiffe fe former une idée jufte de chaque pièce. En génèral toutes font uniformes en ce point, qu' on $y$ voit des labyrintbes, \& qu'elles reffemblent cn effèt à une cervelle coucbée, ou à une fraife de veau. Pour aller au plus fûr, nous donnerons d'abord la Defcription de la préfente figure, apel. jée fans contertation Madrepora labyrintbiformis, \& enfuite nous examinerons en quoi les autres efpèces en diffèrent, \& enfin en troifième lieu nous laifferons à nos Lecteurs li. berté toute entière d'affecter à ces Champignons corraline

(*) sn allemand Hans Wurf. C'eft le Perfonnage comique des Co. medies allearandes. Il potte un Chapeau dont la forare eft fort haute. 
pierreux les noms additionels, de Labyrinthe, de Cervelle, ou de Fraife, felon le jugement qu'il en portera lui - méme.

Es hat nemlich biefer Filumpe einen feh: breiten 300 ben

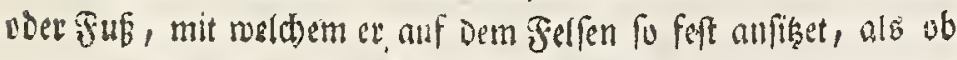
er mit Demferben ein einiges Etuct nusmactete. SSleidy an Diefern breiten 300 en nimmt man foron einen Dsittelpunct waht, ats melderm weite Gänge, nls Strablen nachl Eem ltinfang ju ge ben, und diefes ift foun genug ibn eine Madrepora zu nenuen. Ein fober Canal, Der voul bern Dittelpunct nact) Dem llmfange bu gebet, beftehet in zwey geraeen, parailel liegenden Bjlatern, ober Estbieffern, Dergleitsen wir burher genug beforbieben baben.

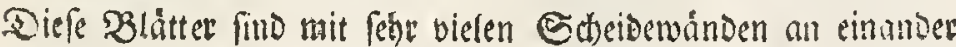

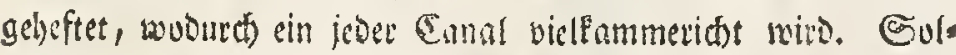
der Sammern giebt eg, nadjoem Der Silumpe gros iff; in cinem

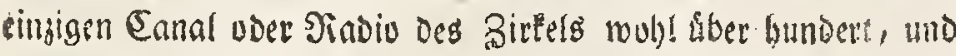

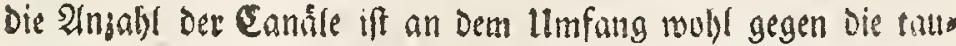

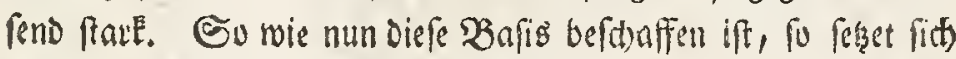
bie ganze Structur in Dem ganzen Silumpen fort, das if es be ftelyet ble ganze Paffe in nidtets anders, als in fuldsen paralleten, uno burd) Sammern an einander gewad) fenen 5 bisttern. Bjegen

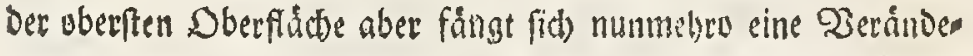
rung an, Die Darinnen beftehet, Dá Die jubur hurizuntal gelegene Edjieffer nach uno radi) perpendicular zu fectsen lummen, beb

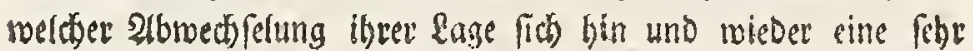

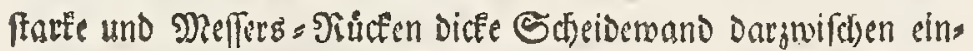

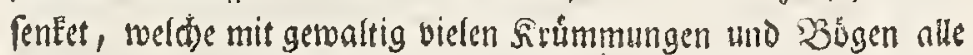

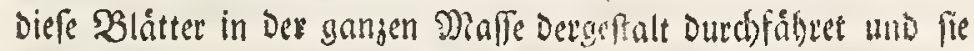
bun einander trennet, Daßi die \$Blátter ober Edjieffer fid nach Den Firummungen bet dicteren ScbeiBcwand ridten und fict Das ferbft angalten moffen. SRunmelyo madte bie Didere, gefraus

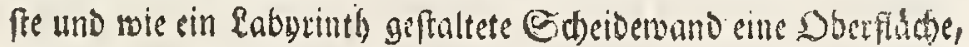
aber fie freiget bun allen Geiten gleich buct in bie 5abthe. Sie

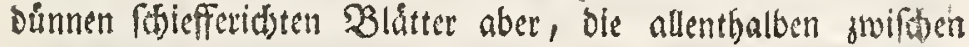
Der Stheidewano freben, reidien nidit fo hud), fondern blciben

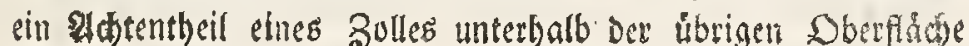
frethen. Diefes macht nun nothwendig auf Der \$noffe verteffer

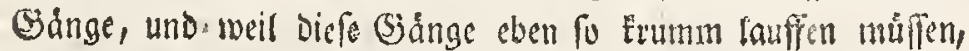
als bie bicfen uno húber frehenden Stheidetwánde, fo bat man Darum Diefen Maffen Den গamen cines Kabyrintbs uder Mæan. driten beugeleget.

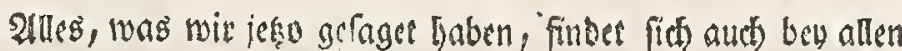

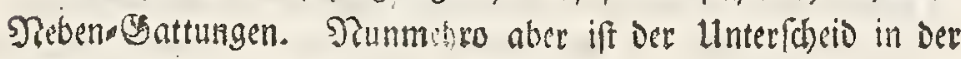
bicfen und in vielen frummen grsindungen beftehenden harten

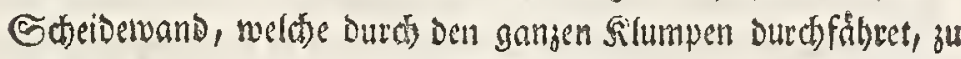

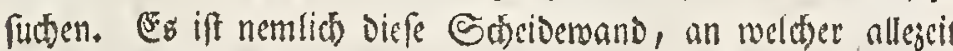

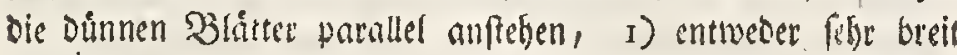

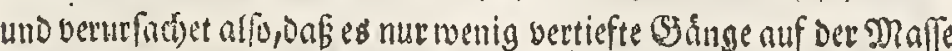

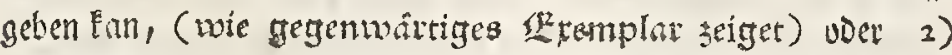

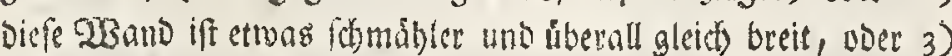
fie tritt mit einem fwarfien Siand berbur, vier 4) fie if gar

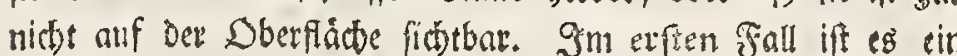
Babyrintbftem. Jim andeven Fall wăren mir gencigt, es

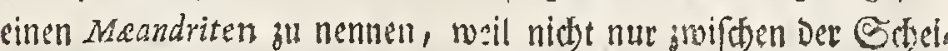
Dewano überall sin febr tiefer Gjang gelbet, Der rundum mit febr

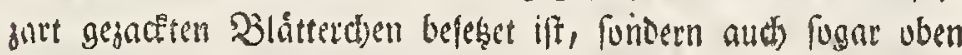
auf Dev $23 a n d$ felter nodh eine bertiefte furche, als ein Sang

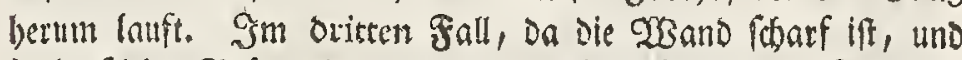

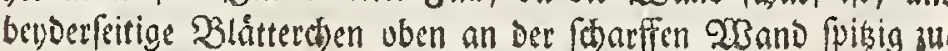
faumen fauffen, mugte man bie Maffe cinen Mefenteriten uder Madrepora areolata, nennen. Jnt lezten Fall aba, Da bir zur

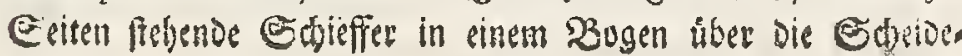

Cette Maffe a une bafe au fond trèsılarge, par laquelle elle fe tient fi fortement attachée au rocher, qu'elle femble ne former avec lui qu' une feule \& mème pièce. On remarque d'abord fur ce large fond un centre, ou point du milieu, d'où partent de larges canaux comme des rayons, qu s'avancent vers la circonfèrence, ce qui fuffit pour donner à cette production de la nature le nom dé Madrepora, ou Corail à étoiles. Chaque canal, qui va ainfi du centre à la péripherie, confifte en deux feuilles droites, ou écailles, couchées en lignes parallèles, que nous avons déja fréquemment décrites. Ces feuilles font liées l'une à l'autre par un grand nombre de parois mitoïennes, par où il arrive, que chaque $\mathrm{C}_{2}$. nal a plufieurs Chambres. Selon l'étendue de la Mafie le nombre de ces Chambres eft plus ou moins grand. Il y en $a$, où chaque Canal ou rayon du cercle en renferme plus de cent, \& la quantité des Canaux va quelquefois à la périphérie jusques à près de mille. Or tout comme cette ftruEture fe trouve faite a la bafe, elle continue ainfi au travers de toute la Mafre, qui n' eft donc compofée que de ces feuilles parallèles, \& des Chambres par lesquelles elles font liées l'une à l'autre. La fuperficie fupèrieure préfente une variation, en ce que les écailles, difpofées auparavant hori. zontalement, s' arrangent ici peu - ̀̀ - peu en ligne perpendiculaire, \& dans ce changement de pofition il s'infinue dans cette furface une paroi mitö̈enne forte \& de l'épaiffeur d'un écu, qui par un trés - grand nombre d'arcs ${ }^{\circ} \mathrm{x}$ de courbures pafie à travers toutes les feuilles de la Mafle, \& les. fépare de façon que les écailles \& feuilles font comme forcées de fuivre cette paroi plus épaifle dans fon cours, \& de $s^{\prime} y$ tenir. C'eft dans cet ordre que cette paroi plus épaiffe, frifée \& arrangée en labyrinthe forme une fuperficie, où elle s'élève de tous les côtez en dégré égal. 'Mais les fevilles écaillées, placées par tout entre les contours de la paroi, n'atteignent pas fi haut, \& demeurent enfoncées à un huítième de pouce plus bas que n'eft le refte de la fuperficie. Cela ne peut que former néceffairement au defius de la Maffe des Allées enfoncées, qui font les mêmes tours que les pa rois mitoïennes plus épaiffes \& plus élevées, \& c'eft de là quion a pris occafion de donner à ces Maffes le nom de $L a$. byrintbe ou de Meandrites.

Tout ce que nous avons dit jusques ici eft applicable à toutes les autres efpèces de cette claffe. Il $\mathrm{s}^{4}$ agit à pré. fent $d^{*}$ en examiner les diffèrences qu'il faut chercher dans cette paroi mitoienne dure \& épaiffe, qui par tant de Contours \& de courbures traverfe toute la maffe en tant de fens diffèrens. Or cette paroi mitoienne, dont les feuilles minces fuivent toûjours le cours en ligne parallèle eft I ) ou fort large, d'où il refulte qu'il ne peut $y$ avoir qu'un petit nom. bre d'Allées enfoncées fur la Mafre, corrme on en peut voi l'exemple à la pièce figurée ici, ou 2) cette paroi eft un. peu plus étroite, \& cela par tout également, ou elle a 3 ) un bord aigu, ou enfin 4) elle n'eft point vifible du tout fur la fuperficie Dans le prémier cas e' eft abfolument une Pierre à labyrintbe, Dans le fecond cas nous fommes fort tentez de lui donner le nom de Meandrite, non feulement parceque l'on remarque par tout entre les Contours de la paroi une Allée fort enfoncée, garnie de tous lles côtez de petites feuilles finement dentelées, mais auffi, parcequ'il y a même au dos de la paroi encore un fillon enfoncé, qui fait le mê the tour. Dans le troifieme cas qui eft celui, où la paroi le termine en tranchant, \& où les petites feuilles des deux côtez vont fe joindre en pointe au deflus de ce tranchant, G 3 
mant beraus fabren, (bergletden uns die folgende Tab. A. XI. zei gen wird) fo Daf man bie Sdreidewand felbft nidbt auf Der Ober.

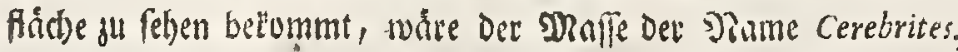
voer Litbocerebrum ivegen Der \$ehnilithert mit einem liegenoun Gebirn, beysulegen.

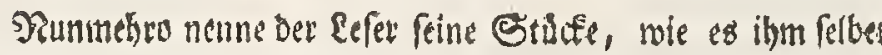
am beften gefallt. Denn Die Beneunung watre willéthrlit') menn man bie Sfters gar zu kurs und zwev日eutig gerathene 2 fobreibung Der Sdbriftfteller nur verftelyen, und einfelyen Bonte, seldje alt fie jedesmahl megnen; fumaht Da Die Siatur allezeit an Diefe Stúcten now eine befondere Fiunft gemendet bat, Die (ich) viel beffer ferbft mit 2lugen anfehen, als Durch 230 ute be

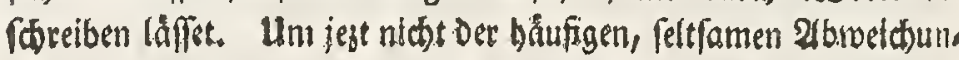
gen in Anfebung Der figur gu gebenten, Denn eg fino etlldie biefer (Sel)irn, ober Raburinth , Curallen fo runo wie eine urdent lidbe balbe sugel, andere find langlidt tand formal role ein Dicfe 2If einer Baumer, no und Soffer, oder fino ganz flact. Ino was Die Briofe betrifi, fo werben fie oun einem Boll anl, Jig zu anderthalbe Sout in Duthmeffer grob gefunden.

Fig. 2. Diefer tleime Situamm if eine Madrepora farofa uno fiefiet einem Zienenftod febr äbntia. Das innere Se. båud fómmt mit Der vurigen 2 th Tebr überein, Denn Das meiffe ftellet in Der Figur Dis Dicke Stheidewand, uno Die forwarje

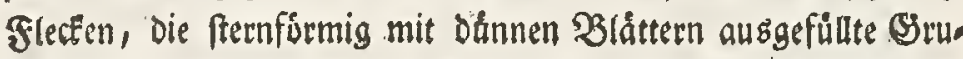
ben vor. In ftatt aber, Dak ber Den vorker beftriebenen die

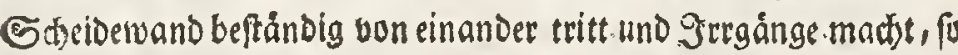

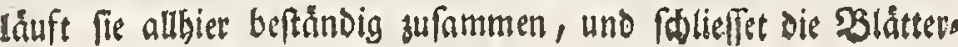
den in unordentlicbe Stern=Seftalten sin.

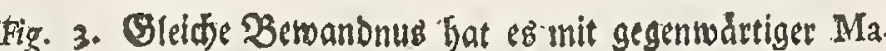
drepora Aftroites, Doer Dem Gteruftein. Es find aber Die

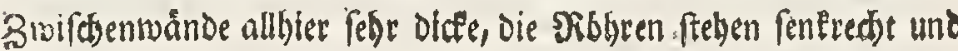

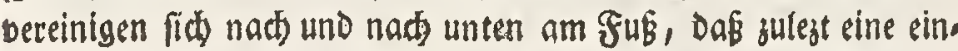

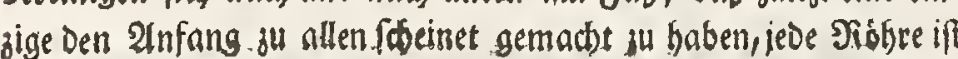
mit fternformigen uno in einem. Birfel geftellten Blättern angefüllet, and Da biefe Blåtter auf oer Dberfiảege nidot gan binauf rei. chen; fo ffellen fis allezeit wertiefte sidoer bur. 2un Dergleidsen Stern. Steinen giebt es nun faft fu biele Fteten, als man fid Sroffen uon Stennen indem Siaum eines Galben Julles vorftellen Fan. Denn swir baben.Dergleidyen mit ungemein Éleinen und feinen, aud andere mit febr groffen Sternen vun eimem balben Sull in

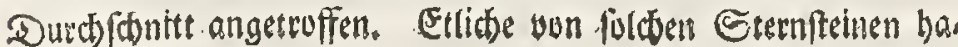
ben bie Sterne didste an einander, etliche abev weity und bey cinigen.ftelten fie uber cinen Bull weit auseinander. Defters fino Diefe Gterne Birketrund uft find fie effigt, und fiegen entweder nur vben auf., voer geber in einen fiócher ganj Durd; niḑt felten

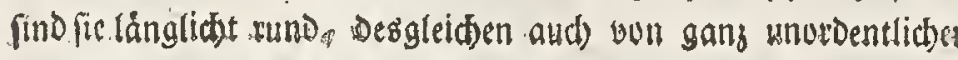

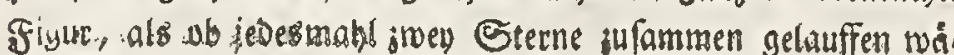

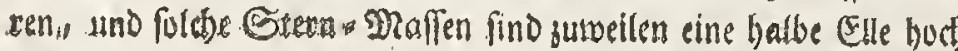
Uni breit. Don biefer 2int leiten suir biejenigen Sofpios artigen Steinfteine ber, welde man unter Den ederen Steinen auflyebet. Sie fino sine Derfteinerung diefer Eocallen= Sobmammez. on peut apeller cette Maffe Mefenterites ( $*$ ), ou Madrepora areolata. Mais dans lc quatrième \& dernier cas, c'eft - ̀े-dire celui, où les écailles, qui font à côtè, s’élèvent en arc au deffus de la paroi, comme nous en verrons cy - deffous un exemple à la Planche $\mathbf{A}$. XI., de façon qu'on ne peut plus la voir fur la fuperficie, alors on peut donner à la Mafte le nom de Cerebrites, ou Litbocerebrum, à caufe de fa reffemblance avec une cervelle couchée.

Il eft libre à préfent au Lecteur de donner aux pièces qu'il pofêde le nom qu'il voudra. Car cette dénomination feroit entièrement arbitraire, s'ilne dévenoit néceffaire de la déterminer pour l'intelligence' des Auteurs, dont les defcriptions font fouvent trop courtes, ou tellement équiv.oques, qu' on eft quelquefois dans le cas de deviner quel peut être leur véritable fens, d'autant plus que la nature a toûjours employé à ces pièces quelque art de plus, qu'on peut voir plus facilement; 'qu' on ne l'exprime par des paroles, pour ne rien dire des fréquentes \& fingulières anomalies quant à la figure, qu' on rencontre dans les pièces de cette efpèce. Car on voit de ces Coraux à labyrinthe, ou à cervelle, qui font ronds com. me un demiglobe, d'autres oblongs \& étroits, comme pourroit être la branche épailfe d'un arbre, d'autres encore, qui portent de hautes montagnes, ou des bolles, ou d'autres enfin qui font plats. Pour la grandeur on en trouve depuis un pouce jusques à un pied \& demi de diamètre.

Figure 2. Ce petit Champignon eft une Madrepora favo. fa fort femblable à un gatéau de rucbe. Sa ftructure eft trés. conforme à celle du précèdent; car ce qu'il y a de blanc dans la figure repréfente la paroi mitoïenne épaiffe, \& les foffettes en forme d'étoile remplies par des feuilles minces font figurées par le refte. Mais au lieu qu'à la Plante précèdente la paroi mitoïenne fe fépare fouvent, $\$$ forme des allées en labyrinthe, ici elle eft par tout continue, \& environne de toutes parts les petites feuilles en étoiles de figure irregulière.

Figure 3. On peut dire la même chofe de la préfente fizure, qui en une Madrepora aftroites, ou Pierre toilée (**). Mais les parois mitoïennes font ici fort épaiffes. Les tuïaux font difpofez perpendiculairement, \& fe réüniffent peuà - peu au pied, de façon qu'un feul tuiau femble être l'origine de tous les autres. Chaque tuiau eft rempli de feuilles formées en étoiles \& pofées en rond, \& comme ces feuilles n'atteignent pas jusques à la fuperficie, elles ne paroiffent que comme des trous enfoncez. Or il y a presque autant d'efpèces de ces Pierres étoilées, qu'il eft pollible de s'imaginer d'Etoiles de diverfe grandeur dans l' efpace de $12 \mathrm{moi}$ tié d'un pouce, c'eft à dire, de la plus petite efpèce jusques à la plus grande. Car nous en avons trouvé dont les étoiles étoient extraordinairement petites $\&$ fines, \& d'autres où les étoiles étoient trés - grandes, \& avoient un demi. pouce de diamètre. A quelques unes de ces pierres étoilées, les étoiles font fort près l'une de l'autre, à d'autres elles font éloignées, \& il y en a où l'intervalle emporte presque un pouce de diftance. Souvent ces étoiles font rondes comme un cercle, il n'elt auffi pas rares d'en trouver d'angulaires, quelquefois timplement couchées fur le haut de la pierre, d'autres fois perçant la pierre de part en part en figure de trouffe, ou de carquois, afiez fouvent d'un rond oblong, \& d'autres fois de figure très-irrégulière, comme li 
deux étoiles $s$ étoient combinées. On rencontre de ces Maffes à étoiles, qui ont jusques à une demi - aune de hauteur, \& autant de largeur. Selon nous, c'elt de cette efpè. ce de pierres étoilées que proviennent celles qui ont un peu de la nature du Jafpe, \& qu'on a coutume de conferver parmi les pierres précieufes. Elles ne font qu'une Pétrification de ce Champignon coralin.

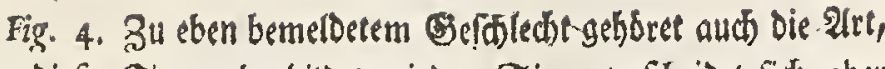

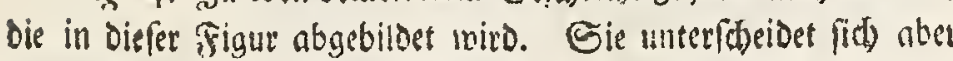

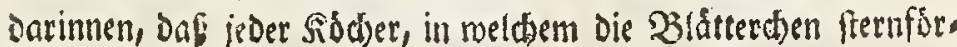
mig ftethen, ein befonderes Sebiufe our fid) filbit ausmacht, und

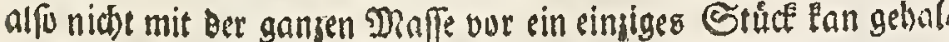
ten werben. Dabero teidben auth alle Sibber eimzeln uno befun Das aนs Der Mafle, bie gleidjam in einem fald)artigen Funba ment ftect, beraus, uno find nur Durct) ein foblefferictes 215 fen mit einander befeftinet. Es Ebmm dieles Ctift bey Dem Linnæus unter Dem Namen Madrepora fafcicularis, und beum Imperatus unter Dem ఇamen Milleporus bor.

Fig. 5. Endring befdrlieft die befondrre शebenarten die fich in Dem Sefwlect)t Der Steinfditwåmme finoen, Der auf burbergeben Der Safel Fig, I. beforiebene Amaranthus Saxeus. Er if neme lid beubem Ptnbrud am Gtiel mit einem einjigen grolfen Etern auggefüllet, welder fid bernad in vier aefte ausbreitet, Die in ifren groffen und tiefen Soblungen, wie fernformige Srich ter ausfehen, renn man nemlich von oben hinein fhauet. Di am iuneren Lmfang ftebende BIatterden eretten vben mit Baden uno Siraufen aus jeben Sridter beraus, Dafjer Der ganje uber Siano getrdufelt ju fegn theinet. Fusiwendig aber ift Die Dber fladbe glatt; uno gleidfam wie ein Syurn, nls ub fie mit einem Surnilenartigen Seefdlamm úbergugen måre. Maegen Der grup

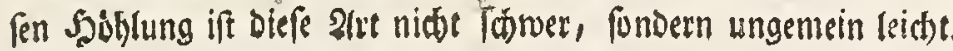
Die Farbe ift gelblict, guweilen auch) weis, uno bie gånge pfleget soobl sinen balben S\$ub) ju cireiden.

\section{TAB. A. V.}

Fig. 1. Fuf gegenvadrtigen Felfen oslumpen erbliteet man Des Mercati fogenannte Ifidis palma. Es ift aber biefelbige ein Fehr zartes Sorngetodidfe ober Keratophyton yon afd grauer, etroas ins braune fallender Farbe, Deffen Teebenåftgen

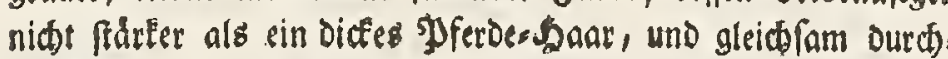

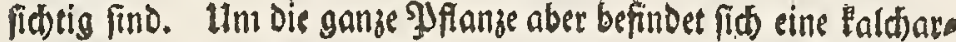

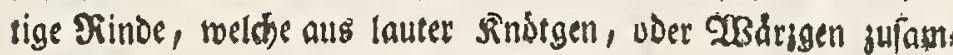

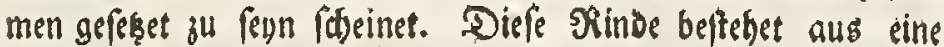

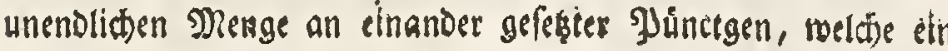
Deutlides Merfmall fino, Das fo viele Shierden in Denfelben als in ihren Bellen nuthnen. Des Silumpe felbit aber if ein

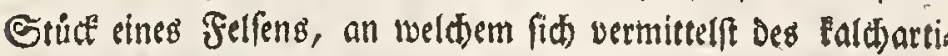

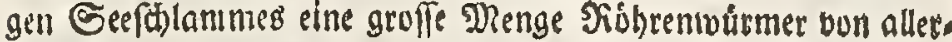

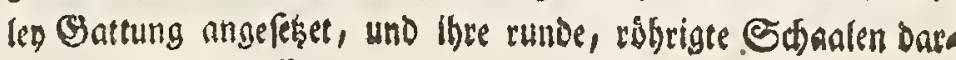
an baben fişen laffen.

Fig. 2. Diefe Curalle tf ebenfalls ein baumformiges

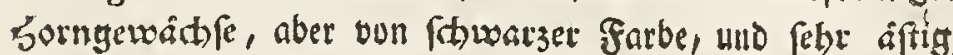
welder bey Dern Befler unter Dem Namen Erica mariha, ader Gee Cubftana if nicht nóthig năber su befthreiben, weil fie mit Dero

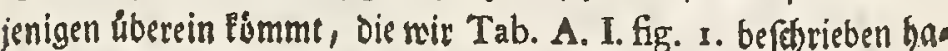
ben; nus if fie nidts fo glatt, fondern man fieket auf Der Obera

fịd)
Figure 4. Il faut mettre au rang de la pièce précèdente celle que la figure prélente dépeint. Ce en quoi celle - ci diffère de l'autre, c'eft que la trouffe ou le carquois, où fe trouvent les petites feuilles en forme d'étoile fait un étui féparé, \& n'eft par conféquent pas une feule \& même pièce avec le total de la Maffe. C'eft par cette raifon que chaque carquois dépaffe la Maffe entière, qui eft comme envelopée dans un fondement, qui tient de la chaux, \& l'un n'eft lié à l' autre qưe par une fubftance écaillée. On trouve cette pièce dans Linnaus, fous le nom de Madrepora fafcicularis, ou à faifceaux, \& Imperatus lui donne celui de Milleporus.

Figure 5. Enfin voici l' Amaranthus Saxeus, par où nous finirons ce que nous avions à dire des efpèces particulières, qui apartiennent à la Claffe des Champignons pierreux. Nous en avons déjà parlé à la Planche précèdente, fig. I. On voit qu' une feule grande étoile remplit toute l'entamure du pédicule, qui de là s'étend en quatre rameaux, lesquels par leur cavité grande \& profonde reffemblent, quand on y regarde du haut en bas, à un entonnoir formé en étoile. Les petites feuilles, qui fe trouvent à la circonférence intérieure, fortent hors de chaque entonnoir dentelées, \& garnies de frifure, ce qui donne un air frisè à tout le bord fupèrieur. Mais au dehors la fuperficie eft unie, \& reffemble à de la corne, tout comme fi elle étoit couverte $\&$ enduite du li. mon coralin de la mer. Les pièces de cette efpèce font trés-legères, ce qui provient de leurs grandes cavitez. La Couleur en eft jaunâtre, quelquefois blanche, \& quant à la longueur elle va communément jusques à un pied.

\section{PLANCHE A. V.}

Figure I. On voit fur ce morceau de rocher ce que $M$ Mer. catus apelle Ifidis palma, ou la Palme d'Ifis. C'elt une Plante de nature de corne, ou un Keratophyton trés - delicat, de couleur cendrée tirant un peu fur le brun. Les rejettons qui en fortent ne font pas plus épais qu'un gros crin de cheval. La Plante entiere $\gamma_{e}$ trouve enduite, ou envelopée, d'une écorce de nature de chaux, qui paroit n'étre compofée que de petits noeuds, ou de petits boutons. On voit fur cette écorce une infinité de petits points pofez l'un contre l'au. tre, ce qui indique autant de petits animaux qui $\mathrm{y}$ habitent, comme dans leurs cellules. La Maffe mème n'eft qu'un ta. pon de rocher, auquel fe font attachez moiennant un limon de mer, qui tient de la chaux, une grande quantité de vers à tuyau de toute efpèce, \& qui y ont enfuite laiffé leurs co. quilles rondes faites en tuyau.

Figure 2. Le Corail de cette figure eft auffir une Plante de nature de corne en forme d'arbriffeau, mais noir de couleur, $\&$ trés-brancbu. Besler la nomme Erica marina (*). Comme fa fubftance noire de nature de corne elt de tout point con forme à celle dont nous avons donné la defcription cy. deffus en parlant de la prémière figure de la Planche $\mathrm{A}$. $I_{\text {. }}$ il eft fuperflu d'en rien dire $\mathrm{ici}$; fi ce n'eft que celle-ci $\in$ ft $\mathrm{H}$ moins 


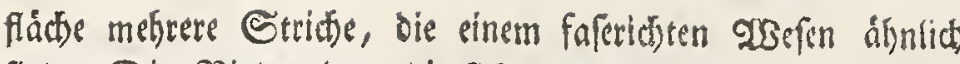
fino. Die Sinde aber, bie fict nuth mehrentheils saran ber

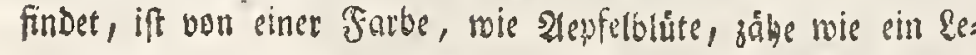
Der, aber mit unentlidsen SJuneten, nis eine Millepora Dutch. brodsen, und firefifidt. Eben diefe nemlict)e gionie befindet fith

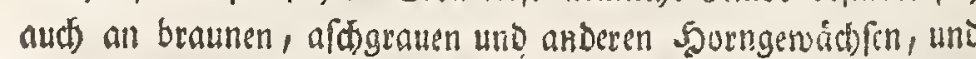
forougt an glatten als ftads)lidten, rtno affigen und phatt= âfiger.

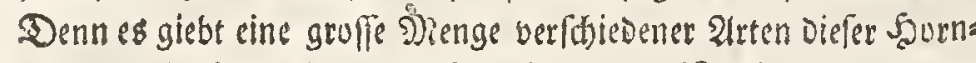

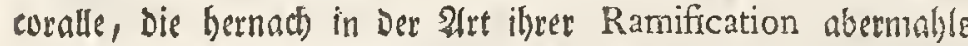
abseiten, indern etliche breite, snoere fotmale Dergliederun gen Haben, und an Denen Die Aefte Esaudenfornig ober Siabelformig Geraus tretten. 2alle diejenigen Keratophyta nun, meldise mit einer 乌olypen.Sinde umgeben find, werden befunders gun Dem Boerhave Titanoceratophyta genennet.

Fig. 3. Eben ein Dergleides Keratophyton, aber ofine Cruftz swird uns in biefer Figur gejeiget, weldbes eine braunrothe Furbe und Eeine Binde bat, und Da es ein fisabhaftes Exemplar ift, Deffen zartere Aleftgen abgebrochen fino, fo lan es vermuthlich Die Sinde verlubren haben. Indef wollen wir keinesroeges da Durch) bebaupten, und (E) als eine ausgemadte Eache annel).

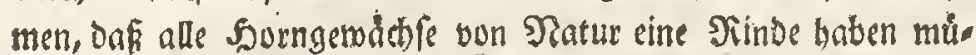

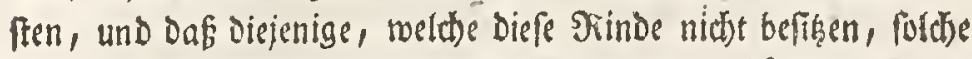
Durch eiren Bufall unwiberfpredblitit verlobren badten. Denn man hat \$eeres. Sregenden, oder Decerbufen gefunden, Da alle Shurngewådfe Esine Finde faben, vielleid)t beswegen, weil bas Serwaffer Dafeltbit keinen Sdjlamm bey fid führte, Der fids anlegen Eonte, und ben \$olypen eine Șerberge verfothaffen. 2(ut) werven vidt allenthalben Die Jjolupen fo băufig zugegen fenn.

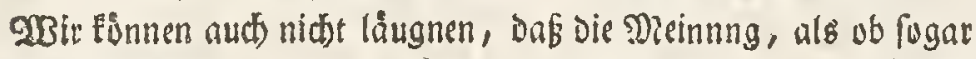

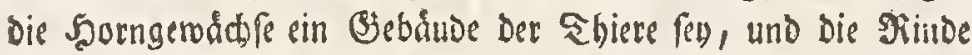

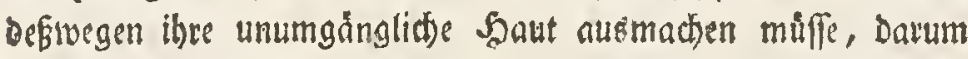
unz fohr sweiffelhaft burlomme, weil einerles Shurncorall, aller hand ant von Sinden haben $\mathfrak{E}_{\mathfrak{n}}$. Denn wir haben fumarze Keratophyta mit einer Sinde won Madreporen, und audi bon Milleporen, Desgleiden mit vermengter Sinde, und aud gan

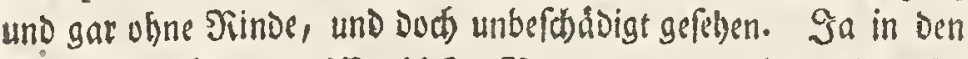
freenigten unåditen weiffen dicfen Baumcorallen baben wir mely. rentheil's ein Keratophyton gefunden.

\section{TAB. A. VI.}

Fig. J. Ein voliftåndiges Exemplac eines fitharzen Scorns

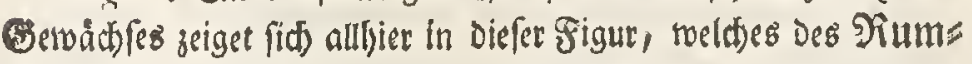
pfeng Acarbaricum nigrum ramofum ift. Das bols zlgte 2 Befen Diefer Staude iff fehr ftreifigt, und ftheinet geo sounden, oder gedrellet zu feyn, als ob die fafern woer Fil bern pon einander gervictsen wăren. Die Maffe ife dicht, hart, und lohlfomars, an Den jüngeren Epigen aber nur etrwas bráunlidt und Durchfictig. Das Sthaf Des Selfeng, norauf es fithet, ift mit einer Eorallen " Dafle befestet, in weldier man groffe aber gleichfam abgenugte Sternaugen fiethet. Diefe Malje gehoret unter die Aftroiten und twird vom Linneus $\mathrm{Ma}$. drepora Ananas genennet. moins unie que celle -là, y ayant fur la fuperficie plus de raïes, qui reflemblent à une matière compofée de filamens. Mais four ce qui concerne l'écorce, qui s'y trouve encore en grande partie, la couleur en eft femblable à celle des fleurs de pommier. D'ailleurs cette écorce eft coriace, corr me le cuir même, \& percée d'un nombre infini de trous ccmme une Millepora, au refte raiée. Cette même écorce fe trouve à des Plantes de nature de Corne brunes, cendrées, \& autres, foit qu'elles foit unies ou non, \& que les branches en foient rondes ou plattes. Car il y a une quan. tité d'efpèces de ces Coraux de nature de corne qui diffèrent enfuite encore par leur branchage, puisqu'on en rencontre dont les articulations font jarges, tandis qu'à đ’atztres elles font étroites, \& qu'aux uns le branchage croit en arbufte, à d'autres en fourche. Boerbave donne en particulier à tous les Keratophytes envelopez d'une écorce de Polypes le nom de Titanoceratophyta, c'eft-à - dire, Corail pierreux terant de la nature de come, \& ayant quelque chofe de femblable à la chaux.

Figure 3. Un Keratopbyton pareil paroit ici, mais fans Crônte. T.a couleur en eft rouge tirant fur le brun. Il n'y a point d'écorce. Comme ceci eft une pièce endommagée, dont les rameaux les plus fins fe font rompus, il eft à préfumer qu'elle peut avoir perdu fon écorce. Cependant nous ne prétendons point dire par là, ni donner pour un axiome; que toutes les Plantes de nature de corne doivent nécerfairement avoir une ècorce, ni que celles, où cette écorce ne fe rencontre pas, doivent abfolument l'avoir perduë par quelque accident. Car il y a des plages de la Mer, \& des Golfes, où toutes les Plantes de nature de corne font dénuées d'écorce, parceque l'eau y elt privée de ce limon né. ceffaire pour couvrir les Plantes, \& fournir aux Polypes les matériaux de leur habitation. D'ailleurs les Polypes n'abondent pas par tout en quantité égale. De plus, nous conviendrons de bonne foi que l'opinion que les Plantes de la nature de corne font aufin un édifice conftruit par des animaux, \& que par cette raifon l'écorce en doit abfolument conftituer l'envelope ou la peau, ne nous paroit pas fondée fưr un raifonnement fort affüré, vû que des Coraux de nature de corne d'une même efpèce peuvent avoir toutes fortes d'écorces. Car nous avons vû des Keratophyta de couleur noire ayant une Ecorce de Madrefores, ou auffi de Millepares, ou encore d'une écorce mêlangée, \& de même tout - à - fait dénuez d'écorce, \& cependant non-endommagées. Outre cela nous avons trés-fouvent trouvé un Keratophyton dans les Coraux pierreux bâtards épais de couleur blanche, qui font formez en arbriffeaux.

\section{PLANCHE A. VI.}

Figure I. La figure que nous préfentons ici à nos LeEteurs eft une Plante de nature de corne, noire de couleur, \& cette pièce eft complette. C'eft celle que Rumpff nomme Acarbaricum nigrum ramofum. (*) La partie de cet arbufte qui a quelque chofe de la nature ciu bois, eft garnie de beaucoup de rayes, \& paroît être tordue ou tournée, tout comme fi les fibres ou filamens s'étoient écartez les uns des autres. La Maffe eft compakte, dure, \& noire comme du charbon, mais aux rejettons plus jeunes elle n'eft qu'un peu brunâtre \& transparcnte. Le lieu du rocher, où cette Plante elt attachée eft couvert d'une Maffe coraline, où l'on obferve de grands yeux étoilez, mais qui paroiffent comme Fig. 
Fig. 2. Git ein Keratophyton mit unuritgebogenen 2teften,

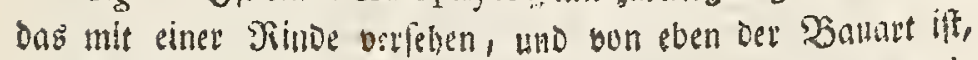
alo die Tab. A. II. fig. I. befdrictene Madrepora Abrotonoi-

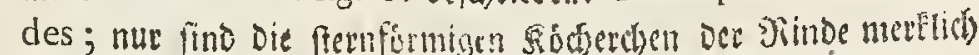
barter. Sab Keratophyton filbj aber bat leine runde foniern gang platte uno berite siefle, bie lich mit gerwifen breiten braus

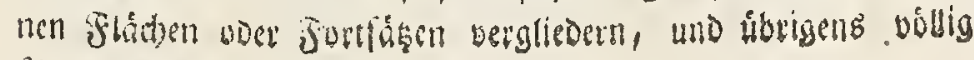
fortorars jino.

Fig. 3. Stufier wiro ung cin nfitgraus Keratophyton mit Fnutigten Sergliederungen gezeiget, an weldem befunders die

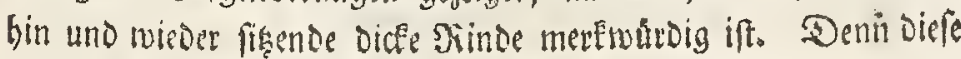

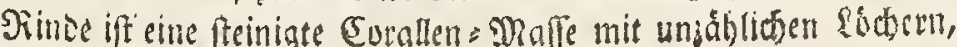
uno Forectsterting mit iener Millepora einerley, die, und Dergleichen mir Tab. A. II, fig. 3. weitlduftiger Gefthricben bas ben. WSir atweife!n gar nidyt, Daf biefes Keratophyton, wern

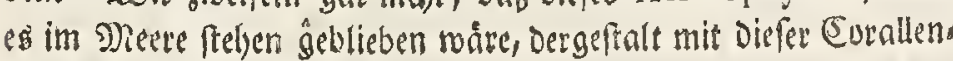

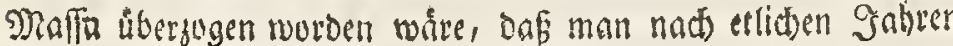

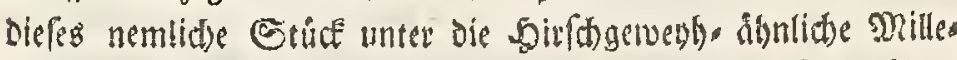
puren, und folglich unter bie harte Eteincoralle hătte zadhlen múfen; tmo Ba vermuthlict Das Keratophyton Dured alter uno

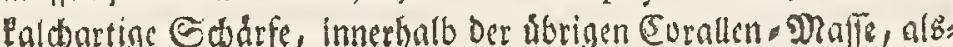

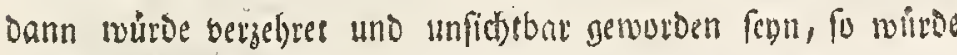

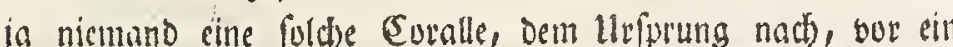
Sourngervadthe anfelten, fondern, wie ber Gebrand) jerso ift, belaupten; es butsen fict) bie SJulapen alfo baumformig anges bautet.

\section{TAB. A. VII.}

Fig. I. Eine atite rothe Earaile, Dergleitien wir Tab. A. Fig. I. befortieben baben, wiro uns in biefer Gigur bergeftetles,

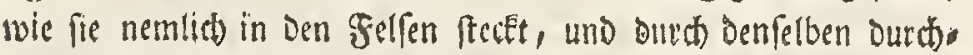

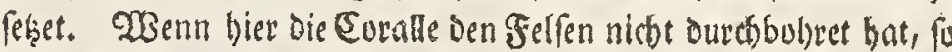

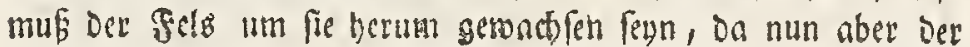
Etcin bes Sellens, - Feiner Soante nad), bur áleer, als bie Curalle

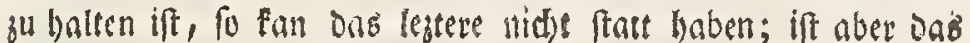
erfiere, uno bat fith Dir Coralle Durct Den Felfen ourebgebobret,

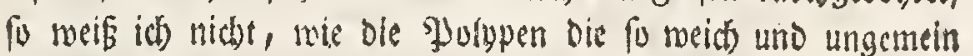
sant find, (weenn fie nemlich, mie man will, bicke Binken folber

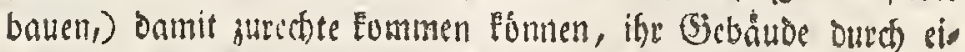
nen fo barten Segenfent aufzuführen. OSenigfens wiro man,

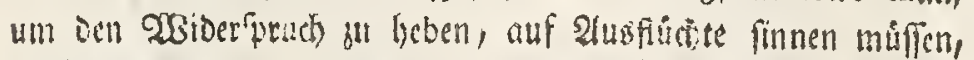

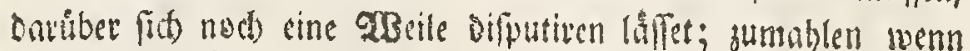

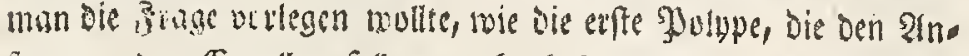
fung iu ien Corallen foll gemacht baben, mitten in bie MRafe

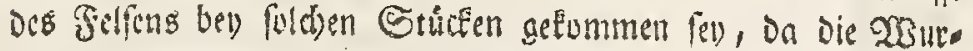

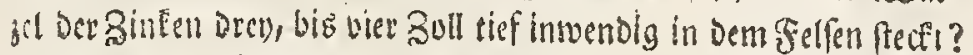

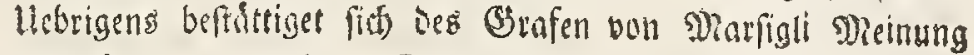

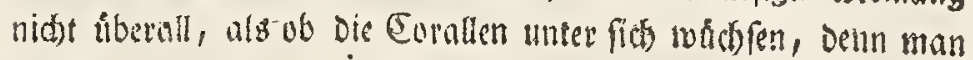
firlost auch bier, man imag ben silumpen oreben whe man will,

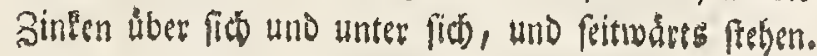

ufe2. Cette Maffe doit être mife au rang des Aftroittes, \& c'eft ce que Linnous apelle Madrepora Ananas.

Figure 2. C'eft un Keratopbyton à rameaux courbez en arrière, \&z garni d'une écorce toute pareille à celle dont nous avons donné la defcription cy - deffus en parlant du Corail étoilé d'Atronne, (Madrepora Abrotonoides) voy. P1. A. II. fig. I. Cie en quoi celle-ci diffère; c'eft que les petites trouffes ou gaines en forme d'étoiles font ici beaucoup plus fines. Les rameaux de la Plante même ne font point ronds, mais tout à fait plats \& larges, \& fe joignent au moyen de quelques articulations à d'autres rejettons larges \& bruns. Au refte la couleur en eft abfolument noire.

Figure 3. On produit ici un Keratophyton de couleur cendrée, à articulations noueufes, particulièrement remarquable par l'écorce épaiffe qu' on y voit en divers endroits. Car cette écorce eft une Maffe coraline, marquée d'une infinité de trous, \& abfolument la mème que la Millepora, $\&$ d'autres femblables que nous avons amplement décrit cy. deffirs, voyez P1. A. II. fig. 3. Nous ne doutons nullement que fi cette mème Plante de nature de corne fut demeurée plus long - tems dans la Mer, la Malfe coraline qu'on y obferve çà \& là l'auroit entièrement couverte, de façon $q u^{2}$ après quelques années, on n'auroit pû fe difpenfer de la comprendre fous l'efpèce des Millepores formez en bois de cerf, \& de la mettre ainfi au nombre des Coratux pierreux durs Et comme il eft probable, que foit par laps de temps, foit par cette acreté de nature de chaux que l'eau de la Mer renferme, ce Keratopbyton auroit été confumé \&z détruit au dedans de la Maffe coraline de manière à ne laiffer aucun veftige, perfonne ne fe feroit avifé de regarder cette piècé comme ayant êté originairement une Plante de nature de corne; on n'auroit pas manqué au contraire de foûtenir, $e^{e-}$ lon la façon de penfer reçüe aujourdbui, que des Polypes auroient conftruit ainiti cette pièce en arbriffeau.

\section{PLANCHE A. VII.}

Figure 1. Voici un véritable Corail rouge pareil à celui que nos Lecteurs ont vî fur la Pl. A. fig. I. La préfente Pièce eit toute enfoncée dans le rocher qu'elle perce de part en part. Si l'on ne velut paš admettre l'hypothère, que le Corail a percé le rocher, on fe trouvera obligé de fupofer que le rocher a fait fon crû peu - à-peu autour des branches du Corail. Or cette dernière fupofition ne peut point étre admife, puisque naturellement la pierre du rocher eft plus dure \& plus ancienne que le Corail: \& quant à la prómiere hypothèfe fuivant laquelle le Corail doit avoir percé à travers le rocher, il eft affez incompréhenfible que les Polypes, fi tendres \& fi délicats ayent pû (puisqu'on prétend qu' ils font eux mémes les Architętes du Corail) conftruire leur habitation, au travers d'un Corps auffi dur, \& où ils n'ont pû manquer de, trouvet une refiftance invincibl. Tout - au - moins, on fe trouvera reduit, fi l'on veut lever cette objection, à recourir à des faux-fuians, fur lesquels il y aura bien des argumens à allèguer pour ou contre, fur tout fil l'onmet en queftion comment le prémier Polype, par lequ?l on prétend que l'édifice de la Plante du Corail a êté commencé, a pû pénètrer en pièces auffi grofres jusques au milieu de la Maffe du rocher, vî. que la racine des branches s'y trouv. avancée de trois jusques à quatre pouces au dedans du rocher? Au refte le fentiment du Comte de Marfilli, que les Coraux pouffent vers le bas ne trouve point d'apui ici, car do quel fens qu' an tourne \& qu'on confidère la préfente Malfe, 
Fig. 2. Diefe rỏhernformige Stern. Maffe ift Des Imperati Porus matronalis ramofus. Sie nimmt auE einem einjigen Daumens Diffen fernformigen Etamm ithern Iltfwrung, und aus bemfelben geken allentbalben zur Seisen Fingers bicke 2tefe, als eine junge 2 rut aud, bie fich bernat wicierum in 2efte, eines Federticls biff, jertheilen. Sie baben alle inwen. big eine geftirnte Södser o Gigur, vben aber geigen fie fith allegeit Whatt abgefdnitten, und offen. In biefen Defiuungen trift man

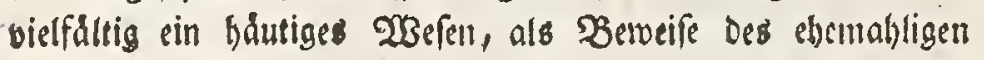
Baumeifter und surmformigen Jyalgpen an, und ift bier ein foldter Ur.preung nicbt ju láugnen.

\section{TAB, A. VIII.}

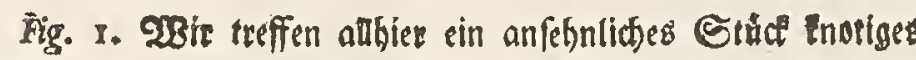
Sorncurall an, welderes bon sben ber 2Art ift, wie wir bereits Tab. A. I. n. I. uneer ben Namen Antipathes befcerieben bae ben. SRan bat vormahts noch bictere Selüten gefunden, allein jege find Dergleiden ziemlid felten. $230 \mathrm{~m}$ gegenwadrtigen if Der

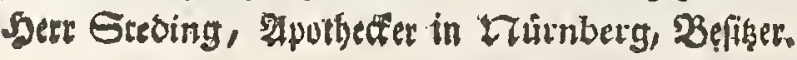

Fig. 2. Sft etme 2Irt won bem \&ebten ruthen Steincorall, mit burtbrodener Dberfadde. Die Daffe if insueribig jiemlict bidete, und rou man auct) eille Birife bon einander brictst, fo fin bet fich nur eine geringe Spur bun einer Belle, bie eimigermaffen fternfarmig feteinet getwefen zu fegn. Die Dberfidche if rings. berum mit Streiffen und Surden beferget, toelde) Der \&ånge nad an Den Aeftgen berunter geben. Sie if ferner mit Srübgen ver.

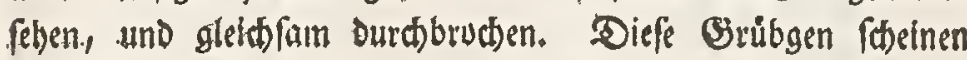
ebenfaills berlorthene Sterndien ju Reun, uno baben alte die Droffle, wie ein Souf einer Eleinen Stectnadel, mie foldes an Dem Original bes 亏etrn Stebings in trünberg ju erfechen iff.

Hig. 3. If vermutblid sine jüngere Coraten $=$ Binke von

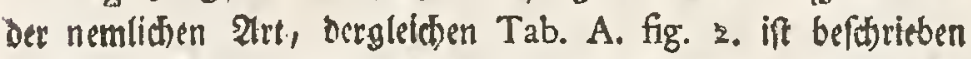
worden. Tenn bie Farben beránoern fid snit tern शlter. Es

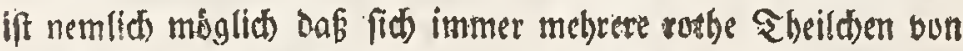
nemlicher 21rt anlegen; soern nun immer eine fleifdfarbene

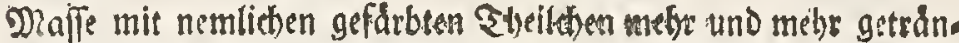

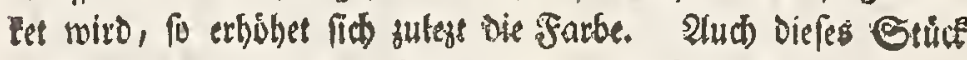
niso bey mebr gemeloeten berrn Gteding aufgehuben.

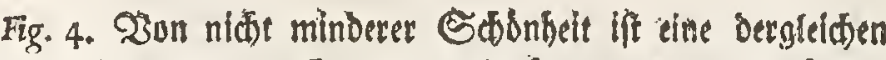
Eurallens:Binke aus Dem Cabinet bez berủbmiten Werrn Syofraths Frew (weldem wix fo viele ausnebmende Originaie in in biefer Garnmlung 34 danten baben.) und die fier in diefer Figur gegeiget mirb. Sie if befonders megen Der freven aluse breitung ibrer 2lefte mertwưrsig.

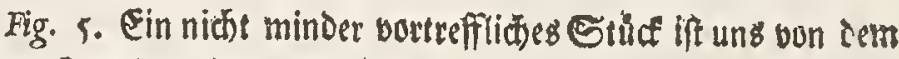
berrn Jrediger Schadelock in râtrnberg mitgetheilet worn Den, Das in biefer Figur burgegeiget wire. Da Dergleiten bize ber noch nithe vorgefummen, fo if nóthig, baf wir es nibler ke. idseiben. Es if nemlid) ein fernformiget Gteinf(d)tramm on verra qu'il en fort des Chevilles ou bouts, en haut, en bas, \& par les côtez.

Figure 2. Imperatus donne à la préfente Mafje êtoilée

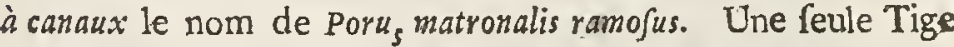
en forme d'étoile \& épaiffe d'un pouce en fait le commencement \& de là partent par tout vers les cotez des rameaux de l'épaiffeur d'un doigt, comme un jeune nourrain, qui produit d'autres petits rameaux, lesquels ne font pas plus gros .qu'un tuyau de plume. Ils ont tous intérieurement la figure d'une trouffe ou gaine faite en étoile, \& font coupez \& ouverts en haut. On trouve affez fouvent dans ces ou. vertures des reftes d'une efpèce de pellicule, qui prouve que le prémier Architęte de cette habitation, nous entendons par là un Polype formé en ver, $\mathrm{y}$ a fait fa demeure, ce qu'il n' eft pas poffible de contefter.

\section{PLANCHE A. VIII.}

Figure s. Nous trouvons ici une pièce confidèrable d'un Corail de nature de carne noueux de la: même efpèce dont nous avons déjà parlé cy deffus, P1. A. I. fig. r. Tous le nom d'Antipatbes. Autrefois on trouvoit des pieces encore plus épairfes de la même forte, mais à préfent elles font rares. Le Sr. Steding, Apoticaire à Nuremberg, eft Poffeffeur de l'original de celle - ci.

Figure 2. Ceci eft une efpèce du Corail rouge pierreuxi vtritable à fuperficie percée. La maffe au dedans en eft affez compacte, \& iors même qu' on en rompt une cheville on ne remarque à l'entamûre, qu'à peine le petit veftige d'une cellule, qui en quelque façon pas oit avoir eû la forme d'etoile. Tout le tour de la fuperficie eft marqué de rayes $\&$ de cannelures, qui defcendent tout du long à côté des petits rameaux. La Plante a d'ailleurs des folfettes, dont elle femble-comme percée. On peut conjecturer que ces foffettes ont auffi êté des petites étoiles dont la figure s'eft effacée. Elles font affez grandes pour qu'on puiffe y faire entrer 12 tête d'une petite épingle, comme on le peut voir à l'original que le Sieur Steding de Nuremberg poffède.

Figure 3. Selon les aparences c'eft la petite branche d'un jeune Corail de la même efpèce que nous avons décrite cydeffus, voy. Pl. A. fig. 2. Car les couleurs changent à méfure que le Corail vieillit. On conçoit qu'il s'attache toûjours davantage de particules rouges de la même efpèce à la plante. Or quand une Maffe, qui eft originairement couleur de chair, continuë de plus en plus à être imbibée de particules colorées homogènes, il eft naturel qu'd la fin la cou. leur s'exhauffe. La préfente pièce eft auffi entre les mains du Sr. 'steding.

Figure 4. Nous devons à Monfieur le Confeiller Aulique Treve quantité de superbes originaux qu'on voit dans la préfente Collection. En voici un qui repréfente une branche de corail, qui n'eft pas de moindre beauté que la précèdente, $\&$ qui eft aufi tirée du riche Cabinet de ce Sçavant. Celleci eft particulièrement remarquable par l'extenfion dégagée de fon branchage.

Figure 5 . Une pièce toute auffi admirable que la précè. dente nous a êté communiquée par Monfr. Scbadelonk, Prédicateur à Nuremberg. On la voit dépeinte dans la préfente figure. Comme nôtre Collection n'en a jusques ici point produit de pareille, il conviendra d'en parler un peu en dé. 
nit gesactern Slättern, und de Bauart ift eben die, weldye roir fhon bun ben Gtern. Figuten mebrmablen angegetget hoben. Denn zwifhen zwey boben 5 láttern felben orey andere nieorige Davon Das mittleve wiederum Das bódse ift. Die Bacten fins bulfurnmen einer Såge gleid), uno find an ben grofen soláttern

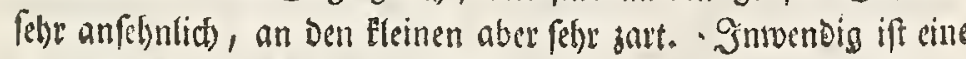

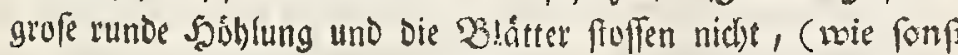

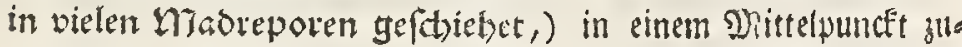
fammen. Sie Farbe Der Edhieffer if weis. Diefe bläteridte Sirone fiehet auf einem Eurzen und faft eben fo Diden Eriel, seel d)er aber mit vielen foldben frernformigen siocbern angefüllet iff, Die fief enolid in ben ubern eingigen uno allgemeinen frernformi gen Sing endigen. STan nimmt aud an bem áuferen $\mathfrak{H}_{\mathrm{m}}$ fang oes Juffes getviffe Decfen, voer fteinbarte Schute wahl, botaus erbellet, bas fid immer eine neue Srone iber Der andern angefeget habe. Diejenige nun, weltbe die Corallen nur für ein Sebádue bon Shieren anfehen, foreiben diefem Exemplar einen Jolypen jum Einroobner zu, beffen Corper in Der Mitte lieger,

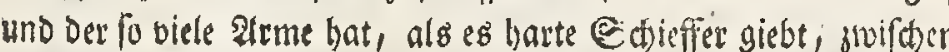

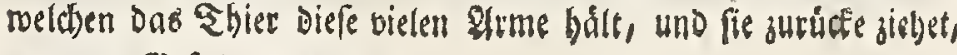
renn es Sefagr bemerfet.

\section{TAB. A. IX.}

Diefe fipfertafel ftellet uns nur eine einjige, aber fefor muntor

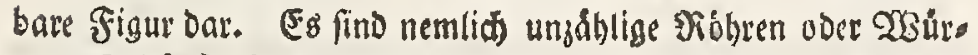
mer= Sebåufe die theils untereiuander, theils gemeinfitaftlich an

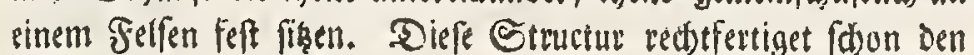
allgemeinen Namen Tubularia; leood if fie forwerlid) unter bie Elaffe ber Corallen zu bringen. Denn bie Daffe ift nitbt fo, wie an anderen Corallen beftraffen. Die Siobren fint unten enge, uno werben nach und nath seiter. Ste facinen aus lau ter Dueerisingen zu befteben, bie fith nath uno nach auf cinan.

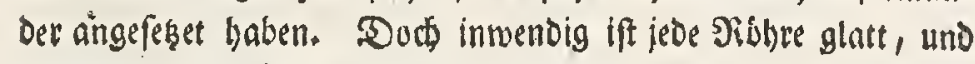
gleictfam mit einem rótblid) braunen uno hart gerourdenen Gd)lamm ubersugen. Don biefen Siobren ftehen mebrentheils viele auf einem $\mathfrak{F u E}$, uno fino wenig, ober mebr Durd einen Meer. 佸lamm, Der fie gleid) fam überzugen bat, an einander getüttet. Ulebrigens aber fichlingen fie fich Durcteinander, uno weidenen ein. ander aus, wie fie nemlit am beften baben Jjlas finden lunnen. Wegen Der Maffe, womit biefe Sobren mehrentheils úberzogen find, Esnte biefer Slumpe mohl vor Des DRarfigli Corallium Tubulofum, oder Tubularia alba, gehalten, nuth beffer aber einem Halcyonio duro beygefüget twerten. Eben bergleityen Siobren finden fieb oft eindeln, fo robl an Felfen, wie man an bem unterften Sheil biefes Silumpen fiebet, als audb an Schnes

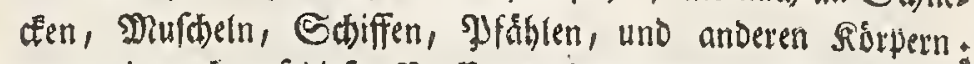

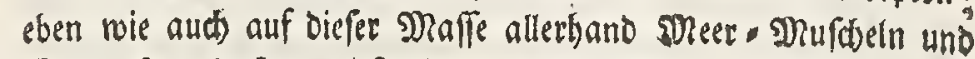
Edonectgen ia fogar Asteriten und bergleiden fefte fisen.

\section{TAB. A. X.}

Fig. 1. Cine ungemein nicolid) blåtterfêrmige mit unzåbliz sen Eternden befeste Curallen - Maffe wird in gegenwadrtiger tail. C'eft un Champignon pietreuxt en forme d'étoile à feuilles dentelées, \& fa Atructure eft la même que celle des autres figures étoilées, dont nous avons fouvent etî occafion de faire mention. Car on y obferve entre deux feuilles élevées trois autres baffes, dont celle du milieu eft encore la plus haute. Les dens en font de tout point femblables à celles d'une fcie, grandes aux grandes feuilles, \& trés - fines aux petites. Au milieu il y a une grande cavité ronde, car ici les feuilles ne fe réuniffent pas au centre, comme cela arrive à quantité de Madrepores. La couleur des feuilles ou écail. les eft blanche. Cette Couronne feuilletée eft pofée fur un pe: dicule court \& trés épais, qui elt remplí par un grand nom. bre de trouffes ou gaines en forme d'étoile, qui vont re terminer enfin à l'unique anneau génèral, qu'on voit en haut, lequel eft auffi figuré en étoile. On obferve en même tems à la périphérie extèrieure du pied certaines couvertu. res, ou écorces dures comme de la pierre, d'où il paroît que fucceffivement une Couronne s'eft toûjours porée fur l'autre. Ceux qui font pour le fiftème, que les Coraux font un édifice conftruit par des animaux, attribuent à cette pièce un Polype pour habitant, dont felon eux le corps fe tient a milieu, \& qui a autant de bras que cette piece a de feuilles ou d'écailles dures, entre lesquelles l'Animal étend fes bras nombreux, \& les retire, quand il coupçonne quelque péril.

\section{PLANCHE A. IX.}

Cette Planche ne produit aux yeux du Leeteur qu'une Figure unique, mais d'une itru\&ture merveilleufe. $\mathrm{O}_{\mathrm{g}} \mathrm{y}$ voit une infinité de tuyaux, ou d'habitations de vers, attachées à un rocher, tantôt fans ordre \& entremêlées, tantôt en commun. Cette ftrueture indique déjà la raifon pour laquelle on donne à cette pièce le nom géneral de Tubularia, ou Corail à tuyaux. Cependant nous ne croyons pas qu' on la doive regarder comme un Corail, parceque fa Maffe n'a pas les qualitez des autres Coraux. Les tuyaux font étroits en bas \& vont peu-à - peu en s'élargiffant. Ils ne paroiffent être compoféz que d'anneaux en travers, qui fé font pofez fucceflivement l'un fur l'autre. Cependant dans l'intérieur chaque tuyau eft uni, \& comme enduit d'un li. mon brun tirant fur le rougeâtre, qui s'y eft durci. Ces tuyaux repofent pour la plus grande partie fur un pied \& font plus ou moins maftiquez l' un à l'autre par un Limon de mer, dont ils font comme couverts. Au refte ils s'enlacent entre eux, ou gauchiffent, felon que la place le permet. Quant à la Maffe, qui couvre la plus grande partie de ces tuyaux, il y a lieu de croire que c'eft ce que Marfilli apelle Corallitm tubulofum, ou Tubularia alba, c'eft-à-dire le Corail à tuo yaux , ou la Maffe à tuyaùx de couleur blanche; mais nous efti. mons qu'on feroit mieux de la joindre à l'alcyonium durum, le nid d'Alcyon. (*) On trouve auffi fouvent de pareits tuyaux feuls, ou féparez, comme on peut voir à la partie infèrieure du préfent tapon, \& qui fe rencontrent également fur des Coquilles de toute efpèce, fur des navires, des pi. lotis, \& d'autres corps; tout comme on aperçoit fur cette Maffe - ci toutes fortes de Coquilles de mer, de petits Efcar. gots, \& mêmes des Aflerites, \& pièces pareilles fermement attachées.

\section{PLANCHE A. X.}

Figure 1 . Ine Mafle coraline à feuilles garnie d'un nombre infini de petites étoiles, paroit ici, \& mérite bien par fa beauté $I$

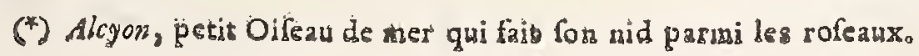


F)igur vurgegeiget, und fie if merth, bas boir fie genauer betrads.

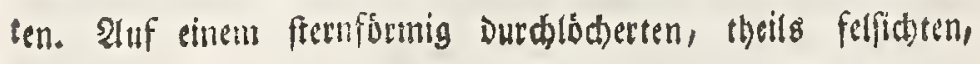

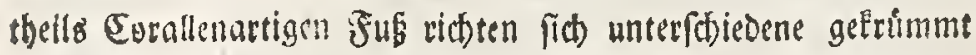
an einander frebenoe breite Blatter in Die Spible, welde eine fols

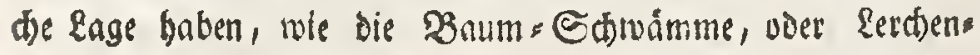

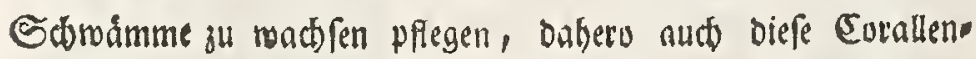
Daffe den $\mathfrak{R}$ amen Madrepora agaricites fúbret. Diefe Blấts

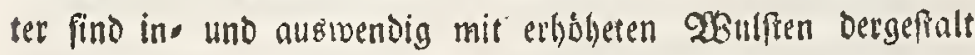

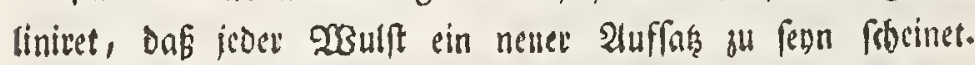

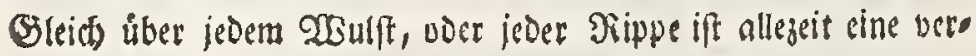
tiefte Furde, in woldser ein jierlid)er Stern in einer vrbentlidsen Sinie an bem anoern frebet. Diefe Sterne beffehen aus lautet ungemein feinen Blattertben, weldse in Der Jimoung feken,

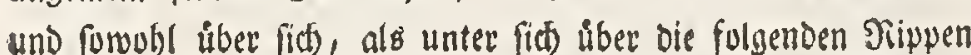
bin, uno in bie andere Sielibe Sterne linein laufferi, $\partial a \mathfrak{B}$ Da. burch ble ganze Naffe won allen Seiten fely: zart liniret gle feon 伍etnet. Beq dem \&nbrud) fiehet man, dab bie Sterne von beyben Seiten nidit gang bis in die Mitte Der $\mathfrak{B}$ tâtter Dringen, die Biátter felbft aber find von Der nemliden. Didtigkeir, voer von eben foldeen Beftandthellen, whe bie harten meiffen Eurallen, bie in den Officinen gebraudtet werben, uno baben mit den bicfen

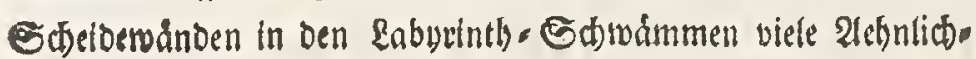
Eeit. SGre 2abweidfungen in Der $\mathfrak{E}$ age Der $\mathfrak{B}$ låtter fino ungeo mein mannlgfaltig; ja man trift ole nemliche 2 trt als flacte Yfannenkuden, woer Feller, ober aud mie ein fucus fimbriatus an. Der Farbe nact fino fie, wie befe mets, voer gelb, oder blau, oder aud faft fitroar. Zumeilen fino aud) Bact. Peine, Duftheln, uno anbere Córper mit Der nemlichen Diaffe, als mit einer Deate übergugen.

Fig. 2. Diefe Figur fellet eine geboppelte und um einander geftulungene Wourm=Róbte vor. Sie ift volleumen colin, orifक, inwendig róthlich und.glatt, eines Fingers bice, uno mit einer milleporen = Maffe incruffiret uno überjugen, woran fict nac) Int ber פMilleporen Eleine \&eftgen befinben. Unten werben bie Sioffren teeiner, of fie aber julegt in eimander laufen, laffitet

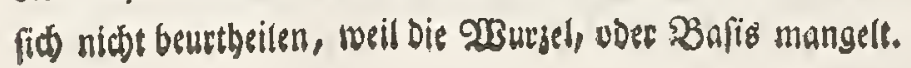

Fig. 3. Son Den baumformigen Mabrepoten befinbet fitit aulbier eines Daumens dicles Stúck bon einem aft, weldter eine befonbere $\mathfrak{A n t}_{\text {ju }}$ erEennen giebt. Denn es befechet bie \$iaffe nidt nur aus einem gand ungemein freinbarten $293 e$ en; fondern if über Dies mit fegt fetnen tief bineingshenden Sterndien verfether, fheinet aud nidt bon Der Ant Der Madreporæ abrotonoides ju fegn, weil an berfelben bie Sternden nur in ben Sisctern, ble auf Der Oberfådre fitgen, gefunden werben, bier aber bringen fie faft bis an Den Rern Durt. Won eben biefer Aint giebt es Curallen.

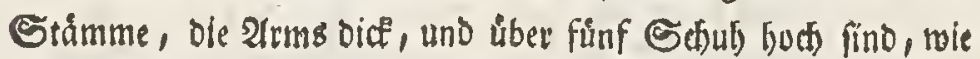
biejenigen uns verfictern, bie fie in ben zencillen gefeben baben. extraordinaire d'ètre confidérée de près. Diverfes feuilles larges \& courbées, pofées l'une à côté de l'autre, s'élévent fur un pied percé en forme d’étoile, qui tient autant de la nature du rocher, que de celle d'une Maffe coraline, poftée de la même façon que croiffent les Champignons d'arbre, ou les agarics, ce qui a fait donner à cette pièce le nom de Madrepora agaricites. Ces feuilles font garnies en dedans \& en dehors de bourrelets élevez, rangez en lignes, de façon que chaque bourrelet femble avoir ête pofé comme une pièce nouvelle fur celui qui le précède. Au deffus de cha. que bourrelet, ou de chaque côté, fe voit un fillon fur lequelfe trouvent plufieurs étoiles fines rangées au cordeau. Ces étoiles ne font compofées que de petites feuilles extrèmement fines pofées en rond, qui tant au deffus qua au deffous, paffant d'une côte à l' autre, vont fo joindre à la rangée fuijvante d'étoiles, \& font paroître la Maffe comme étant marquée finement de tous les côtez d'étoiles à la ligne. L'on remarque à l'entamûre que ces étoiles d'un côté comme de l' autre ne pénétrent pas jusques au milieu des feuilles; mais les feuilles en elles-mêmes font tout auffi compactes, \& compofées de la même fubftance que les Coraux durs de couleur blanche, dont on fe fert dans les Apoticaireries, \&z ont beaucoup de reffemblance avec les parois mitoïennes épaiffes des champignons à labyrinthe. On trouve beaucoup d'anomalies \& de variations eû égard à la pofition des feuilles. Car il y en a de cette efpèce qui ont la figure d'une omelette platte, ou d'une affiete, ou auffi celle d'un fucus fimbriatus, ou mouffe de mer bordée. Quant à la couleur, ces Plantes font ou blanches, comme celle - ci, ou jaunes, ou bleuës, ou quelque fois presque noires. On rencontre par fois des briques, des coquilles, \& d'autres corps couverts de cette même maffe, comme d'un enduit.

Figure 2. Ceci repréfente un tuyau à ver, double छ̋ entrelacé. Sa figure eft entièrement cilindrique. La pièce eft intérieurement rougeâtre \& unie, épaiffe d'un travers de doigt, \& incruftée, ou cotverte, d'une Maffe de Millepores, où l' 'on trouve des petits rameaux, comme on a coûtume de les rencontrer aux Millepores. Les tuyaux deviennent plus petits en bas, mais nous ne pouvons décider fi à la fin ils fe réuniffent en un feul, parceque la racine; ou la bafe nous manque.

Figure 3. Nous produifons ici une pièce de rameau d'un Madrepore en arbriffeau, épairfe d'un doigt, qui nous découvre une efpèce particulière de ces fortes de Coraux. Car cette Maffe a non feulement une fubftance extraordinaircment dure, à l'égal de la pierre, mais elle eft auffi garnie d'étoiles trés-fines, qui pénétrent fort avant dans la pièce, \& de plus elle ne peut être regardée comme une Madrepore d'Auronne, parcequ'à celles de cette efpèce on ne trouve les étoiles que dans les trouffes, qui font vifibles à la fuperficie, au lieu qu’à la préfente pièce les étoiles percent pres. que jusques au coeur, ou à la moëlle. J1 y a des troncs de cette efpèce gros Łomme le bras \& hauts de plus de cinq 
pieds, à ce que nous ont affüré ceux qui prétendent en avoir vû de pareils aux fles Antilles.

Fig. 4. Zun nid)t minterer Eeitenbeit ift diejenige Pugelo formige Madrepora, reelde wir bier yor und feben. Die 28 ste

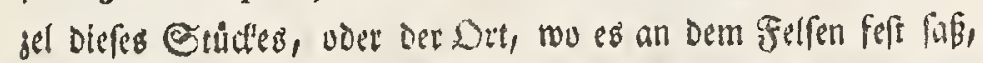
if nidtet groffer, als ein Durate, son ba an aber ift Der gange

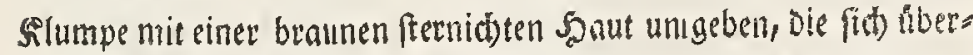

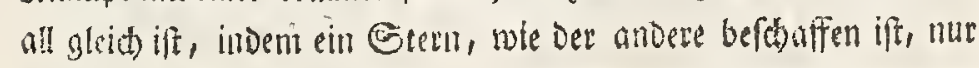
frehen die 'Eterne am Driginal viel Didter' beyfammen, io, Daf gleichfam ein Etern aus Dem andern fieff... Dell Durd) par. gung einer ábnlicten \$raffe baben twir gefunden, daf Die Eeterne oun allen Eeiten Strablen nach ber Trsurjel gu madten, und baß einer peinen lurfiprung aus Dem anderen befummen babe.

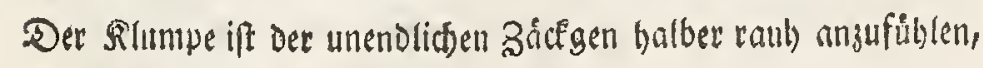
Denn es hat jebes Sternden noubl vier und jwangig Bhätterthen, und jedes Blat iff fein und faft unfictbtbor gesactet. Es giebt

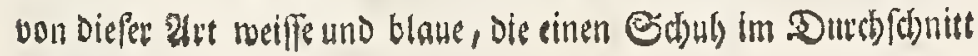
balten.

\section{TAB. A. XI.}

Fig. I. 2. Writ haben bereits bey Der Tab, A. IV. fig. I. exllokret, wab wir unter Cerebrites uno Lithocerebrum verften ben. Die gegentråtrigen Figuren 1,2 , zeigen uns nun ein Ders gleldsen fonuthl wun Der untern als ubern Cetite. Dan trift faft unter alten Corallen. Maffen feine fo prát)tige und reişend

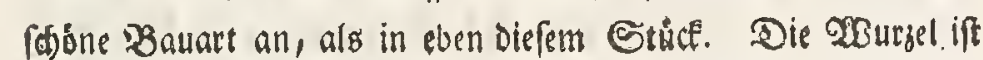
nicbt über Singers dict, etwas erbaben, verluften feernformig, uno giebt allenthalber affigraue Strablen ab. Snnwenotg ift bie ganje Maffe blátterid), Duch trift man Darin, wie in anderen Saburint theteinen, eine bickere und in weiten Bugen burdseinan. Der berumlauffende Edjeidemand an. Diefe Sdeidemand

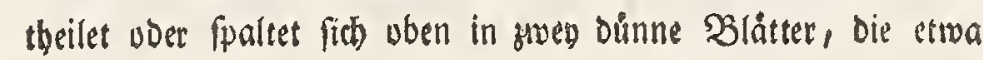
vier \&inien reit von einander frehen, und allenthalben mit einan Der parallet in vielen $\mathfrak{B u g e n}$ berum laufen. 2en Diefen ounnen

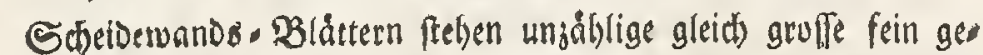

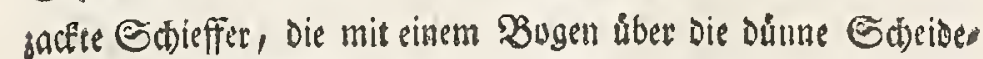

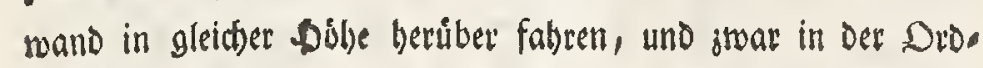
nung, Daß Diejenigen Sdieffer, die fif an Der einen Edyeides want befindern, mit den andern Sddieffern fo an ber andern pas

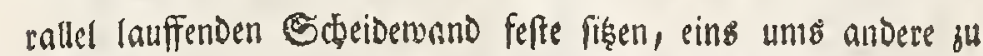

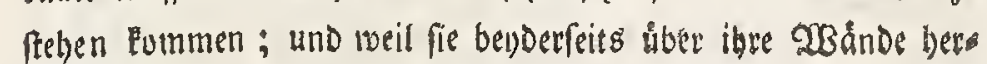
uber furingen, einander allegeit etwas vorbey fabren.

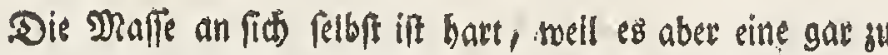

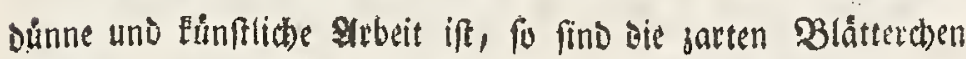
siemlid brétig. Shan trift fie, (aber ungemein felten,) einen
Figure 4. Une rareté, qui n'eft certainement pas de moindre prix, c'eft la Madrepore en boule, que nous voyons dé. peinte ici. La racine de cette pièce, ou l'endroit par lequel elle fe trouve attachée au rocher, n' eft pas plus grand qu'un Ducat, mais de là toute la Maffe eft envelopée d' une peau brune, toute parfemée d'étoiles, \& par tout égale, les étoi. les étant abfolument femblables l'une à Pautre. Il faut pour. tant avertir ici le Lecteur qu'a l'original les étoiles font beaucoup plus près l'une de l'autre qu'à la figure, \& femblent même naître l'une de l'autre. Et en effèt en fciant en deux une Maffe pareille, nous avons trouvé que de tous les côtez les étoiles jettent des rayons vers la racine, \& que l'une a tiré fon origine de l'autre, La Maffe eft rude à tou. cher, \& cela provient d' une infinité de pointes, qui y font, car chaque petite étoile a bien vingt - quatre petites fevilles, \& chaque feuille eft dentelée, quoique ces dens foient furt fines \& presqu' invifibles. Il y a des pièces de cette efpèce, qui font blanches, ou bleuës, \& qui ont jusques à un piê de diamètre.

\section{PLANCHE A. XI.}

Figure 1. \& 2. Le Leeteur aura ta bonté de fe fouvenir qu'à l'occafion de la prémière figure de la Planche A. IV. nous avons expliqué ce que nous entendons par Cerebrites $\& z$ Lithocerebrum. Les figures $1 . \&$ 2. de la préfente Planche nous font voir comment eft fait un Corail de cette efpèce en haut \& en bas. La ftrueture en eft pompeufe \& belle á ravir, \& de toutes les Mafres coralines, il n'y en a point qui puiffe être comparée à celle-ci, relativement à la beauté de la conftruation. La racine n'a pas plus d'un travers de doigt d'épaiffeur', elle eft un peu élevée, formée à la verité en étoile, mais un peu ufée, \& lance de tous côtez des rayons, qui font de couleur cendrée. Au dedans toute la Maffe eft feuilletée; cependant on y trouve comme à d'autres pierres à labyrintbe une paroi mitoïenne un peu plus épaiffe, \& qui en fait le tour en arc en s'entrelaçant. Cette paroj mitoienne fe partage en haut en deux feuilles minces, éloi. gnées l' une de l'autre à peu près de quatre lignes, qui font le tour en plufieurs arcs, mass toûjours en parallèle. On remarque à ces deux feuilles minces de la paroi mitoïenne un nombre infini d'écailles finement dentelées, de grandeur égale, qui dépaffent en arc la paroi mitoienne mince en même hauteur, \& cela dans un tel ordre que les écailles qui tien. nent à l'une des parois font pofées alternativement avec les écailles attachées à l'autre paroi parallèle, \& comme elles paffent les unes \& les autres leurs parois, il en refulte qu'elles fe dépaffent aufil reciproquement quelque peu entre elles.

La Maffe en elle mêtme eft dure, mais comme les piéces, dont elle eft compofée font extrèmement minces, \& fine. ment travaillées, les feuilles délicates, qui en font partie, font
I 2 


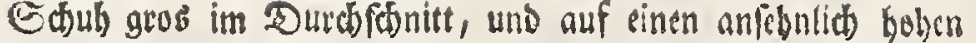
Stamm, oder 23 Burgel an. Etlicbe fino aud) son getber Farbe.

Fig. 3. Diefes Etald if won ber nemliten ant, als bey Der britten Figur Der vorigen fiupfertafel if befobrieben worben. Siur treffen mir bier einige rotbe Glecten an, Dergleidjen fith offers an Curaden. Siaffen zeigen, und wobon wir nur baben erinneren wollen, Daf felbige nidts aubers, als eine Efchara millepora minima cruftacea fino. Sn biefer Efchara befinoen

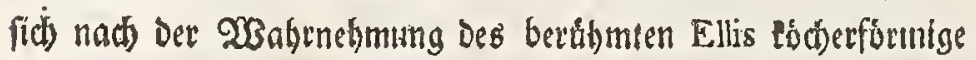
bablten, bie alle in einerley Dronung und faft warallel neben ein. anter ftethen, und find oft bee Corallen gand bite Damit befeset.

Hitg. 4. Bun Den Milleporis haben mir oben im Befdreibun's Der Tab. A. II. fig. 3. gefaget oaf ettlid)e in vielen breicen Lap: pen beftehen, die triedetum in tleinere Rappen und 251 tex unterfhieden fint. Daв Exemplar, melater wir in biefer Figur bor uns felben, iff bon ber $2 \mathfrak{n t}$, unb folglid eine Millepora lobata, befonders nethemen fict bie Blätter, Deren oft viergis auf einem Stamm beyfammen feelyen, und zuweilen munderbar ges bugen fino, fefry beraus. Diefe Ant ift er vorgúglich, Baran die Pori, whe fthen an ubgedacteren Dot ift gefagt worben, in ela nem urosutliden Günfect frehen, uno ob gleid) Die Sberfidcte

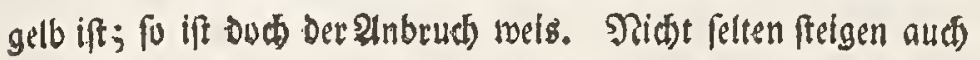

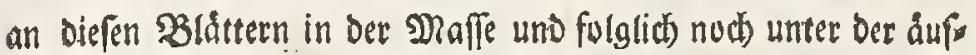

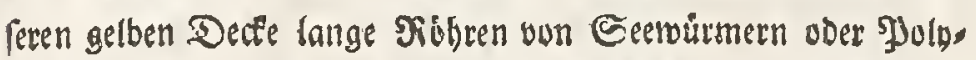
pen binauf, fis bas man bon auffen die Pscherformige Erlbothung

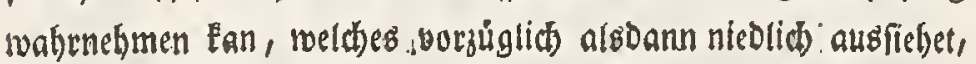

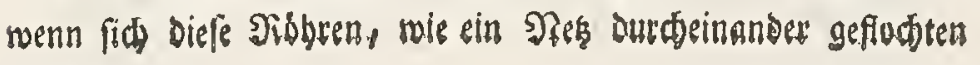
babero.

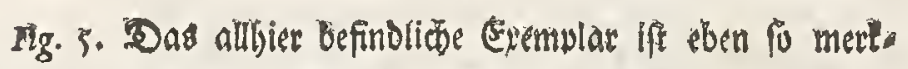

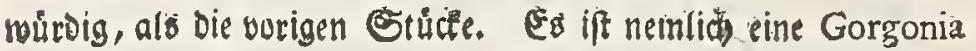
fimpliciffima recta von einer Subftanz, wie Die Surncuralle, buch fo hart, wie bie adtete Steincuralle, uno gleidfam mit ber nemlitsen Shaffe Durdborungen. Der 2unbruct) seiget einige Singe und einen Sern, wie ein Şulb, und auf Der Dberfläche zeiget fict) ein bråuntidter Flecten, Der einem aft in einem bar.

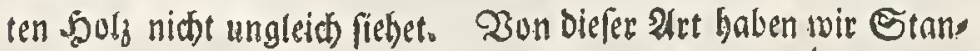

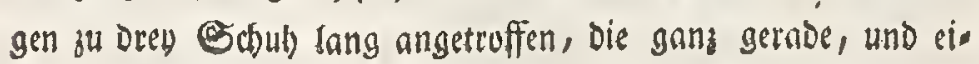

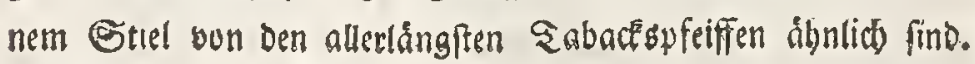

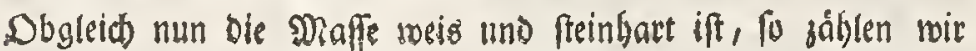

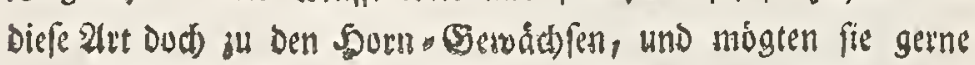

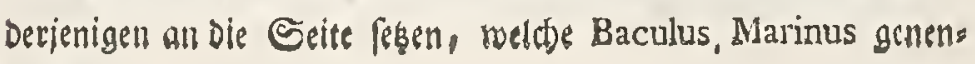
net rirt. affez fragiles. On en trouve, qui ont un pied de diametres (mais cela eft extrèmement rare) \& qui font pofeés Lur une racine ou tige de hauteur confidérable. Il y en a aufis de couleur jaune.

Pigure 3. eft une pièce femblable à celle dont nous avons donné la defcription en parlant de la troifième figure de la Planche précedente. Ce qui fé trouve ici de plus, ce font quelques taches rouges, qu'on voit affez fouvent fur d'autres Maffes Coralines, dont nous dirons feulement qu' elles font ce que les Auteurs apellent Efcbara millepora minima cruftacea, c'eft-à-dire, la plus petite Aillepore à cronte galeufe. Le célèbre Ellis remarque qu'il y a à cette Efchara, ou Cronte galeufe, diverfes cavitez faites en trouffe ou en gaine, toutes arrangées dans le même ordre \& presque en ligne parallèle l'une à côté de l'autre, dont les Coraux font couvent garnis en grand nombre.

Figure 4. Nous avons dit cy-delfus en parlant de ia troifième figure de la Planche A. II. qu'ily avoit quelques Millepores compofez de plufieurs larges lambeaux, lesquels fe fub. divifoient en d'autres lambeaux \& feuilles de moindre grandeur. Cette figure - ci repréfente un Corail de cette efpèce, qui par conféquent doit être nommé Millepora lobata, ou Millepore lambeaux. Les feuilles, qui fe trouvent fouvent au nombre de quarante fur une même tige bizarrement recourbée, s'etendent confidérablement: C'eft principalement cette efpèce, où les Pores, comme nous l'avons dit au lieu cité, font difpofez en Pentagone regulier, \& quoique la fu. perficie en foit jaune, l'entamure ne laiffe pas d'être blanche. L'on remarque affez fréquemment au dedans de la Maffe de ces feuilles, \& par conféquent encore au deflous de la couverture jaune, de longs tuyaux de Vers de mer, ou de Polypes, dont la hauteur eft aperçùe au dehors en forme de trouffe, ce qui ne produit jamais un plus bel effet i la vî́ë, que lorsque ces tuyaux font entrelacez à la façon des rêts.

Figure ५. Voici une pièce, qui eft tout aufí remarquaBle que les précèdentes. C'eft une Gorgonia fimplicifima ređa , d'une fubftance pareille à celle des Coraux de nature de corne, \& cependant auffi dure que celle des Coraux pierrreux, de laquelle cette pièce-ci femble avoir êté imbi. bée. On voit à l'entamûre quelques anneaux \& un coeur ou moëlle, comme au bois, \& l'on peut obferver fur la fuperficie une tache brunâtre, qui reffemble beaucoup à un noeud, tel qu'on en trouve au bois durr. Nous avons vu des pièces de cette efpèce, longues de trois pieds, droites comme un jonc, \& femblables à un tuyau de pipe extrèmement long. Quoique fa Maffe foit blanche, \& dure comme de la pierre, nous croyons pourtant que cette pièce doit ètre mife au rang des Plantes de nature de corne, \& qu'on pourroit Ia mettre à cóté de celle qui porte le nóm de Baculus màrinus, ơ Bâton de mer.

PLAN. 


\section{TAB. A. XII.}

Fig. I. Eleichnic es Keratophyta fruticofa unb ramofa,

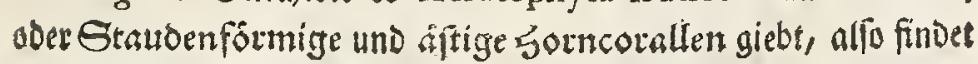
fich audh eine ungemein fibune (Sjattung, weldbe flabelliformia, woer fâcherfortmige genennet werben. She Structur if fonderbar. E⿺ gehen nemlid aus einer breiten faft lederartigen, und nuв un.

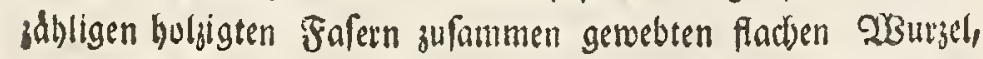
bie wben auf tem Selfen anfitset, unterfojiedene, mit einander ver

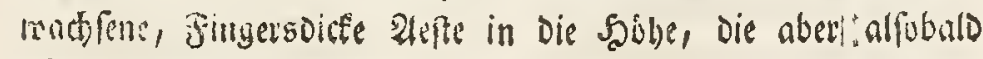
búnuer werden, fid yon einander foseiden, und in einer geraden Flådbe bis in bie Epiręen hinauslauffen. Diefe Dauptâfle, weldse fidt) oben in Der Dicfe elnes Fadens endigen, geben auf beyoen Seiten Pebenáfte in Der Dicfe eines Febertiels ab, bie bis an ben Fiand mit einer zarten Spise ausgelyen, und alle flach) wie ein Fådber liegen. Siunmehro aber fteigen aus Den

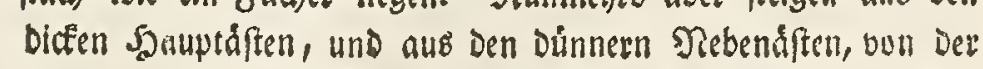
203urjel an, bis jur Splse und nadb bevden Seiten binaus, eine

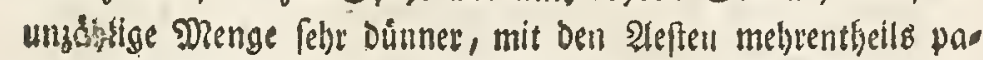

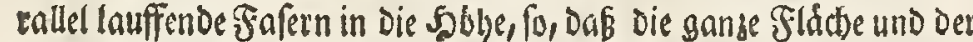
Tiaum jwifchen uno ju Den Ceiten Der S.auptôfre Damit angefültet

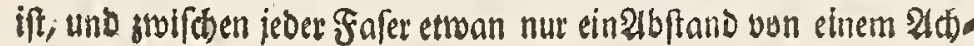
tele \& Boll leer bleibt. Diefe paraliel lauffende Bafern und \&efte merden fooann oun unten auf, bis an Den Siand, mit nod feir nern quer liegenden gafern verbunden, bie alle aude einen 2(t)

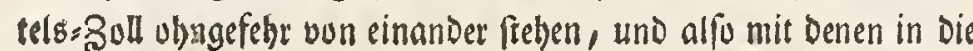

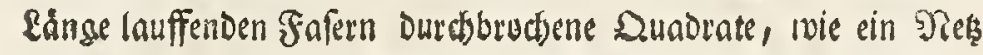
machen, yon welder Structur man fith gleich einen Bgrgvil maden Ean, wenn man einen neşfótumigo geftricteten feloenen Gelobeutel aubeinander jerret.

atle biefe Gafern liegen nun ordentlider arseife fiad, mie

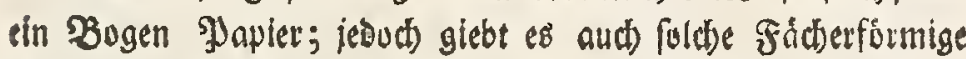
Corallen, Die binten uto vorne mitten aus Den Ileferen Eleine uno

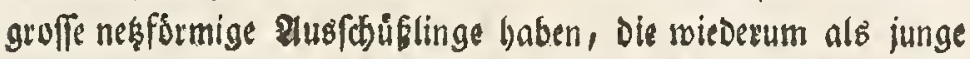

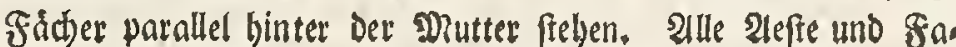
fern fino burnartig, Dunfelo braun, nach Dem Dánneren Fande

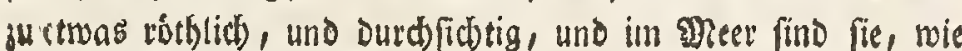
alle Keratophyta, meich) wie Reoer, biegfam mie \$ुJeitfocen, und potranten mit ben $23 s e l l e n$.

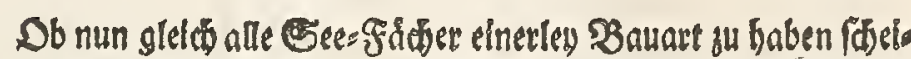

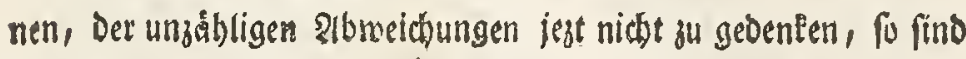

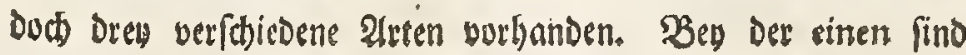
alle 2lefte und Fafern mebrentheil\$ runo. Ben ber anderen find die 2lefte und Fafern platt gedructe, und jwar fo, Daß ficf

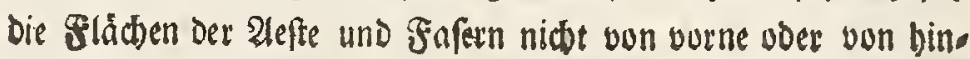

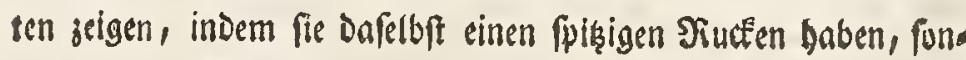

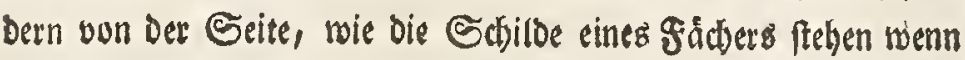
Derfelbe jugefilagen if. Bey Der britten aber fino die Aefte

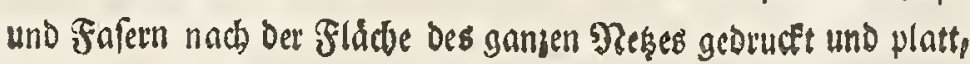
fo wie Die Schilde eines Fáderb liegen, wenn er aufgemadt

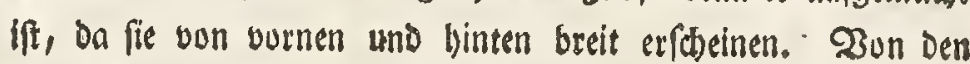
beyden lejteren 2rten wirb eime Gorgonia Ventalina, und die andere Gorgonia Flabellum bey den berúhmten SRitter Rinnåus

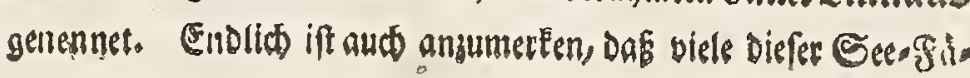

\section{PLANCHE A. XII.}

Figure I. Tout comme il y a des Keratophyta frut:cofa 80 ramofa, ou des Coraux formez en arbuftes E brancbus, de mề. me il s'en trouve une efpèce tout - à-fait belle, qu'on nomme flabelliformia, ou faits en éventail. La ftructure en eft trés - particulière. La racine en eft platte, large, compofée d' une maffe coriace, \& d'une infinité de filamens de la nature du bois, \& attachée au haut du rocher. On voit partir de cette racine divers rameaux, qui s'entrelacent en croiffant, épais d'un doigt d'abord, diminuant bientôt, qui fe féparent après, \& pouffent enfuite en droite ligne jusques enhaut. Ces rameaux principaux, qui à l'extrèmité fupèrieure ne font pas plus épais qu'un fil, fourniffent auparavant des branches de l'épaiffeur d'un tuyau de plume, qui vont aboutir au bord en une pointe fine, \& font toutes plattes, comme les côtes d'un éventail. De là l'on voit s'élever un nombre infini de filamens extrèmement minces, qui fortent tant des gros rameaux que des moindres branches, \& s'étendent júsques à la pointe \& des deux côtez, allant le plus fouvent en ligne parallèle avec les branches, \& rempliffant tous les efpaces, de forte qu'il ne refte toûjours entre deux filamens qu'un petit vuide d'environ la huitième partie d'un pouce. Ces filamens, de même que les branches avec lesquelles ils font difpofez en ligne parallèle, font traverfez par d'autres filamens encore plus fins rangez horizontalement, aufi dans la diftance d'un huitième de pouce l'un de l'autre, ce qui forme une quantité de petits Quar. rez femblables à ceux des filits, fous lesquels on prend les oifeaux. Pour fe faire une idée jufte de cette ftrukture, il n'y a qu' à prendre une bourfe de foie tricotée en rêts, \& z̀ en écarter les mailles en la tirant comme pour l'étendre.

Tous ces filamens donc font regulièrement pofez à plat, comme une feuille de papier; on voit cependant des Coraux de cette efpèce formez en éventail, où quelques rejettons tant grands que petits, zuffi faits en forme de rêts, fortent du milieu du branchage, \& fe rangent de même en ligne parallèle derrière la Plante-Mère, comme autant de jeunes éventails. Tous les rameaux, branches, \& filamens font de nature de corne, de couleur brune foncée, un peu rougeâtre vers le bord où ils font plus minces, \& trans. parens. On obferve que dans la Mer ils font, comme tous les Keratopbyta, tendres comme du cuir, flexibles comme une gaule, \&z que les ondes de la Mer les agitent.

Or quoique tous ces éventails marins femblent être de fructure égale, fans parler des variations innombrables, qu on y rencontre, il eft à remarquer qu'il y en a principale ment trois efpèces. A l'une tous les rameaux \& filamens font le plus ordinairement ronds. A la feconde les mêmes Rameaux \& Filamens font comprimez \& plats, \& cela-de façon que la partie platte des rameaux \& des filamens ne parô̂t ni devant ni derrière, où l'on ne voit que du tranchant, mais feulement de côté comme les Côtes d'un Eventail, quandil eft fermé. Mais à la troifième efpèce les Rameaux \& les filamens paroiffent comprimez \& plats dans toute l'étenduë de la figure, comme on voit les cótes d'un éventail, quand il eft entièrement ouvert, de forte que la Plante fe préfente auffi large par devant que par derrière. Des deux dernières efpèces le celèbre Chevalier Linnaus nomme l'une Gorgonia Ventalina, \& l'autre Gorgonia Flabellum. Enfin il y a encore à remarquer que beaucoup de ces Eventails marins ont une K 
Wer mit, uno biele olyne einer glolypen Sinde voer Efchara bie viederum manill juli ig ift, gełunden werden.

WBas nun Dasjenige Exrmplar betrift, fo in Diefer Figur vorgezeiget wiro, fo fino Die Aefte melhrentheils runo, inwendig

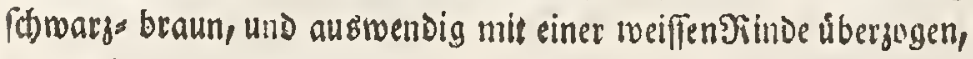
in melterer fich Dzillionen Rosthertben zelgen, Die in einem gewiffen

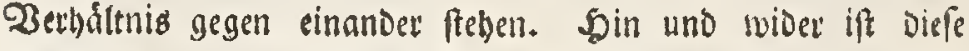
rinde abgefallen, weil fie fich febr teidft abfundert, und wann fie truct:a ift, foly bald abbrocfelt. Sain und wicier trift man audt) beraustrettenoe und boppelte $\mathfrak{B}$ látter an, weldhe aus Der Dritte Der andern Xefte feitwárts betaus wadpen.

Fig. 2. Segenfuartige Corallina reticulata befeefet aus einem nesformigen Siemebe einer zarten bornartigen Curalle, welo We aus lauter fidwarzen Fafern beftehet, und mit einer purpur. rothen Efchara tuberiogen iff. Diefe Efchara beftelyet aus lau ter eins ums andere und in vier Sieifen didte an einander gee fektten 238 árgen, Daber die Safern alle vierectigt erfiteinen. In

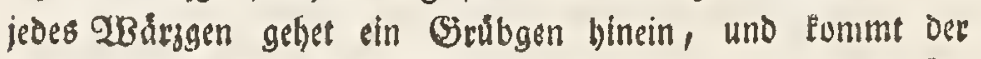
Etructur nach mit Der Efchara úberein, die mir Tab. A.V. fig.

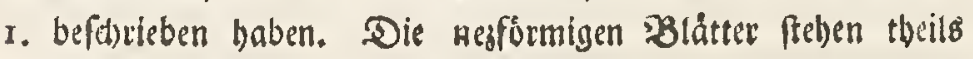
flach), theilz find fie aus den andern in bie Suere heraus gewat). Fen, und, werden aud Deswegen Ger . Zouquetgen genannt.

\section{TAB. A. XIII.}

Fic. 1. Da mir faton bed der burhergelenden Safel eine meitlåuftige Beftoreibung von Den Seergdddern gegeben haben; fo ift oun bieferm meiter nidats anjumerfen, als Das er aus vies Ien bicfen fotrarzen Stámmen beftelle, die an Den dufferfien Episęen roths braun find, bermutblith aber audi mit ber Beit Dafelupt fdwarz werben. Es bat Diefes Ejemplar gar Feine

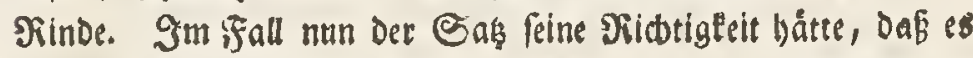
gar keine Syorngewdede be Natur gebe, Die leine Sinde baben, weil biefelbe ibnen gleidffam zur Şaut bienet, ( muran mir buch) aus vieles Urfacben zweiffeln) fo hat Diefes Evemptar die ßinde Durch einen Sufall verrobren. Denn es if uns nidts unbelannt,

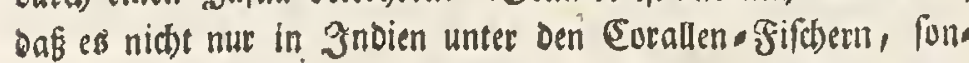
Dern auch mürelith unter Sammlern in Europa Jjerfonen gebe, Die diefe 3at Eorallen mit der gróften Sorgfalt und mit ausneid mendem Eifer von iheern Unrath, (wie fie es nennen, ) fäubern, und mit Bürffen puşen. Es gehóret aber diefes 3 erfabren un ter die Súnoen der Unwiffenbeit.

Fig. 2. Diefer Eleine Seterfäber if megen der goldgelben simbe oder Efchara ju betractiten, indem biefeftee fict toie eine lederartige Saut um die 2effrgen und Fafern angeleget bat. In

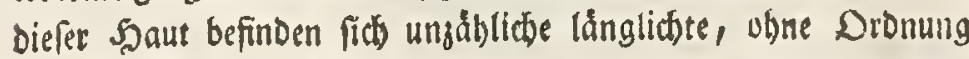
ftehende Sodser, als ob fie mit einer Stectnadel eingeftucben rodren, Daher die Efchara unter die Milleporen gehoret. Sie reiro jutweilen roth, jumeilen aber aucb viofetfárbig gefunden.

\section{TAB. A. XIV.}

Fig. I. Den Befdluk aller Eurallen - Berwdafe madit endo

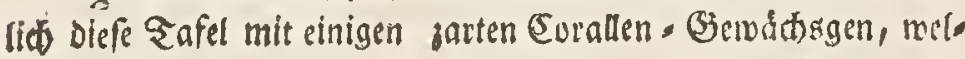
de am ßurgebíng Der guten Sofnung, und in Den Deeren, um
Ecorce de Polype, ou Efchara, \& que beaucoup d'autres n'en ont point, \& que cette écorce a auffi fes variations.

Quant à la pièce dépeinte dans la préfente figure les rameaux en font pour l'ordinaire ronds, de couleur brune tirant fur le noir au dedans, \& au dehors couverts d'une Ecorce blanche dans laquelle on obferve un million de petits trous difpofez \& arrangez entre eux, dans une certaine proportion. Par - ci par - là l'écorce en eft tombée, parce qu' elle fe fépare facilement du tronc, \& fe brife par morceaux, lorsqu' elle eft sèche. On rencontre auffi fur cette Plante des feuilles doubles, qui fortent du milieu des autres branches, s'étendant vers les côtez.

Figure 2. Ceci eft ce qu'on apelle Corallina reticulora, ou Coraline en rêts. C'eft un Corail fin de nature de corne, tiffu en forme de rêts tout compofé de filamens noirs, qu' une Efcbara ou Croûte de couleur de pourpre enduit. Cette croûte eft couverte de r etits boutons difpofez alternativement en quatre rangées, \& fort ferrez les uns contre les autres, ce qui fait paroître tous les filamens en figure quarrée. Une foffette entre dans chaque petit bouton, ce qui fait reffembler cette Efcbara à celle que nous avons décrite cy-deffus Pl. A. V. fig. I. Les feuilles formées en rêts paroiffent en partie à plat, \& en partie elles fortent des autres en travers. La figure qui refulte de là a auffi fait don. ner à cette piece le nom de petit bouquet de mer.

\section{PLANCHE A. XIII.}

Figure r. Comme à l'occafion de la Planche précè. dente nous avons donné une ample defcription des Eventails de Mer, nous n'aurons pas beaucoup à dire de cette piéçe-ci, fi ce n' eft qu'elle confifte en quantité de tiges épaisfes noires, qui aux extrémitez de leurs pointes paroilient d'un brun rougeâtre, à quoi probablement la couleur noire auroit auffi fuccèdé avec le tems. Cette Plante n'a point d'écorce du tout. Ainfi en admettant l'hypothè'é qu'originairement il ne croît point de Plante de nature de corne qui n'ait fon écorce, laquelle leur fert de peau pour ainfi dire (ce dont nous doutons cependant par plufieurs raifons), il faut qu'on fupofe auffi que la prèfente pièce a perdu fon écorce par quelque accident. Car il ne nous eft pas inconnu que non feulement aux Indes quelques Pêcheurs de Coraux, mais auffi en Europe quelques Collecteurs de Curiofitez naturelles, ont grand foin \& fe peinent pour nettoyer cette efpèce de Coraux de ce qu'ils nomment leurs ordures, \& les broffent bear. coup dans cette vûë, procedé qu'on ne peut fe difpenfer d'apeller un péché d'ignorance.

Figure 2. Ce petit Eventail de mer eft remarquable par fon Ecorce, ou Efcbara couleur d'or, qui envelope les branches ou filamens comme une peau, ou comme un cuir. On obferve fur cette énvelope un nombre infini de trous oblongs difpofez fans aucun ordre, qui femblent y avoir êté piquez avec une épingle. On met par cette raifon cette Efchara au rang des Millepores. On la trouve auffi quelquefois rouge, \& quelquefois violette.

\section{PLANCHE A. XIV.}

Figure $\mathrm{x}$. Nous allons finir nos defcriptions des Plantes Coralines par quelques petites piéces fines qu' on trouve au cap de bonne espèrance, \& dans les Mers qui environ- 


\section{量 盟}

Der Evige son Africa berum, gefunden merben. Dabjenige, toas biefe Figur vorledtet, ift eine zarte roth und gelbe Sautneor ralle Deren Spiggen bhafenformig uno febr fein find. Die Aeftgen find theils gegen einander über, theils eills umb andere verglievert und faft burdjictig.

Fig. 2. Jit ein Dergleichen Keratophyton, aber nur Der

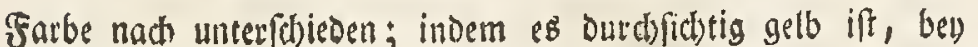
Den Sduriftefellern aber Den Namen Keratophyton album tenuiter ramofum apicibus bullatis füfret.

Fig. 3. Diefer Fucus longifoliis fimbriatus, ift gtwar von nemlider burnartiger Subftand, aber ungemein breit, und

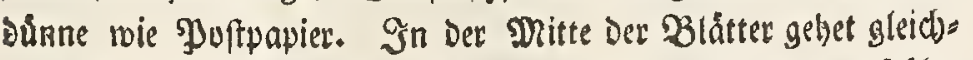
fam ein Siem in Geftalt elner weislidten Fafer in Die Şobe. Im Siande firen überaus feime Bdffgen mit blafenformigen Sinopfgen. Diefe Eoralle if ebenfalls surdefidstig uno fleifd. fárbig.

Fig. 4. Faft oon eben Der ant ift auch Diefer Fucus, nur fino bie $\mathfrak{B l a t t e r}$ breiter, baben leine fajericbte 2(ber, fondern

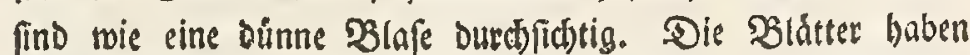
Eeine Bacten, fondern find eingelerbt, und tberall, roo Die Ferbe bineingebet, fiset eine Blafe, uber ein Snutgen. Die Farbe if braun=roth. 2uf Der Oberfiche Deb Blats hat fich eine gan: feine Sertularia, Deb Siitters Linnæi Lichenaftrum, angeféget.

Fig. ร. Enditis madt nods cine Sertularia pennata folli.

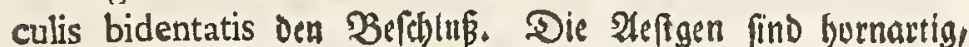
fotwars, eins uns andere vergliedert, Dânne, und oben an einer

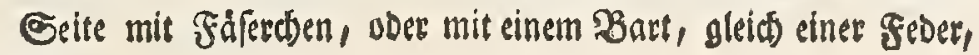
berejt.

Diefes feg genug zu einem Dufter ber Sauptanten Des

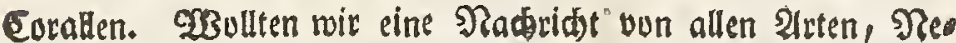
benarten und Abweid)ungen geben, fo thiffen wis sin ganges פus Dawon fotreiben. nent la pointe méridionale de l'Afrique. Celle que la prés. fente figure dépeint eft un Corail de nature de corne de ftructure fine, röuge \& jaune en couleur, dont les petites pointes font formées en vefies, \& extrèmement fubtjles. Les petits rameaux font en partie arrangez les uns vis - à - vis des autres; quelques uns pourtant font entrelacez \& joints enfemble par des articulations. Ils font presque transparens.

Figure 2. eft un Keratopbyton de la même efpèce. Il ne diffère du précèdent que par la couleur, car celui-ci eft jaune \& transparent. Les Auteurs l'appellent Keratopbyton album tenuiter ramofum apicibus bullatis, c' eft - à - dire, le Corail de nature de corne blanc à rameaux minces $E$ a a pointes qui fe terminent en vefle.

Figure 3. Le. Fucus longifoliis fimbriatus ou Mouse de mer à longues feuilles $\mathcal{G}^{\circ}$ bordée, eft à la verité aufí d'une fub. ftance pareille à celle des autres Végètaux de nature de corne, mais il différe des précédens en ce qu'il eft extraordinairement large \& mince comme du papier de pofte. Au milieu des feuilles il s'éléve une efpèce de coeur ou de moëlle, comme un filament blanchâtre. Des dens trés - fines bordent ces feuilles \& font garnies de petits boutons femblables à des veffies. Ce Corail eft également transparent $\&$ couleur de chair.

Figure 4. Voici èncore un Fucus, qui eft spresque de la même efpèce, cependant fes feuilles font plus larges, \& on n'y remarque point de veine en forme de filament, car elles font transparentes comme une Veffe mince; elles ne font outre cela point dentelées, mais entaillées, \& à chaque entaillure il $y$ a une vefie, ou un petit bouton. Une fertularia trés - fine, qui elt lè Lichenaftrum du Chevalier Linnaus s'eft pofée fur la fuperficie de la fcuille.

Figure s. Enfin une autre Sertularia pennata folliculis bidentatis, Sertularia (*) a barbe de plume EO petites vefles fur deux pointes ferme ici la marche. Les rameaux en font de nature de corne, noirs de couleur, à articulations qui fe fui. vent, minces, \& garnis en haut d'un côté de barbes telles qu' on en voit aux plumes.

Ce que nous avons dit jusqu'ici fuffit pour donner ¿ nos Lecteurs une idée des plus belles, des plus rares, $\mathscr{E}^{\circ}$ des principales espèces de Coraux. Si nous entreprenions de parler de chaque efpèce \& fous-efpéce en particulier, de même que de toutes les anomalies \& variations qu' on rencontre nous nous mettrions dans le cas d'écrire des volumes.

$\left({ }^{*}\right)$ Sertularia eft une efpece de Mouffs marige.

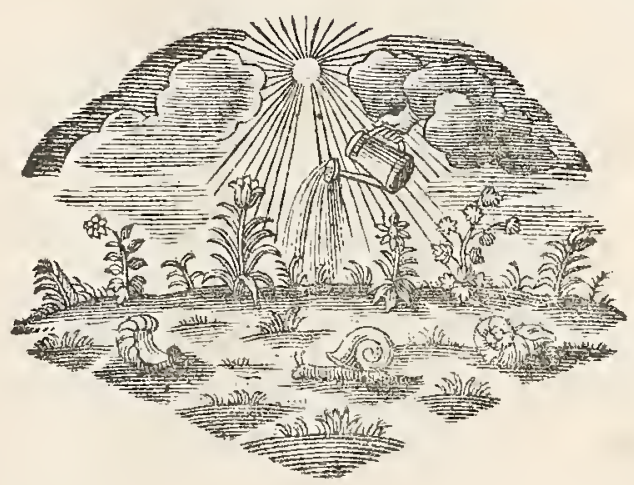

Eitnleis

INTRO. 



\section{cinleitung}

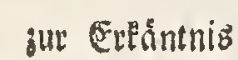

\section{Der Sollied uno}

\section{$\mathfrak{R} \| \mathfrak{i b} \mathfrak{e} \mathbb{1}$.}

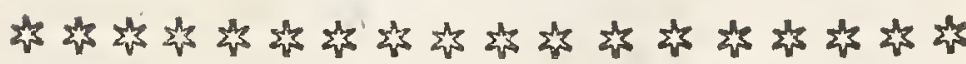

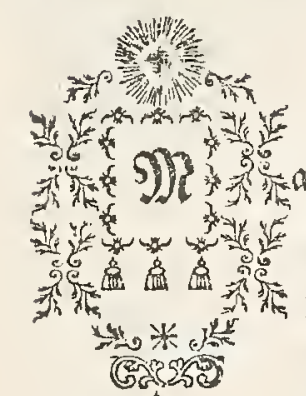

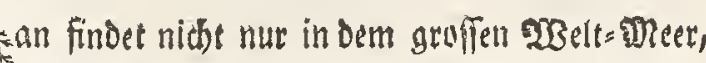

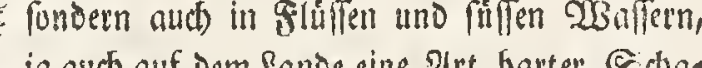
ja audb auf Dem ?ande eine 2trt harter Cdia len, rourinnen Shicre wollnen, und welche

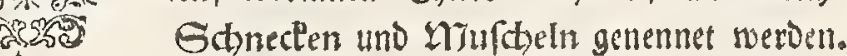
sDzan rectinet zmar audi) Die Gee=2lepfer und See= Steme zu Den Ethalen. Thleven; allein von blefen lez.

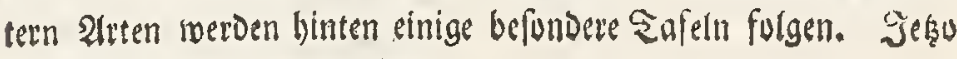
if pon Der erferern atrt Die ßiede.

Man nennet nemlfd betejenigen, itweld)e um cinn Rittelpunce

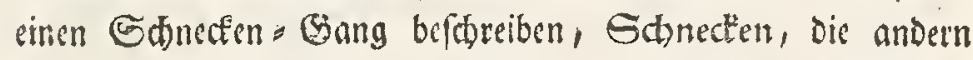
aber, Die nur in flacten, minoev voer melle biudjigten Schar len befteben, uennet man biufteln. Es Elinget Dolter mien Drig, wenn mande slebljaber bie gange Sammlung biefer been

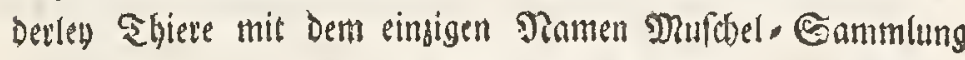

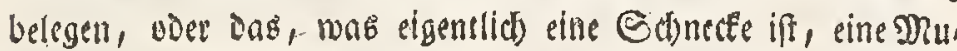

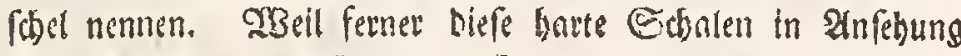
ibret Etructur uno Bauart auf eine merwundernstwirbige Fat von einander abweictien unt unterf(ciseden find, fo bat man fid lángft bemibet, fie in gewiffe Claffen einzufgetlen; we aber bie.

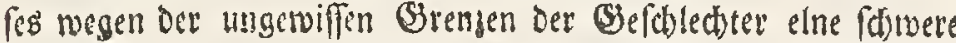

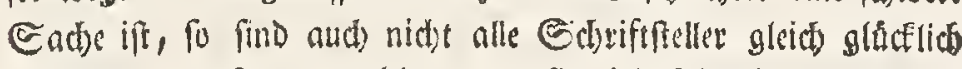
Darmuen serwefen; sumallen wenn fic viele stbrosidsungen unter cin Sefthledts baben bringem, und Die Siegel beobadbten wollen,

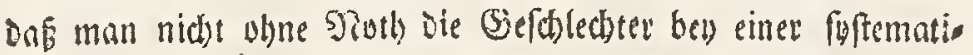
foten Eintheilung vermelyren muffe. Innoere bingegen baben

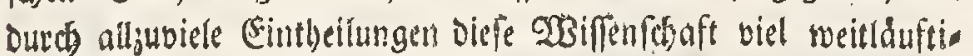
ger gemacht, als notbig ifi, und nur bloffe Fibreidungen

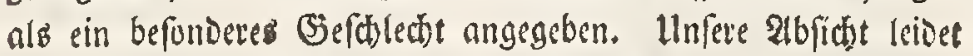

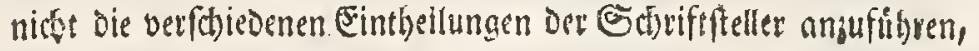
weer zll when. Es fino unter andern Sonanni, Kumpf, Lio

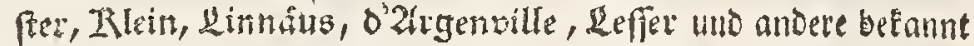
genug, uno wer bon allen dicfen berúlumten Estriffifelleen einen Furjen uno zureichenden Unterridt in anfetyung oer atr, wie fie

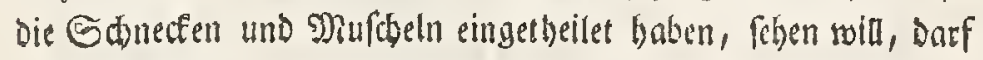
nur Des Jerrn von Bergett Claffes Conchyliorum lefen, Der

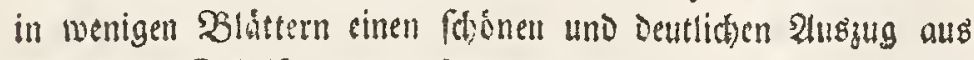
fohr vielen Sdriffeftlern bufammen getragen, uno an Das Sitht

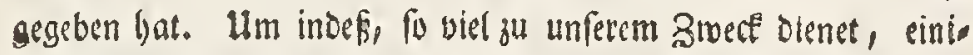

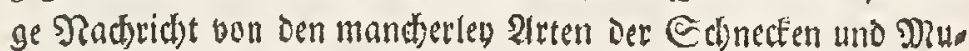

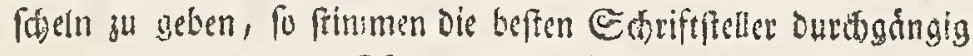

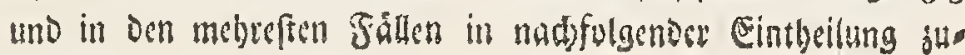
formmen.
INTRODUCTION

A LA CONOISSANCE

DES

E S C A R G O T S

LIMACONS, \& des MOULES,

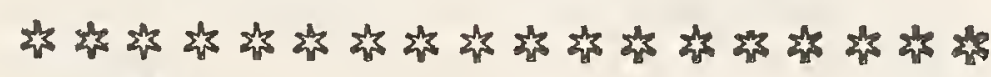

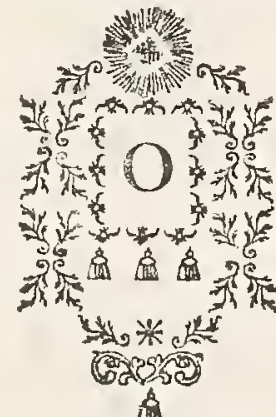
n trouve non feulement dins l'Océan \& dans toutes les Mers du Monde, mais auffi dans les fleuves \& autres Eaux douces, \& même dans le Continent \& fur Terre ferme des Coquillages durs, habitez par des Ani maux, auxquels on a donné le nom d'Efcargots ou de Limaçons, ${ }^{*}$ ) \& celui de Moules. Quelques Auteurs mettent à la vérité auffi les Heriffons de Mer \& les Etoiles marines au nombre des Animaux teftacez; mais comme nous donnerons cy - deffous quelques Planches particulières de ceux-cy, nous y renvoyons le Lecteur, ne prétendant parler ici que des deux prémiéres fortes.

Les Limaçons font ceux où l'on voít un Conduit, qui fait en ligne fpirale le tour d' un centre, au lieu que les Moules n'ont que des Coquilles plattes, plus ou moins ventruës, Nous ne pouvons par cette raifon approuver ceux, qui apel. lent en general fimplement Collection de Moules ce qui eft une Collection de ces deux fortes d'Animaux, ou qui don. nent le nom de Moule à ce qui n'eft proprement qu'un $L i$. maçon. La diverfité merveilleufe qui règne dans la ftructure \&z conformation de ces Coquilles a excitê il y a longtems des Amateurs zèlez à les ranger en certaines Claffes, mais tous n'ont pas réuffi également dans cet ouvrage, que les variations \& déterminations incertaines des Claffes rendent trés-difficile. Les uns, s'attachant à la règle, que dans une Divifion Syftèmatique on ne doit pas multiplier les Claffes fans néceffité, ont fourré trop de variations dans la même Claffe, pendant que d'autres, multipliant plus que de raifon les Divifions, \& faifant une Claffe feparée, de ce qui $n$ 'en eft qu'une efpèce variée, ont rendu cette fcience trop diffufe. Nôtre but préfent ne nous permet pas d'allèguer \& encore moins d'examiner la Méthode qu' il a plû̀ à chaque Auteur de fuivre dans fes divifions. Bonanni, Rumpf, Lifter, Klein, Linnas, d'Argenville, Leffer \& d'autres, font des Ecrivains connus. Quiconque voudra être informé plus en détail de la manière dont il a plû à chacun de ces hommes célébres d'en ufer dans la Divifion des Limaçons \& des Moules n'a qu'à lire les Clafjes Concbyliorum de Monfi. de Bergen, lequel a publié la deffus un Extrait, tiré de quantité d'Auteurs, \& fait avec beaucoup de clarté $\&$ de précifion. Pour donner cependant, autant qu'il convient à nôtre deffein, une idée des diffèrentes fortes de Limaçons \& de Moules, nous dirons que les meilleurs Auteurs en genèral s'accordent ou fe ra. $\mathrm{L}$ pro-

$\left(^{*}\right)$ Efcargots, ou Liwaçors, font en quelque façon fynonimes, quoique quelques Auteurs n'apellent Efcargots que ceux que wous thangeons en Europe. 
Es rectern nemlid fuetf brely Dronungen angenommen,

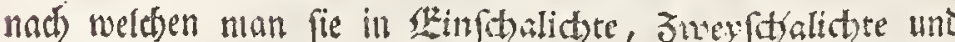

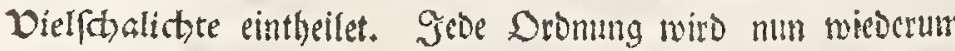

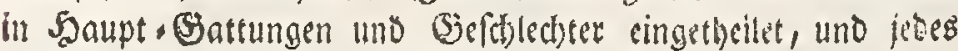

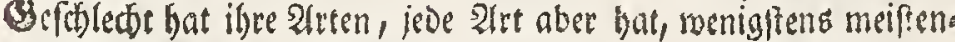
theitg, ifre Unterarten und aldweitfungen.

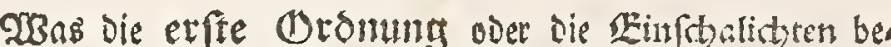

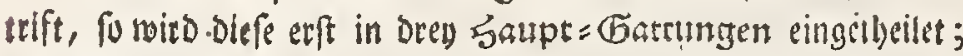

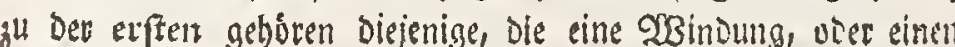
Ethnectengang um einen Witttpunct haben, und Die eigentlitif Gdonecten genennet werben: zu Der anderen rectinet man for We, Dle flact) und nidjt gerounden find, und gub Der oritren Dicienigen,

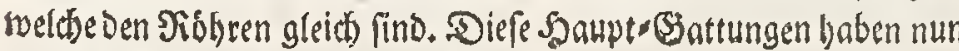
ifre Bseftilecter folgender Siefrilt :

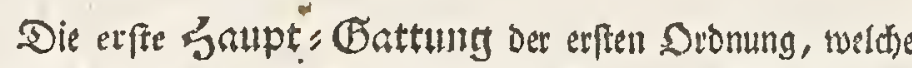
aus fulctien beffehet, Die gecrounden find, hat wenigfens eilf (Ses feslecteter, als Da find: I) Nautili, bie Schiffsturtel, 2) Cochleæ lunatæ, bie Monofdinecten, 3) Cochleæ valvatæ, bie Zilappenfchnecten, 4) Cafides, bie Sturmbauben, 5) Cochleæ globofæe, Die Kungelfduecten, 6) Buccina, Die Rinthorner, 7) Strombi, bie ravelfdunedten, 8) Volutæ, Die Regelfhneclen, 9) Alatæ, ble flügelfthnecken, I0) Porcellanæ majores \& minores, gie porzellanen, II) Cylindri, Die Rolfer.

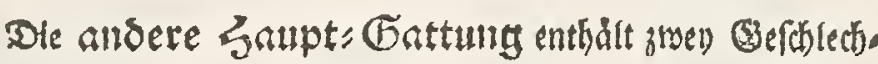
ter, nemlith ble Aures marinæ, Mreer. Obren, uno Patellæ, Die Zliptleber.

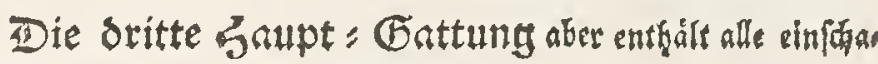
lidte Solenes oper Riobrenfthnelten.

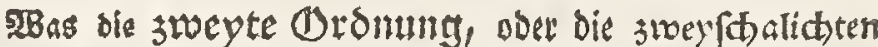
betrift, fo betffen biefe eigentlid, struftheln, und man hat folgen. De (Stuftect)ter. I) Chamæ, Giemmuf(teln, 2) Peetines, Zamunuffbeln, 3) Tellinæ, Telinuf(t)elit, 4) Solenes bi-

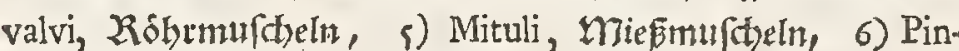
næ, Gtedinu(t)eln, 7) Oftreæ, 2(ufferm.

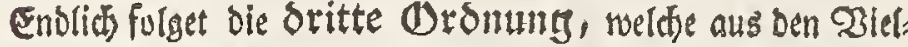

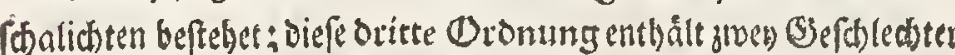
1) Die Balanos, Gee= Eulpen, und 2) Conchas Anatiferas, Langhaffe, welden andere hernadt nod bie Echinos marinos, - Der GeezZlepfel, und Stellas marinas, voer Gee.Sterne beyfügen,

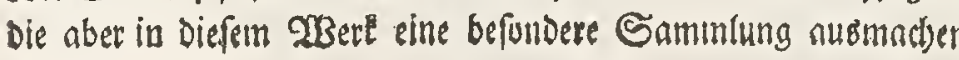
weroen.

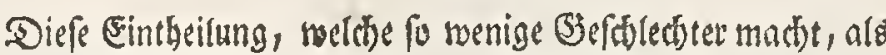

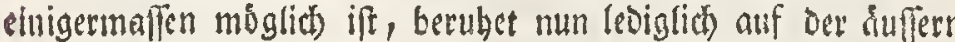

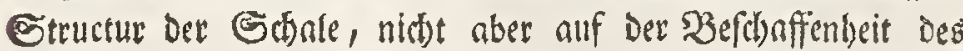

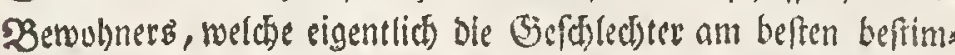

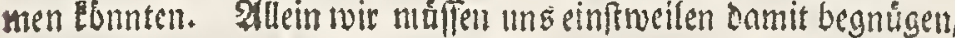
weil bisber bie Sbiere, fo fict in biefen Edyalen aufluatten, now nidft fo genau unterfucter warden fimo; wir wollen inatwifiben gerne geffehen, daf die Structur mandjer Edhate, befonder

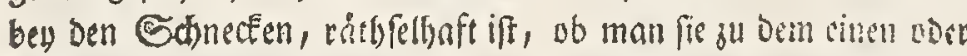

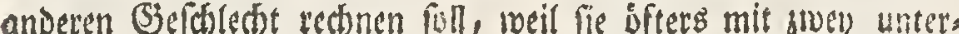

prochent dans la plûpart des cas en faveur de la Divifion, dont rous allons rendre compte.

On fupofe d'abord trois Ordres de Conques ou Coquilles, qui font les Univalves, les Bivalves, \& les Multivalves. Chaque Ordre a enfuite fes Claffes principales \& Genres, chaque Geñre fes Efpèces, \& chaqueiEfpèce a le plus fouvent fes Sousefpèces \& fes variations.

Quant au prémier Ordre, qui eft celui des Lnivalves, or en fait trois Clajjes principales. Les Coquilles de la prönière ont un Tour, ou une Voye fpirale autour d' un centre, \& c'eft ce qu'on nomme proprement Limacons. Les Coquilles de la feconde font plattes, \& n'ont point de Tour en ligne firirale, $\&$ enfin celles de la troifieme reffemblent à des tuyaux caves. Ces Claffes principales ont leurs Genres.

On peut compter tout au moins onze Genres ou Familles dans la prémière Clafje principale du prémier ordre, qui ont un Tour fpiral, fcavoir I. Les Nautiles ou Voilters, lat. Nautili, 2. les Coguilles en Lune, Cocblea Lunate, 3. Coguilles à valvules, lat. Cocblee valvate, 4 . les Cafques, lat. Caffides, r. Les Conques fphériques, ou bulles, lat. Cocblea globofe, 6. les Buccins ou Trompes, lat. Buccina, 7: les Strombes, ou Coquilles en vis, ou la Vis, lat. Strombus vel Terebra, 8. les Caquilles en cone, ou Volutes lat. Voluta, 9. les Coquilles ailées, lat. alata, , $\mathrm{o}$. les Porcelaines majeures \& mineures, lat. Porcillane majores \& minores, 11. les Rouleaux, lat. Cylindri.

La Seconde Claffe principale ne renferme que deux genres, qui font les Oreilles de mer, en latin Aures marina, \& les patelles, ou fucceurs de rocher, en latin Patelle.

Tous les Limaģons à tuyaux, ou folenes univalves, ou Mancbes de Couteau, forment la troifieme Clafje principale.

Venons au Second Ordre, qui eft celui des Bivalves, \& $\mathrm{ce}$ font là proprement les Moules. Nous trouvons ici les Genres fuivans. I. Les Cames, ou Moules béans, lat. Cbame, 2. les Peignes, en latin Peltines, 3. les Tellines, ou Conques anatiféres, lat. Tellina 4. les Solenes bivalves, ou Tubulaires, ou Coquilles en Tuyau, en latin Solenes bivalvi $\varsigma$. les Coquilles a mouffe marine, ou Confalmes marines, lat. Mituli, $\left.{ }^{*}\right)$ 6. les Moules en pieu, ou Pinnes, en latin Pinne, 7. les Huities, lat. Oftre.

Le troifieme Ordre ne confifte qu' en Multivalves. Nous n'y trouvons que deux Genres, qui font :. les Glands de mer, ou Tulipes marines, en latin Balani, \& 2. les Conques anatiféres à long cou, lat. Conche anatifere, à quoi quelques autres Auteurs joignent encore les Heriffins de mer, \& les Etoiles marine; , dont nous ferons dans cet Ouvrage une Seation particulière.

Cette divifion, qui ne confifte qu'en un aufi petit nombre de genres qu'il a êté poffible, n'a pour objèt que la ftructure extérieure des Coquilles, \& non la Conformation intérieure \& les proprietez de l'Animal qui y habite; felon les qualitez duquel il feroit bien plus facilede déterminer les Genres. Mais la Nature de ces Animaux n'ayant pas êté fuffiramment approfondie jusques ici, il faut bien nous arrêter encore aux coquilles. Nous avoüöns au refte de bonne foi que la ftrueture de ces Cóquuilles, fur tout aux Limaçons,

(*) On les apelle aufi en françois Muscleso 
ain

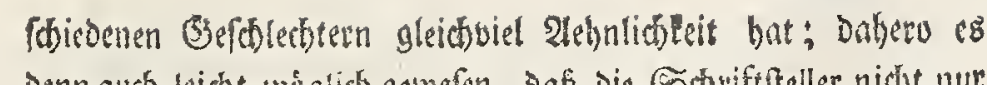

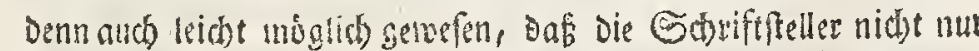

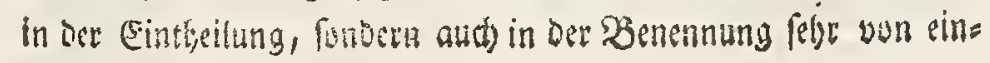
ander abgegangen find.

Es mitre librigens ofles won ber Rebengart, Furtphanjung,

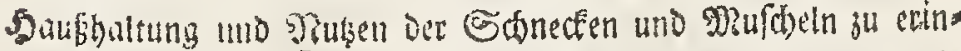

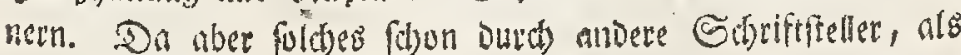

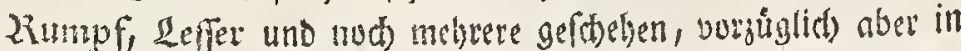

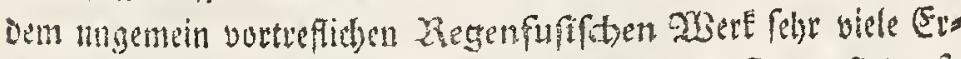

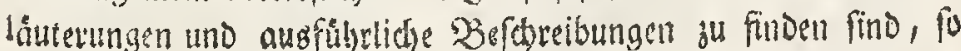

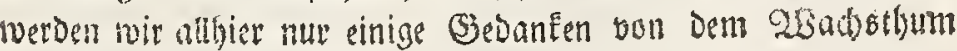
Der Ëbnecten, weltases allerdings wunderbar ift, mittbetlen.

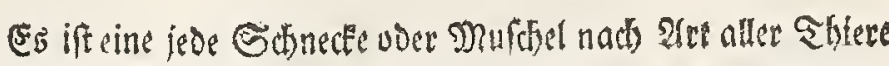
in ber arzelt anfängliof foft unfictstbar Elein, und wird aus Ever. wen erseuget, Die fith in einem getwifen Shand Der aus ber Sfinecke uder Dhufdel heraustritt, befinden. Diefer Gdyaum beftethet in vielen Bellen oder Sabblungen, faft wie bie berwireten

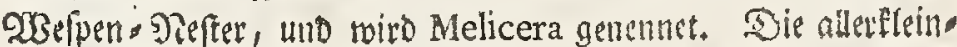

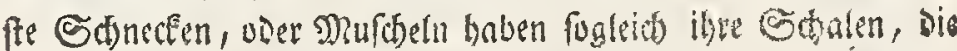

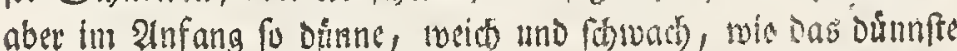

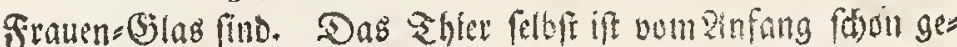

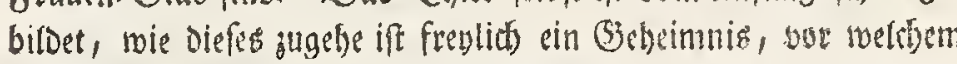
uns nutb ein Didfter Burhang vorgezugen ift, gletchwie stir audf

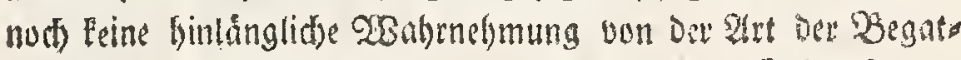

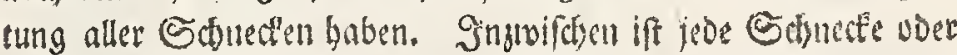

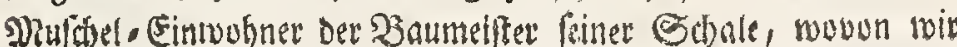

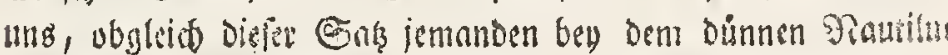

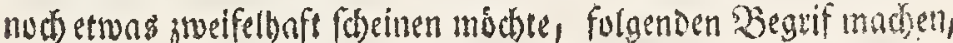
fo weit nemlid $2 B$ ahrnebnungen und Edliffe binreithen not

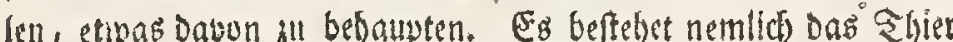
aus verfojedenen mufaldofen, faferitaten, háutigen und anberen

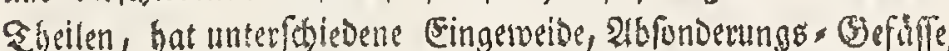

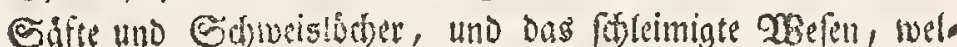

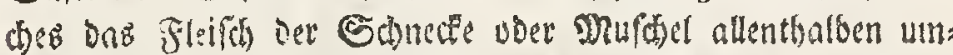

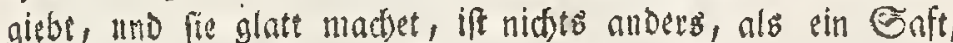

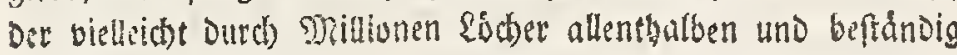

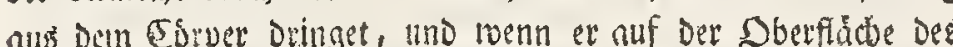

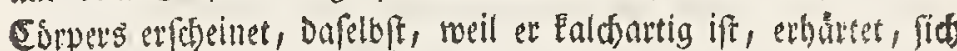
auch ferner, weil intmer ein anderter wether Saft nadffulget bun Dern (Serper ablofet, uno gleich elner Decte voer Echale

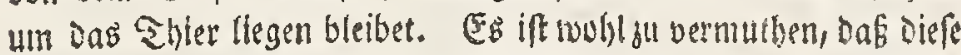

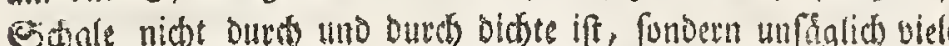

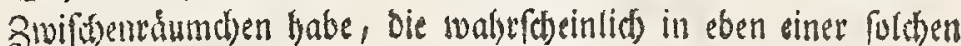
Eage neben einander fetenen, alo bie Jyori Des ₹lieves, auz weld

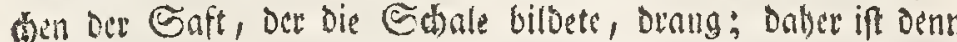
aud) glaublith, Dar bun Dens neuen Eaft fich nicht nutr immer

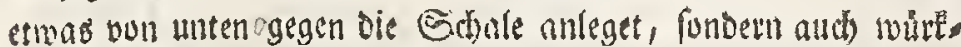

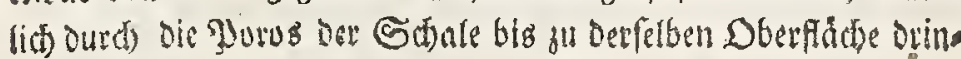

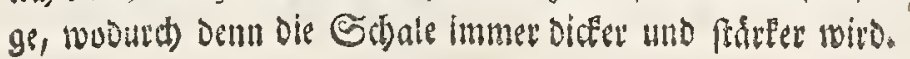

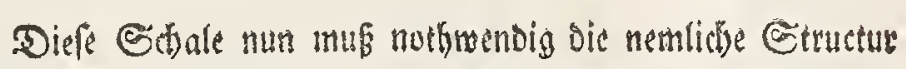

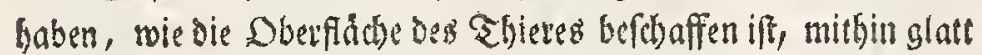

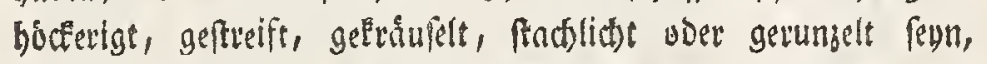
inenn Das Stsier felber eine folthe Etructur hat. So bnlo aber

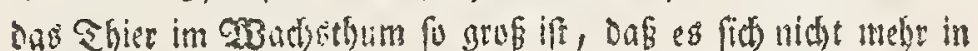

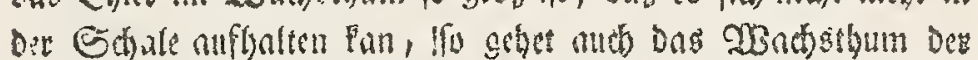

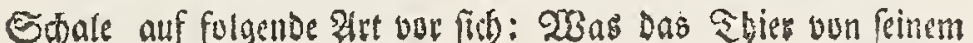
giteich eft quelquefois tellement problématique \& équivoque, qu'il eft difficile de refoudre à quel Genre elle doit être attribuée, parce que fouvent telle Coquille fe trouve, qui a une ref. femblance égale avec les Coquilles de deux Genres diffè. rens. De là vient la diverfité d'opinion des Auteurs, tant par raport aux divifions à faire, qu'à l'égard de la dénomination des pieces.

Au refte la façon de fublifter, la Propagation, l'écono. mie, \& l'utilité des Limaçons font autant d'objèts, qui fourniroient une ample matière à étendre nos defcriptions, fi plus d'un Auteur ne nous avoit déjà prévenu à cet égard, comme Rumph, LefJer, \& d'autres, particulièrement Mr. Regenfus dans fon excellent Ouvrage, où l'on trouve un grand nombre d'éclairciffemens \& d'amples defcriptions à ce fujet. Nous pouvons donc nous difpenfer d'entrer dans ce détail, nous contentant de dire ce que nous penfons fur $c \theta$ qu'il y a de merveilleux dans l'accroiffement des Limaçons.

Soit Limaçon, foit Moule, ces animaux ont cela de com. mun avec tous les animaux du monde, c'eft qu'au prémier moment de leur exiftence ils font petits, au point d'être imperceptibles. lls s'engendrent de trés-petits oeufs, lesquels fe trouvent dans une certaine écume qui fort du Limaçon, otr du Moule. Cette écume qui porte le nom de Melicera $\left(^{*}\right)$ confifte en un grand nombre de Cellules, ou de Cavitez qui en corps reffemblent à un nid de guêpes confu. fément arrangé. La Nature pourvoit d'abord les plus pe. tits Limaçons \& les plus petits Moules de leurs coquilles, mais ces Coquilles font au commencement aufi minces, auff fragiles, auffi fines, que la pierre fpéculaire la plus deliée. L'Animal a dés fa naiffance fa figure complette. Si l'on nous demande comment cela fe fait, nous ne pouvons que répondre qu' un voile epais nous cache jusques ici ce myftère, \& nous empêche de même de pouffer nos obfervations jus ques à la manière dont tous les Limaçons s'aparient. Nous croyons cependant que chaque Moule ou Limaçon eft le propre Architecte. de fa Coquille, \& quoique cette propofi. tion foit fujette à quelque doute par raport au Villier ou Nautile dont la Coquille eft fi mince, nous croyons pourtant en fuivant pié à pié les obfervations que nous avons faites, \& les conféquencas qui en découlent, pouvoir hazarder les conjeetures fuivantes. C'eft que l'Animal étant compofé de plufieurs parties mufculeufes; filamenteufes, membraneufes, \& autres, a auffi diffèrens inteltins, il a fes Vaiffeaux de féparation ( $\left.{ }^{*}\right)$, fes Sucs, fes pores; or cette matière vis. queure qui environne de tous côtez la chair du Limaçon ou du Moule, \& la rend fi glifiante, n'eft autre chofe qu'un Suc, qui fortant du corps perce fans ceffe au travers peut être d'un million de petites ouvertures vers la fuperficie, ou il fe durcit, par ce qu'il eft de nature calcaire, \& fe fe. pare du.corps, d'où il fort continuellement du fuc nouveau, \& tendre encore, auquel le prémier cède la place \& de meure autour de l'Animal en forme de Couverture ou de Coquille.

Il eft aifé de préfumer que cette Coquille n'eft pas ab. folument compacte, \& qu'il y a une infinité de petits inter. valles, lesquels fe trouvent vraifemblablement rangez l'un à coté de l'autre, dans la même pofition que ces Pores, d' où fort le fuc qui forme la coquille. Il eft donc auffi croïa. L 2

(*) Aielicera, efpèce de Sang corronipu, épais, gluant, \& blanchàtre.

(**) Dafa fecretoria. 


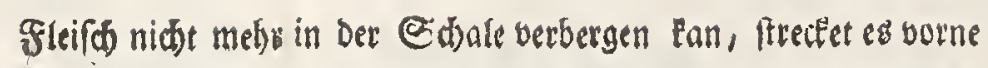

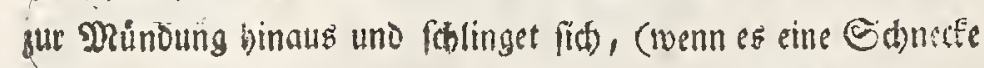

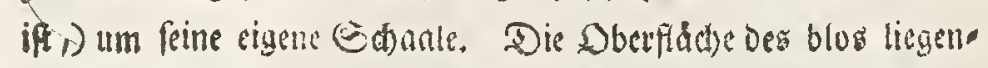
ben sbieres laffet eben einen fuitben eaft von fich, als vorker,

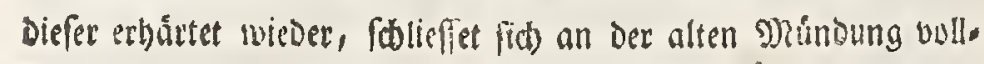

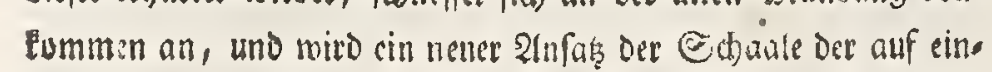

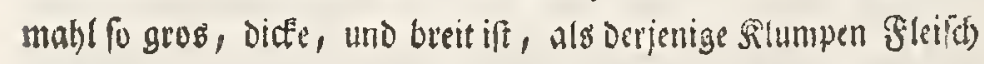
gros ift, den das Sbier gejwungen war, twegen ies engen

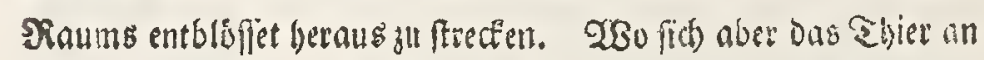
Der untern Seite um ole Schale gefthlungen und feft gebalten batte, on lofet Der Saft bes Ebieres die alten Saúcer Der Sthale, bie ba waren, auf, uno madit fie glutt. 2luf biefe 2Beile entfehen bey Dell Edynecten . Sadufern Die Sieminoe, bey

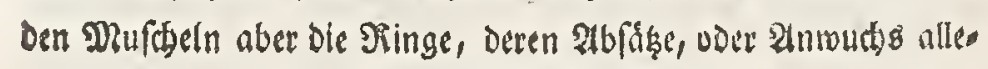
geit nud zu feben find, es mag fid auch Der neue Saft an Des alten Siand Der Sthale nocb fo fein angeleget baben und erhár.

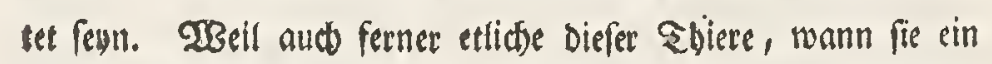
gewiffes alter erreidjen, an Dem áuferen shand eine andere Structur, ober gans neue Eappen belummen, uno Darinnen mit bielen anderen Sbieren etwas gemein haben, bie erfit in einem

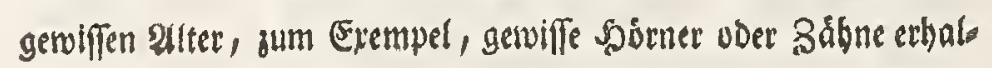

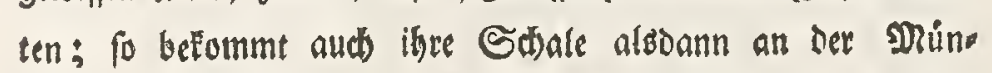
Dung eine andere Seffalt. Es ift biefes zum Exempel an Den

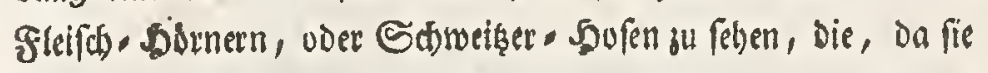
erft eine gerade und gleidfam abgebrudbene MRündung obne Siand baben, endidf einen gruffen breit heraustretenden \&appen beîum.

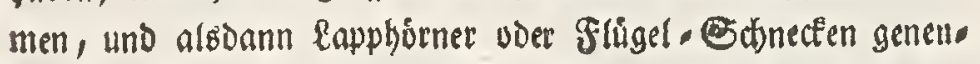

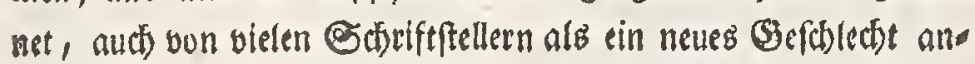
sejehen werden, ofyeractetet fie wireflich mit Ben antern Das

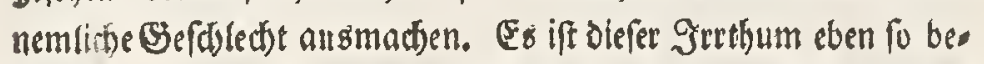

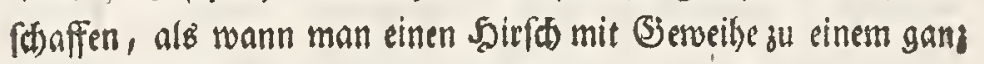

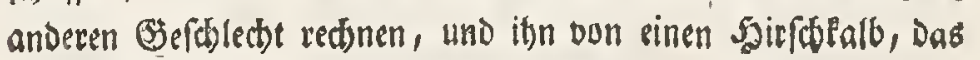

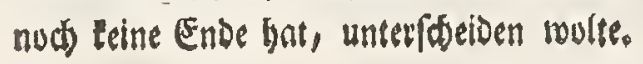

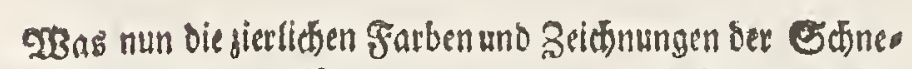
eten und Muffeen betrift, fo glauben wir, Das foidhe aus Den

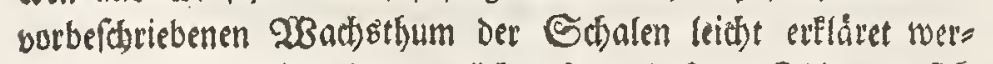

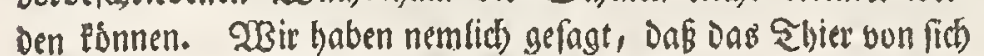
einen Saft zur SGale laffe, diefer Saft mus nuthiwendig in Dem nemlichen Shier nad) 2tet Der berfdjiedenen Beftandetheile und

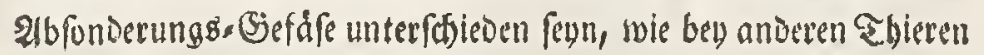
Das rethe Blut, die grine Salle, der gelbe lltrin, Der weiffe Eyter,

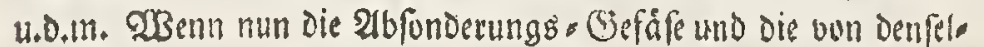

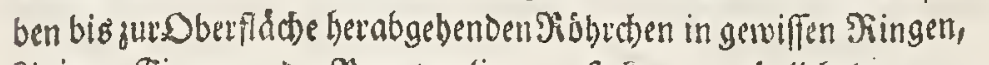
Sinien, Stiguren voer \$uncten liegen, fo Ean unmugglitg Der ver.

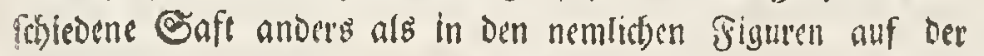

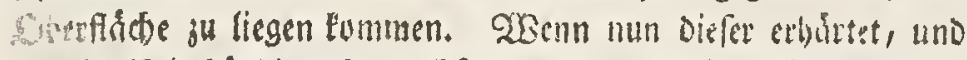

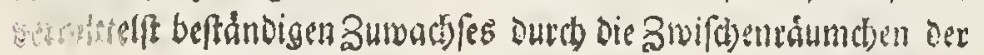

Ebale ble qu'une partie du nouveau fuc, qui fort des Pores de l'animal, s'attache toûjours non feulement au bas de la coquille, maix qu'il pénètre auffi de là à travers les pores de la coquille jusques à fâ fuperficie, ce qui la rend de plus en plus forte \& épaiffe. Il s'enfuit de tout cela que la Coquille ne peut être conformée que felon la direction de la ftruEture qu'a l'Animal à fa fuperficie, \& etre ainfi unie, tuberculée, rayée, frifée, pourvuë d'aiguillons, ou ridée, felon que l' Animal eft fait lui - même. Mais dés-que l' Animal eft parvenu à un point d'acroiffement, qui lui rend fon habitation trop étroite, alors la Coquille "commence à crô̂tre à fon tour, \& cela de la façon fuivante: L'animal étend cette partie de fa chair, qui ne trouve plus de place dans fon habitation, hors de la coquille, au devant de l'embouchure, \& quand c'eft un Limaçon il monte fur fa propre coquille. La fuperficie du Limaçon, qui fe trouve là à decouvert rend un fuc pareil à celui dont nous avons parlé, ce fuc fe durcit encore, \& s'ajufte à la vieille embouchủre; de là fe forme la Continuation de la coquille, laquelle aquiert par là tout d'un coup le degré de longueur, d'épaiffeur, \&z de largeur néceffaires pour que cette partie de fa chair, que l'animal avoit êté forcé de laiffer dehors faute de place au dedans, y puiffe rentrer. Du coté infèrieur, là où l'animal $s^{\prime}$ étoit attaché en faifant le tour de fa Maifon, le même fúc de l'Animal diffout les anciennes élévations \& les rend unies. C'eft ainfi que fe forment aux coquilles de Limaçon les Contours, \& aux Moules les Zones ou Anneaux qu'on peut toû. jours remarquer, \& voir par conféquent comment s'eft formé fucceffivement l'accroiffement de la Coquille, quel. que finement que le nouveau fuc fe foit attaché \& durci à fon bord. Mais comme ces Animaux, quand ils parviennent à un certain dégré de vieilleffe, changent de ftrueture au bord, où il leur vient des lambeatux tout nouveaux, ce qui leur eft commun avec d'autres animaux, qui par exemple parvenus à un certain age prennent des tubercules, ou mettent des dens toutes nouvelles; de même auffi leur Coquille prend une nouvelle conformation à l'embouchure. C'eft ce qu'on peut obferver, pour en fournir un exemple, 2ux Limaçons cbarnus, autrement dits Culottes de fuiffe, lesquels n'ayant eû au Commencement qu'une embouchure droite, \& comme coupée, fans bord, nrennent enfin en víeilliffant un lambeau grand \& large, qui s'avance au dehors, ce qui a teduit plufieurs Auteurs, lesquels les regardant alors com. me étant d'une efpèce toute nouvelle, les apellent Limaçans a Lambeaux, ou Limaçons ailez, quoiqu'ils foient toûjours du même Genre que les autres, erreur femblable à celle dans Jaquelle tomberoit un homme qui prétendroit qu' un Cerf qui a fon bois n'eft pas de la même efpèce d' animaux que le Fan, qui n'en a point encore.

Pour ce qui concerne la beauté des couleurs \& des deffeins qu'on remarque fur les Limaçons \& fur les Moules, nous croions qu' on en peut dériver l'origine, avec probabilité du même accroiffement des coquilles que nous venons de décrire. Nous avons dit que l'animal lache un fuc, qui va à la coquille, \& ce fuc eft néceffairement divers dans le même animal, felon les parties \& vaiffeaux de léparation, par où il paffe, comme on voit en d'autres animaux que le fang eft rouge, le fiel verd, l'Urine jaune, le pus blanc, \&c. Or quand les Vaiffeaux de feparation, \& les petits tuyaux, qui en defcendent jusques fur la fuperficie de la Coquille, fe trouvent dans une certaine pofition, rangez en certains anneaux, lignes, figures, ou points, il faut néceffairement que le fuc divers opère fur la fuperficie des defièns, qui ré- 


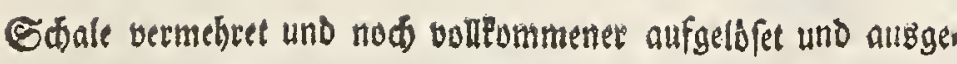

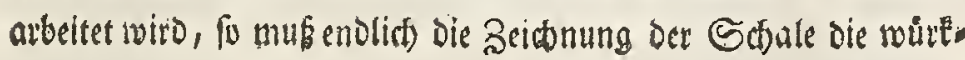

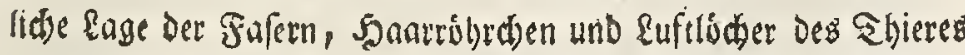
verratben. Dak aber biele Shiere würflid) forthe Etructur Gaben Eơnnen, Darf une nid)t frembo vortommen, Da wir fajun auf Dem Rande uno in feutiten Siellern allertley bunt geftreifie Sathes

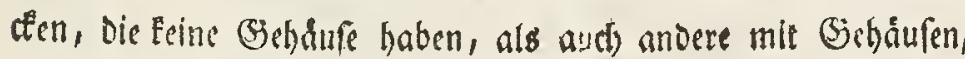

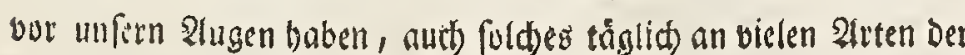
Siaupen fehen. Egeil nun ferner bie Farben von Der Bretbung Der Sidutfrablen, und diefe von der \$Befhaffenteir ber Ediefer

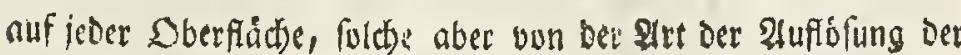

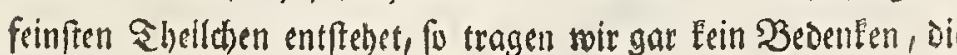

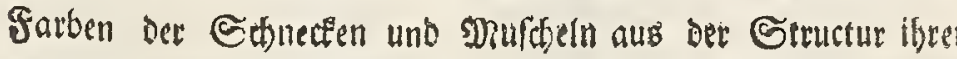

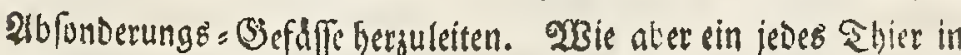

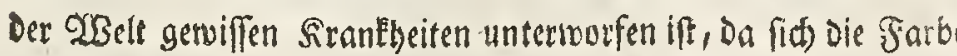

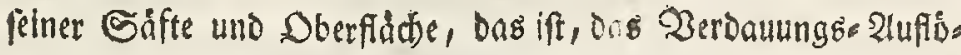
funggr und affonderungs. Sieftidfte ándern Ean, alfo gellet es

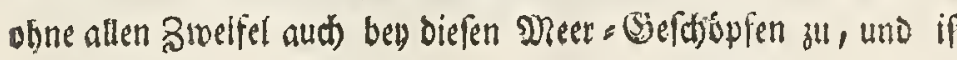
Urfactse von vislen alsweiffungen ber Farben. Daher glouben wir, Daf Derienige, toelcher zun Evempel eine braune, eine gelbe, und

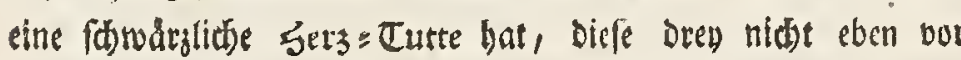

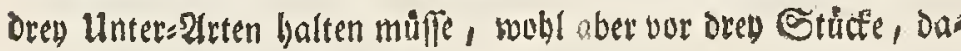

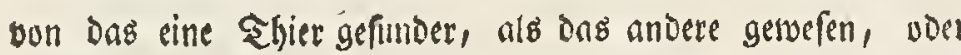
vietletdst in einem beforbern See = Elima selebet, boer aud sine eigene शabrung genoffen bato

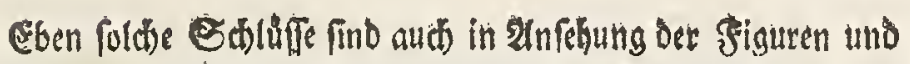

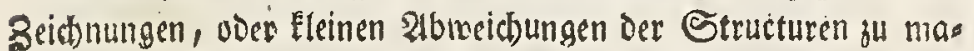
() pers, woer Der Fafern fatt haben; $e$ Ean enge uns weite

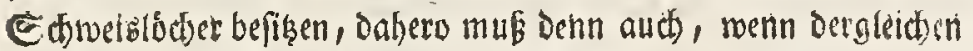
fich) ben Diejen Shieten erelgnet, Die Edale nothwendig eine andere Bieftalt oder Beichnung betemmen, und fie if Deswegen nid)t gleid) won einer andern (Sjattung, over Unter $\approx$ Int ; wels (d)es wir Darum anführen, steil es etwas bentragen Ean, die

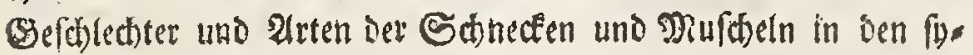

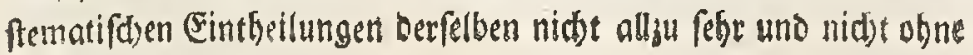
פioth ju vernetgeet.

2Ba nun biejenigen Supfertafelt betrift, bie wir von bett

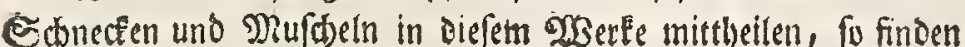

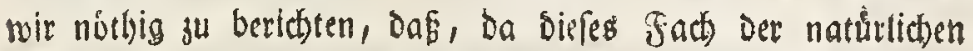

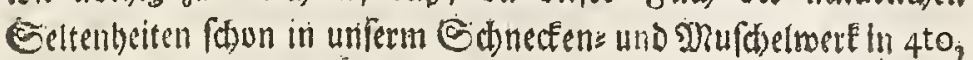
nobin wir aucb) ben geneigten Sefer verweifen, ausfúthrlicther auso

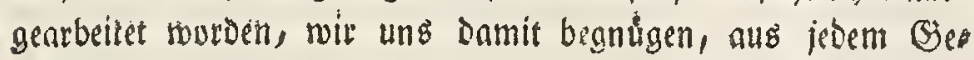

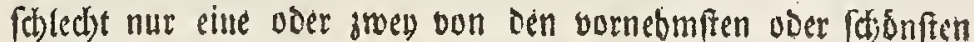

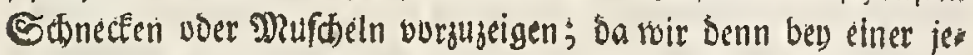

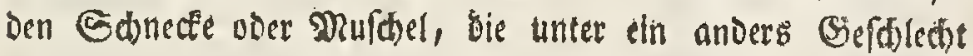
gethuret, Eelegenbeit nebmen werben, einige Erlduterung urio

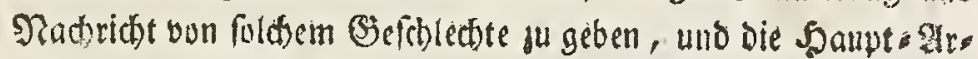

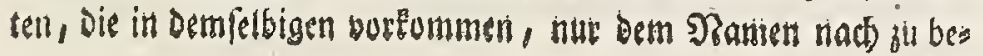

pondent a la pofition des tuyaux \& a la couleut du the qui eft forti de chacun. Lors donc que ce fuc $s^{3}$ eft durci, quand par l'accroiffement continuel, qu'il reçoit à travers les petits intervalles qui font dans la coquille, il $\mathrm{s}^{3}$ aug. mente, \& qu' il eft bien diffous \& préparé, il n'en peut refulo terr d'autre conféquence, fi n'eft que les Deffeins qu'on voit fur la coquille décèlent la véritable pofition \& l'arrangetnent des filamens, des petits tuyaux capillairês, \& des Pores ou autres ouvertures dont l'Animal eft compofé au dedans. Nous ne devons nullement être furpris que ces animaux puiffent être conformez ainfi, puisque nous voyons, même aux endroits de la Terre ferme que notus habitons, dans des caves humides, non feulement toutes fortes de Limaçons, rayez de couleurs variée \& denuez de coquilles, mais que nous en trouvons auffi d'autres pareils, pourvûs de coquilo les, \& qué la même chởe parô̂t fưr plufieurs efpèces de chenilles. A I' '́gard des couleurs, comme elles proviennent de la refraction des rayons de la lumière, laquelle dépend de la qualité \& de la pofition des écailles qui couvrent chas que fuperficie; ce qui s'opère par la façon dont les parties les plus fines s'y diffolvent, nous ne trouvons aucune difficulte à chercher l'origine \& la qualité des Couleurs qu'on remar. que fur les Limaçoñs \& fur les Moules dans la ltrueture de leurs vaiffeaux de féparation. On fçait au refte que tous les animaux da monde font fujèts à de certaines maladies, pendant lesquelles la couleur de leurs fucs \& de leur fuper. ficie peut changer, parcequ'alors l'opèration de la digettion, de la refolution, \& de la féparation intérieure des alimens foufo fre une alcération, \& la même chofe arrive fans doute aufii à cès Créaturés niarines, à quoi on doít attribuer lés aria tions fréquentes des couleur's. Ainfín noús croyöns qut tun Collecteur qui fe trouve avoir dans fon Cabinet trois Cornitus en Coeur, l'un brun, l'autre jaune \& l'autre inoiratre, the doit pasfe figurer d'abord que ce folent trois Sous - èfpèces diffe. rentes, mais il doit juger que ce font trois individus de la même efpèce, ou fous - efpèce, dont l'un des animaux étoit moins fain que l'autre, ou bien que les Climats où ils ont êté pêchez ne font pas les mêmes, ou encore que leur nour. riture a êté différentes

On doit raifonnèrè de mên deffeins, \& aux petites variations qu'on remarque quelgues fois dans la ftrueture. Car il le peut qu'un animal foit mal conformè, ou quant àu corps, out eû egard aux filamens; is peut avoir des Pores étroits \& larges, \& lorsque cela arrive, il eft naturel que la Coquille prenne une forme \& des defo fèns anomales, ce qui ne prouve abfolument point qu'elle foit d'une autre forte, oti d'une Sous - efpece; ce que nous difons parce que cela peut contribuer à empêcher que l'on ne multiplie fans néceefité dans une Divifion Syftématique les Genres \& les Efpèces des Limaçons \& tes Moules.

Nous àvons à đire icì encore un thot touchant les Figu. res des Limaçons \& des Moules; que nous communiquons au Public $C^{\prime}$ 'elt -que, comme nous avons déjà traité am. plement la matière des Coquillages, \& cette Partie de l'Hiftoire des Curiofitez de la Nature, dans hôtre Ouvrage in 4to (*) où nous renvoyons le Leeteur, nous nous contente. rons de produire fur chaque Planche du préfent Ouwrage une ou deux des principales \& plus belies pièces, foit Limaçon foit Moule de chaqueGenre, \& prendrons de là occafion de donner une information \& explication génèrale de ce qui concerne ce Genre, nous bornant au refte à en nommer fimplement les M efpè- 
rưfren, Damit es den EiebĞabern als ein 28 egneifer dienen fénne,

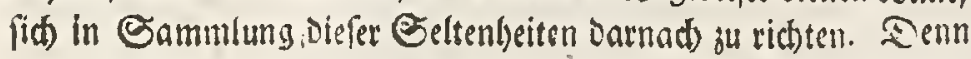

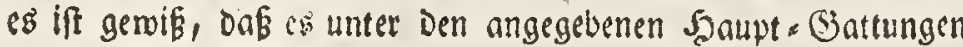

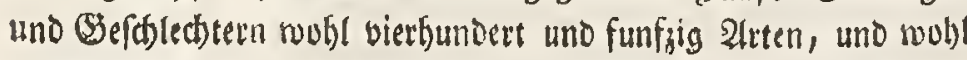
3roiffiundert und mebe Unter. 2arten und 2abweidungen gebe. Ja toenn man auf Die Berinderungen Det Farben und Beiduun.

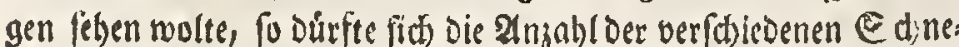

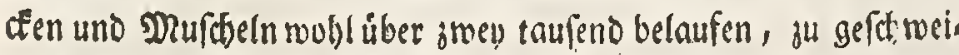

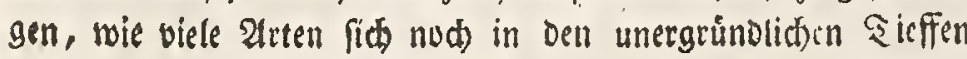
Des SReers auflalten migen, die jeeso vor uns verburgen fino, und beren Dafelun man bod aus bielen Derfeinerungen fatief ren mus.

Uebrigens aber máffen wir bie Terfitherung geben, oa bie abgejeicteneten Originale swie etwa einem, Der nidht vie

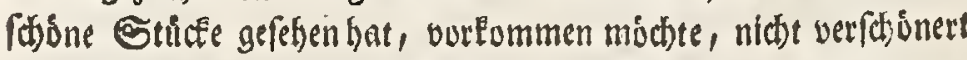
oder hocbfarbigter vorgeftellet fino, fondern wie man Der Patur

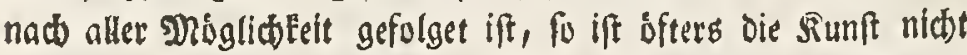
cinmal im Stande getwefen, Der Natur volleummen nach zuab. men, uno fino mande Originale nud weit vortreflicter uni praidf

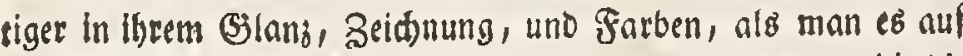

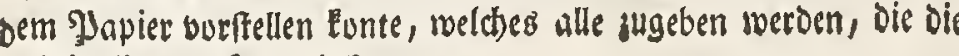
Originalia ous feben betommen.

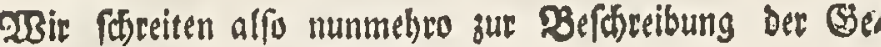
F⿻ledter naథ \&nleitung Der Figuren.

\section{TAB. B.}

Fig. 1. Das Befकledt Der Ghiffskuttel hat faft bed

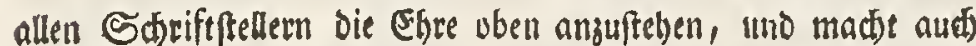

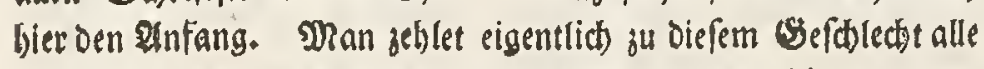
vielkammerid)te Gchnetfen uno einige menige, die zivar nur

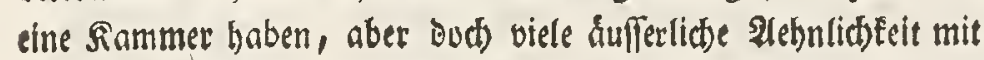
Den ủbrigen berigen. Biellammeridte fino der Dicke, fo mobl gruffe, als Eleine trautilus, einige 2tmmons =5ôrner, und oas Doftbornden. Eine Rammer haben nur Der groffe und Elleine

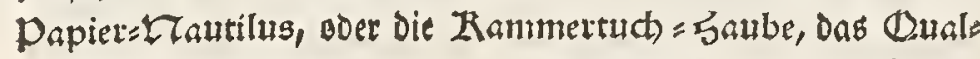

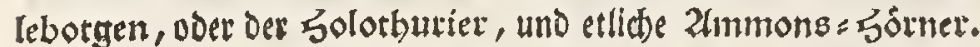

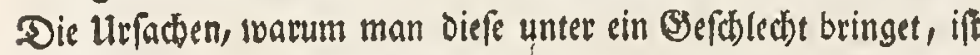
nifit einerley, uno Daherv die Eintlyeilung aud) gar nidt ridtig. Denn etliche getsuren zror, als Wieltammerigte jufammen; aber weil der dưnne গRautilus, Der nur cine Fammer bat, auss

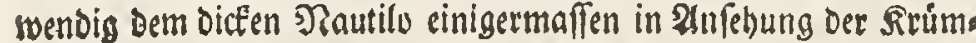
mung und Des Solknoung gleid fosmmt, fo mird er mit ju diefem

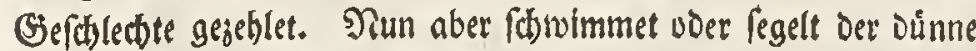
Nautilus, und das thun die Solotfhurier aud), Daber zeflet man

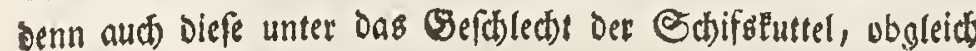

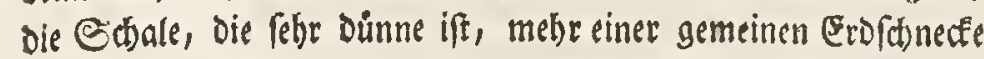

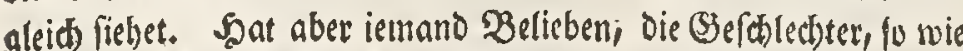

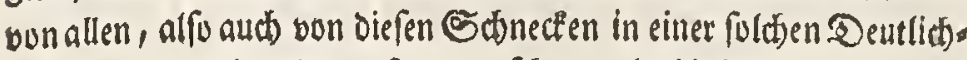
Eeit genau auzeinander geferet zu fehen, als bisher noch oon nie. mano gefweten if, der lefe ons Syftema Naturæ des groffen Sitters Linnæi. 2OSir berthren nur, wie melurmablen erintert suroen, einige der burnelymften, bie getwólgnlich zu einem (Ge) folectie gezeblet werben, Damit diefes WBerk einigermaffen Dienen lonne, Den Riebhabern eine Gelegenbeit ju verfitaffen, bey Erbliffung Der allfier vortummenden figuren einige fer. nere 2fnleitung ju den úbrigen Stúcten zu finden, auf welde man bev Eammlungen vorzaglid ju Tehen hat. efpèces principales, ce qui fuffira pour guider les Amateurs dans ce qu'ils ont à obferver pour faire leurs Collections avec fruit \& avantage. Les Claffes principales qu'on conoît, \& leurs Genres contiennent au moins quatre cent cinquante Efpèces, où l'on trouve encore bien douze cens ou plus de Sous-efpèces \& de variations. Que fi l'on s' attache à éplucher fcrupuleufement les différences des couleurs \& des deffeins, le nombre des Limaçons \& des Moules de fortes diverfes s'étendra à plus de deux mille, fans parler de la quantité immenfe d'efpèces qué la Mer renferme fans doute outre cela au fond de fes abîmes, \& qui font encore cachées à nos yeux, quoiqu'un grand nombre de Pétrifications ferve de preuve à leur exiftence.

Tel Leeteur au refte, qui n'a pas encore eû occafion de.voir beaucoup de belles pièces, pourroit peut être s'imaginer que les nôtres font flatées dans les figures que nous en donnons, \& que ces figures rendent les pièces originales plus belles, \& plus brillantes en couleurs, qu'elles ne font en effèt. Pour prévenir cette erreur nous pouvons affut. rer qu'on a taché d'imiter la nature au jufte, autant qu'il a êté poffible, mais qu' on n'en a pas toûjours parfaitement atteint la beauté, y ayant des originaux, qui par leurs couleurs, par leurs deffeins, par leur brillant, font réellement beaucoup plus magnifiques que le burin \& le pinceau n' ont pû les rendre, ce que tous céux qui ont vâ les pièces mêmes dans les Cabinets où elles fe trouvent, ne refuferont pas d'attefter.

Procédons à préfent d̀ la defcription des Genres en fuivant l'ordre de nos Figures.

\section{PLANCHE B.}

Figure I. Presque tous les Auteurs mettent dans leurs Ecrits le Nautile, ou le Voilier à la tête de leurs Coquilles. Pour ne lui pas ôter la poffeffion de ce rang nous allons commencer par là. On met dans ce Genre tous les Limaçons à plufieurs chambres, \& un petit nombre de ceux qui n'ont à la verité qu' une feule Chambre, mais qui ne laiffent pas de reffembler beaucoup extèrieurement aux prémiers. Ceux qui ont plufieurs chambres font le Nautile épais, tant grand que petit, quelques Cornes d'Ammon, \& le petit Cornet de Pofte. Ceux qui n'ont qu'une chambre font le grand \& le petit Nautile de papier, ou de Cambrefine, la Carène des bolotbures, \& quelques Cornes d'Ammon. Ce font des raifons differentes qui font ranger toutes ces pièces dans une feule \& même Clafe, $\&$ c'eft là un défaut à cette divifion. Car les Coquilles à plufieurs chambres doivent à la vérité être mifes enfemble, mais le Nautile mince, qui n'a qu'une Chambre n'eft mis au même rang que parceque par fa courbure \& par fon embouchure il imite le Nautile épais. Or le Nautile mince nage ou va à la voile, 'c'eft ce que fait auffi la Carène des Holothures, \& c'eft par cettę dernière raifon qu' on la tolère dans la Claffe des Voiliers, quoique fa Coquille qui eft trés. mince ait beaucoup plus de raport avec celle du Limaçon terreftre ordinaire. Il n'y a qu'à lire le Syftema Nature du grand Linneus, pour être au fait du détail de toutes les Claffes, \& par conféquent de celle - cy, \& y trouver des lumiéres qui ne fe rencontrent nulle autre part. Notre but ne nous engage, comme nous l'avons dit, qu'à indiquer les principales pièces d'une même Claffe, pour guider les Amateurs, \& leur foumir par les figures que nous leur préfentons un enfeignement pour le clioix des pièces, qui méritent le plus d'être recherchées, quand il s'agit de faire une Collection. 
Es ift alfo in blefer figur ein vollftsndiger gruffer didter

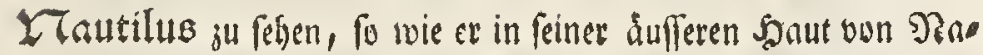

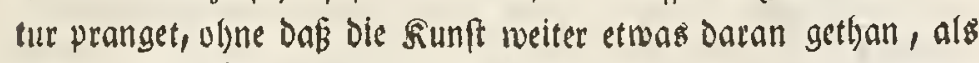

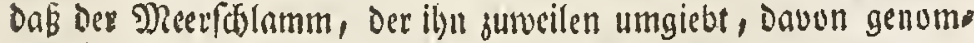

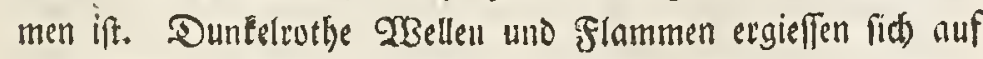

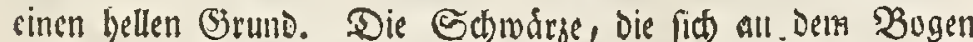

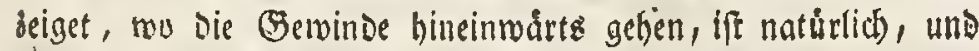
rủbret bon Dem Eaft ber, Den Das Sbier, fo fith obern in Der

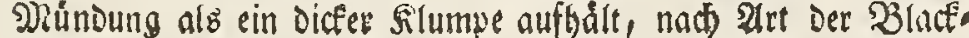

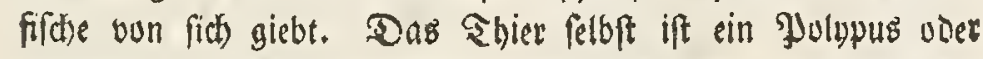

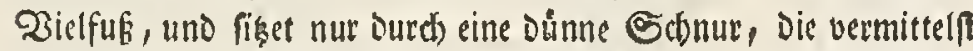
einer Siólge, ourd alle scammern gehet, an ben Dittelpunet feffe, Davon wir bey Der Fig. I. Der folgenden Tafer melbere Diacts.

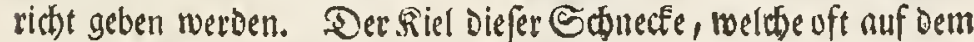

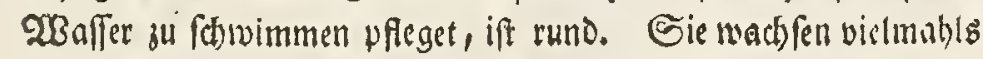

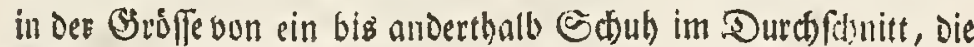
Saljale aber wito niemabls dicfer, als ein Louis d'Or. Wan findet fie am båufigften an Der Epişe von affrica bey Dem Zuor gebúrge Der guten Shofnung, wo fie nad Dem Sturm auf Der

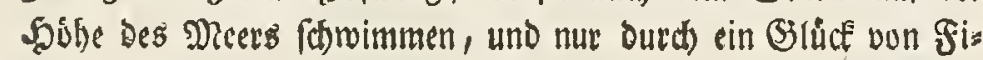

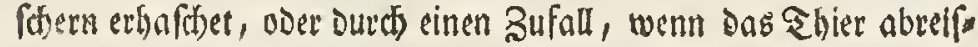
fet, und beraus fidleudert, an Dem Strand geworffen werden.

Fig. 2. Der oben ertrethnte bicte Nautllus ertitietnet in bies Fer Figur shue Der duffern bunten Decke, uno if abgesegen, Da. bey denn nidut ău láugnen, Das diefe untere Shaut mit ber obern

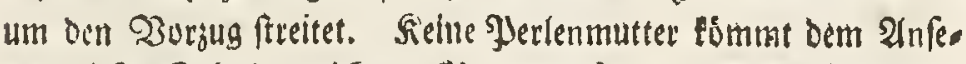
ben Diefer Ethate gleith. Eine bellglánjende Silberfarbe mit

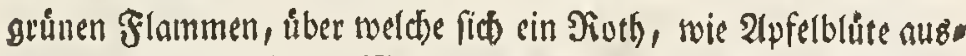
breitet, Das bey jeber 203endung in Siegenbugenfarben folelet,

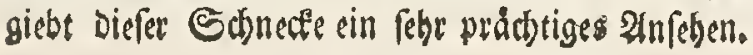

In Den vorigen Beiten haben fith Die Sủnfter Fehr Damit abgegeben, fie zierlich ju fatneiden uno mit erbabener voev Durd).

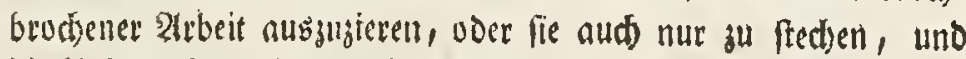
die Einien mit Sublenftaub cinzurciben, Da man Denn ifters bie

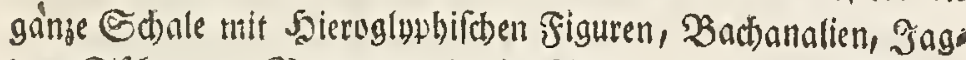

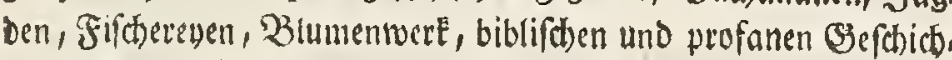

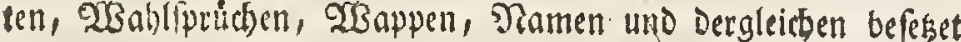
finder. Diefe alfo jubereitete Scthalen wurben Denn ferner in Eilber und Bold gefolfet, nuf einen Fub gefeşet, uno ju Erine gefdirren gebruutet, weil fie sfters thehe, als ein Dhans Seo

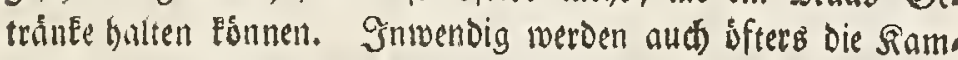
mern bis auf Den 2Rittelyunct ourdfiftnitten, und Dafelbof eime feltr nieolide Figur eines 5atms angebrad)t.

Ifn Der gegennartigen figue nimette man unter andern in Der Mitte cinen groffen nufférbbigen Flecten wable, dabon wi nuthwendig eine Erflárung gu geben Gaben, weil derfelbe ein ger

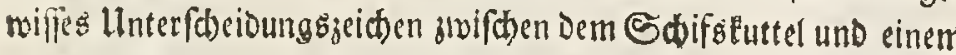
2(mmonthorn ift. Denn bey allen 2linmonsbúrnern find an Dem

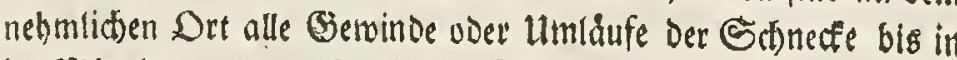

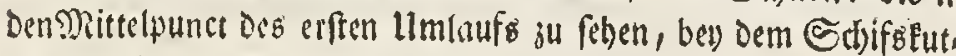

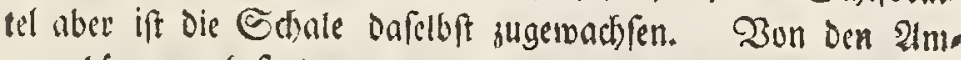
munshornern, befoniers bon Den groffen, befomint man genus in

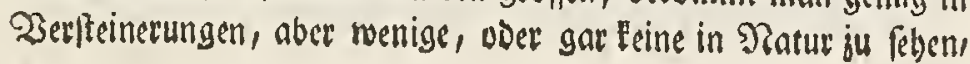

La préfente Figure eft donc un Nautile épais de la grande forte, pourvû au dehors de cette envelope brillante, qư il a recûë de la nature, fans que l'art y ait eû̀ d'autre part que d'en ôter le limon de la mer qui le couvre quelques fois. Des ondes \& des tlammes d'un rouge foncé y font repanduës fur un fond clair. Ce qu'on voit de noir à l'are de l'embouchure où les Contours rentrent, eft naturel, et provient du fuc que l'animal, lequel fe tient en tapon épais au haut de l'embouchure, rend, à la facon des Seches (*). L'animal même eft un Polype, qui fe tient attaché au milieu de la coquille par un cordon mince, lequel paffe au moyen d'un tuiau par toutes les chambres, dont nous parlerons plus amplement quand nous vỉendrons a la prémière figure de la Planche fuivante. La quille de ce Limaçon, qui ñage fouvent fur l'eau, eft ronde. Cet animal grandit fouvent jusques à un pié, ou un pié et demi, de diamètre, mais la Coquille ne devient jamais plus épaiffe qu'un Louis d'or. L'endroit où l'on trouve ces Limaçons en plus grande quantité elt le Cap de bonne efpèrance, à la pointe méridionale de l'Afrique, où ils ont coûtume de nager fur l'eau après les tempêtes. Ils font difficiles à prendre, et quand un Pê. cheur en attrape quelqu'un ce n'eft que par bonheur, à moins que le Limaçọn ne fe détache par accident \& qu'en s'elançant il ne foit jetté fur le rivage.

Figure 2. Voici le même Nautile, ou Voilier épais, dépouillé de cette Envelope extérieure, bigarrée, \& avec laquelle on ne fauroit nier que la peau infèrieure, qu'on voit ici, difpute de beauté, Aucune Nacre de Perle, fi belle foit-elle, n'aproche de cet ẻclat. Un fonel de couleur ar. gentine claire fur lequel des Hammes vertes, \& un rouge pareil à celui des fleurs de Pommier, fe jouent, avec les couleurs de l'Arc-en=ciel, toûjours nouvelles, de quel biais qu'on tourne la coquille, \& donnent à cette pièce un de. hors pompeux.

Autrefois les Artiftes le font fort peinez pour donner à cette coquille un noldveau prix par les traits de leur art. Les uns y ont entaillé des figures, d'autres les ont travaillées en relief, \& à jour, d'autres fe font contentez d'y buriner toutes fortes de deffeins, dont ils noirciffoient les lignes avec de la pouffière de charbon, de forte que l'on voyoit fouvent de ces coquilles \& qu'on en trouve encore, ornées de tous les cotez de figures hieroglifiques, de bacanales, de chaffes, de péches, de bouquèts ou autres ramages, d'hiftoires faintes \& profanes, de fentences, d'emblèmes, d'Armoiries, de noms, \&c. On mettoit ces Coquilles, decorées ainfi, en oeturre en or ou en argent fur un pied de même metal, \&, comme elles tiennent fouvent plus d'une pointe, on s'en fervoit comme d'un vafe à boire. On coupe quelques fois les Chambres par le milieu jusques au centre, $\&$ alors la Coquille repréénte un héaume trés élégamment figuré.

Ici le Lecteur voit entre autres vers le milieu une tache de couleur fombre, dont nous lui devons néceffairement rendre raifon, parceque cette tache eft un carątère diftinctif entre le Nautile \& la Corne d'Ammon. Car à la Corne d'Ammion on peut voir au dit endroit tous les Contours du Limaçon jusques au centre du prémier Tour, au lieu qu'au Nautile la Coquille eft fermée au même endroit. Les Cornes d'Ammon pétrifiées, fur tout les grandes, fe trouvent en abondance, mais on en voit très-rarement de $\mathrm{M}_{2}$

(*) Poifon fort baveux, latin Sepia. naturel 


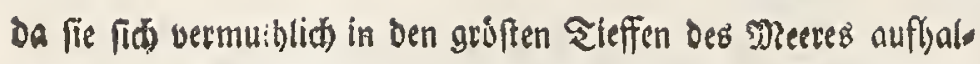

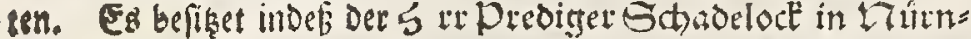
berg in feiner burterfiden Sammlung ein Derglciten Anmuns.

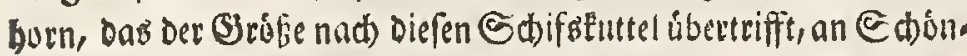
heit aber demfelben volleummen gleid) Pormmt. Die Echale ift

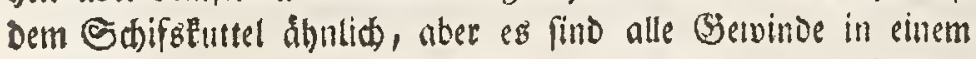

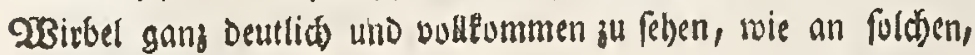
Die berfernett find.

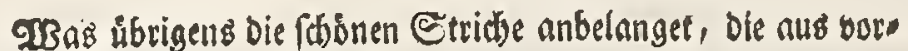
erwethnten miffárbigen Flecten bis zum limfang binanshaufen, to fino ferbige nud Meetmable, roie bie Sthaale filbit istesmabl einen neuen Buroabs betummen bat, uno von Batt ju Zeit grúfler worden ift.

\section{TAB. B. I.}

Fig. r. Der auf ber vorlhergellenden Safel sorlommende

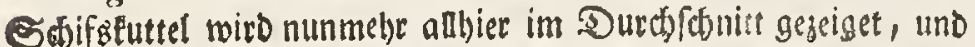
zarar fo, Daß alle Sammern bis jur Eleinften, Die in Mitteipunte

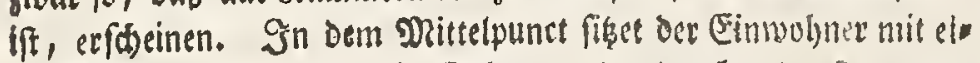

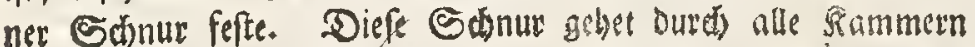
vermittelfe einer Siobre, bie úberal in Der Mlitte Der Edeiderwan. be befeftiget ift, bis in Dle forderffe uno weiteffe Sammer Durd,

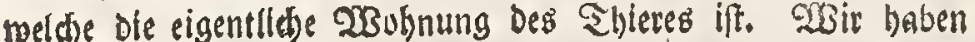

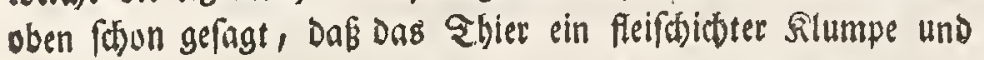

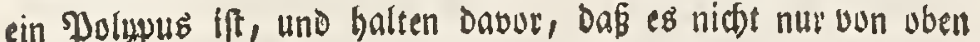
bie Edale burd einen neuen Zuwatis vergréffere, fondern auch jedesmabl, fo oft Das slier weiter bersur rúcfet, mit Dena Sain.

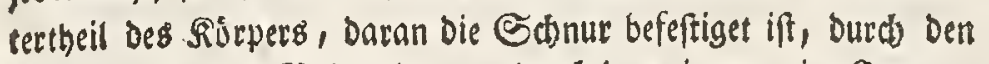

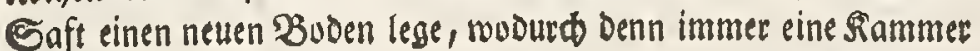
nad) Der andern entfethet. STun fibeinet es zrwar, als ob bie voro ber gebauten Sammern bem Shier bernach nidtet melyr nựen;

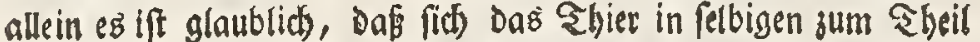

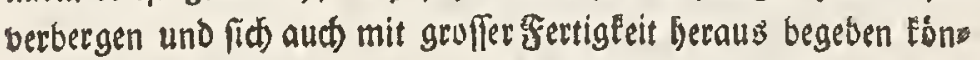

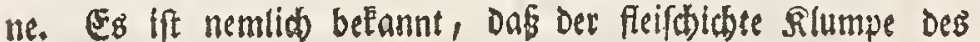

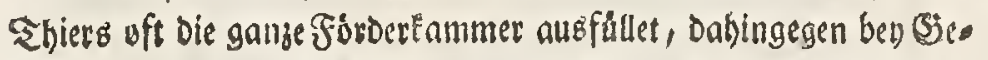

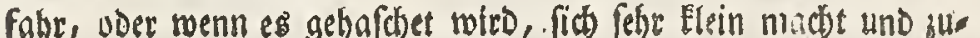
fammen Entechet. WSas Ean bier wubl anders vorgehen, als dás

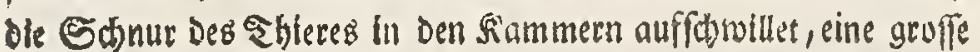

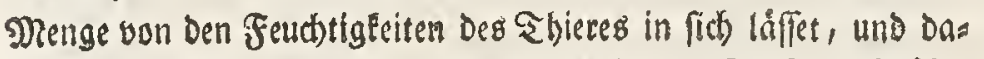

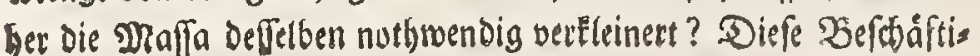

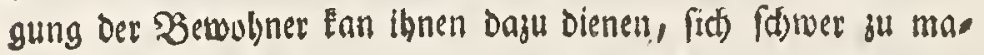

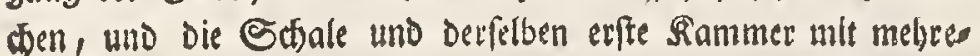
sen Wisafer anjufüllen, bamit fie finken uno unfidtbar twerden Pónnet. Dabingegen im andern Fall die Senmmern mieder leer und reidjer, aud alfo bie Bewobner zum fónimmen und feegeln túdtig gemadit twerden.

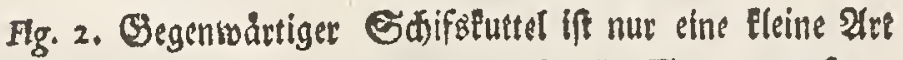
Des buebefthricbenen grufien, meldjer Tab. B. Fig. I. jul Fehen war, und bie felten gróffer wirb. Man bat dergleiden als Zweers

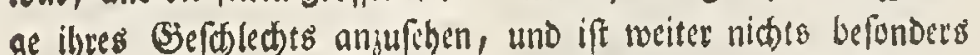

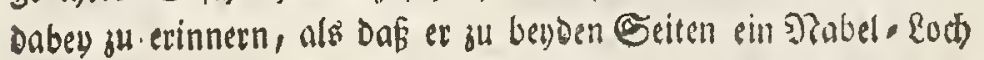
bat, Durd) weldtes man Durd Den Dittelpunct Der Gerwittbe gings

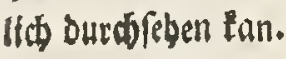

Fig. 3. Funmelyo aber folget etne gang andere 2lat Der

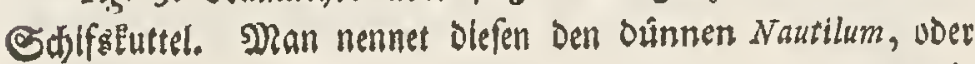

naturelles, parceque celles-ci habitent vraifemblablement les lieux les plus profonds de la mer. Cependant il y a dans ladmirable Collection de Mons. Le Pafteur Schadeloock à Nuremberg, une de ces Cornes d'Ammon, qui pafte le préfent Nautile 'en 'grandeur, \& qui l'égale parfaitement en beauté. La coquille en eft femblable à celle de nôtre Nautile, mais tous les Contours en peuvent être parfaitement \& diftinctément obfervez en tour fpiral, comme à ceux qui font pétrifiez.

A l'égard des belles lignes, qui, partant de la dite tache de couleur fombre, vont fe terminer à la Péripléerie, elles ne font que marquer. l'accroiffement fucceffif de la Coquille.

\section{PLANCHE B. I.}

Figure 1. Nous produifons dans la préfente figure encore le même Nautile ou Voilier, que nous avons vû fur la Planche précedente, mais ici il eft coupé par le milieu, \& cela de façon qu'on .en peut obferver toutes les chambres jusques à la plus petite, qui fe trouve au centre. L'animal fe tient attaché à ce milieu par un cordon, qui au moyen d'un tuyau, lequel eft affermi par tout au milieu des parois de féparation, paffe par toutes les chambres jusques à la prémière, qui eft la plus fpacieufe \& eft proprement la demeure ordinaire de l'animal. Nous avons déjà vû cy-deffus que ce Limaçon eft un tapon charnu, \& un Polipe, et nous préfumons non feulement qu'il aggrandit la partie fupèrieure de la coquille en lui fourniffant fans ceffe un nouvel accroiffement, mais auffi qu'à méfure qu'il avance avec la partie poftèrieure de fon corps, où le cordon eft attaché, il pofe au moyen de fon fuc un nouveau fond de chambre, ce qui produit une nouvelle chambre après l'autre. Il femble à la vérité ainfi que les prémières chambres conftruites par l'anitral lưi deviennent inutiles, mais il eft probable qu'elles lui fervent en partie pour s'y cacher en cas de befoin, \& pour en refortir auffi avec beaucoup de promptitude quand cela eft néceffaire. Il-a êté dit déjà que le tapon charnu de ce Limaçon remplit fouvent entièrement la prémière Chambre. Mais s'il lui furvient quelque péril, ou qu' il lui arrive d'être pris, il s'appetiffe alors, tant qu'il peut, \& il fe recoquille. Son unique moyen de falut en ce cas, eft de faire enfler fon cordon, \& de le remplir de tous les fucs dont il peut fe paffer, pour rendre fa Maffe plus petite. Cette précaution, \& celle de remplir d'eau fa prémière Chambre lui peut fervir à augmenter le poids de fon Total, pour aller plus aifément à fontis \& échaper de cette manière à la pourfuite de fes Ennemis. Dans le cas contraire, les chambres fe vuidant \& devenant plus legères, il revient fur l'eau, plus difpos que jamais, nager \& mettre à la voile.

Figure 2. Ce Nautile - ci n'eft qu' une petite efpèce du grand Nautile, que nous venons de voir fur la Planche précedente B. fig. I. Rarement ceux de cette efpèce deviennent-ils plus grands. On peut les regarder comme des nains dans leur Genre. La feule chofe, qui y elt particu. l.èrement remarquable, c'eft qu'il y a de chaque côté un trou umbilical, par lequel on peut voir de part en part au travers du centre des contours.

Figure 3. Mais voici toute une autre forte de Nautile, qu' on apelle le Nautile mince, ou de Nautile de papier, (Nau- 
Nautilum papyraceum, und verolenet Devfelbe eine genauere Bes foretibung. EB bat nemlid) biefer Slapirt. nautilus unten cinen platten Silel, Der uben an Der Sirummung formal, an Dem an.

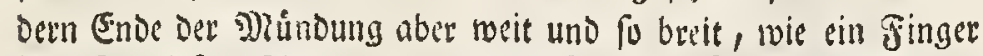

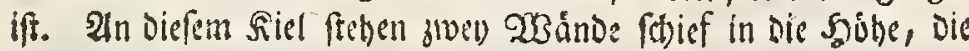
ween etwa viermahl fo breit vun einander abweicten, als unten Der Siel if. Diefe 2 Binde fino unten mit Bacten verfeten, bie úber ben stiel beraus faringen, und inmendig bobl fino. Bemeldete Zauten find Die Enden Der Falten, welde Die Schaale als gerunselt burftellen, und Da iberois die Edanale fo Dimne wie \$lapier ift, fo nenuet man fie diefer beyben 1trfatben balber Die Xammertubsbaube. Don Diefen dunnen Edjifstuts

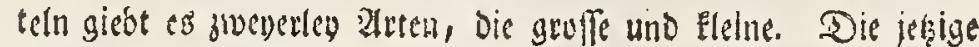
if Die grofie, uno wiro zumeilen nutbeinmal fo grof gefuncen:

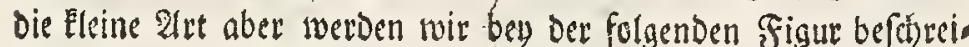

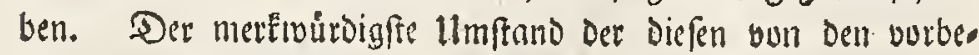

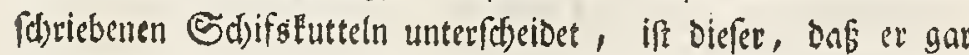
Eeine Farnmern hat, fonbern efnem bublen Salun bullEummen gleid Ift, am allerfeltenften aber ift es, dab ber Finmolyner, ben man barinnen finder, nirgenos an ber Edjaale feft fiter, weier ver= mitteft einer Sthnur voer 2oer, wie bey Dem Dicfen Esthifs. futtel, nud mit einer Senne, wie bey Den झlurdseln. Es if

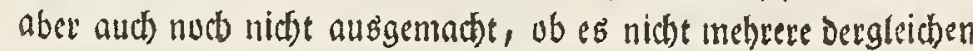

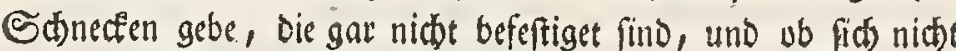

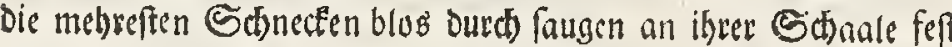

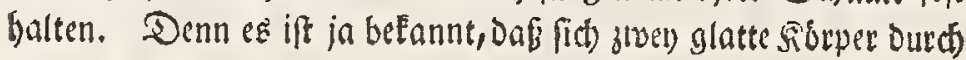

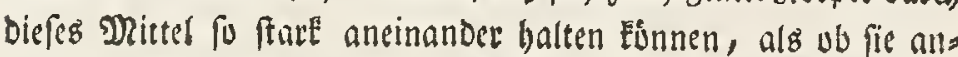
einander gewadbfen watren, weil fie fich in bielen Juntern bes túbeen, uno wer weis, wb nidt ber Einmobner biefes ounnen Sdbifsutulels Durd) undent(id) zarte Fafern in Den Sirúbgen feft. fig̨e, weldbe Die Zacken unten ain Siel baben, uno ob nicht biefe fafern in einem foldsen Shleim befteben, welder fich gleith auflufet, uno batier modj nidft hat entocetet weroen Eunnen? Indef bat Diejer llmftant die $\mathfrak{2}$ rt, wie Diefer Eintoubner fein

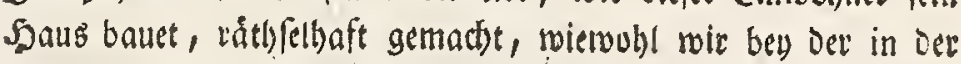
Einleitung angegebenen Meinung bon Dem Ilefprung ber Shan

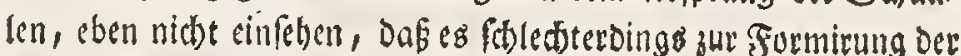
Sebaalen nuthwendig fey, Daf Dab Shier mit einem Sheil Des Siorpers an ber Edbaale feft fiben múffe. Denn wenn biefes cin notbiger limftuno wire, fo wurde nur ber llefprung voil Dem Sheil Der Ghanle, Der wưklid mit bem Slyier befeftiget ift, Deutlith gemaut, nidst aber gezeiget, wie denn Der ubrige frebe Sbeil Der Echaale fortmadje. E⿺ mangslt in ber शatur io nid)t an álnlicben Fållen. WWenn fid ein Seidentourtn eingeo fuonen, uno aus feiner wbern Decte eine Suppe verfertiget, felbiger aber bie $\mathfrak{G}_{\text {eftalt eines }}$ Schmetterlings angenummen bat, fo fict er in Der leşren Zcit in ber Juppe, ubne an Derfelben befeftiget uno angewad)fen zu feun, uno. Etrectit zu feiner Beit freu heraus. Sollte nun Der Eintoubner biefer Schnedfe ntcht auch alfo aus feinem eigenen Eaft rings um fid) herum sine

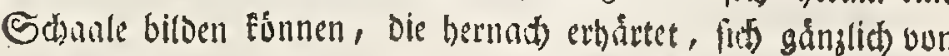
ilym ablifet, und ilgn fobann frey belierberget? Ja fulte, wenn

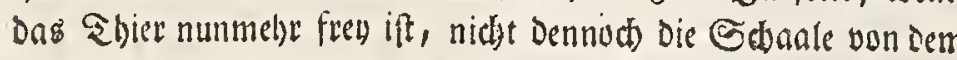
Snft, Der immer aus des Shlewes Sbrweifludern Dringet,

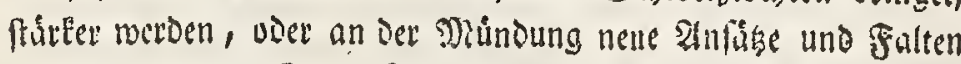
befummen, Das Sigia felber aber nid) immer groffer roetDen Bunnen ? WBir finien alfo Eeine siotbmendigkeit, anjunebmen. Daf Der in Diefer Génale gefundene \$olypus sin fremoer Ein roobner fetsn maffe. Belannt iff es jwar, Daf die Cumans,

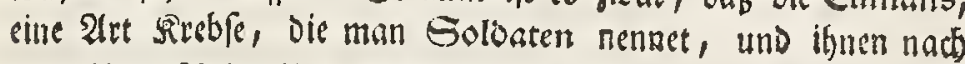
Dem Unterfdeid ibrer Scteeren ben Namen Diogenes voer

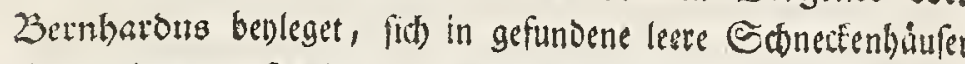
cinquartieren. allein bon folften Sonecten find ibre eligent. lidbe Einwobner becante. In biefem Stbifaluttel aberift, fo viet ilus papyraceus) qui méritc d’être examiné \& décrit en décail. Ce Nautile de papicr a en bas une Quille platte; il eft étroit en haut à la courbure, mais à l'autre bout de l'embouchure, il' eft large d'un travers de doigt. Sur cette Quille s'elèvent deux parois en ligne oblique feparées en haut par un efpace qutatre fois auffi large à peu près, que la Quille. Ces pa. rois font garnies en bas de dens, qui depalfent la quille, \& qui font intérieurement caves. Ces dens font les extrémitez des plis, qui font paroître la Coquille comme fi elle étoit rídee, laquelle étant d'ailleurs auffi mince que du Papier à occafionné par cette double raifon le nom qu' on lui donne de coife de Cambrefine, ou de toile de Cambrai. Il y a deux fortes de ce Nautile ou Voilier mince, la grande, \& la petite. Celle dont nous parlons ici eft la grande, qui l'eft quelque fois au double de ce qu'elle paroît fur nôtre Plan. che. Nous parlerons tout - à - l'heure de la petite. L'articie le plus remarquable qui diftingue cette pièce des Voiliers précèdens, c'eft qu'elle n'a point de chambres du tout, \& qu' elle reffemble parfaitenent à une nacelle vuide, \& ce qu'il y a de plus rare encore, c'eft que l'Animal qui habite cette coquille n'y eft attaché $d^{\prime}$ aucune façon, ni par un Cordon ou une Veine comme cela fe voit au Nautile épais, ni par un nerf ou une membrane comme on le re. marque aux moules. Il n'eft cependant pas décidé encore, s'il n'y a pas d'autres Limagons, qui comme celui-ci font attachez par aucun bout à leur maifon, \& fi la plus grande partie ne fe tiennent pas ferme à la coquille par le fimple fucement. On n'ignore pas que deux corps parfaitement polis peuvent fe tenir ainf l'un à l'autre auffi forte. ment, qụe s'ils ne compofoient qu'une feule \& mêtme pièce, parce qu'ils fe touchent bar plufieurs points, \& pourquoi ne voudroit - on pas admettre, au moins comme une poffibilité, que l'Habitant du Nautile mince tient à fa coquille par des filamens infiniment fins, qui s'infinuent dans les foffettes qu'on remarque en bas à la Quille aux dens qui $y$ font? \& qui f̧̧ait fi ces filamens ne font pas compofez d'une bave visqueufe, qui fe diffout d'abord, \& qui par cette raifon n'a pû être découverte jufques ici? Cependant cette difficulté a rendu problématique la manière dont cet animal conftruit fon habitation. Il n'en eft pas moins vrai qu'en fuivant le fentiment que nous avons hazardé dans nôtre Introduction fur lorigine des Coquilles, il n'eft pas effentiellement néceffaire que l'animal foit attaché à la $\mathrm{co}$ quille par quelque partie de fon corps. Car fi on le fupo. foit cela ne ferviroit tout au plus qu'à expliquer lorigine de cette petite partie de la coquille où l'animal eft effecti. vement attaché, \& la formation du refte de la coquille de. meureroit toûjours un problème. Il y a plufieurs cas femblables dans l'Hiftoire naturelle. Un ver à foie, quand il a paffé dans le Cocon, où il s'eft enfermé, le tems qui lui eft prefcrit par la nature, y eft à lá fin en pleine liberté, fans être attaché par aucun endroit, \& c'eft ainfi qu'il en fort transformé en papillon fans que rien l'arrête. Pourquoi le Limaçon ne jouiroit-il pas du même Privilège de fe con. Atruire une Coquille, qui fe durciffe autour de lui, qui s'en détache, \& qui le héberge enfuile en pleine liberté? Et pourquô̂ lui refuferoit - on dans cet état de liberté de ren. forcer fa coquille \& de l'aggrandir du coté de l'embouchure au moyen de ce fuc qui fort continuellement de fes pores, \& de prendre lui-même de l'accroiffement? Nous ne trouvons donc aucune néceffité à fupofer que lê Polipe trouvé dans cette coquille foit un hôte étranger. Il eft connu à la verité que les Camans, une forte d'Ecreviffes 
42

mir wiffen, nu(t) niemalls ein ander ₹bier, als eben diefer Syoly.

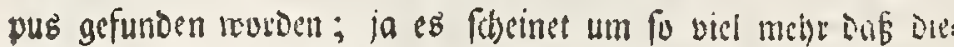

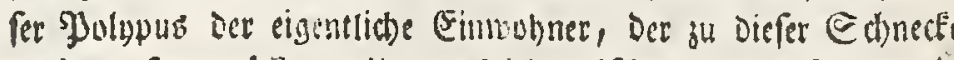

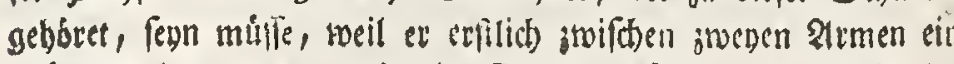
Wảutgen bat, Das er wie ein Coegel ausfyannet, um mit die fem Edifgen berumjufegeln, weld)es Şäutgen man ä anderen

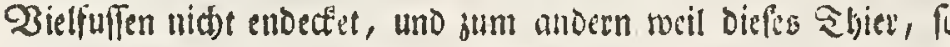
ungemein jart ift, gleid) ftirbt, menn man er aus ier Edjtale bló in ein 2 Saffer thut. Diefer befondere llmftano deg Ees

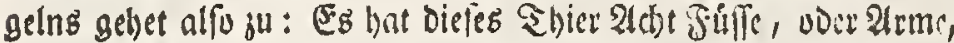

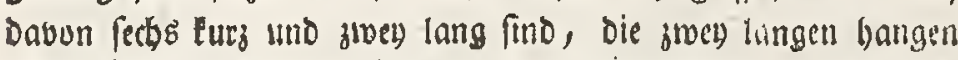
binten úber Der Schaale feraus, und Damit rubert es; Die zmey forberften 21 rme aber fipannen eine febr bưnne Szout aแż, in

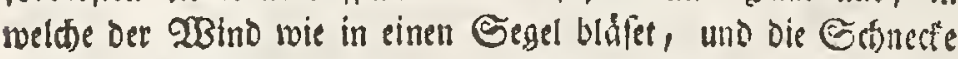

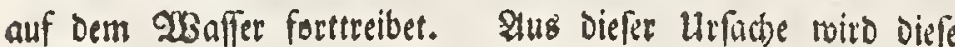
Sdnnede aud Argonauta, ober Das Gdiffergen genennet.

0

Fig. 4. Die andere 2 ant, weldie in defer figur abgebilbet noiro, if Elein, Durchadingig etwas gelblicht, oa jene fajneetweis

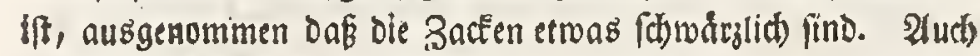
taufen an Der Eleinen bie Galten etwas weiter aus einander, uno bie Mảnoung ift oben viel breiter uno gerdumlider, als an Der gruffen, und biefer iftes alles, was twir von biefer Eleinen 2art зH erinnern finden.

\section{TAB. B. II.}

Fig. 1. Man madtt bey Der Rbtheilung ber Esthecfen eim

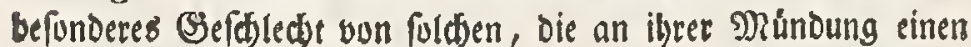
beraustrettenden \&appen haben, und diefe nennet man Alatæ oder Flugelf fhreden. Diefe theraustrettende fapts al fino num am Fianbe entweder glat, uber es ragen an demfelben nud Bacten, ober Stad)el hervor, im leșten Sall baben aud) einige fie Stathel. fChnecten genennt ; fie find aber bon folden, bie Murices belfen, uno

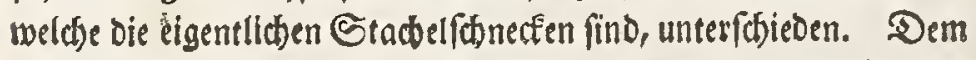
aber ju folge, was wir in Der Einleitung von Dem 23 achsthum

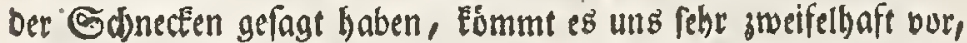

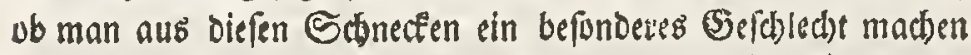

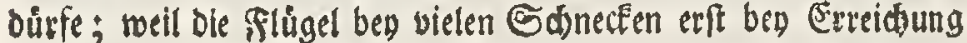
eines getwiffen Alters angebauet werben, wie mir foldtes an ben

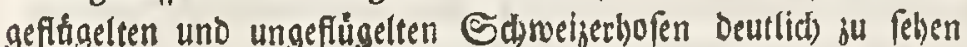

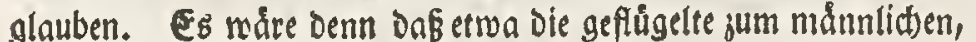

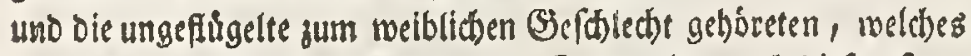
ung bis dalyin nuch unbelannt ifs. Collte aber audi) biefes fiun, fo músen Doch bie gefluggelten mit ben ungeffigetten in gleichers

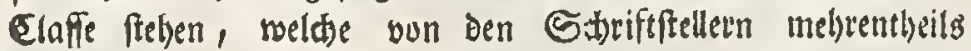
getrennet worben find. Dem fey injwiften, wie ilym wolle,

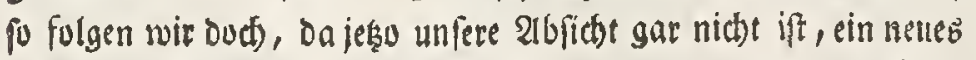
Evfrema zu mad)en, ber allgemeinen uno angenvtamencn Dei-

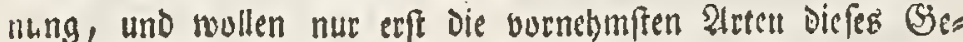

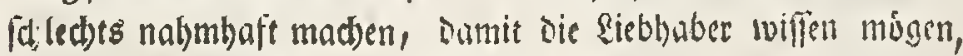

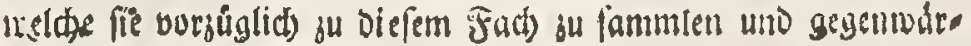
uger Figur beyjufígen baben.
逼

qu'on apelle soldats, \& qui, felon que leurs ferres font faites, portent le nom de Diogènes ou de Bernards, \& le logent volontiers dans les coquilles de Limaçon, quand ils les trouvent vuides; mais les Limaçons, dont on trouve ainfi les coquilles vuides, font connus, et jamais, que nous fçachions, on n'a trouvé dans ce Nautile d'autre Animal que ce même Polipe. On a outre cela deux preuves, qui rendent l'opinion, que ce Polipe eft réellement l'Habitant propre de cette coquille, trés - vraifemblable, c'eft qu'en prémier lieu il a entre les deux bras une Membrane deliée qu'il met au vent comme une voile, pour nager \& aller du côté qu'il veut, \& qu'àcun autre Polipe n'a la même Mcm. brane; \& qu'en fecond lieu cet animal, naturellement trésdélicat, meurt fur le champ, quand on le tire de fa coquille, \& qu' on le met fimplement dans de l'eau. A l'égard de la qualité propre à ce Limaçon, d'aller à la voile, il y a les remarques fuivantes à faire. Il a huit pieds, ou bras, comme on voudra les nommer. Six de ces pieds font courts, \& d'eux font longs. Les deux pieds longs pendent fur le derrière hors de la coquille, \& fervent à l'animal de rames. Les deux pieds ou bras de devast fe tiennent élevez, \& tendent une membrane trés - mince qui fert de voile, au moyen de laquelle le Vent qui y donne fait aller la $\mathrm{Co}$ quille fur l'eau. Cette fingularité a fait donner à ce Limaçon le nom d'Argonaute, ou le petit Nautonnier.

Figure 4. Ceci eft la petite forte du même Nautile. La Coquille de celui-ci eft un peu jaunâtre, au lieu que celle de l'autre eft blanche comme neige, aux dens près qui tirent fur le noirâtre. Les plis du. petit Nautile font auffi moins ferrez que ceux du grand, \& fon embouchure eft beaucoup plus large \& plus fpacieufé qu'au prémier. $C^{\prime}$ eft là tout ce que nous en pouvons dire de particulier.

\section{PLANCHE B. II.}

Figure I. Les Auteurs, qui ont écrit fur les Limaçons, ont coûtume dans leurs Divilions de faire un Genre particulier de ceux, qui ont à l'embouchure un lambeau fortant, \& qu'on apelle Limaçons ailez. Ces Lambeaux fortans font ou unis au bord, ou on y remarque des dens ou aiguil. lons. Dans le dernier cas quelques Ecrivains leur ont auff donné le nom de Limaçons à aiguillons. Cependant ceux-ci diffèrent de ceux qu'on apelle Murices, \& qui font propre ment les Limaçons à aiguillons. Avec cela, en fuivant les principes que nous avons pofez dans nôtre Introduction fur l'accroiffement des Limaçons, il nous paroit douteux qu' on doive faire un Genre particulier de cette forte-ci, parceque quantité de Linaçons ne prennent ces ailes on lambeaux qu'en vieillifant, ce dont felon nous les Culotes de fuiffe ailées \& non-ailées fourniffent une preuve. Peutêtre les ailées font-elles les mâles \& les non-ailées les femelles, ce que nous ignorons jusques ici; mais quand cela feroit, on ne s'en trouvercit pas moins dans le cas de les ranger dans la méme Claffe, au lieu que plufieurs Auteurs les ont féparé. Quoiqu'il en foit comme ce n'eft pas nôtre intention préfente d'établir un 'sifteme nouveau, nous fuivrons l'opinion génèralement reçîè, \& nous nous contenterons d'indiquer les noms des principales efpèces, afin que les amatetrs conoiffent les pièces qui apartiennent préferablement à cette Claffe, \& qui font les plus dignes d'être rangées auprès de celle dont nous donnons ici la figure. 


\section{(4)}

Bu ben Flůgelfonecten beren \&appen Bacten baben, gebos ren unter andern bie Tenfelsetaue, welde in gegenwarrtiger sio gur su fehen, fodann ber Siorpion, Der Zorsbacte, die Rrabbe, ons Taufenobein, uno die Poongra Shnnette,

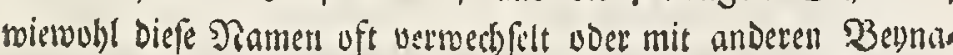
men, wie er Denn bey allen Sodrecten und Dufabeln gehet, vermelyet werden.

3u Den Flügelfóneffen aber Deren \&appen am Siande gleid

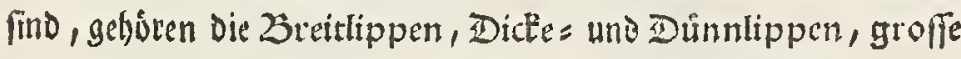
und teine bezansfeegel, fedter, Gommeriproffen, Sar mat, Subonefer, Canatien=Srbnecten, Lapboriter, und Dergleithen mely.

Nod) wird gu diefen Glighelftonecten eine \{rt geredinet,

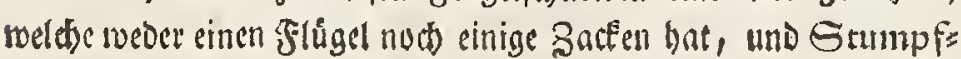
gen genennet wiro, weil man fie vor arseibgen in Dieper Elaffe bâlt.

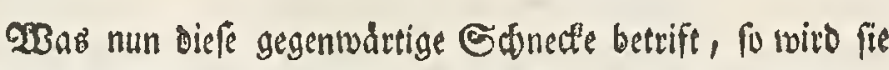

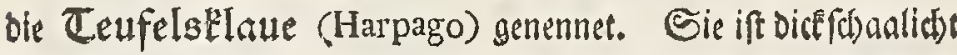
uno fahwer, wiro ofs fehr gros, bat an dem limfang bes unter fren Gerwinder dicke und grufe Sinuten, ift íber und úber mit

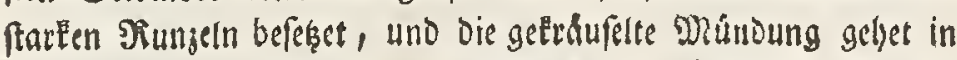
fúnf langen Zacten aus, Dabingegen Der fechfre Zacten bie

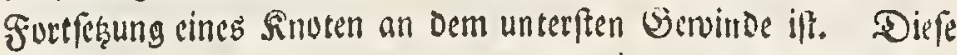
Zacten find bey etliten von unten tobl, wie die Situnen, bey

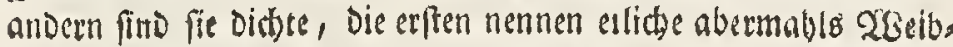

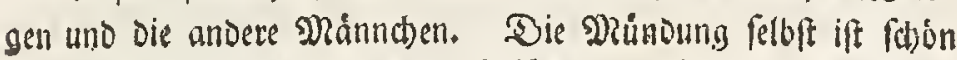

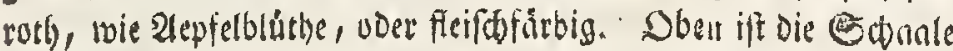
gefprenfelt und hat Dunteltuthe woes braune Flammen auf sinen wertien Sirund.

Fig. 2. Gn biefer und in Den Drey folgenden figuren formunt

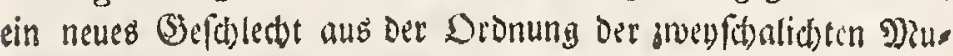

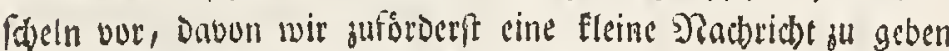

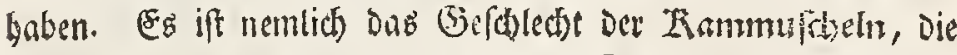
swar in groffe uno kteine, Das if in Peetines uno Pectunculos eingertheilet "werden, aber vorjúglich) Daran ju Eennen fino, Dak Die erfisen Dhreen haben, Die andern aber Eeine.

Sie weroten alle mitcinandit Khammuftheh, voer auds Gtrablunufatehr genennet, weil fie uben vom Sdlub an bi unten zam Siande ju Falten uner Futden baken die minoer vDer melys tief und neben cinander liegen, uno roie Strablen aub cinem MRittelpunct austaufen. 23on Denen, bie Disen haben grebtes etlicber, bie jwey gleidbe, ober ungleitfe, voer auch nur ein Dhe

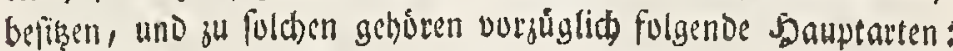

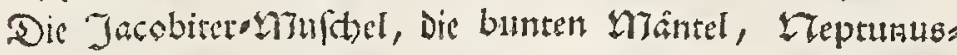
Dofen, Compas:triufthel, Gonnenseiger, Corallen:Doub Let, und geripte Denus=0 onblet, und pon brefen find atlide an

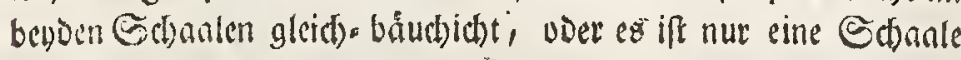
biuchidtet uno die andere plats. Die andere, Die mit Eeinen Dhren

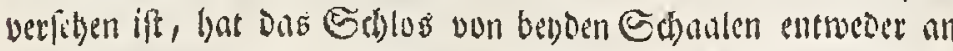

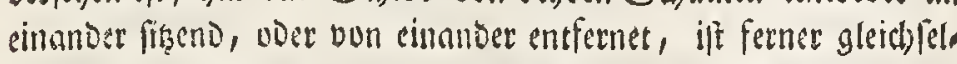

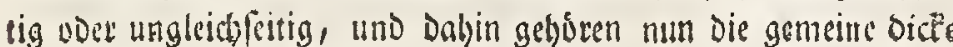

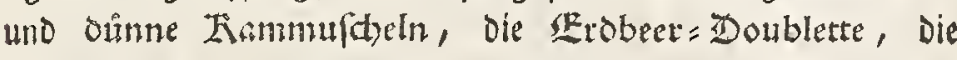
Rafpel, die Jungferns Rammufhel, fodann Die oumes

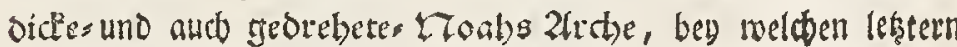
Das Schlug porn cinawber entfernet felhet.

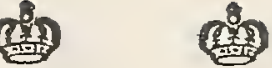

La Griffe du Diable, dépeinte dans la prélente figure, enfuite le Siorpion, le Hirpon de nacelle, le Cancre ou Crabe, le Millepieds (*) le Limacon gouteux, doivent entre autres être mis au rang des Limaçons ailez dont les lambeaux font dentez. Nous devons pourtant avertir le Lecteur, qu'on n'eft pasigénéralement d'accord fur ces dénominations, que l'on échange fouvent, ou y en ajoute d'autres, ce qui arrive à tous les Limaçons, \& à tous les Moules.

Les Limaçons ailez dont les lambeaux font unis au bord, c'eft-à - dire fans dens, Sont les 'Babines larges, les Babines épraifes, \& les minces, la grande \& la petite Voile d"artimon, le Tireur d'armes, les Roufjeurs ou Lentilles, le Samar ou la Queuë (**) le Limaçon de Luhon, le Eimaçon en Serin de Canarie, le Limaçon à lambeaux, \&c.

Il y a encore une efpèce qu'on range parmi les Lima. çons ailez, quoi que celui-ci n'ait ni ailes ni dens. C'èft le Moignon, qu'on regarde comme la femelle de cette Claffe.

Venons à nôtre figure. C'eft ce qu'on apelle la Griffe dis Diable. La Coquille en eft épaiffe, péfante, \& par vient fouvent à une grandeur confidérable. On voit fur la circonférence du plus bas Contour des Tubercules gros \& épais, \& toute la coquille eft couverte de fortes rides. L'Em. bouchure, qui eft frifée, aboutit à cinq crocs longs. Ce qui parôt faire le fixième n'eft que la Continuation d'un Tubercule, qu' on remarque au deffous du plus bas Contour. A quelques uns de ces Limaçons les Crocs font cavez com. me des goutières, aux autres ils font folides \& pleins. Quelques Ecrivains prennent les prémiers pour des femel. les, \& les autres pour des mâles. L'Embouchure même eft d'un beau rouge femblable à celui de la fleur de Pommier, ou couleur de chair. La Coquille eft tachetée, \& l'on y voit des flammes d'un rouge foncé ou brunes fur un fond blanc.

Figure :- Cette Figure \& les trois fuivantes font d'un genre tout nouveau de l'Ordre des Moules bivalves. Nous en dirons quelque chofe en général avant d'entrer dans le détail. Ce Genre eft celui des peignes, que l'on divife en grands \& petits, c'ett-à-dire en' Peignes \& en Pétoncules. qu'il eft facile de diftinguer, parceque les prémiers ont des oreilles \& que les autres n' en gnt point.

Ils portent tous le nom de Peignes, ou de Moules a rayons, c'eft à dire ftriéz ou cannelez, parce qu'ils ont depuis la fermeture jusques au bord des plis \& des canne. lures, plus ou moins profondes, qui partent d'un mème centre, toûjours placées l'une à côté de l'autre. Parmi les Peignes à oreilles il y en a quelques uns, qui ont deux oreilles égales, d'autres les ont inégales, \& d'autres encore n'en ont qu'une. Il faut y compter comme des Efpèces principales celles - cy: La Coquille de St. Laques, les Manteaux bigarrez, la Tabatière de Neptune, la coquille à boufjole, le Cadran Solaire, le Doublet de Corail, le Doublet de Venus à côtes, entre lesquelles quelques unes ont la Coquille fupèrieure \& l'infèrieure auffi ventruë l'une que l'autre, à d'autres l'une eft feulement ventruë \& l'autre eft platte, Quant à celles qui n'ont point d'oreilles, elles diffèrent entre elles en ce que la fermeture des deux Coquilles fe trouve jointe l'une à l'autre par les deux pointes, ou les deux pointes font feparées l'une de l'autre, \& encore en ce qu'il y eñ a à cotez égaux \& d'autres à côtez inégaux. $\mathrm{N}_{2}$

$(*)$ Ou la Scolopendre.

(**) s'cricrend la Queuë de robe ou d'habit, que les Dames de ditinition tont porter par un Page. 
Tels font les Peignes. épais ou minces, les Doublets de fraife, la Rape, le Peigne des Demoifelles, \& enfuite les Arcbes de Noë minces, épaifes, ou tournées où une partie de la fermeture eft éloignée de l'autre.

WBas num biefe figur betrift, fo wird ung in felbiger eine

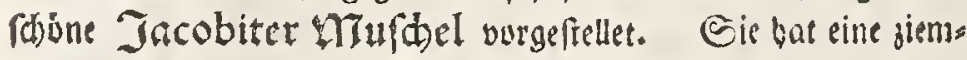
lid) Didfe Eduale, breite uno tiefe Falten, nuf welden bicle Furden liegen; grwifden Diefen Furdien find eine Minge Sierben befindlit, Die in einem rumben Bougen liegen, uno von Dem

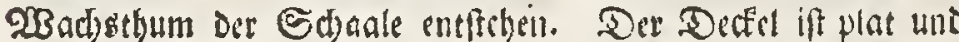
Thtieffet mit dunlititen Fralten in Die Furthen Der unteren Sdjale,

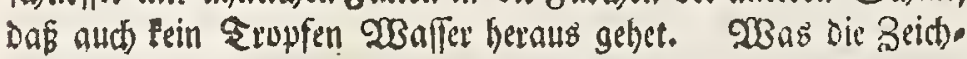
nung uno bie Farben betrift, fo giebt es erftaunlidis diele sabuei dungen; Denn etlid)e find weis, gefprentelt, vuth), gelb, braun,

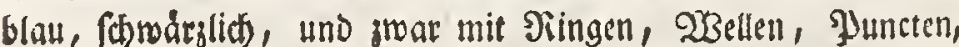
Flecten, vier auth einfárbig. Lleberdas hat man audt) eine Élcine und eine groffe Art ju betnerlen, Da es Denn bie meifen 2er.

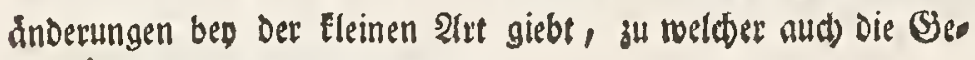
gentwarttige nodb geredonet wird.

Fig. 3. Die in biefer Figur abgebildete Ctratimuftat

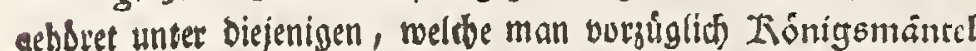

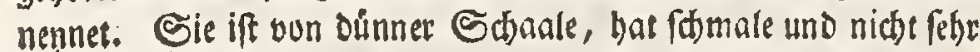
erhabene Siippen, einen nidst febr baductidten Dectel, uno prano get mit Den fésunften Farben, Die allenthalben mit Dem Sianbe gleidfeitig laufen, und aus der Figur felber náber zu erfehen find.

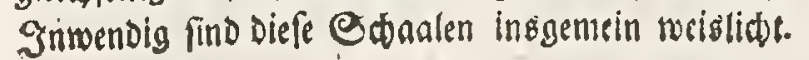

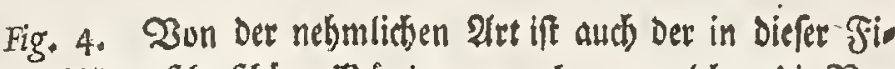

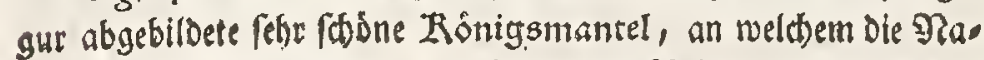
tur alle moglidbe Gunft Der Nablerel foteinet angerwendet gu baben. Die Beffiffenteit Der Earale if mit Der vorigen gleid, wegen den fitionen zarten Einien aber, die bum Gojluffe an bis zum Fiande auslaufen noird fie aud) ber Gomnenzeiger, ja von etlicten (wiewobl mit tlneecht, ) Cumpas - DRuffiel genentret, Denn bie dadte Compas. Muffiel if bun gan anderer

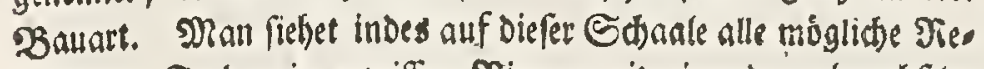
genbugen Farben in gerviffen Fingen mit einander abwedsfeln,

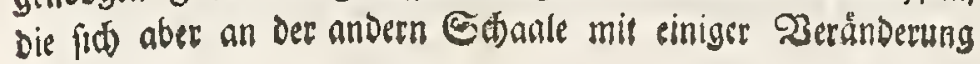
zeigen.

Fig. 5. Qtus ber \&ufferlichen Ettuctur biefer Doufcel et:

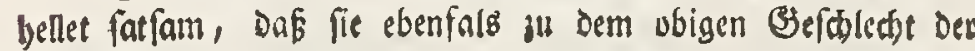
Gtrablmuftheln voer bunten Miântel gebóre, detur fie if mit eben foldeen grufen Fralten ver fehten, als Diejenige, Die twir in Der Fig. 2. erbliften, nur belismmt fie zweyerley Himfránde balber eis nen befundern Tamen. Waseil fie eine fegr bud rutbe Curallens farbe und auf jeber Falte untell gerum ein paar ergabene DBudel hat, Die Den gearbeiteten Corallen nidt ungleid) find, fo beifet fie Das Corallen'Doublet. Die huderuthe Farbe if nicht bey allen gleith, benn ers giebt auth blaffe, Jjumerauzenfárbige

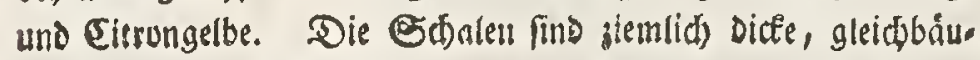

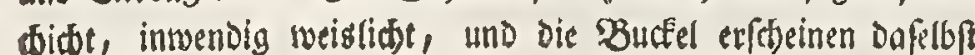
ausgetsiglet. Das siefe nur ein Oby but, if tridst allgemein, fone Deen tan Durd einen Bufall gelummen fegn; inderm die meifen

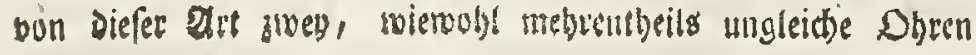
haber.
La préfente figure eft celle d'un beau. Moule de St. laques. Il a une Coquille affez épaife, \& des plis larges et profonds, fur lesquels on voit plufieurs cannelures. Entre ces cannelures on remarque beaucoup d'entailles rangées en arc, qui proviennent de l'accroiffement de la coquille. Le Couvercle eft plat, \& fes plis s' ajuftent fi parfaitement à la cannelure de la coquille inférieure, que quand les coquilles font fermées, il n'en peut pas fortir une goutte d'eau. Pour ce qui concerne le deffein \& les couleurs, qu'on y remarque, il y a à cet égard un nombre étonnant de variations. On en voit de blancs, de tachetés, de rouges, de jaunes, de bruns, de bleus, de noirâtres, dont les uns font marqués d'anneaux, d'ondes, de points, de taches, \& quelques uns font de couleur unie. Outre cela il eft à obferver qu'on a de grandes \& de petites cöquilles de cette efpèce. C'eft parmi les petites qu' on aper. çoit le plus de variations, \& c ceft de cette forte qu'elt nôtre figure.

Figure 3. Le Moule à rayons, ou ftrié, qu' on voit ici, eft de ceux qui portent par préfèrence le nom de Manteau royal. La Coquille en eft mince, \& a des côtes étroites \& péu élevées, un couvercle peu ventru, et qui brille des plus belles couleurs, qui vont toutes en paralléle avec le bord. On voit cela mieux à la figure même, qu'il n'eft facile de le décrire. Au dedans cette coquille eft ordinairement blan. châtre.

Figure 4. La nature femble avoir épuifé l'art de la Peinture fur le magnifique Manteau royal qui fe' préfente ici \& qui eft de la même efpèce que le précèdent, qui refièm. ble parfaitenient d'ailleurs à celui - ci quant à la qualité de la Coquille. Les lignes belles \& fubtiles, qui vont de la Charnière au bord, font donner par quelques Auteurs à cette coquille le nom de Cadran Solaire, \& d'autres l'apellent aufif la Coquille à bouffole, mais ces derniers ont tort, car la véritable Coquille à bouffole, a une ftructure toute diffè. rente. On voit fur cette piece toutes les couleurs poffibles de l'Arc-en ciel, alternativement placées en forme d'anneaux. Les mêmes couleurs paroiffent fur ' 'atre coquille, mais avec quelque variation.

Figure 5. La ftructure extérieure de cette coquille prouve affez qu'elle eft du Genre des Coguilles à rayons cannelées, ou des Manteaux bigarrez, car elle a les mêmes grands plis que nous avons vû fur fig. 2. Deux raifons lui ont fait donner le nom, particulier de Doublet de Corail, l'une eft que fa couleur eft la même que celle des plus beaux Coraux rouges, \& l'autre qu'il y a fur chaque pli au bas deux boffettes élevées qui ont beaucoup de raport avec les Coraux travaillez. Toutes les coquilles de cette espèce n'ont pas la méme Couleur ponceau, car on en voit auffi qui tont pâles, ou couleur d'orange, ou couleur de citron. Elles font affez épaiffes, ventruës également, \& au dedans blanchâtres. Dans cette partie intérieure les mêmes boflettes qu'on a vîës élevées au dehors parciffent cavées. C'eft un cas particulier que la préfente coquille n' ait qu'une oreille, ce qui ne peut être que l'effett d'un accident, car génèralement les coquilles de cette efpèce en ont deux, le plus fouvent inégales. 


\section{(1) 6}

Fig. 6. Zon ben groeyftalidieen Muftheln gehen wir wles

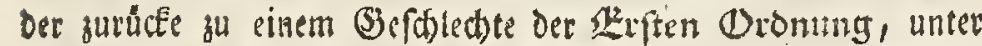
roel. begreift. Ulnter fotchen lommt nun auch sas Befthlect)t vor, wethes man ZKinthórnev, voer Succina nennet, und da

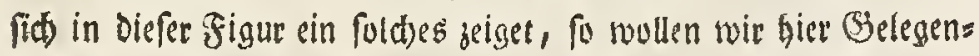

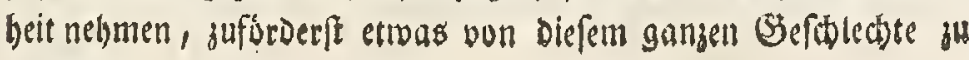
ragen.

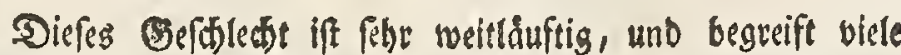

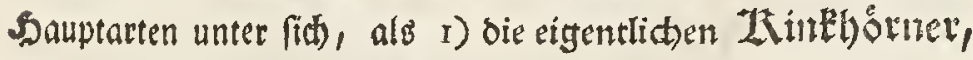

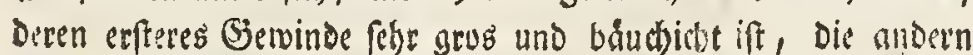
aber Ilciner fino, unt wie eine Eurze Piramioe in einer Exighe austaufen. Gbre Mrúnoung ift mittelmápig weit uno geher in eine Eleine ftumpfe ausgebogene Epalte aus. Dahin gethoren

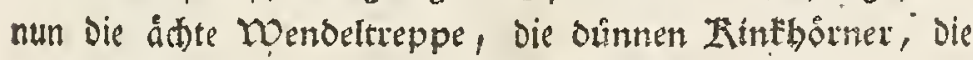

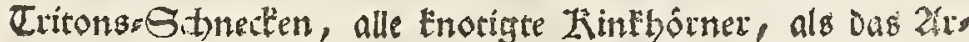

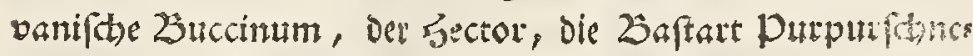
cke, und alle Derfelben Llnterarten und Abtweidjungen. 2) Die Etraubfinnecien, (Strombi) uber fuctere, Die eine formable SMandung haben, und in eine långere Syiramide ausgeben; alo die Z3ifhofsmitsen, Pabfteronen, unådte Wendelterppen,

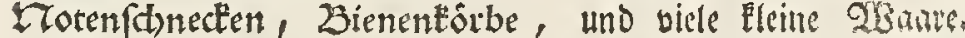

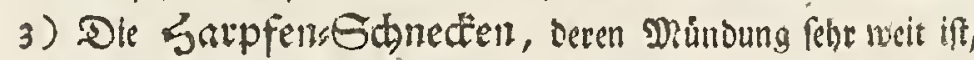

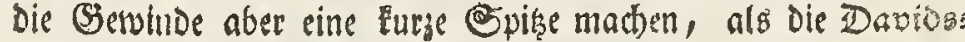

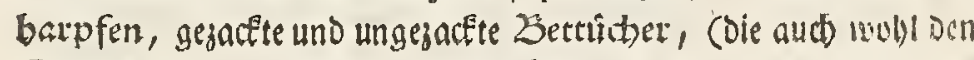
Sturmbauben (caflides) beugęållet werven) fleberntâufe, 25abylonifine Tburme, u. D. m. 4) Die Gpindeln, Deren mR unoung in einer langen Siine austăuft, als bie lange uno kurze Spindeln, 5) alle Zituformitge Situdeden,

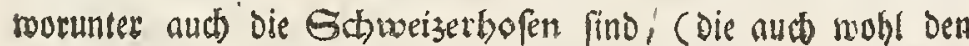
Stadbelfonecten (murex) bengeballat merien.) 6) Die

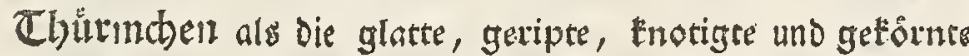

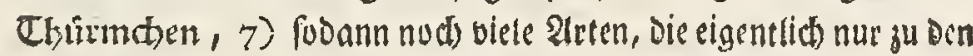

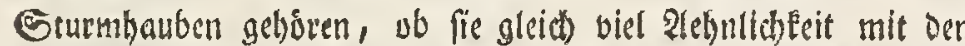

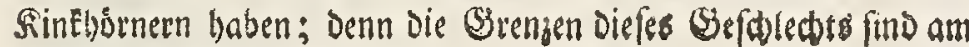
allerformerferen ju beftimmen.

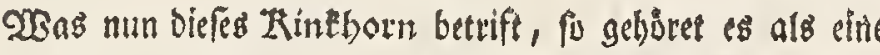

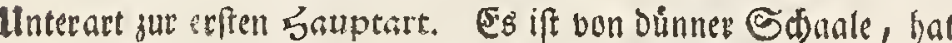
einen róthlithen Sruno mit breiten braunen Wasellen, blettet aber Elein. Won bicfer nelymlitsin Unterart fino nun viele æloweis

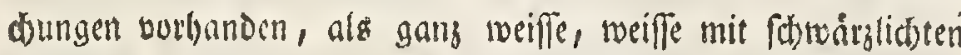

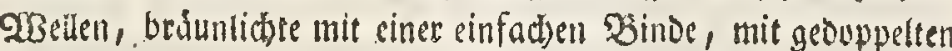
gilsen, selben uno ruthen, weiffen uno fitwarzen, fdymablen uno breiten Binben, die um die Serwinde herum laufen. 'OSBir führen biefen llmftano nur besroegen einmal an, Danit man

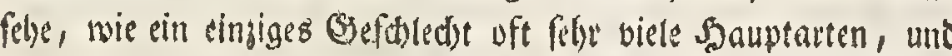
cine linterart oft ungemein viele abtoeidungen babe; Hebrigell aber iftes eine Seltenbeit, das diefe Gesnecte tines getwanden iff.

Fig. 7. Diefe uno Die ztwen folgende figuren liefern abere

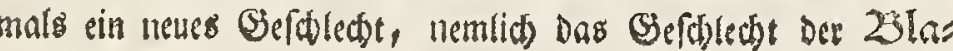

Figure 6. Nous quittons ici les Moules bivalyes pour revenir à un Genre du piémier Ordre dont l'une des Claffes principales renferme tous les Limaçons à figure tournée. C'eft dans cette Claffe qu'il faut ranger ceux qui portent le nom de Buccins, \& comme en voici un de cette forte, nous en prendrons occafion de dire quelque chofe du genre entier.

Ce Genre eft fort étendu \& renferme un grand nombre d'espèces. Telles font $r$. les Buccins proprement ainfi dits, dont le prémier Contour eft trés-grand $\&$ fort ventru. Les Contours qui le fuivent font plus petits, \& aboutifent en pointe en forme d'une Piramide courte. L'Embouchure eft médiocrement fpacieufe \& fe termine en une petite ouverture obtufe \& retournée. C'eft ici qu'il faut placer le véritable Efcalier en caracol, les Buccins minces, les Limaģons en Triton, tous les Bucrins noueux ou à tubercules, tels que le Buccin d' Arvan, le Hector, le Limaçon de pourpre bâtard, \& toutes les Sous - efpèces \& V Variations de ceux que nous venons de nommer. 2. Les Strombes, ou les Limaçons à embouchure ctroite, qui fe termineint en une Piramide plus longue, tels que la Mitre Epifcopale, les Couronnes Papales, ou la Tidre, les Efaliers en caracol bâtards, les Coquilles notées, la Rucbe, \&z bien d'autres petites piècès. 3. Les Limaçons en barpe, dont l'embouchure eft trés-large, mais dont les Contours fe terminent en une pointe courte, tels que la Herpe de David, les Linceuls, ou Draps de lit, dentelez, \& non-dentelez, (que quelques uns, mettent auffi au nombre des Cafques) les Cbauve-Souris, les Tours de Babilone, \&c. 4. les Fufeaux, dont l'embouchure fe termine en une longue rigole, tels que les Fufeaux longs ou courts. 5. Tous les Limą̧ons formés en poire, au rang defquels fe trouvent les culotes de Suiffe, que quelques uns mettent auffi au nombre des Lima. çons aे aiguillons. 6. Les petites Tours telle que l'unie, celle à côtes, la noueufe ou tuberculée, et les petites Tour's grainées. 7. Et enfin encore quantité d'efpèces qui apartiennent proprement au Genre des Cafques, quoiqu' elles ayent beaucoup de reffemblance avec les coquilles Sabotes, ou Buccins. Rien n' eft plus difficile que de déterminer avec jufitefie les limites de ce Genre.

Quant à ce Buccin ici, il faut le regarder comme une Sous-efpèce de là prémière espèce principale. Sa Coquille eft mince, la Couleur du fond eft rougeâtre, \& l'on voit au deffus de larges undes brunes; mais il demeure ton̂jours petit. On a quantité de variations de cette Sous - efpèce. Les Coquilles font ou abfolument blanches de tout point, ou blanches à ondes noirâtres, ou brunettes à bande fim. ple, ou à doubles bandes jaunes, jaunes \& rouges, blanches \& noires, ètroites \& larges, lesquelles environnent les Contours. D'où il refulte entre autres qu'on trouve fouvent dans un feul \&z même Genre quantité d'efpèces principales, que chaque efpèce principale renferme beaucoup de Sous-efpèces, \& qu'on obferve à chacune de ces Sous-efpè. ces un nombre extraordinaire de variations. Ce qu'il y a de très - particulier à cette coquille \& qưon rencontre trés rarement, c'eft que les Contours vont de la droite à la gauche.

Figure 7. La préfente Coquille \& les deux fuivantes font auffi d'un Genre tout nouveau, c'eft celui des Lima- 
46 身

fenformigen, ober Ituget und Gbellenfinnedent. She

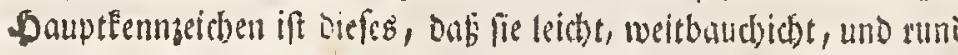

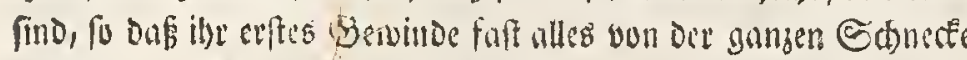
ausmadst. Sie junt aber oemucts in volltemmen rumoe uno in

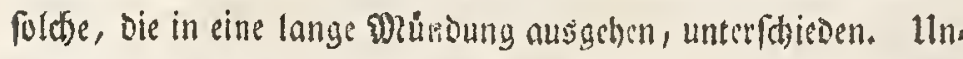

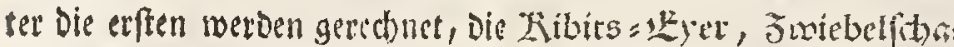

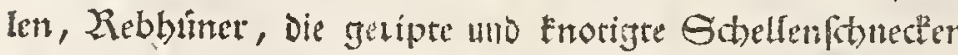
u. D. Su Den andern aber zehlet man Die Seizen, Die Slajdzem

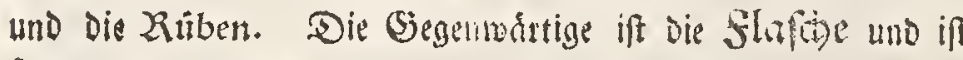
faft mit Den Feigen einerley, nur find Die Jeseigen etwas mibr Bimformig, an Den flafchen aber ift Der Sals melye einges Druct, und Der úbrige Fiorper mebr tugelfónnig. Es ift die

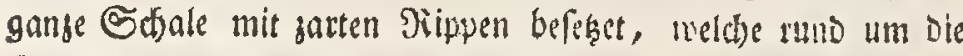

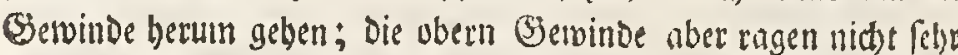
hervos. Die Farbe ift an diefer getblidst, beg anderen meis

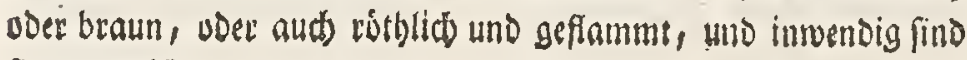
fie alle weis.

Fig. 8. Nach Der flafdye fulget ber Rettig (Rapa).

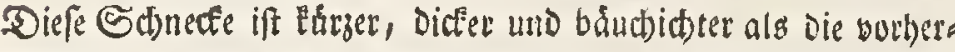
gebende, fo Dás man fie gar nobll einem Siettig vergleichen fan.

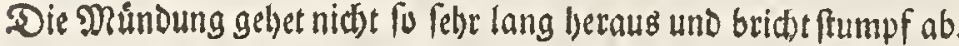
Es ift aud bie buble Siinne, toomit fich die Mủnoung endiget,

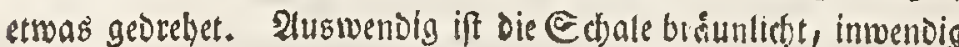

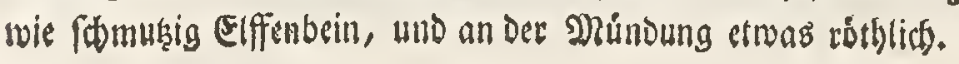

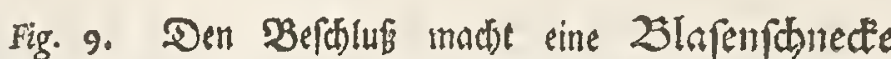
ohne Salb, meldfe man die J̈wibelifhale ju nennen pfeget. 2)at bat zwar Edfrifteteller, Die biefe Ethnecte unter die

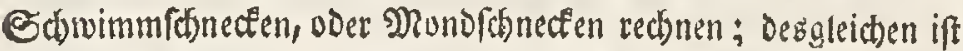

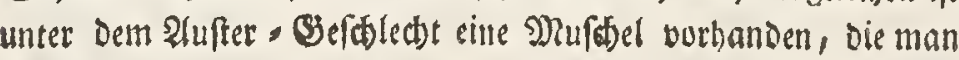

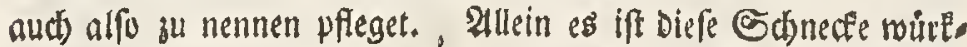
(iid) eine Pebenart von ber banditten Jiviebelfthale, bie alles.

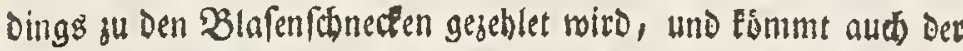
Structur nad) mit jener volfummen überein. Die Farbe ift rotblid und bat weiffe Slammen, inmenoig iff fie blabgelb.

\section{TAB. B. III.}

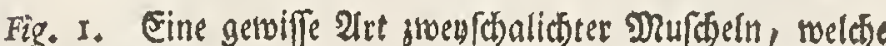
burchgangig uffen frelyen, und gleitffaun gaffen, werden Chamæ, oder Gientmuftheln genennet, und macten in Der zweyten Dronung ein befonderes Gefofledts aus. Sie merden aber in raube und glatte Sienmulfifeln cingetleilet. Su ven rauben ges

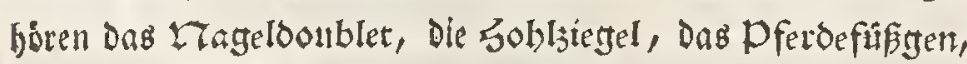

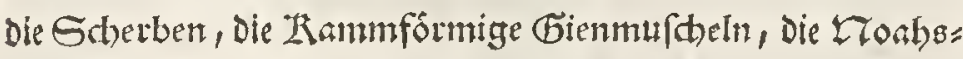
Mufthel, Der Q Qutadrant, U. D. m. Su Den glatten aber gelobren alle Enten sun glatten Gienmufiteln, Die Buscter, uno pers

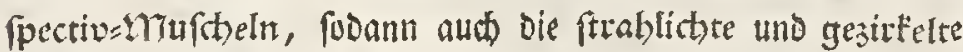

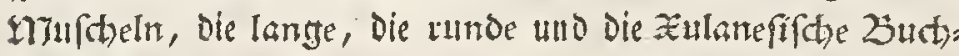

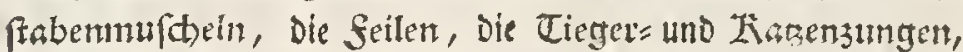

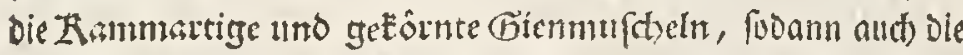

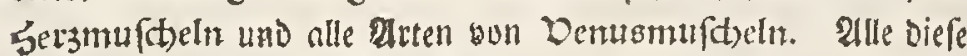

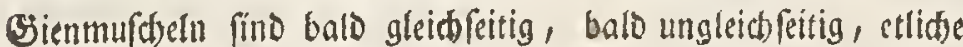

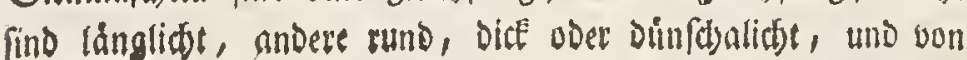
mall i⿱

çons formez en Veffe, ou en Globe, ou en Grelot. (*) Le caractère diftinctif particulier de ce Genre, c'eft que les Coquilles en font légères, fort ventruës, \& ont une figure fphérique, tellement que le prémier Contour forme pour ainfi dire le Limaçon tout entier. On les divife en deux fortes, qui font les parfaitement rondes \& celles qui fe terninent en une longue embouchure. On met au rang de la prémière forte les Oeufs de vanneau, les Pelures d'oignon, les perdrix, les Coquilles en grielot à côtes \& tuberculées, \&c. On place dans l'autre forte les Figues, les Bouteilles \& les Raiforts. Celle que nôtre figure dépeint eft la Bouteille, qui reflemble tout-à-fait à la figue, car l'unique différence qu'on y peut obferver c'eft que la figue eft un peu plus formée en poire, \& qu' aux Bouteilles le Cou eft plus enfoncé, $\&$ le refte du corps plus arrondi. Toute la coquille eft garnie de côtes fines, qui font tout le tour des Contours. Les Contours fupèrieurs n'avancent guères au dehors. $\mathrm{La}$ Couleur de celle-ci eft jaunâtre, d'autres font blanches, ou brunes, ou quelques fois rougeâtre à fiammes. Elles font toutes blanches au dedans.

Figure 8. Après la Bouteille vient le Raifort. Ia Coquille en eft plus courte, plus épaiffe et plus ventruë que celle de la précèdente, de forte qu' on peut bien la comparer à un Raifort. L'Embouchure n'avance pas tant en long au dehors, \& fe termine en nez camard. La rigole cavée, - où l'Embouchure fe termine, eft un peu torfe. L'extèrieur de la coquille eft brunet, la couleur de l'intèrieur reffemble à de l'Yvoire fali, \& eft un peu rougeâtre près. de l'embouchure.

Figure 9. La dernière pièce de cette Planche eft un Limaçon en veffie fans cou, qu'on a coûtume d'apeller la Pelîre d'oignon. Quelques Ecrivains le mettent au nombre des Limaçons nageans, ou des Limaçons en Lune, \& il y a auffi dans le Genre des Huitres un Moule, auquel on fait porter le même nom; mais tout cela n'empêche pas que ce Limaçon ne foit réellement une Sous - efpèce des Pelûres d'oignon à bandes, qu'on place avec raifon dans le Genre des Limaçons en veffie, auxquels celui - ci reffemble pårfaitement à l'égard de fa conformation. La Couleur en eft rougeâtre décorée de flammes blanches. Au dedans la Co. quille eft d'un jaune pâle.

\section{PLANCHE B. III.}

Figure 1. Une certaine forte de Moules bivalves, qui génèralement font ouverts \& beient, porte le nom de Cames ou Moules béans. C'eft un Genre particulier du fecond Ordre. On les divife en Cames unies \& Cames raboteuSes. Celles-ci font le Doublet aux Clous, la Tuile faitière, le petit pied de Cheval, les tefts de pots caffez, la Came en peigne, le Moule de Nöé, le Quart de Cercle, \&cc. II faut mettre au nombre des unies toutes les fortes de cames unies, les Coaffateufes, les Moules à Perfpective, les Moules à rayons ou Striés, les Moules cerclés, les Moules d' $A B C$, longs, ronds\& de Xulan, les Limes, les Langues de Tigre \& de Chat, les Moules béans femblables aux Peignes, \& les grainés, les Mosles en coeur, \& les Moules de Venus de toutes les fortes. Toutes ces Cames font tantôt à côtez égaux, tantôt à côtez inégaux, quelques unes font oblongues, d'autre rondes;

(*) Mr. Bertiand les apelle Bulles. 


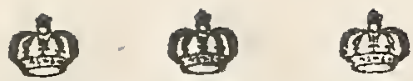

47

mamuigfaltigen Garben. Die Schalen firen binten mit einem Jjergaunenthäutlein an einanoer, uno $\mathrm{Dag}$ Sbier if an beyben Edalen mit einer Senne befeligt, ourdit deren Saúlfe es die Sd)alen fehr Didte aneinander bielten uno dergeftalt feft halten

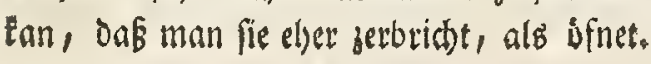

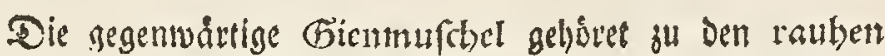

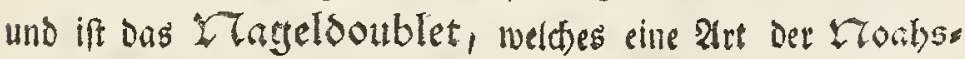
mulithel iff. Sie roiro alfo genennet, weil Die Falten Der Echate

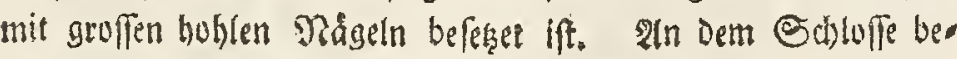

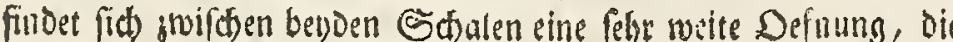

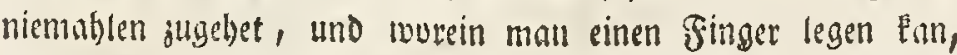

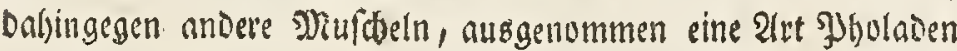
und Sinnen Doubletten, fehr genau zu fotliefen pflegen. Diefes Siageloublet wiro felten ibber eine Spanne gruf, abee die anoere

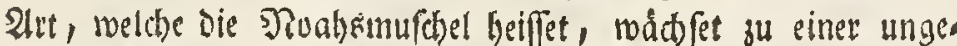

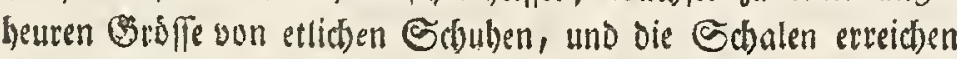

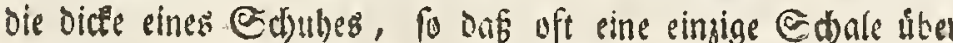
Dres Centner mieget. WBeil man nun aus diefer ungebeuren Bróffe gefblofien, eg miffen biefe $\mathfrak{M}$ ufdeln, (jumnabl man fie auth) oben auf den Indianifthen Bergen verfeinert findet, ) von Den

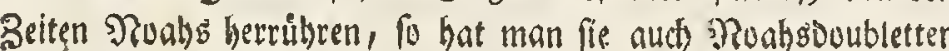
genennet. Soldse groffe Doubletten fino im Etande, eiten

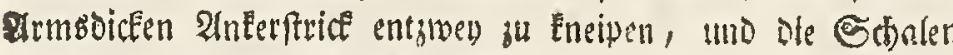

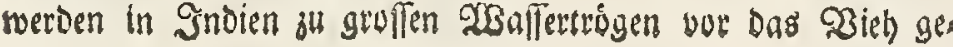
braudbto

Fig. 2. 23ir treffen in bieper Gigur aberthals ein neues

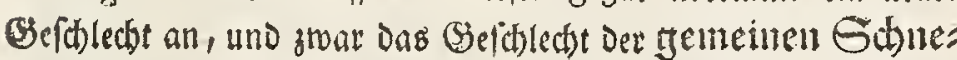
dell (Cochlea) weil fie den gemeinen fanofdnecten unter allen anderen am meiften äbnlich fehen. (Es wiro aber diefes bjes Thletht eingetbeilet in tronoftherten (Cochleas lunares, und in 弓albmonofthneten (Cochleas valvatas). Die IMonofhnecken find foldte, Deren Mrúnoung rund, wie Der wolle smond ift, und bun ber 2lat giebt es grofe und Eleine, glatte, geripte, Enotigte uno folde die 3acten, Lappen ooer Kram fert haben. Sie werden aud Alykruiken, voer Oebleringe genennet, uno Dahin geloóren namentlid, der groffe Oebletrug

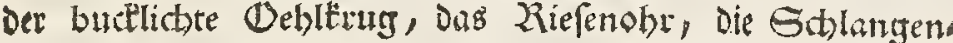
bant, die Taffaner, Die Gilber uno Golsmunde, die ges

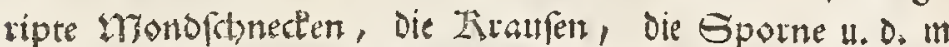

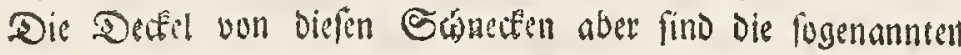
n7eerbobnten uber Geenthel (Umbilicus marinus).

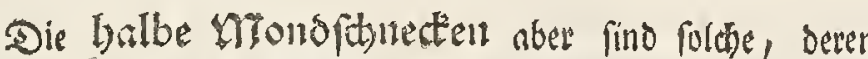
Mủnoung nur einen balben Mono vorfeellet. Eie beiffen auth Cochleæ valvatæ, ober Xlappenfifhederi, weil ifre De.

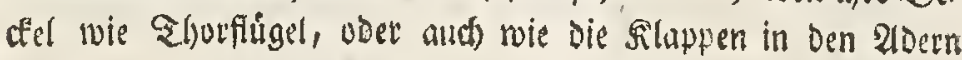
ausfohen. Cie weroen abermabla in glatte und in geftreifre eingetheilet, und fino entweder regulår ober,geftroben, haben

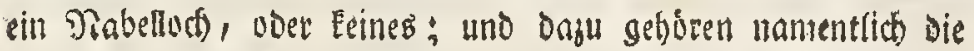

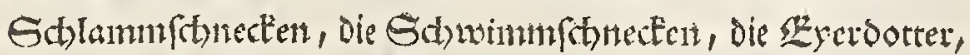
die St)warstmunde, Die Camelotte, die Rotbahtent, die

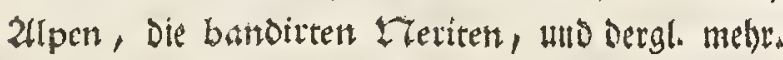

203as nun bie gegentodrtige foigur betrife, fo ift fie eine Enotigte Monofthtecte, ober Dehletrug, Dergleicten man aud) Zinobethóriter zu nennen pfleget. Das erfte Giewinoe if mit einer rothen, Das andere mit eiuer fobrwarzen, uno bie ibrigen mit einer rothen rauben Saut umzugen; alle Selvinde fino mit Suctel befegete, die mit einer gyenlenmutterfarbe berour glånzen.
11 y en a à coquille épaiffe \& coqulle mince \& leurs coù leurs font diverfes. Les Coquilles font jointes fur le derrière par une Membrane mince, \& l'Animal eft attaché atux deux coquilles par un nerf, au moyen duquel il peut les tirer Pune à l'autre, \& les tenir ferrées avec tant de force, qu'il efti plus ffacile de les rompre que de les ouvrir.

Pour ce qui concerne la Came repréfentée ici, elle eft des raboteujes. ("eft le Doublet aux Clous, qui eft une forte des Moules de Nö́́. On luj a donné le nom qu'elle por. te, parce que les plis de la coquille font garnis de grands Clous cavez. (n oblerve à la Fermeture entre les deux coquillés une ouverture fort fpacieufe, qui ne fe ferme jamais, \& dans laquelle on peut mettre un doigt, au lieu que d'autres Moules, à la referve d'une efpèce des Pholades $\&$ des Doublets en rigole, fe ferment ordinairement avec beaucoup de jufteffe. Ce doublet à Cloux ne paffe jamais un Pan dans fon étendue, mais l'autre forte qu'on apelle Moule de Nöé, parvient à un dégré énorme de grandeur, au point qu' elle 2 quelques fois plufieurs pièds d'étendue, \& un pied d'épaiffeur, tellement qu'une feule Coquille péfe fouvent plus de trois quintaux. Cette énorme Grandeur jointe à ce qu' on trouve de ces Moules pétrifiés aux Indes fur le Sommèt de quelques Montagnes, a fait naître l'idée qu'elles exiftoient dès les tems de Nöé, \& c'eft ce qui leur a fait donner le nom de Doublets de Nöé. Cet animal eft capable de couper en deux un Cable gros comme le bras. Les Coquilles fervent aux Indes d'abbreuvoir pour le gros bêtailo

Figure 2. Cecì eft encore un nouveaul Genre. Ce font les Limaçons ordinaires, ainfi apellez à caufe qu'ils reffemblent le plus aux Limaçons terreftres communs. On les divile en Limaçons en Lune, \& en Limaţons en demi - Lune, ou à valvule. Les Limaģons en Lune font ceux dont l'embouchure eft ronde comme la Pleine - Lune. Il y en a de grands \& de petits, d' unis, à côtes, noueux ou tuberculez, ou qui ont des dens, des lambeaux, ou des frifures. On les apelle auff Alykruyken, qui eft une forte de petits Limaçons, ou Crucbes à buile. De cette efpèce font fa grande Cruche à buile, ta Crus che à buile tuberculée, l'Oreille de Géant, la peau de Serpent. les Nofjaux, les Bouches d'or \& d'argent, les Coquilles en Lune à côtes, les Fraijes, les Eperons, \&zc. Ce qui fert de Cou. vercle à ces Limaçons eft l'Umbilic marin, ou le Nombril marin.

Les Limaçons en demi-Lune font ceux dont l'embouchure eft faite en demi-Lune. On les apelle auffi Limaçons à valuule, parceque le Couvercle eft fait comme un Battan de porte, ou comme les Valvules que nous avons dans le fang. On divife encore ceux - ci en unis \& en rayez, \& ils font ou reguliers, ou en biais, les uns ont un umbilic, d'an tres n'en ont point. Les noms de ceux qui apartiennent à cette efpèce font le Limaçort limonneux, le Limaçon nageant, le Iaune d'oeuf, les Embotichures noires, les Camelots, les geü rouges, les, Alpes, les Nerites à bandes, \&c.

A l'égard de la figure dépeinte ici, c'eft un Limą̧on en Lune tuberculé, ou une Crucbe à buile qu'on apelle auffi $l a$ Coquille noueufe ou à bofjettes. Le prémier Contour eft envelopé d'une peau rouge, le fecond d'une peau noire, le troifième d'une peau rouge. Tous les Contours font couverts de tubercules, qui ont le brillant de la nacre. $\mathrm{Ce}$

$0_{2}$ Lima= 
48

glånjen. Es ift aber blefes niche die natinllide Eseftalt Der

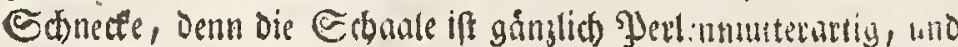

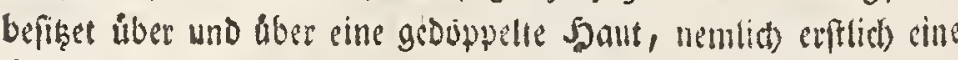
fetwarge, fooann eine ruthe. Sin Dem zweyten Siminde if sic

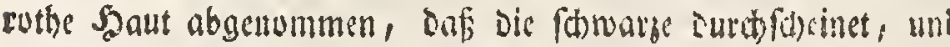

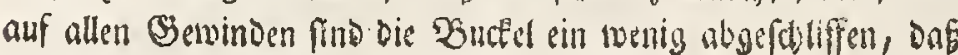
Das \$Jerlenmutter herbor lendtet.

Fig. 3. Wुir baben bey Der ₹ab. B. II. fig. 6. 16yon the

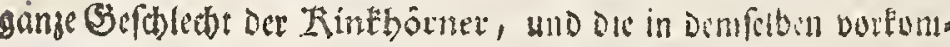

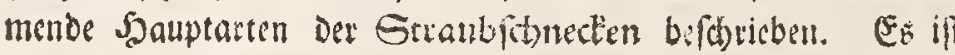
nemfit) Die Bsegenndertige eine Dergleichen, und wird die $23 i$ fibofennuse, Mitra Epifcopalis, genennet. Eie if oldefona

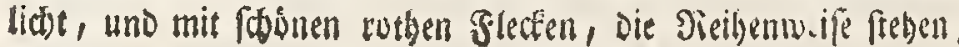
gejieret.

Fig. 4. Delefe Figur giebt uns Brelegentyeit eine Tadjo

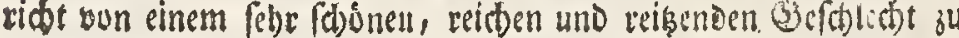

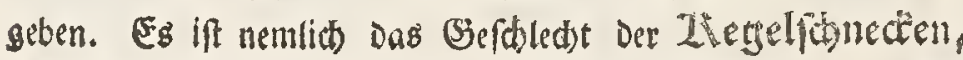
Cutten voer Molsenfithecten, Die man Volutæ nenset. Sin

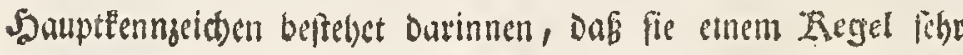
ábnlid fehen, meldier einen breiten Buben bat, uno rove eine

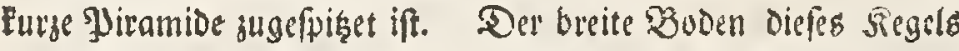

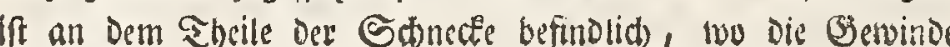
beraus tretten. Die Spisęe aber fetelet dieferm gegenúber, und in berfelten endiget fich bie lange Mủnoung, weldie die ganze Seite Der Schnecfe cinnimmt, und oun Der Flad)e, wo fid bie Serwinde befinden, anfánget. OEseil bie Serwinde alle fiad) über einanber berlaufien, wie wenn man sin Yjapier zufammen rollet,

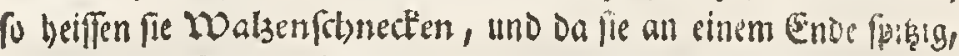
am anderen Ende breit fino, wie man Die papierene zufammen

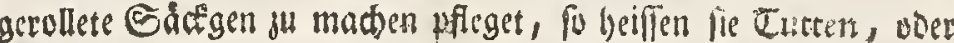

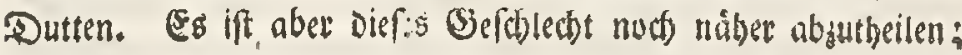

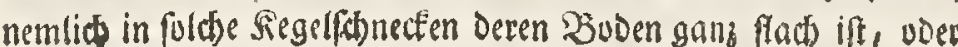
in folde, an Deren 'Buden die Geewinde mit silter Spize beraus tretten, voer endict in foldbe, Die bun der segerfigur etwas ab. meiden, uno nebfe eines Febr fuben, heraustagenden Splize au den

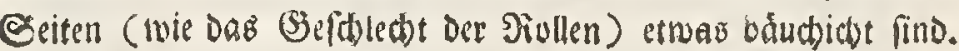
Die erfeern find volleummene Siegel, die leętern find die Zörtger:

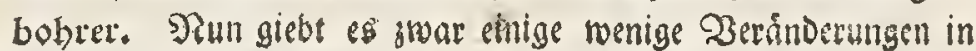

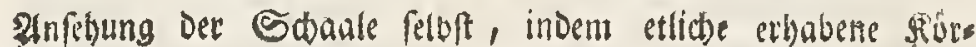
ner auf Ber Edyale liserno baben, welde man granulite nen, net, andere mit erthabenen Bieffien umgeben fitto; icoud) beftebet Die mebrefte Serdittoerung in Den Beidnungeli, uno nach Diefen

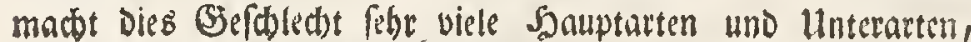
unter weldben alle dicjenise, weldse 'Binden baben, und die man volutæ fafciatæ nennet, Die vornebmften find. Es weroen nemlich alle bicenige, welde bandiret fino, woer um beren Soljaale fidarfe, breite voer fidmale Binden von einer anderen Sarbe liegen, zu Den 2tomirals gered)net, welde Beneunung

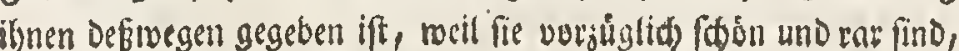
Dabey aber aud einige 2tehnlitéteit mit Den bandirten juglugen

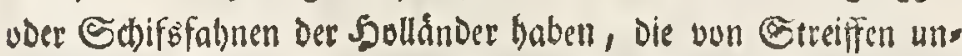
terfatiedener Farben zufammen gefetet fino, und Diefe aldomirals Fin neben Der unter Dem Sef(c)led)t Der Sinfhórner Tab. B. II. fig. 6. nabmbaft gemadten áufierft raren âdten Wendeltrep.

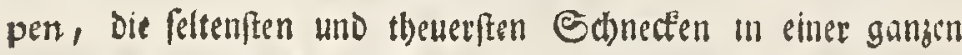
Sammlung. Whan trift alfo in Diefem Sefteledts an die Ober= Zomirals, Wranien 20mirals, Guinefifhe Tutten, Vices

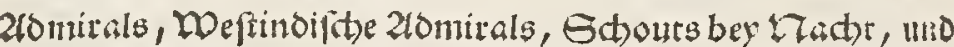
abrige bandirte Turten, ferner die 21. b. c. Zutten, bebrâ.

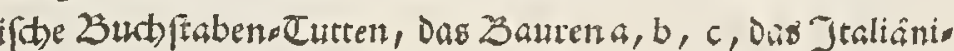

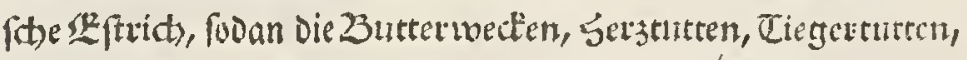

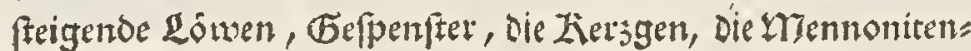

Eutten,
凰

(3)

Limaçon n'eft pas fait ainfi naturellement, car fa Coquille entière eft une efpèce de nacre. Mais elle eft couverte entièrement de deux peaux, dont la prémière eft noire \& l'autre rouge. Au fecond Contour on a ôté la peau rouge, pour faire paroître la noire, \& on a un peu émoulé les Tubercules fur tous les Contours, afin que l'on vit l'éclat de leur nacre.

Fioure 3. Nous avons déjá donné P1. B. II. fig. 6. la defcription du Genre entier des Buccins, \& de l'espèce principale des sirumbes, gui y eft comprife. Ceci eft une Coquille de cette efpèce. On la nomme la Mitre épifcopale. La Coquille en eft épaifre, \& décorée de belles taches rouges, rangées à la ligne.

figure 4. Cette figure nous fournit l' occafion de donner une idée genèrale d'un Genre beau, riche, \& qui renferme des pièces charmantes. C'eft le gente des Limaçons en cone, des Curnets, ou des Volutes. Son Caractère diftinetii principal confifte en ce que les Coquilles qui le compoient ont la figure d'un cone ou d'une Quille, qui repofe fur une bafe large, \& fe termine piramidalement en pointe. La bafe large de ce Cone fe trouve à ce Limaçon là, où fes Contours paroiffent. La pointe eft vis-à-vis, \& c'eft lá que fe termine la longue embouchure, qui occupe tout un côté de la coquille, \& qui a commencé près des Contours. Le nom de volute vient à cette coquille de ce que tous fes Contours paffent l'un fir l'autre fans fe dépaffer, à l'initar dיu papier roulé, \& cumme elle a la forme d'un cornet de papier en ce qu'elle eft pointue par un bout $\&$ large de l'autre, on l'apelle Cornet. Mais on peut donner une divifion encore plus détaillée de ce Genre en difant qu' une partie de ces Coquilles font en Cone à fond plat, une feconde où les Contours, avançạnt un peu hors du fond forment une pointe, \& enfin une autre qui s'écarte un peu de lu figure conique, dont les individus, avec une pointe haute, qui avance beaucoup, font un peu ventrus fur les cótez, comme on le remarque de même aux Cylindres. Les prémières font des Cones parfaits; on apelle les dernières des Barroirs de Tomelier. Il y a dे obferver encore un petit nombre de variations à l'égard de la coquille même. Car qquelques unes font marquées de grains élevez, qu'on nomme grainées, \& d'autres font entourées de cercles élevez. Mais la variation la plus confidèrable concerne les deffeins qui font fur les coquilles, \& à cet egard ce Genre a fans doute un grand nombre d'efpèces $\&$ de fous.. efpèces. Les plus remarquables font les Volutes à bandes. Onz met donc au rang des Amiraux toutes les Conquilles bandées, c'eft à dire toutes celles, dont des bandes de couleur différente du fond, font le tour, \& la raifon de cette dénomination c'eft qu'elles font éminemment belles \& rares, \& qu' outre cela elles ont quelque reffemblance avec les Pavillons, \& Enfeignes à bandes que l'on voit fur les Navires Hollandois, \& qui font compofées de bandes de couleuxs diverfes coufuës enfemble. Ces Amiraux; de même que l'Efcalier en caracol véritable, dont nous avons parlé cy-deffus à loccafion des Buccins, (PI. B. İI. fig. 6.) font les Coquilles les plus rares \& les plus iprécieufes de toute une Collection. On trouve ainfi dans ce Genre les Grands-Amiraux, les Amiraux d' Orange, les Cornets de Guinée, les ViceAmiraux, les Amiraux des Indes occidentales, les Contre-Amiraux, \& autres Cornets à bandes. Il y a après cela les cornets 


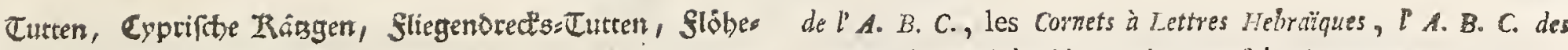

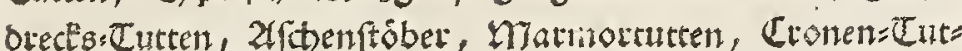

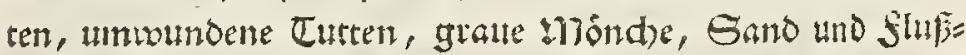

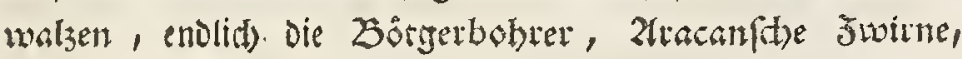

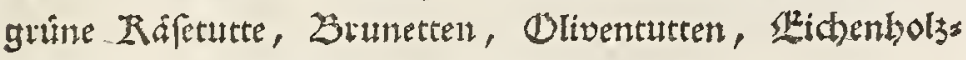

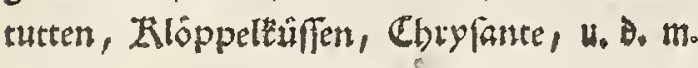

2ale diefe Sauptarten haben hernach nocti viele Ilnterarten

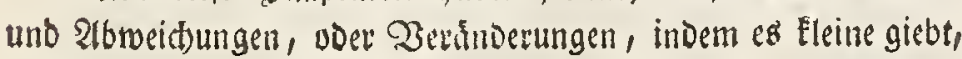
bie allejeit llein bleiben, uno groffe, die bie \&ange eines Fingers,

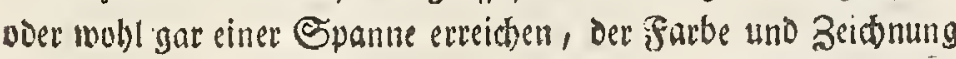

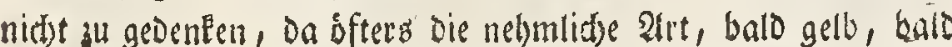
braun, balo fhwars voer mit ingend einer andern Farbe erfecei

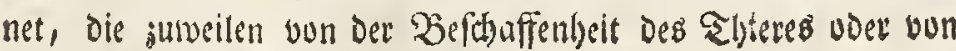
Der Şegend Des DReeres abbánget.

2Bas nun die in blefer Figur abgebildete Schnecte betrift, fo if fie eine 24.23. C. Tutte, welche Benennung fie Daber erthalten hat, weil sie vierectigte fobwarge Flesten auf Der werifien

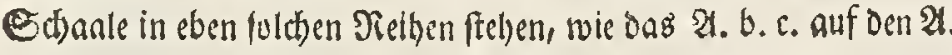
b.c. Bretgen Der sinder. Seic ift jugleid) von Der ant Derjentgen Sutten, die cinen bollummenen siegel ausmadien, dus ift, bie

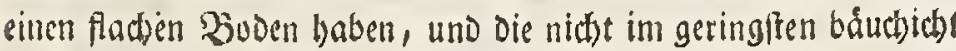
fino. Es mangelt. Diefer Ant Eeineswegs an Lnteraiten. Man firbet etlitbe mit braunen, andere mit gelben voer \$yumeranzen. fárbigen Flecten, beil einigen find die Flesten vierectigt, bely ans Dern lange unterbrvbene Sinien, woer nur \$tunete uno Erumme Shacten. Bell einigen fino alle filecten gleidh grub, voer es bee finden fith exte ein waar Jicitent breite, Dann ein paar Sieithen

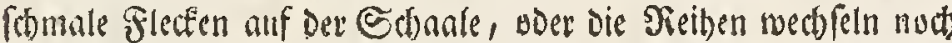

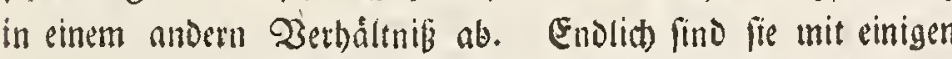
selben Simien juiften Den Beeilen Der Flecten umzugen, uno diefe Einien fino bey einigen bopwelt, bey alderen breyfady, woer fie

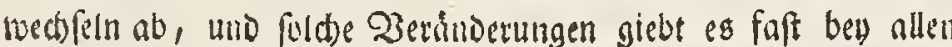

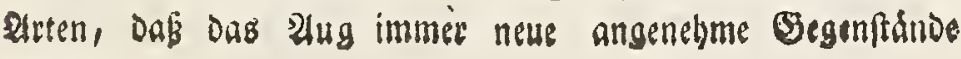
fincet.

an, le Pave dé plaire italien; enfuite les Gateaux au beurre, les Cornets en coeur, les Cornets tigrez, les Lions rampans, les Spectres, les petites Bougies, les Cornets des Mennonites, le Chaton de Cbypre, les cornets de fiente de Mouche, le Cornet de fiente de puce, les. Fouilleurs de cendres, le Cornet de Marbre, le Comet en Couronne, le Cornet entortillé, les Moines gris, les Volutes de sable EG de fleuve, enfin les Barroirs de Tonnelier, les filets d'Aracan, le Cornet de fromage verd, les Brunettes, les Cornets d'Olive, les Comets de Bois de Chêne, le Coufjin dentelles, le cbrifant, \&c.

Touras ces efpèces fupèrieures ont enfuite encore beaucoup de Sous - efpèces \& de variations, s'y trouvant de petites coquilles qui demeurent toûjours petites, \& de grandes qui atteignent la longueur d'un doigt, \& quelques fois d'un Pan, fans parler de la diverfité des couleurs \& des deffeins, les coquilles de la même efpèce étant fouvent tantôt jaunes, tantôt brunes, tantot noires, ou de quelque autre couleur, ce qui dépend quelquefois de la qualité de l'Animal, ou de la Plage de la Mer où il eft pris.

Pour en venir enfin au Limaçon dépeint dans la préfente figure, c'eft un Cornet d'A. $B . C_{*}^{*}$, dénomination qui lui vientide ce que les taches noires quarrèes, dont cette Coquille eft marquée fur un fond blanc, s'y trouvent rangées dans le même ordre que les Lettres de l'Alphabet fux ces petites Planchettes qu' on nomme en France Croix de par Dieu, dont on fe fert pour enfeigner l' A. B. C. aux Enfans. Elle eft aufii de l'efpece de coquilles, qui forment un Cone parfait, c'eft à dire qui ont un fond plat, \& ne font point ventruës du tout. 。Cette efpèce a auffi fes Sous-efpèces. On en trouve dont les taches font brunes, ou jaunes, ou couleur d'orange. Sur quelques unes les taches font quarrées, sur d'autres on ne voit que de longueś lignes inter. rompuës, ou feulement des points, ou des crochets courbes. A quelques unes les taches font toutes de grandeur égale, ou l'on y voit alternativement deux rangées de taches larges, \& enfuite deux rangées de taches étroites, ou les rangées varient encore de quelque autre façon. Enfin l'on y remarque de plus quelques lignes jaunes, qui font le tour de la coquille entre les rangées des taches, \& ces Lignes font quelques fois doubles, quelquefois triples, ou elles alternent auffi. Il y a tant de variations pareilles à toutes les efpèces que l' oeil y trouve toûjours quelque recré. ation nouvelle.

Fig. 9. 2h diefer Sutte tretten bie Sertinde fogon in einer Eleinen Epitge heraus, und fir geljoret unter die 26gatetuttent,

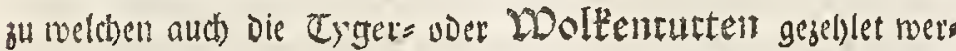
Den. Dir Echanle ifi, wie aut an jener dic und frart, und invendig meis.

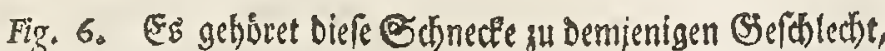

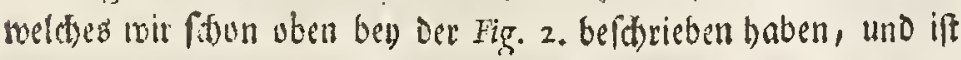
eine grine geripte, voer tief gefurdite Monofotnecfe, welche, on Die Dánoung inmenoig einen filberfấrbigen DJerlenmutterglans hat, Der grume Gilbetmunt genennet wird.

Fig. 7. Bu eben Dem Giefthectht, in twelthes ber bongedactite

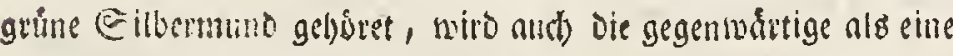

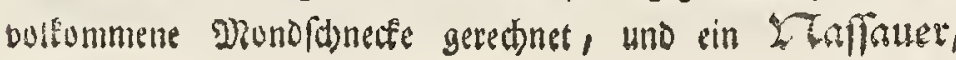

Figure 5. Les Contours de cette Coquille avancent un peu en dehors, \& fe terminent en une pointe courte. Elle doit être placée parmi les Cornets d'Agate, nom qu'on donne auffi quelquefois aux Comets tigrez, ou aux Cornets à nuages. La Coquille en eft forte \&z épaille comme à la précèdente, \& blanche en dedans.

Figure 6. Cette Coquille apartient au même genre que nous avons décrit cy - deffus en parlant de la figure 2. C'eft un Limaçon en Lune verd, à côtes, où à cannelures profondes. Comme fon embouchure a au dedans un éclat argentin femblable à celui de la nacre de Perle, on l'apelle 12 Boucbe d'argent verte.

Figure 7. 11 faut regarder cette coquille comme aparte. nant au même Genre que la Bouche d'argent verte dont nous venons de parler. C'elt un Limaçon en forme de Lune 
Davon es viele 2rten gist, genennet. Die Cabale ift oidf, auswentig glat, ghingens, uno mit vilten breiten bunten sinisn bejeidnet, inwendiy wer lvie fdumbsiges Elffenbein anjufeben.

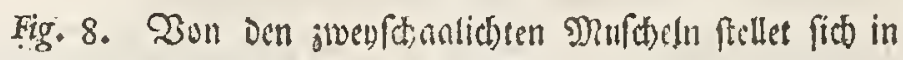
Diefer Figut abermals eit n:uis (Sjefidelet unfern \&ugen bar;

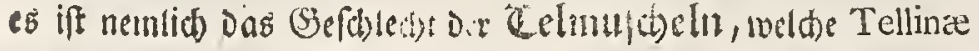

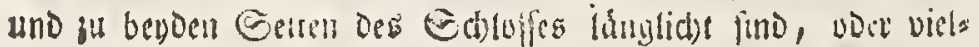
mebr in die Breite anklaufen. Es gisut in Diclem (Seldliclete nitft viele Fitcin, Denn man bat nut Die Sonnenftrable, Die Polnifhen Mieffer, dis Zlâter, die Sd)inten, uno die Ros fenooubletre, welden von einigen die Ratsenzuigen bugejeblet

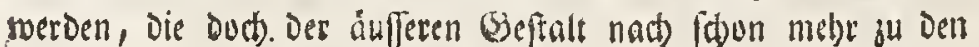
Dûninen Gienmufd)eln oelyo ren.

Tn biefer Figur wiro uแs nun ein Purpur: Gomen: ftrabl gejeiget, roeldbe Benennung Daber entfethet, weil fids

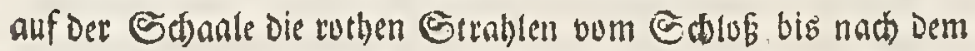
Эiande zu immer breiter ausiberfen, rrie wenn die Eunne,

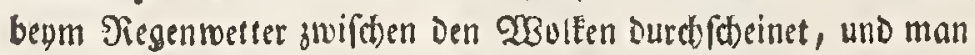
bun ibre faget, Dás fie frark, ungemein glat tmo glånzend, bat lauter Singe, fo wie

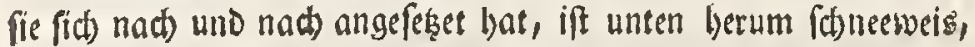
inmenoig mebrentheilz gans, uno aubrwendig nur am Schlof getblid)t. Die Strablen fino vortrefild) rutt). SDtan bat die nemliche 2att aud) mit metreren uno fitmablen (Strablen, aud giebt esfolde, bie nut Duerringe, und gar Eeine Strablen baben.

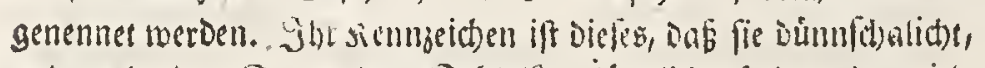

parfait. On l'apelle un $\mathrm{Naffau}$, dont on a quantité d'efpèces. La Coquille eft épaiffe, unie au dehors, brillante, \& marquée de plufieurs lignes larges de diverfes couleurs. Le de. dans relfemble à de l'lvoire fali.

Figure 8. Voici encore un nouveau Genre des Moules bivalyes qui fe préfente à nos yeux, c'elt celui des Tellines. On les reconoit à leur coquille mince, \& en ce qu'elles font oblongues aux deux côtez de la Fermeture, ou plutôt en ce qu'elles s'étendent en large. Ce genre n'a pas beaucoup d'efpeces. On n'y trouve que les Raïons du Soleil, les Coutteaux de Pologne, les feuilles, les petits rambons, \& les Dortblets de rofe, auxquels quelques uns ajoutent les Langues de cbai, qui, vư leur conformation, devroient bien plûtôt être mifes au rang des cames minces.

Quoiqu' il en foit, la préfente figure dépeint un Raïon du Soleil de couleur de pourpre; dénomination qui tire fon origine des raions rouges, qu'on y voit s'étendre depuis la Fermeture jusques au bord, en s'élargiffant à méfure qu'ils avancent, femblables à ceux que darde le foleil, lorsqu'en tems de pluye il perce à travers les nuées, \& qu'il attire à foi les vapeurs de la terre. La Coquille en eft affez forte, trés - unie \& brillante, \& elle eft toute compofée d'anneaux, qui décèlent fon accroiffement fuccelfif. En bas elle eit blanche comme neige. Le dedans eft le plus fouvent jau. nâtre par tout, mais le dehors n'eft de cette couleur que près de la Fermeture. Les rayons font d'un rouge admirablement beau. On en a de la mème efpèce, dont les raions font plus nombreux \& moins larges, \& d'autres qui n'ont que des anneaux en travers, \& point de raïons du tout.

Figure 9. Cette Telline eft beaucoup plus rare que la précèdente, de laquelle elle ne diffère d'ailleurs qu'en ce que fes raions font d'un bleu de Roi, ou de couleur violette. On lui donne par cette raifon aufi le nom de Raïon $d u$ Soleil violet. Cette Couleur violette relève d'autant plus la beauté de la pièce qu'elle eft placée fur une Coquille blanche comme neige, à l'égal de la Porce. laine, \& qu'on ny' remarque rien de jaunâtre.

\section{TAB. B. IV.}

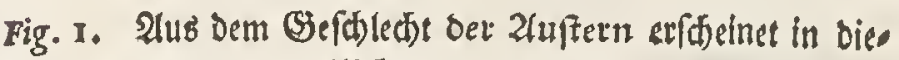
fer Figur die Lazarus: Zlappe, die nidt nur ihrer গigel balbet, weldhe die Gdaale befersen, fundern auth wegen des Sd)luffes feltr merfwúrbig ift. Ebe wir aber diefelbe náber

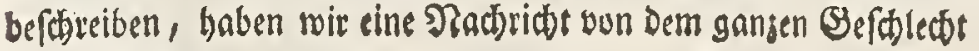
Der Zuftern su geben.

Es mat)en nemlid die 2 Huftern im eigentidien ftande ein befonderes Geftled)t aus, wb man gleich gewolgnt ift, bberhaupt alle Shiere ober Einmobner, Die fich formobl in Den

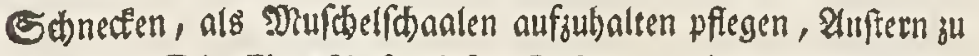
nennen. Die Eigenfid)aft diefes Sefdledhts ift, exftich oaf fie niemalen fres im Deer fotwimmen, noer auf dem Buden, voer an Den Felfen herumeriecten, wie bie meiften Sdineden und Dofufteln su thun pflegen, fondern fie fino ingetmein an Fetfen oder an orm Boden Des Meeres mit Der Llnterfatuale befeftiget,

- Daber man allezeit an Derfelben die Stelle, wu fie abgebrudten ift, wabrnimmt. Jum sndern find libe Sqaalen allezeit oun

\section{PLANCHE B. IV.}

Figure 1. L' on trouve dans le Genre des Huitres le Claquét de Lazare, dont voici la Figure. Cette pièce eft remarquable non feulement par les Clous dont la Coquille eft garnie, mais aufii par $\mathrm{fa}$ Charnière. Mais avant que nous procèdions à fa defcription particulière, nous devons, pour remplir nos engagemens, donner à nos Lecteurs une information génèrale relativement au Genre entier.

Nous dilons donc que les Huitres, prifes dans le fens propre de leur dénomination, font un Genre particulier, quoiqu'on ait affez coûtume d'apeller de ce nom tous les animaux indiftinctément qui habitent les coquilles de Limaçon, ou de Moules. Trois proprietez diftinguent ce Genre. En prémier lieu, l'Huitre ne nage jamais dans la mer, ni ne rampe au fond, ni fur les rochers, comme font la plûpart des Limaçons \& des Moules, car elle eft ordinairement attachée par fa coquille infèrieure foit au fond de la Mer, foit à quelque rocher, d'où on ne peut l'arracher, fans que la marque en paroiffe fur la coquille. En fecond lieu, la 
auffen fobieferict)t, oder blattericht, oder zactigt, folglict) rauth, und niemals glat, es wáre denn dä man iljnen die áliere Şaut berunter nelimete. Drittenz haben fie foledfteroing eine unbe. frimmte Figur, uno Pommen in diefem (Sefohletbst allerband (jes ftalten vor. 2Bas nun die Sausptarten betrift, fo findet man'

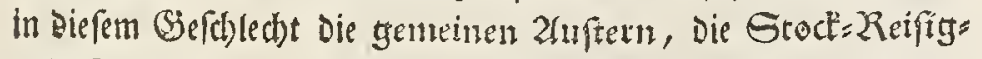
uno Steinauftern, Die Sattel, fomoblenglifa)e als polnifatse, Die gefoltene uno Die gesacte 2 uftern, Die Perlemmutee: anfifern, die ciensooutblette, voer polnifbe 5ammer, bie Wintclbatten, Die Lazarustappen, Die Sabnentånme, die Rorberblatter U, D. m.

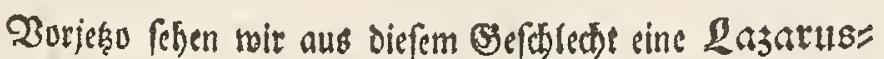
Elappe our uns, uno fie fülyret diefen গamen, weil die Ectias len gegen cinander Elappen wie die Bettlersflappen. Es ift aber

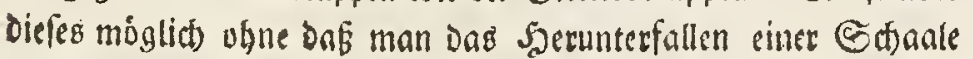

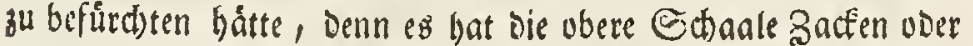
Ingeln, weldte in Die (strubgen Der untern Ethaale fo feft fobliefen, und fo genau eingedrellet find, wie Der Decfel an einer Ednupftobacts Dofe mit einem Selenfe, zu thun pfleget.

Die untere Edjaale fit gang weis, und forieferidt, bie obere aber ruth, uno mit etlicten gieihen Eraufer Zucfen verfelhen,

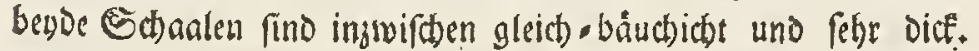
Einige Siebbaber nennen fie auch wobl bie Kafelobufe, Duds

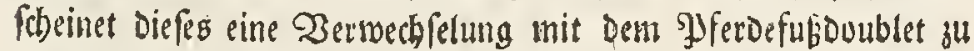
feren, fo in Das Sieftelectst Der Sienmufchetn gethuret. Diefe Lazarustappen find oft fehr verfeticden, Denn man hat aub foldte, Deren Deffel Falten, andere bie lange Bacten, und nud andere, die fịighige Stadjeln baben.

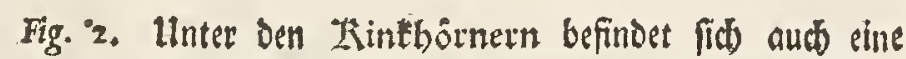

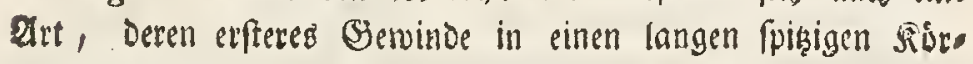
per ausgehet, uno gleidfam Dreyectigt ift. Diefe wird Das oreyectid te thintyorn, die Enotigte $23 i r n$, voer auth

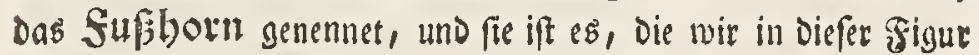
vor uns fehen. Sie hat auf Dem Siúcéen zuweilen eine, oft

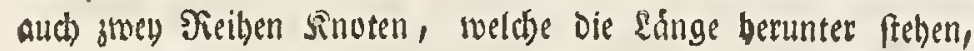
von diefen Sinuten geben ju benden Seiten quer über die Ethaale Dicke Falten, und bie Mrundung bat cinen boblen und umgebo. genen Sano mit Falten. Jinnendig if fie fothneetweis, auswen.

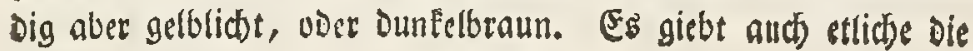

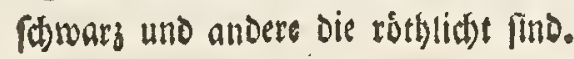

Fig. 3. 2Bir baben fiton borber erinnert, Dás man unter

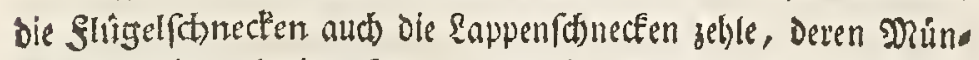
Dung nit einem breiten sappen austritt, zugleid) aber haben wir audi) erinnert, Daf nid)t alle Sannecten mit foldhen sappen ein

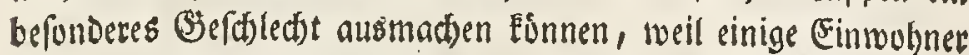
in einem gewifien Alter exft einen Rappen an ihr Gethdufe an.

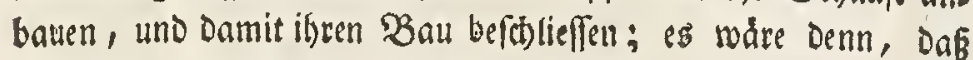
einen Sappen ju haben, voer nidht al haben, einen llnterftheio des

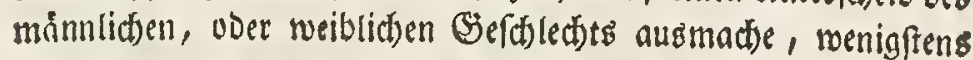
baben mir Dergleichen an Den gezaften Gdhmeiserbofen, uber Sleifb botrnetn wabrgenummen, da sinige einen \&appen hats

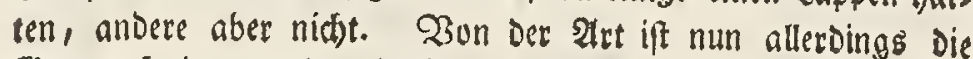
Gegenwårtige, uno wir halten fie vor eine Eleine 2(rt Der Edwoeizerbufen mit einem Rappen. Einen Ulmftano aber, Der partie extérieure de la coquille eft tonte couverte d’écailles ou de feuilletage, ou dentée, par conféquent rude, \& jamais unie, à moins qu'on ne la dépouille de cette Couverture extérieure. En troijième lieu, les Huitres n'ont point de figure abfoiument déterminée, ce Genre renfermant nombre de variations à cet égard. Les efpèces principales font l'Huitre ordinaire ou commune, les Huitres qu' on trouve aux Solives, aux brouffailles qui fe trouvght dans la mer, ou aux Ro. chers, la felle à $l^{2}$ Angloife \& la selle à la Polonoise, l'Huitre pliffece, l'Huitre deatée, l'Huitre de la Nacre de Perle, le Doublet au Crucifix, ou le Marteau à la Polonoife, les Equerres, les Claquets, de. Lazare, les Crêtes de Coq, les feuilles de Laurier \&c.

La Coquille que nous voyons ici eft le traquet ou le Claquet de Lazare, qu'on apelle ainfi parceque quand les deux coquilles font l'une fur l'autre, elles rendent le même fon qu' un claquet de Mandiant. Et cela fe fait fans qu'on doive craindre qu'une des deux Coquilles tombe à terre, parceque la Coquille fupèrieure a des dens ou des pivots, qui s'ajuftent \& entrent dans les foffettes de la coquille inférieure, par où les deux coquilles font auffi affürées qu'u u Couvercle de Tabatière l'èft par fa Charnière.

La Coquille infereme eft abfolument blanche \& pleine d'écailles, la fupèrieure eft rouge \& garnie de quelques rangées de dens recourbées. L'une \& l'autre font cepen. dant également ventrues, \& fort épaiffes. Quelques Ama teurs ont aufí apellé cette coquille le Sabot d’âne la con. fondant vraifemblablement avec le Doublet du pied de cheval, qui apartient au genre des Cames. Ces Claquets de Lazare diffèrent fouvent beaucoup entre eux, car il y en a dont les Couvercles font pliffez, 'd'autres qui ont des dens ous crochets longs, d'autres enfin qui font pourvûes d'aiguil. lons pointus.

Figure 2. Il y a parmi les Buccins une autre forte de Coquilles dont le prémier Contour va fe terminer en un long corps pointu \& préfente ainfi en quelque façon trois coins. On apelle cela le Buccin triangulaire, ou 12 Poire tuberculée ou aufi la Coquille faite en pied. c'eft celui dont nous voyons ici la figure, Cette Coquille a fur le dos quelques fois une, \& d'autres fois deux ran. gées de noeuds ou de tubercules qui y font pofez en long. Des plis épais partent de ces noeuds \& vont en travers des deux côtez de la coquille. L'embouchure a un bord re. courbé \& cave, avec des plis. Le dedans eft blanc comme neige, \& le dehors jaunâtre, ou brun-foncé. On en voit auffi de noires, \& d'autres qui font rougeâtres.

Figure 3. Le Leeteur fe fouvient fans doute que parmi les Limaçons ailez, il y a des Limaçons á lambeaux, dont l'embouchure fe termine en un lambeau large. Nous avons dit à ce fujèt que tous les Limaçons à lambear ne compo. fent pas pour cela un Genre particulier, puisqu' il y a des Limaçons, aux Coquilles defquels ce lambeau ne vient qu’à un certain age, \& eft comme la dernière pièce que l'animal conftruit à fon habitation, à moins que d'avoir ce lambeau ou de ne l'avoir pas ne faffe la diffinction du fexe mafculin ou féminin, comme on obferve une pareille différence aux Culotes de Suifje dentées, \& aux Limaçons charnus, dont quelques Coquilles ont ce lambeau, \& d'autres ne l'ont pas. Voici donc une pièce de cette forte, que nous croyons être la petite espèce des Culotes de Suifé, à un lambeau. Nous ne pouvons paffer fous filence une circonftance qui 


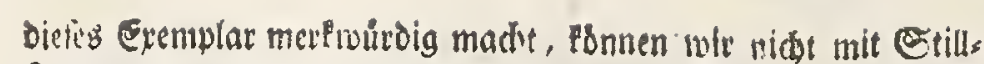

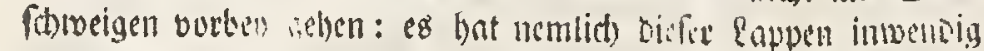
an Der Seite Jer Jitnoung nud einen andern Eappen, uno if

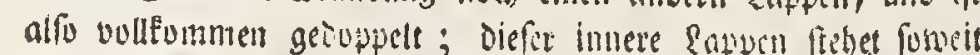
unter bem uberen bon Demfelben ab, Das man cinen Froerfiel zwifden bevie legen Eals, und bieriber mad)ent wir folgende

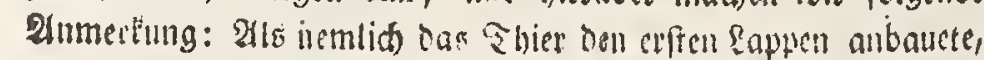
if es vermutblich ourd cine befondere sage gegen einen folfen

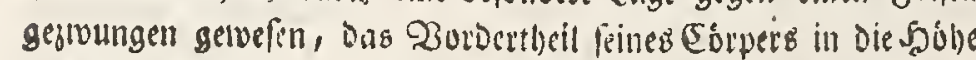
zuheben, Daher Denn ber sappen zu hud binauf und nidit buri.

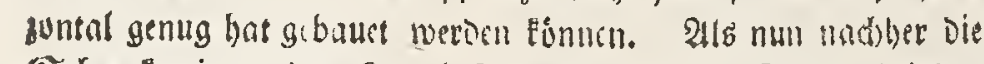
Edinecte eine andere sage befunmen, und Das 2 orbertheil bes Curpers am Sbier mebr berunter gefallen ift, fo but ber anges baute sappen eimen alljweiten gbfand vón Dem Corper bes Qbieres gebabt, uno itn nids gelsorig umfulieffen, vDer oid)te geutrg bedecten fónnen, Daher bat orr neue Caft Des Shicres

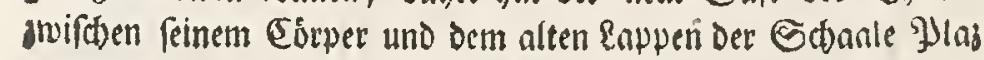
gefunden, einen neuen und tiefer liegenden Rappen anjulegen.

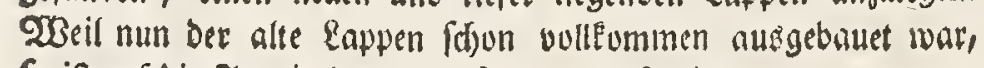
fo ift auf bie Ant cin Doppelter Eappen entftanden.

Fig. 4. Ein neues Sefthlect wirb uns in biefer Figur ges zeiget, und zwar Das (Siefdlectst Der Rollen, (Cylindri) voer Der Dattelfituedten. Sie haben alle einerley (Sieftalt, find lang uno runo, wie cine Siulle, in Der Mitte etwas báuctigt, nach Den Enden ju etruas foumaler, uno die Geminde ragen nur mit einer febr Eleiten Epike hervor, fo baji fie aud ben Dliven

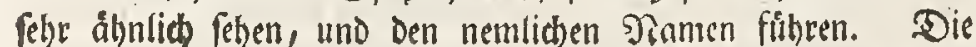
Núnoung ift an Der Geite, wie bey Den 23 alyen, voer Siegel. fonecten. Man bat in biefem Gefdelectst vorzuglid die grofle Panemazholle, voer Das Turtifde Lager, welthes fich in diefer Figur in befonderer Strofle zeiget, fooann Das Primsen

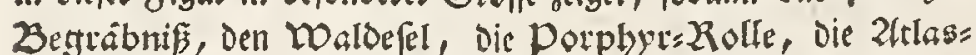

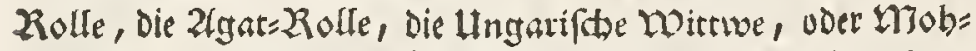
rin, Die glúende Toblen, die Z3laue Tropfen, die Camelotte u. D. m. ju merken.

Das gegentwårtige Tiurtifibe Lager glånzet nad Wre aller Follen wie ein Eplegel, ift unvergleidblich fein gejeidynet,

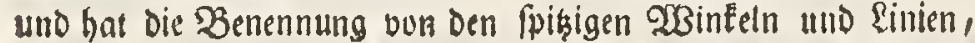
Dic gleithfam Belter vorftellen, erbalten. Sie Eommi bun Parte ma in 2lmerica aus Dem MTericanifden Meerbufen, uno miro

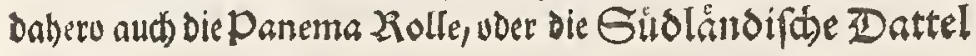
genennet.

Fig. 9. Dem Sefthlecte Der Rolfen ift ein anderes fehr nahe berwandt, nemlich Das Sefoblectit Der Porcellanent. Eg find Diefe Edtnecten mebr Enerformig, haben Die Drúnoung,

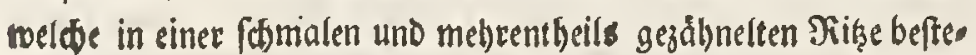
bet, unten, und die Jerwinde tretten faft gar nid)t bervor. In Diefem (S5efdledt mathi man sine Saupteintbeilung zwifdsen Den groffen und Eleinten Poizelfanen, weldbe leştere bey Den mebreften Soriftetellern als ein befonderes (Gefdblecht angefeben werden. Su Den groffen Đo rsellanen geloren nun viele unver

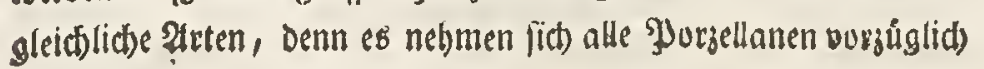

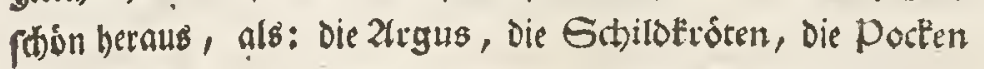
und Mafern, die Waffertropfen, die Mautwuinfe, die Capfanedin, Die Klipbónet, Die Giblangentöpfe, Die bobe Ricten, bie frithe, die Galjtôner, Die Rrabifhe

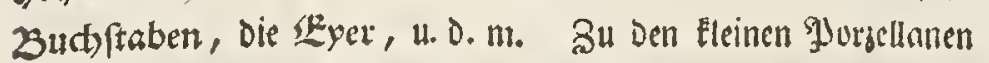
merben gered)net alle Cauriffe, als die ângigre, die gelbe, voer Das Guinefifde Golo uno. Die blake; die Jäbelle, die rend cette pièce particulièrement remarquable. C'eft-que ce Lambeau a au côté intérieur prés de l'embouchure en. core un autre Lambeau, \& cela fait parfaitement un Lambeau double. L'intérieur eft placé au deffous du fupérieur à la diftance de l'épaiffeur d'un tuyau de plume. Nous fondons fur ces Obfervations la conjęture fuivante: c'elt que lors. que l'Animal etoit occupé encore à la conftruition du prémier lanbeau, il s'eft trouvé vraifemblablement géné par fa pofition contre quelque rocher, ce qui l'a mis dans la néceflité d'élever la partie antérieure de fon corps, par où il elt arrivé que le Jambeau a êté conftruit trop haut, \& pas affez en ligne horizontale. Or l'Animal s'étant procuré cnfuite une fituation plus airée, \& la partie antérieure de fon corps étant redécenduë, le lambeau conftruit en haut s'elt trouvé trop éloigné du corps de l'Animal pour l'embraffer, \& le couvrir d'affez près. De là il eft refulté que le nouveau fuc de l'animal ayant trouvé une place libre entre le corps \& le prémier lambeau de la coquille bâti trop haut, $\mathrm{y}$ a formé plus bas un nouveau lambeau. Or comme le vieux étoit dejà fait, cela a produit un Lambeau double.

Figure 4. Le Leeteur rencontre ici un Genre nouveau, qui eft celui des Rouleaux, ou Cylindres, ou des Limacons formez en datte. Ils font tous faits l'un comme l'autre, f̧̧avoir longs \& ronds comme un rouleau, un peu ventuus vers le milieu, plus étroits aux extrèmitez, \& les Contours n'y paroiffent qu'en une trés-petite pointe, ce qui les fait reffembler extrèmement aux olives, \& leur en fait auffi porter le nom. L'embouchure y eft a un côté comme aux Volutes, \& aux Cones. On trouve dans ce Genre le grand Rouleau de Panema, ou le Camp Turc, qui a une grandeur peu commune fur cette figure, enfuite la Sepulture du Prince, l' Ane jauvage, le Rouleau de Porpbyre, le Rouleau de Satin, le Rouleau d'Agate, la Veuve Hongroife ou l'Etbiopienne, les Charbons ardens, les couttes bleuës, les Camelots \&c.

Ainfi que tous les autres Rouleaux le Camp Turc réprefenté ici a l'éclat d’un miroir, \& eft marqué de deffeins fins incomparables. Sa dénommation lui vient des Lignes \& Angles pointus, qui femblent repréfenter des Tentes. On reçoit cette pièce de Panema en Amerique, au Colfe du Mexique, \& c'eft ce qui lui a fait donner le nom de Rouleau de Panema, ou de Datte du Sud.

Figure 5. Le genre des Cylindres a beaucoup de raport avec celui des Porcelaines. La forme de ces Limaçons eft plus ovale. L'embouchure, qui confifte en une longue fente étroite, le plus fouvent dentée, eft en bas, \& les Contours n'y paroiffent point. On divife d'abord génèralement ces coquilles en grandes \& en petites Porcelaine. Bien des Auteurs font de ces demières un Genre particulier. L.es grandes Porcelaines ont quantité d'efpèces d'une beauté incomparable. Telles font les Argus, les Tortues, les Grains de petite vérole, les Gouttes d'eau, les Taupes, les Limaçons des Caps, les Limaģons des rocbers, les têtes de Serpent, les dos voutés, les Renards, les Grains de Sel, l'Alphabet Arabe, les Oeufs, \&c. On met au rang des petites Porcelaines tous les Cuiraffez, (*) (çavoir ceux qui ont des yeux, les jaunes, ou l'argent de Cuinée, \& les bleuë;, l'llibelle, les têtes de Dragon, les petits yeux blancs, les Boutons unis, les Poux, les Perles, 'D Agate, les Souris, \&c.

(*) Nous avons rendu le terme da texte allemand Caurifs par Quant Cxirafez, non feulement parceque ces Conques ont quelque chofe de reffemblant au devant d' une Cuiraffe, mais antii parceque "le Auteurs Latins les apellent Tboracia, \& qu' enfin la dénominatio
hollandoife eft Borf. Stukjes. 
Drachentopfe, weiffe 2leuglein, Die glatten Krópfe, bie

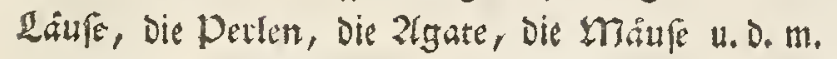

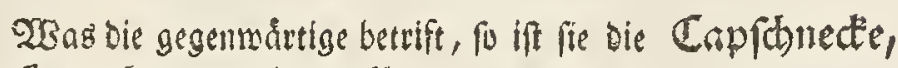
voer Randhartent Porcellane. Diefe Benennung hat fie won Dem gefdllángelten Bante, melthes uben auf Dem Siúcten

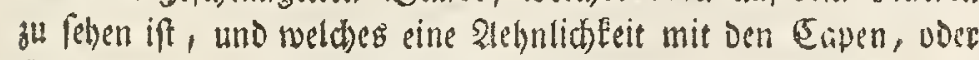
Sorgeburgen an Den berfthiebenen Dreerbufen haben full, wie man etwa Das Borgebưrg Der guten Sofnurig uno Baaj falfo

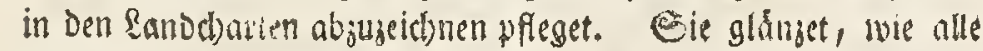
Şorzellanen, unvergleidblich, und Darf nicht erf puliret wersen! indem alle Jurzzlltanen alfu aus Dem Meer fummen. Sie if

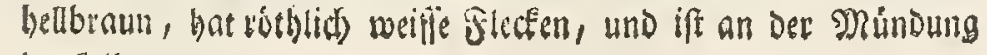
Dunfelbraun.

Fig. 6. 23u Dem Sefdeledte Der Kinthorner twerben aud

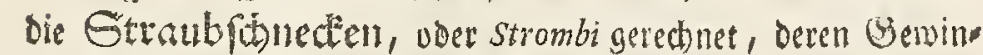
De lang bervor gethen, und an Der Murnoung nach strt ber Epirbelir einen langen Ednabel haben. Babin gehoret unt ter andern aud die gegennártige, welthe Dar 25abplomifite Thurm genennet wird. Diefe Benennung eneffehet oun ben Fismarzen vierectigten Flecten, welthe gleidfam die Fenfer, voer

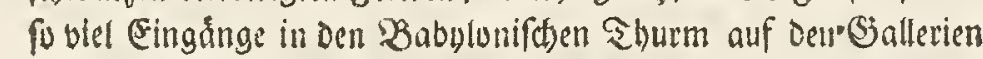
borfellen follen. Sonft hat diefe Sannecte nudb etwas befon=

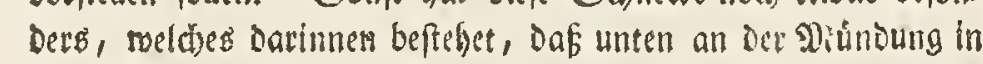
Dem erfen Berwinde ein Einfthnitt ift, als bb Durd Die Sumfte ein beereftigtes Stủc berausgenommen náke.

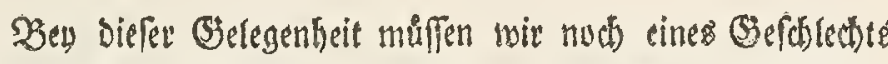
Erwethung thun, weldek Der Structur Diefis Babylonifiten Thurms febts nabe fómme, inbern fie even alfo in eine lange uno fofmable Evige mit febr vielen Steminden ausgebet, nur aber unten Eeituen folden langen Sedmabel bat, und Dá if

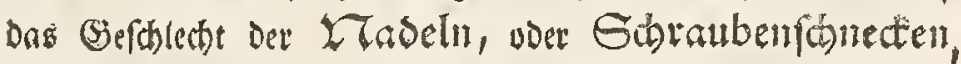
bie aber auch Strombi genennet werden. Tn biefem (5iefoledt) Eommen folgende Etriffe bor: Die Trommelfarauben, Die Etrictradeln, Die grantulirten und Die Enotigten Fiadeln, die Miagnetnadeln, Die Pickenter, Die Tiegerbeine, Die weiffe Ed)neppen, die Sumpfnedeln, bie Flup̃nadelin, u. D. m.

Fig. 7. Diefe Figur giebt uns 2nlab, won einem

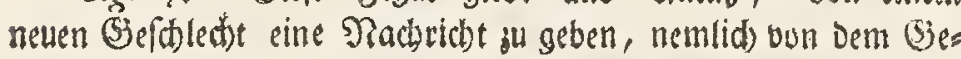

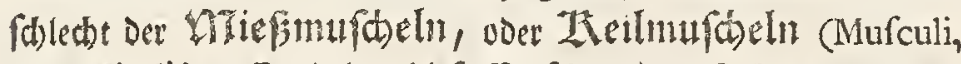

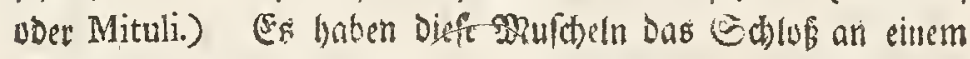
Ende freben, von ba fie in einem langen Sirigel aubgehen, oer

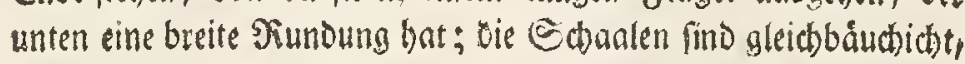

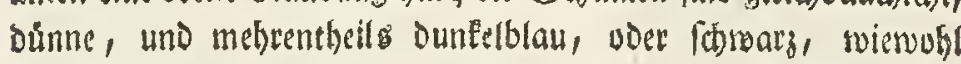
etliche menige aud eine broune Barbe baben. Zu biefan geho. ren Die gemeinen Mießrmulcheln, Die Gatto = und Die Stein

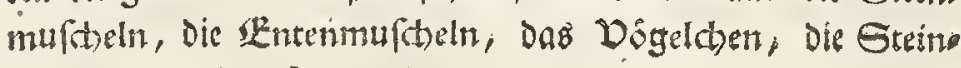
(Wheiden und die Jol3murtseln.

Die Siegentrårtige if bab vögeldtent, und wirt alfo

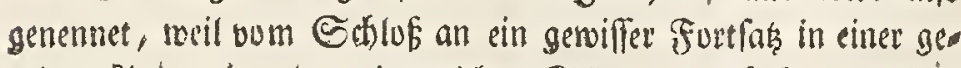
raben Rinie neben ber etgentliden Edjaale binlduft, welthes, menn bie zwen Ëchaalen aufgemadite gegen einander liegen, dré Geftalt eines fliegenden $23 u g e l s$ giebt, Da Denn Die beyden

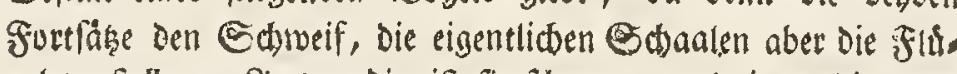
gel vorftellen. Sturwendig ift fie fohwars, uno inwendig bla mit einem गु)etlenmutterglang。
Quant à la préente figure c'eft un Limaçon des Caps, ou la Porcelaine géograpbique. Ce nom lui vient de la bande en ligne ferpentine, qu'on aperģoit fur fon dos, \&t où l'on prétend trouver une reffemblance avec les Caps ou Promontoires fituez au bord de plufieurs Golfes, comme on a coûtume de tracer quoiqu'à tort la Situation du Cap de bonne efpèrance, \& des Bayeș fur les Cartes Geografiques. Cette Coquille a un brillant incomparable, comme toutes les Porcelaines, \& n'a pas befoin de poliment, puisqu'elles font déjà toutes telles quand on les tire de la Mer。 Sa Cou. leur eft un brun-clair, fur lequel on remarque des taches rougeâtres \& blanches. L'embouchure eft d'un brun. foncé.

Figure 6. On range auffi parmi les Buccins les Strombes, dont les Contours s'étendent en long \& qui, comme les Fufeaux, ont un long bec à l'embouchure. La pièce re. préfentée ici eft de ce nombre, \& porte le nom de Tour de Babylone, nom, dont nous ne pouvons donner d'autre étimologie fi ce n'eft qu'il provient des taches quarrées noires, qui paroiffent fur cette pièce, \& ou l'Imagination féconde de quelques Amateurs prétend trouver une reffem. blance avec les portes \& fenêtres qu'on fupofe avoir êté aux galeries de cette Tour. D'ailleurs il y a encore une particularité à obferver à cette Coquille, 'c'eft qu'il y a en bas au prémier Contour près de l'embouchure une 'entaille quarrée comme fi on l'avoit faite exprès.

Nous devons à cette occafion faire mention d'un autre Genre, dont les individus aprochent beaucoup, à l'égard de la Strueture, de cette Tour de Babyloné Les Coquilles de ce Getre aboutiffent de méme en une pointe longue \& étroite, \& font comporées d'un trés grand nombre de Cons tours, mais elles n' ont pas en bas un bec auffi long que les Tours. C'eft le genre des Vis, ou des Aiguilles, qui portent aufin le nom de Strumbes. L'on met dans ce Genre la Vis du Tambour, les Aiguilles à tricoter, les Aiguilles grainées, \& les tuberculées, les Aiguilles d'Ainan, les Piguiers, les jambes de Tigré, les Becs d’éguière blancs, les Aiguilles de marais, les Aiguilles de Fivière, \& $\mathrm{c}_{\text {, }}$

Figure 7. La préfente figure nous donne lieu de parler d'un nouveau Genre encore qui eft celui des Mytules, ou Mufcles. La Fermeture eft à l'une des extrèmitez, d'où le noule s'étend \& forme une aile longue, qui fe termine en bas en un large demi-Cercle. Les Coquilles font aufí ven. truës l'une que $l^{\dagger}$ autre, minces, \& pour la plûpart noires ou d'un bleu-foncé, quoiqu'il y en ait aufic dont la couleur eft brune. C'eft ici que l'on place les Mytules communes ou ordinaires, les Mytules de Sable, ou de rocher, les Mytules en canard, le petit Oifeau, la Gaine aux Rocbers,
\& la Mgtule de bois.

Celle qui eft dépeinte ici eft le petit Oifeau. La raifon de cette dénomination vient d'une certaine Continuation, qui part de la Fermeture \& va tout à côté de la véritable Coquille tout du long en ligne droite, ce qui, quand les deux Coquilles font ouvertes, \& couchees l'une à coté de l'autre, produit la figure d' un Oifeau volant, dont la Queuë eft repréfentée par les deux Continuations, \& les ailes par les deux coquilles. Cette Mytule eft noire ait dehors. Le dedans eft bleu \& brille comme de la Nacre. 


\section{4}

Fig. 8. 3u Anfang biefex Riupfertafel haben wir erimnert

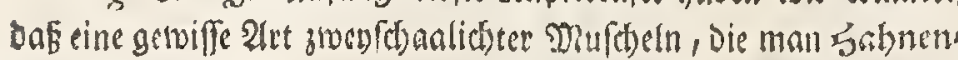

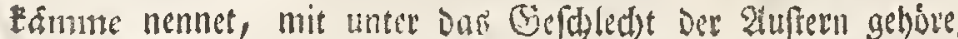

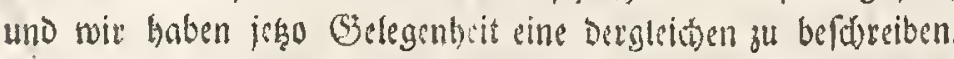
E. if nemlith bie in Diefer Sigur vertummende J) Jufchel eill

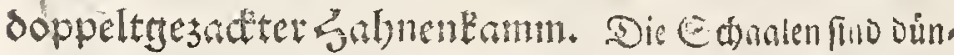

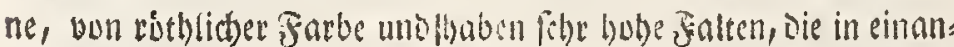

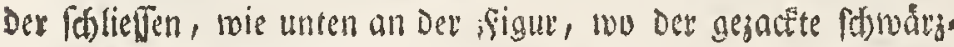

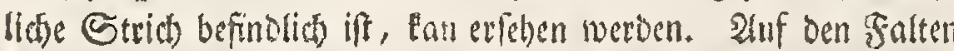

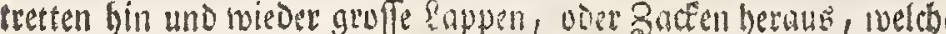
inwendig bobl find, und Der sinufdel eine befondere Bierde geben.

Fig. 9. Endids befthlieffen wir biefe Sofel mit einem Exem.

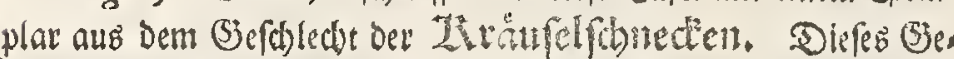

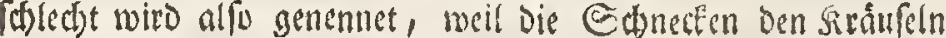

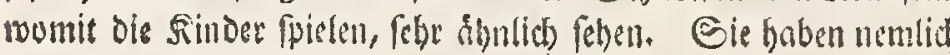
einen flacten Buben und selfen fribig ju, aber fie fino nicht fo

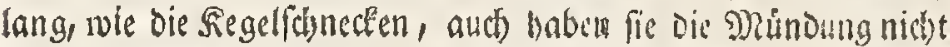
wie die Segelfatnecfen, an Der Seite, fundern unten. Su diefen

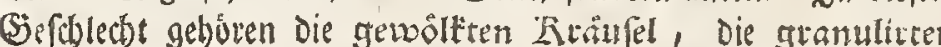

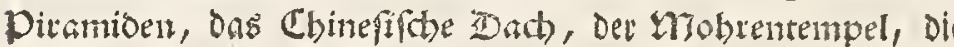
Tonnenfürtsgen, Die Geetonnen, Die Eridser, Die Wir bel=ober Perfpectivfhnecten, die Dickmäuler, u. D. m.

Эn gegenwårtiger Figur wiro unz eine Geetontme vorge

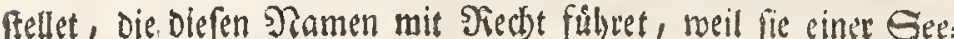
ronue vollesumen dyntict) fiefet. Unter einer Sectunne aber verfebet man Diejenigen Sunnen, weld)e auf Eandobánte jut orsarnung Der Echiffer getworfen werden. Diefe find unten fpisigig, uno baben an Der Epyige eine stette, mit wether fie an Der Eanobane befeftiget werden, wben aber fino fie breit, und rings berum mit eifernen \$reiffen umgeben. 30 on Der nematiden Bauart ift diefe braune Schnecte, Denn es liegen um Die Gie rinde herum eine Menge jierfictser erlyabener Sieiffe, fo dabi man

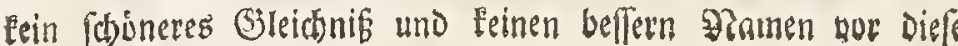

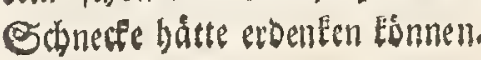

\section{TAB. B. V.}

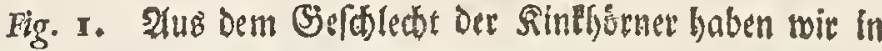

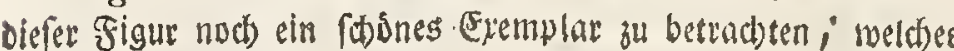
Das Sreitwelligte Buccinum genennet wiro. Es if die Gouale an Derfolben fehr Dúnne, weis, glaft uno glånzend und über Derfelben geben fitoine braune uno breite 233 ellen herunter.

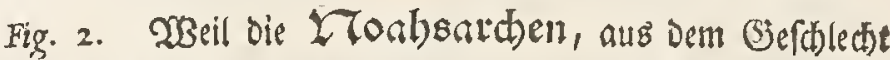

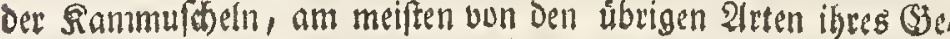

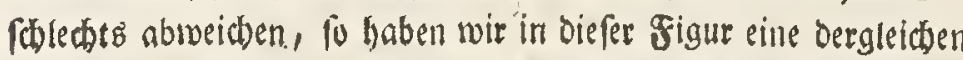
burgeftellet. Sie hat oben eine Fläble jwiftien ben arsitubeln,

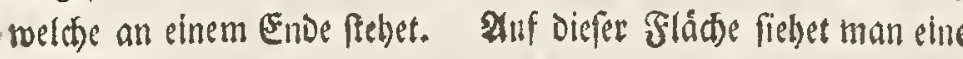
פiabt, vermittelit reldser beybe Sthalen mit ungemein feinen

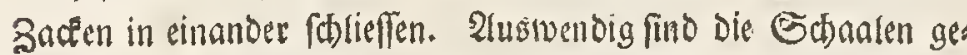
sipt, und unten bhangefegr in Der Witte Elaffen fie, Dafelbft trif man eine solenge Fafeen an, womit fie fids in Sande feft fau

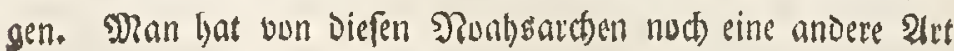

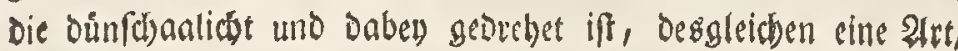

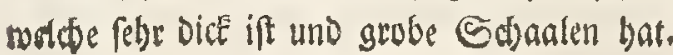

Fig. 3. In Diefer Figur miro uns eine Gdintemmufatel Doer Gtedimufithel vorgeftelle?, uno felbige getioret zu cinem

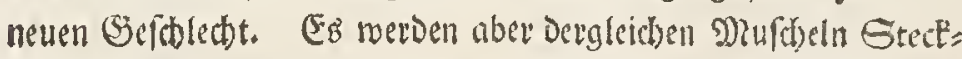
mufcheln genelinet, weil fie mit ber Epige im Sande voer

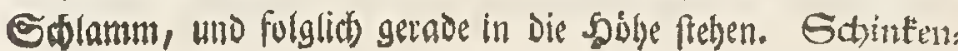
muftheln

\section{(5)}

Figure 8. Nous avons dit au commencement des defcriptions de la préfente Planche qu'il y avoit une certaine efpèce de Moules bivalves, que l'on nommoit Crêtes de Coq, \& qui entroient dans le Genre des Huitres. En voici la figure qu'on apelle la Crête de Coq à doubles dents. La Coquille en eft mince, \& la couleur rougeâtre. Elle a des plis fort élevez, qui fe joignent, comme on le peut obferver au bas de la figure, là où l'on remarque une raje noirâtre dentelée. On aperçoit fur les plis çà \& là de grands lambeaux, ou dents, dont le dedans eft cavé, \& qui fervent d'ornement à cette coquille.

Figure 9. La dernière pièce que nous produifons fur cette Planche eft tirée du Genre des Toupies. Elles portent ce nom à caufe de leur reffemblance avec les Toupies qui fervent de jouët aux Enfans. Ces Coquilles ont un fond uni \& vont fe terminer en pointe, mais elles n'ont ni la même longueur que les Cones, ni une embouchure pareille fur le côté, car l'embouchure de celles-ci eft en bas. On compte dans ce genre les Toupies à nuages, les Piramides grainées, le Toit Chinoiis, le Temple des Maures, les petits Pets de Nonne, les Tonnes de mer, les Entonnoirs, les Tournans, ou Limaçons à perfpective, les grojes Boucbes, \&c.

Ce que nous voyons dans cette figure eft une Tonne de mer, qui porte ce nom à trés - jufte titre, puisqu' elle reffemble parfaitement à ce que ce nom défigne. On doit entendre par là ces Tonnes, qu' on jette fur les bancs de fable pour fervir d'avertifiement aux Gens de mer d'éviter ces lieux. Elles font pointues en bas où tient une chaine par laquelle on les attache au banc de fable. L'extrémité opofée à la pointe eft large, \& munie de cercles de fer tout autour. Tout cela fe rencontre de même à la prèfente Coquille brune, car on voit autour des Contours un grand nombre de jolis anneaux élevez, de forte qu'on n'auroit jamais pû imaginer une Comparaifon plus jufte, ni un nom plus convenable à cette pièce.

\section{PLANCHE B. V.}

Figure 1. Voici encore une trés-belle pièce du Genre des Buccins, qu'on nomme le Buccin à larges ondes. La Coquille en eft trés-mince, blanche, unie, \& brillante. Elle eft couverte de belles ondes brunes \& larges.

Figure 2. Nous avons cru devoir produire ici une Arche de Nöé du Genre des Peignes, parce qu' elle diffère le plus des autres efpèces du même Genre. Elle a en haut entre les deux fommèts qui font à une extrèmité de la $\mathrm{Co}_{0}$ quille un efpace plat, fur lequel on voit une efpece de coû. ture, au moyen de laquelie les deux Coquilles fe joignent l'une à l'autre par des dents extraordinairement fines. Au dehors elles font pourvûës de côtes, mais environ vers le milieu elles font béantes. On trouve là une quantité de fila mens, qui fervent à l' animal à s' attacher fortement au fable en fuçant. On a une autre Efpèce d'Arche de Nöé dont les Coquilles font minces \& tournées, \& encore une qui n'a que des Coquilles fortes \& épaiffes.

Figure 3. Cette Figure nous dépeint un Iambonneau, ou une Moule fichée, qui apartient à un nouveau Genre. On apelleces pièces Moules fichées, parceque leur pointe fe fiche dans le Sable ou dans le Limon, \& par conféquent la partie large opofée va directement en haut; \& lambonneaun; par- 
mufthen aber heiffen fre Deswegen, well fie wie ein Echineen unten fpiţig uno vben breit find, Dabero man fie audf Sullfter:

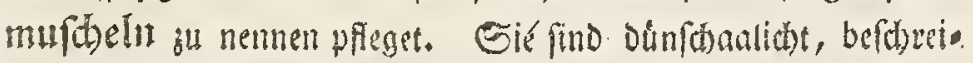
ben ein Drenect, und die Sotwalen fighen an Der geraden Eeite an

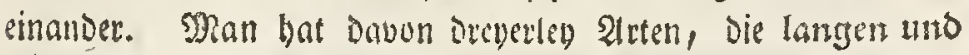

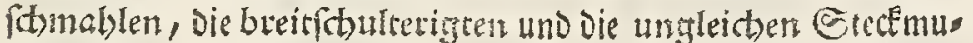
fiteln, und diefe find alle entwoder gezact woer ungezact.

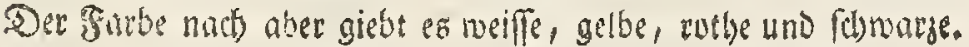

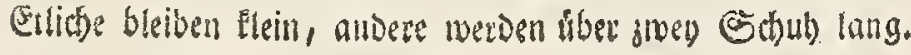

Die gegenmartige if oie fitwarze bieitfoulteritgte gescidte Grectmufiret. Wre Zacten fino nichts anders, als

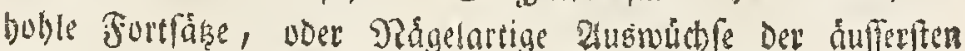
Schale. Sumenoig baben fie einen ounflen Jyerlenmutterglan.

Fig. 4. Es weidet bis Bauart ber Estinecten und Mu.

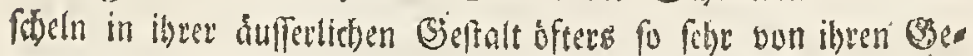
foslettetern ab, Da man ibeifelhaft gemadyt wird, ub eine voer

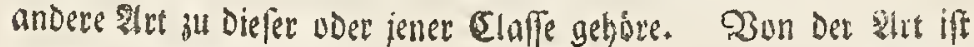

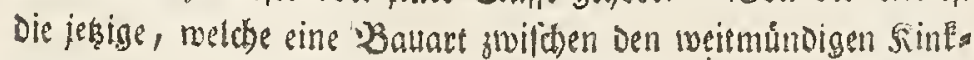

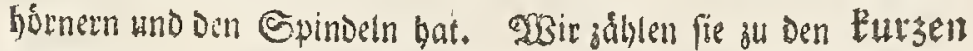
Gpirdelin, indern fie unten uno oben, wie jine, in eine Evise

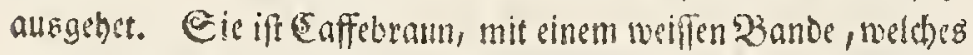
fich oben um alle Gerwinde berum fóltinget, gejietet, und bat eine máfig dicke, etroas gefurd)te Edaale.

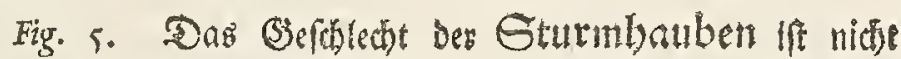
weniger, als andere (Siefchledter zallevich who mit vieten atrten

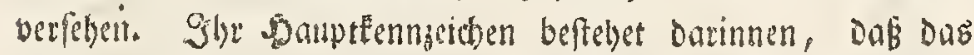

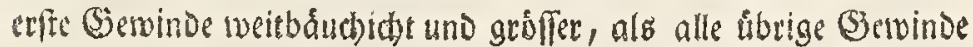

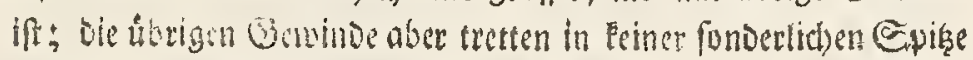

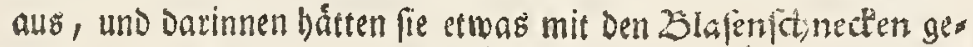
mein, wie Denn aud gewiffe Dänne geripte iBlafenfd)necten, dime Stumbabuen genennet werden, und noju man audi) Die Cymbia voerstabnfdonecécn rechnen Eúnnte; allein man jeblet

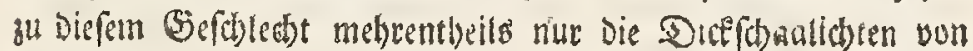

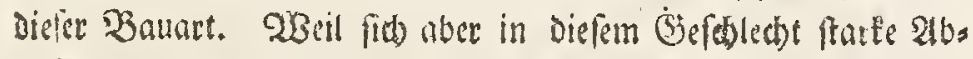
toeid)ungen zeigen, fo mus man nuthwentig fulgende vick (Fin. theilungen madien. Es giebr nemlid 1) hơteríchte Esurm.

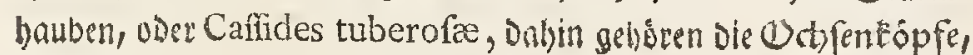

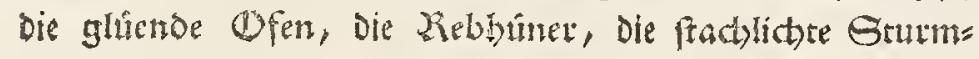
banben. 2) Es fino auth watrigte Giturmiauben (caffides verrucofæ) burbanden, namentid Die Pimpelden, Zirôten,

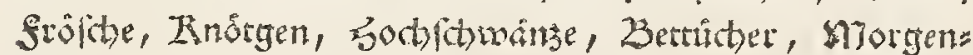
fterne, Karaentopfe uno Mratlbeete, woul einige audb bie

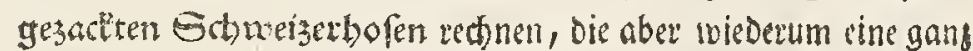
andere grigur haben. 3) Node fino de glatten Sturmlauben (caffides laves) ill mereen, worunter es aber viele giebt, bie aud

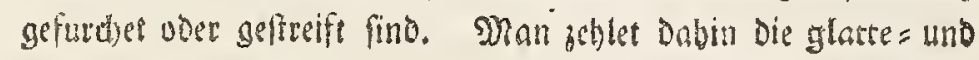

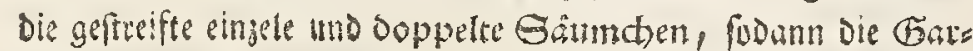

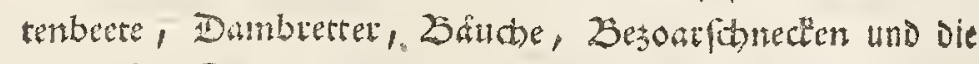
geftreifren Summauben. 4) Enolid abse folgen Die elgent.

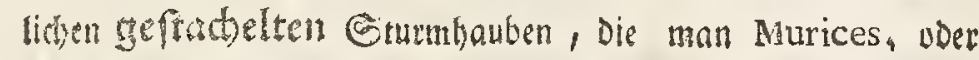

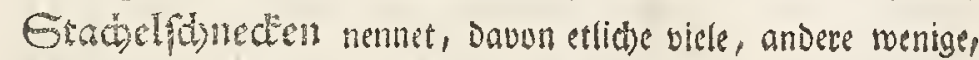

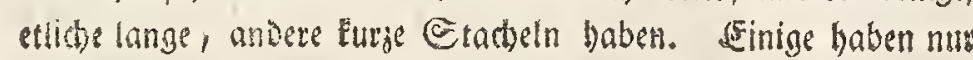
Sraufen uno sappen, anoere find glatt; sinige geben in einem Inngen Connabel, andere aber nur in einer furzen Mündung

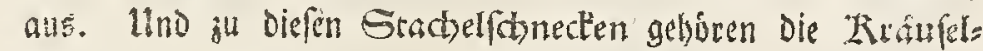
foneten, Branoboner, Edmepfentopfe, Ecorpionen,

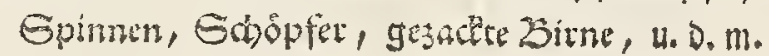

cequ' elles font comme les lambons, pointuës d'un bout $\$$ larges de l'autre, ce qui leur fait aufif donner le nom de Fourreau de Piftolet. Les Coquilles en font minces, de figure triangulaire, \& jointes enfemble du côté rectiligne. On en a de trois fortes, qui font les longues \& étroites, celles à larges épaules, \& les inégales, qui font toutes ou den. telées, ou non-dentelées. Quant à la couleur, il y en a de blanches, de jaunes, de rouges, \& de noires. Quelques unes reftent petites, d'autres atteignent la grandeur de plus de deux pieds, en longueur.

Celle-ci eft la Moule fichée dentée noire à épaules larges. Les dents n'y font autre chofe que des Continuations caves, ou des excrefences femblables aux ongles, de la Coquille extérieure. Le dedans a un brillant de nacre; mais la couleur en eft fombre.

Figure 4. Les Moules \& les Limaçons s'écartent fi fou. vent quant à la ftructure de leur propre Genre, que l'on eft quelques fois embaraffé à décider dans quelle Clafie telle ou telle pièce doit être mile:- Telle eft la pièce que la préfente figure dépeint, dont l'Architecture tient de celle des Buccins à large embouchure, \& aufi de celle des fúfeaux. Nous la plaçons au rang des Fufeaux courts à caufe qu'elle fe termine à chaque extrèmite en une pointe. Sa couleur eft un brun de Caffé, décorée d'une bande blanche qui fait en haut le tour de tous les Contours. La Coquille en eft médiocrement épailie, \& un peu cannelée.

Figure r. Le Genre des Cafgues eft auffi riche que d'autres, \& a quantité d'efpèces. Le Caractère diftinctif principal de ces Coquilles-là confifte en ce que le prémier Contour en eft extrèmement ventru, \& plus grand que tous les autres, \& que les Contours qui fuivent ne fe terminent pas en une pointe fort remarquable, en quoi elles ont quelque chofe de commun avec les Limaçons en Veffie, \& de fait il y a certains Limaçons en Vệie à côtes qu' on apelle les Cafques minces, ce qu' on peut dire de meme des Limacons en nacelle. Cependant génèralement on ne regarde commie étant de ce Genre que les Cafques à coquille épainle de cette con. formation.' Mais comme ce Genre eft fujèt à de grandes Variations, on à trouvé bon d'y établir la Divifion fuivante. Il y a d'abord I) les Cafques a bofjettes, ou tuberculez, dont les efpèces font les Tetes de Boeuf, les Fourneaux ardens, les Perdrix, les Cafgues a Aiguillons. Après cela viennent 2) les Cafques à verruës, où l'on trouve les petits Verres à Liqueurs, les Crapaux, les Grenouilles, les petits Noeuds, les Queuës bautes, les Linceuls ou Draps de lit, les Etoiles du mom tin, les Tètes de cbat, \& les Meures. Quelques uns y ajoutent les Culotes de Suiffe dentelées, qui ont pourtant une toute autre figure. 3) Enfuite on a les Cafques unis, parmi les. quels on en trouve beaucoup qui font auffi cannelez ou rayez, où l'on range les petites bordures ou Ourlets unis \&z rayez fimples \& doubles, les Quarrez de Iardin, les Damiers, les Ventres, les Limaçons de Bezoar, \& les Cafques ragez. Enfin il y a encore les Cafques à aiguillons proprement ainfi dits, qu' on nomme Murices, dont quelques uns ont beaucoup d'aiguillons, d'autres en ont peu, quelques uns les ont longs, d'autres les ont courts, quelques uns n'ont que des frifures \& des latnbeaux, d'autres font unis, quelques uns fe terminent en un bec long, d'autres n' ont qu' une embouchure courte. Les efpèces de ces Limaçons à aiguillons font les Toupies, les Limaçons en Tifon, les Tetes de Becaffe, les Scorpions, les Araignées, le Puijoir, la Poire dentelée, \& $\mathrm{c}$. 


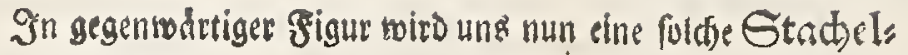

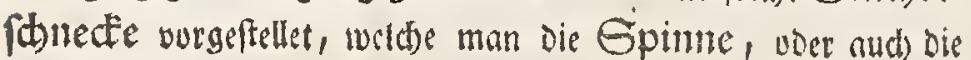

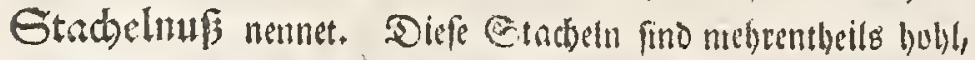

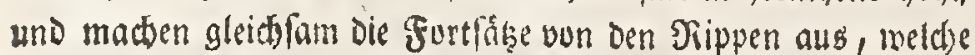
auf ber Sthate liegen. Der lange Estmabut befechet in einer bublen Siinne. Die Sdjaale if nidit gar bitt, und ber Sarbe

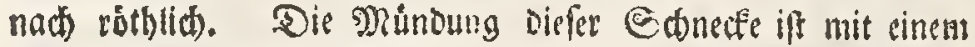

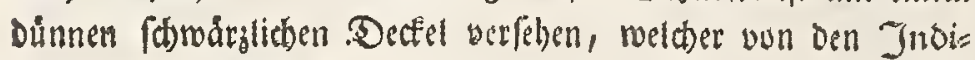
anern zum Iiáucherwert gebraud)t, ung Der Onyx, woer Unguis odoratus, in den atputbecten aber Blatta byzantia genennet roiro, uno su den treernabelit gefammlet verden muf.

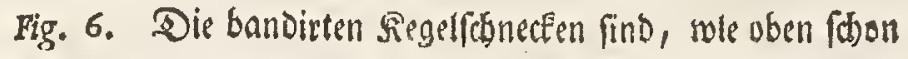

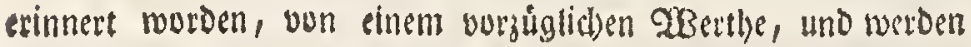
2lounirale genennet. Einen foldben 2lomiral finden wir in Diefer figur zu betradsten. Die Shante hat einen gelben

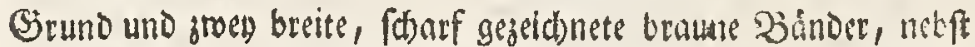
einem fotmablen brounen Faden in der Ditte. Diele braunen

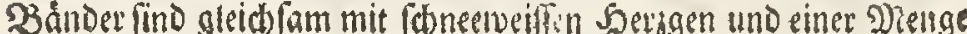

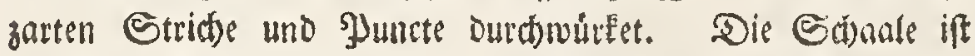
fuiegelglatt uno glánzend. Ge reiner bie sarben, je fohatrfer bie

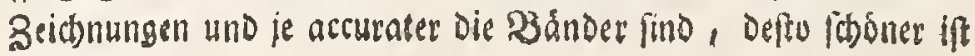
Der Romiral.

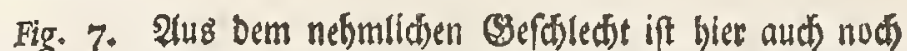

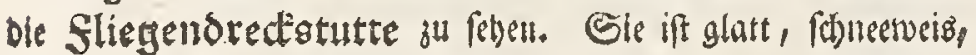

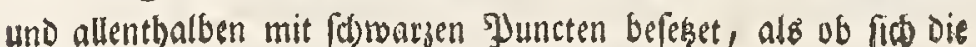
Filiegen darauf gefestet, und fie berworfen båtten.

Fig. 8. Den einfwanliditen Søneten wiro aud now

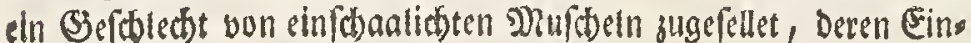
roukner von Der einen Eseite gegen Die Silipgen, voer Den Buden Des Dreeres anfingen, won Der andern aber mit elnes minder uder

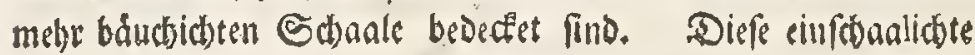
Druftheln beftehen in oreverley Stauptarten, nemliti in Den Gees obren, "Liliptlebern, uno Gabullendedeln (operculi callorum). Die Geeolyren find entroeber lang doer breit,

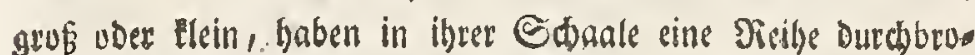

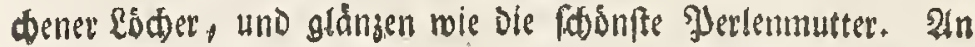
Dem einen Ende lif inzgemein nur sine verluethene Spubr von einem einfacten Gerbinde zu fetsen. Die Xlipleber, wetche

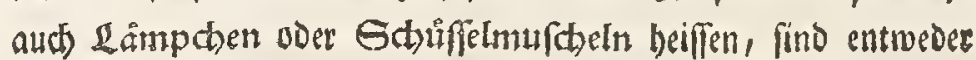
ylat, woer erhaben, glat, woer geftreift, mit ober ulye Siippen, am Siande gleid), uber gezactt, ober aud effigt uno mit Strablen

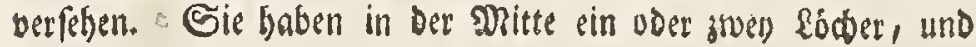
etlidje baben gar kenes. Sino oft rectst runo, oft lénglidtst. Einige baben eine Sthetbeswano, andere leine; ettidte tragen foe

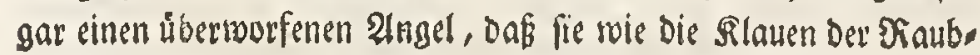
biggel ausfeben. Siele fint ungemein bick, andere bünner, unto etlide gar Durdiftutig; Die Zerånderungen Der Farben und

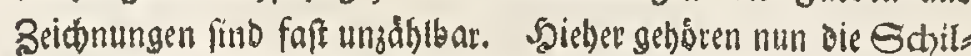
oe, Die Lampen, bie fifthmeiberbauben, Die Datrenkappen,

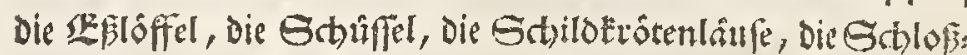
loduer 4. D. m. Die Gdbruilylendedel endich find Eeine harte Echaalen fondern nur Đergamentartige Edjiefer, bie, roie ein Jingel ben Finger bebectet, aud) eine befondere Ant won Sofnedeen zu bebecten pflegen, weldse fonft Eeine barten Sthate baben. Dan theilet fie ein in runde uno lóng

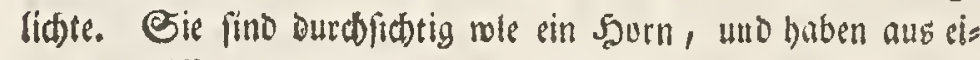

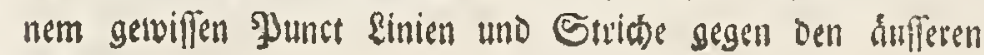
Fiant.

\section{$\$$}

Ce que nous voyons dans cette Figure eft un de ces Limaçons à aiguillons, qu'on apelle Araignées, \& quelques fois Noix à aiguillons, (c'eft la Pourpre). Ces Aiguillons font le plus fouvent caves, \& paroiffent être une Continuation des côtes, qui font fur la Coquille. Le long bec n'eft qu'une rigole cavée. La Coquille n'eft pòint trop épaiffe, \& rougeâtre de couleur. L'Embouchure de ce Limaçon eft pourvîë d'un couvercle mince \& noirâtre, dont les Indiens fe fervent pour leurs Parfums, \& qu' on nomme Onyx, \& aufi rOngle odorant. Les Apotiquaires l'apellent Blatia byzantia. Dans la Collection il faut la mettre parmi les Umbilics marins.

Figure 6. Les Cones à bandes ont, comme nous l'avons dit plus haut, un prix prééminent \& portent le nom d'Amiraux. Tel eft l' Amiral que la figure préfente dépeint. La Coquille même eft jaune, entourée de deux bandes brunes larges nettement marquées entre lesquelles paffe un fil brun étroit au milieu. Des petits coeurs blancs comme neige, \& une quantité de raies fines $\&$ de points femblent être tiffus dans ces bandes. La Coquille eft unie comme un miroir, \& brillante. Plus les couleurs font pures, plus les deffeins font nets, plus les bandes font exactement marquées, \& plus cet Amiral eft beau.

Figure 7. Le même genre nous fournit encore le Cornet de fiente de mouche que nous voyons ici. Cette Coquille eft unie, blanche comme neige, \& toute marquée de points noirs, comme fi des mouches y avoient pofé leur fiente

Figure 8. Il y a un Genre de Moules univalves que l'on joint aux Limaçons univalves. L'Animal Habitant de cette forte de Coquilles s' attache d' un côté aux rochers, ou au fond de la mer, \& de l'antre il fe trouve couvert d'une Coquille plus ou moins ventruë. Il y a trois efpèces principales de ces Moules univalves, Eģavoir les Oreilles de mer, les Succeurs de rocber, \& les Convercles des Calus. Les Oreilles de Mer font ou longues ou courtes, grandes ou petites. On voit dans la coquille une rangée de trous percez à jour. Elles ont le brillant de la plus belle Nacre. A I'un des bouts on aperçoit le plus fouvent une trace presqu' effacée d'un Contour fimple. Les Suceurs de rocher, qui portent auffi le nom de petites Lampes, ou de Moules en Plat, ont la Coquille ou platte ou élevée, unie ou rayće, munie de côtes ou fans cótes, à bord uni ou dentelé, \& par fois à angles \& à rayons. Cette coquille a au milieu quelquefois un ou deux trous, \& quelquefois elle n'en a point. Ces trous font fouvent abfolument ronds, \& fouvent il 6 font oblongs. On remarque dans quelques uns une paroi de féparation, d'autres portent un Clou recourbé, qui reffemble aux Serres d'un Oifeau de proie. Ces Coquilles font pour la plûpart fort épaiffes, il y en a quelques fois pourtant de minces, \& même des tranfparentes. A l'égard des couleurs \& des deffeins les Variations font prefque innombrables. L'on trouwe ici les Boucliers, les Lampes, les Coirfes des Pniffomières, les Calottes de fou, les Cuilliers de table, les Plats, les poux de Tortue, les Trous de Serrure, \&c. Enfin les Couvercles des Calus ne font pas des Coquilles dures, ce font plûtôt des Ecailles femblables à une Membrane forte, ou pour mieux dire aux ongles du corps humain, \& c'eft de cela qu'eft couverte ordinairement une efpèce particulière de Limaçons, à qui la Nature a dénié une Coquille 
dure. On divife celles - ci en rondes \& oblongues. the font tranfparentes comme de la corne, \& garnies de lignes \& de rayes, qui partant d'un point déterminé vont aboutir au bord extérieur.

2Bas nun bie gegentsartige Figur betrift, fo fellet ferbige

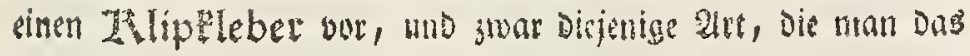
Gibilo nennet, Danon es viele tlnternten giebt. Diefe mitd

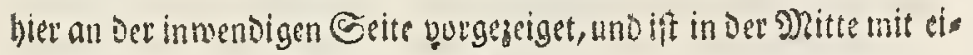

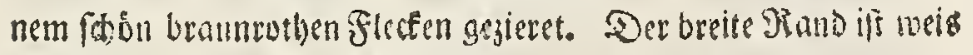

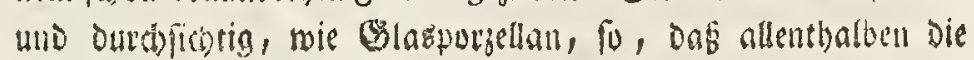
Flecten durchidseinen, weld)e an der andern Geite befindich jint ;

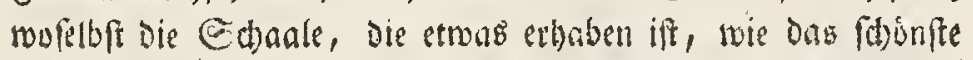

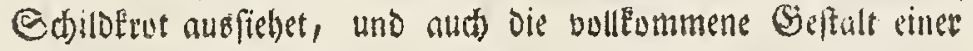

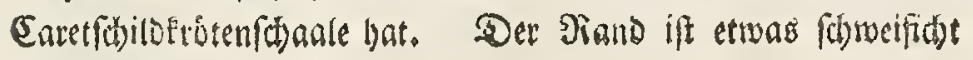
aurgejarit.

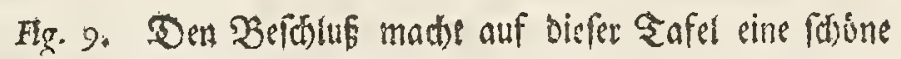

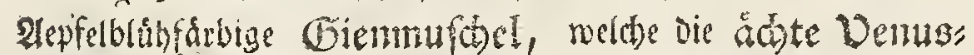
mufdel genennet wito. Eie hat auf ber Oberfinde ber Sdjnale

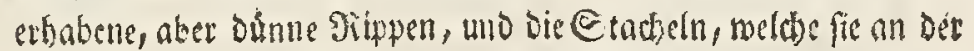

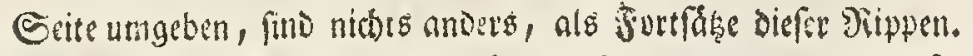

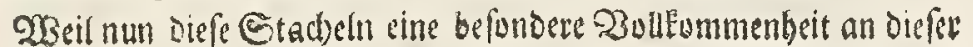

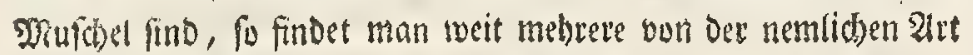

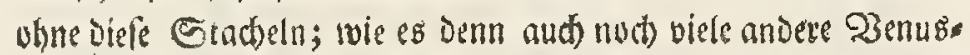
mufteln girbe, Darunter aud) Das alte Weib aus diefem (Jiss

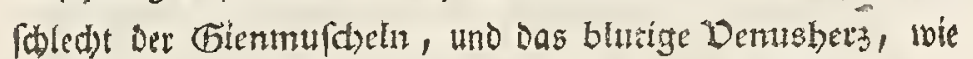
auch Das geripte Denusbonblet aus Dem Befthlecte Der Sammmulityeln gebivet.

\section{TAB. B, VI.}

Fig. I. Ilnter Den sin fig. 6. Evwelfnung gethan lyaben, fino vbnfireltig die Tritonsbirner, oergleiden nir eines in biefer stigur abgebiloet finden, bie

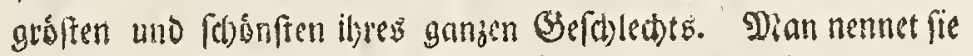

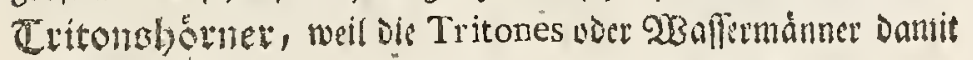
abgebildet werben; nud) Trompetenftheden, weil bie Ins

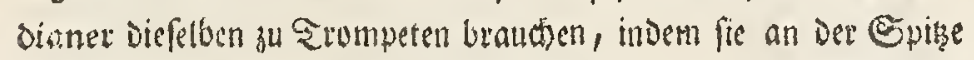

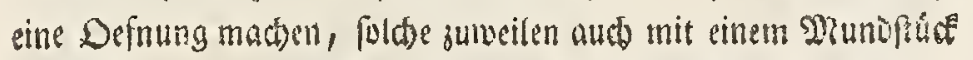

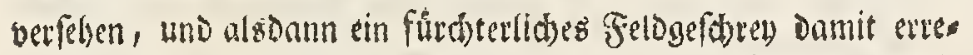
gen Eunnen. Das ungentein fdyóne, glatte uno glănzende Origi-

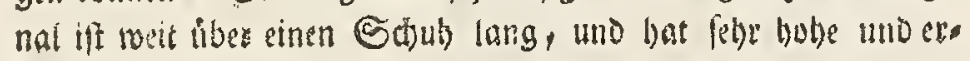
baben gefarbte 2 sellen, Die in gedowpelten brounrothen und mit

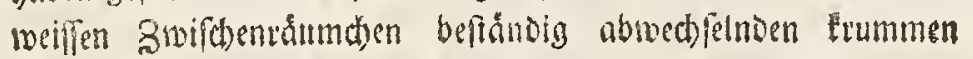

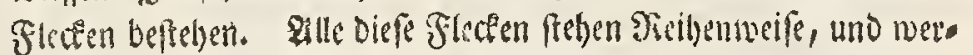
ben ntit Ouerlinien, Die in geperbten etwas flud liegenden Furden

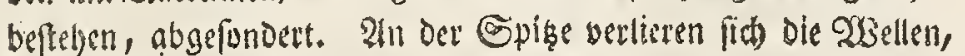

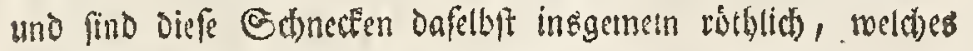

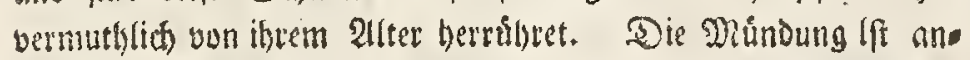

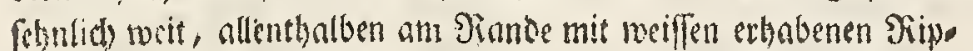

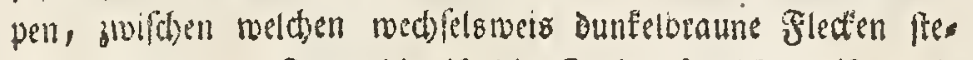

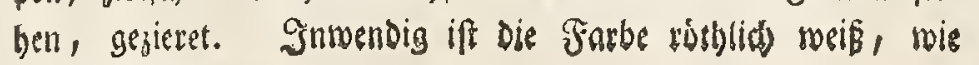

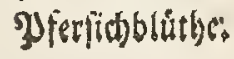

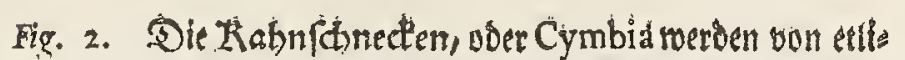

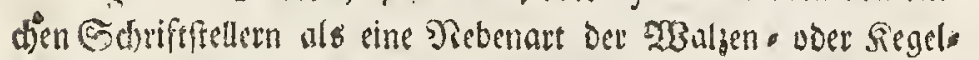

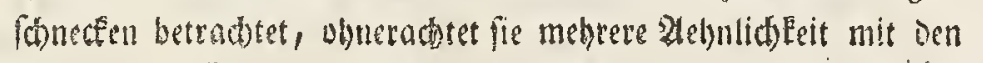

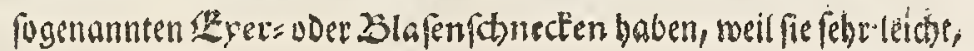

Quant à la Coquille repréfentée ici c'eft un Succur de Rocber, \& dans l'efpèce c'eft le Bouclier, qui a quantité de Sous - efpèces. En confidérànt la partie intérieure de cette pièce, on voit qu'elle eft décorée au milieu d'une belle tarhe d'un brun-rougeâtre. Son bord eft large \& tranfpaz rent comme la Porcelaine de verre, ce qui fait que les ta. ches, qui font de l'autre côté paroifient par tout à travers. La Coquille de cet autre côté eft un peu élevée, \& refrem. ble à la plus belle Ecaille de Tortuë, \& a d'ailleurs parfai tement la figure d'une Coquille de Tortue de Caret, comme on les nomme en Hollande. Le bord eft un peu échana cré \& dentelés.

Figure 9. Nous finiffons ici par the belle Came de cous. leur de fleur de Pommier, qu'on apelle la véritable Moule de Vemus. On voit fur la fuperficie de la Coquille des cô. tes élevées, mais minces, \& les Aiguillons dont elle eft garnie à coté ne font autre chofe que des continuations de ces nêmes côtes. Ces Aiguillons font une des perfections de cette pièce, car on trouve un grand nombre de Coquilles de cette forte, où P'on ne voit point d'Aiguillons. Il y a encore d'autres Moules de Venus, parmi lesquelles on ren. contre la Vieille de ce même Genre des Cames, le coeur Saignant de Venus, \& le Doublet de Venus a côtes du Genre des Peignes.

\section{PLANCHE B. VI.}

Firqure t. Parmi les Buccins, dont nous avons déjà parlé cy-defius P1. B. II. fig. 6., il y a aufii les Cornets de Triton, \& ce fọnt même les plus grandes \& les plus belles pièces de ce Genre. Telle eft la Conque de cette figure. On apelle ces Conques Cornets de Iriton, parce que l'on donne aux Tritons, à qui la Fable a affigné l'emploi de Trompettes do Neptune, un Cornet figuré ainfi pour attribut, dans les peintures qu'on en fait, \& on leur donne auffi le nom de Limaçons-Trompetíes, parceque les Indiens au moïen d'unie ouverture qu'ils font au bout de cette Conque, \& quelques fois d'une embouchtre qu'ils y ajoutent, s'en fervent dans leurs guerres comme de trompettes, \& font avec cet in ftrument un bruit épouvantable. L'Original, qui eft extrèmement beau, uni, et brillant, a beaucoup plus d'un pied de longueur. On y remarque des ondes colorées, fort have tes \& élevées, qui font compofées de taches courbes doubles de couleur rouge tirant fur le brun, entre lesquelles on voit toûjours un petit efpace blanc. Toutes ces taches font pofées en rangées, lefquelles font féparées l'une de l'autre par des ligneś tranfverfales qu' on voit fur des Cannelures entaillées, qui ne font guères profondes. Les Ondes fe per. dent vers la pointe, où la Coguille eft ordinairement rou. geâtre, ce qui provient vrairemblablement de fon age. "L'embouchure eft fort large, \& décorée tout autour du bord de côtes élevées blanches, entre lefquelles on obferve alter. nativement des taches d'un brun foncé. La Couleur en eft au dedans blanche, tirant fur le rouge, femblable a celle des tleurs de pêche.

Figure 2. La Nacelle, ou Gondole, en latin Cymbium, eft regardée par quelques Auteurs comme uneSous-efpècedes Roulcau $x$, ou des conts, quoiqu' elle ait plus de reffemblance avec ce qu' on apelle le Limaçon ovale, ou fait en vefjie, parce 


\section{8}

Difnne, und giemlid Guhl find, ob fie fid gleid etwas in bie sange

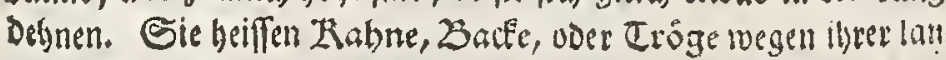

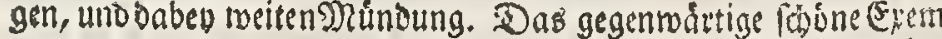
plar aus Dem Eabinet Bes Seern Sufratl) Trews iff Der geteron

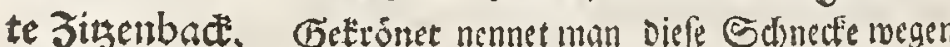
Den an Dem ubern \$iand Des erfern Giendindes befindlidjen Baffen,

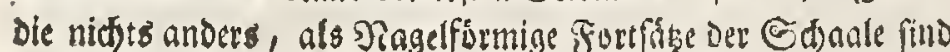
Zitsenbad" aber foul fo viel beiffen als eine Baaten= nòer sróge

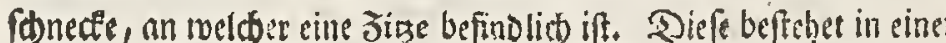

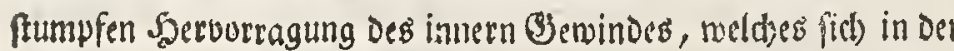

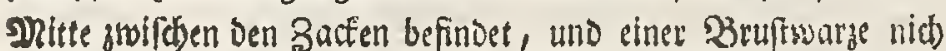

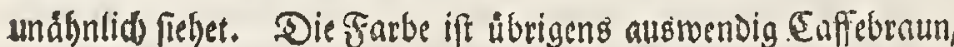

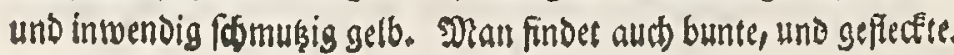

Fig. 6. Diefem Gaben roir eine andere Trabnftancele bu Gellerer farbe beygefúget, welite aber diefes fonderbare an firf bat, Daß̧ fie weder mit einer zacticisten Srune, nodb auch mit ciner

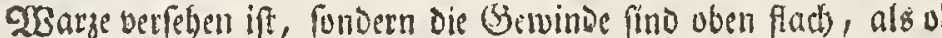

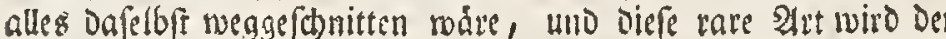
Sd)weimruffel genennet. Das Driginal if úber jelhn ăbl lang.

Fig. 4. 2us Dem Cabinet Des bereits gedacten 5eren 5of ratb Trems in Thirnberg riro unter andern allfier auch eine

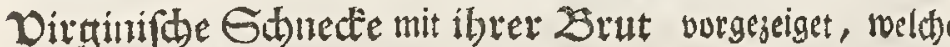

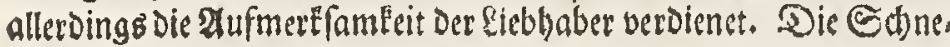
cle felleft wird bum $\mathbb{L}_{\text {iffex }}$ Dar Buccinum ampullatum genernet, getgoret aber zu Den Feigen, mit welden é die groffe Heberein frimmung hat, ausgenommen da jebes Serninde vben platt und

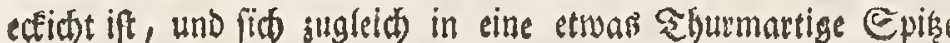
mit beriern umlauffenden (Janngen endiget. Der Sanuptend jmeet aber, marum diefe Sannecte vorgegeiget woroen, if die 23 rut Derfelben", weldge twir ctwas náber befasreiben wollen.

(E) wådfet nemlid) aus der fleiffidten Subftand ber Sajne

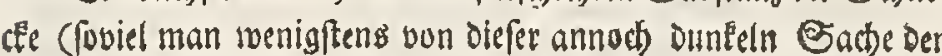

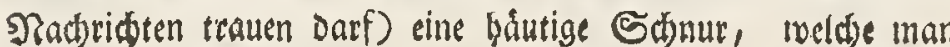
etwan eine Jiabelfature nennen lónnte, uns die bey ben

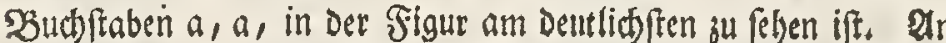
Diefer Ě Fet, litget eine DRenge tweiffer, Gdutigen uno biffen Blåtter unit Der einen Ṡeite befeftiget, meldbe alle obngefebr einen fedffen Theil ber aulls yon einander entfernet find. 2Alle biefe 2Blátter

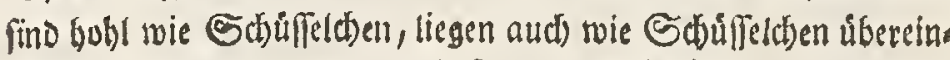
anber, und find bon unten mit Silppen verfiben, weldse madien, Daś ille runder Siand eine vielectigte Beftalt getvinnet. Diefe

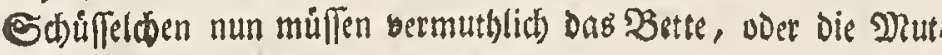
ter feun, worinne firt) bie jungen Schnecten erseugen, wenigftens if diefes wabrefteinlid, vblnerabtet man es ehedem vor eine Art von Eurallen voer Alcyonium gelyalten, Das fich an Ber Edfnecte angeferset hatte. Midifte fid aber jemano verwundern twie defe 23 rut gleidfam auflerbalb Der eigentliden \$Nutter

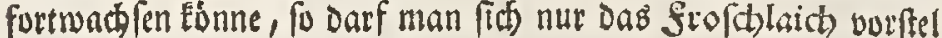

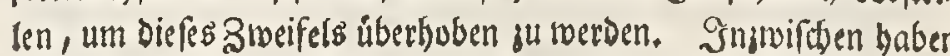
nidte alle Schnecfen eine åhnliche Zrut, fondern diefelbe Eomun

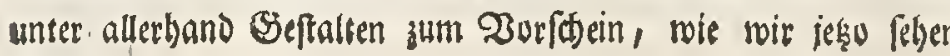
noerden.

Fig. 5. 2Win Gaben nemlid) ju meftrerer Erld́uterung Der vorigen vieuten Figur diefe uno die folgende nodib binzugethan. Es ift folglid Diefe Sdjnecfe die gesact te Fledermaus, welde regen ibrer Beidjnung fo genennt mird, weil diefelbe den Slúgeln oer
为

qu' elle eft fort legère, mince, \& affez cave, quoiqu'elle s'étende un peu en long. On leur donne le nom de Gondole, de Baquet, ou d'Auget, à caufe de leur embouchure longue, qui ne laiffe pas d'avoir une largeur proportionnée. La belle pièce, que nous voïons ici, nous vient du Cabinet de Mons. le confeiller Aulique Treqw \& s'apelle le Baquet couronné ' mammelon. L'épithète de couronné a été donnée à ce Baquet à l'occation des dens ou pointes, qui paroiffent au bord fupèrieur du prémier Contour, \& qui ne font autre chofe que des Continuations de la Coquille en forme de Clouds, \& le nom de Baquet àmamimelon ne provient que de ce que cette $\mathrm{C} \odot$. quille a la figure d'un Baquet, ou d'un Auget, au bout duquel il y a ure éfpèce de Niammelon, qui n'eft qu' un bout avancé des Contours intérieurs, placé au milieu des dens, \& fort reffemblant à un bout de teton. La Couleur extérieure en eft un brun de Caffé, \& l'intérieur eft d'un jaune fale. On en trouve aufli de bariolées \& de tachetées.

Figure 3. Nous avons joint à ce Baquet une autre Gondole de couleur plus claire, qui a ceci de particulier, c'eft qu'il n'y a ni couronne dentée, ni mammelon, les contours en étant abfolument plats, comme fi on en avoit retranché tous les ornemens. Cette efpèce rare porte le nom de Groin de Pourceau. L'Original dépeint ici a plus de dix pources de longueur.

Figure 4. Cette figure repréfente un Limaçon de Virginie avec fon Nourrain, pièce rare, que Mons. le Confeiller Aulique Trero a auffi eû la bonté de nous communiquer, \& qui eft biell digne de l'attention des Amateurs. Lifter apelle cette Conque Buccinum ampullatum, le Buccin ampoulé. Proprement elle apartient à l'efpèce des Figues, auxquelles elle reffemble le plus, excepté que les Contours font en haut plats \& angulaires, \& qu'ils fe terminent en une pointe formée en quelque façon en Tour, par de larges conduits qu'on voit tout autour. Notre but ici eft moins de décrire cette coquille, que le Nourrain qui en fort.

Il naît de la fubftance charnuë de ce Limaçon, (autant qu'il eft poffible de faire fonds fur des probabilitez dans une matière envelopée de tant de voiles) un Cordon membra. neux, qu'on pourroit apeller Cordon ombilical, qui paroît le plus diftinctèment à nôtre figure près des Lettres a a. Ce Cordon, qui fort par l'Embouchure de la Coquille, eft entouré d' un grand nombre de feuilles blanches, membraneufes, \& épaiffes, qui y font attachées par un côté, diftantes l'une de l'autre environ de la fixième partie d'un pouce. Toutes ces feuilles font cavées comme des petits plats, \& pofées ainfi l'une fur l'autre. Elle font pourvîës au deffous de côtes, qui donnent à leur bord, naturellement rond, une figure polygone. On peut donc conjecturer que ces petits Plats font le prémier lit, ou la inatrice, où fe forment les Limaçons naiffans. Du moins ce fentiment eft-il plus vraifemblable, que l'idée où l'on étoit anciennement que ce Nourrain n'étoit qu'un efpèce de Corail, ou d'Alcyonium, qui s'attachoit au Limaçon. Si quelqu' un trouve étrange que ce Nourrain puiffe prendre de l'accroiffement hors de fa propre Mère, nous n'avons, pour lui ôter ce doute, qu'à le renvoyer au frai des grenouilles, où la Nature opère de même. Cependant on ne remarque pas la même chofe à̀ tous les Limaçons, dont le Nourrain diffère fouvent, \& paroit fous toutes fortes de figures, comme nous l'allons voir.

Figure 5. Nous avons ajouté ici la préfente figure, \& celle qui la fuit, pour donner plus de jour à ce que nous avons dit de la précèdente. Ce Limaçon porte le nom de Chauve-Souris dentée, On l'apelle Chauve-Souris, à caufe 


\section{電}

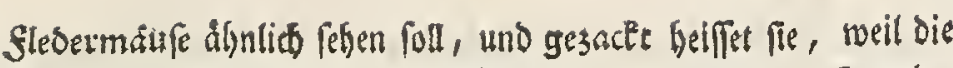

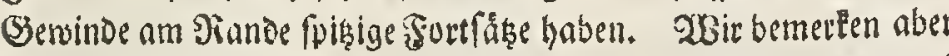
jeşo nur vorigh

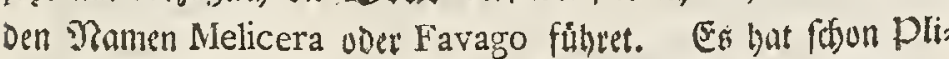

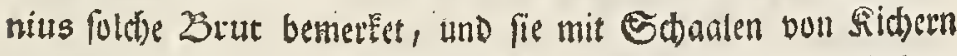
verglithen, Da er Denn Die Fithnchen, iveldse Diefe Brut haben, Melicembales nennet. Es beffeber sber Dieferbe in einem $\subseteq$ d)aum voer vielen aneinander gewarbfenen bublen 33 láágen, die mit vies Ien Sincamenten, und mit einer Bleinen Defnung an Der untern

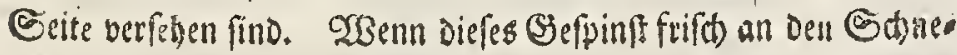
ceen gefunden wird, weldbes nur zu gerwiffen Gablecsieeten, als im Dian ung Dectuber gefdjellyet, fo fehen Diefe Bblábgen belle und

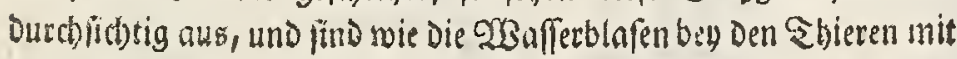

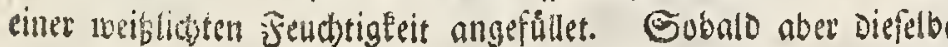
auštructinen, merden fie gelb und ЭJergamentartig; uno felben

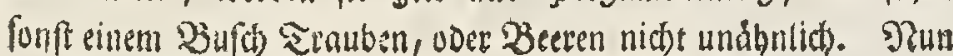
rwill zwar Rumpf defes vor Eeine Brut voer Eyernefi an.

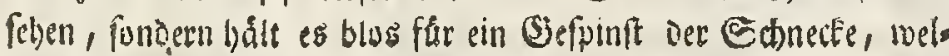

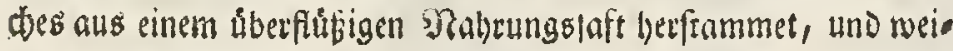

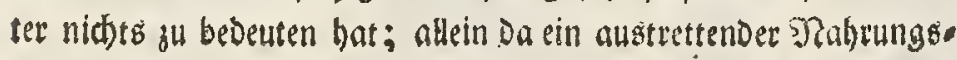

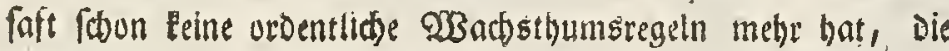
Dod) allhier beftándig, wahrgenummen werden, fo iff uns diefes fthon genug, Dak wir biefem Sodriffteeller bierinnen nidbt bego pflideren Esment.

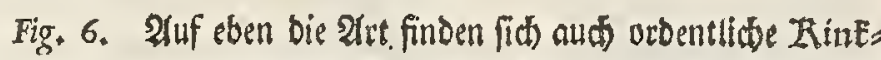
bórner mit einer folden Brut, uno if Das gegentwártige Buc. cinum ein gemeines Sinfliburn aus Der Siovofee, Dergleichen báufig an ver Snful Zmeland und an Den umliegenden Stranoen ausgeo

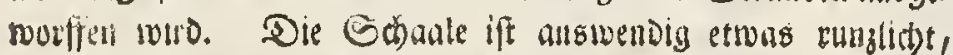
blau geffárot, und inwendig bláulictst weib. Was nun aber ibre Brut betrift; fo mero zowar feloige aud eben fo beym Dlinius beidwrieben, mie Diejentge, Die wir in Der fünften Bigur geiel)en

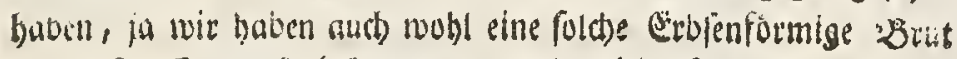
mit biefer Edynette befummen, allein nidbt fetten ift uns eine

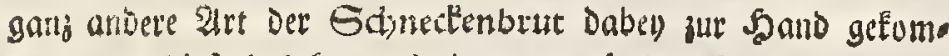
men, und biefe befteriet, wie in gegenwartiger sigur in erfelyen

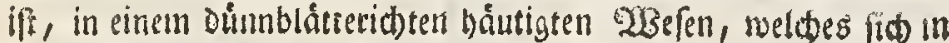
bielen Sirsulen un Sirtímmungen unificlinget, unten aber an einer fosmalen Edyur zufammen tummt. Diefe sraufen, bie gletch) Dem SeEkróle alle aneinander langen, find auf beyden Sei

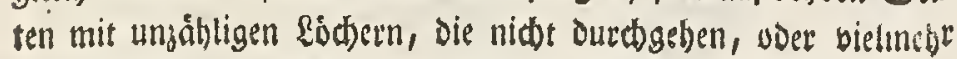

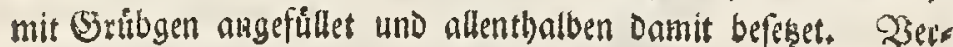

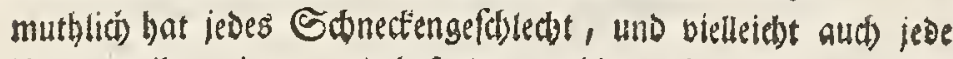

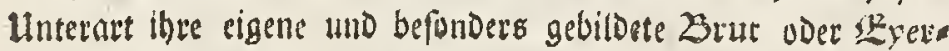
neft. Denn unter Den Segelfednecten trift man eine ald an, Daran man bie $\mathfrak{B}$ rut in langen Sotten findet, die eben wie

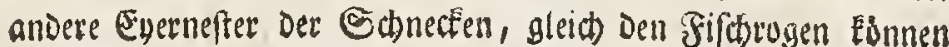
gegeffen merden. Dian muś fith aber bier nur mit Detuthmas fungen belyelfforn; Dann Das ganje Erzeugung, oder Sortpflan.

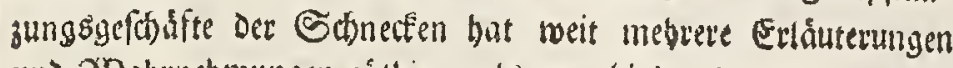
und 23 abrnebmungen nóthis, als man biobst bat erbalten voer anfellen tónnetr.

$$
* * *
$$

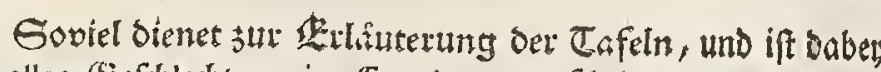
bon allen (Gefdlecttern eime Erroehnung gefdethen; nur fino bon

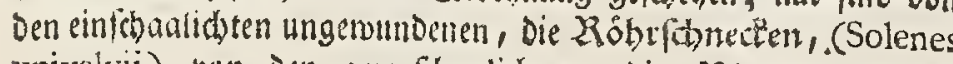
univalvii) uon Den zweufdualidgten, Dis Rimnenooublette (Solenes bivalvii) und endich Die Sronung Der vielffinalidten

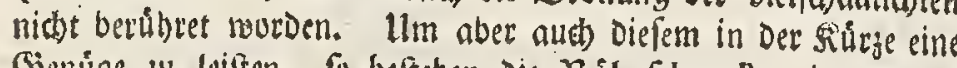
Genuge zu leifren, fo beffeben die Robbrfthredien in boblen,

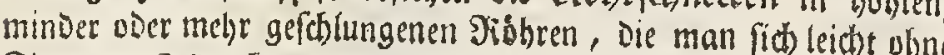
Figur vorffellen Ean, uno neldie ein Siebbabcr, fobald et fie nur in Patur ä Selicot betónmt, gleid Eennen wiro. du raport qu'on prétend trouver entre les deffeins qu'on y remarque \& I'Aile de la Chauve-Souris; \& l'épithète de dentée lui vient des pointes qu' on voit au bord des Contours, \& qui font des Contininations de la Coquille. Nous ne fixons ici nôtre attention proprement que fur le Nourrain, auquel Rumpf donne le nom de Melicera, ou de Favago. Pline conoiffoit déjà ce Nourrain, \& le comparoit à des Coffes de Pois chiches. Il apelloit Melicembales les Limaçons, où on le trouve. C'eft une Ecume ou un Compofé de quantité de petites Veffies vuides, crîës l'une contre l'autre, \& marquées de quantité de lignes, avec une petite ouverture en bas. Quand on rencontre un Limaçon avec ce Nourrain, ou ce Frai, encore tout frais, ce qui n'arrive que dans les mois cle Mai \& d'Oetobre, ces petites Veffies font claires \& tranfparentes, \& remplies d'une Liqueur blanchàtre. Mais dés-qu'elles fe defrèchent, elles deviennent jaunes, membraneufes, \& refremblent à une grappe de ràifin. Rumpf ne veut point accorder que ceci foit un nourrain, ou un frai, ou un ovaire, \& prétend que ce n'eft qu' une expulfion du fupertlu des fucs nourriffiers du Limaçon, \& rien autre. Opinion à laquelle nous ne pouvons adhérer, vû qu'un fuc rourriffier expulfé ne fuit plus aucune règle d'accroiffement, telles qu'on remarque conftamment au Nourrain dont il eft queftion ici.

Figure 6. On a aufi des Buccins ordinaires, où ce Nour. rain, ou ce Frai, fe trouve. Tel eft le Buccin commun qui eft dépeint ici, \& qui nous vient de la Mer Germanique. On en trouve de cette efpèce en quantité fur les côtes de l'lle d'Ameland, \& fur celles qui en font les plus proches. La Coquille en eft un peu ridée au dehors, \& colorée de bleu, \& le dedans eft d'un blanc bleunâtre. Pline donne du Nour rain, qui fort de cette Coquille une defcription toute femblable à celle que nous venons de donner de la figure 5 , \& il nous eft venu en effet un Limaçon avec fon Nourrain formé comme une gouffe de Pois. Mais nous avons vû auffi affez fouvent une efpèce de Nourrain, ou de Frai, toute diffèrente. Ce Frai confifte, comme on le voit à la préfente figure, en une fubftance membraneufe, compofée de feuilles minces, entortillées \& entrelacées par diverfes courbures \& frifures, qui fe réuniffent en bas â un Cordon étroit. Ces frifures, qui tiennent toutes l'une à l'autre, comme les diffèrentes parties d'une fraife de veau, font garnies de tous côtez d'un nombre infini de petits trous, qui ne percent pas, ou pour mieux dire de forfettes. Nous préfumons que chaque Efpèce de Limaçons, \& peut - être chaque Sous - efpèce a une forme ou figure de Frai, ou d'Ovaire, qui lui eft propre \& parti. culière, fupolé que notre hypothèfe foit jufte. Car parmi les cones on en trouve une forte, dont le Nourrain paroit en longs floccons, qu'on peut manger de même que d'au. tres Ovaires de Limaçons \& comme on mange les Oeufs de poiffon. Au refte il eft indubitable que l'Oeuvre de la Génèration \& de la Propagation des Limaçons exige encore bien des éclairciffemens, \& des Obfervations, auxquelles on n'a pû atteindre jufques ici.

\section{* *}

Ce que nous avons dit jufques ici fuffit pour l'explication des Plancbes que nous avons produites. Nous y avons parlé de tous les Genres, autant qu'il étoit néceffaire, \& nous n'y avons paffé fous filence que les Tuiaux, ou Solenes de l'ordre des univalves, les Doublets en rigole ou Solènes de 1'Ordre des Bivalves, \& enfin l'Ordre entier des Multivalves. Nous allons tacher de fatisfaire encore à cet égard nos LeEteurs en peu de mots. 
60

影

Es gehbren oabin ber lange OHfnoarm, Der Denus:

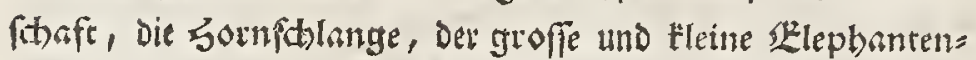
3abn, uno viele andere robridte 23 urmgehdure. Bu Den zweis

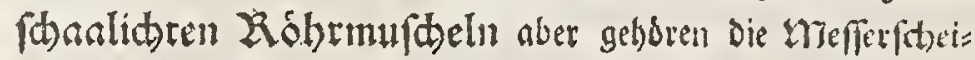
den, Polnifase Säbel, Die eigentlictse Rinnendonbletre, be

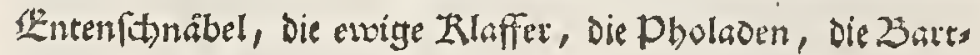
3angen, meerpinfel, U. D. m.

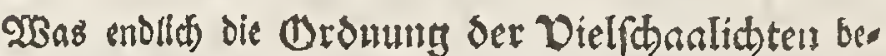
stift, fo beftehen fie aus vielen jufammengefesten SBlfttern, in

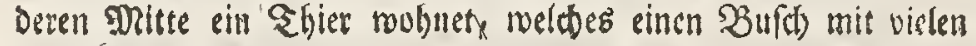

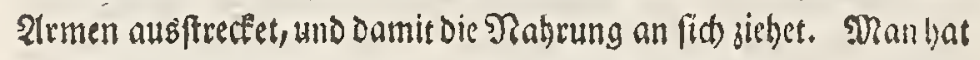
Die Seetulpen, (balani marini) meldse rotb), ober weis, zunueiten auch grun find, uno entweber einzeln, voer in Denge, an Sstfen,

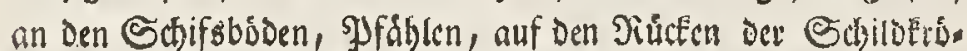
ten uno Taftbentrebfe, auf silipleber, auf andern sroffen und

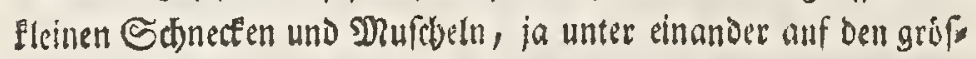

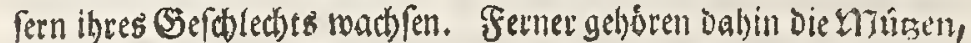
weiche nur eine Rebenart Der Sulpen fino, und endich Die Lang. bälfe, voer. Conchæ anatiferæ, Diefe lestetn fino blaulicht, beftoben aus fünf Schaalen uno ons Shiex, meldjes ebenfald, wie bie andern, einen Feberbufth ausftecft, um Nabrung zu

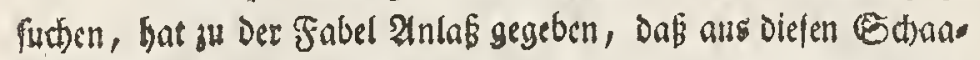
len Gånfe voer Enten múcten. Sie beilfen aber Rangbåle, reil fie mit einer langen lederartigen Senne an Den Đुfăhlen, woer an Den Sduffen anfitien, wofelbft fie fid) zumeilen Dergeftalt ftare

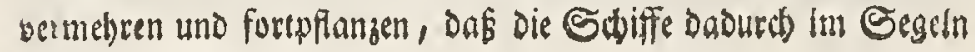
gebindert weroen.

Schlieflich baben wir nur nod erinnern roden, Das, wie

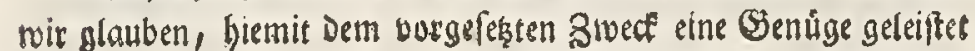
ju haben, roir einem jeden die Freubeit lajien, melgreve Ses

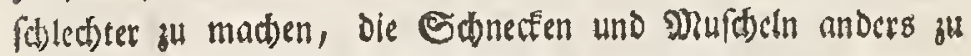
vronen, ibnen andere গamen zu geben, wie es nur einem jeden gefällig ift, Denn wir wollten fonft niots thun, als nut anzels

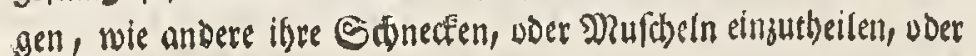
ju benennen wfiegen. Sft eb nidt redt, fo tommt uns die (E)uld Davon nidte zH. Soviel aber Dirfen roir Dennud) fagen, bas roir aus Dergleid)ung vieler Soriftiteller dic befte (Eintbei. lung, und Die beften oder gebráud)licbften 2 Eenennungen aus. Beluct)et haben, um nicbt Iveitlauftig, und Dennud), foviel bey siner mangelbaften crsiffenfthaft geftheben Eann, grinditi zu renn. Diefes bleibt indeflen gemif, Das nod) febrivistes in Der SRatur verborgen ift, und Das ınan, wenn man aud viele Jabre

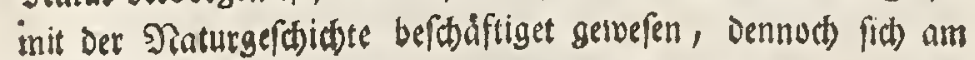
Ende nidbt fodamen Darf, etwas neues Darinnem Ju lernen, voer zu biennen, Dab man nicht alles roife.

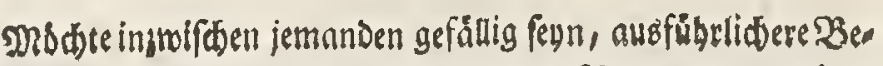
forreibungen su baben, Der erboblefic) bey Den fothon oben angetuhys. ten Soriftellern, und den bey Sbnen befindichen forwobl illu. minirten als unilluminirten Figuren weitern Siath).

TBir aber fobreiten nunmebro zu Der Beftseribung Der Sommetterlinge, uno balten bafelbft die netgmlicbe Stonung.
象

\section{歌}

Ce qu'on apelle les Tuiaux, ou Solenes uniwalves, font des Tuiaux caves, plus ou moins tortus, dont il eft facile de fe former l'idée fans figure \& que tout Amateur reconoîtra dés-qu'il s'en préfentera un à fes yeux. Tels font le long boiau de boeuf, le Fut de Venus, le serpent à corne, la grande \& la petite Dent d'Elephant, \& bien d'autres Coquilles de Vermiffeaux, formées en Tuiaux. Parmi les Solenes bivalues l'on trouve la Gaine de Couteau, le Sabre Polonois, les Doublets en rigole proprement ainfi dits, les Becs de Canard, les Bícurs éternels, les Pbolades, les Pinces de barbe, les pinceaux marins, \&c.

Pour ce qui concerne enfin l'Ordre des Multivalves, ils confiftent en plufieurs feuilles jointes enfemble au milieu tiefquelles habite un Animal qui étend au dehors une Touffe, de laquelle fortent quantité de bras au moien defquels l'animal tire a foi fa nourriture. On place dans cette forte les Glands de mer, ou Tulipes marines, qui font rouges, blanches, quelquefois vertes, \& qu'on trouve qiuelquesfois feules, d'au. tres fois par troupes aux rochers, aux Carènes des Vaiffeaux, 2ux Pilotis, fur le dos des Tortuës \& des Ecrevilfes faites en poche, fur les Suceurs de rocher, \& d'autres Limaçons grands \& petits, \& de meme fur les Moules de toute grandeur, \& qui plus eft fur les plus grands Individus de leur propre Genre. Il faut ranger encore ici les' Bomets, qui ne font qu' une Sous-efpèce des Glands, \& enfin les Longs-Cous, ou Conques anatifères. Ces dernières font bleuâtres \& confiltent en cinq Coquilles. L'animal qui y habite, \& qui, comme tous les autres, étend au dehors une efpèce de Plumet ou de Touffe, a donné lieu à la Fable ridicule qu'il nait dans ces Coquilles des Oies ou des Canards. Au relte on les appelle Longs - Cous à caufe d'un long nerf coriace, au moyen duquel ils s' attachent aux pilotis \& aux Vaiffeaux, où leur propagation \& multiplication eft quelquefois fi conlidérable que leur quantité retarde le Cours des Vaiffeaux.

Pour Conclufion, croiant avoir rempli le but que nous nous étions propolé, nous, laiffons à chacun la liberté d'imaginer un plus grand nombre de Genres, d'arranger autrement les Limaçons \& Ces Moules, \& de leur donner d'autres noms, $n$ ' ayant eû d'autre deffein que d'indiquer les divifions \& les noms qu'on trouve dans d'autres Auteurs. Si nous ayons manqué à cet égard, ce n'eft pas à nous qu’on en doit imputer la faute. Mais ce que nous pouvons affürer avec certitude, c'eft qu'en conferant plufieurs Ecrivains l' un avec l'autre nous avons toujours choifi les divifions \& les dénominations qui nous ont paru les meilleures \& les plus génèrale. ment approuvées, nous attachant, en évitant d'être prolixe, à ne rien omettre de tout ce qui peut être dit de folide dans une Science encore imparfaite. Il eft de fait qu'il $y$ a dans la nature bien des chofes, qui nous font demeurées cachées jusques ici, \& que lors même qu'on a employé plufieurs années à l'étude de l'Hiftoire naturelle, on ne doit pas avoir honte d'aprendre quelque chofe de nouveau, ni de confeffer qu'il y a bien des chofes qu' on ignore encore.

Si quelqu' un en defire davantage, \& d'avoir des defcriptions plus amples, il peut recourir aux Auteurs que nous avons allèguez $c y$-deffus, \&z y confulter les figures enluminées \& non-enluminées qu'on trouve dans leurs Ouvrages.

Pour nous, nous allons procèder à la defcription des $\mathrm{Pa}$. pillons, où nous obferverons le même ordre. 


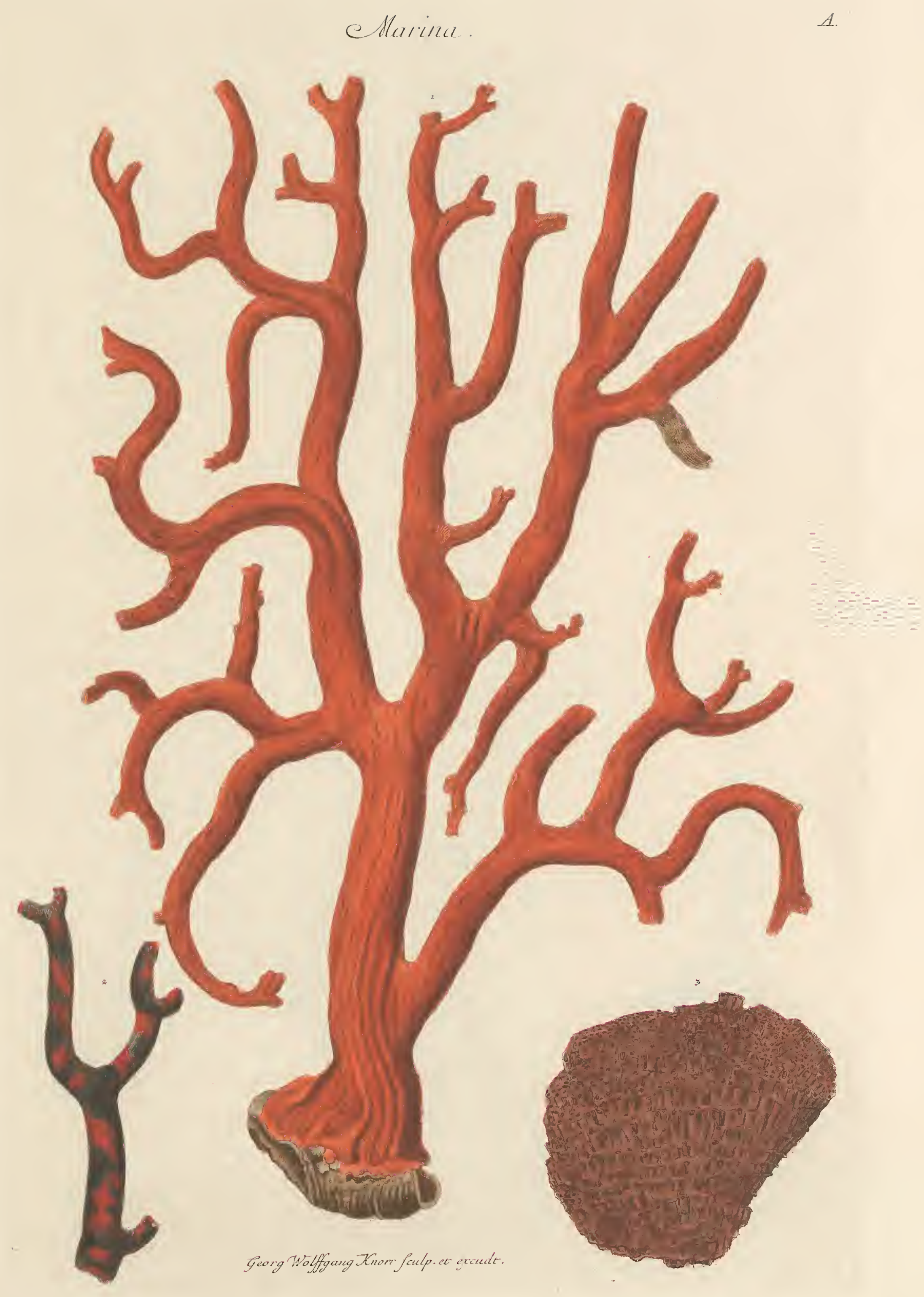



Cllarina.

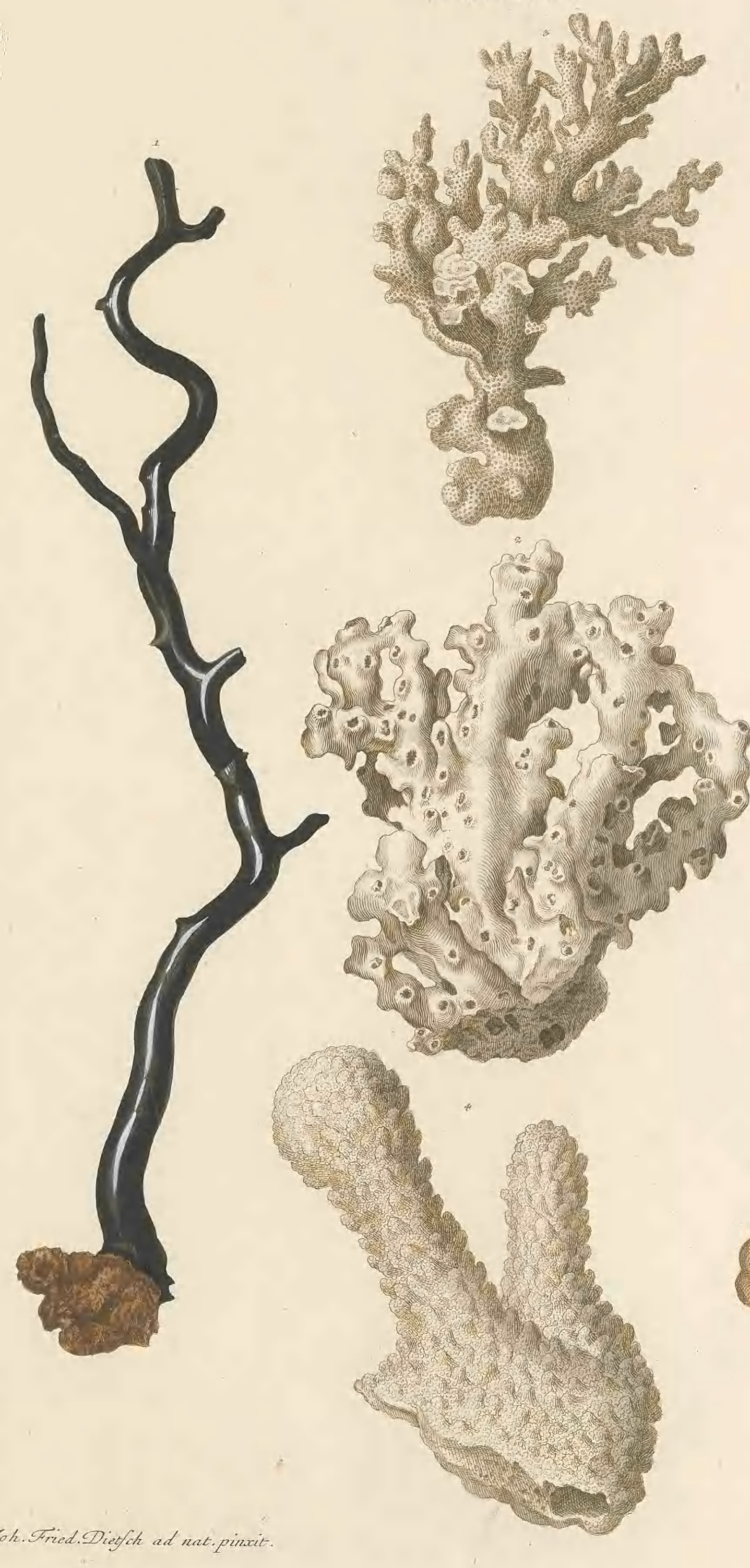

Tab.A.I

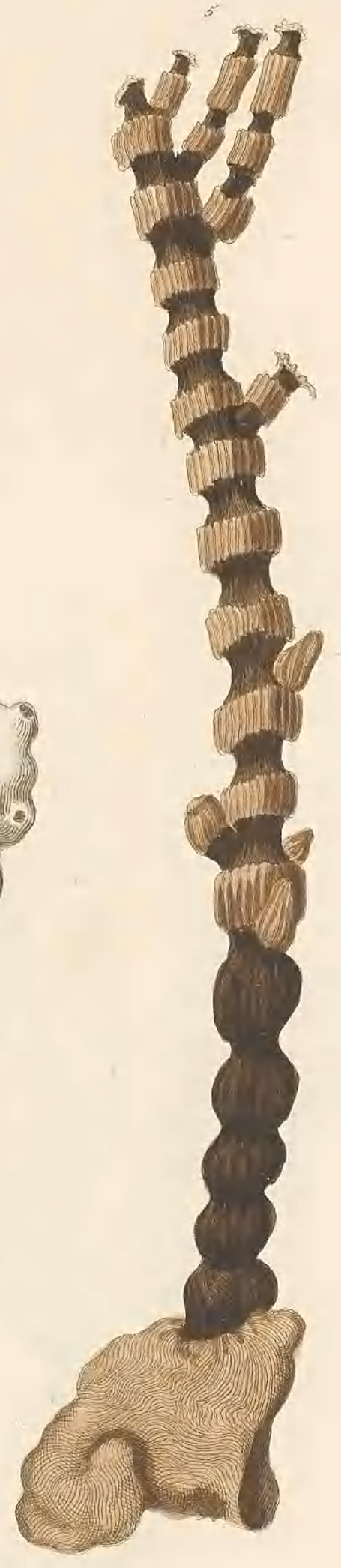





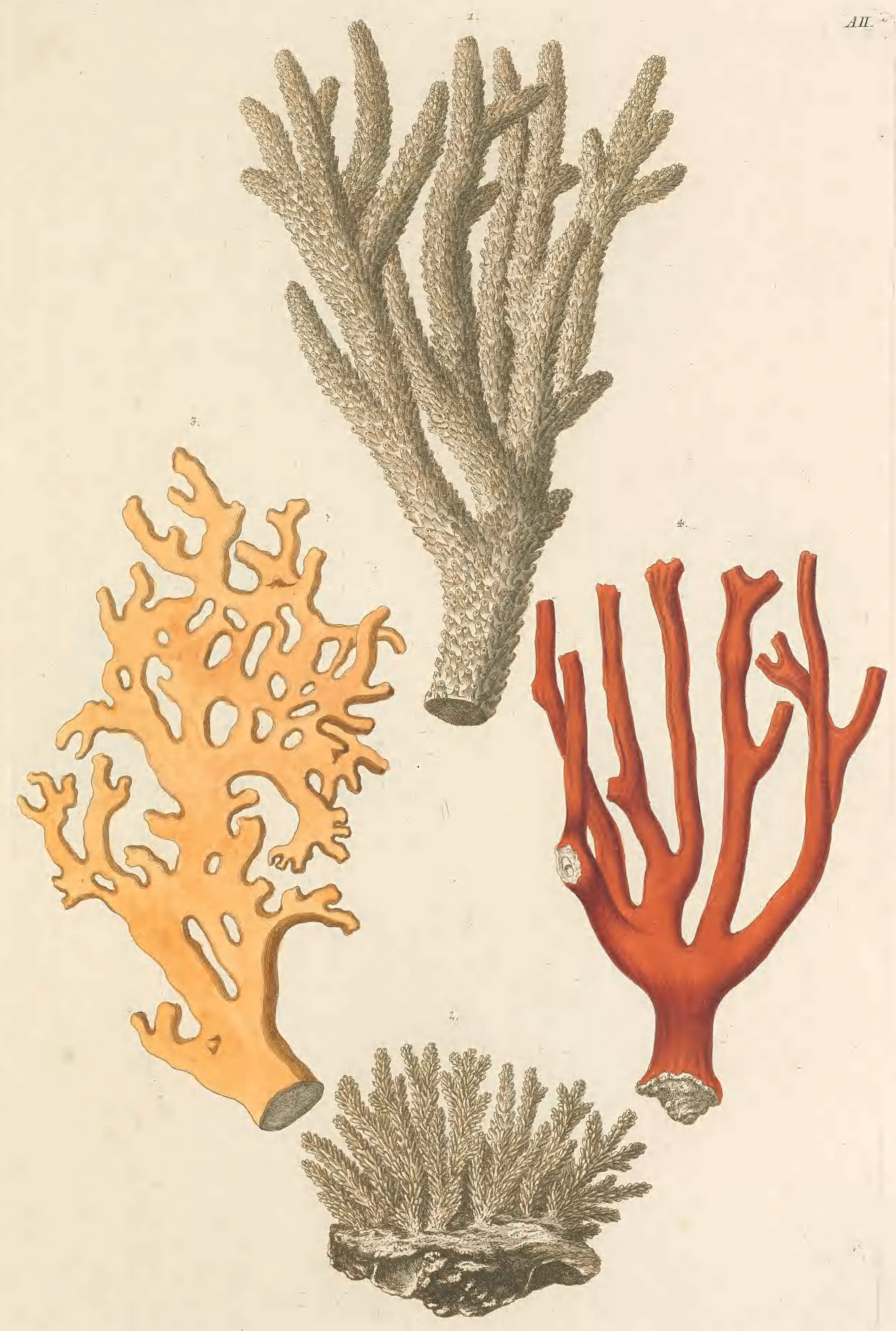







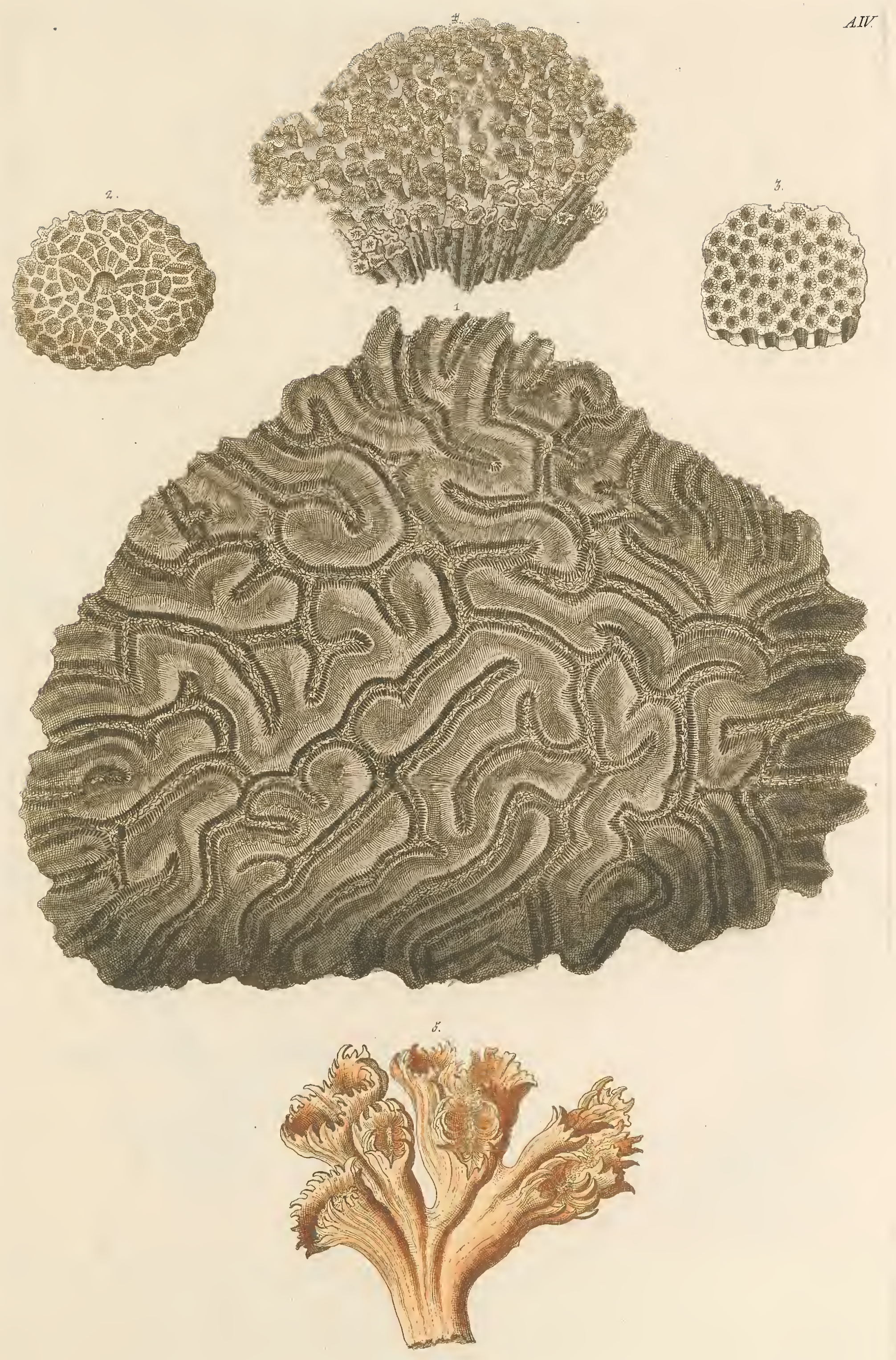





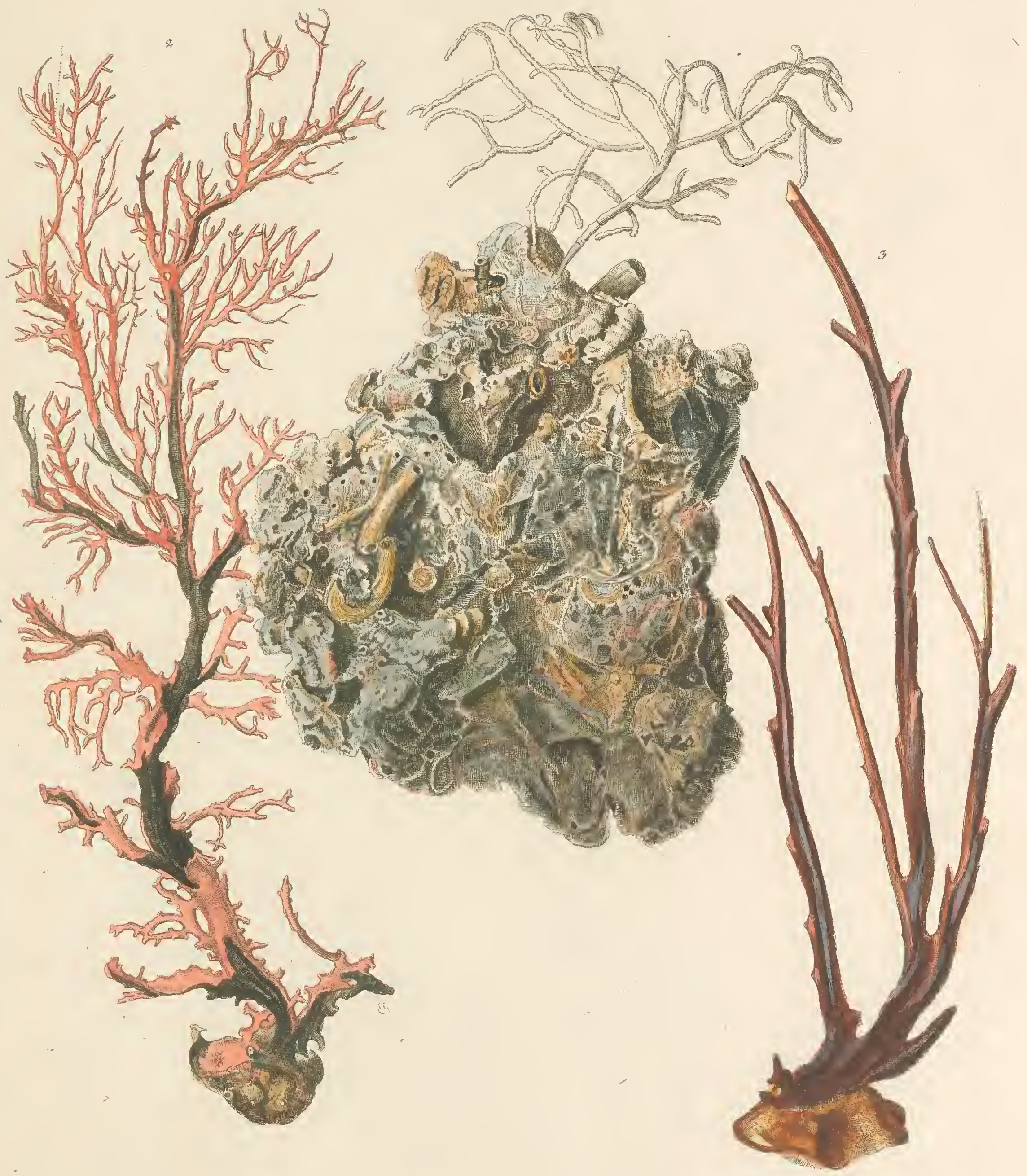

Excthuseo Eacell. D.D. Chrift. Tac. Trew. S.f. 



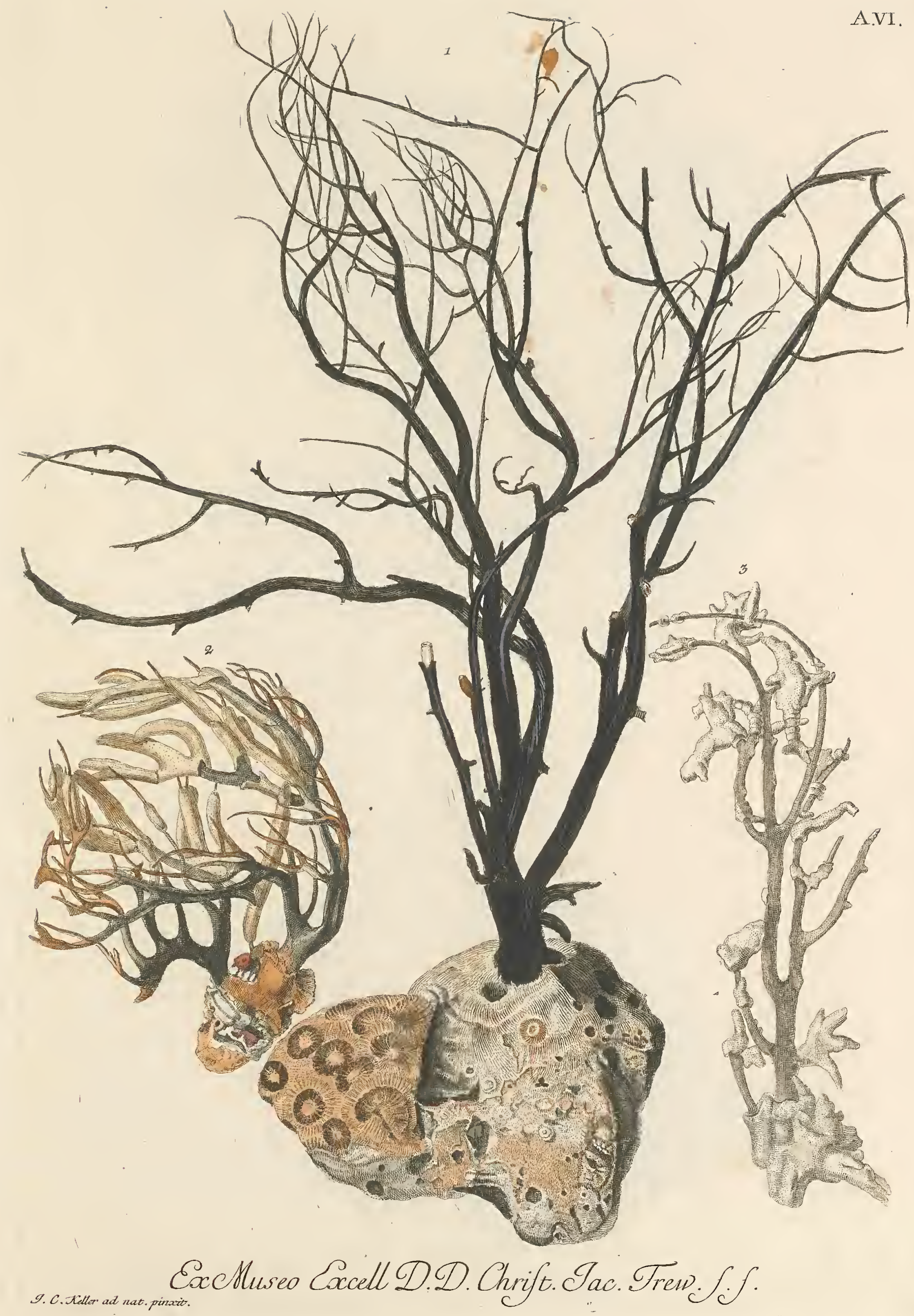




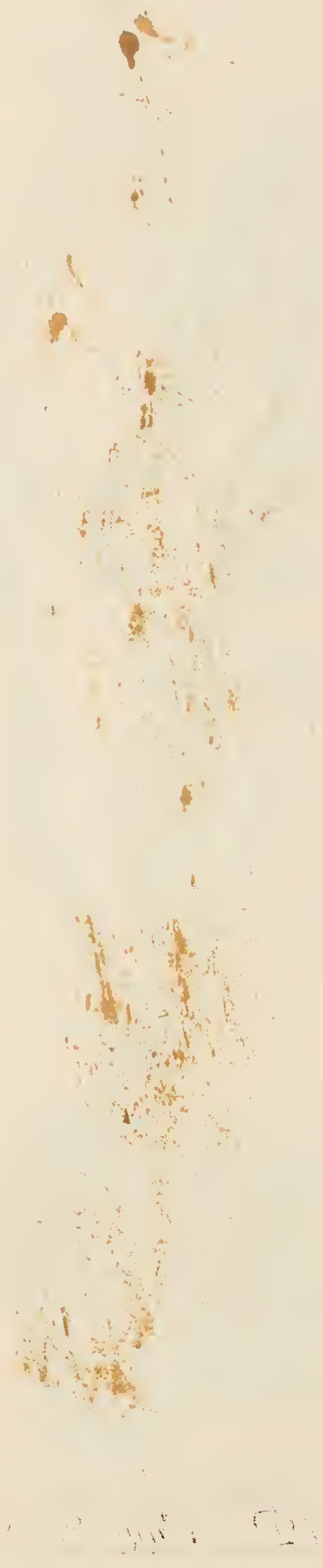




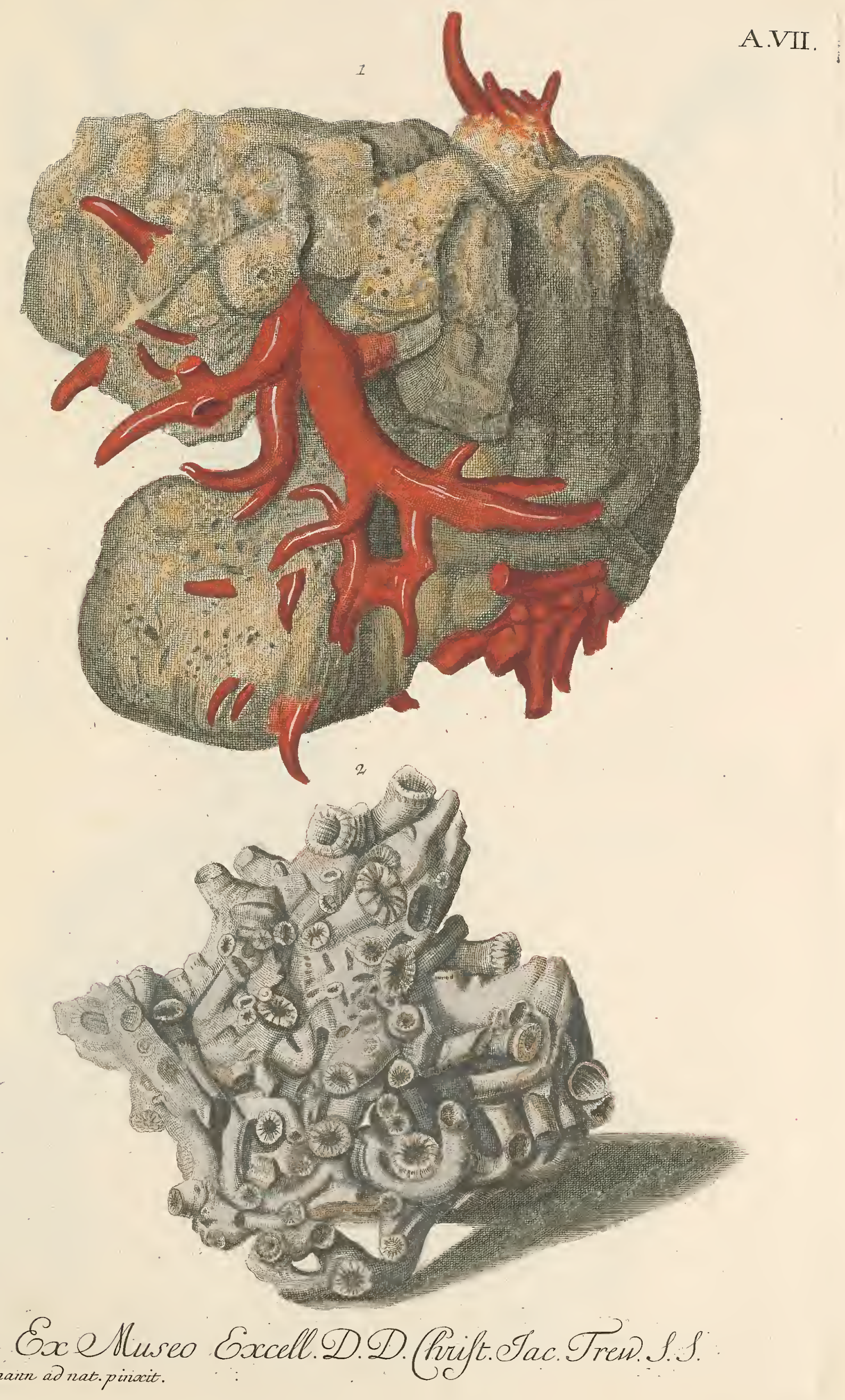





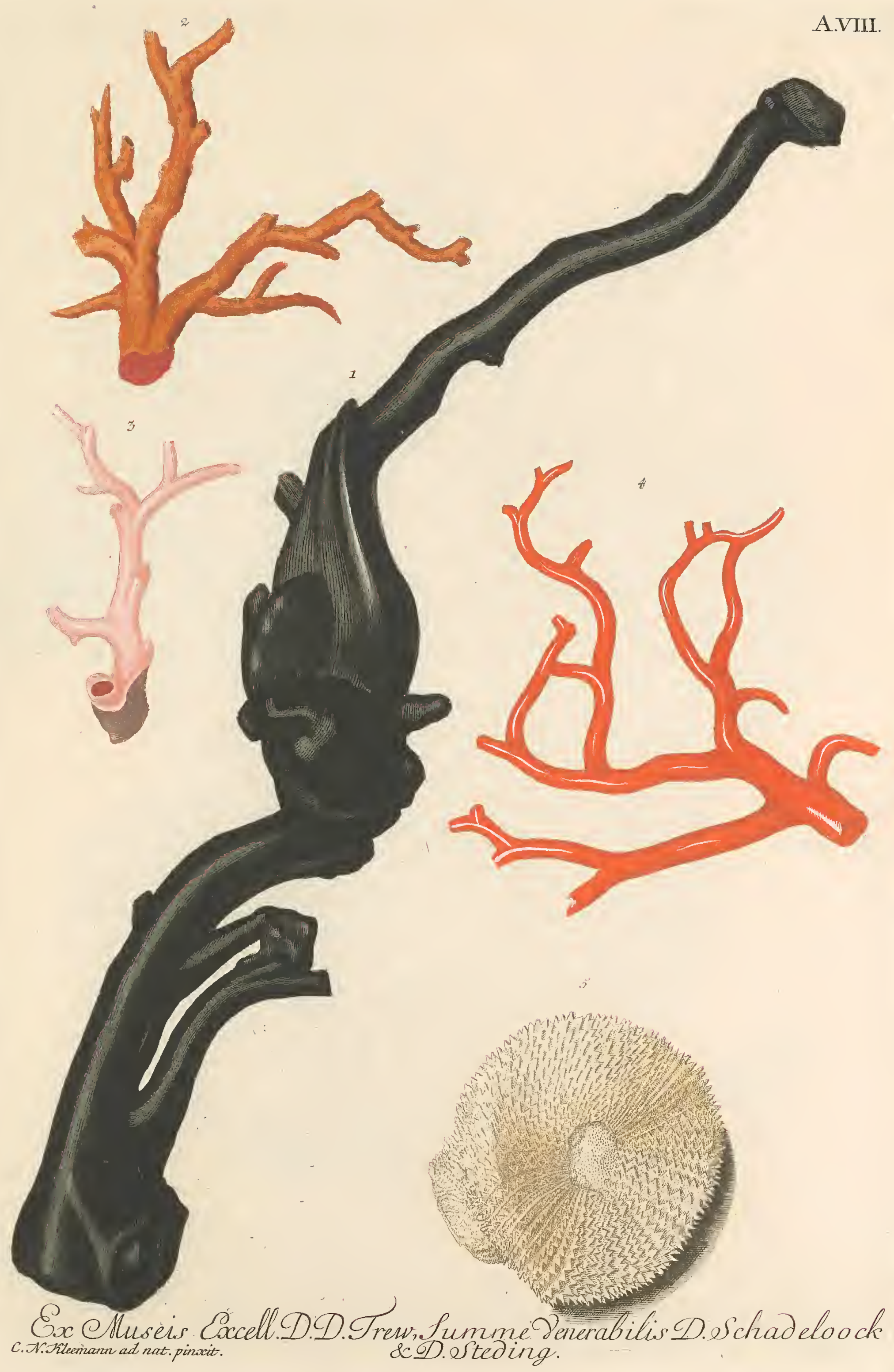



A.IX

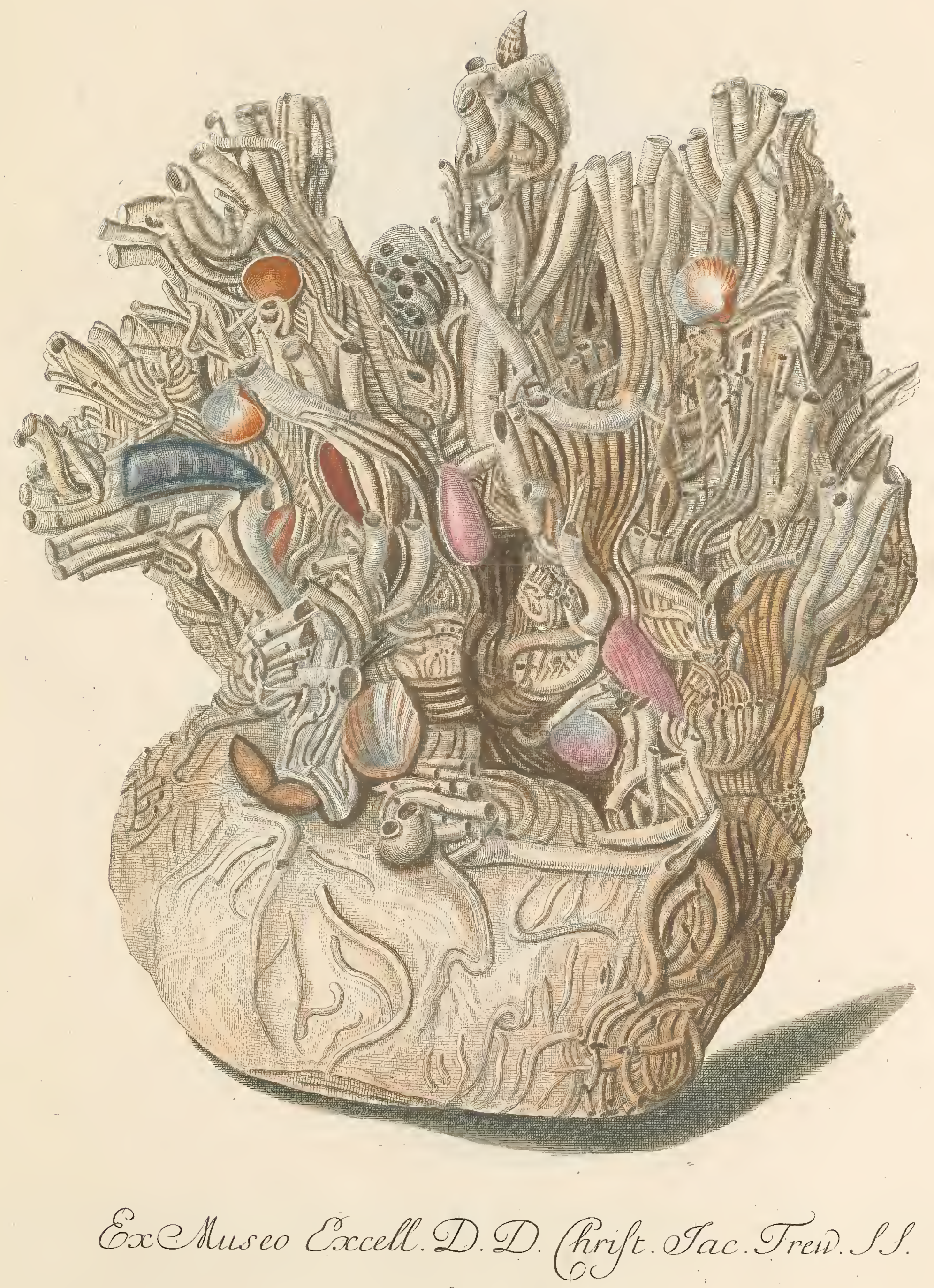



A.X.

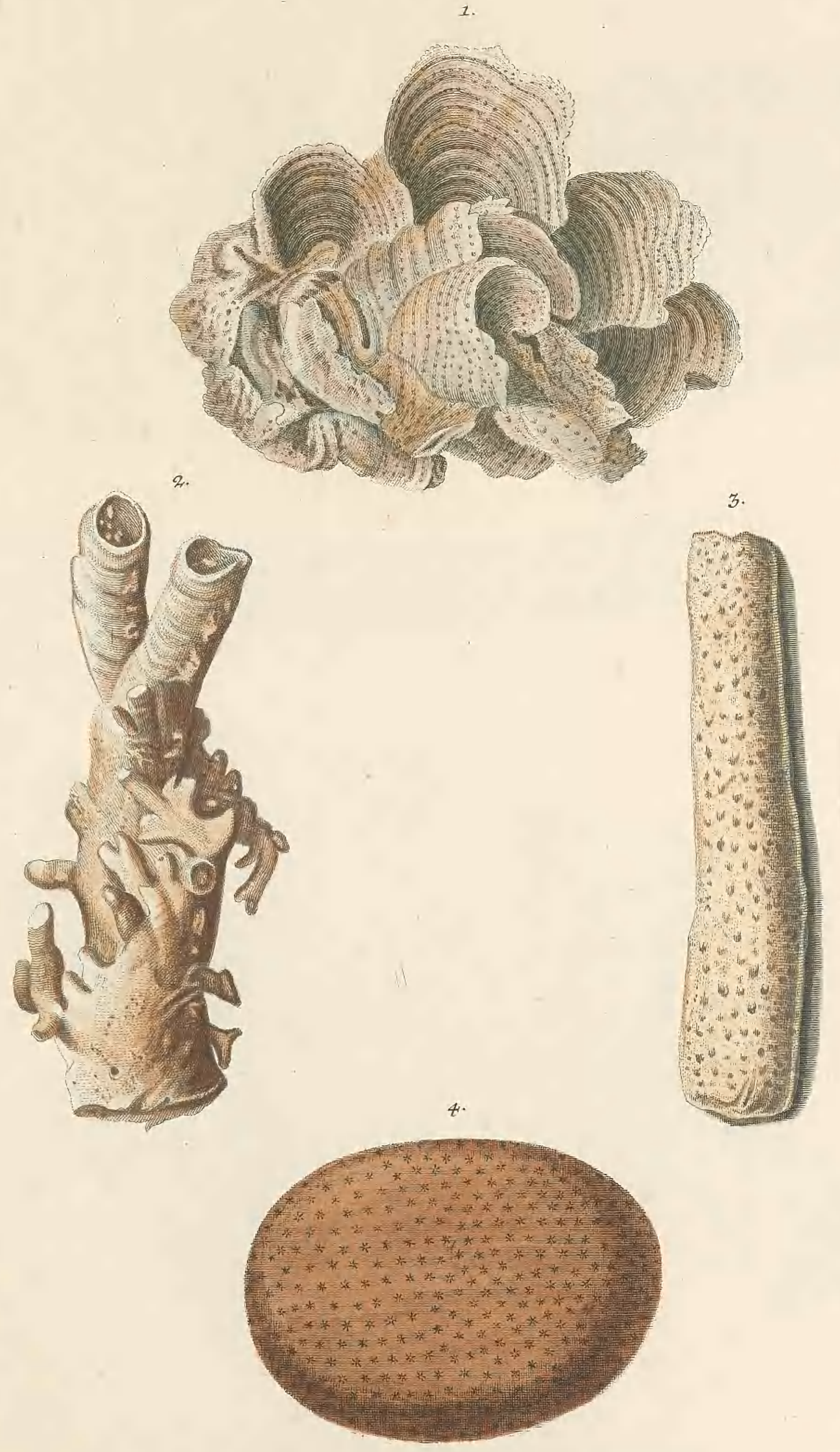

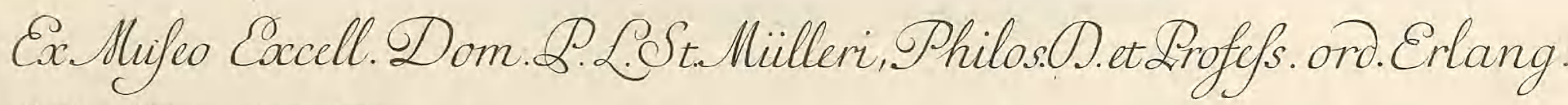
Chriftian Seirberger ad nat. pinaxit. 


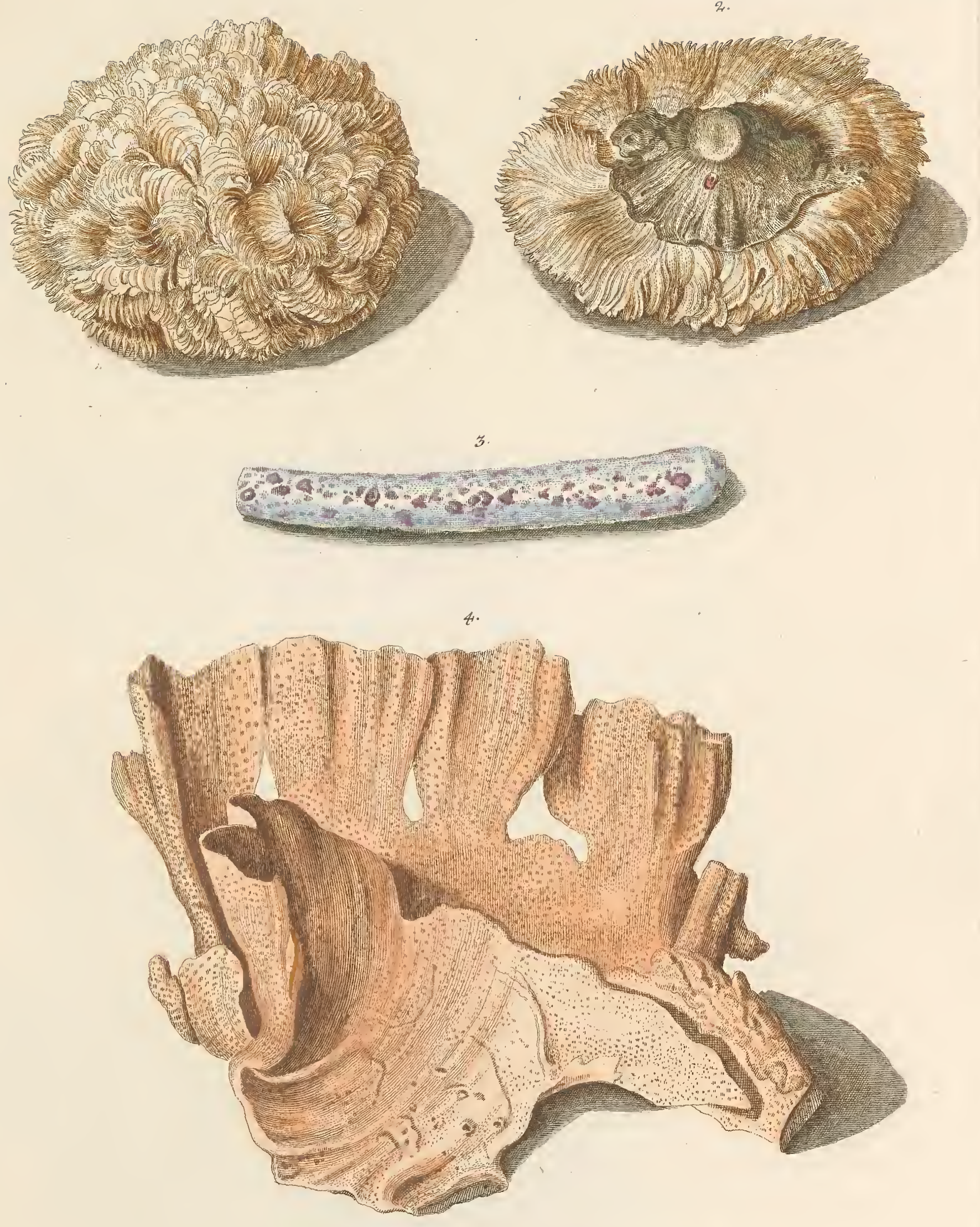

5.

Ex Mufeo Cxcell.Dom. P.SE. Mülleri, Philos. D. et Drofefs. ord. Erlang. Chriftian Leinberger adnat. pinxat. 



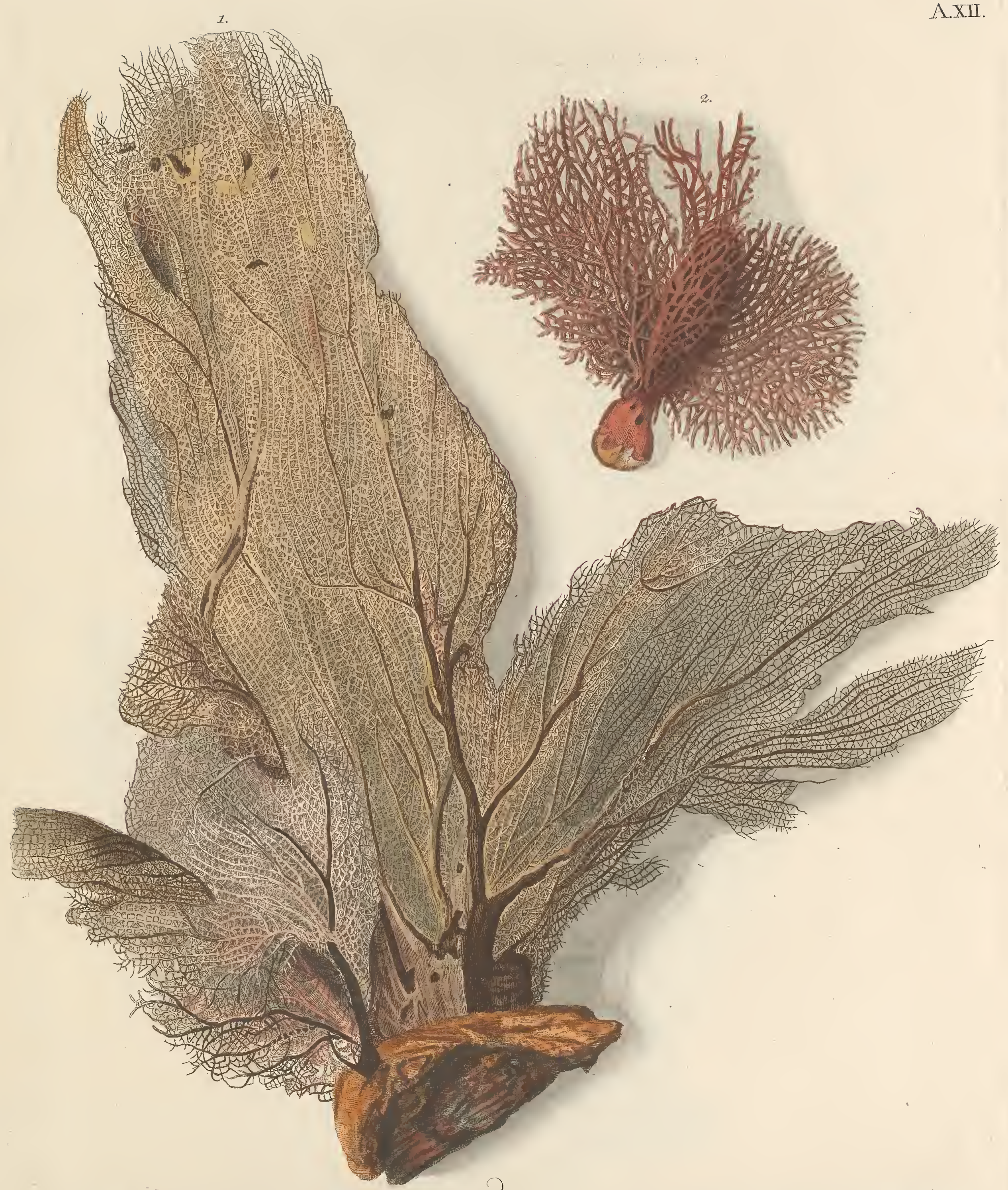

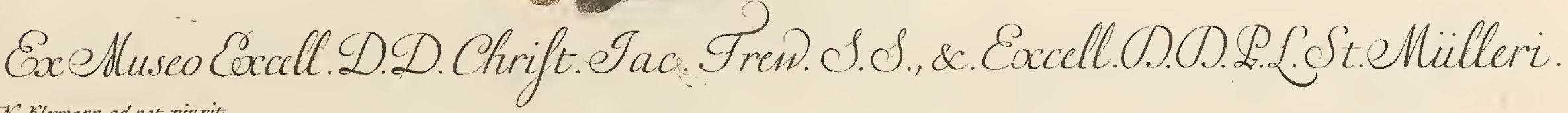





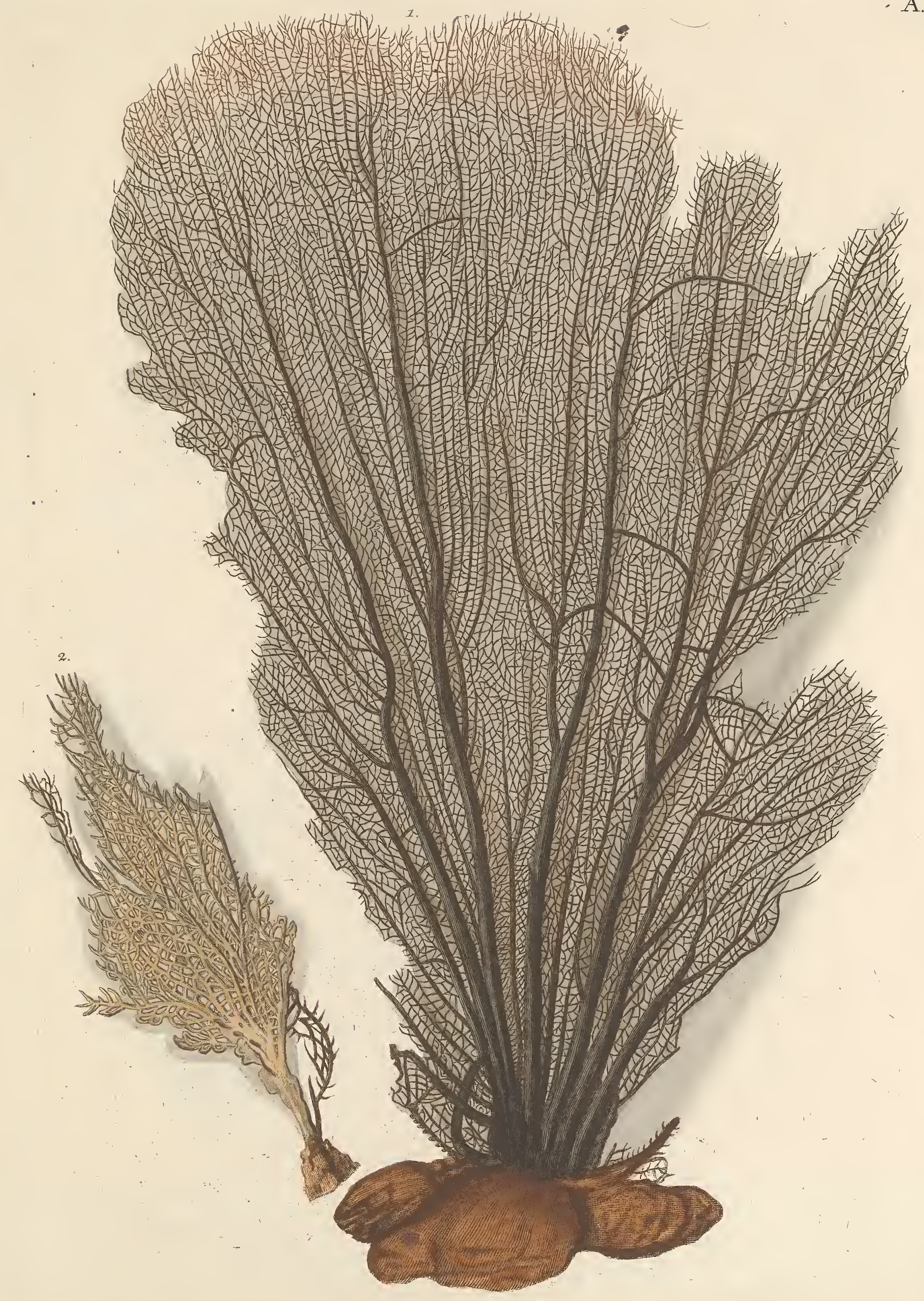

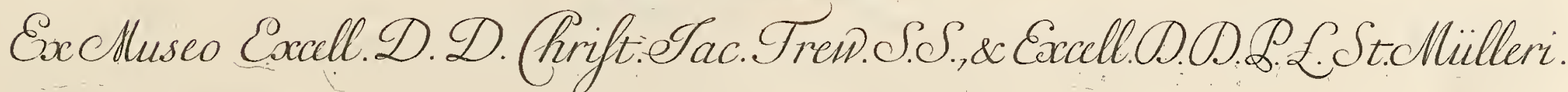



A.XIV.
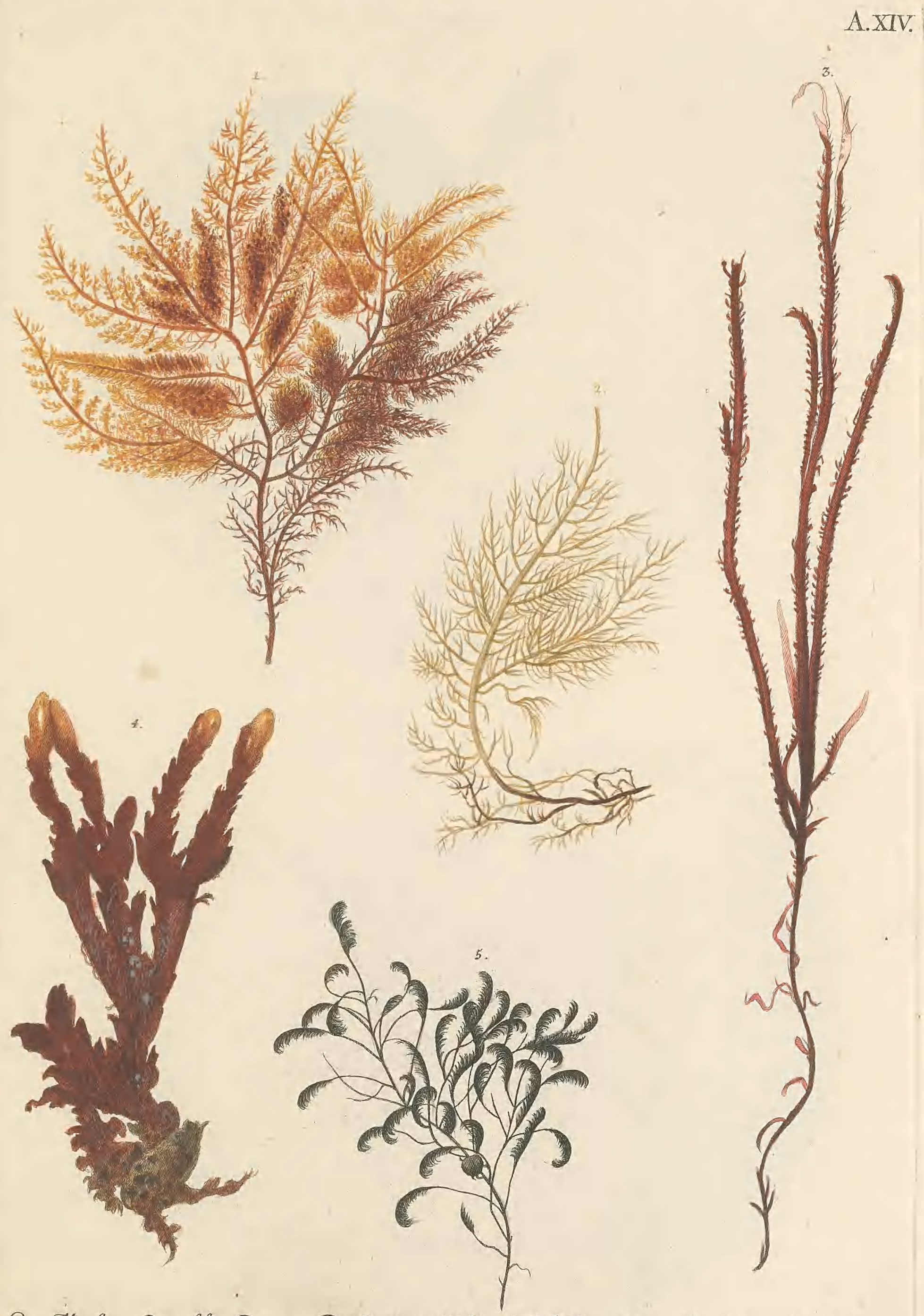

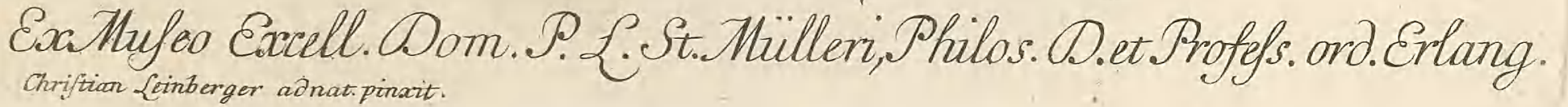





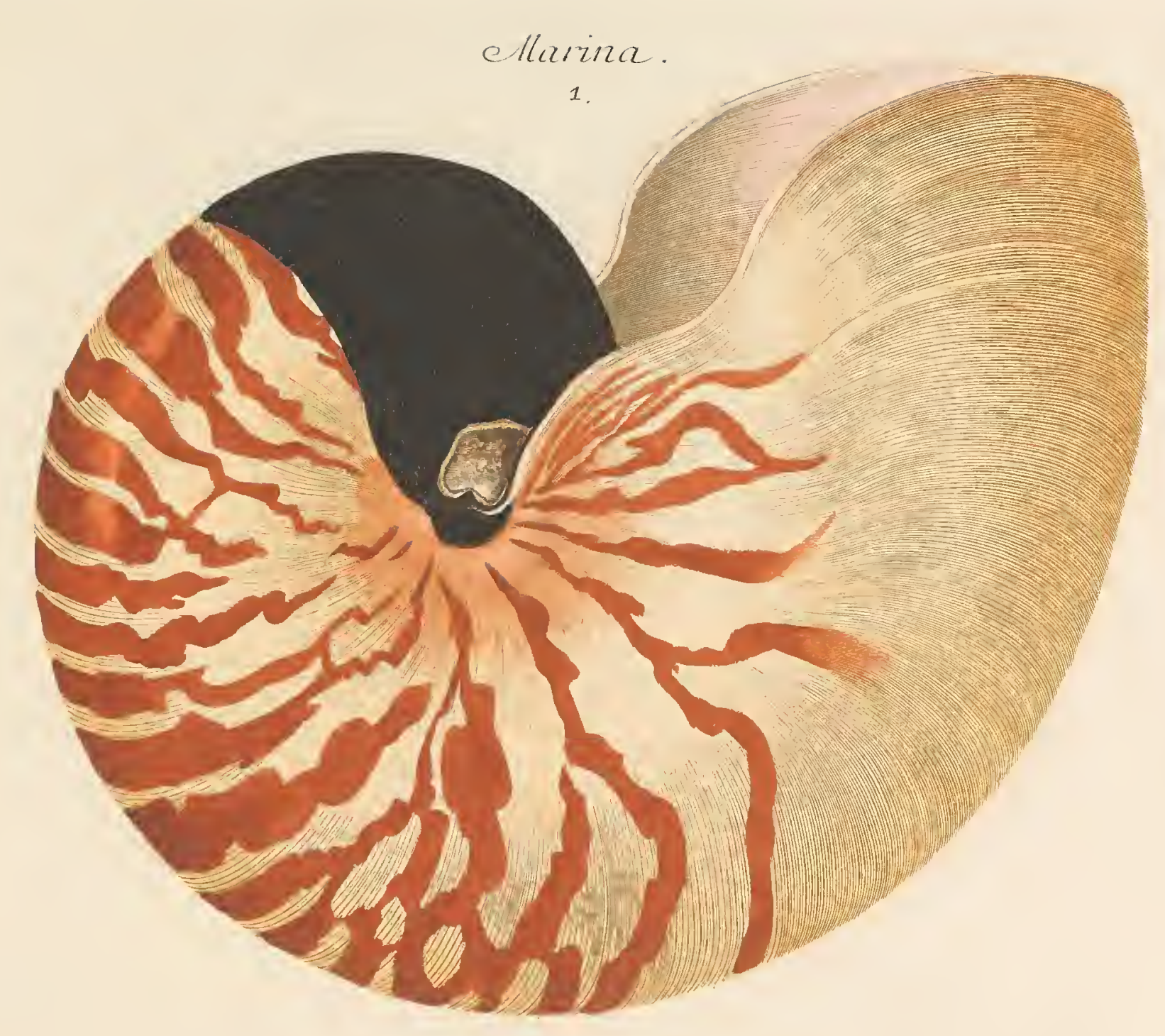

$B$.
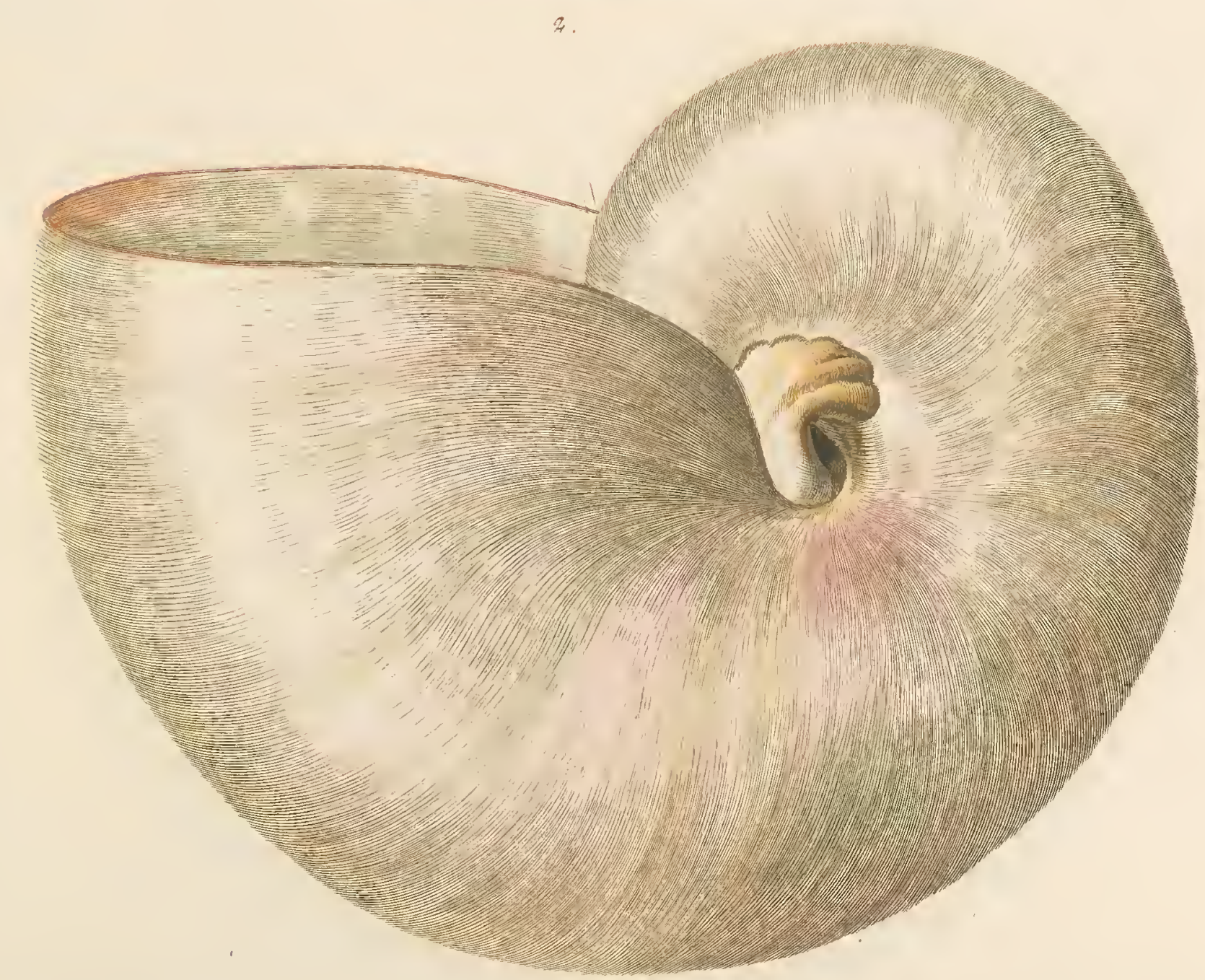



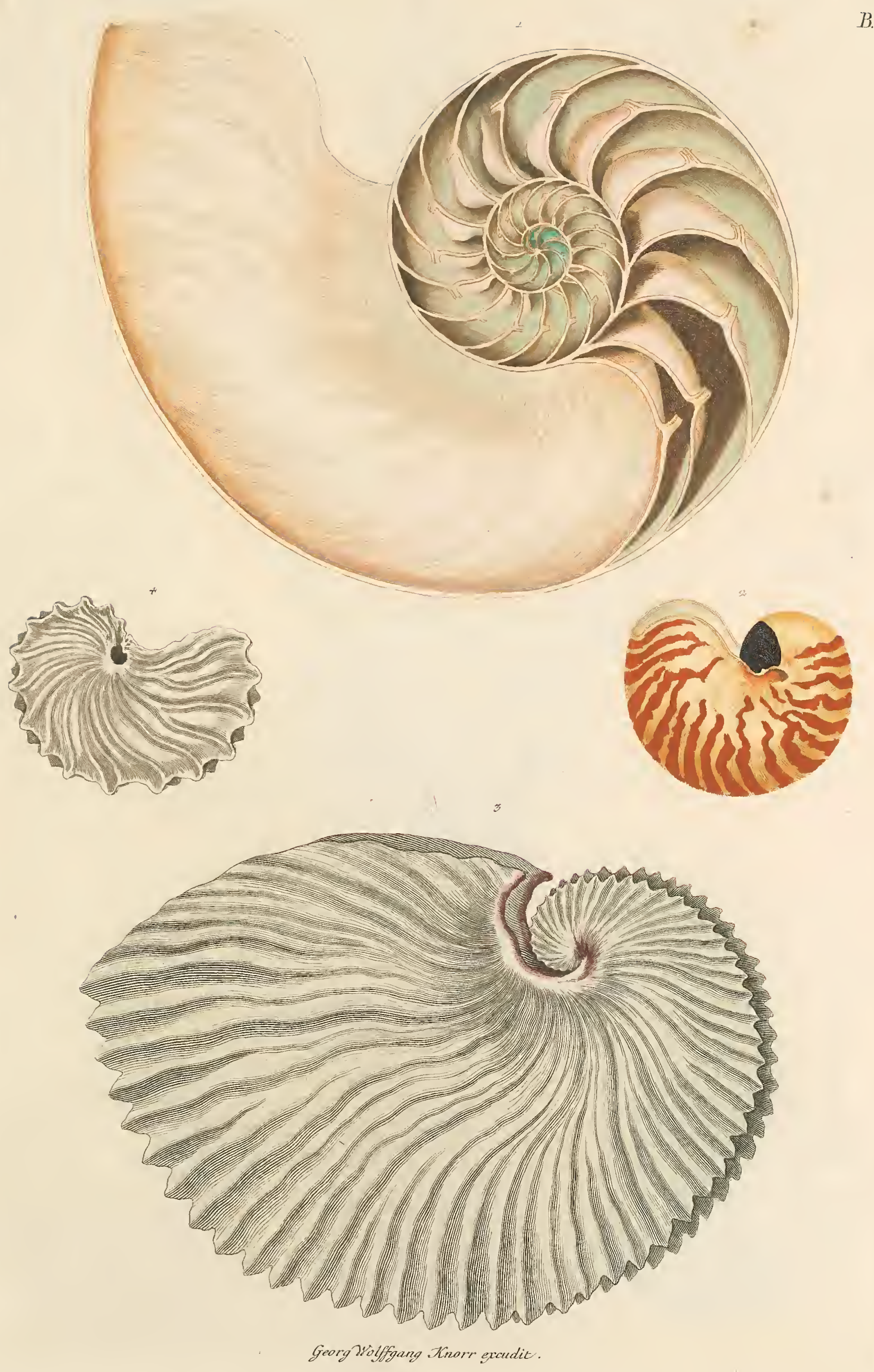




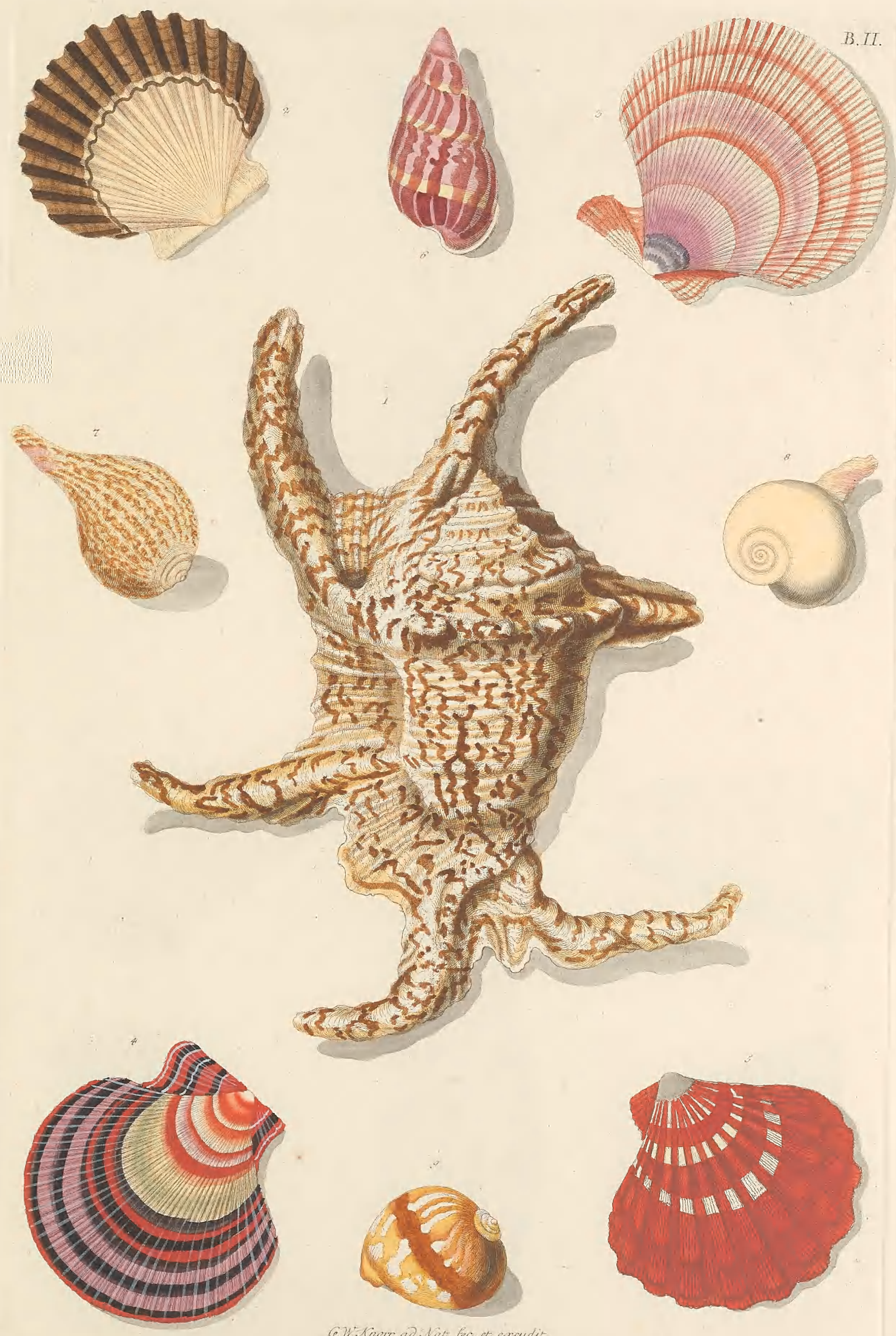

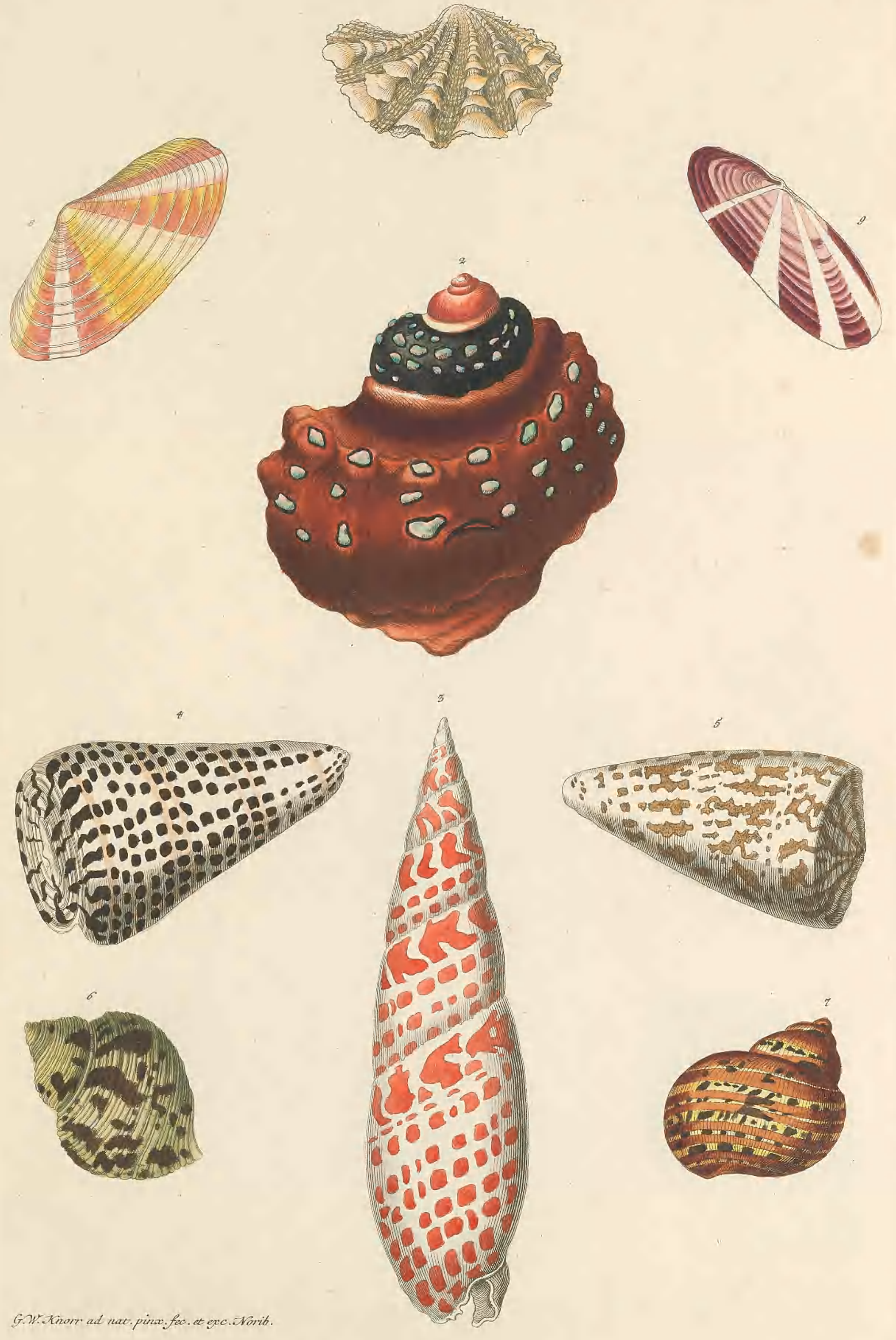

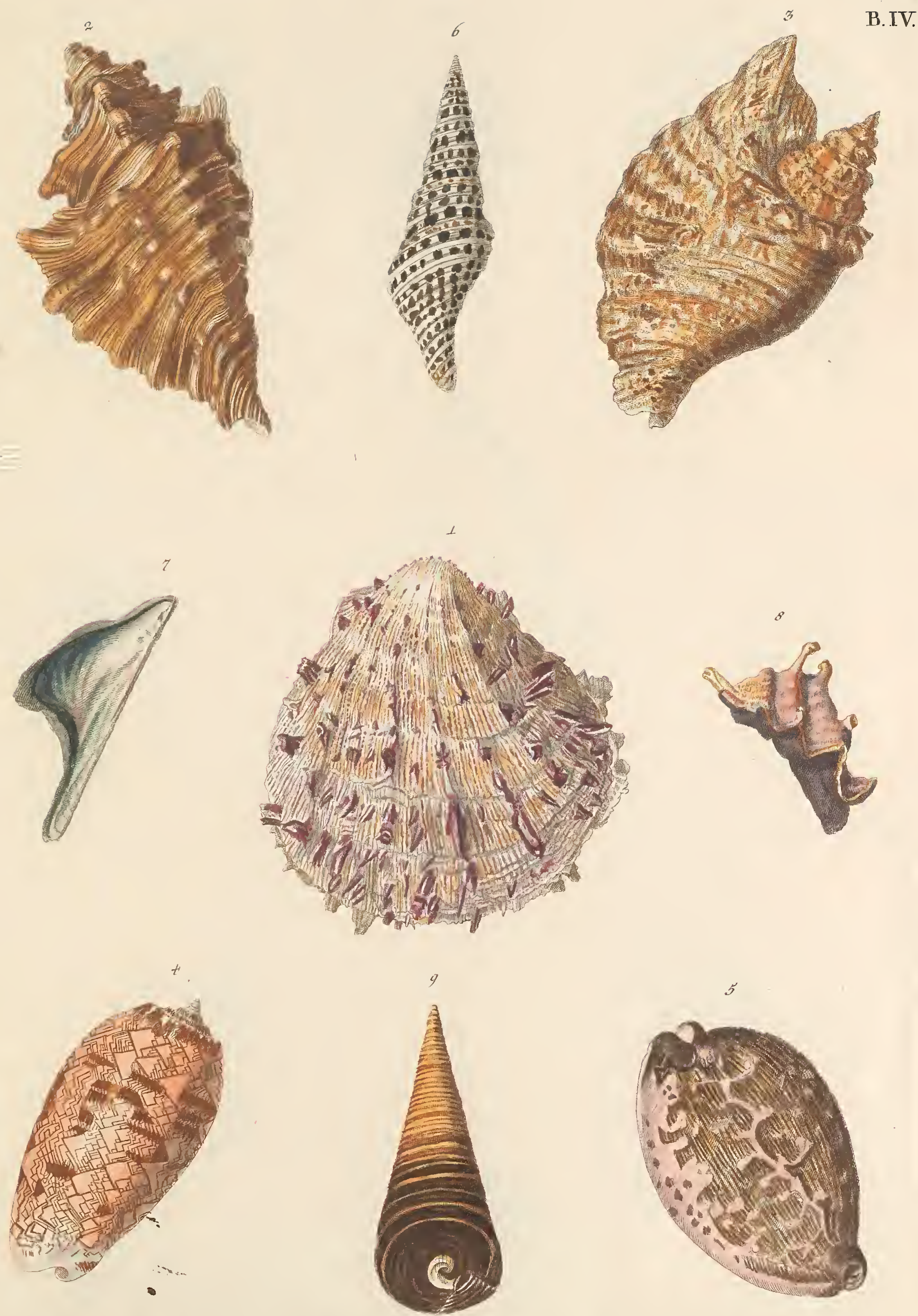

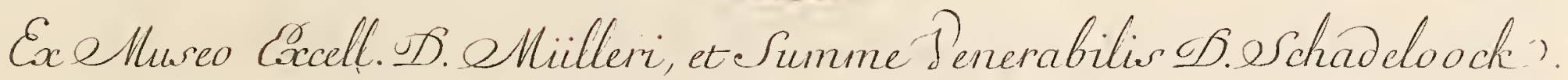





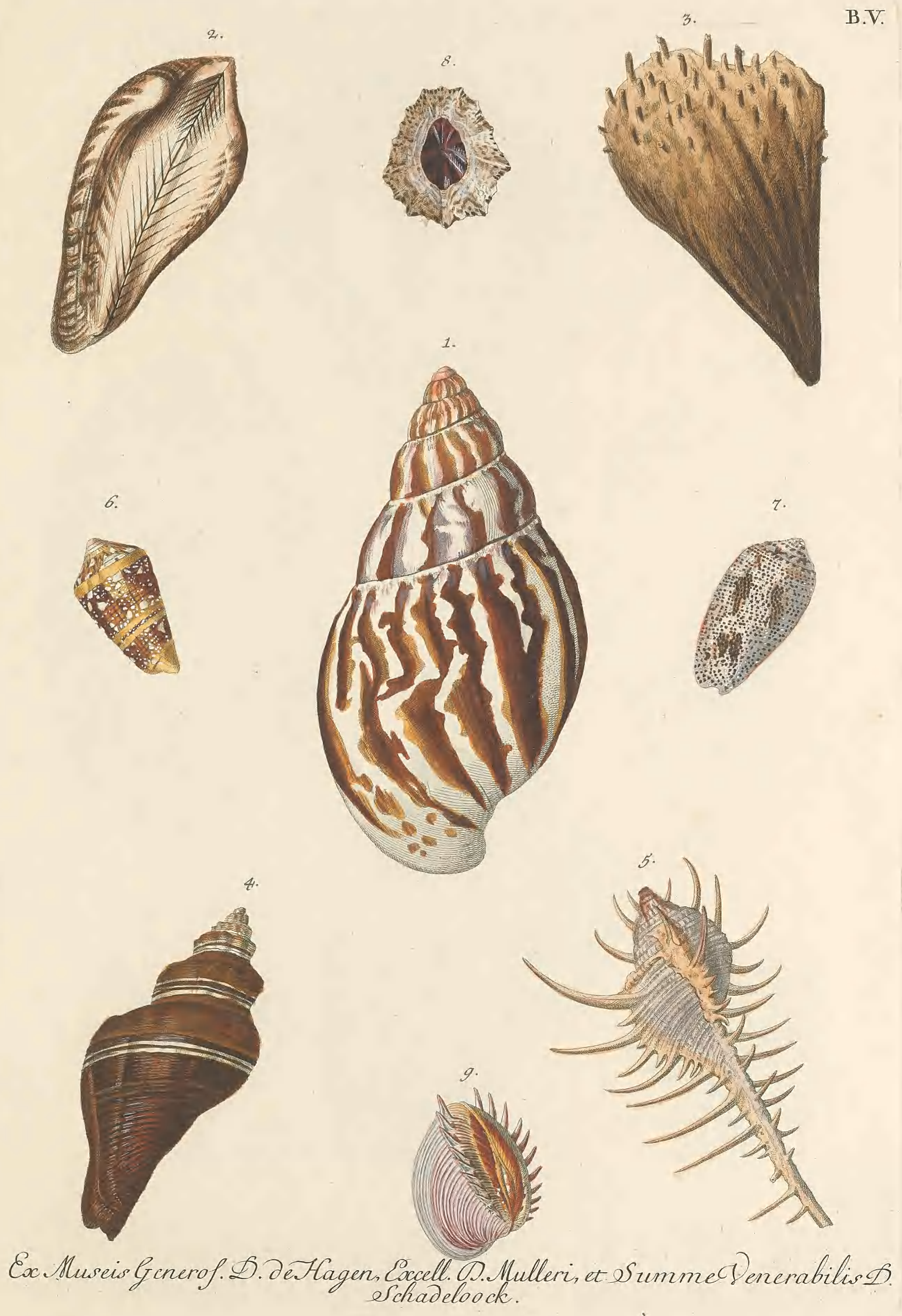



B.VI.

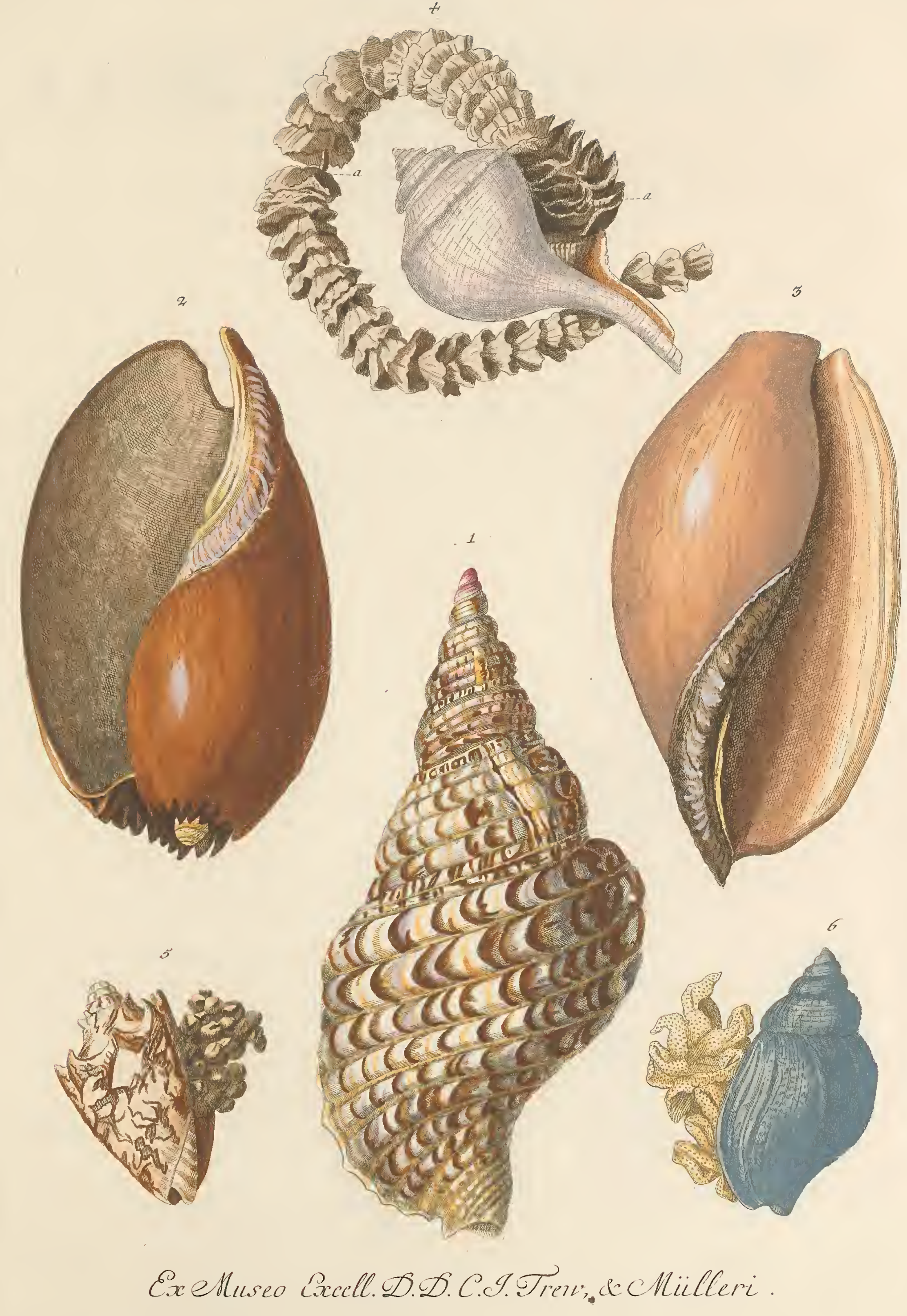

Chrtistian Leinberyer ad nat. pinocit. 



\title{
R E G I S T E R
}

\author{
VA N D E
}

\section{AFBEELDINGEN,}

I N D T T E E R T E DE E L.

\section{A. $\quad \begin{array}{llllll}\mathrm{K} & \mathrm{O} & \mathrm{R} & \mathrm{A} & \mathrm{A} & \mathrm{L}\end{array}$}

Tabula Figura

A. Fig. I. ft roodkoraal uit de Middelandiche $^{\text {gee. Corallium rubrum Orric. }}$

8. Een diergelyk met fwarte vlakken。 Ejusdem Varietas variegata.

3. Een Koker- of Pyp-Koraal. Tubularia Purpurea. Tubipora Muffaca. L INN.

A. I. Fig. I. Een fwart Hoorn-Koraal. Corallium nigrum arboreum. Antipathes LOBELIr.

2. Een wit Starre - Koraal. Corallium album Stellatum CASP. BAUH.

3. Een wit Oog-Koraal. Corallium album oculatum offic. J. B BuU H.

4. Een wit Steen - Koraal. Madrepora Abrotonoides. BOERI.

5. Een Hoorn - Koraal met Ringen, of Leedjes - Koraal. IJiss Hippuris LINN.

A. II. Fig. I. Een Steen-Koraal met veele kleyne Starretjes, Madrepora Abrotonoides BoERH.

2. Een diergelyk van een kleinder zoort. Corallium porofum alburn nizinus. SLOAN.
Tabula Figura

3. Een Vingervormig Oog - Koraal met aan malkander gewasfe Takken. Millepora digitata. LINN. MORIs.

4. Een geel Hoorn-Koraal, met Puntjes op de Schors. Litopbyton aureum punctatums.

A. III. Fig. I. Een Paddeftoel - Koraal, Zeeblocmkool, Amarantbus Saxeus. BESSL。

2. Een diergelyke van dezelve zoort, met veele gangen, Harsfenfteen. Madrepora Meandrites, vel areolatz. LINN.

3. Een Netvormige Koraal-Schors, Ejchara retiformis. RAJt.

4. Een Paddeftoel-Koraal. Madrepora fungites. LINN. Fungus Lapideus. BESLER:

A. IV. Fig. I. Een Doolhofs Steen - Koraal, Madrepora Labyrintbiformis. LINN.

2. Een Starre - Koraal - Paddeftoel. Madre pora favofa. LIN .

3. Een diergelyke van cen andere zoorto Madrepora Afroites. LIN 
4. Een Koker-Starre-Koraal. Milleporus IM. PERAT I. Madrepora fafcicularis. LinN.

5. Een Paddeftoel-Koraal. Amaranthi Saxei Species.

A. V. Fig. r. En fyn Hoorn-Koraal op een fulk van een Rotz. Ifais Palma. MrRcat.

2. Een fwart Hoorn-Koraal, Zee-Heidekruid. Erica Marina. BesLer.

3. Swart Hoorn-Koraal met Doornen. Keratophyton Spinofum nigrum. BOERH.

A. VI. Fig. I. Swart Hoorn-Koraal. Corallium acarbarium nigrum ramofun. $\mathrm{R}$ UMPH.

2. Een Hoorngewas met de Schors van Polypusfen. Keratophytons crufta Muricata.

3. Een Hoorngewas, overtrokken met SteenKoraal.

A. VII. Fig. I. Egt rood Koraal op een brok van een Rotz.

2. Pypvormig Starre-Koraal. Porus matronalis ramofis IMPERATI.

A. VIII. Fig. I. Knobbelig fivart Hoorn-Koraal.

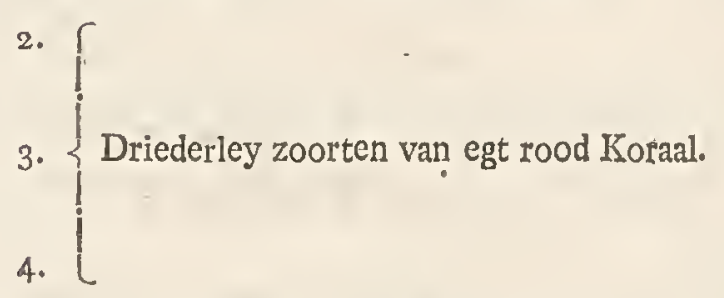

5. Een Paddeftoel - Koraal met Starretjes, Madrepora fungites.

A. IX. Fig. I. Een Neft van Wormbuizen in een klomp. An Halcyoniun durum, vel corallium tubulofum MARSIGLT?

A. X. Fig. r. Blaaderagtig Koraal met Starretjes. Malrepora agaricites.
2. Een Wormbuis met Punt-Koraal overtrokken.

3. Een Tak van de Madrepora Abrotonoites.

4. Een Kogelvormige Koraal klomp, met Starretjes.

A. XI. Fig. I.

2. $\{$ Een Harsfenfteen Cerebrites. Lithoce ebrum.

3. Een Tak van een Madrepora bezet met een Schors van het kleinfte PuntKoraal.

4. Een geel Oog-Koraal in Bladen. Mil. lepora lobata.

5. Een ftuk Stok - Koraal. Baculus marinus. Gorgonia Jimpliciffima recta.

A. XII. Fig. I. Een Zeewatijer met de Schors. Kerato. pbyton fabelliforme, Gorgonia L I N N. Titano ceratopbytion B OERH.

2. Een Netvormig Hoorn-Koraal met een roode Schors, Zeebouket. Corallium reticulatum.

A. XIII. Fig. I. Een Zcewaajjer zonder Schors.

2. Een dergelyke kleinder, met een geele Schors.

A. XIV. Fig. I. Een fyn Hoorngewas van de Kaap de Goede Hoop.

2- Een dergelyk geelagtig wit. Keratophyton album tenuiter ramofun, aticibus bullatis.

3. Zee-Mofch, Fucus longifoliis finbriatus.

4. Een dergelyke met het Lichenaftrum. LINN.

5. Sertularia penzata folliculis bidentatis. 


\section{B. HOORENSEN SCHULPEN.}

Tabula Figura

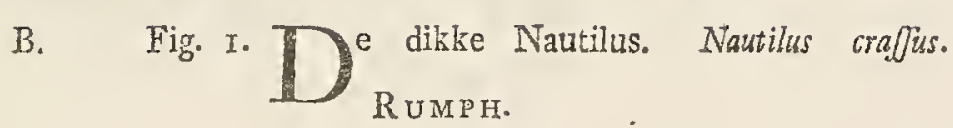

2. Dezelfde, fchoon gemaālzt.

B. I. Fig. I. Dezelfde, doorgezaagd.

2. De kleine Nautilus.

3. De dunne Nautilus met een fmalle Kiel. Nautilus papyraceus.

4. Dito, met een breede Kiel.

B. II. Fig. I. De Duivelsklaauw. Harpago. RUMP

2. De St. Jacobs Schulp. PeEter. $R$.

3. Een Konings Mantel.

4. Een Zonnewyzer.

5. Een Koraaldoublet.

6. Een linkze Kinkhoorn. Buccinum.

7. De Fles. Lagena $R$.

8. De Raap. Rapa. R.

9. De Ajuinfchil.

B. III. Fig. I. Een Nageldoublet. Chama Jquamat $\boldsymbol{R}_{\text {. }}$

2. Een Olie Kruik.

3. Een Bisfchops Muts. Mitra Epifcopa. lis. $R$.

4. De A. B. C. Toot. V̌luta Muficalis. $R$.

5. Een Agaat - Toot.

6. Een groene Zilvermond.

7. Een Nasfaùver.
Tabula Figura

8. Een Purpure Zonneftraal.

9. Een Violette Zonneftraal. Tellina Violacear $R$.

B. IV. Fig. I. Een Lazarusklap.

2. De driekantige Kinkhourn, geknobbeldo Peer, Voethoorn.

3. Een Lảphoorn. Alata.

4. Eèn Turks Leger, Zuidlandfche Dadel. Cylinder Maximus.

5. Een Caap-Porcelein, Landkaart Porcelein. Porcellana montofa. $R$.

6. Een Babylonfche Toorn. Turris Babylonica. $R$.

7. Het Vogeltje. Avicula.

8. De dubbeld getakte Hanekam, Oftreutrs Plicatum Majus. $R$.

9. Een Zee-Ton.

B. V. Fig. I. Een Kinkhoọn met breede Golven.

2. Een Noachs Arke.

3. Een breed getalkte Hamdoublet. Pinno.

4. Een korte Spil. Tufus brevis.

5. Een Stekelhoorn. Spinnekop. Tribulus $R$ 。

6. Een Admiraal.

7. Een Vliegefcheêt. Voluta arenata $R$.

8. Een Klipklevèr. Patella.

9. De egte Vèntus Schufp. 


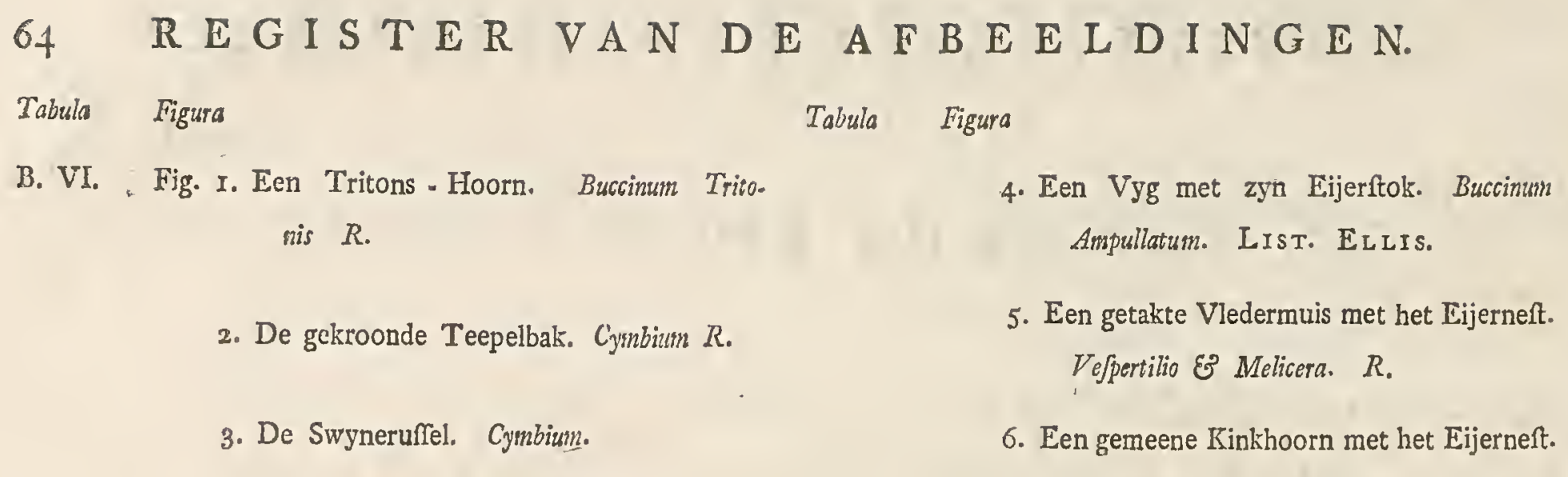

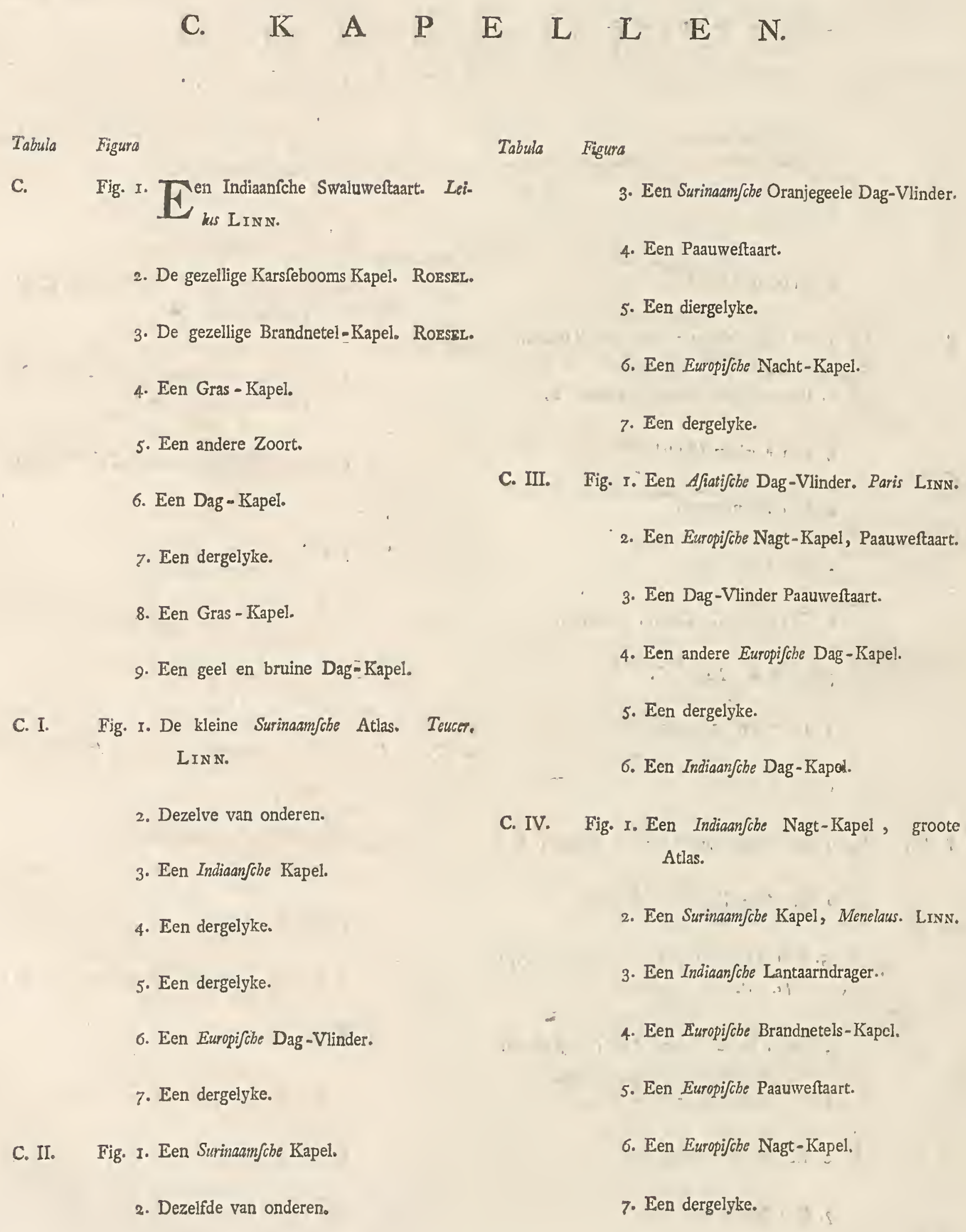




\section{VOOR R E D E.}

ET Werk, het geene wy thans aan de Liefhebbers van de Natuurlyke Hiftorie aanbieden, behelsd een Verzameling van eenige der voornaamfte Natuurlyke Zeldzaamheden, welken men in de drie Ryken der Natuur, veronderftellende dat men het Koraal of eenige Zoorten daarvan tot het Ryk der Planten rekene, ontmoet, en die alle met hunne natuurlyke koleuren afgebeeld zyn.

De oorfpronkelyke egte ftukken daarvan zyn hier en daar in de Kabinetten van die voornaame $T$ ieflichhere to zien: vrellze dezclve gulhartig leenden, om tot bevordering van de kenniffe der Voortbrengfelen der Natuur in het Koper gebragt te worden, ten einde aan een jegelyk, die zulke Meesterftukken der Natuur niet bezit, of ooit gezien heeft, gelegenheid te geeven om ze egter te leeren kennen.

Wy betuigen hier mede vooreerft an alle Bevorderaars van ons oogmerk, die ons eenig ftuk medegedeelt hebben, onze fchildpligtige dankbaarheid, en oordelen het niet overtollig te zyn, hun van het eigentlyke oogmerk van dit Werk, dat niet zonder groote koften ondernomen is, te onderrigten.

De Liefhebbery tot de Natuurlyke Hiftorie heeft zig door het goede voor"beeld, dat verfcheide voornaame en geleerde Natuuronderzoekers gegeeven hebben, in onze dagen dus verre uitgebreid, dat ook zulke Perfoonen daar mede bezield zyn, welker Karakter en Beroep hun nog gelegenheid nor tyd verleend, om moeite en koften tot verdere nafpooringen der Natuur te befteeden; wy zien immers. dat zo wel ongeletterde als geletterde aan de Natuur de fchuldige Eere bewyzen, om haar tot verheerlyking van den 
Schepper, met verwondering, te befchouwen. Men heeft dus zedert eenigen tyd meer Verzamelaars als Kenners van de Natuurlyke Hiftorie gevonden, welke uitgelokt door het fraaije der Natuur, met groote begeerte tragten haare Voortbrengzels magtig te worden. Maar gelyk het veele van zodanige Verzamelaars aan genoegzaane aanleiding ontbreekt om de waardy en de hoedanigheid van de verfchydene ftukken, die zy by een brengen, te leeren kennen, zo is hun ook de Rangfchikking, Verdeelinge, Benaaming, Meenigvuldigheid, Verandering, Oorfprong, Vaderland en Nuttigheid der zelven onbekend, uit dien hoofde hebben ook wel geleerde lieden, wier ftudie juift niet op de Natuurlyke Hiftorie geveftigd is, egter gewenft, eenen korten Wegwyzer te mogen hebben, door welken zy de Voortbrengzelen der Natuur, die zy verzamelden, gemakkelyk konden leeren kennen: Want terwyl de Werken van de vermaardfre Natuuronderzoekers niet zo gefchikt zyn, am Kahinetren of Verzarnelingen te maaken, of reeds toegeftelde daaraan te kunnen toetzen (*), zoo wierd de wenfch algemeener, om een Werk te hebben, waarin de Hoofdzaaken, die in de Kabinetten gevonden worden, met eigene koleuren naar het leven afgezet en befchreeven waaren, en dat des niet te min niet al te groot, of al te koftbaar, zyn mogte.

Het ontbrak juift wel niet aan zulke Werken, in welke men ten opzigte van het een of ander Geflagt, van de Voortbrengzelen der Natuur, deezen wenfch vervult zag, maar dit niet voldoende zynde, om aan de Liefhebbers in een Boek eene Verzameling van allerhande Zeldzaamheden te gelyk te vertoonen, en, als waare het, hun tot de kenniffe van een geheel Kabinet beknopt op te leiden, zoo bleev' 'er nog overig, een zulk Werk te bearbeiden, waarin men de voornaamfte ftukken van een Kabinet by een vond. 


\section{$V \quad O \quad O \quad R \quad R \quad E \quad D \quad E$}

Tot zodanig een Werk gorde zig de eertyds beroemde Nurenbergfe Konstenaar en Plaatfnyder, de Heer Georg WolfGANG KNORR, voor eenige Jaaren aan, die door eige Liefhebbery gedreeven, en onderfteunt door de genegenheid en briefwisfeling van geleerde Verzamelaars, zo-wel uit zyn eigen als uit andere Kabinetten eenige fraaje ftukken aftekende, en ze op eenige bladen in het koper bragt, en zonder Befchryvinge uitgaf. Dog de Ziekte, en daarop gevolgde al te vroegtydige Dood van deezen wakkeren Man daar tuffchen komende, bleef dit fraaije Werk een tydlang fteeken.

De Erfgenaamen, den Voorraad van Kopere Plaaten, die gedecltelyk uitgewerkt waaren, en gedeeltelyk niet, voor zig ziende, naamen het befluit dit Werk voort te zetten, en raadpleegden daar over met ons, wat in deeze zaak te doen ware? Wy gaaven hun daar op den raad, ieder begonnen Vak nog met eenige Plaaten in dezelfde fmakk te vermeerderen, de ontbreekende Vakken te varrrrllan - eene Befchryvinge daar hy te doen, en het Werk dus in een par Boekdeelen het licht te doen zicn. Zo ras zy dit goedkeurden, wierden wy teffens verzogt, het beftier van dit Werk op ons te willen neemen, eene korte Befchryvinge daar by te voegen, en ieder Vak met eene algemeene Inleidinge te verzellen, op dat in alle Deelen aan het oogmerk, dat wylen de Heer Knorr met dit Werk gehad had, mogte voldaan, en daar by alle wydloopigheit verhoed worden, ten einde het niet al te koftbaar wierd, het geene wy dan ook gewillig op ons genoomen hebben, gelyk wy ook op verzoek van de Heeren Bluffé en Zoon deeze Nederduitfche Verklaaring toeftelden, en met eenige Aanmerkingen verrykten, en het is door hunne vlyt dat het zelve zoo luifterryk in een $\mathrm{Ne}$ derduitfch gewaad te voorfchyn koomt.

Zie daar dan den Oorfprong van dit Werk. Wy zyn dus bepaald geweeft om de Befchryving daar naar in te rigten. Wy konden niet Syftematis zyn, om dat de Plaaten reeds een mengeling van verfcheide ftukken behelsden, en zogten alleen maar door eene algemeene Inleiding tot ieder Vak 
dit gebrek te vergoeden. En terwyl het befluit genomen was, om niet wydloopig te zyn, zo hebben wy ons ook met de verfcheide gevoelens der Natuuronderzoekers niet kunnen inlaaten, te meer, om dat die het zelfs ook geenzints eens zyn, maar zyn over,l kort, en zo veel wy vertrouwen duidelyk geweeft, om dat het ons oogmerk niet was, voor geleerde te fchryven, maar alleen voor allerhande Rag van Liefhebbers, die men eene beknopte handlyding geeven wilde on de fmak van een NatuurKabinet te leeren kennen, en hunre ei-ene fukken, die zy mifchien bezitten, eenigermate te beoordeelen. Zoo wass ten minften het oogmerk van wylen den Heer Knorr, en cie Affprak der Erfgenaraen (*).

Mogelyk zullen eenige Lieíhebbers van ojided zyn, dat wy omtrent de ftukken, die wy hebben laten afbselden, geen goerle keufe gedaan hebben; en dat wy andere zaaken of beetere oorfpronkelyke hadden behooren te plaaten äat ten miniten de Tytel van dit Werk te hoogdravend is, om die ftukken te $z_{\text {ana }}$ an ean uitgerogte Verameling te noemen. Het is niet te loochenen, dat 'er wel frasijere zaken in Groote Kabinetten zyn, en dat zulke bezitten, of ze gezien hebben, veele die hier afgebeeld zyn, als gemeen goedje zullen agten, maar dit Werk is voor lieden die eerft beginnen

$$
\text { - n te te }
$$

(*) De Hecr Knorr, een Man van keurigen fmaak, en grooten vlyt heeft veele Werken van dergelyke Natuur met afgezette Kopere Plaaten begonnen, die naderhand alle door deszelfs Erfgenamen zodanig voortgezet zyn, dat zy, door dien zy geen vlyt nog koften fpaarden, 'er Ecre van hebben; ten bewyze willen wy eenige aanhaalen, die alle voor Liefhebbers der Natuurlyke Hiftoric van veel waarde zyn; als het Steenwerk in Folio tot Tytel voerende Lapides dilwvii tefles, $\mathcal{E}^{2} c$. in drie Deelen met ongemeen veel heerlyke afgezette Plaaten, en zeer geleerd befchreeven door de Heer Profeffor Walch in fena. In dit Werk vind men alle mogelyke Verfteeningen natuurlyk afgebeeld. Verder het Bloemwerk in Folio, tot Tytel voerende: Thefaurus rei berbarice Hortenfisque univerfalis, met 300 geillumineerde Kopere Plaaten Als mede het Hoorn. en Scbulp-Werk in Quarto, vier Deelen, met I 20 gekouleurde Plaaten \&c., beneffens veele andere kleinere. Werken, die alle by de gemelde Erven van W: Knorr in Neurenberg en by Bluffe en Zoon te Dordregt te bekomen zyn, en waar van werkelyk eenige in het Nederduitfch uitgegeven worden. 


\section{$V \quad O \quad O \quad R \quad R \quad E \quad D E$.}

te verzamelen, en voor zulken is alles zeldzaam, voorts hebben wy by de keufe te gelyk ook daar op moeten zien, of een ftuk onderregtende was, en niéc alleen of het pragtig is. Vervolgens zyn al te koftbare en voortreffelyke ftukken niet voor dit Werk gefchikt geweeft, alzo die meerder ruimte, en veel meer koften hadden vereifcht, het geen tegens ons cogmerk was. Het is voldoende, dat ieder ftuk, het geen wy hier afgebeeld hebben, in zyn zoort kenbaar en onderregtende is, en dat de Leezer door dezelve in ftaat gefteld word, om verder op grootere en uitgewerktere, die in aanzienlyke of Vorftelyke Kabinetten zyn, met een oordeelkundig oog, te letten. En genomen, een ftuk is gemeen, dat is, in overvloed en overal in de Kabinetten te vinden, zo blyft het dog altyd waardig, om afgebeeld, befchouwd en befchreven te worden, vooral voor zulken, die die zaaken niet kennen, nog bezitten; dus al waare een zaak nog zoo dikwils in de wereld te vinden, zo verdiend zy egter onze opmerking, en zulks des te meer, wanneer het ftukken zyn, die in der daad niet zo overvloedig gevonden worden, gelyk wy in het algemeen van de Zeldzaamheden der Natuur en van alle Kabinetfukken bekennen moeten.

Veele zullen mogelyk tegenwerpingen maken, en zeggen: "s Het Ko "raal is geen zeldzaamheid, wy vinden het by alle A pothekers en Drogis"ten, en in Indiën brand men het en makt 'er kalk voor de Huizen van. "De Hoorens en Schulpen zyn niet raar, men vind immers dezelve in me"nigte in de Grotwerken en Bloemtuinen. De Kapellen vliegen in alle "Landftreeken. De Zee-Appels worden in meenigte gegeeten, geheel "Europa is vol van Bergwerken, en 'er zyn Mineralen in grooten over"vloed? hoe kan men dan die zaaken alle zeldzaambeden noemen? hoe kan men "voorgeven dat die ftukken na hare onderlinge evenredigheid koftbaar zyn"? Zy zullen uit dien hoofde dan ook mogelyk in de verbeelding ftaan, dat men de Naturalien zeer gemakkelyk en voor geringe waarde krygen kan, 
en dat zy by gevolg zulke koftbaare Afbeeldingen niet verdienen. Of fchoon nu wel de Ondervindinge de Liefhebbers het tegendeel leerd, wanneer zy met het verzamclen van een Kabinet een begin maaken, en of fchoon zy gewaar worden, dat, veele Zaaken magtig te worden, veel moeite koft, zo willen wy egter ten overvloede eenige zwaarigheden opperen, die het ver:amelen van een Kabinet verzellen, om daar door te doen zien, dat men aan de Voortbrengzelen der Natuur niet ten onregte den Naam van Zeldzaambeden en Kofbaarbeden geeft, en dat het in lange zo gemakkelyk niet valt, een Kabinet van Zaaken, die in dit Werk vertoond worden, by een te brengen, gelyk zig zommige verbeelden.

Het is wel waar; dat de Natuur, waar zy zonder verhindering; en als in ftilte werken kan, ryk genoeg is om niet alleen veele Veranderingen, maar ook van eene iegelyke Verandering eene meenigte voor den Dag te brengen, en zy doet ook zulks in der daad, zo al niet met alle, ten minften met de meefte Zaaken; maar hoe groot zyn niet de zwaarigheden, die wy ontmoeten, eêr wy haare Voortbrengzelen magtig worden? Hoe ontocgankelyk zyn de meefte Platfen, daar men de eigentlyke Konftfukken van de Natuur vind, en hoe weinig Lieden worden 'er gevonden, die men in afgeleegene Waerelddeelen de Zorge aan vertrouwen kan, om de Natuur in hare verborgene Werkzaamheden na te fpooren? En, gelukt dit al, hoe veel moeite en koften veroorzaakt het naderhand, de gevonde Stukken zelf uit de hand van de Onkundigen te verlosfen, en ze voor den ondergang, war voor zy op allerhande wyze bloot ftaan, te bewaaren, door hun een Plats in onze Kabinetten aan te wyzen? Wy willen maar eenige Voorbeelden aanhaalen, die in ftaat zyn ons te overtuigen, en van welke men een nader Befluit op meer dergelyke zwaarigheden maaken kan. Men frelle zig by Voorbeeld maar eens voor, de gevaarlyke wyze, hoe het Koraal gevift, en opgevangen word. 


\section{$V \quad O \quad O \quad R \quad R \quad E \quad D \quad E$.}

Het Koraal zit aan Klippen in eene verfchillende Diepte van eenige Va* demen. De Plaatfen waar het eigentlyk is, moet men mar gisfen, om dat men ze niet zeeker weet. 'Er word eenige Manfchap met de nodige Barken, Sloepen, en andere Vaartuigen met een groote meenigte van Touwen, Hakken, Kruishouten, Netten, Hennep-Ballen en dergelyk Gereedfchap vereifcht, wanneer 'er gevift zal worden. Hier mede begeeft men zig op de Zee, en werpt de Kruishouten met Netten en Hennep in de grootfte Onzeekerheid uit. Indien het nu gevallig treft, dat 'er eenig Koraal door de Netten of het Hennep gevat word, zo veroorzaakt het geweld, waar mede men de Kruishouten wederom om hoog haalen moet, om het Koraal van de Klippen af te fcheuren, dikwils onder de fraayfte Stukken de droevigfte verftooring en vernietiging: en, zo ras het Koraal maar aan de Punten afbreekt, zo beftaat de Vangft in niets anders als in een meenigte onaanzienelyke Brokken. Ja zomtyds gebeurt het by geval ook wel, dat men de Touwen en Netten kappen, en alles Prys geeven moet.

Hoe ongemeen zelden gebeurd het dan, dat men eens een geheele Koral-Tak, die mar eenigermate goed en gaaf is, om hoog haald? En hoe ras verfwinden niet deeze weinige fraaije Stukken voor de Oogen van byzondere Liefhebbers, terwyl groote Heeren, die niet noodig hebben met haar Beurs raad te pleegen, van voor langen tyd een waakend Oog houden, om goede Kabinet ftukken ook met goude Angels weg te Visfen? Dit is nu reeds het Noodlot van het egte rood en wit Koraal, dat in de Apotheeken gebruikt word, en om het welke te krygen veele Visferyen aan de Europifche Kuften gedaan worden. Hoe gering moet dan wel onze Verwagtinge omtrent het fraaje, zo wel egt als onegt, fwart, rood, wit, en ander Koraal zyn, dat in de verre afgelegene Indiën van de Natuur voortgebragt word, het welk nog geen Tak van Koopmanchap geworden is, ook in geene A potheeken of Fabryken gebruikt word, en maar alleen tot een Pronk-Stuk 
voor Kabinetten diend? Waar vind men in die Geweften een genoegzaam aantal van Perfoonen, die 'er zig mede bemoeijen, om ze voor ons te Verzamelen? Dan ontbreekt het aan de kennisfe der Stukken, dan eens zyn hun de Plaatfen der Zee onbewuft, waar men zodanige Stukken haalen moet, of het ontbreekt aan de Gereedfchappen, welke tot die Visfery noodig zyn, of aan het Vermogen om de onkoften goed te maken, terwyl men alles in die Geldryke Landen zeer duur, en zomtyds zes dubbeld betaalen moet.

Dit is de Reden, warom de Europefche Liefhebbers wel tienmal aan hunne Correfpondenten in de Indiën fchryven, (en het is nog een geluk, wanneer men daar Correfpondenten heeft) eer zy maar eens een fraay Stuk voor hun Kabinet verkrygen. En zo men zig op zulke Bezending niet ongemeen mild en rykelyk dankbaar betoond, kan men lang na cen tweede Bezending wagten. Maar gefteld ook, dat voor alle deeze Zaaken op het befte gezorgd ware, zo vinden dog de Correfpondenten zelfs ongemeen veel zwarigheden, om aan het Verlangen der Liefhebbers te voldoen.

Zig in de allerheetfte Lugtfreeken verre van Huis naar het Strand te begeeven, waar men dikwils wegens de Klippen met geen Barken naderen kan, en waar heen men zig eerft dwars door het Land en zulks veeltyds over hooge Bergen en ruwe Wegen begeeven moet, aldaar eenige ongefchikte Indianen of Slaaven tot hulp te hebben, die alles verkeerd aangrypen, de gevonde Stukken ruw en onkundig behandelen, het fyne zamenftel (waar aan de Liefhebbers het meefte geleegen legt) door onvoorzigtigheid breeken, en verderven, en naderhand onbedagtzaam nog dikwils eenige Mylen verre naar Huis moeten dragen, verder by zulke niet zonder groote koften aangeftelde Onderzoekingen zyne andere bezigheden te verzuimen, en zoo al niet het Leeven, egter veeltyds de Gezondheid daar by in de Waagfchaal te leggen, en dat alleen maar, om 
aan een Vriend genoegen te geeven, die 'er in Europa om gefchreeven heeft, zulks zyn altemaal omftandigheden, die alleen maar een groot Vorft door aanzienelyke Belooningen weet te overwinnen, en war toe dezelve nog heeft om te zien na zulke Lieden, die uit Liefde voor de Natuur. lyke Hiftorie luft hebben, alle die befwaarlyke en gevaarlyke Omftandiga heden te ondergaan.

Maar gefteld eens, dat ook deeze fwaarigheden alle met elkander verliolpen waaren, heeft men dan terftond het oogmerk bereikt? Neen! De Natuur heeft veeltyds haare pragtigfte ftukken, het diepfte verborgen.

Men zoekt dikwils een geheele week en vind nog niets, men vift, en vangt niets, dat de gemaakte onkoften, en gedaane moeite eenigermate vergoeden kan. Want men dwaalt grootelyks, indien men geloofd, dat de fraaije Kabinetftukken in Indiën zoo voor de voet leggen, dat men ze maar behoefd op te raapen. En ingevalle men ook eenige ftukken by een brengt; zoo zynze voor het meerder gedeelte nog in lange zoo niet gefchaapen als die, welke wy in dit Werk komen te vertoonen. Want dan zynze eens befchadigd en gebrooken, of door het weêr bedorven, of verkalkt, dan eens ontbreekt 'er koleur en glans aan, of de fyne bearbeiding van de Natuur is 'er aan mislukt, of door toeval bedorven, gelyk zulks door honderd om ftandigheden gebeuren kan, of 'er ontbreekt iets anders aan, dat ze niet als Kabinetfukken dienen kunnen, zoo dat het in Indiën, of ter plaatfe, daar. de ftukken gevonden worden, al reeds iets zeldzaams is, wanneer zy top. fchoon en zonder gebreeken zyn. Dit is dan de oorzaak, waarom wy dikwils met zulke ftukken te vreeden moeten zyn, die maar eenigermate goed zyn, en reeden hebben om ons te verblyden, wanneer wy zodanige flegts kunnen magtig worden.

Zoo als het nu met het Koraal geleegen is, zoo gaat het ook met andere Zeldzaamheden der Natuur. Wie gaat tog in het heete Indiën zoo vlytig op 
de Kapellen-Jagt, dat men 'er alle Europefche Liefhebbers van voorzien kan? Hoe veelen zyn 'er die geen geduld genoeg hebben, met deeze Diertjes zoo voorzigtig om te gaan, dat hun niets van het Stof der Vleugelen afgaat, waarin de grootfte fraaijigheid beftaat? Of dat zy regt opgeftooken zyn, zonder dat hun de Sprieten of Pooten afvallen? Of ook datze voor Motten en Mieren beward blyven, om niet befchadigd, of opgevreeten te worden?

Hoe zelden vind men de Hoorens en Schulpen in haare volkomene fchoonheid? Immers is het bekend genoeg, dat aan die geene, die aan het Strand geworpen worden, of die dood zyn, hunne natuurlyke pragt en luyfter nooit weder door polyften kan mede gedeeld worden.

Hoe weinig menfchen verftaan de Konft om deeze Schaldieren fchoon te maken, en hoe weinige hebben daar geduld genoeg toe? Is het niet aldus, dat ook veele Correfpondenten in de Indiën gelooven zig wel gekweeten te hebben, als zy aan de Europe Che Liefhebbers fchurfde, verkalkte en gebrooke ftukken toezenden?

Wat koft het niet al een moeite, de groote Zee-Starren zodanig te droogen, dat zy niet inkrimpen, rimpelen, of haare natuurlyke houding en gedaante verliezen? Hoe zwaar is het, ze voor verrottinge of voor de Wurm te bewaaren? Het teeder Gebouw van de Zee-Appels, hunne fyne Banden en Veezelrjes, waarmede haare ontelbaare Deeltjes en Naaden aan elkander gehegt zyn, en waarmede hare Stekels op hunne Wratjes beveftigd worden, toonen reeds oogenfchynelyk, dat het zeer bezwarlyk is, volkome Stukken te krygen, om nu niet te fpreeken, dat 'er veel Zoorten onder zyn, dic by uitftek raar zyn, om dat zy zig in onpeilbaare dieptens ophouden.

Wel is waar, dat het de Europeërs niet aan vindingen ontbroken heeft, om aan de Correfpondenten in Indiën middelen aan de hand te geeven, door welke zy (naar hunne meeninge) de Naturalien konden magtig worden. Men heeft namentlyk op het Papier agter een meenigte van Koraal, Hoorens 


\section{$V \quad O \quad O \quad R \quad R \quad E \quad D \quad E$.}

en Schulpen, Zee-Starren, Zee-Appels en dergelyke, zeekere Zoorten van Schep-en Stryknetten afgebeeld, uit welke Tekeningen men vermoe. den zoude, dat men door trek op trek een zeer ryke vangft doen moeft. 'Er' zyn ook Liefhebbers in de Indièn geweeft, en zy zyn ons van naby bekend, die uit groote begeerte, om die Zeldzaamheden uit Zee op te viffchen, zig zodanige gereedfchappen met groote koften hebben laaten vervaardigen, en zyn daar mede verfcheide maalen op den togt uitgegaan, maar de uitkomft heeft niet aan de verwagting; nog veel minder aan de gedaane koften, beantwoord. Want als men met een nyvere begeerte de bezwarde Netten moeijelyk uit het waater ophaalde, vond men of een ftuk van een afgebrooke Rots, of een ftinkend geramte van een Zwaardvifch, of eenig ander bedorven Zeegedrogt daarin. Dan eens bleef Net en Touw aan de verborge Klippen hangen, zo dat men het kappen moeft, of het Net was nict diep genoeg en gleed over de Zeedieren weg, die zig in het zand op den bodem van de Zee vaftzuigen. Dus dat het zoeken van Naturalien altyd eene moci. lyke zaak blyft, waartoe zeer groote koften vereifcht worden, en alles wat wy gezegd hebben is nog maar een klein gedeelte van de Hinderpaalen, wel: ke beletten, dat in alle Kabinetten, geen uitgezogte Stukken zyn kunnen: Zoo het ook al eens gebeurd, dat men tot een en ander Stuk eene gunftige geleegenheid vind, zo heeft men dog van den anderen kant weder honderd zwaarigheden, en men moeft door de gantfche Waereld Dienaars en Vrien: den hebben, wanneer men van alles wilde voorzien worden: Behalven dit alles zo komt het ook zeer veel op de bekwaamheid aan, om de Naturalicn goed te pakken, want hoe ras breekt door het fchudden een punt van een Koraal-Tak af? Hoe ligtelyk fpringen de Zee-Appels door het ftooten en fchudden van elkander? Hoe gaarne trekken de Zee-Starren het Vogt aan zig, en verrotten onderwegen, onaangezien alle áangewende voorzorge? De Infecten zyn meeft al door Motten opgevreeten, of befchadigt? Veci- 


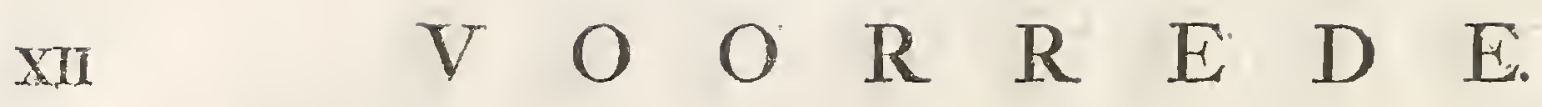

tyds verlind de Zee het overgezondene of het ontbreekt aan eene getrouwe beftellinge.

De mineraalen hebben geen beeter Lot. De onderregtende, rykhouden. de, en voor het oog fraaije Stukken, de byzondere en zeldzaame Ertzgewaffen, warrom het de Liefhebbers het meeft te doen is, worden op hoog bevel doorgaans in de Verzamelingen der Landheeren, die de Tiendens van de Bergwerken hebben, gebragt, en zyn weggepakt eêr een byzonder menfch dezelve kan magtig worden. De ftrenge Lyfsitraffen, die 'er op het uitvoeren van meenig Bergvoortbrengzel ftaan, fluiten ook veeltyds de weg, om maar eenige Stukken voor een Kabinet magtig te worden, en de meenigte van Liefhebbers maken door hunne greetigheid, waarmede zy fraaije Berggewaffen, zoeken magtig te worden, dat de Berglieden, of derzelver Opzienders niet meer weeten, hoe hoog zy wel de Pryzen opjaagen zullen. Dus het van alle kanten zwaarigheden veroorzaakt. Edog, al genoeg hier van, wy willen geen zwaarigheden meer opperen. Die, welke wy aangehaald hebben, zyn genoeg, om het Oogmerk en de Inrigtinge van dit Werk te regtvaardigen, wy geloven dus geen ondienft met de Afbeelding van verfcheide Stukken gedaan te hebben, en vertrouwen dat niet alle Kabinetten zulke oorfpronkelyke, of die zo onderregtende zyn, opleveren kunnen. Verfcheide zyn ook maar afgebeeld, om gelegenheit te hebben, van die geheele Claffe te kunnen fpreeken, en gelyk 'er dagelyks nog nieuwe Zaaken ontdekt worden, zo vertrouwen wy, dat de Leezers vooreerft in dit Werk genoegen neemen zullen, als die weten, dat de Natuurlyke Hiftorie eerft in het klimmen; en in der daad nog met veele onzekerheden en duisterheden beneveld is, tot dat de tyd, en de meenigte van Ontdekkingen der Natuur onderzoekers, het geene nu nog verborgen is, in een helder Dagligt ftellen. 


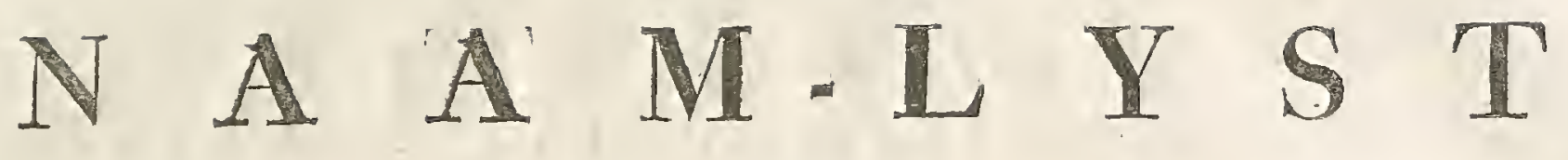 \\ $\begin{array}{llllllllll}D & E & R & H & E & E & R & E & N \text {, }\end{array}$
}

DOOR WIENS BEGUNSTIGING,

\author{
D I $T$

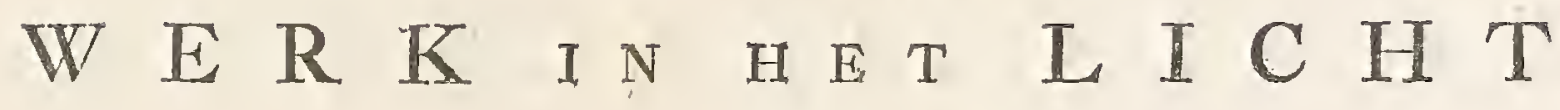

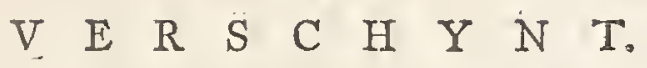

De Hoog Wel Geboore Heer Aarfe wan Hogerhyde, Heere van Voshol, \&c. \&c.

De Wel Ed. Geftr. Heer Alphen, (Daniël wan) Griffier der Stad Leiden.

De Wel Ed. Heer Ameldung, (Mr. Adriaan) Advocaat voor den Ed. Hove van Utrechto

De Heer Ancona, ( $\mathcal{F}$. de) Medicina Doctor te Amfterdam.

De Heer Atbias, (IJaac da Cofta) te Amfterdam.

De Heer Bafter, (Alphonfus) Notaris te Z. Zee.

De Wel Ed. Geboore Heer Bellaerts, (Mr. G.) Vryhcer van Binkland, Heer van Wieldrecht; Secretaris van de Provintiale Reekenkamer van Holland en Weftvriesland, Oud Prafident, Schepen en Raad in de Vroedfchap der Stad Dordrecht.

De Wel Ed. Geftr. Heer Blommenftein, (WTillem wan) Medicinx Doctor, Raad en Prafident Schepen der Stad; mitsgaders Ontfanger van 's Lands Gemeene Middelen te Delft.

De Uitgeevers Bluffe en Zoon, (Abrabam) Boekverkoopers te Dordrecht 3 Exemplaren.

De Wel Ed. Geftr. Heer Boreel, (Mr. Facob) Fanzz., Raad en Adrocaat Fifcaal van het Ed. Mogende Collegie ter Admiraliteit van Amfterdam.

Dë Heer Bouman, ( $f$ an $)$ Notaris en Makelaar te Middelburg.

De Heer Brouwer, (Nicolaas) te Rotterdam.

De Heer Browwer, (Elias) te Rotterdam.

De Heer Bruine, (Fobames de) Koopman te Amfterdani.

De Heer Copello, (Mr. Servaas vain de)

De Wel Ed. Geftr. Heere Croye (F.P.) Capitein ten dienfte van den Staat der Vereenigde Nederlanden.

De Heer Fan Dane, Boekhandelaar te Middelburg.

De Heer Decker, ( $F$. G.) te Haarlem.

De Wel Ed. Geb. Jonkvrouwe De la Faille, (H. \%.) te Delft.

De Heer Detert, (Bernardus) te Rotterdam. 
De Wel Ed. Geftr. Heer Does, (Mr.W. F. van der ) Raad in de Vroedfchap en Oud Scheepen der Stad Utreclit.

De Heer Draveman (Melcbior) Koopman te Amfterdam.

De Wel Ed. Heer Dufart, (Hendr.) Heere van Noordgouwe, en Secretaris te Ooltgensplaat.

De Wel Ed. Gr. Agtb. Heer Fagel, (Mr. F. B.) Burgermeefter der Stad Haarlem.

De Wel Edele Heer Falkenier de Fonge (Gillis) te Amfterdam.

De Heer Gilliflen (Pieter) Boekhandelaar te Middelburg.

De Wel Ed. Geb. Heer Groeninx wan Soelen (Cornelis) Heere van Ridderkerk:

De Wel Edele Heer Heemskerk (Mr. C. van) in 's Hage.

De Heer Hoek (Facobus wan) Koopman te Amfterdam.

De Heer Holfteyn (Pieter) Boekhandelaar te Rotterdam:

De Wel Ed. Hoog Geb. Heer Hoogendorp (Mr. Foban François, Grave van) Baron van St. Jan Steen, Ontfanger Generaal der Vereenigde Nederlanden, \&c. \&c.

De Heer Hoogenhuyzen, (Fobannes Henricus wan) Med. Student te Leiden.

De Heer Hoogenbuyzen, (W. wan) te Amfterdam.

De Wel Ed. Gr. Agtb. Heer 1febrée (Fob.) Regeerend Burgermeefter der Stad Goes.

De Heer Kemenaar (Georgius) te Rotterdam.

De Heer Kerffeboum ( $\mathcal{F} a n$ ) te Amfterdarn.

De Hoog Edel Wel Geb. Jonkheer Kinfchot Hartoog (Nicolaas wan) te Amferdam.

De Heeren Knorr (Erven George Wolfgang) te Neurenberg, 4 Exemplaren.

De Heer Lever (Cornelis) Koopman te Amfterdam, 3 Exemplaren:

De Heer Martins (Abrabam) in 's Hage.

De Wel Ed. Geftr. Heer Mauritz, (Mr. Jobannes) Scheepen en Raad der Stad Vlisfingen, en Rentmeefter der Domeinen van Zyn Doorl. Hoogh. den Heere Prince van Orange en Nasfau, \&c. \&c. \&c.

De Heer Meer, (Abraham van der) te Maasfluis.

De Heer Meiling (Pieter) Notaris te Amfterdam:

De Heer Meulen, (Willem van der) te Amfterdam:

De Wel Ed. Geb. Heer Merners, D. V. Z. (Mr. Gerard François) Raadsheer in het Ed. Mog. Hof, en Raade van Vlaanderen.

De Wel Eerw. Heer Muilman, (Wigbold) Willemyz. V. D. M., in 's Hage.

De Hooggeleerde Heer Autheur Muller, (Pbilip Ludwig Statius) Doctor en Profeffor in de Philofophic en Natuurlyke Hiftorie te Erlang, Medelid van de Keizerlyke Academie der Natuur-Onderzoekers, \&c. \&c. 3 Exemplaren.

De Heer Nooten, (Sebaftiaan wan) Fanfz., te Amfterdam:

De Heer Noy, $(P$. de) te Amfterdam.

De Heer Papillon, (Charles) te Dordrecht. 
De Wel Ed. Geftr. Heer Picbot, (Daniell Conftantius) Raad in de Vroedfchap en Regeerend Scheepen te Schiedam.

De Wel Ed. Gr. Agtb. Heer Prins, (Adriaan) Oud Burgermeefter der Stad Rotterdam, en Bewindhebber van de Ooft-Indifche Compagnie, ter Kamer aldaar.

De Wel Ed. Geftr. Heere Putte Scborer, (Mr. A(fuerus wan de) Scheepen en Raad der Stad Middelburg.

De Heer Rademacher, ( $\%$. C.) te Amfterdam.

De Heer Reelyk, (C.) Mr. Chirurgyn te Charlois.

De Heer Rofcam, $\left(P_{0}\right)$ in 's Hage.

De Heer Ruiter, (Gerrit de) Koopman te Amfterdam.

De Heer Ryckeworfel, (Mr. C. wan) in 's Hage.

De Wel Eerw. Heer Sappins, (Facobus) V. D. M. te Oud Beierland.

De Heer Schagen, (Goan wan) te Amfterdam.

De Heer Scheffer, (Cbri/toffel) in 's Hage.

De Heer Scheltus, (Mr. IJaac) Ordinaris Drukker van Hun Edele Groot Mog. de Heeren Staaten van Holland en Wefturiesland, in 's Hage.

De Edel Mog. Heer Scborer, F. A. Fil. (Mr. Willem) Gecommitteerde Raad, en Raad ter Admiraliteit van Zeeland, te Middelburg.

De Heer Scbrevelius, (Abrabams) te Leiden.

De Heer Schultz, (Adriaan Gotlob) te Amfterdam?

De Heer Sepp, ( . C.) Boekhandelaar te Amfterdam:

De Hoog Geleerde Heer 's Graauwen, Sib. Car. Fil. (Paulus) Doctor en Profeffor Primarius, Med. Unir. Theor. \& Pract. Anat. Botan. \& Chym. te Harderwyk.

De Wel Ed. Geftr. Heer Smeth, (Theodorus de) Vryheer van Deurne en Lieffel, Ambachtsheer van Alphen en Rietveld; mitsgaders Oud Præfident Scheepen te Amfterdam.

De Heer Smith, (Willem Hendrik) te Rotterdam.

De Heeren Spriet en Zoon, (Pieter) Boekhandelaars te Amfterdam.

De Wel Ed: Heer Steenbergen, ( $\%$. W. wan) Stads Med. Doctor \& Lector Anat. te Dordrechto

De Heer Sterling, $\left(\mathcal{F}, V_{\text {. }}\right)$ te Langeraar.

De Wel Ed. Geftr. Heer Sweers, (Mr. Ifaac) Hoofd-Officier te Amfterdam.

De Wel Ed. Geftr. Heer Tarelink, (Fan wan) Scheepen der Stad Amfterdam.

De Heer Textor, (Fobannes) Commiffionair te Amfterdam.

De Heer Tonger7o, (Kornelis van) Boekhandelaar te Amfterdam, 2 Exemplaren.

De Heer Troncbin, $(\mathcal{F}, P$. ) te Amfterdam.

De Heer Upwich, (Foan Carl. vain der) te Amfterdam.

De Wel Ed. Geftr. Heer Visvliet, (Mr. Pieter wan) Scheepen en Raad der Stad Middeiburg, en Be. windhebber der Ooft-Indifche Compagnie ter Kamer Zeeland. 
De Wel Ed. Geftr. Heer Visvilet, (Mr. David wan) Scheepen en Raad der Stad Miuddelburg.

De Wel Ed. Geftr. Heer Visvliet, (Mr. Egbert Pbilip van) Medicinæ Doctor en Kiezer der Stad Middelburg.

De Heer Vollenbowen, ( $\left(\right.$ an $_{\text {wan }}$ ) Corneliz, te Rotterdam.

De Heer Vosmadr, (A.) Directeur der Vorfelyke Natuur- en Konf-Kabinetten, Lid der Keizerlyke Academie \&c. \&c., in 's Hage.

De Heer Walle, (Tjaard wan der) te Leeuwarden.

De Heer Weteling, (Pieter) te Rotterdam.

De Hoog Geleerde Heer Willemfen (Facobus) S. S. Theol. Profeffor en Predikant te Middelburg.

De Wel Ed. Gr. Agtb. Heer Winkelman, (Ifaac) Raad en Burgermeefter der Stad Vlisfingen, Commis Generaal der Convoyen en Licenten in Zeeland.

De Wel Ed. Gr. Agtb. Heer Wit, (Mr. Francois de) Burgermeefter der Stad Amfterdam.

De Heer Wit, (Hermanus de) Boekhandelaar te Amfterdam.

De Heer Wittert, (Adriaan) te Rotterdam.

De Wel Ed. Heer Zuylen wan Nyevelt (Mr. Aarnoud wan) Secretaris van de Weeskamer der Stad Rotterdam

In kennis/e der waarbeid dat geene meerdere Exemplaren dan deeze, welke Ingefchreven zyn wierden Gedrukt: zoo bebbe die alle Genominert en Ondertekent; en. buiten deeze. zyn 'er geen, die voor Ecbt erkent worden,

$\mathrm{N} \cong j_{0}$
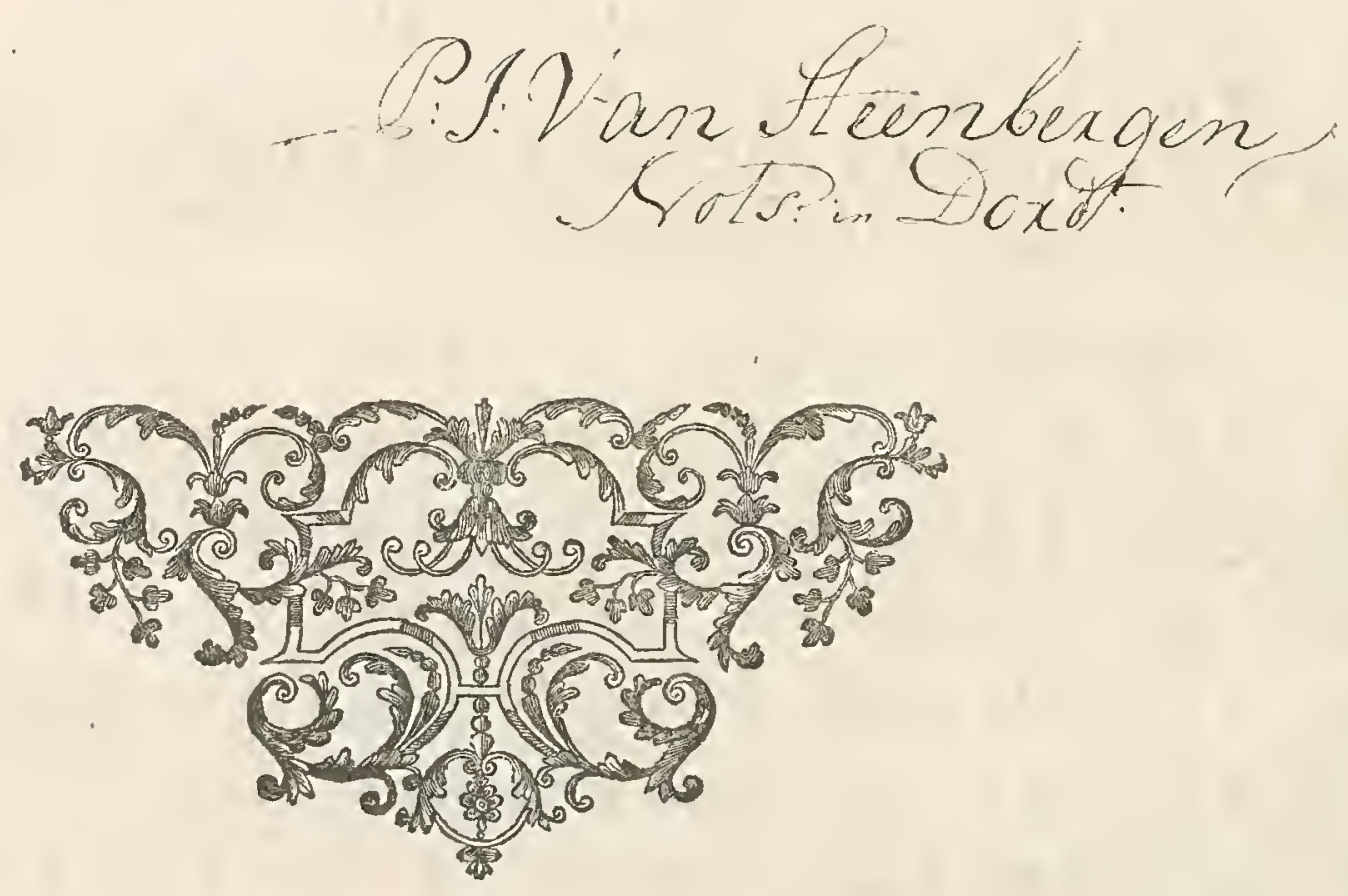


\title{
ALPHABETISCHE LYST
}

\author{
D $\mathrm{E} \cdot \mathrm{R}$
}

\section{AUTHEUREN,}

\section{Van welke men eenig gebruik gemaakt heeft in het toeftellen van dit Werk.}

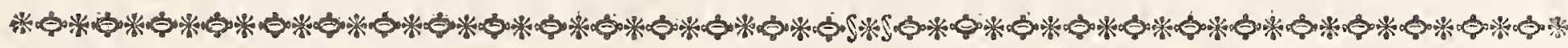

\begin{abstract}
A. 1

Abbandlungen, der Naturforfchenden Gefellfchaft in Danzig. Dansig 1747. 4to.

Abbandlungen (Pariffche) zur Natur und Cbimie. Leipzig i 752.8vo.

Acta Academ. Elector. Moguntinæ. Erford, \& Goth. I 757.8 vo.

ACia Phyfico-Medica Nature curioforum. Norimb. I 727 . \&c. 4to.

Acta (nova) Phyf. Medica Naturæ curioforum. Norimb. I 757 . \&c. 4to,

Ača Philofophica Societ. Regix in Anglia. Leipz. I $6 \% 5 \cdot 4$ to.

Adanfon Hiftoire Naturelle des Coquillages dủ Senegall. à Paris I 757. 4 to.

Ailiani de Natura Animalium Libri XVII. cum animadverfionibus C. Gesneri D. W. Trilleri, curante A. Gronovio Heilbronne I 765 . 4to.

Agricola (Georgius) de re Metallica Bafilix 156 . fol.

de Ortu, Natura \& caufis fubterran. foffil. Mctall. Wittemb. I6I 2. Svo;

Alberius de Animalibus. Venet. I 5 I 9.

Aldrovandi (Uliffis) Ornithologia. Bononix I 599. fol.

de Animalibus, Infectis, \&c. Libri VII. Francof. 1623 . fol

Quadrup. bifulc. Hiftoria. Bon. I 642 . fol.
\end{abstract}

Anderfon (Games) Hiftoire Naturelle de l'Islande, à Paris I750. 8vo.

Angeli (Baldi Abbatii) de admirabili Vipere natura \&c. Hage Com. 1660. I 2 mo, 
Anfon (Admiraal) Reize rondom de Waereld. Leiden en Amfteldam I765, gr. 4to.

Anfeigen (Erlangifche gelebrte) auf die Gabre I 749, 50, 51, 52. 4to.

D'Argenville Conchyliologie. à Paris I 757 . klein fol.

Ariftotelis Opera omnia de animalibus, de partibus animalium \& de generatione animalium graece \& lat. Aurelix Allobrog. I 605. fol.

Ardeti (Petri) Ichthyologia. .o opera omnia de Pifcibus. Lugd. Bat. I738. 8vo.

"Tỏ Avily Defcription générale de l'Afrique. à Paris 1643 .

\section{B.}

Backer (H.) Het Mikroskoop genakkelyk gemaakt, enz. en Berigt van Ontdekkingen enz. Amfterdam I $760.8 \mathrm{vo}$.

Natuullyke Hiftorie van de Polypen. Amft. 1 756 . 8 vo.

Baldaei (Pbilipp.) Befcbreibung der Oft-Indifchen Kuffe Malabar, Coromandel und Zeylon. Anft I 672. fol.

Barba (Al.) Verhandeling over de Metallen, Mynen, en Mineraalen. Leiden I 740 . gr. 8 vo.

Barbinais ( $L$. G. de) Nouveau Voyage autour du Monde, à Paris I728. 8vo.

Bartholini (Thom.) Acta Medica \& Philofophica Hafnix I673. 4to.

Baubinus (Capp.) De Lapidis Bezoaris ortu, natura differentiis \&c. Bafil. I625. 3vo.

Bowner (D. Gob. Wilb.) Naturgefchichte des Mineralreichs mit befonderer Anwendung auf Thuringen, in swey bucbern. Gotba I 763 . und 64. 8 vo.

Bafer Natuurkundige Uitfpanningen. Haarlem I 762.4 to.

Bayer ( $(j o b . ~ F a c$.$) Oryctographia Norica. Norimb. I 758$. fol.

Becber (goh. Foach.) Phyfica fubterranea. Lipf. I $703.8 \mathrm{vo.}$

Beckers (Fob. Godeb.) Mineralifches A. B. C. Nurnb. und Altorf I $723.8 v 0$.

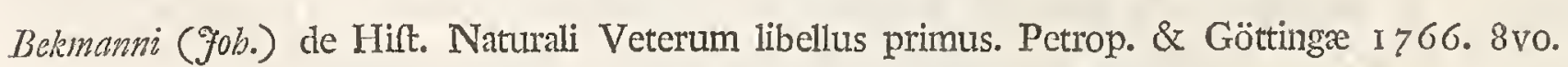

Anfangsgrunde der Natur Hiflorie. Göttingen und Bremen I 767.8 vo.

Belon (Pierre du Mans) L'Hiftoire de la Nature des Oifenux. à Paris i 555. fol.

Obfervations de plufieurs fingularités \& chofes memorables trouvés en Grece.

it Paris I 588.4 to.

la Nature \& diverfité des Poifons. ̀̀ Paris 1555.

Bergivercken, (avabrer and klarer Unterricht von) Wittenberg 4 to.

Bermies (Frani.) Voyages contenant la Defcription des Etats du Grand Mogol. Amft. I 699. 8vo. 


\section{ALPHABETHISCHE LYST DER AUTHEUREN.}

Bergen (de) Clafl. Conch. 4 to.

Bertrand Diction. univerfel des Foffiles \&c. à Avign. 1763.8 vo.

Befchreibung (ausfubrlicbe) des Fiecbtelberges, Leipzig I 7 I 6. 4 40.

Bierings (Fob. Alb.) Hiffor. Befcbreibung des Mansfeldifchen Bergwercks 1734. fot.

Biafii (Gerb.) Anatome Animalium. Amft. I68 I. 4to.

Bocbardi Hierozoicon. Lond. I 664 . fol.

Bomare (Vallmont de) Algemeen en Beredeneerd Woordenboek der Natuurlyke Hiftorie, uit het Franfch vertaalt door Charles Papillon, Dordr: I 767.2 deelen 4to.

Bonami ( P. Pbil.) Recreatio mentis \& oculi. Romr I684. 4to.

Obfervationes. Romæ I691. 4 to.

Mufeum Kircherianum. Romæ r 7̧09, fol。

Bosmans Befchryving van Guiné. Amft. 17 I 8.

Bradley ( $R$. ) Wysgeerige Verhandeling van de Werken der Natuur. Amf. I 744.

Bresslauifcbe Sammlungen.

Breynii ( $f 0$ b. Pbil.) Dirl. de Polythalamiis. Gedani $1732.4^{\text {to. }}$

Breynifchen Naturalien-Cabinets (Berzeicbnifs des). Danzig.

Bromel (Magni von) Mineralogia Suecan. Stockbolm und Leipzig x 740.8 vo.

Bruckmanni (F. L.) Epiftolæ itinerar. \& Tractat. Var. 4to.

Bruyn (Cornelis de) Reize door Moscoviën en Perfiën naar de Indiën. Amft. I 7 \$8. fol

Reize door Azia. Amft. fol.

Buffon Hift. Naturelle du Cabinet du Roi, à Paris 1 $750.4^{\text {to. }}$

Buttners (Dav. Sigism.) Coralliographia fubterranea. Lipf. I 7 I 4 .

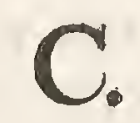

Caefalpini (And. Aret) de Metall. Norimb. I602. 4to.

Caji ( Foan) de Canibus Brittannicis, \& rarior. animal. \& Stirp. Hift. Lib. unus. Lond. I729. 8vo.

Cardani (Hier:) Opera Lugd. I 663 . fol.

Careri Voyage à Paris I 727 .

Catelanus vom Bezoarfein. Frankf. I $627.8 v 0$.

Catesby Nat. Hift. of Carolina. Lond.

Catrou \& Rouille Hiftoire Générale de l'Empire de Mlogol. à Paris 1705.4 to. 
Chabraei (Dominici) Stirpium Icones. Genevae I 666. fol.

Chombon Traité des Metaux \& des Mineraux. it Paris I 7 I 4 . 8vo.

Cbambre (de la) uber der Thiere Erkentnisz, Naturtrieb und Abfcheu. Leipzig 1751. 8 vo.

Cbardin Voyage en Perfe. à Rouen I 723 . 8vo.

Charleion de nominibus \& differentiis anim. Oxon 1677 . fol.

Cbarlevoix (Pierre Franc. Xovier) Hiftoire de l'Ine Efpagnole du Paraguai, du Japon \&c. à Paris I73i. 36. 56.4 to.

Chemnis (Gob. Hieronym.) Beytrage zur Tefaceotbeologie. Nurnb. I 760. 4 to.

Cbomel ( $P$. Noel) groffes und wollftandiges Oeconomifches Lexicon. Leipzig I 750 . fol. 8 theile.

Clufii (Carol. Atreb.) rariorum Plantarum Hift. \& Exoticorum libri X. Antw. I60I. fol.

Commentarii Academire fcientiarum Imperialìs Petropolitanx. Petrop. I 728 . \&c. 4to.

Commentarii de rebus in fcientia naturali \& Medicina geftis. Lipfize I 750. \&xc. 8vo.

Commercium literar. Noricum. I 740 . \&rc. 4 to.

Condomine (de la) Reize gedaan ter ondekking van de Waare Gefteltheid des Aardkloots. I 752.8 vo.

Crans (David) Hiftorie van Groenland. 3vo.

\section{D.}

Dale ( Samuel) Pharmacologia feu Manuductio ad Materiam Medicam. Lond. I 695. 8vo.

Dampier (Willem) Reize rondom de Weereld. 4to.

a Voyage to New-Holland in the Year I 699. London I 709.3 vo.

Dapper (Olphert) Befchreiving van het Ryk van den Grooten Mogol, Mefopotaniën, Babyloniën, Asfyriën, Syriën, Perfiën, Georgiën, Mingreliën. Amfteldam I679. fol.

Befchreiving van America. Amfteldam I 67 I. fol.

Befchreiving van Azia, benevens geheel Syriën en Paleftina. Amfteldam I680. fol.

Befchreiving van de Eilanden in den Archipel. Amfteldam I 70 I. fol.

Dellon Nouvelle Relation d'un Voyage aux Indes Orientales. Amft. I 699. i 2 mo.

Derbam (Willian) Godleerende Natuurkunde. Amfteldam I 74I. 4to.

Defcription du Cabinet Royal de Dresde. à Dresde \& Leipzic. I $755 \cdot 4$ to.

Defcription of three Hunderd Animals. Lond. 1734. I 2 mo.

Denfignii (Anton) Exercitat. de nutritione \& mota Animalium. Groninge i 660. 61. I 2 mo. 
Diderot Encyclopedie. it Paris I 75 I. fol.

Donati. (Biotal.) Auswug der Naturgefcbicbte des Adriatifcher Mecres. Halle 1753.4 to.

\section{E.}

Eckard (Fobdin Gotil.) Experimental Oeconomic. Fena I 754 . 4 to.

Edward Nat. Hift. of Birds. Lond.

Ellis (Foan) Natuurlyke Hiftorie van de Koraal Gewaffen. 's Hage 1756.4 to.

Entzels (Cbriflopb) Syftema rerum Metallicarum Francof. I698. fol.

Epbennerides Academix curioforum. Lipr. I670. \&c. 4to.

Erckers (Lawari) Aula fubterranea. Francf. 1684:4to.

Befcbreibung der allerneweften Mineralifchen Erfte und Bergwerks.Ader. Frankf. 1580 . fol.

\section{F.}

Fabricius de different. Anim, Quadrup. Tigur. 1555 . 8vo:

Fuchjen (Modefin.) Probier Bucblein der Meialle. Leipz. I689. 3vo.

Fuillée (R. S. Louis) Joumal des Obfervations Phyfiques \&c. à Paris I I I 4 4to.

Franci Caftrologia. Aug. Vind. I 685.

Firthtaii Hiftor. Animal. Sacr. Witteb. I 6 I 2.8 vo.

Frey (Herm. Heinr.) Bibliches Tbierbucb. Leipzig I 595. 4to.

Biblifches Vogel-Buch. Leipzig I 595. 4to.

Frifc (\%. L.) Befchreibung von allerley Infecten in Deutfchland. Berlin I 730. ECc. 4to.

Vorftellung der Vogel nach einigen Claffen. ibid.

\section{G.}

Gage (Thomas) Reize naar de Spanfche Wert - Indiën. Amfteldam 4to.

Gonzii ( 70 b. Lut.) Coralliorum Hiftoria. Francf. 1669. 8 vo. 
Gemes (de) Voyage aux cotes d'Astique. Amft. I699. 8vo.

Geatndlfbappen (Tweede en Derde) der Ooft-Indifche Maatfchappy an de Keizeren - van China. Amft. I 676 . fol.

Gesseri (Comradi) Hiftoria Animalium. Tigur. I 554 . fol.

de Avium Natura, Francof. 1617 . fol.

- Thierburcb, Fifcbbuch, Vogelbucb. Zurich I 583 . fol. Frankf. I 598. fol

Nomenclator Aquatilium Animalium. Zurich I 560. fol.

Gevens (Nic. Georg.) Monatblicbe Belufigungen. Scbneken 4to.

Gilberti (Guil.) Tracatus de Magnete, 4to.

Gillius Defcriptio Elephanti. Hamb. I6 I 4 .

_- de vi \& Natura Animalium 4 to.

Glauberus (Fob. Rud.) de Natura Salium 1658.

- vom Urfprung der Metalle. Amfl. 1653. 8vo:

Gmelins ( Fob. Georg) Reize door Siberiën naar Kamfchatka. Haarlem 4 declen gr. 8vo.

Goedart ( 90 b.). Metamorphofis Naturalis. Middelb. 3vo.

Grewo Mur. foc. reg. angl. Lond. I 68 I. fol.

Gronovius (L.Tb.) Zoophylacium. Lugd. Bat. I 763 , fol:

Mufeum Ichthyologicum:

Grusmon de Avibus Paradifiacis. I 667 :

Gualtieri (Nic.) Index Teftarum Conchyliorum. Florentix: I 7 44. fols

Guet Tiftoire Critique de l'Ame des Bêtes. Amft. I 749.8 vo.

\section{$\mathrm{H}$.}

Halle (Yoh. Sam.) Naturgefchicbte der Thiere. Berlin I757. und 60:8vo.

Hanows Erlautere Merkwurdigkeiten der Natur. Dans. 4to:

Harvaleus (Guiliel.) de Generatione Animalium I680. I $73 \%$. I2mo?

Hebenfereit ( $g \circ$ b.) Mufeum Richterianum. Lipfix I 733. fol.

Helwingii (Georg. Andr.) Lithographia Angerburgica. Regiom: 1747. 4to.

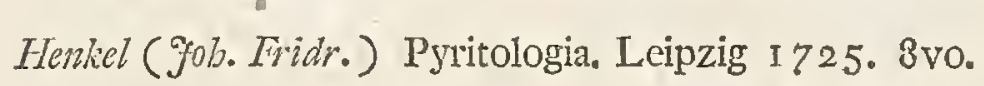

Flora Saturnizans. Leipzig I 722. 8vo:

Kleine Scbrifter. Dres\%. 756 6 8v0. 


\section{ALPHABETISCHE LYST DER AUTHEUREN.}

Hertzuigs (Cbrif.) volkommenes Bergbucb. Dresd. I 734. fol.

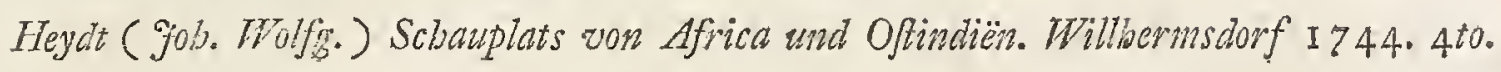

Hiemeri (Eberh. Friedr.) Caput Medufa nov. diluv. univ, monumentum, Stuttgardiæ 4to.

Hijforia Piantarum Generalis. Lugd. I 587 . fol.

Hifloire de l'Academie Royale des Sciences. à Paris won Anfang bifs I $760.4 \%$.

Gencrale des Voyages. à la Haye I 747 . 4to. nebf der deutfchen Ueberfetzung. Leipzig i $74 \%$. enz.

Hurnii Elephas. Norimb. I 629. 4to.

Hibners (Gob.) Natur, Kunft-Berg-Gezverck-und Handlungs Lexicon. Leip\%. I739. 8 vo.

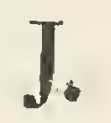

Facubci (Oligeri) Mtufeum Regium Chrift. V. Regis Dan. Haf. 1 696. fol.

Imperati (Ferrandi) Hiftoria Naturalis. Col. I 695. 4to.

Yonftont Befchreiving van alle de Dieren. Amft. I 660, fol.

Jugels (Fob. Gotifr.) von Metallifchen Sachen I 755 .

gungius (Foach.) Hift. Vermium. Hamb. I691. 4to.

\section{K.}

Kabinet der Natuurlyke Hiftorien, Wetenfchappen, Konften, enz. Amft. I 7 I9. enz. 8vo,

Kaempferi (Engelberti) Amonitates exoticæ. Lemg. I 7 I2. 4to:

Befchreiving van Japan. fol.

Kellners (David) Nutslicbes Berg- und Salswercksbucb. Franckf. I 702. 8vo.

Kircberi (Aib.) Onderaardfche Waereld. 2 deelen fol. Verheerlykt China. fol.

Kircbmayers (Georg. Caßp.) de Bafilifco, Unicornu, Phœnice, Behemoth, Leviathan, Dracone, Arnneo, Tarantula, \& Ave Paradif. Differt. Witteb. I 669.

Kleemann (E. F. C.) Beytrage zur Natur oder Infecten-Gefcbicbte 4to.

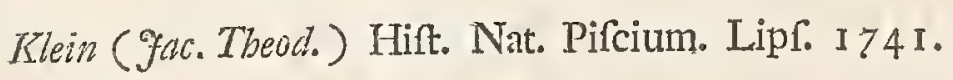

Mantifla de Sono \& Auditu Pirc. ib. 1745.

Hiftor. Avium Prodromus. Lub. I 750.4 to.

Hift. Nat. Quadruped. I752. 4to. 
Klein (gac. Theod.) Stemmata Avium. Lipf. I 758.4 to.

Tentamen Method. Oftracologicx. Lugg. Bat. I 753.4 to.

Koenig (Eman.) Regnum Minerale. Bafil. I 684. 4 to.

Regnum Animale Colon. I682. 4to.

Knox Relation ou Voyage de l'Ine de Ceylon. Amft. I693. I 2mo.

Knorr (G. W. ) het Groot Petre Facten Werk, of Verzameling van de Merkwaardigheden der Natuur, en Oudheden des Aardbodems. Amft. by J. C. Scpp. I 7 \% . fol.

Verluftiging der Oogen en van den Geeft, of Verzameling van Hoornen en Schulpen. Amft. by Houttuyn 4 to.

Kơlbe Befchrciving van de Kaap de Goede Hoop. Amft. I 7 I I. fol.

Krautermanns (Valent.) Neu-vermebrtes Regnum Minerale. Franckf. I 726.8 vo. Lexicon Exoticorum. Amft. I 730.8 vo.

Aitndnanai (Fob. Chrift.) Rariora Naturx \& Artis. Bresfl. I 737. fol.

Promptuarium Rerum Naturalium \&c. Vratislav. I 726.4 to.

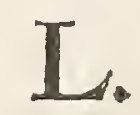

Labat Reize naar de Franfche Eilanden van Amerika, 4 deelen 4to. Amft. I 726.

La Hontan Reize naar Noord. Amerika. 8vo. Hage I 703.

Lanzonius Zoologia Parva 1738 . 4to.

Le Blanc (Vincent) Vermaarde Reizen. Amft. I 654 4 4 to:

Ledermullers (Mart. Frob.) Microfcopifche Gemuths- und Augen-Ergotaungen. Numb. I 76 I. 4 to.

Lebman (Gob. Gottlob) Einleitung in einige Theile der Bergwescks - Wiffenfcbaft. Berlin I 75 I. 8vo.

Abbondlung von der Metallenmutter und Erseugung der Metalle. Berl. I 75 I. $8 v 0$.

Leo (Afric.) de l'Afrique \& fes Animaux. ì Lion I 556. fol.

Lemery (Nic.) Woordenboek der Enkele Droogeryen. Amft. I 766.4 to.

Lefer (Friedr. Cbr.) Lithotheologia. Hamb. 175 I. 8 vo.

Infectotheologia. Franckf. I 740.8 vo.

Teftaceotheologia. Leipz. I 756. 8vo.

Kleine Scbrifien zur Gefcbichte der Natus. Nordb. I 754: 8vo.

Lexicon (Allgemeines Oekonomifcbes) Vermebret won Zincken. Leiprig I 753.8 vo.

Groffes Univergal. Leipaig I 73 I. bifs I 749. fol. 
Linckii ( 90 . Heirr.) de Stellis marinis Liber fing. Lipfix I 733. fol.

Limaei (Car.) Syftema Nature Edit. X. Holm. Halæ Magd. i 760.8 vo:

Syft. Nat. Edit。 VI. Holm. Lipf. I 748.8 vo.

Fauna Suecica fiftens Animalia regni fuec. Holm. I $746.8 \mathrm{vo}$

Linocier l'Hiftoire des Oifeaux. I584.

Lifter (Mart.) Hift. five Synopfis methodica conchyliorum. Lond. I685. fol.

Löbnenss (Georg. Enggelb. von) Bericbt von Bergwercken. Stockbolm und Hamb. I 690.

Lucas (Paul.) Voyage au Levant. Amft. I7 I4. \& I 720. 8vo:

Ludolfs Hiift. IEthiop. fol.

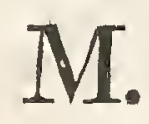

Magazin (Hamburgifches) I74\%. E2c. 8vo.

Majii, Brevis \& Accurata Hiftoria Animalium in Sacro Codice, \&c. Erf. \& Spiræ 1685. 8vo.

Maillet, Befchryving van Egypten. 4to. Hag. I 737 :

Marcgravii, Hift. Nat. Brafil. fol.

Marii (Foan.) Caftorologia, Auguft. Vind. $1685.8 \mathrm{vo:}$

Marfilli ( L. F. Comte de) Hiftoire Phyfique de la İMer. Ámft. I

Martens (Fredrik) Befchryving van Groenland en Spitsbergen. Amfteldam 4to. I 7 10.

Martiniere (Bruzen la) le grand Dictionaire Geograph. \& Critique à la Haye, Amft. \& Rotterd $17 \% 26$. \&c. fol. Introduction a l'Hiftoire de l'Afie, Afr. Amer. Amft. I 735 . I $2 \mathrm{mo}^{\circ}$

Majcrier (l'Abbé le) Defcription de l'Ëgypte. à Paris I 735. 4to;

Maffa (Ant. a) Salis Anatomia. Wratisi. 8vo.

Maundrel (Henri) Voyage d'Alep à Jerufalem I 705. I 2mo.

Melle ( $f a c o b a)$ de Echinitis Wagricis. Epift. Lub. I 7 I 8. 4to:

Mercati (Micb.) Metallotheca Vaticana, cura M. Lancifii. Rom. I 7 19. fol.

Merckleins Thierbuch 1 7 39.8 \%。.

Merian, (Mar. Syb.) Differt de Generatione \& Metamorphofibus Infect. Surinämenf. Hage 1726. fol. Der Rupfen Begin, Voedzel en wonderbare Verandering. Amft. 4 to.

Merret, Pinax Rerum Britannic. I 7o4. 8vo.

Musleri, Bezoardic. Anim. 164 I. I $2 \mathrm{mo}$. 
Irffon (Maxim.) Reyzen door Italiën. Utrecht 4to:

Monconys (de) Journal des Voyages. ì Lion 1665.4 to.

Moro (Ant. Lazar.) Veranderungen des Erdbodems. Leipsig I75I. 3vo.

Moufeti (Thom.) Infectorum feu Minimorum Animalium Theatrum. Lond. I634. fol.

Mufeum Besleri, Hoefnagel. Norimb.

(Brittifches) des Ritter Hans Sloane. Berl. I $764.12 m 0$.

Mylius (Cbr.) Befcbreibung einer neuen Gronlandifchen Thierpfanze. Lond. I753. 4 to.

In dern Knorrijcben Werk van Verfteinerungen.

\section{N.}

Natuurlyke Hiftoric, volgens 't Samenitel van Limneus. Amft. I761. \&c. 8vo.

Natuurkundige Verhandelingen uyt de nieuwfte Werken van de Societeiten. Amft. 1755. \&c. 8vo. Nieremberg, Hift. Nat. Antw. 1635. fol:

Nordten, Reifebefcbreibung nacb Norden ens. Numb. 1728.8709

Nylands, Scbauplats irdifcber Gefchopfe. Osnabr. 1678.

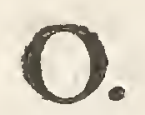

Otearii (Adam) Gottorffjche Kunftrammer. Scblessw: 1674:470.

Reifebefcbreibung nach Moscau und Perfen. Hamb. 1696. fol.

Oliger ( Facobai) Mur. Reg. Hafnienfe. Hafn. I696. fol.

Olon ( St. $_{\text {. }}$ Befchryving van het Keizerryk van Marocco. 's Gravenhage I 698. 8vo.

Onomatologia Hiftorix Naturalis: Frankf. und Leipzig i 758. und I 76 I: 8vo:

Ovington (fean) Voyages faits à Suratte. aे Paris I $725.8 \mathrm{vo}$ 


\section{P.}

Pallas (P. S.) Elenchus Zoophytorum. Hagæ-Comitum I 766. 3vo.

Paré (Ambroife) deux Livres, 1. de la Génération de l'Homme, \&c. 2. Des Monftres tant Terreftres que Marins avec leurs Porttraits. à Paris I 573.8 vo.

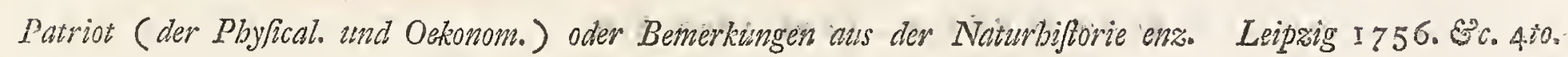
Paul Defcription Geogr. de $1^{\prime}$ thide Orient. it Paris i 556.4 to.

Paulini (Cbrifl. Frid.) Talpa Francof. \& Lipfo I 639. I 2 mo. de Lumbrico Terreftri Schediafma Francof. I $303.8 v 0$.

de Anguilli.

Paullini Curiofes Cabinet auslandifcher Merkwurdigkeiten. Frankf. I 7 I . 8 \%。

Peier Mericologia, feu de Ruminantibus. Bafil. 5685.4 to.

Petiver ( $g a c o b)$ Mufeum. Lond. 1695:

Gazophylacii Nat. \& Artis decad. X. Lond. I. I 3!

Plantar. Itallize Marinarum \&c. Icones \& Nomina: Lond. I 7 I5. fol.

Pterigraphia Americ. I's I2:

Pbilofopbie (die Naturlicbe) won Verwandlung der Metalle: Drefsd. I 724, 8vio:

Pifonis (Guilielmi) de Indix Utriusque re Naturali. Amft. 1658. fol.

Planci ( $G a n i)$ de Conchis minus notis Libel. Venetiis 1 \%38. fol.

Plinii (Secundi) Hiftoria Naturalis. Hagenox: I518. Francof. ad Moen. I582: Colon. Allobrog I 6 I 5. fol. Venet. I $530.8 \mathrm{vo}$

Ploucquet (Godofr.) de Corp. Organ. Generatione. Stutg. 1749. 4to.

Plucknet (Leonard) Phytographia: Lond. I69 I. 92. fol.

Pomet Hiftoire Générale des Drogues. Paris 1694. fol.

Pontoppidans (Ericb) Verfuch einer naturlicben Hiftorie won Norwegen, Koppenbag. I 752. E2. 8vo

Potter Thierbuch. I 664.

Pretorius de Elephanto. Hamb. 1601. 8vo: 
Rallius (Georg. Fried.) de Generatione Animalium. Stetini. I 2mo.

Raji ( Fob.) Hiftoria Infectorum. Lond. I 7 10. 4 to.

- Synopfis Methodica Animalium. Quadrup. \& Serpentini generis. Lond. I693. 8vo. Synopf. \&c. Avium \& Pifcium. Lond. I 703. 8vo.

Recumur, Memoires pour fervir à l'Hiftoire des Infectes. Paris I 734. 4to.

Recueil des Voyages au Nord. Amft. I 73 I. I 2mo.

- C de la Compagnie des Ind. Orient. Rouën I725. I 2mo:

Redi (Francifci) Experim. circa generationem Infectorum. Amft. I671: I 2 mo.

Experim. circa varias res naturales, quæ ex Indiis afferuntur. Amit. I685. I $2 \mathrm{mo}$.

Regenfuls (Frans Mich.) Aufferlefene Scbnecken und Murcheln Ẽc. Koperbag. I 75 . fols

Reiske ( $f 0 b_{.}$) de Gloffopetris Luneb. Leipzig I 684. 4to.

Ritteri (Alb.) de Zoolitho dendroidis. Guelph. I736. 4 to.

de Itinere in Herciniæ Montem Bructerum: Guelph. I $740:$ 4to:

Roefel (Aug. Foh.) Infecten-Beluffigung. Nurnb. I 746. Eंc. 4to.

Rocbefort Hift. Nat. des Antilles. Rott. I 665. 8vo.

Robr ( $g u l$. Bernh. v.) Merkwurdigkeiten des Overbarzes. 8vo.

Rondeletii (Guilielmi) Libri de Pircibus marinis. Lugd. I 553. fol'

Univer. Aquatilium Hiftorix. Lugd. 1555 . fol.

Roque (de la) Voyage de Syrie \& du Mont Liban. Amf. I $723.8 \mathrm{vo:}$

Voyage dans la Paléftine. Amft. I乌ı8. I $2 m 0$.

Ruell ( $F 0 a n$ ) de Natura Stirpium. Baf. I 537 . fol.

Rumph (G. Everbard) Herbarium Amboinenfe. Amft. I 750. fol.

Amboinfche Rarieteytkamer. Amft. 1705. fol.

Amboinifche Rariteitenkammer von Scbnecken und Mufcheln, mit Sufaken von Gob.

Pier. Cbemnit/s. Wien. I 766. fol.

Ruyfcbii Theatrum omnium Animalium. Amft. I 7 I 8:

Opera. Amft. I $737 \cdot 4$ to. 


\section{$\mathrm{S}$}

Sacble (Pbilipp. Gacob) Gammaroitum vulgo Cancrorum confideratio. Francf. I 665. 8vos

Sammlungen (Franckifche) aus der Naturlebre, enz. Nurnb: I 755. enz: 8vo.

Sartorius (Goannis) de Anima Brutorum. Witteb. I680. 4to.

Scbaffer, (Fac. Cbrift.) vön den Polypen. Regensb. I 754. I 755. 4to.

Scheffers, Lapland. Frankf. I $675 \cdot 4 t 0$.

Scbeucbzer, (Fob. Gac.) Phyfica Sacra, Aug. Vindel. I 73 I. \&c. fol.

Hiftoria Naturalis Helvetix. Zurch I 7 I 6.4 to.

Scbmidelii, (C. C.) Ests-Stuffen und Berg-Arten. Nurnb. I 753 . 4 to.

Scholtz (Fob. Friedr.) von der Selenwanderung bey den Thieren. Helmat. I 753.8 ro.

Theorie von den Naturlicben Trieben. Halle I755. 8 vo.

Scbotti ( Casp. ) Phyfica curiofa. Herbip. I662. 4 to.

Scoti, Hift. Anim. fol.

- Rerum Natural. Perfcrutat. Francof. 1615. I2mo:

Scbrvenkfeld; Theriotropheum. fol.

Scba, (Alb.) Locupletiffimus Rerum Naturalium Thefaurus. Amft. I 734 . \&c. fol.

Seligmann, ( Gob. Micb.) Sammlung verfcbiedener Auslandifcber und Jeltener Vogel. Nurnb. I749. fol. feltener Vogel von Catesby und Edruard I 755 . fol.

Sellii (G.) Hiftoria Naturalis Teredinis Marini. Traj.ad Rhen. I733. 4to.

Sermertus (Dan.) de Origine Animarum in Brutis, in Operib. Lugd. $1650 . \mathrm{fol}_{3}$

Severini (Marc. Aurelii) Diatribe de Refpiratione Pifcium. Amft. I 66r. fol.

Vipera Pythia, five de Viperis. Patavii I 65 I. 4 to.

Zootomia. Nor. I 645. 4 to.

Sbazu Voyages dans pluf. Prov. de la Barbarie \& dü Levant. à la Haye I 743.4 to.

Sibbold (Robb.) Scotia Illuftr. Edimb. I684. fol.

Sloane Voyages to Jamaica.

Smidt ( Joban Gacab) Bybelfche Phyficus. Dordregt en Amfteldam I 768.

Spectacle (le) de la Nature. à Utrecht I 73 б. \&x. 8vo.

Siellers (G. Wilh.) Befchreibung won fonderbaren IMeertbieren: Halle I $753.8 \mathrm{Vo}$. 


\section{ALPHABETISCHE LYST DER AUTHEUREN.}

Stobci (Kiliani) opufcula. Dant. I 752.4 to.

Syfteme Naturel du Regne Animal fuivant Mrf. Kléin, Limmeus \& Artecli , par M. D. L. C. D. B. à Paris I $754.8 \mathrm{vo}$

Swcmmerdan, ( $\left.90 b^{\circ}\right)$ Bybel der Natuur. Leyden $173 \%$. en 1738.

Swedenborgii (Eman.) Opera Philofophica \& Mineralia. Dresd. \& Lipr. I 734 . fol.

Mifcell, Obfervata circa res Naturales. Lipr. 1.722. 8 vo.

\section{T.}

Tacbard Reife nacb Siam. Hamb. I 709. 8 vo.

Taverniers ( $\%$ B. ) Reizen. Amfteldam I 682.4 to.

Tertre (du) Hift. Nat. des Antilles.

Thefoum Imaginum Pifcium. Teftac. \&c. Lugd. Batav. 17 I 1: fol.

Theopbrafi Paracelfs opera omnia. Genev. $165^{8}$. fol:

Tilas (Dan.) Scbwedifche Mineralbiforie. Leips. I $76 \%$ 8vo:

Torrubia ( 905 .) Aparato para la Hiftoria Natural Efparnola. Madrid $17540^{\circ}$ fol.

Tournefort, Reize na de Levant. 4to. Amft. I $737^{\circ}$

Tranfactions Philofophiques de la Societé Royale de Londres. Paris 1740.4 to.

Transformation Métallique. Lion 1618.3 vo.

Trembley (Abr.) Memoires pour fervir a l'Hiftoire d'un gendre de Polypes \&rc. Leyde $\mathbf{1} 744$. 4 to.

Tirneri Hiftor. Prrecipuarum avium I 544:

Turgot Memoire inftructive fur la manière de raffembler, de préparer, de conferver, \& d'envoyer les diverfes curiofités d'Hiftoire Naturelle. À Lyon I75 I. 8vo.

Ty/on Tajacu, feu aper Mofchif. Mexic.

\section{V.}

Valentini (Mich. Bernb.) Hiftoria Simplicium reformata. Francof. ad Moen. 1716 . fol.

India Literata. ibid.

Mufeum Mufeorum. Franckf. I ? I 4. fol.

Amphitheatrum Zootomicum: Francof: 1720: fol. 
Valentya (Francifc.) Verhandeling der Zeehoornkens, dienende tot een Vervolg op Rumphius. Amft. I 754 . fol.

Venette, (Nicol.) Traite des Pierres dans les Terres \& Animaux. Amft. I zo 1. 3vio:

Verfuch einer Befcbreibung des allerfchonflen Vogels Colibrit. Lub. I 754. 4 to.

und Abbandlungen der Naturforfcbenden Gezellfchaft in Danis I 752 enz. 4.to.

Veraldanio, (Bacon. de) Opera. Francof, ad Moen. I 665 . fol.

Vogel (Rud. Auguffin) Practifches IMineralfyftem. Leips. I762. 3v0.

Vosmar, Algemeen Natuurk. en Hift. Befchryving der zeldzaamfte Schepzelen in het Cabinet en Diergardet van Zyne D. L. H. den Prins Erfftadhouder. Amft. I 766.

Urfarus Mifcell, de Avibus biblicis I 656. 8vo.

\section{W.}

Wagrzer" (Pet. Chrift.) Befchreibung des Hocbfurflichen Bayreutifchen Naturalien-Cabinets I 752. enz. fol. 8vo Ilerausgabers.

Walcb. ( $\%$. E. $\mathcal{F}_{0}$ ) Steinreich.

Befcbreibung des Kroorrifcbet Steinwerks, Bekannt unter dent titel: Lapid. diluvii univert, teftes. fol.

Wallerius, (Gob. Gottchatck) Mineraireicb: Berlin 1763.800.

Walpurger ( 90 b. Gottl.) Cofnotbeologifche Betracbtungen。 Chemniti I748. 4to.

Watbonizs (Micb.) Theattum variar. Rerum. Bremæ. I663. Svo.

Experiences \& Obfervations pour fervir à l'explication de la Nature. à Paris I 748.8 ro,

Willugbby (Franc.) Ornithologia. Lond. 1676. fol.

Willis (Thom.) de Anima Brutorum. Lond. I672. 4to.

Woltersdorff, (Goh. Luc.) Mineral. Syftem. Berlin I 748. 4to.

Wormius (Ol.) Hift. Anim. Norweg. Hafn. I 653.4 to.

Mufeum Wormianum. Lugd. Bat. I 655. fol.

Woyts $\left(\xi \wp_{0}\right)$ Schatkamer der Droogbereidende Geneeskonft. 4to. Amft. I 768 . 


\section{$Z$.}

Zabareila ( $F a c$. ) de Rebus Naturalibus Lib. XXX. Francof. I 6 I \% 4 to.

Zanicbelli ( $\mathfrak{F}_{0} b_{.} . \mathcal{F} a c_{0}$ ) de Myriophyllo Pelagico. Venez. I 7 I 4.8 vo.

Zinani de Ovis \& Nidis Avium. Venet. I 737.4 to.

Zoomorpbofe, (la) ou Repréfentation des Animaux vivans qui habitent les Coquilles. à Paris I 75 7. 4to.

Zorn, (Fob. Heinr.) Petinotheologia. Pappenb. I 742 . und Scbrwab. I 753 . 3 vo.

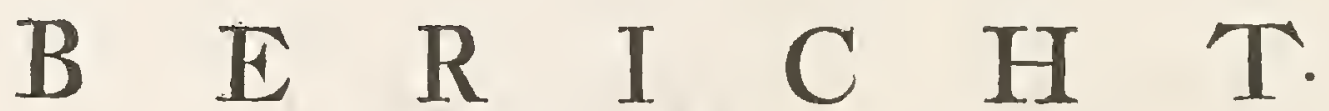

De voorfcbreve Nadmlyft bebelft alieens bet voornamfte gedeelte dier Scbryveren, welke bet geene in dit Werk voorkomt verbandelt bebben, andere Scbriften, welke of zeer kort waren, of alleen by geval over bet een of ander gedeelie der Natuurlyke Hiftorie bandelden, bebben wy om de kortbeid te betracbten'er afgelaten, gelyk ook verfcbeide Differtationes, Catalogen of diergelyke overgefagen zyn, als bebelzende zomtyds maar eenige zaaken die ter opbeldering nodig waren, veele daar en tegen zyn'er nog overig die wy niet by de band gebad bebben on ons daar van te bedienen, dat egter voor 't overige byna alle de Scbryvers, welke de Kinidkunde, de Verfteesingen en enkele Steenen bebandeld bebben en waar van een groot a antal is, in de voor $/ 2$. Nacmlyft niet gevonden worden, zulks zal een ieder ligt willen verfcboonen, ondat wy in dit Werk geen gelegenbeid gebal bebben on over dit wydloopig Deel der Natuurlyke Hiflorie te bandelen.

- Intuffchen zo weinig als alle de in de voorfz. Naambyf aangebalde Autbeuren met den anderen overeenfernmen, zo weinig bebben wy ook by dezelven de nodige opbelderingen kunnen vinden, omdat geene, 't welk zy adn de band gaven, ons by onzen arbeid ten mutte te kunnen maaken, of wy ecbter in de uitkiezing van verfcheiden narigten, Befcbryvingen en Benamingen gehukig gefangd zyn, laten wy den gunftigen Leezer beoordeelen, $\approx 00$ veel is watr, dat de vergelyking van verfcheidene Naturalien cener Claffe, welke onze verzadmelplats ons opleeverd; gelyk ook de correfpondentie en onderbandelingen met welke Hoog - gefcbatte Vrienden en Begunftigers ons vereerd bebben, in eenige twyffelogtige gevallen, ons bet meefe licbt bygezet bebben: Alle nieuwere Autbeuren vain dese Eeuw, waaronder de voortreffelyken Syftematici, en die geene wier Werken met geillhmineerde Plac. ten bet licht wien, verdienen over 't algemeen den voorrang, tot welken wy ook zeer veele enkele Leaenswardige Verbandelingen wan de Mastfcbappyen der Wetenfcbappen reekenen, en daar deze bereids bet beffe der oude Autbeuren in bet dagligt geftelt bebben, zo konnen veele Liefbebbers, welke geene gelegenbeid bebben om in de wydloopige Naturngebeimen in te dringen, de oude des te gemakkelyker te ontbeeren, quanneer ay bet vaortreffelykifte der nientue bezitten. 


\section{O O R R E D E.}

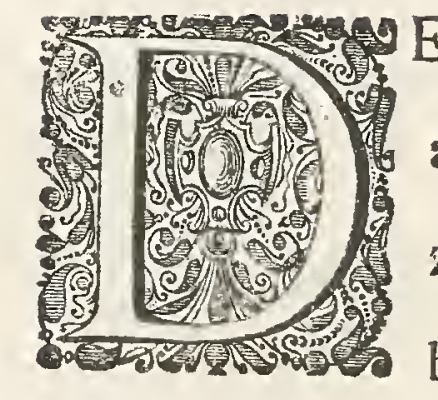

$E$ fraaifte en koftbaarfte dingen in de Weereld verliezen in 't algemeen veel van hunne waardy en anzien, wanneer men ze niet naar behooren fchikt, of zodanig plaatft, toebereid en bewaard, dat derzelver fchoonheid op de beft mogelykfte wyze voor het oog zig vertoont: en dus is het ook in het byzonder met de natuurlyke Zeldzaamheden gelegen. Men moet aan dezelve eere aandoen, ze met oordeel toebereiden, zorgvuldig voor het verderf bewaaren, en tot een vernuftig oogmerk gebruiken, wanneer zy in hunne natuurlyke pragt verfchynen, het oog van den Liefhebber ftreelen, en zyn gemoed vermaaken zullen. En in der daad, zy verdienen het ook, dat men hun decze agtinge toedraagt, wordende de Natuur door haare heerlyke Werkingen voor een ieder vernuftig Menfch altoos eerwaardig. Behalven dit alles zyn ook die fraaije Natuurftukken, die zoo meefterlyk uitgewrogt zyn, moejelyk te bekomen, en moeten veeltyds met grooten arbeid en koften verkreegen worden: Men is dus ook verpligt ze hoog te fchatten. Ondertuffchen is de fmaak en de zorgvuldigheid der Liefhebbers omtrent dit ftuk niet altyd overeenftemmende, ja zelfs vind men Verzamelaars, die het met zig zelve niet eens zyn, hoe zy hunne Natuurlyke Zeldzaamheden plaatzen, leggen of fchikken zullen, als onkundig zynde, in wellke ordre ze te fcharen, door welke middelen voor het bederf te bewaaren, of hoe die, wanneer ze door toeval een zonderling aanzien verkregen hebben, op te çieren en in een Natuurlyke Pragt te fteken zyn. Mogelyk zullen wy hicrom aan eenige Liefhebbers geen klynen dienft doen, wanneer wy thans het 
een en ander VAN DE WY⿱宀匕 dien wy in de Voorreede tot het Eerfte Deel reeds iets van de Ziwaarigbeeden angehaald hebben, die men by bet Veraamelen van een Kabinet ontmoet.

Om dan van de fchikkinge der Kabinetten eerft te fpreeken, zullen wy eenige Vragpunten ontwerpen, welke ieder afzonderlyk een nader onderzoek en beantwoordinge waardig zyn.

I.) Naar welk zamenftel zal men de Zeldzaamheden der Natuur fchikken?

2.) In welke Kaften en Laaden moet men ze leggen of plaatzen?

3.) Hoe heeft men ze door de hand der Konftenaren op te çieren, om haare innerlyke fchoonheit voor den dag te brengen of te verheffen?

4.) Waarop ftaat een Verzamelaar te letten, als hy ze onbefchadigt behouden en voor het bederf bewaaren wil?

5.) Welk is het vernuftig gebruik van een Kabinet, en wartoe konnen de Verzamelingen dienen?

Deeze vraagen zyn te minder met een onverfchillig oog an te zien, om dat de verlegenheit van veele Verzamelaars in dit ftuk, en hunne tegenftrydige handelwyze mar al te wel hekend zyn. Wy zyn 'er ver af om te geloven, dat alle het geene wy op deeze Vraagpunten ftaan te antwoorden onfeilbaar en gantfchelyk voldoende zal zýn, of dat juift alle Verzamelaars naar ons Ontwerp zig fchikken zullen, want ieder Menfch heeft by deeze meenigvuldigheid van zaaken zyn eigen zin, oogmerk en fmaak; dog wy vermoeden, dat wy voor de zulken, die eerft beginnen Verzamelingen te maaken, geen geheel onnutte Aanmerkingen zullen opgeeven, en zullen derhalve ook tot de vrymoedige Beantwoordinge der geopperde Vraagftukken overgaan.

I.) Naar welk Samenftel dan wal men de Zeldzaanibeden der Naturur fcbikken? Men vind veele Liefhebbers die van hunne Verzamelingen niet dan een bonten Regel maaken, en de Zeldzaamheden van alle Gellagten en Soorten 


\section{$V O O \quad O \quad R \quad R \quad E \quad D \quad E$.}

wonderbarlyk onder een haspelen. Eenige deezer Liefhebbers hebben geen het minfte begrip van eenige verdeelinge of orde, zy vermaaken zig flegts met alles wat blinkt en glinftert en in het oog ftraalt, of wat maar cene zeld. zaame gedaante heeft, en zyn daar mede vergenoegt, dat zy dic dingen tot pronk ergens heen ftellen of leggen. De zulken bekommeren 'er zig weinig over, of de ftukken egt zyn, of niet, zy verwonderen zig over een ftuk, dat de handvan de eene of andere Konftenaar naar ecn valfche cygendun. kelykheit verandert, en verbafterd heeft, even zo, als of het van Natuuic dus gebeeld ware, en zyn bygelovig genoeg om de belaggelykfte geftaltens der dingen voor een arbeid van de verborgene Natuur aan te zien. Zelfs het woord RARITEIT of zeldzaamheit alleen is bekwaam, zulke Lieden zo danig te betoveren, dat zy een fteen, war eene vernuftige hand met. fterk water een vreeslyk Hellen-Aangezigt opgeëtzt heeft, veel hooger fchatten als een Goudklomp van een foortgelyke zwaarte (a). Het eenigfte, wat

deeze

(a) Een Liefhebber, willende zig eens van eenen bedorven Orbis Spinofius of Stekelvis ontilaan; gaf dien tegen iets anders aan een Onkundigen Verzamelaar. Deeze lapte den Vis met gedroogde Palingvellen , en ftak "er de Stekels van een Hiftrix of Stekel Zwyn in, vervolgens gaf hy aan den Vis een paar Uyls Oogen, en maakte een zeldzaame lange Snavel daaraan, het geen hy met zo veel kunft wift te doen, då hy die het niet naauwkeurig befchouwde; de voegen en de famenlappingen niet zien kon. Het gerugt van deezen zeldzaamen Vis kwam ras ter ooren van een ander niet minder onkundigen Verzamelaar, die met gec‘ weld en onbefuift verzamelde. Deeze liet den Bezitter geen ruft, maar kogt van hem dien Vilch voor een ongeloovelyke Somme Gelds. Een ander die een kenner was, en reeds van verre dit fiuk voor een valfch maakzel anzag, bood den nieuwen Bezitter uit Joks tweemaal zoo veel daar voor, zyn Goudbeurs uithaalende, en zig houdende als of hy dadelyk het Geld hem toe tellen wilde. De Bezitter zag dir Bod voor "ernft aan, maar was egter niet te beweegen om zyn zeldzam Gedrogt daar voor te geven.

Een ander kogt uit een Natuur Kabinet eenen bedorven Struisvogel, die geen vederen meer had. Ity nam hierom de vederen van verfcheidene Goud- en Zilverlakenfche Hoenderen en bedekte den Struisvogel zeer konftig daar mede met afwiffelende ftreepen gelyk de Kaapfe Ezel of Zebra, en tot meerder fieraad gaf hy aan dien Vogel een fraaije Pauwertaart. Het was nauwelylss gefchied, of 'er kwam een yverige Ver - 
deeze Liefhebbers fchikken noemen, is, dat zy hunne zaaken, waar van haar zelden zelfs de blote naamen bekend zyn, in Laadjes op Wolle, of in Kasjes volgens zeekere Figuuren leggen, en de Regels alzo buigen, dat ze Roofen, Ringen, Hartjes of dergelyke verbeelden $(b)$.

Andere Verzamelaars integendeel kennen het famenftel der Natuurlyke Hiftorie zeer wel, en zyn gantfch geen Vreemdelingen in deeze Weetenfchap. Zy zyn gewoon ook hier om eenige Hoofdverdeelingen te makken, namentlyk zodanige ftukken, die tot een Klaffe behooren, by elkanderen te leggen, dog voor het overige beminnen zy een Bonte Regel, en mengen de Geflagten, Soorten en Onderfoorten geheel onder malkanderen, zo als het de plaats ter invullinge en de gedaante der ftukken toelaat. Zy verdedigen namentlyk deeze handelwyze daar mede, dat de verandering beter aan het oog behaagt, en wy hebben in dit geval tegens de aangehaalde

reden

zamelaar opdagen, die deezen raaren Struisvogel, dergelyke hy nooit nog in Prent gezien had, voor een groote Somme inkogt.

Het is bekend hoe de Italiaaners van den Raja of Rogvis allerhande gedrogten maaken, als Draaken, Duivels, Monnikken, en meer andere gedaantens. Wy hebben een kapitaale Tak Bloedkoraal gezien, die by nader onderzoek uit enkel Zegellak beftond, en buiten gemeen cierlyk en konftig in een vorm naa een oorfpronkelyke Tak gegoten was, en den beften Liefhebber zoude hebben kunnen bedriegen. Desgelyks een Witte Koraal-Tak, die als een Tak van Rood-Koral was, dien men met Wafch uitgekookt en van de kleur beroofd had. Zo vind men ook een meenigte nagemaakte Petrefacten, uit Florentynfch Marmer, waarin de indrukzels door Sterkwater zyn te wege gebragt, en hoe veel nieuwe Zoorten van Hoorns en Schulpen heeft niet de Kunft van Polyften uitgedagt?

(b) Deeze wyze van Schikkinge komt ons tamelyk Popagtig voor, ẹn heeft zeer veel overeenkomft met de wyze op welke de Vrouwen hare Porcelynkaffen gewoonlyk oppronken, zy verraad doorgaans de onkunde der Bezitters, die geen bezef van de Geflagten en Ondergeflagten der Schepzelen hebben, en by de befchouwinge der Natuur niet veel meer denken, als de Kinderen by hun verfchillend Speelgoed. Een fchikkinge egter, die, zedert dat de kenniffe der Natuur meer gevordert is, tamelyk uit de mode raakt, en alleen maar van de Minwetende onderhouden word. 


\section{$\begin{array}{llllllll}V & \mathrm{O} & \mathrm{O} & \mathrm{R} & \mathrm{R} & \mathrm{E} & \mathrm{D} & \mathrm{E}\end{array}$}

reden niets in te brengen, wanneer iemand zyne Verzameling voornamentlyk maar fchikt, om aan het oog te voldoen, en geenzints het oogmerk heeft, eene volledige en naar het zamenftel der Natuur gefchikte Verzame. ling te bezitten, waar in de ftukken als in een keten op elkander volgen. Wy moeten zelf bekennen, dat de Plaaten, die in dit Werk voorkomen, alleenig maar naar dien fmakk ingerigt zyn, on door de geftadige verandering en afwiffeling het oog te vermaken; want hadden wy de Afbeeldingen naatr een żamenftel willen fchikken, zo hadden wy het gemeene en bekende zo wel moeten laten aftekenen, als de dingen die minder bekend zyn, en dit zoude dan een zo weidlopig Werk hebben moeten worden, dat eens Menfchen leeven, en het bepaald vermogen van byzondere Uitgevers niet tocrykende zouden zyn, om zulks uit te voeren, of zodanig een Werk zig magtig te maken.

Steld men ondertuffchen de verluftiging van het oog alleen maar als ecn oogmerk van Verzameling, dan verlieżen veele zaaken haar regt, om in de Kabinetten bewaard te worden, want in dit geval word altyd uitgemonsterd wat gemeen of bekend is, of geen byzonder ànzien heeft, fchoon het, gelyk veeltyds gebeurd, zeer zeldzame en wonderbaare ftukken mogten zyn, en men is te vreeden met flegts uit Befchryvingen of Prenten te weeten, dat 'er zulke zaaken in de Natuur gevonden worden.

Van deze beide manieren om Verzamelingen te maken is thans ons oonmerk niet om te fpreeken, want wy hebben zudilken Kabinetten niet in het oog, die uit eene mengeling van zeldzaame of fraaije zaaken beftan, en zonder kenniffe verzameld ofte bewaard worden, ook niet zodanige, die flegts voor de pronk dienen moeten, en daar men niet eens eene enkelde Bende van Schepzelen zoekt by elkander te hebben, maar wy fpreeken van zulke, daar men ten minfte in ech Vak alles by elkander verzameld, wat tot dat Vak behoord, voor zo verre het te krygen is, om niet alleen het oog door de menigvuldigheid te vermaken, mar ook het verftand met de 


\section{VI $\quad V \quad O \quad O \quad R \quad R \quad E \quad D E$.}

overweginge en nafpooringen van den Oorfprong, Bouwaart, Afwykinge en Oogmerk der gefchapene zaaken beezig te houden.

Het is by gevolg nodig, dat een Verzamelaar kennis heeft van de Natuur, en van haare maniere om te werken, en van hare wyze, om de dingen voor den dag te brengen, onderregt zy. Hy moet de Wetten weeten, naar welke de Natuur werkt, hy moet de trappen kennen, die de Natuur gemeenlyk waarneemt, wanneer zy van de eene werking tot de andere overgaat, Hy moet uit veele waarnemingen geleerd hebben, dat de Natuur niets gewoon is over te flaan. Hy moet de oogmerken, die de Natuur by de vorming van de Schepzelen heeft, onderzoeken, en zulks zal hem in ftat ftellen, om te kunnen beoordeelen, waarom een zaak deeze en geene andere gedaante of geftalte heeft. Hy zal zo doende beginnen eenige Hoofdregelen en Wetten in de Natuur te ontdekken, en door deze ontdekkinge zal hy gelegenheid hebben gewaar te worden, welke Ligchamen in de Waereld tot eenderly oogmerk gemaakt, of naar een en dezelfde Wet geformeerd zyn, en dit zal hem eindelyk in ftaat ftellen het groote Heiër der Schepzelen in Rangen, Benden, Klaffen, Gellagten, Zoorten, Onderzoorten en Afwykingen af te deelen, naar welken Regel hy dat weinige, wat hy 'er van bezit, in een natuurlyke ordre en fchikkinge zal konnen plaatfen.

Het ontbreekt in deezen opzigte geenzints aan voomame Voorgangeren, met welker Boeken en Schriften een Liefhebber raadpleegen kan. Zommige derzelver hebben den Oorfprong en de Eigenfchappen der Ligchaamen onderzogt en andere hebben zig llegts benaarftigd, dezelve in een zekere ordre te fchikken; en de eene is hier in gelukkiger geweef als den andere. In dit geval moeten wy aan den Ridder Linncus den voorrang laaten, wiens groot zamenfel der Natuur door de geheele geletterde Wereld een algemeenen roem behaald heeft, niet tegenftaande tegens verfcheide zyner Rangfchikkingen van andere, niet minder geleerde, Natuur onderzoekers, groote twyffelingen zyn geopperd, en veele ftellingen tegengefprooken worden. 


\section{$\begin{array}{llllllll}V & O & O & R & R & E & D & E\end{array}$}

Terwyl wy egter nog zo gelukkig niet zyn om het Mineraalryk van deezen Schryver by zyn groot zamenftel gevoegd te zien (c) zo kan het zamenftel van Wallerius voor alle andere zamenftelzels dienen, voor zo verre men de Klafjfikatie en Rangfchikkinge der fukken in een Kabinet beoogt.

Ondertuffchen openbaard zig voor beginnende Liefhebbers terftond een groote zwaarigheid, dat zy namentlyk de korte fchryfwyze van den beroem. den Limneus niet zo ligt of zo fchielyk verftaan, weshalve zy geraaden vin: den, andere bekende Schryveren ter hulpe te neemen, die eenig zamenftel van de een of andere Rangfchikkingen der Schepzelen uitgegeven hebben, en de Naamlyften der Boeken, die in jegelyks handen zyn, kunnen reeds genoeg aantoonen, wat Jonston; Aldrovandus, Gesner, Rumpir, Seba, Klein, Marsigly, Ellis, Lesser, Vogeì, Woltersdorf, Walci, Halle en meer andere $(d)$ in het ligt gegeven hebben. Door behulp vain deeze Schryvers kan men ligtelyk zien, hoedanig men de Natuur ftukken żal kun. nen fchikken, fchoon het niet te lochenen is, dat deze Schryvers geenzints met elkander overeenftemmen, door dien een jegelyk de Geflagten uit cen verfchillend oogpunt befchouwt, en daarnaa de Rangfchikkingen ingerigt heeft.

Ori:

(c) Zederd de Uitgaave van het Duitfche Werk is ook het derde Deel van Limaus zamenftel, handelende van de Mineralen, in het ligt gekomen, behoorende tot de twaalfde Uitgave van het zamenftel dct Natuur. In het zelve bevinden zig almede veele ftellingen, die nog groote twyfiel en onzeekerfeid onder. worpen $\mathrm{zyn}$, als by voorbeelt het plaatfen van de Kryftallen onder de Zouten en het verklaren van alle Kalk voor een dierlyk gewrogt, om van andere ftellingen niets te gewatagen; welker byzonderheid men dan het duidelykfte gewaar word, wanneer men een Mineraal Kabinet naar het zamenftel van deezen ver. maarden en in der daad grooten Natuuronderzoeker fchikt.

(d) Men mag hier onder reekenen de Mineraalkunde en het Woorden-Boek van Bomarei, en het geen de Nederlandfche bekwaame Natuur Onderzoekers gefchreeven hebben, zynde de Naamen van Growo-

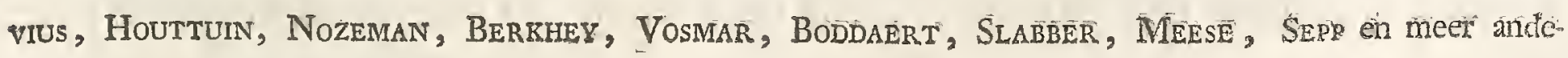
re, beroemd en bekend genoeg. 
Ondertuffchen kunnen wy niet onaangemerkt voorby laaten gaan, dat het geheel een andere zaak is, de Schepzelen in een Boek of op het Papier in een zekere ordre te fcharen, of die in een Vertrek en in Kabinetten ordentelyk te plaatzen. In een Boek kan men ze naar hare Natuurelyke merktekenen afdeelen, zo als ze volgens de Werkingen der Natuur op elkander moeten volgen, maar in een Kabinet laat zig dit nooit naar de ftrengfte regels doen, want men moet in het laatfte geval dikwils met de groote en het beloop der ftukken, als mede met de plaats, waar zy ftaan, of leggen zullen, en met de welvoeglykheid, die men ten opzigte van het uitterlyke oog cn aanzien in een Kabinet te overwegen heeft, te raade gaan. Dus paffen op het Papier een Rbinoceros en een Muis wel by elkander, maar in een Kabinet zoude zy niet gevoeglyk naaft elkander kunnen geplaatft worden. Een eenig onvormlyk ftuk, dat volgens zyn Aart en Natuur mede tot een meenigte fraaije en çierlyke ftukken behoord, zoude dikwils het aanzien van de fraaije ftukken verdonkeren, of ten minften altoos een aanftoot voor het oog zyn, als men het by de andere ftukken wilde laaten leggen. Wy zyn derhalve van gevoelen, dat men by de Rangfchilkinge van een Kabinet wel op cen zeker zamenftel te letten hecft, maar zig ook teffens van de vryheit bedienen moet, zo dikwils van de ftrenge regels eener Claffificatie af te wyken, als het uitterlyk aanzien der ftukken, en de hoedanigheid van de plaats, waar men ze leggen wil, zulks vereifcht. Het uitterlyke aanzien is in dit geval de befte Leermeeftereffe, om een oplettend Liefhebber te onderregten, welke zaken te zaamen paffen of niet, wanneer men maar de moeite neemt, de zaaken niet oppervlakkig, gelyk de meefte beginnende Liefhebbers gemeenlyk doen, maar met eenige naauwkeurigheid te befchouwen.

Terwyl nu de Natuur niet van boven af neederdaalt, maar van onderen opklimd, en niet eensklaps maar trapswyze ter volkomenheid overgaat, zo houden wy ook het daar voor, dat men 'er by de Rangfchikkinge van een Kabinet hoofdzaakelyk ook op letten moet om telkens van den onderften 


\section{$V \quad O \quad O \quad R \quad R \quad E \quad D \quad E$.}

trap af te beginnen, en zo tot fraijer en edelder ftukken over te gaan, op dat het Oog by het befchouwen van Kabinetten niet alleen altoos wat nieuws, maar ook altyd iets volkomeners en beeters te zien kryge. Wel is waar, dat dit tegens de Ordre aanloopt, die de meefte Schryvers in hunne Zamenftelfels waarneemen; meeft al van de befte Stukken beginnende, en dus tot de geringfte Voortbrengzels der Natuur nederdalende. Maar by de fchikking van een Kabinet behaagd ons die wyze daarom niet, dewyl het Oog, wanneer het terftond de befte en raarfte Stukken, die het meeft uitgewerkt zyn, te zien krygt, in de overige en minder keurige Stukken naderhand zo veel Vergenoegen niet vind, waaren tegen het zelve in het andere geval altoos by opklimminge iets fraajers te befchouwen, en zig daar over te verwonderen, heeft $(e)$.

Deeze Regel dan vind plaats, het zy iemarid flegts in een byzonder en enkel Vak verzameld, of dat hy een groot en uitgebreid Natuur-Kabinet by één brengd. Wy zyn derhalven vari gevoelen, dat men żo wel om de goede Ordre te onderhouden, als om het Oog beftendig met iets níeuws en beters te verluftigen, in een groot Kabinet de Rangfchikkinge der Natuullyke Zaaken op de volgende wyze behoorde te bepaalen.

(e) Deeze Rangfchikkinge van een Kabinet van onderen opklimmende diend, fchoon niet altoos, dog egter in veele gevallen tot Opheldering van de Trappen, naar, welke de Natuur werkt. Uit de Befchouwinge der meenigerley Zoorten van Zand, Aarde, Kley en Kryt, is het immers gemakkelyk op te klimmen tot de kennisfe van alle Steenen van den Muurfteen af tot aan den Diamant. De Zouten en Zwavel-Zoorten geeven een goede Grondflag om tot het Mineraal over te gaan, en de Vorming. der ruwe Klompen geeft Trapsgewyze de befte Opheldering tot de befchouwinge der byzondere Gewasfen in het Mineraal-Ryk. Wie zoude immers in ftaat zyn, die fraaije en byzonder geformeerde Stukken in het Mineraal te beoordeelen, die geen kennisfe van den Oorfpronk der ruwe Klompen had, en hoe zal men deeze beoordeelen zonder de beftanddeelen te kennen, war toe de Zwavel-Zoorten en Zouten benevens de Aarddeeltjes niet weinig uitleeveren? Wie eindelyk zal een Steen kunnen beoordeelen, die niet de minfte kennis van de Aarde heeft.

\section{DEEL。}


Men maake een begin met de gemeene Zoorten van Aardens $(f)$, en laate darr op de verfcheide Kleiagtige en Gezegelde Aarden, en dan de verfchillende zoorten van Zand volgen. Na deeze konde men de Drup-Steenen en Tophi, de gemeene Zand-en Rots-Steenen; de Kalk-Steenen en Marmers, en dat wel naar hun Vaderland; voorts de Gypfen, Spath, en Ley; dan de Kleijen, Kwartz en Kryftallen plaatfen; bekomende de Jafpis, Agaat, de ondoorfchynende, half-en geheel-doorfchynende Edel-Gefteentens tot den Diamant toe, een byzondere Plaats, gelyk mede de Glimmers, Talk-Steenen, Serpentin, en Asbeft by elkander geplaatft worden. Is dus de Bende van

(f) Wy verftaan onder de gemeene Aarde alle Zoorten, die doorgaans het Veld bedelken, en zonderel daar van de Metallägtige Aarde af, want zodanige Aarde behoord na de Zouten tot cen' iegelyk Metal gerekend te worden; waar van 'er Beftanddeeltjes in gevonden worden, als Yzeragtige Aarde by Yzer, Loothoudende Aarde by Loot, en zo verders. Maar mogelyk kon het iemand wonderlyk voorkomen, dat wy in een groot Kabinet ook eene Verzameling van gemeene Aarde veronderftellen, men zal misfchien vraagen: waar toe dog eene Verzameling van dergelyke dienen, alzoo aan gemeene Aarde, die overal in de geheele Wereld is, niets byzoniders of raars te zien is. Wy antwoorden, dat eene zulke Verzameling van groot nut is, en dat het iammer is, dat men daar op tot nog toe niet mecr vlyt heeft aangewend. Immers de Aarde is de Moeder van alles, wat daar op waft, en in de Aarde fteekt de Vrugtbaarheid der Zarken. Nu is 't bekend, dat niet alle Veld en Land, ook niet alle Landftreek een en dezelve Zaaken voorbrengt, want op de ecne plaats waft by voorbeeld goede Tabak, die cene andere nooit voortbrengt, in de ééne Grond komt het ééne Zoort van Hout beeter voort als het andere, en wy zien aan veele Uit. landfche Gewasfen, dat zy alleen maar eigen zyn, aan humne byzondere Landftreek. Wy fluiten hier het Klimat of de Lugtftreek geenzints uit, en weeten zeer wel, dat zulks een groot verfchil in het voortbrengen der Gewasfen geeft; maar gelooven teffens, dat de Gefteltenisfe van het Aardryk geen minder oorzaak van dat verfchil is. Dat blykt, om dat niet alle Planten uit zeekeren Lugtftreek, in alle die Landen voortkomen, die onder een en het zelfde Klimaat leggen. Ja men ziet by voorbeeld dat de Hop, de Mechrap, en veel honderd andere Zaaken op een plaats heerlyk wasfen, en maar weinig Mylen daar van daan geheel niet voortkomen. Wat is daar de Oorzaak van? Zekerlyk hecft de gefteldheid van het Aardryk de fehuld daar van. Wat zoude dus nutter kumnen zyn voor het Huyshoudelyke en de Koopmanfchap als een Onderzoek van alle mogelyke Aarden, welker Beftanddeelen men Scheikundig uitgevorfcht en met eene 
alle Steenen gedeeltelyk naar een vernuftig Zamenftel, en gedeeltelyk naar het uiterlyke aanzien gefchaard, dan kan men die Steenen laaten volgen, die maar een Speeling van de Natuur, (gelyk men gewoon is te fpreeken) opleeveren, als by voorbeeld byzonder geformeerde Kogels, Arend-Steenen, Boom-Steenen, en wat dar toe verder behoord. Op deeze behoorden de Verfteende Lichaamen uit het Dier- en Planten-Ryk te volgen, egter zo, dat zy niet door elkander gehaspelt worden; maar dat ieder Gellagt en Zoort by elkander geplaatft word. Na alle deeze Stukken makken eerft de Zouten het begin tot het Ryk der Metallen, men laat 'er de Zoorten van Zwavel

Onderrigting verzeld hadde, welk Gewas op die Aarde eigentlyk het befte waft, en hoe nuttig zoude ecn zodanig Kabinet zyn? Men moeft dan by voorbeeld van de Aarde die men elders van daan bekomt, de helft Scheikundig onderzoeken, en dit gedaan zynde de andere helft in een Glas in het Natuur-Kabinet bewaaren met het Berigt hoedanig de Beftanddeelen daar van bevonden $z y n$; en dus moet dan de Lyft daar van de volgende Befchryvinge behelzen. By voorbeeld:

Aarde van : : . . . in Virginiert inhoudende zo veel deelen doode Áarde, zo veel Salpeteri, zo veel Vitriool, zo veel Kley, zo vel Kalkagtige deelen, of Kryt, of Gyps enz., waar op weelde: rig en beft waft die, of die, Zoort van Tabak, enz-

Aarde van ..... in Ceylon houdende, enz. war op de Kaneel-Boomen groeijen.

Aarde $\operatorname{van} \ldots .$. in Meklenburg houdeade, enz. waar op de befte Hop waft.

Aarde van . . . . op Martinique houdende, enz. waar op dit of dat Zoort van Koffy-Boonen groeid. Aarde van ..... houdende, enz. waar op Dennen of Eyken, of Cederen, of Wynftok voordeelig wasfen, en zoo verder:

Dus zoude men uit de Vergelykinge van veele Zoorten van Aarden met hunne Beftanddeelen en Gewasfen in ftat zyn, beft te beoordeelen, welk Aardryk vereifcht word, om in een en het zelfde Klimaat zeeker uitheems Product met fucces voortebrengen, en welk nut zoude dit niet kunnen doen? want men is nu reeds volgens de Regelen van het Huyshoudelyke onderregt, hoedanig een Aarde toe te bereiden is, dat ze een zeeker Zoort van Beftanddeelen heeft; en bekwaam word, een bepaalt Gewas voort te brengen.

Zie daar een Nieuwe, Nuttige, en Leerzaame Beezigheid voor Verzamelaars van Natuurlyke Zaken, zullende die geene, die het weezentlyke Nut daar van bezeft, het niet meer voor ydel of belachelyk houden, dat men ools de gemeene Aarde verzameld. 
en Arzeniek op volgen, gaat zo tot de halve Metallen over, en van deeze tot de geheele Metallen, tot dat men den Rang in het Mineraal-Ryk met de Zilver en Goud-Stuffen befluit.

Het Ryk der Dieren fchynt voor het Oog in een Kabinet op het Mineraal-Ryk te moeten volgen. Het begin daar van kan onzes oordeels het beft gemaakt worden met eenige Schepzelen uit de Zee, als Zee-Starren, ZeeAppels, Hoorns en Schulpen, (die, wanneer het moogelyk is, by Paaren moeten geplaatft worden en ieder Gellagt by elkander, als by voorbeeld de Tooten byzonder, de Kink-hoorns byzonder, en zo verder, waar by het uitterlyk aanzien reeds, veel bepaald, welke Stukken tot een en het zelfde Geflagt behooren). Na de Hoorns en Schulpen laaten zig de gedroogde of opgevulde Visfen gevoeglykft vertoonen, (indien zy niet al te groot zyn,) dan de Kreeften, van welke men tot de Infecten en Vlinders overgaat, waar door men gevoegelyk op de Vogelen geleid word, die het beft naar hunne Bekken en Pooten konnen gefchikt worden.

Terwyl men ook een aanzienelyk gedeelte van de Half-llagtige Dieren of Amphybien in Glaazen met Spiritus bewaren moet; zo is het noodig, niet alleen alles, wat tot die Clasfen behoord; maar ook andere Zaaken, die men in Spiritus beward, by elkander te voegen. Wat de Viervoetige Dieren aanbelangt, zo moeten die naar hun Gebit afgedeeld worden, men plaats dezelve met en benevens de enkelde Deelen van de Dieren terftond na de halfflagtige, kunnende dan eindelyk den Trein van het Ryk der Dieren met cenige Geraamtens van Menfchen beflooten worden, agter welke men de Anatomifche Toebereidzelen zo drooge als die in Spiritus ftaan, laat volgen.

Van het Ryk der Dieren kan men tot dat der Planten overgaan, en daar tusfchen (naar het nieuwe en hedendaagfche Zamenftel) het Koraal plaatfen $(g)$, waar toe eerft het Punt-Koraal, dan het Sterre-Koraal, eindelyk

(g) Wy hebben deeze Rangfchikkinge verkoozen, niet om het nieuwe Zamenftel, dat namentlyk de 


\section{$V O O \quad \mathbb{R} \quad \mathbb{R} D E$}

de Hoorn-Koraal-Gewaften, Zee-Heefters en Spongies, als meede ZeeMofch, behoort, waarop men de Aard-Mofch en verder het geheele Ryk der Kruiden laat volgen, dat ten laatiten met de Verzameling van vireemde Vrugten, Gewaffen, Zaaden, en derzelver buisjes en huisjes naar hunne Geflagten en Zoorten bellooten word, kunnende dan eerft voor de, door 't Menfchelyke vernuft, toebereide zaaken, en Konftfukkèn, die men doorgaans ook in de Natuur Kabinetten vind, fchoon ze daar toe niet behooren, een plaatsje vergund worden.

Een jegelyk ziet wel, dat wy hier flegts de Namen van eenige Hoofdzadelyke Claffen opgenoemd en ons geenzints aan een ftrenge orde van een zeker zamenftel gebonden hebben. Des niet te min geloven wy; dat alles, over het geheel befchouwd, gevoegelyk onder deeze Hoofd-Claffen zal kunnen gefchikt worden, zoo dat jegelyke Claffe in het byzonder voor een nadere en bepaalde Rangfchikkinge volgens 't een of ander zamenftel vatbaar is. Zo veel is 'er ten minften van zeeker, dat wy by het dikwils befchouwen van verfcheide groote Kabinetten altoos gevonden hebben, dat die Rangfchikkinge, die wy zo eeven opgegeven hebben, altoos het meeft in de Oogen ftraalt, en den Aanfchouwer in eene geftadige verwondering onderhoud. Het ontbreekt ons ook geenzins aan goede gronden, waarmede wy deeze, anderzints tamelyk willekeurige Rangfchikkinge van een geheel Kabinet zouden kunnen regtvaardigen, fchoon ze met geen zamenftel van eenig Schryver overeenftemd. Ten minften komen naar deeze onze Rangfchikkinge altoos

Koralen Plantdieren zoudén zyn, daarméde te begunftigen, mar om dat het gevoeglyl fchynt te zyn, voor het oog van dien dewelke een Kabinet befchouwd, en van het een tot het andere overgaande in een zekere ordre egter nieuwe Vertooningen van Schepzelen ontmoet, want hoe verre wy nog daar van af zvn, om het Koraal als een middelweg tuffchen het Ryk der Dieren en Planten aan te zien, kan blyken uit het klein Tractaatje van ons kortelings onder deezen Tytel uitgegeven: Dubia Coralliorum Origini animali oppofata. Erlange I 7 \% . 4to. en 't welk eerlang in 't Nederduits zal het licht zien.

\section{DEEL.}


aitoos alle zaaken van een Hoofd-Claffe by elkander te ftaan, en men zal dus altyd in ftaat zyn, een ftuk, dat men verlangt te zien, terftond te konnen vinden, of te ontdekken, wat in een of ander vak nog in het Kabinet ontbreekt, of wat 'er dubbeld of overtollig is. Zulke Liefhebbers integendeel, die een bonte regel makken, bezitten veeltyds een en dezelve zaak meenigvuldig, zonder dat zy het weeten, alzo niet zelden in de eene laade wederom gevonden word, het geen reeds in een andere te zien was. Behalven dien ftaan ook zodanige Liefhebbers, (als zy groote Kabinetten bezitten ) altoos in het onzekere, of zy een of ander onder zoort hebben, dan of ze hun nog ontbreekt $(b)$.

Terwyl ondertufichen alles, wat wy tot hier toe gezegd hebben, nog niet alle omftandigheeden bepaald, die by de Rangfchikkinge van een Kabinet overwogen moeten worden, zoo gaan wy nu tot de beantwoordinge van de tweede Vragge over.

(b) Wy kunnen hier niet nalaaten eene kleine Aanmerkinge over het byeenbrengen van eenige Natuurftukken, by te voegen. 'Er zyn namentlyk veele Liefhebbers die zomtyds een en dezelve zaak veelvou. dig bezitten, en het lukt zomtyds den een of anderen zulke zaaken meervoudig magtig te worden die tegens andere ftukken gereekend, raar, en zeldzaam te bekomen zyn, terwyl een ander door de halve wereld bykans na dergelyke zoekt, en het nog door moeite nog geld magtig worden kan. Het wonderlykfte is, dat veeltyds de zulken, die een zaak twaalfmaal bezitter, nog door geld nog door andere zaaken, die men daar tegens aanbied, te beweegen zyn, een enkeld ftuk van hunnen overvloed tot aanvulling van een ander Kabinet af te geven. Dit komt by veelen uit een grilligen eigenzin voort, om juift iets te bezitten, en zulks wel meervoudig, dat andere geheel niet hebben, nog krygen kunnen. Dit zoort van eigenbaat en inhiaalentheid ftroolit niet met de pligt van mededeelzaamheid, die voornamentlyk by de Liefhebbery van de Natuurlyke Hiftorie plaats behoort te vinden, daar het zeker is, dat men een Kabinet zonder onderlinge hulpe niet voltallig krygen kan. Ten minften is het voor ons vry meer vergenoegen, wanneer wy eenige Vrienden, Bezitters van dezelfde zaaken, die wy overvloedig hebben, maken kunnen, als zelfs een zaak twaalfinal te bezitten, want ons oog word met veele gelyke ftulkken van een zoort niet meer verzadigt als met een paar, zelfs houden wy het geen wy enkeld hebben meer in eere en waarde, als het geen in meenigte voor ons legts 


\section{$\begin{array}{llllllllll}V & O & O & R & R & E & D & E & x V\end{array}$}

2.) In welke Kafen, Kabinetten, of Laaden, en op welke woyze wal men de Natunrlyke Zeldzambeden in een Vertrek platifen of leggen? Deeze Vragg laat zig niet regt bepaalen, alzoo dit van eenes jegelyks zinnelykheit en gelegenheid afhangt, egter kunnen wy eenige algemeene Aanmerkingen makken, daar van zig iemand bedienen kan, zo veel hy daar toe gelegenheid heeft, indien hy 'er fmaak in vind. Zommige Liefhebbers vinden geraden al haar zaaken in Doozen te doen, (gelyk veele de Vlinders en Infecten bewaren,) en op de Dekzels te fchryven wat 'er in is, dog het geftadig openen der Dekzels veroorzaakt veel moeite, en voor het oog geeft zullks geen vergenoegen. Want voor wien kan het angenaam zyn, zo veel Doozen beftendig open en toe te maaken? Andere in tegendeel vervalien op eene andere wyze die tegens de voorgaande regtftreeks overgefteld is. Zy breiden namentlyk alle hare zaaken op bloote Tafels jen opene Boekekiften uit, op datze in het oog vallen zullen; Maar ook deeze wyze is met twee zwaarigheden verzeld. Eensdeels, dat men de zaaken dus voor't ftof en voor een vog. tige en invretende Lugt niet bewaren kan, het geen, zo als wy naderhand aantoonen zullen, voor veele Naturalien ten uiterften fchaadelyk is, en ze van hunne aanzienelykheid berooft. Anderdeels word by veelen, die zodanige Kabinetten zien, de Nieuwsgierigheid te fchielyk 'en op eenmaal verzadigt; dewyl alle zaken te gelyk en op eenmaal in het oog vallen, want de Aanfchouwer ziet minder, als hy van regtswege zien moet, door dien zyn oog op eenige weinige uifftekende zaaken valt, en het andere overziet, het geen dog tegens het oogmerk van een Kabinet is. Wy geloveri over zulks, dat een Verzameling niet beter als in Kaften of Kabinetten met fchuiflaaden, of in Kiaften met glaaze deuren, waarin breede en fmalle planken leggen, kan geplaatt worden.

Wat de Kaften met fchuiflaaden aangaat, zo verftaan wy daar onder zulke, die op een voet ftaan met vier pooten, nieuwerwets als Harte of Reepooten uitgewerkt, en van den grond twee voet verheeveri, op dat de onderfte laade van de Kaft niet te laag kome, want om niet te fpreeken, dat 
het diep bukken by een groote Verzameling zeer onaangenaam en laftig is, zo heeft men ook aan te merken, dat het aan het oog hindert, de Natuurftukken zoo laag aan den grond te befchouwen. In het boveneind van deze voet kan men een eenige groote en geheel doorgaande laade met twee hengzels maken, die van binnen dieper is als alle boven laaden, ten einde daar in zodanige groote ftukken te plaatfen, die in de overige ondiepe laade niet gevoegelyk leggen kunnen. De Kaft zelve, die op deeze voet geplaatf word, beftaat uit twee langwerpige, op elkander geftelde, en wel op clkander fluitende Kaften, waar van yder een middelfchot en an yder zyde van dien zes laaden heeft, dus ieder der twee Kaften i2: en de geheele Kaft of Opftel 24. laaden in twee ryën heeft. De gantfche hoogte van de Kaft moet zo zyn, dat cen Perfoon van middelmatige groote gevoeglyk in de bovenfte laade zien kan, als men ze uithaald, zonder dat men nodig hebbe, de geheele laade uittetrekken, en om laag te houden. Ieder laade moet nict over de anderhalf voet lang, en twee voet breed $z y n$, en als elke laade op zig zelf drie duim diep is, dan zal alles gevoegelyk daarin konnen geplaatft worden. Worden in tegendeel de laaden dieper gemaakt, dan vinden I2. laaden in de bepaalde hoogte van de geheele Kaft met de voet daartoe gerekend geen plaats, behalven dat dan de kleine zaaken zig te veel verbergen en geen aanzien hebben, als zy in al te diepe laaden leggen. Veel eer kan men fomtyds de laaden vry ondiep onder drie duim laaten maaken, wanneer 'er vlakke en platte zaaken in de geheele Kaft zullen geplaatft worden, zoo dat 'er na vereifch der omftandigheden 18. tot 24. laaden boven elkander komen. Terwyl wy nu te vooren reeds aangetoond hebben, dat het beeter is, alle zaaken van een Zoort en Gellagt by elkander te leggen, waar door het veeltyds gebeurd, dat een plat ftuk en een verheeven ftuk by elkander moeten geplaatft worden, zoo kunnen wy 'er onze toeftemminge niet an geeven, wanneer de Liefhebbers in een Kaft laaden van verfchillende hoogte by wege van evenreedige vermindering ma- 
ken, om de groote ftukken onder, de kleindere in het midden, en̂ de platte fiukken in de bovenfte laaden te leggen. Want dit veroorzaakt, dat men die zaaken niet by elkander plaatfen kan, die dog by elkander behooren:

Wy hebben boven gezegd, dat decze Kaft uit twee langwerpige op elkarder ftaande Kaften moet beftaan, konnende in het midden afgeligt worder. Dit oordeelen wy deswegen goed te zyn, om, wanneer ieder langwerpige Kaft aan weerskanten een hengzel heeft, (gelyk de regiftratuur Kaften ín de Secretaryen, ) in tyd van brand of eenig gevaar dezelve en op die wyze een geheel Natuur-Kabinet gemakkelyk weg te dragen en te bergen, of te verhuizen is, zonder dat men noodig hebbe de Laaden uit te haalen of de Naturalien aan te raken. Eyndelyk kan men zodanig Kabinet of Kaft van boven plat laten, of 'er een Opftel van één twee- of drie Trappen opzetten, en in beide gevallen eenige groote ftukken, die geheel in geen laade gaan, 'er op plaatfen, om daardoor aan te toonen, welk zoort van Naturalien in zodanig Kabinet leggen. Edog kan men ook, indien de meenigte van groote ftukken zulks vereifcht, byzondere ftellagies daar toe vervaardigen, die in de Vertrekken of vry ftaan, in de gedaante van Piramiden, of tegen een ward leunen met het opfchik van een Turfche Tent, waarin twee, drie of meer boogsgewys uitgeholde planken leggen.

Wat de Glazekaften aanbelangt, zo fteld men dezelve, gelyk de voorgaande, op een zoortgelyken voet met twee doorgaande glaaze deuren, zynde van binnen of met planken belegd, of tegens den wand met verfcheide vaftgemaakte cardoezen, waarop men groote zaaken ftellen kan, voorzien; Het oog moet zelve de fchikkinge daarvan aan de hand geeven; gelyk het dan ook voorts van den fmaak en het vermogen van den Bezitter afhangt te beraamen, wat verder tot pragt en verfiering van alles vereifcht word. Want wy zouden onnodiger wyze wydlopig zyn, wanneer wy alle zinryke uitvindingen aanhaalen wilden, die men wel in Keizerlyke, Koninglyke en Vorftelyke Kabinetten ontmoet.

II. DEEL. 
Is men nu met goede Kaften en Kabinetten voorzien, zo is het wederom thict even eens, hoe men de zaaken in dezelve legt, maar men heeft ook hier nog op verfcheide omftandigheden te letten. Want gelyk het 'cr kaal uitziet, wanneer 'er te weinig ftukken in een laade leggen, zoo is ook cen al te groote meenigte van zaaken in eene laade voor het gezigt onaangenaam, dewyl het oog daar door in verwarringe geraakt, en de ftukken niet duidelyk in het gezigt vallen. De befte en fraaifte wyze is zonder twyffel, om deftukken, indien men het zo krygen kan, paar aan paar in egaale reegels te.plaatfen, zoo dat altyd twee gelyke ftukken by elkander, en ieder paar een weinig van het andere afgezondert komt te leggen. Deeze regels kunnen door laagen roode of groene lyftjes van elkander afgehouden werden, om het verfchuiven, by het uittrekken der laaden, te verhoeden, mar de geheele vlakte van den bodem word met Boomwoll, Zyde, Tryp, Fluweel, of Fluweel-Pluis overdekt. Terwyl ook de ftukken verfcheide koleuren hebben, zo vereifcht veeltyds ook de vlakte waarop zy komen te leg: gen een byzondere koleur, om het geen 'er op legt dies te beter te doen afftecken. Dus ftaan by voorbeeld Witte Natuurftukken frai op een Violet koleurde grond, Afchgraauwe ftaan goed op een Oranje koleurde, en fwarte ftukken worden op wit geplaatft, Geele zaaken op Hemelsblaauw, en zo verder, kunnende de Boomwol Watten, of wat men tot onderlaage gebruikt, daarna geverwt worden. Het zelfde vind ook by de Glaze-Kaften plaats, welkers wand met de vereifchte koleur gefchilderd word, om aan de zaaken, die'er in ftaan zullen, een aanzien te geven. Dus is de Witte en Roode koleur voor verfcheide zaaken goed, de Blaauwe voor Vogels, de fwarte, donkere of Violette koleur voor de Witte Koraalen en Zeegewasfen, ten minften hebben wy, indien ons onfe eigen fmaak niet bedriegd, in verfcheide gevallen gevonden, dat die wyze van fchikkinge fierlyk en aanrallig is.

Men heeft ook Naturalien, die uit enkel kleine brokken en koritjes beStaan. 


\section{$V O O \quad R \quad R \quad E \quad D \quad E$.}

ftaan. Het is daarom nodig, op een byzonder foort van bakjes of huisjes be. dagt te zyn, in welke men zulke zaaken leggen kan, om ze voor verftrooiinge te bewaaren. Zoo men hier toe geen vakjes van kaarte blaaden, bordpapier, of goudpapier verkieft, zo kan men ook de kleinfte foort van zuiker glasjes met wyde openingen alle van een groote daartoe neemen, wel. ke men toebind, en overzyde naif elkander in een laade legt, het geen zeer wel met de Verzameling van Aarden, of van Zaaden gefchieclen kan. De overige groote Natuurftukken, als Dieren en dergelyke worden, nar dat men 'er veel of weinig van by een heef, vry in het Vertrek geplaatf, of ook op en ter zyde van de Kabinetten gefteld, of aan den wand en zol. dering opgehangen.

By allen deze heeft men egter niet uit het oog te verliezen de zorge, om ieder fuk behoorlyk met zyn Nommer of Cyffer te voorzien, die vervolgens in een Catalogus overgedragen werd, alwaar men de Befchryving en het Vaderland van ieder fruk aangeteekend vind: $\mathrm{Nu}$ zoude het wel goed zyn, indien dit volgens het zamenftel van Limneus gefchieden konde, maa dit is geheel geen arbeid voor elk Liefhebber, want men diende byna in de Natuurlyke Hiftorie zelfs een Linnaus te zyn, indien men overal den Linnaus verftaan wil, want 'er word een byzondere Geeft toe vereifcht, zo veel byzondere Namen by een te fmelten en te verftaan, door dien men te ver. geefs met de Woordeboeken daar omtrent raadpleegen zal.

3.) Wat heeft de arbeidwaame Hand der Konftenaars aan de Natuirfulken te doen, om haare imnerlyke fchoonheid te onidekken en te verbeffen? Wy zyn 'er niet mede te vreeden, de Natuur alleen van buiten te betragten, wy verlangen ze ook van binnen te zien, en haare hoedanigheid te kennen. Terwyl evenwel de Natuur het befte van haare Kunft in de meefte gevallen op het Op. pervlak der Ligchamen ten toon ftelt, zo kunnen wy daar mede te vreeden zyn, vooral wanneer door de onderzoeking van de inwendige gefteldheid der zaaken, de uiterlyke Pragt en fchoonheid zoude bedorven worden. Men 


\section{$\begin{array}{lllllllll}X X & \mathrm{~V} & \mathrm{O} & \mathrm{O} & \mathrm{R} & \mathrm{R} & \mathrm{E} & \mathrm{D} & \mathrm{E}\end{array}$}

moet dús een onderfcheid maken tuffchen zaken; die door de Kunft opgeheldert, of die door dezelve bedorven worden, waar over wy thans eenige Aanmerkingen willen mede deelen.

De Soorten van Aarde en Zand hebben geene veridere toebereidinge no. dig, als dat men ze van vreemde deelen zuiverdi De enkelde Steenen vercifchen aan eene kant gepolyft te worden, wordende die vlakte gepolyft, die het gevoeglykft boven legt. Men kan ze in klompen behouden, of in vierkante blaadjes zagen, en in het laatfte geval zorgt men 'er voor, dat zy eenderly groote hebben, van boven gepolyft zyn, en van onderen in hunne ruwe gedaante blyven, om het oog dus daar aan te gewennen, dat men de Steenen in haare ruwe geftalte leert kennen, wanneer ze nog op het Veld leggen; of in de Steenbreuken fteeken. De zyde waar men de Steenen of Marmers wil gepolyft hebben; moet kundig en met oordeel aangetoont worden, want laat men dit in de keufe van de Steenfnyders, zo doen zy het zomtyds aan de onfchikkelykfte vlakte, zo dat men de ftukken dan nooit zodanig leggen kan, dat de gepolyfte zyde altoos regt boven op komt. Van de Edele Gefteentens tragt men altoos een ftuk ruw, en het andere gepolyft te hebben, en daar de uitgevonde Glas-Compofities van dezelfde koleur by te doen; om zo het egte van het onegte wel te leeren onderfcheiden.

De Verfteeningen moeten eerft gewaffchen, en met een llap fterkwatertje fchielyk afgeborfteld worden, op dat het verfteende Ligchaam voor den dag komen, en van het aankleevende Steen of Zand gereinigt worde: Aan de onvormlyke ftukken kan men met een hamer het wilde Gefteente afbikken, en hun een beter fatfoen geven. De oppervlaktens van verfteeningen worden niet gepolyft, mar men zaagt ze door midden, en polyft de inwendige vlaktens, indien men vermoed, dat zy van binnen iets merkwaardigs hebben, dog de meefte ftukken zyn beter, zo te behouden, als 'er iets aan te veranderen. Indien het zyn kan, zoekt men de doubletten by elkander, om de Moederfteen zo wel te hebben, als het verfteende, het geen men in 


\section{$V \quad O \quad O \quad R \quad R \quad E \quad D E$.}

dien klomp vond. Zyn het Verfteeningen in groote brokken, zo maakt men gereguleerde vierkanten daaruit, indien men ze daardoor niet van hun merkwaardigfte deel berooft.

Aan de Metal ftuffen is verder niets te doen, als ze rein en blinkende te hebben. Men kan dus de meeften, indien ze vafte klompen zyn, met heete Loog of met Zeepwater boenen, maar om ze te polyften is zeer onnut, en beneemd hun doorgaans het leerzame en fraaje, mitsgaders de rariteit.

De Hoorns en Schulpen, by welke de koleur en glants een Hoofdzaak uitmaken, moeten van hun buitenfte ruwe huid gezuiverd worden, om hunne koleuren yoor den dag te doen komen. Dit kan by zeer weinige met Sterkwater, by meerder zoorten, met Loog van Houtaffche en by de meesten met Azyn, waarin ze geweekt worden, gefchieden. De glants geeft men hun door het wryven met een wolle lap tot zy warm worden: Alle gebruik van Vernis en Wafch, alsmede het flypen, berooft hun van hare natuurlyke fchoonheit. Men zaagt van ieder Hoofdzoort een Hoom geheel door, om de kamers van binnen in den Hoorn te zien.

De Zee-Appels, die geen fteekels hebben, -kunnen met drooge pençeelt. jes rein gemaakt worden, en het zelve is toerykende by alle Zee-Starren, Kreeften, en zoortgelyke Schepzelen.

De Koralen moeten voor het meerder gedeelte geheel niet behandelt worden, maar het is beft, dat men ze in hunnen natuurlyken ftat laat. Want borfteld men ze, zo bederft men de Starretjes; komt men met een bytend water daaraan, zo vreet het zelve terftond gaaten, of maaks vlakken, en door Vernis bederft men de wonderbaare oppervlakte. Dit is in het byzonder ook by het Hoornagtig Koraal of by de Zee - Heefters te overwegen, op dat men ze vooral niet van hunne kalkagtige fchors berove, onder voorwendzel van ze fchoon te maken, want deze fchors is haar voornaamfte fieraad. Dog men kan aan de ingekrompe Hoorngewaffen, die geen fchors hebben, een goed fatfoen en beloop geeven, wanneer men ze op een rogtige plaats

\section{DEEL。}




\section{$\begin{array}{lllllllll}\text { XXVI } & V & \mathrm{O} & \mathrm{O} & \mathrm{R} & \mathrm{R} & \mathrm{E} & \mathrm{D} & \mathrm{E}\end{array}$}

legd tot zy week worden, en ze naderhand nar welgevallen verbuigd en ze dus weer laat droog worden.

Alle Vogelen en Dieren, die opgevult worden, moeten dezelfde geftalte behouden, die zy te vooren hadden, en men moet zorge draagen, dat nog de Hals nog het Ligchaam te dik of onvormlyk worden. De Oogen moeten zo gekoleurd zyn als de natuurlyke, en het Poftuur, waarin men ze fteld, moet met dat overeenkomen, het geen naar hunne byzondere Levenswyze gefchikt is. By de Vlinders en Infecten is 'er voornamentlyk mar op te letten, dat zy alle hunne Ledematen en Gevoelhoorens behouden, en niets van het ftof hunner vleugelen verliezen.

Om de Visfchen goed op te zetten, kan men van Boomwol een Rol of Ligchaam evenredig met hunne groote op een Tafeltje vaft hegten, en daar over de natte Huid met de Schubben en Pinnen met Kop en Staart heenen trekken.

Wat in Spiritus komt, is het beft in Koorn-Brandewyn te bewaren, dewyl die, altoos blank en helder blyvende, de zaaken het befte vertoont, waar tegens andere Spiritus geelagtig of bruin word, of de Infecten te veel aangrypt.

De verzameling van Houten beftaat in Plaatjes, die uit het Hout naar de lengte gefpleeten zyn, en aan een kant de Boomfchors nog hebben moeten, om dus niet alleen het beloop der Houtaderen, maar ook het uitterlyke aanzien van het Hout te leeren kennen. Dog wy gaan het overige van het Ryk der Planten voorby, terwyl aan het zelve de bloote Natuur, zo als zy is, zonder eenige Kunft, vereifcht word, en gaan dus tot de Beantwoordinge van de volgende Vraage over.

4.) Waarop faat 'er te letten, als men de Naturalien onbefchadigt onderbouden, en woor het verderf bewaaren aal? Vooreerft heeft men op het Vertrek zclve te zien, warin de zaaken komen. Het moet of naar het Noorden toe leggen, waar in geen Zon fcheind, of zo het aan de Zuidzyde gelegen is, moet 
het voor de Zon wel bewaard worden, door dien anders de meefte zaaken door de lengte van tyd haar koleur verliezen. Men moet zelden in zodanig een Vertrek de vengfters geheel openzetten, op dat 'er geen Vliegen, Motten of andere Infecten inkomen. Ten dien Einde heeft men ook alle reeten en hoeken voor het inkruipen van Spinnen, Muifen, of eenig ander Ongedierte te bewaren. Het Vertrek moet vervolgens volkomen droog zyn, en geene vogtige of zweetende Muuren en Vloeren hebben, daar en boven van een Engelfche Schoorfteen voorzien zyn, fchoon 'er nooit ingeftookt word, alleen maar om beftendig Versfche Lugt in het Vertrek te hebben, door dien alle Damp en Reuk van Naturalien daar door uit trekt.

Wat de Naturalien zelfs aanbelangd, zo onderhoud zig het geheele Ryk van Steenen van zelve, uitgenomen dat zomtyds de Marmer-Kalk-Gyps- en Spath zoorten door de Lugt aanflaan, zig ontbinden en verderven; om dit te verhoeden moet men ze in Water uitkoken, en in laaden voor de Lugt wel toefluiten. Het zelfde moet men by de Arfenicaal- en Vitriool-Ertzen, alsmede by Verftecningen, die met zulke Stoffen doortrokken zyn, waarnemen, die alleen maar door ze uittekoken, en ze naderhand in doozen met glaaze dekzels te leggen, kunnen bewaard worden. Terwyl ook de Bergzouten ligtelyk het vogt aan trekken, zo moet men ze beftendig toegefloten houden, op dat ze droog blyven, en men moet derhalve nu en dan naar deeze ftukken, gelyk haar alle andere zaken, zorgvuldig omzien.

De Zee-Starren, Kreeften, en dergelyke Schepzelen mocten vooraf zeer wel in een Oven gedroogt, aldus in de Kaft gelegd, en voor de Lugt bewaard worden, om dat ze ligt het vogt aan trekken: en vooral moeten die laaden wel fluiten, warin zaken leggen, naar welken de Wormen trag. ten, die men ook door ftukken Kamfer en Terpentyn-Olie zoekt te rugge te houden.

Wanneer men de Verzamelingen van Infecten, Kapellen, en dergelyke in laaden heeft, dan moeten de reeten van het hout wel met Was toege- 
$\begin{array}{lllllllll}\text { xxvm } & V & \mathrm{O} & \mathrm{O} & \mathrm{R} & \mathrm{R} & \mathrm{E} & \mathrm{D} & \mathrm{E}\end{array}$

fmeerd ch met Papier overkleed, vervolgens de geheele laade met een groote en wellfuitende Glafenruit overdekt zyn, en daar nogthans het een Infect na het andere aan het Bederf onderworpen is, zo houd men een laade met versfche Infecten in voorraad, om de befchadigde beftendig te verwiffelen. Ondertusfchen behagen ons de kleine raamen, die met glas bedekt zyn, en als Schilderyen tot verfiering der leedige plaatfen aan den muur opgehangen worden, veel beter als laaden. Deeze raamtjes moeten klein zyn, en niet veel meer als vier of zes van de, grootfe Kapellen houden, op dat, zo 'er al een raam van de Worm aangetaft word, niet zo veel Infecten op cenmaal bederven. Uit deezen hoofde verkiezen wy ook liever, de Vogels, in plaats van ze in groote Glaaze-Kaften by elkander te ftellen, veel meer ieder apart in vierkante vakken agter Spiegelglas, tegens een IIemelsblaauw befchot te ftellen, welke vakken naaft en over elkander geplaatf zynde, een fraai Tapyte Behangzel voor een wand zyn. Men heeft wel een middel om de Vogelen beeter voor het verderf te bewaaren, wanneer men de bloote Vederen naar de Natuur op een van drooge Boomfchors of Kulk gefneden Ligchaam fteekt, het geen de doorgefnede helft van een Vogel verbeeld, en op een plankje vaftgemaakt is; maar om nu nict te zeggen, dat deeze maniere van toebereidinge ongemeen veel moeite koft, zo fchynt dit dog meer Kunft als Natuur te zyn, en valt niet zo fraai in het oog als een vrye, geheel opgevulde Vogel.

Zaken, die in Spiritus ftaan, maaken by de Kabinetten den meeften omflag en onkoften, om ze goed te houden. Alles komt in dit geval op de wetenfchap aan, om de Spiritus wel te onderhouden, Hiertoe dienen fmalle kokervormige glaazen van allerhande groote, met een breede voet, waarin juif een Dier, en niet meer, ingaat. Over dit Dier word Koornbrandewyn, die behoorlyk fterk, of overgehaald is, gegooten tot dat het glas vol is, dan overdekt men het geheele glas met een fchyf Boomwafch, drukt op het zelve cen rond uitgefnede glasfchyf, die net in den rand van het glas 


\section{$\begin{array}{llllllllll}V & \mathrm{O} & \mathrm{O} & \mathrm{R} & \mathrm{R} & \mathrm{E} & \mathrm{D} & \mathrm{E} & & \mathrm{XXIX}\end{array}$}

fiuit, legt wederom een fchyf Boomwafch daar over heen, zoo dat die over den rand heen fpringt, en overtrekt dit met een regt drooge en van alle vet gereinigde of uitgekookte en weer gedroogde blaas, en vervolgens met goud papier, waarna het ftyf toegebonden word. Door dit middel blyft de Spiritus eenige Jaaren lang goed, dog daarna word het weer nodig, dezels ven op nieuw te deftilleeren, of over te haalen, en de glaazen wederom aan te vullen. Slegts hebben wy nog maar aan te merken, dat men zorge dragen moet, dat niet eenig droog deel van het Dier digt tegens het glas fluite zonder dat de Spiritus daar tuffchen getrokken is, want in dat geval verrot dat gedeelte ligtelyk, het geen tegens het glas aangedrukt zit.

De viervoetige Dieren, die los in het Vertrek ftaan, moeten noodzake. lyk ten minften eenmaal in de Zomer in de heete Zon gefteld, met roeden uitgeklopt, afgefchuiert en met ftof van Tabak en Peper (daar geen Worm in is, gewreeven, en tuffchen de Hairen beftrooid, maar aan de Oogen, Neusgaaten, Mond en Voeten met Terpentyn-Olie beftreeken, en dan we derom op hun plaats gefteld worden.

De Houten, droge Vrugten, Zaadhuisjes en dergelyke moeten voor de Worm bewaard worden. Men droogt ze daarom zomtyds in een warme Bak-Oven, en kunnen in denzelven des noods wel eens gezwaveld worden.

Het befte middel om Kruiden en Mofch te bewaaren beftaat daarin, dat men, wanneer ze anders behoorlyk opgeplakt en in kasjes, die het fatfoen van een Boek hebben, wel beflooten en bewaard zyn, dezelve zomtyds doorbladere.

By de meefte, en vooral by durine en breekbaare zaaken, als Zee-Appels, dunfchalige Hoorns, Koraalgewaffen, als mede zaaken, die in Spiritus ftaan, is aan te merken, 'dat men ze niet dikwils of onnodiger wyze moet behandelen, of heen en weer fchudden: men doet derhalve wel, wanneer men een Kabinet aan vreemde Perfoonen toond, die geen kennis van zulke zaaken hebben, haar het aantaften van die fraaiheden te beletten, want deeze voorbaari-

II. DEEL。

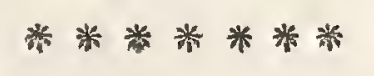




\section{$\begin{array}{lllllllll}\operatorname{xxx} & V & \mathrm{O} & \mathrm{O} & \mathbb{R} & \mathrm{R} & \mathrm{D} & \mathrm{E}\end{array}$}

ge Lieden verbeelden zig dikwils een grooten Zec-A ppel als een Steenklomp van eenige Ponden, zwaar te zyn, die dog naauwelyks twee loot weegt, taften hem dierhalven vrypoftig, en als met yzere handen aan, zo dat iemand, die deeze voorbaarigheid mede aanfchouwt, daar van fchrikken en beven moet. Om kort te gaan, men moet de zaken met alle voorzigtigheid behandelen, en op deze wyze kan men een Kabinet, een groot aantal van Jaaren, in den beften ftaat onderhouden. Dog wy komen nu tot de laatfte en wel zeer gewigtige Vragg?

5.) Hoe «al men een Natuur Kabinet met orugt gebruiken, en op welke wyæe kan men van zodanige verzamelde Natuurfukken de regte muttigheid hebben? Mogelyk zullen zig eenige Liefhebbers over deeze Vraage verwonderen, cn geloven, dat men van een Kabinet verder geen voordeel hebben kan, als om het nu en dan te bezigtigen, en aan anderen te toonen. Men trekt na. mentlyk het eene laadje na het andere uit, lacht de zaaken eens aan, en verheugd zig dar over, gelyk de Kinders, die in een Porçelein of Spiegelkraam kyken. Dit gefchied van dag tot dag, of yan week tot week, men agt zig gelukkig, die zaaken te bezitten, men is onvermoeid omze te zaam te brengen, en ten laatften is het verder niets als een verzadiging van een hartstogt. Dog wy geloven, dat men geheel andere voordeelen uit een NatuurIKabinet kan trekken, namentlyk zulke, die de bloote verluftiging van het Oog, en de voeding van een bloote hebzugt verre overtreffen.

Men behoord flegts de Verzameling van de Aarden voor zig te neemen (zie boven onze Aanmerkingen $(f)$ op de eerfte Vraag, ) zo zal men reeds het voordeel zien. Men verzameld namentlyk de verfcheide zoorten van Aarden, uit verfcheide Landen en Luchtftreeken, men onderzoekt haare hoedanigheid en onderling verfchil, men vorfcht uit, welke Gewaffen op die Aarde het befte groeijen, men verneemd, welk zoort van Vaaten, of Aardewerk in zommige Landen uit zodanige Aarde vervardigt word, en dit geeft gelegenheid tot nieuwe ontdekkingen ten opzigte van den Akkerbouw cn de Handwerken. Men word 'er dikwils door in ftaat gefteld, aan een 
Land zekere fchatten aan te wyzen, waarop nog oit iemand gedagt heeft, en dus meenig huishoudelyk voordeel te doen. Even het zelfde zoude uit een nauwkeurig onderzoek van de zoorten van Zand volgen, want het is bekend dat 'er Metal- of Goudhoudend-Zand gevonden word, en dat men in latere tyden eerft zulk Zand ontdekt heeft, waar over men voortyds onkundig heen liep. Hoe veel meer zoude zodanig voordeel ten opzigte van het Ryk der Steenen plaats vinden, als men in de Kabinetten dezelve ten opzigte van haren gepolyften ftaat, in tegenftellinge van hunne ruwe gedaante, leerde kennén. Hoe meenig ftuk Jaspis, Agaat, of Granit, of Marmer heeft lang ftil in den grond geleegen, terwyl 'er niemand was, die uit de ruwe geftalte van die Steenen vermoeden kon, dat ze gepolyft zynde zo pragtig 'er uit zouden zien? en hoe dikwils komen uitheemfche Kenners der Natuur, en dragen uit andere Landen hunne Bezitteren de befte Steenen voor den Neus weg? (i)

Hoe dikwils heeft iemand op en in zyn Grond en Land de heerlykfte zaaken, en hyvalt noit op de gedagten om ze op te zoeken. In der daad een naauwkeurig onderzoek der Natuur, en een vernuftig gebruik van een Natuur-Kabinet, zoude zeer fchielyk meenig voordeel ontdekken (k).

Het is dus onnodig om van de Metaal-Stuffen te fpreeken, want een iegelyk ziet nu wel, hoe nodig deeze Wetenfchap in de Bergwerkskunde is,

(i) De Iialianners, by Voorbeeld, die met Korfjes, Muize-vallen, en dergclyke Waaren, door Duitfchland trekken, en te gelyk goede Kenners van ruwe Steenen zyn, hebben in hunne te rug Reize dikwils het Duitich-Gebergte doorgekruift, en, gelyk onder anderen van den Vermaarden Ficbtelberg in het Baireutfche, een meenigte van fyne-Steenen, als Robynen, Sapphiren, en dergelyke, als mede Goudhoudende Steen-korreltjes weggevoerd, waar mede zy weder in hun Vaderland hun Voordcel gemaalkt hebben, zo dat eenige onder hun aanzienelyk Ryk geworden zyn.

(k) Het is zeer pryswaardig, dat verfcheide Steeden, en Academien zeederd eenigen tyd begonncn hebben ten nutte van het Publyk niet alleen Natuur-Kabinetten op te ftellen en te Verzamelen, waar in zy voomamentlyk alle Voortbrengzels van hun eigen Land in goede Monfter-Stukken vergaderen, maar ook 


\section{XXX.II \\ V O O O R R E}

en hoe men door onderzoekingen in Mineraal-Kabinetten in ftant gefteld word, nieuwe Bergwerken te ontdekken, en te beoordeelen, welk een Mineraal zeker Gefteente inhoud, en hoe rykhoudende het zelve is? Immers door deezen weg zyn meenige nieuwe Steenkool-Zwavel-Vitriool-Spiesglas* en andere Bergwerken aan de gang gebragt, en daar door meenig voordeel aan de Menfchelyke Maatfchappy gedaan. Hoe veel ftaan dan deeze voordeelen te worden, wanneer men eens de Natuur-Kabinetten beter weet te gebruiken, als tot hier toe gefchied is?

Wie kan wel het groote Heir der,Verfteende Ligchaamen met een vernuftig Oog befchouwen, zonder op hunnen wonderbaaren oorfprong oplettende te worden?

Als men in de Verzamelingen Zee.Hoorens ziet, die midden op het vafte Land, of op het Gebergte uitgegraven zyn. Âls men midden uit de groote Steenbreuken, Visfen op Ley gedrukt vind, of dergelyke, zoude dit niet in ftaat zyn, iemand op de gedagten van de Zondvloed, en dus tot de waarheid van dat geene te doen opklimmen, wat de oudfte Gefchiedenis Schryver Mofes ons mede gedeeld heeft? Zoude het niet kunnen dienen, om, over de verandering van onzen Aardbol, en over de voortduurende onbeftendige gedaante van deszelfs Oppervlakte Geographifche en allerhande nuttige Aanmerkingen te maaken? Wie kan by de oneindige meenigte en agtervolgende

Perfoonen daal toe beftellen, die over de Natuurlyke Hiftorie geregelde Lesfen geven moeten. Dit kan en zal met 'er tyd verfcheide voordeelen aan de Maatchappyen toebrengen, gelyk daar van reeds doorflaande Bewyzen kunnen opgegeven worden, dus de koften die een Land of Stad ter Bevordering van de kemnisfe der Natuurlyke Hiftorie aanwend, van den anderen kant weder rykelyk vergoed worden. Een Zaak, die in deeze tyden voor de Academien onontbeerlyk word, zeederd men begonnen heeft, de Na. tuurlyke Hiftorie niet voor een bloote Liefhebbery, maar voor een Zakelyke Wetenfchap aan te zien, die niet allcen haare groote Nuttigheit in ieder Gemeenebeft heeft, maar onder welke nog zeer veele groote Ontdekkingen tot Nut der Menfchen verborgen leggen. 
veranderingen der Ligchaamen, Planten en Dieren gevoelloos zyn, om niet de Werkende Natuur, en door dezelve de werkende Hand van den Almagtigen, die alles gewrogt heeft, met eerbied te erkennen, en in een diepe verwondering weg gerukt te worden?

Een iegelyk, voorzeeker, die by zyn Natuur-Kabinet oplettende is, om de verfcheide gedeeltens der Ligchaamen, mitsgaders hun onderfcheid, de oorzaken van dat verfchil, de oogmerken van haare gedaantens, de overeenftemminge der Geflagten en Zoorten, haar konftig zamenftel, hunnen geringen oorfpronk, hunne groote pragt, de levenswyze en huishoudinge der Dieren, en honderd andere zaaken en omftandigheden te onderzoeken, dien kan zyne Verzameling dienen om hem tot God opteleiden, den Schepper in de wegen zyner wysheit en goedheit te zien en Hem te verheerlyken, het geen zekerlyk het befte oogmerk is, waar toe ons de befchouwinge der Natuur moet opleiden.

Wat kan ondertuffchen voor de zintuigen en byzonder ${ }_{4}$ voor het oog aangenaamer zyn, als in een zaal om te wandelen, waar men een groot gedeeltc der Natuurlyke zaaken, en als waare het, de Waereld in het klein by een vergaderd vind, waar men zig te gelyk in Aziën en America verplaatıt ziet, en de koftelykheden van den Oceaan, die veeltyds in onpeilbaare diep. tens verholen zitten, voor zig uitgebreid te zien. Men kan dus de Waereld der Natuur met groot gemak en in weinig uuren doorreizen, en zig zulks tot ruft, verkwikkinge en verpoozinge van veel Ampts - Arbeid laten verftrekken.

Behalven dien vind een Geleerde by de befchouwinge van de Natuurlyke Zeldzaamheden ftoffe genoeg, om zyn verftand op te fcherpen, en tot bevordering van verfcheide nutte Weetenfchappen onderzoekingen te doen. Want hoe veel Werktuigkundige Handgreepen heeft ons de Natuur in de vorming van de Ledematen en Gewrigten der Dieren niet getoond? Hoe veel nieuwe vermengingen zyn niet door de fcheikunde uitgevonden, zederd men op de Natuurlyke mengeling der Iigchamen en derzelver evenredig gewigt te. gens elkander gelet heeft? Hoe wydlopig is het veld der Schilders en Beeldhouwers niet geworden, zederd zy een grooter verfchot van Dieren en Schepzelen met meerder naauwkeurigheid leerden befchouwen, om de Natuur na te 


\section{$\begin{array}{lllllllll}\text { XXXIV } & V & \mathrm{O} & \mathrm{O} & \mathrm{R} & \mathrm{R} & \mathrm{E} & \mathrm{D} & \mathrm{E}\end{array}$}

bootzen? Hoe zinryk is in de Bouwkunde de manier niet geworden, om de Palyzen te verfieren, zederd men beter agt gaf, hoedanig de Natuur hare IKunftukken bearbeid? Welkefterke bewyzen, en groote ophelderingen omtrent de kragt, fwarte, en drukking van Lugt en Water en alle overige Ligchaamen worden niet afgeleid uit de befchouwinge der Viffen, Vogelen, en andere Schepzelen tot beveftiging der Natuurkunde? Hoe veele Plaatlen in de Heilige Schriftuure die van reine en onreine Dieren, van Vrugten, Gewaffen, van zeeker zoort van Steenen, Edelgefteentens, en dergelyke, handelen, zouden duifter blyven, en van een Godgeleerden niet regt verftaan worden, indien hy geen moeite wilde doen, deeze zaken zelfs uit de befchouwinge der Natuur te leeren kennen? en hoe luttel zoude hy cie regte kragt der Loffpreuken verftaan, die tot verheerlyking van den Schcpper in de gantfche H.Schriftuur en voornamentlyk in de Pfalmen gevonden worden, wanneer hy de Werken des Heeren nooit regt befchouwen, of zig de zeldzaamheden der Natuur bekend maken wilde? Ja hoe veel is'er nog altyd overig ter navorfchinge, dat ons tot nog toe duifter is ten opzigte van de wording en de gedaantens der Steenen, van de Wasdom der Planten, en het leven der Dieren? Welker onderzoekinge, die niet anders als aan de zaaken zelfs gefchieden kan, voor de Menfchen ongemeen nuttig zoude zyn.

Dog wy hebben reeds het Perk van een Voorreeden te veel overfchreeden, en moeten flegts tot flot ons jegens die Liefhebbers, die te gelyk kenners zyn, en deeze Verhandeling voor overvloedig houden mogten, verontfchuldigen. Wy hebben namentlyk volgens ons oogmerk maar alleen voor zulke Liefhebbers gefchreven, die eerft, beginnen te verzamelen, en dikwils veel moeite doen, van andere uit te vorfchen, hoedanig zy hunne zeldzaamheden fchikken en bewaren moeten. Wy hebben getragt, haar door onze Aanmerkingen eenigermate op het fpoor te helpen, en terwyl het oogmerk was, dit Werk voor de beginnende Liefhebbers nuttig te maken, zo hopen wy, dat de zulken, wien deeze zaaken even zo goed, of beter bekend zyn, ons dit niet zullen gelieven kwalyk te duiden. Erlang den IO. Febr. I770.

P. L. St. MULLER. 

f QH Knorr, Georg

41 Wolfgang.

Wolfgang.
Deliciae natura

K72
1766

selectae, oder,

$\begin{array}{ll}\text { SCNHRB } & \text { Auserlesenes- } \\ \text { p广. I } & \text { Cabinet ... [partial }\end{array}$ Cabinet ... [partial
and incomplete set] 1766 

